\title{
ANÁLISE DO COMPORTAMENTO MECÂNICO DE COMPÓSITOS LAMINARES CONSIDERANDO A VISCOELASTICIDADE
}

\author{
CARMEN ELENA RAMIREZ MENESES
}

DISSERTAÇÃO DE MESTRADO EM ESTRUTURAS E CONSTRUÇÃO CIVIL

\section{FACULDADE DE TECNOLOGIA}


UNIVERSIDADE DE BRASÍLIA

FACULDADE DE TECNOLOGIA

DEPARTAMENTO DE ENGENHARIA CIVIL E AMBIENTAL

\section{ANÁLISE DO COMPORTAMENTO MECÂNICO DE COMPÓSITOS LAMINARES CONSIDERANDO A VISCOELASTICIDADE}

\section{CARMEN ELENA RAMIREZ MENESES}

ORIENTADOR: FRANCISCO EVANGELISTA JUNIOR

DISSERTAÇÃO DE MESTRADO EM ESTRUTURAS E CONSTRUÇÃO CIVIL

PUBLICAÇÃO: E.DM - 014 A/15

BRASÍLIA/DF: MAIO - 2015 


\section{UNIVERSIDADE DE BRASÍLIA}

FACULDADE DE TECNOLOGIA

\section{DEPARTAMENTO DE ENGENHARIA CIVIL}

ANÁLISE DO COMPORTAMENTO MECÂNICO DE COMPÓSITOS LAMINARES CONSIDERANDO A VISCOELASTICIDADE

\section{CARMEN ELENA RAMIREZ MENESES}

DISSERTAÇÃO SUBMETIDA AO DEPARTAMENTO DE ENGENHARIA CIVIL E AMBIENTAL DA FACULDADE DE TECNOLOGIA DA UNIVERSIDADE DE BRASÍLIA COMO PARTE DOS REQUISÍTOS NECESSÁRIOS PARA A OBTENÇÃO DO GRAU DE MESTRE EM ESTRUTURAS E CONSTRUÇÃO CIVIL.

\section{APROVADA POR:}

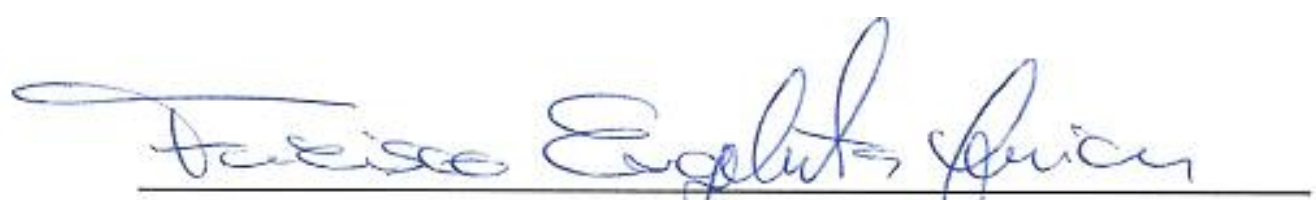

Prof. Francisco Evangelista Junior, PhD (ENC-UnB)

(Orientador)

Prof. Gilberto Gomes, DSc. (ENC-UnB)

(Examinador Interno)

Prof. Edgar Nobuo Mamiya, DSc. (ENM-UnB)

(Examinador Externo)

BRASÍLIA/DF, 28 DE MAIO DE 2015 
RAMIREZ MENESES, CARMEN ELENA

Análise Do Comportamento Mecânico De Compósitos Laminares Considerando A Viscoelasticidade [Distrito Federal] 2015.

XXIV, 173p., 297 mm (ENC/FT/UnB, Mestre, Estruturas e Construção Civil, 2015). Dissertação de Mestrado - Universidade de Brasília. Faculdade de Tecnologia.

Departamento de Engenharia Civil e Ambiental.

1.Viscoelasticidade

3. Elementos laminares compósitos

5. Algoritmos numéricos

I. ENC/FT/UnB
2.Séries de Prony

4.MEF

II. Título (série)

\section{REFERÊNCIA BIBLIOGRÁFICA}

RAMIREZ M., C. E. (2015). Análise Do Comportamento Mecânico De Materiais Laminares Compósitos Considerando A Viscoelasticidade. Dissertação de Mestrado em Estruturas e Construção Civil, Publicação E.DM - 014 A/15, Departamento de Engenharia Civil e Ambiental, Universidade de Brasília, Brasília, DF, 173p.

\section{CESSÃO DE DIREITOS}

AUTOR: Carmen Elena Ramirez Meneses.

TÍTULO: Análise Do Comportamento Mecânico De Compósitos Laminares Considerando A Viscoelasticidade.

GRAU: Mestre

ANO: 2015

É concedida à Universidade de Brasília permissão para reproduzir cópias desta dissertação de mestrado e para emprestar ou vender tais cópias somente para propósitos acadêmicos e científicos. $\mathrm{O}$ autor reserva outros direitos de publicação e nenhuma parte dessa dissertação de mestrado pode ser reproduzida sem autorização por escrito do autor.

Carmen Elena Ramirez Meneses

Pital - Huila - Colômbia.

ramirezmenesescarmene@gmail.com

Skype: carmen.elena.ramirez.meneses 


\section{AGRADECIMENTOS}

Agradeço a Deus, porque a cada passo tem andado e segurado na minha mão, guiando-me pelos melhores caminhos ao longo da minha vida. Sem sua força, incentivo e ajuda, nunca teria conseguido chegar até aqui.

Aos meus pais José Miller e Mercedes que dedicaram suas vidas para fazer de mim uma pessoa de bem. Agradeço-lhes por seu amor, a sua confiança e motivação. Eles deram-me o melhor presente: minha irmã Lina, a quem agradeço imensamente pelo seu apoio, suas palavras de alento, sua energia para não desistir. Agradeço também pelos meus amados sobrinhos: Fabiana e Santiago. Vocês, minha família, são a razão da minha existência.

Ao meu orientador Prof. ${ }^{\circ}$ Evangelista pela dedicação, compreensão e paciência, pois sua orientação foi essencial para o meu trabalho de mestrado. Muito obrigada por cada exercício, cada desafio, cada novo ensino. Aos outros professores do PECC, especialmente aos Professores Luciano e Lineu, agradeço seus conhecimentos e experiências transmitidos ao longo do curso. O pouco que sei da Ciência e da pesquisa, aprendi com vocês.

Ao Tiago, a Helena, o Leonardo e o Rafael, agradeço-lhes por me acompanhar e apoiar até o fim, me adotando com carinho como parte da sua família e dando-me a força para concluir o meu trabalho. Ao meu amigo Miguel Enrique, quem aconselhou-me fazer meu mestrado em Brasília e como um irmão carinhoso limpou cada lágrima derramada, sendo meu apoio ao chegar em casa. Ao Osmairo por abdicar muito do seu tempo para me ajudar.

Aos amigos obtidos nesta luta: ao Nelson, ao Gelson, ao Fabiano, ao Carlos Mariano, ao Uchôa, ao Marcus, ao Halley, ao Vitor, ao Rafael, além da Marília, a Isa, a Damaris, a Eva e, especialmente, ao Juan Pablo e ao Edgar, a todos eles, obrigadíssima por me fazer sentir no Brasil a sensação de estar em casa. Agradeço também aos meus colegas, amigos e familiares que acreditaram sempre em mim, que sempre me apoiaram para a conclusão deste trabalho, agradeço pelas boas vindas ao voltar para casa, e cada a cada "não desista" quando tinha que pegar um avião de novo. Levo vocês no meu coração para cada local do mundo onde o destino me levar.

Ao PECC (Programa de Pós-Graduação em Estruturas e Construção Civil) da Universidade de Brasília pelo aprendizado e ao CNPq (Centro Nacional de Desenvolvimento Científico e Tecnológico) pelo apoio financeiro, sendo fundamentais para a conclusão deste trabalho. 


\section{DEDICATORIA}

A Deus, por me deixar permanecer nesta Terra o tempo suficiente para me formar como Mestre.

Aos meus Pais Mercedes e Miller, minha irmã Linita e meus sobrinhos Fabiana e Santiago, os amores da minha vida, pilares de força em todos os momentos de fraqueza e tristeza, e razão para a minha felicidade e entrega. Ao Tiago e sua família, aos meus amigos, familiares e a todos aqueles que com sua estima e apoio me honram, pois sem eles a minha profissão e minha vida seriam muito sem graça 
“Confie no Senhor de todo o coração e não se apoie na sua própria inteligência. Lembre-se de Deus em tudo o que fizer, e ele lhe mostrará o caminho certo". (Provérbios 3:5,6) vii 


\title{
RESUMO
}

\section{ANÁLISE DO COMPORTAMENTO MECÂNICO DE MATERIAIS LAMINARES COMPÓSITOS CONSIDERANDO A VISCOELASTICIDADE}

\author{
Autor: Carmen Elena Ramírez Meneses \\ Orientador: Francisco Evangelista Junior, PhD. \\ Programa de Pós-graduação em Estruturas e Construção Civil \\ Brasília, 28 de Maio de 2015
}

Depois de falhas em estruturas tão importantes quanto em pontes, devido ao efeito da viscoelasticidade considerada no projeto muito aquém dos valores das deflexões reais, o estudo e compreensão do fenômeno da viscoelasticidade é mais que necessário para o projeto de estruturas. Nos modelos descritos na literatura para o cálculo de deflexões em estruturas laminares sanduíche ignora-se a interação da variação de cargas mecânicas, a diferença do comportamento do material do núcleo quando este é submetido à tração ou compressão, e o efeito da viscoelasticidade dos materiais. Neste trabalho avaliam-se modelos mais complexos comparados com as simplificações dadas na literatura, analisando os efeitos de flexão e cisalhamento, baseados na solução analítica e considerando-se um núcleo com propriedades viscoelásticas, ou suscetível aos fenômenos de fluência e relaxação.

Assim, o presente trabalho resolve por algoritmos numéricos a quantificação das deflexões para compósitos laminares, utilizado para isto o princípio de correspondência elástica viscoelástica e obtendo a solução total ao longo do tempo, com base na solução elástica linear correspondente, sendo um método confiável, portável e rápido. Considerou-se também a variabilidade das cargas impostas, oferecendo nos resultados análises paramétricas dos elementos de viga e placa sanduíche, descrevendo as variáveis que mais afetam o incremento ou a diminuição das máximas deflexões desses elementos.

Palavras chave: Métodos numéricos, vigas sanduíche, placas anisotrópicas sanduíche, viscoelasticidade, séries de Prony, materiais laminares compósitos. 


\begin{abstract}
ANALYSIS OF MECHANICAL BEHAVIOUR OF COMPOSITE LAMINAR MATERIALS CONSIDERING VISCOELASTICITY

Author: Carmen Elena Ramírez Meneses

Supervisor: Francisco Evangelista Junior, PhD.

Programa de Pós-graduação em Estruturas e Construção Civil

Brasília, 28 of May of 2015
\end{abstract}

After failures in such important structures like bridges, because the effect of the viscoelasticity considered in the design is significantly below compared with the actual deflection values. For this reason, the study and understanding of the phenomenon of the viscoelasticity is more than necessary for the structural design. In the models described in the literature for calculating deflections in laminar sandwich structures ignores the interaction of varying mechanical loads, the difference in the behavior of the core material when this is subjected to traction or compression, and the effect of the viscoelastic material. In this study, more complex models are evaluate and compared with the given literature simplifications, by analyzing the effects of bending and shear, based on the analytical solution and considering a core having viscoelastic properties, or susceptible to the phenomena of creep and relaxation.

Accordingly, this work resolved by numerical algorithms the quantification of the maximum deflections of laminar composites, using the elastic viscoelastic correspondenceprinciple obtaining the total solution over time, based on corresponding linear elastic solution, demonstrating to be a reliable, portable and fast method. Additionally, are considered the variability of the loads imposed, providing the parametric analysis of the sandwich beams and plates, describing the variables that most affect the increase or decrease of the maximum deflections of these elements.

Keywords: Numerical methods, sandwich beams, anisotropic sandwich plates, viscoelasticity, Prony series, composite laminar materials. 


\section{SUMÁRIO}

UISTA DE TABELAS

LISTA DE QUADROS.................................................................................................... XVII

LISTA DE FIGURAS....................................................................................................XVIII

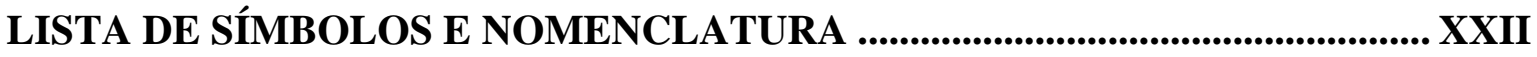

LISTA DE ABREVIAÇÕES E SIGLAS....................................................................XXIV

1 - INTRODUÇÃO ................................................................................................................. 1

1.1 - CONSIDERAÇÕES INICIAIS .............................................................................. 1

1.2 - JUSTIFICATIVA …………..................................................................................... 3

1.3 - OBJETIVOS ................................................................................................................. 4

1.3.1 - Objetivo geral ........................................................................................................ 4

1.3.2 - Objetivos específicos .............................................................................................. 4

1.4 - RESUMO DA METODOLOGIA ….......................................................................5

1.5 - ORGANIZAÇÃO DA DISSERTAÇÃO..............................................................6

2 - REVISÃO BIBLIOGRÁFICA ............................................................................... 8

2.1 - VISCOELASTICIDADE ......................................................................................... 8

2.1.1 - Analogias mecânicas .........................................................................................9

2.1.1.1 - Modelo de Maxwell .................................................................... 9

2.1.1.2 - Modelo de Kelvin-Voigt .............................................................. 12

2.1.1.3 - Modelo do sólido linear padrão.................................................... 14

2.1.1.4 - Modelo de Boltzmann ............................................................... 15

2.1.1.5 - Modelo de Burgers ....................................................................... 16

2.1.1.6 - Modelo Generalizado de Maxwell ou Modelo de Wiechert ......... 17

2.1.1.7 - Modelo Generalizado de Kelvin - Voigt ......................................... 18

2.1.2 - Séries de Prony ..................................................................................................... 18

2.1.3 - Princípio de superposição de Boltzmann ................................................. 20

2.1.4 - Princípio de correspondência elástica - viscoelástica (PCEV) ............ 22

2.1.5 - Inversão numérica de funções desde o espaço de Laplace para o

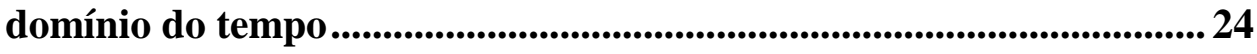

2.1.5.1 - Método de Gaver-Stehfest ............................................................2 25 


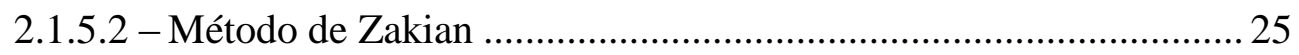

2.1.5.3 - Método de Schapery............................................................... 26

2.1.5.4 - Método das séries de Fourier ........................................................ 26

2.1.6 - Princípio de superposição tempo - temperatura (PSTT) ................... 26

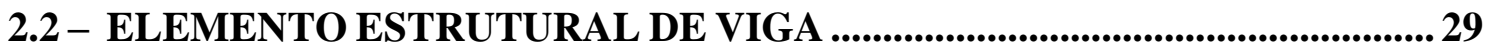

2.2.1 - Modelo de viga de Euler-Bernoulli (MVEB) .....................................29

2.2.2 - Modelo de viga de Timoshenko (MVT)................................................. 33

2.2.3 - Modelo de viga sanduíche elástica ............................................................... 35

2.2.4 - Modelo de viga sanduíche considerando a viscoelasticidade dos

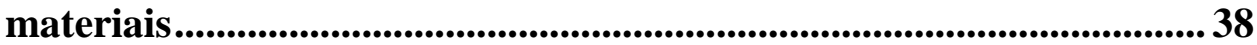

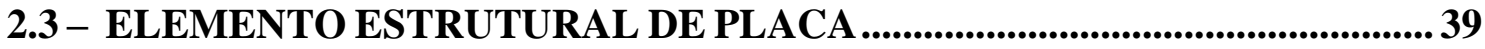

2.3.1 - Modelo de Lovel-Kirchhoff placa anisotrópica compósita ...................39

2.3.2 - Modelo de Lovel-Kirchhoff considerando a viscoelasticidade dos

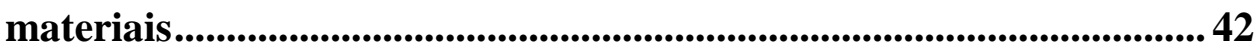

3 - FORMULAÇÃO DA ABORDAGEM..........................................................43

3.1 - ALGORITMO DE REGRESSÃO ÀS SÉRIES DE PRONY ............................ 43

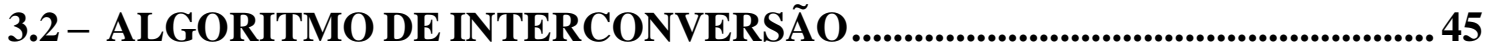

3.3 - ALGORITMO INCREMENTAL DAS RELAÇÕES VISCOELÁSTICAS

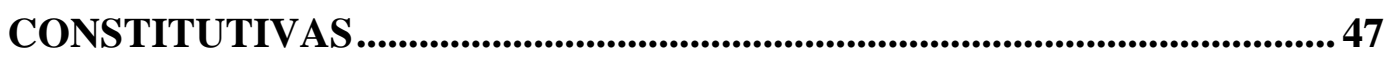

3.3.1-ALGORITMO INCREMENTAL PARA CÁlCULO DO HISTÓRICO DE TENSÕES.................................................................48

3.3.2-ALGORITMO INCREMENTAL PARA CÁlCULO DO HISTÓRICO DE DEFORMAÇÕES ............................................................5 51

4 - VERIFICAÇÃO DOS ALGORITMOS PROPOSTOS......................................54

4.1 - ALGORITMO DE REGRESSÃO ÀS SÉRIES DE PRONY ........................... 54

4.2 - ALGORITMO DE INTERCONVERSÃO........................................................56

4.2.1 - Função obtida pelo algoritmo comparada com a resposta analítica do Modelo de Boltzmann ..................................................................................56

4.2.2 - Interconversão da série E(t) do Poliuretano............................................... 57 
4.2.3 - Interconversão de séries com maior número de coeficientes ................ 58

4.2.4 - Interconversão elástica .....................................................................60 60

4.2.5 - Interconversão inversa ....................................................................61

4.3-ALGORITMO INCREMENTAL DAS RELAÇÕES VISCOELÁSTICAS CONSTITUTIVAS. .63

4.3.1 - CALCULO DE TENSÕES OU TESTES DE RELAXAÇÃO ............ 63

4.3.1.1 - Modelo do sólido linear padrão.................................................. 63

4.3.1.2 - Modelo de Boltzmann ............................................................... 65

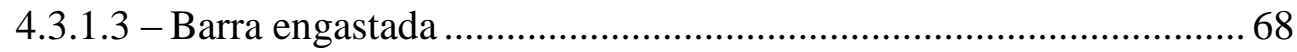

4.3.2 - CÁlCULO DE DEFORMAÇÕES OU TESTES DE FLUÊNCIA .... 70

4.3.2.1 - Modelo de Boltzmann ................................................................. 70

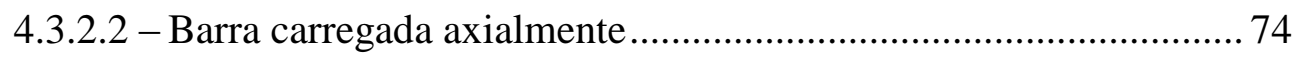

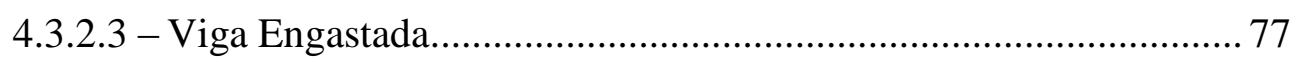

5- ANÁliSE DO COMPORTAMENTO MECÂNICO DE ELEMENTOS ESTRUTURAIS COMPÓSITOS.......................................................................................8 84

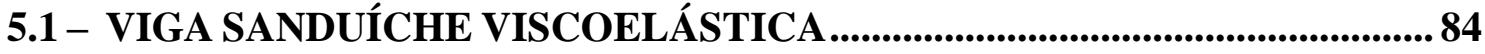

5.1.1 - PARÂMETROS GEOMÉTRICOS, MATERIAIS E CARREGAMENTOS ...............................................................................8 84

5.1.2 - VERIFICAÇÃO DO ALGORITMO PARA O PCEV DE VIGAS SANDUÍCHE............................................................................................88 88

5.1.3-ANÁliSE DOS MODELOS MATEMÁTICOS CONSERANDO VARIAÇÃO DE PARÂMETROS..............................................................91

5.1.3.1 - Caso I: MVEB elástico linear ...................................................... 91

5.1.3.2 - Caso II: MVEB viscoelástico.................................................... 93

5.1.3.3 - Caso III: MVT elástico............................................................... 96

5.1.3.4 - Caso IV: MVT flexão elástica e cisalhamento viscoelástico ........ 98

5.1.3.5 - Caso V: MVT viscoelástico $\boldsymbol{\alpha}=1$............................................ 101

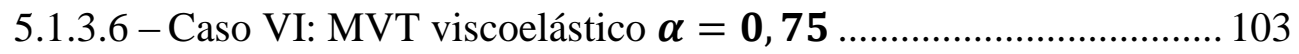

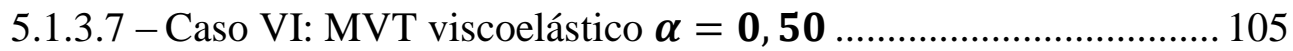

5.1.3.8 - Caso VI: MVT viscoelástico $\boldsymbol{\alpha}=\mathbf{0 , 2 5} \ldots \ldots \ldots \ldots \ldots \ldots \ldots \ldots \ldots \ldots \ldots . . . . . . . . . . . . . . . . . .106$

5.1.4 - COMPARAÇÃO PARAMÉTRICA NORMALIZADA ................... 108 
5.1.4.1 - $\delta_{\mathrm{N}}$ Caso I: MVEB elástico...................................................... 108

5.1.4.2 $-\delta_{\mathrm{N}}$ Caso II: MVEB viscoelástico .............................................. 109

5.1.4.3 $-\delta_{\mathrm{N}}$ Caso III: MVT elástico ............................................................... 109

5.1.4.4 $-\delta_{\mathrm{N}}$ Caso IV: MVTev flexão elástica e cisalhamento viscoelástico

5.1.4.5 $-\delta_{\mathrm{N}}$ Caso V: MVTvv viscoelástico $\boldsymbol{\alpha}=\mathbf{1} \ldots \ldots \ldots \ldots \ldots \ldots \ldots \ldots \ldots \ldots . . . . . . . . . . . . . . . . . .110$

5.1.4.6 $-\delta_{\mathrm{N}}$ Caso VI: MVTvv2 viscoelástico $\boldsymbol{\alpha}=\mathbf{0 , 7 5} \ldots \ldots \ldots \ldots \ldots \ldots \ldots . . . . . . . . .111$

5.1.4.7 $-\delta_{\mathrm{N}}$ Caso VI: MVTvv2 viscoelástico $\boldsymbol{\alpha}=\mathbf{0 , 5}, \ldots \ldots \ldots \ldots \ldots \ldots \ldots \ldots . . . . . . . . . . . .112$

$5.1 .4 .8-\delta_{\mathrm{N}}$ Caso VI: MVT viscoelástico $\boldsymbol{\alpha}=\mathbf{0 , 2 5} \ldots \ldots \ldots \ldots \ldots \ldots \ldots \ldots \ldots . . . . . . . . . . . . .112$

5.1.4.9 - Comparação dos casos de estudo para o $\mathrm{T}=1[\mathrm{~h}]$......................... 113

5.1.4.10 - Comparação dos casos de estudo para o $\mathrm{T}=100[\mathrm{~h}] \ldots \ldots \ldots \ldots \ldots \ldots . . . . .114$

5.2 - PLACA ANISOTRÓPICA COMPÓSITA VISCOELÁSTICA ...................... 116

5.2.1 - AVALIAÇÃO DO COMPORTAMENTO DA PLACA ANISOTRÓPICA VISCOELÁSTICA PARA $\alpha=\beta=0,5 \ldots . . . . . .117$

5.2.2 - AVALIAÇÃO DO COMPORTAMENTO DA PLACA ANISOTRÓPICA VISCOELÁSTICA PARA $\alpha=\beta=1 \ldots . . . . . . . . . .118$

6- ANÁLISE DE SENSIBILIDADE POR EXPERIMENTOS NUMÉRICOS E

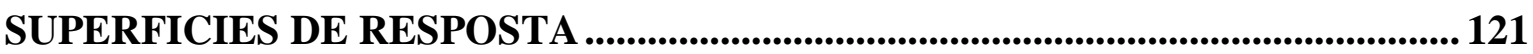

6.1 - VIGA SANDUÍCHE VISCOELÁSTICA............................................................ 121

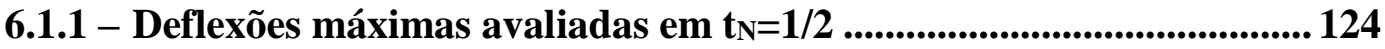

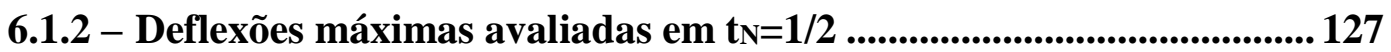

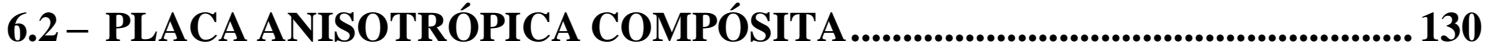

7 - CONCLUSÕES E SUGESTÕES PARA TRABALHOS FUTUROS.................... 132

7.1 - CONCLUS ÕES .............................................................................................. 132

7.2 - SUGESTÕES PARA TRABALHOS FUTUROS .......................................... 133

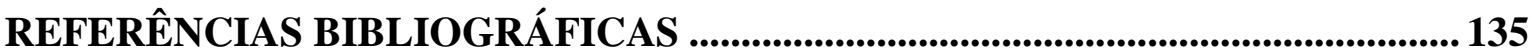

ANEXOS 139

A - DESENVOLVIMENTO MATEMÁTICO DA SOLUÇÃO ÀS EQUAÇÕES DIFERENCIAIS DAS ANALOGIAS MECÂNICAS 140 
A.1.1 - Teste de fluência ............................................................................. 140

A.1.2 - Teste de relaxação ................................................................... 141

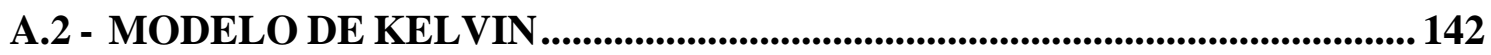

A.2.1 - Teste de fluência ......................................................................... 143

A.2.2 - Teste de relaxação ................................................................... 143

A.3 - MODELO DO SÓLIDO LINEAR PADRÃO ................................................. 144

A.3.1 - Teste de fluência ........................................................................... 145

A.3.2 - Teste de relaxação ............................................................................. 146

A.4 - MODELO DE BOLTZMANN .......................................................................... 147

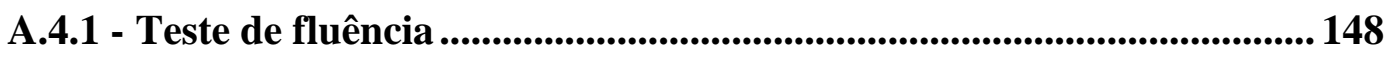

A.4.2 - Teste de relaxação .............................................................................. 150

B - DESLOCAMENTOS MÁXIMOS NORMALIZADOS..................................... 151

B.1 - $\Delta_{N}$ CASO I: MVEB ELÁSTICO .................................................................... 151

B.2 - $\Delta_{N}$ CASO II: MVEB VISCOELÁSTICO ........................................................ 152

B.3 - $\Delta_{N}$ CASO III: MVT ELÁSTICO..................................................................... 153

B.4 - $\triangle$ N CASO IV: MVT FLEXÃO ELÁSTICA E CISALHAMENTO VISCOELÁSTICO.... 154

B.5 - $\Delta_{N}$ CASO V: MVT VISCOELÁSTICO ............................................................... 155

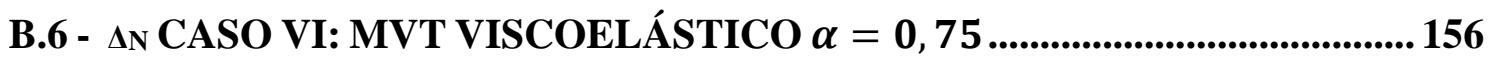

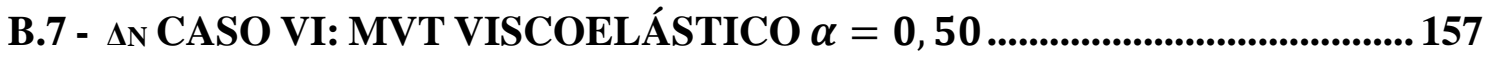

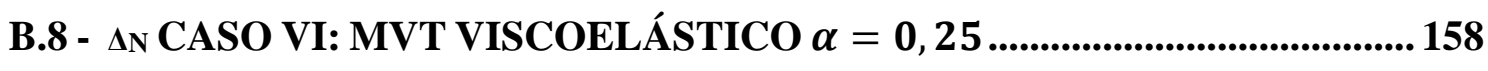

C - PARÂMETROS ESTUDO DE SENSIBILIDADE ................................................. 159

C.1 - DEFLEXÕES DADOS 54 COMBINAÇÕES DE 6 VARIÁVEIS ................... 159

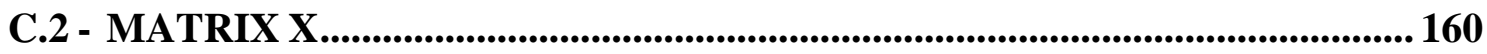

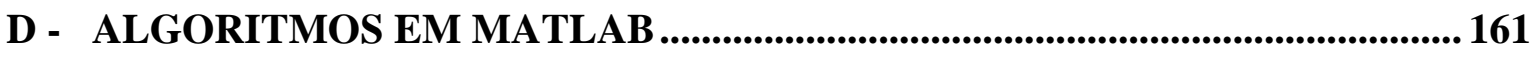

D.1 - ALGORITMO DE APROXIMAÇÃO ÀS SÉRIES DE PRONY APLICADO AO EXEMPLO 4.1.1 ............................................................................................ 161

D.2 - ALGORITMO DE INTERCONVERSÃO DE G(T) PARA J(T) ................... 162 
D.3 - ALGORITMO DE INTERCONVERSÃO DE D(T) PARA E(T) ...................... 164

D.4 - ALGORITMO INCREMENTAL DAS DEFORMAÇÕES APLICADO À VERIFICAÇÃO DO ITEM 4.3.4.2 ……......................................................... 165

D.5 - ALGORITMO INCREMENTAL DAS TENSÕES APLICADO À VERIFICAÇÃO DO ITEM 4.3.2.2 .................................................................... 169

D.6 - ALgORitMo DA FUnÇão PARA AVALIAR Imod E Ac DA VIGA

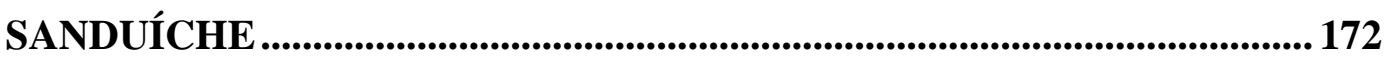




\section{LISTA DE TABELAS}

Pág.

Tabela 2.1 - Coeficientes Ai e $\alpha$ i para o método de Zakian (Torres, 2013)* ...................... 26

Tabela 2.2 - Valores para área ao cisalhamento corregida em vigas.................................. 34

Tabela 4.1 - Dados de entrada para aproximação série de Prony $\mathrm{J}(\mathrm{t})$................................. 54

Tabela 4.2 - Coeficientes da série de Prony $\mathrm{J}(\mathrm{t})$ obtidos pelo algoritmo proposto ............. 55

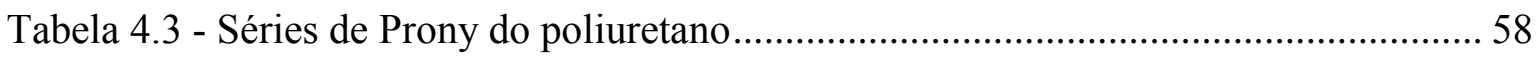

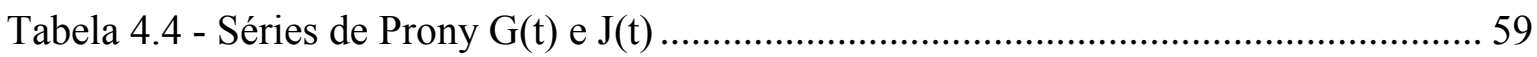

Tabela 4.5 - Séries de Prony dos parâmetros do material poli-isobutileno .......................... 61

Tabela 4.6 - Parâmetros de avaliação para o deslocamento de uma barra viscoelástica ..... 69

Tabela 4.7 - Parâmetros de avaliação para o deslocamento de uma barra viscoelástica..... 75

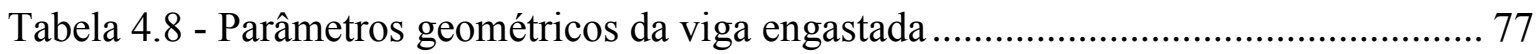

Tabela 4.9 - Carregamentos impostos na viga em balanço ................................................ 78

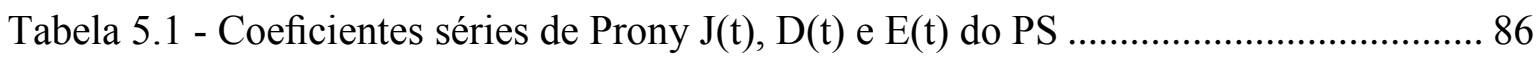

Tabela 5.2 - Condições de avaliação da viga sanduíche.................................................... 86

Tabela 5.3 - Comparação das deflexões máximas da viga ............................................... 89

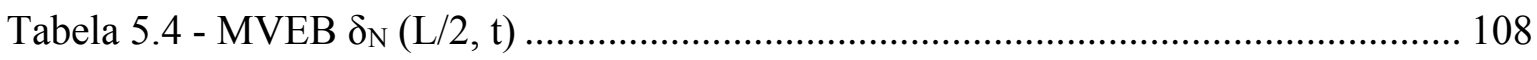

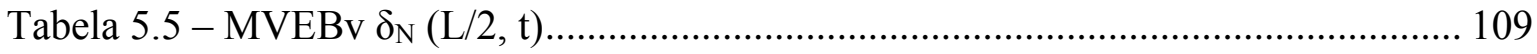

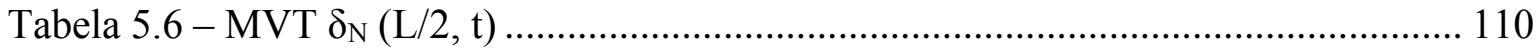

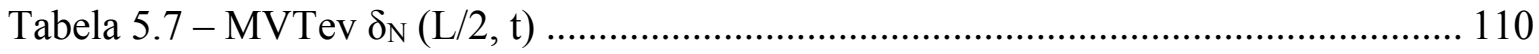

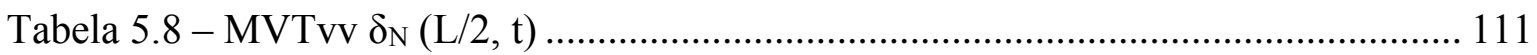

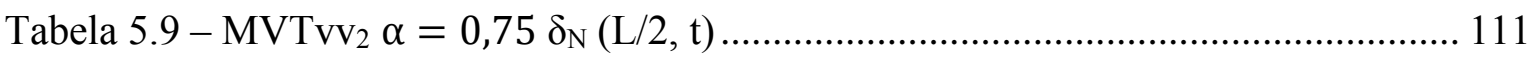

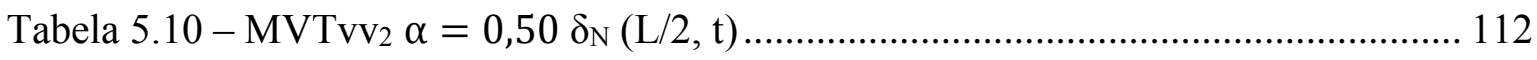

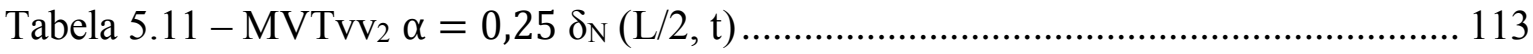

Tabela 6.1 - Variação dos parâmetros de estudo ............................................................... 121

Tabela 6.2 - Coeficientes de regressão da função deslocamento em $t_{N}=1 / 2$ e $t_{N}=1 \ldots \ldots \ldots . .123$ 


\section{LISTA DE QUADROS}

Pág.

Quadro 3.1 - Algoritmo para ajustar séries de Prony aos dados experimentais ................. 44

Quadro 3.2 - Algoritmo de interconversão para as funções de fluência e relaxação........... 46

Quadro 3.3 - Algoritmo incremental para o histórico de tensões ........................................ 48

Quadro 3.4 - Algoritmo incremental para o histórico de deformações ............................... 51 


\section{LISTA DE FIGURAS}

Figura 1.1 - Materiais usados no avião Boeing 787

Figura 1.2 - Seção central típica de um avião................................................................... 2

Figura 1.3 - Ponte Koror-Babeldaob - Palau (Jápão)....................................................... 3

Figura 2.1 -Analogias mecânicas dos modelos elástico e viscoso simples........................... 8

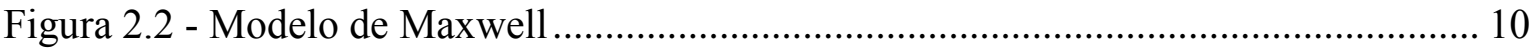

Figura 2.3 - Solicitação e resposta ao teste de relaxação para o elemento de Maxwell ...... 11

Figura 2.4 - Solicitação e resposta ao teste de relaxação para o elemento de Maxwell ...... 11

Figura 2.5 - Modelo de Kelvin .................................................................................... 12

Figura 2.6 - Solicitação e resposta ao teste de fluência para o elemento de Kelvin ............ 12

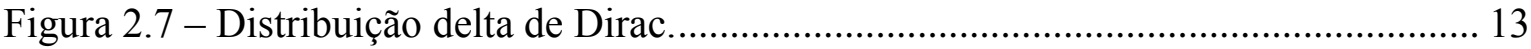

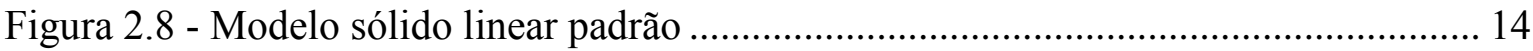

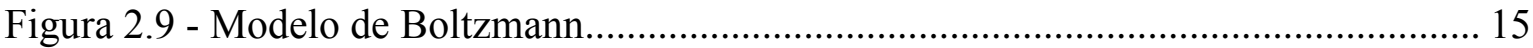

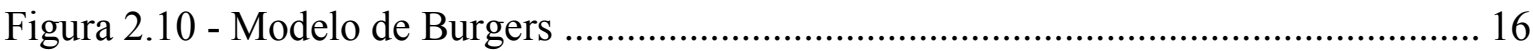

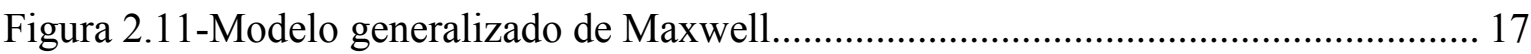

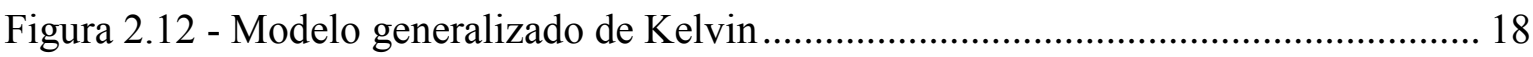

Figura 2.13- (a). Histórico em escada das tensões. (b) Histórico de tensões arbitrárias ..... 21

Figura 2.14 - Fator de deslocamento tempo-temperatura.................................................. 27

Figura 2.15 - Modelo de viga de Euler-Bernoulli ............................................................... 30

Figura 2.16 - Modelo viga de Euler - Bernoulli ................................................................. 30

Figura 2.17 - Viga em balanço com carregamento pontual no extremo livre ...................... 32

Figura 2.18 - Viga simplesmente apoiada com carregamento concentrado no centro ......... 32

Figura 2.19 - Comparação dos modelos de viga de Euler-Bernoulli e de Timoshenko ..... 34

Figura 2.20 - Viga sanduíche simplesmente apoiada - perfil e seção transversal ................ 35

Figura 2.21 - Deslocamentos da placa de Lovel-Kirchhoff................................................. 40

Figura 2.22 - Placa compósita simplesmente apoiada e com carregamento uniforme ....... 40

Figura 3.1 - Descrição gráfica do algoritmo de regressão às séries de Prony..................... 45

Figura 3.2 - Descrição gráfica do algoritmo de interconversão ......................................... 47

Figura 3.3 - Descrição gráfica do algoritmo incremental para o histórico de tensões......... 49

Figura 3.4 - Descrição gráfica do algoritmo incremental para o histórico de deformações 52

Figura 4.1 - Verificação do algoritmo de aproximação à série da função fluência ao cisalhamento $\mathrm{J}(\mathrm{t})$ do material poliestireno.................................................... 55

Figura 4.2 - Comparação das funções viscoelásticas $E(t)$ e $D(t)$ aplicando os algoritmos 
propostos

Figura 4.3 - ER calculado entre a função fluência $\mathrm{D}(\mathrm{t})$ obtida Vs. $\mathrm{D}(\mathrm{t})$ analítica................ 57

Figura 4.4 - Funções relaxação e fluência do Poliuretano ...................................................... 58

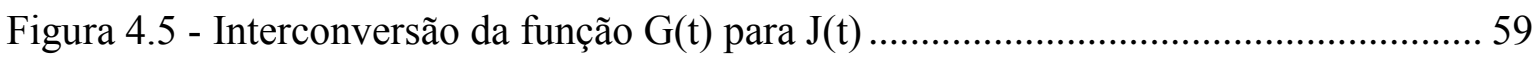

Figura 4.6 - ER calculado entre a série de Prony da fluência ao cisalhamento J(t) Vs. J(t)

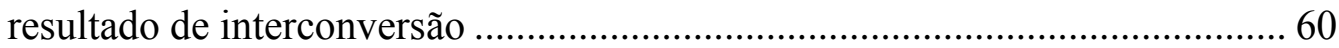

Figura 4.7 - Interconversão elástica das funções viscoelásticas .......................................... 60

Figura 4.8 - Comparação gráfica das propriedades viscoelásticas do material poli-isobutileno

Figura 4.9 - ER função $\mathrm{G}(\mathrm{t})$ recalculada por duas interconvesões Vs. G(t) inicial ............. 62

Figura 4.10 - Valores e unidades adotados para o Modelo do sólido linear padrão ............ 63

Figura 4.11 - Deformação imposta ao Modelo do sólido linear padrão ................................ 64

Figura 4.12 - Função relaxação E(t) para teste do Modelo do sólido linear padrão............. 64

Figura 4.13 - Resultados do algoritmo incremental à relaxação para diferentes $\delta$ t............. 65

Figura 4.14 - Função relaxação E(t) para teste no Modelo de Boltzmann ........................... 66

Figura 4.15 - Resultados do algoritmo incremental à relaxação com $\delta \mathrm{t}=0,2 \mathrm{~s} . \ldots \ldots \ldots \ldots \ldots \ldots . . . . . . . .66$

Figura 4.16 - Segunda deformação imposta ao Modelo de Boltzmann............................... 67

Figura 4.17 - Resultados comparativos método das diferenças finitas vs. método incremental para relaxação $\operatorname{com} \delta \mathrm{t}=0,2 \mathrm{seg}$.

Figura 4.18 - Barra engastada de material visco elástico com deslocamento dependente do

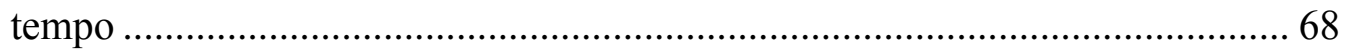

Figura 4.19 - Tensão para barra quando a força $\mathrm{q}(\mathrm{t})$ e o deslocamento $\mathrm{u}(\mathrm{x}, \mathrm{t})$ constantes .. 69

Figura 4.20 - Tensão para barra quando $\mathrm{q}(\mathrm{t})$ é constante e o deslocamento $\mathrm{u}(\mathrm{x}, \mathrm{t})$ variável 70

Figura 4.21 - Valores e unidades adotados para o Modelo de Boltzmann ......................... 70

Figura 4.22 - Função fluência para o Modelo de Boltzmann ............................................. 71

Figura 4.23 - Deformação $\varepsilon(\mathrm{t})$ obtida pelo algoritmo incremental para diferentes $\delta(\mathrm{t}) \ldots \ldots . .72$

Figura 4.24 - Testes 1 e 2 para o Modelo de Boltzmann...................................................... 73

Figura 4.25 - Resultados comparativos método das diferenças finitas vs. método incremental

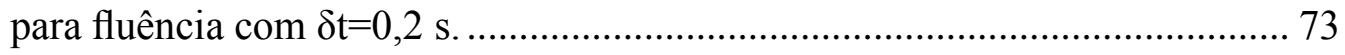

Figura 4.26 - Barra engastada com carregamento axial dependente do tempo ................... 74

Figura 4.27 - Verificação do algoritmo incremental da barra engastada para $P(t)=10$ e

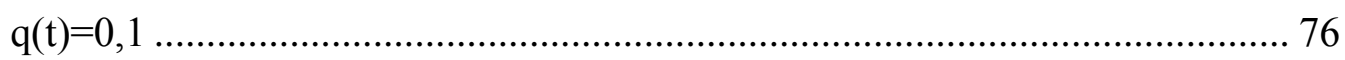

Figura 4.28 - Verificação do algoritmo incremental da barra engastada sendo $P(t)=0,1$ t e

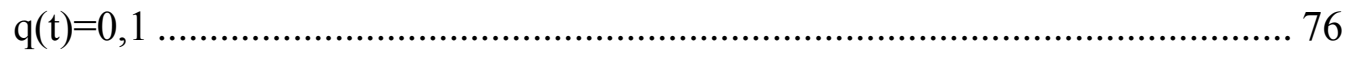
xix 
Figura 4.29 - Viga em balanço submetida ao carregamento $\mathrm{P}(\mathrm{t})$...................................... 77

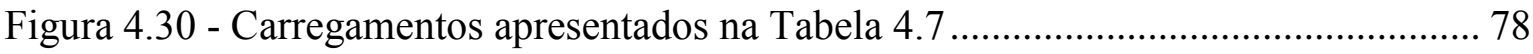

Figura 4.31 - Malha deformada obtido pelo programa SHAY ........................................... 80

Figura 4.32 - Deflexões máximas da viga engastada para os carregamentos constante e de rampa

Figura 4.33 - Deflexões máximas da viga engastada para os carregamentos sinusoidal e de impulso sinusoidal. 82

Figura 4.34 - Diferença quantitativa deslocamento u(t) MEF vs. viga de Timoshenko...... 83

Figura 5.1 - Geometria e propriedades da viga sanduíche analisada................................. 84

Figura 5.2 - Funções de fluência e relaxação da espuma rígida de poliestireno (PS) .......... 85

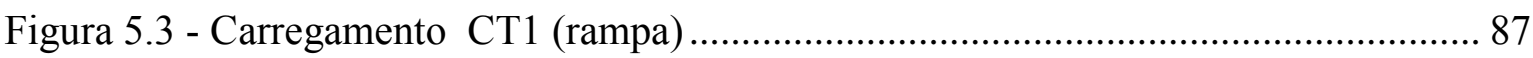

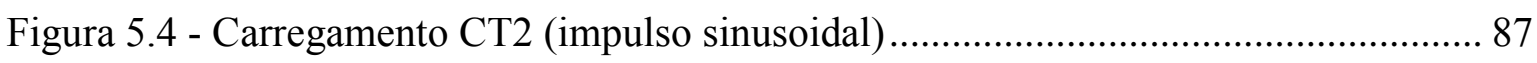

Figura 5.5 - Carregamento CT3 (impulso rampa) …...................................................... 88

Figura 5.6 - Malha deformada da viga sanduíche obtido pelo SHAY ................................. 88

Figura 5.7 - Verificação das deflexões obtidas MVTvv Vs. MEF ..................................... 90

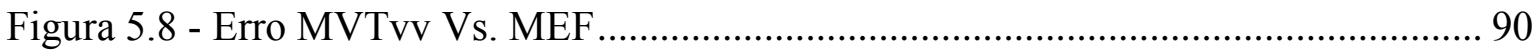

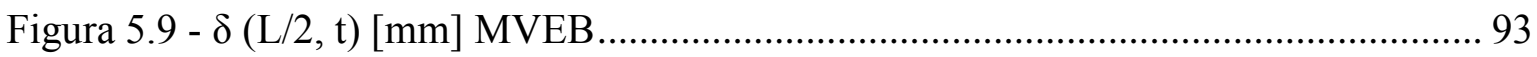

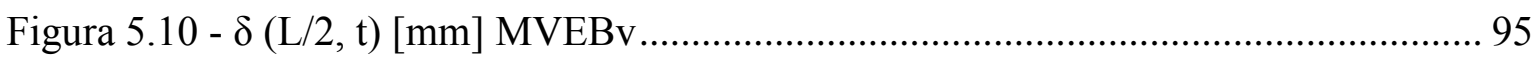

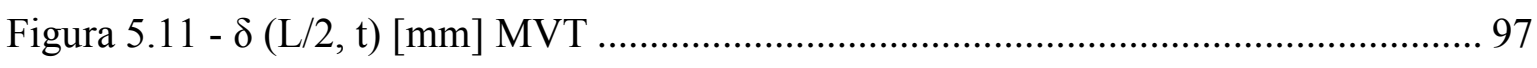

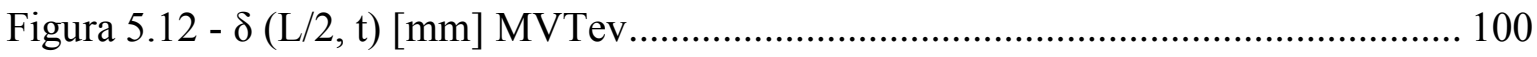

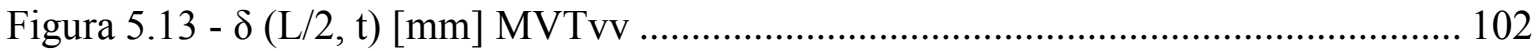

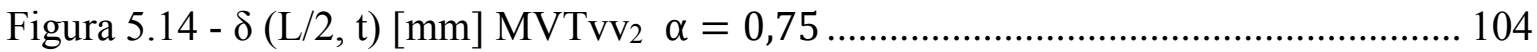

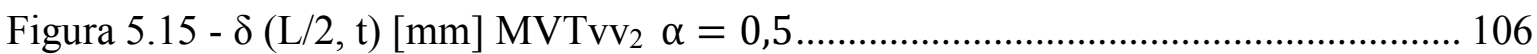

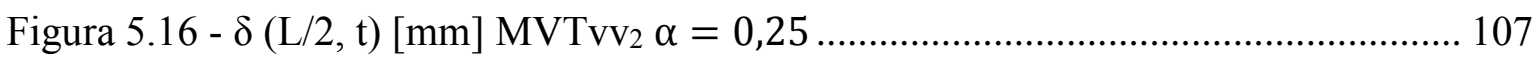

Figura 5.17 - Comparação dos casos de estudo para $\mathrm{T}=1[\mathrm{~h}] \mathrm{t}_{\mathrm{N}}$ máx. ............................. 113

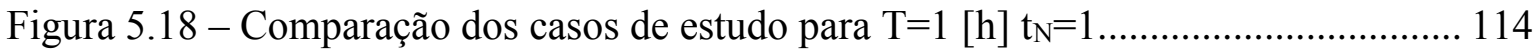

Figura 5.19 - Comparação dos casos de estudo para $\mathrm{T}=100[\mathrm{~h}] \mathrm{t}_{\mathrm{N}}$ máx.......................... 115

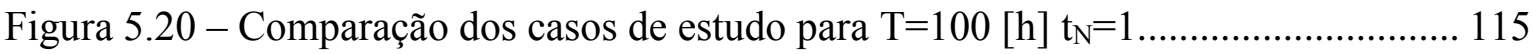

Figura 5.21 - Dimensões geométricas da placa anisotrópica.......................................... 116

Figura 5.22 - Deslocamentos máximos placa anisotrópica $\mathrm{t}=0,1[\mathrm{~h}] \alpha=\beta=0,5 \ldots \ldots \ldots 117$

Figura 5.23 - Deslocamentos máximos placa anisotrópica $\mathrm{t}=10[\mathrm{~h}] \alpha=\beta=0,5 \ldots \ldots \ldots 117$

Figura 5.24 - Deslocamentos máximos placa anisotrópica $\mathrm{t}=1000[\mathrm{~h}] \alpha=\beta=0,5 \ldots \ldots 118$

Figura 5.25 - Deslocamentos máximos placa anisotrópica $\mathrm{t}=0,1[\mathrm{~h}] \alpha=\beta=1$........... 119

Figura 5.26 - Deslocamentos máximos placa anisotrópica $\mathrm{t}=10[\mathrm{~h}] \alpha=\beta=1 \ldots \ldots \ldots \ldots . .119$ 
Figura 5.27 - Deslocamentos máximos placa anisotrópica $\mathrm{t}=1000[\mathrm{~h}] \alpha=\beta=1$ 119

Figura 6.1 - Comparação porcentual dos coeficientes de regressão da função deflexão em $\mathrm{t}_{\mathrm{N}}=1 / 2$. 124

Figura 6.2 - Avaliação de L Vs. P máx. no aumento das deflexões em $t_{\mathrm{N}}=1 / 2 \ldots \ldots \ldots \ldots \ldots . . .125$

Figura 6.3 - Avaliação de L Vs. T no aumento das deflexões em $\mathrm{t}_{\mathrm{N}}=1 / 2 \ldots \ldots \ldots \ldots \ldots \ldots \ldots \ldots . . . .125$

Figura 6.4 - Avaliação de P máx. Vs. T no aumento das deflexões em $t_{\mathrm{N}}=1 / 2 \ldots \ldots \ldots \ldots \ldots . . .126$

Figura 6.5 - Avaliação de $\alpha$ Vs. L no aumento das deflexões em $t_{N}=1 / 2 \ldots \ldots \ldots \ldots \ldots \ldots \ldots . . . . . . . . .126$

Figura 6.6 - Comparação porcentual dos coeficientes de regressão da função deflexão em $\mathrm{t}_{\mathrm{N}}=1$ 127

Figura 6.7 - Avaliação de L Vs. P máx. no aumento das deflexões em $\mathrm{t}_{\mathrm{N}}=1 \ldots \ldots \ldots \ldots \ldots \ldots . . . . . .128$

Figura 6.8 - Avaliação de L Vs. T no aumento das deflexões em $\mathrm{t}_{\mathrm{N}}=1$......................... 128

Figura 6.9 - Avaliação de P máx. Vs. T no aumento das deflexões em $\mathrm{t}_{\mathrm{N}}=1$.................. 129

Figura 6.10 - Avaliação de L Vs. $\alpha$ no aumento das deflexões em $t_{N}=1$.......................... 129

Figura 6.11 - Avaliação de.$\alpha$ Vs. $\beta$ no aumento das deflexões em $\mathrm{t}=0,1[\mathrm{~h}]$................... 130

Figura 6.12 - Avaliação de . $\alpha$ Vs. $\beta$ no aumento das deflexões em $\mathrm{t}=10$ [h] .................... 131

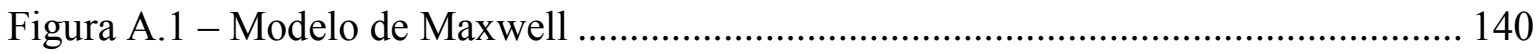

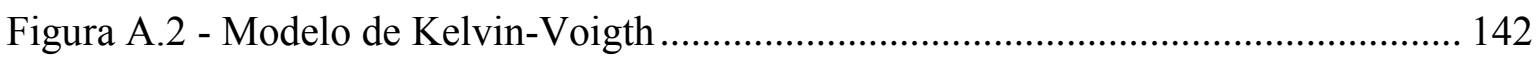

Figura A.3 - Modelo sólido linear padrão ....................................................................... 144

Figura A.4 - Modelo de Boltzmann............................................................................. 147

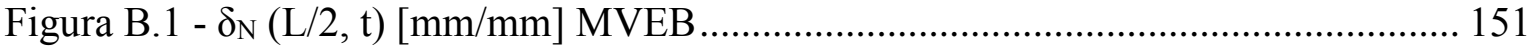

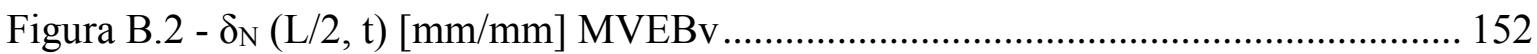

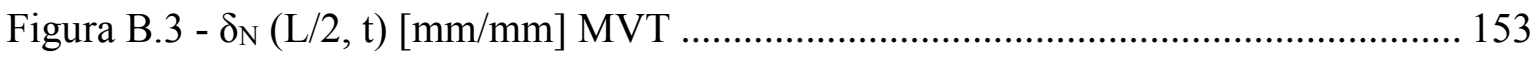

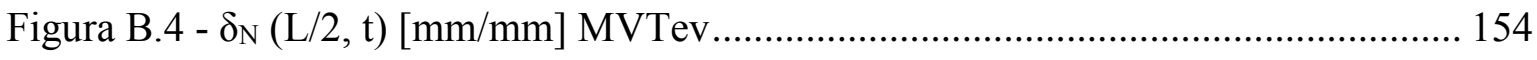

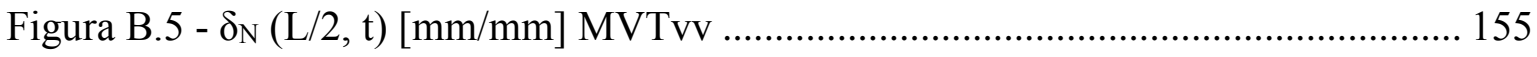

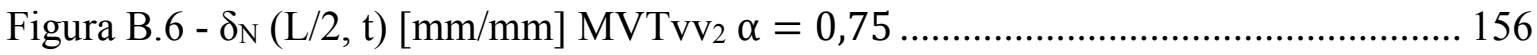

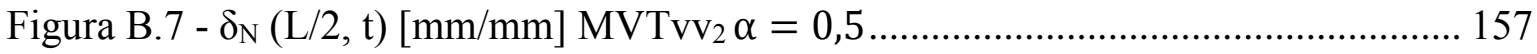

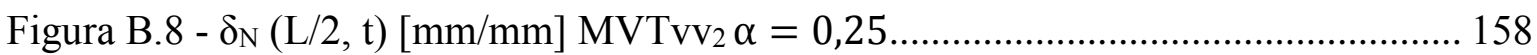




\section{LISTA DE SÍMBOLOS E NOMENCLATURA}

\section{SÍMBOLOS GREGOS}

\begin{tabular}{cl}
$\sigma$ & Tensão \\
$\sigma_{0}$ & Tensão no tempo $t=0$ \\
$\varepsilon$ & Deformação \\
$\varepsilon_{0}$ & Deformação no tempo $t=0$ \\
$\tau$ & Tensão tangencial \\
$\dot{\varepsilon}$ & Taxa de deformação $d \varepsilon / d t$ \\
$\mu$ & Coeficiente de viscosidade \\
$\eta$ & Viscosidade \\
$v$ & Coeficiente de Poisson \\
$\delta(\mathrm{t})$ & Função delta de Dirac \\
$\rho_{\mathrm{i}}$ & Tempo de relaxação correspondente ao coeficiente $\mathrm{i}, \mathrm{i}=1: \mathrm{N}$ \\
$\tau_{\mathrm{i}}$ & Tempo de retardo correspondente ao coeficiente $\mathrm{i}, \mathrm{i}=1: \mathrm{N}$ \\
$\theta(x)$ & Rotação de vigas \\
$\kappa(x)$ & Curvatura de vigas \\
$\varphi$ & Ângulo de rotação da normal à superfície média da viga \\
$\kappa$ & Coeficiente ao cisalhamento de Timoshenko \\
$\delta_{\mathrm{f}}$ & Parcela à flexão da deflexão máxima total de uma viga sanduíche \\
$\delta_{\mathrm{v}}$ & Parcela ao cisalhamento da deflexão máxima total de uma viga sanduíche \\
$\delta_{\mathrm{T}}$ & Deflexão máxima total de uma viga sanduíche \\
$\alpha$ & Fator de diminuição da rigidez da metade inferior de vigas e placas \\
$\delta \mathrm{t}$ & Fator de modificação da rigidez do sentido x ao sentido y em placas \\
\hline & Diferencial de tempo para o algoritmo incremental \\
\hline &
\end{tabular}

\section{SÍMBOLOS LATINOS}

t Variável do espaço do tempo

$s \quad$ Variável do espaço de Laplace

E Módulo de Elasticidade

$u(t) \quad$ Função de Heaveside ou função degrau

$\mathrm{D}(\mathrm{t}) \quad$ Função de fluência no espaço do tempo $t$ 
$\mathrm{D}_{i} \quad$ Coeficiente da função de fluência, $\mathrm{i}=0: \mathrm{N}$

$\mathrm{J}(\mathrm{t})$ Função de fluência ao cisalhamento no espaço do tempo $t$

$\mathrm{D}_{0}, J_{0} \quad$ Valor das funções de fluência quando $t=0$

E(t) Função de relaxação no espaço do tempo $t$

$\mathrm{E}_{i} \quad$ Coeficiente da função de relaxação, $\mathrm{i}=0: \mathrm{N}$

$\mathrm{G}(\mathrm{t})$ Função de relaxação ao cisalhamento no espaço do tempo $t$

$\mathrm{E}_{i}, G_{i} \quad$ Coeficiente das funções de relaxação, $\mathrm{i}=0: \mathrm{N}$

$\mathrm{E}_{\infty}, G_{\infty} \quad$ Valor das funções de relaxação quando $t \rightarrow \infty$

$s \quad$ Variável do espaço de Laplace

$T$ Temperatura dada em graus Celsius $\left[{ }^{\circ} \mathrm{C}\right]$

$E_{A} \quad$ Energia de ativação $[\mathrm{J} / \mathrm{mol}]$

$R \quad$ Constante dos gases ideais [J/ mol.K]

$\mathrm{a}_{\mathrm{t}}(T) \quad$ Fator de deslocamento tempo-temperatura

I Momento de inércia da seção

Imod Momento de inércia da seção da viga sanduíche modificada

EI Rigidez à flexão

$(\mathrm{EI})_{\mathrm{T}} \quad$ Rigidez total à flexão na viga sanduíche

$\left(\mathrm{A}^{\prime} \mathrm{G}\right)_{\mathrm{T}} \quad$ Rigidez total à cortante da viga sanduíche

$q(x) \quad$ Carregamento dependente de $\mathrm{x}$

$w(x) \quad$ Deslocamento transversal ou deflexão da viga

$M(x) \quad$ Momento de flexão

$V(x) \quad$ Cisalhamento transversal

A Área transversal total da viga

$A^{\prime} \quad$ Área da viga corrigida pelo coeficiente ao cisalhamento $\kappa$

$\left\|\mathrm{e}_{N}\right\| \quad$ Erro entre duas funções calculado como norma

\section{OPERADORES MATEMÁTICOS}

$f * g \quad$ Convolução entre as funções $f$ e $g$

$\overline{\mathrm{f}}(\mathrm{s}) \quad$ Transformada de Laplace de uma função geral $\mathrm{f}(\mathrm{t})$

$\mathcal{L}^{\text {inv }}\{\overline{\mathrm{f}}(\mathrm{s})\} \quad$ Transformada inversa de Laplace de uma função geral $\overline{\mathrm{f}}(\mathrm{s})$ 


\section{LISTA DE ABREVIAÇÕES E SIGLAS}

PCEV Princípio de correspondência elástica viscoelástica

PSTT Princípio da superposição tempo-temperatura

MTS Material termo-reológicamente simples

EWLF Equação de Willians-Landel-Ferry

MVEB Modelo de viga de Euler-Bernoulli

MVEBv Modelo de viga de Euler-Bernoulli viscoelástico

MVT Modelo de viga de Timoshenko

MVTev Modelo de viga de Timoshenko : flexão elástica e cisalhamento viscoelástico

MVTvv Modelo de viga de Timoshenko : flexão e cisalhamento viscoelásticos

MVTvv2 Modelo de viga de Timoshenko : flexão e cisalhamento viscoelásticos, metade inferior afetada pelo fator $\alpha$

MEF Método dos elementos finitos

PU Poliuretano

PS Poliestireno

$\mathrm{C} x \quad$ Caso de estudo número $\mathrm{x}, \mathrm{x}=\mathrm{I}: \mathrm{VI}$ nos Capítulos 5 e 6

CTx Carregamento tipo $\mathrm{x}, \mathrm{x}-=1: 3$ no Capítulo 5

Carr. Carregamento

Imp. Impulso 


\section{1 - INTRODUÇÃO}

\section{1 - CONSIDERAÇÕES INICIAIS}

O avanço tecnológico da indústria, tanto nos materiais quanto nas técnicas construtivas como nas necessidades próprias do mundo moderno, fazem imprescindíveis estruturas cada vez mais esbeltas e rígidas. Devido às condições específicas que devem ser atendidas por algumas estruturas, exigindo o melhor do seu comportamento mecânico, aplica-se com sucesso nas indústrias de construção civil, automobilística, naval, ferroviária e aeroespacial, civil, petrolífera entre outras, a utilização da combinação de materiais diferentes, considerando que o comportamento mecânico de um material compósito é geralmente superior de cada material constituinte e são conhecidas como estruturas compósitas.

A estrutura de aviões, devido as condições de trabalho, deve proporcionar alta resistência e além disso, ser o suficientemente leve para não reduzir significativamente a capacidade de carga ou aumentar a demanda de impulso para voar, sendo amplamente usadas as estruturas sanduíche, que são um caso específico das estruturas compósitas, combinando geralmente materiais metálicos com espumas de baixa densidade. A incidência de alguns dos usos das estruturas sanduíche pode ser evidenciada na Figura 1.1, onde os materiais compósitos usados na construção do avião Boeing 787 são o $50 \%$ dos materiais, enquanto o modelo anterior era só de $12 \%$, o que valida o incremento do uso destes tipos de materiais.

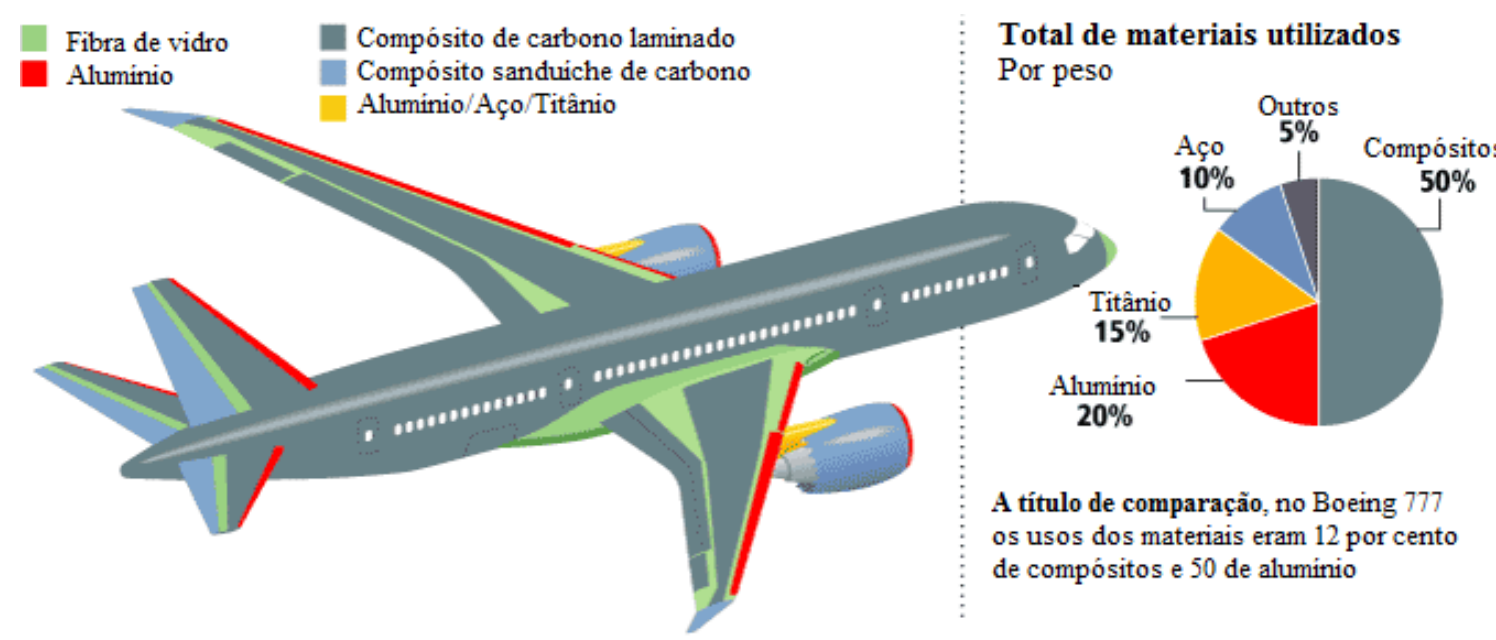

Figura 1.1- Materiais usados no avião Boeing 787

Adaptado - http://modernairliners.com/Boeing787_files/Specifications.html (5/10/14)

Dadas as necessidades específicas, devem ser fornecidos métodos eficientes para o cálculo das tensões e deformações deste tipo de estruturas. Atualmente, com os métodos 
computacionais baseados em métodos numéricos como o método dos elementos finitos, podem-se projetar estes tipos de estruturas mais rapidamente, no entanto, as falhas apresentadas recentemente em algumas destas estruturas permitem mostrar que seu estudo é de vital importância para evitar os onerosos custos de refazer ou reforçar estruturas projetadas inadequadamente onde existe a possibilidade de comprometer vidas humanas.

Assim, e para entender melhor o fenômeno da viscoelasticidade e seus efeitos estudaram-se na presente pesquisa o comportamento mecânico de vigas e painéis sanduíche, chamadas também de estruturas compósitas laminares. O uso de painéis e vigas sanduíche tornou-se muito popular para aplicações que requerem alta resistência e rigidez, como por exemplo as peças específicas de aeronaves indicadas na Figura 1.2, sendo cada vez maior seu uso, devido a serem compostas de um núcleo de baixa densidade colocado no meio de duas camadas de alta densidade, com um comportamento mecânico similar as vigas tipo I, onde em analogia, o núcleo atua como a alma e as camadas elásticas como as mesas, correspondendo ao aumento da inércia aportada pelo núcleo e o controle de deformações suportado nas camadas externas (Ansel C. Ugural, 2009).

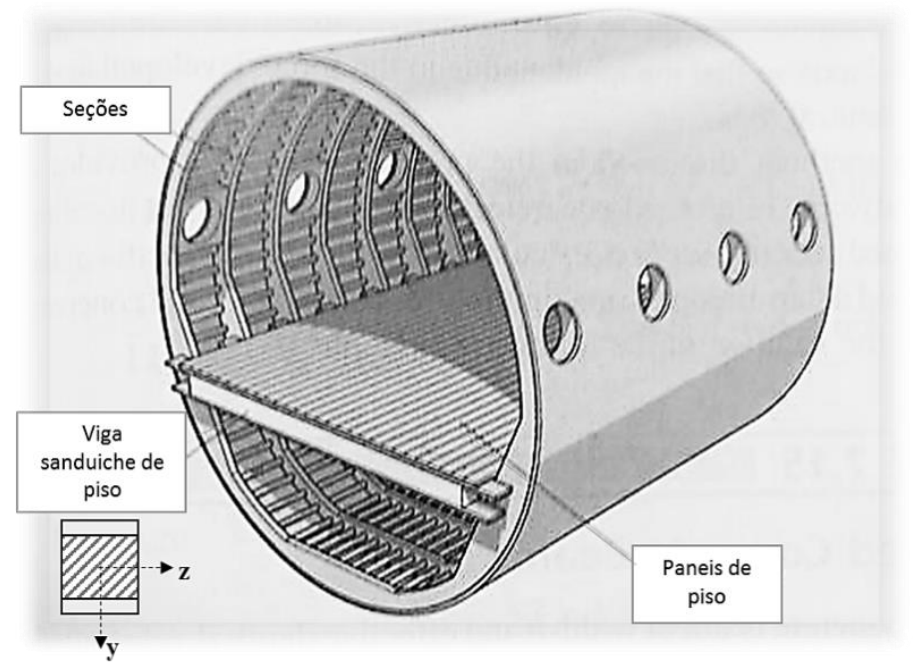

Figura 1.2 - Seção central típica de um avião. Adaptado de Ugural (2009)

Desta forma, foram desenvolvidos na literatura métodos analíticos para a solução elástica das estruturas laminares, que desconsideram a resposta ao longo do tempo dos materiais e a realidade no cálculo das deflexões máximas quando são submetidos a carregamentos mecânicos variáveis. 


\section{2 - JUSTIFICATIVA}

O estudo da viscoelasticidade dos materiais da construção é de vital importância, isto devido a que seu comportamento não é bem entendido e como consequência disso, ao ser erradamente avaliado seu comportamento mecânico podem chegar ao colapso. Exemplo desse tipo de eventos é a ponte Koror-Babeldaob (241 metros), sua construção foi terminada no ano de 1977 e colapsou no ano de 1996 depois do pre-esforço de reparação, como se apresenta na Figura 1.3. O colapso foi dado como consequência de que as estimativas da deflexão máxima aos 18 anos calculadas no projeto foram num $50-77 \%$ menores do que as deflexões máximas reais obtidas nesse tempo, o cálculo da perdas foi menor do que as reais e foram desconsideradas as diferenças na espessura das paredes da seção transversal, o craqueamento da laje superior e o real comportamento da fluência da metade submetida a tensão (Bazant et al., 2011; Bazant, Asce, Yu, \& Li, 2012a, 2012b).

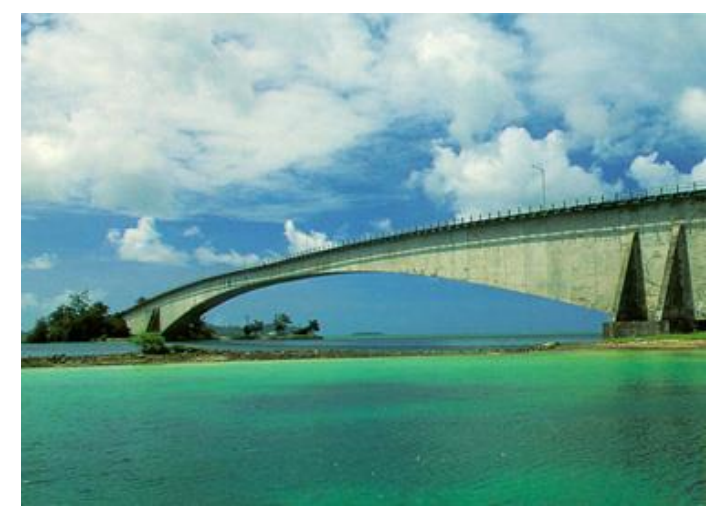

(a) 1977

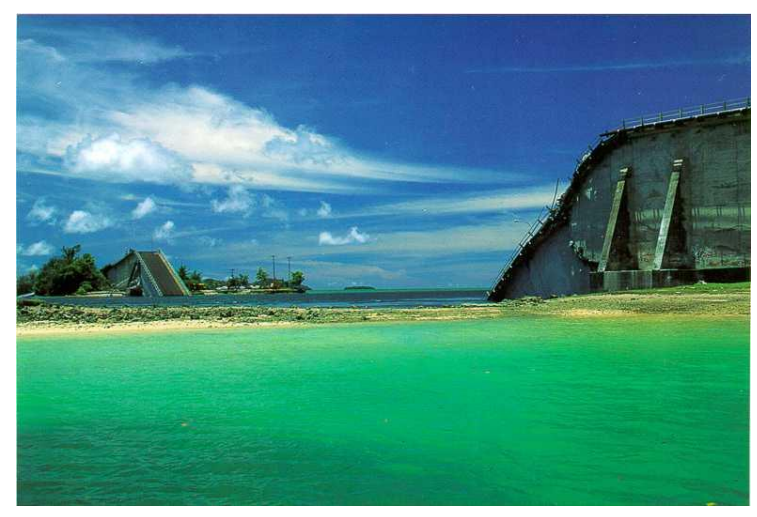

(b) 1996

Figura 1.3 - Ponte Koror-Babeldaob - Palau (Jápão)

Adaptado - http://astronomy.nmsu.edu/geas/lectures/lecture17/slide01.html (5/6/15)

O comprometimento estrutural por efeito da viscoelasticidade reflete numa recuperação ou reforço impossível, complexo ou muito oneroso, tal e como por exemplo no caso da Ponte Koror-Babeldaob da Figura 1.3. Por este motivo, a análise do comportamento mecânico de estruturas laminares considerando a viscoelasticidade, é mais do que necessário e pertinente, mais e com a ampla e crescente demanda nas diferentes industrias.

Baseando-se nesta necessidade, realizou-se o estudo das deflexões dos compósitos laminares, para estudar seu comportamento e a incidência da viscoelasticidade sob os materiais que compõem o núcleo. No caso das vigas e painéis sanduíche, os materiais mais utilizados recentemente para o núcleo destas estruturas laminares, são as espumas de policarbonato, policloreto de vinila (PVC), poliuretano (PU) e poliestireno (PS), no entanto 
curiosamente, os estudos comumente realizados pelo método dos elementos finitos, não têm contemplado os materiais nomeados, deixando a lacuna de um método analítico baseado nas teorias de viga que permita considerar a viscoelasticidade dos materiais e avaliar rapidamente a interação dos materiais e os carregamentos mecânicos, inferindo assim novos usos a este tipo de estruturas, e aproveitar as inúmeras vantagens como elementos estruturais.

Devido a isto, é necessário desenvolver um método fundamentado nas soluções elásticas analíticas dos compósitos laminares, desta vez considerando a viscoelasticidade que podem experimentar os materiais do núcleo, abrindo assim múltiplas possibilidades na implementação destas estruturas para novos usos e materiais.

\section{3 - OBJETIVOS}

\subsection{1 - Objetivo geral}

Esta dissertação objetiva propor uma metodologia de análise do comportamento mecânico viscoelástico de compósitos laminares, utilizando algoritmos numéricos e o princípio da correspondência elástica viscoelástica. Pretende-se quantificar o aumento das deflexões e dos esforços, como sua variação ao longo do tempo, permitindo um melhor entendimento do comportamento dos materiais e da geometria da estrutura, quando são submetidos a diferentes tipos de carregamentos mecânicos.

\subsection{2 - Objetivos específicos}

Para os objetivos específicos deste trabalho, pretende-se:

- Realizar uma análise analítica e numérica da resposta viscoelástica dos materiais e dos compósitos laminares, usando as séries de Prony e o Princípio de Correspondência;

- Propor um algoritmo de interconversão das propriedades viscoelásticas de fluência e relaxação;

- Implementar e verificar com modelos viscoelásticos simples a resposta viscoelástica obtida com os métodos analíticos e numéricos propostos, e posteriormente estender esta metodologia aos elementos compósitos laminares; 
- Analisar a resposta viscoelástica dos modelos estudados, fazendo um estudo paramétrico, contemplando como variáveis os materiais e os diferentes tipos de carregamentos mecânicos.

\section{4 - RESUMO DA METODOLOGIA}

Inicialmente estudam-se as propriedades viscoelásticas dos materiais, sendo para isto necessária a formulação de dois algoritmos numéricos. $\mathrm{O}$ primer algoritmo obtém por aproximação numérica, a série de Prony que melhor descreve os dados experimentais resultado de um teste de fluência ou relaxação, e com essa descrição matemática por séries de Prony da propriedade viscoelástica testada, precisa-se de um segundo algoritmo numérico para obter os coeficientes e exponentes de uma das funções, relaxação ou fluência, conhecendo os coeficientes e exponentes da outra, usando o princípio de correspondência elástica visco elástica, utilizando para estes e todos os algoritmos implementados o software Matlab.

Com as características elásticas e viscoelásticas de todos os materiais que compõem o elemento estrutural laminar sanduíche, como se apresentará em detalhe na revisão bibliográfica, a resposta analítica viscoelástica implica um algoritmo incremental envolvendo uma convolução destas funções viscoelásticas com o carregamento, sendo preciso implementar um novo algoritmo que realize esta convolução tanto no campo das tensões como no campo das deformações.

Realizada a formulação dos algoritmos para o tratamento das propriedades dos materiais e para obter a resposta viscoelástica dos elementos estruturais baseados na resposta elástica, formulan-se variadas verificações sob as respostas de elementos estruturais mais simples, comparando os resultados obtidos com os algoritmos propostos com as respostas dos diferentes métodos estudados na literatura.

Implementada e verificada a metodologia para obter as respostas viscoelásticas em elementos simples, procede-se a ser aplicada nos elementos de compósitos laminares, ou seja, vigas e placas compósitas, onde avaliam-se as variáveis geométricas e de materiais correspondentes, e finalmente realiza-se uma análise paramétrica com diferentes combinações para obter os resultados. 


\section{5 - ORGANIZAÇÃO DA DISSERTAÇÃO}

A presente dissertação está dividida em cinco capítulos. O Capítulo 2 apresenta a revisão bibliográfica que se constitui de duas subseções. Na primeira seção revisa-se conceitos fundamentais da viscoelasticidade, como são os modelos viscoelásticos clássicos, as séries de Prony, o princípio de correspondência elástica viscoelástica, o princípio de superposição e o incremento unidimensional de esforços e deformações ao longo do tempo devido à viscoelasticidade. A segunda seção estuda em detalhe os elementos estruturais compósito tipo viga e tipo placa.

Cada um dos algoritmos implementados no Matlab para o desenvolvimento da pesquisa são explicados e desenvolvidos no Capítulo 3, e as múltiplas verificações para cada um dos quatro algoritmos formulados são apresentas no Capitulo 4, onde são testados desde os modelos viscoelásticos simples comparados com métodos analíticos e numéricos, até modelos mais complexos verificados com modelos realizados pelo método dos elementos finitos, garantindo assim a confiabilidade do método incremental analítico proposto nesta dissertação.

No Capítulo 5, sintetiza-se os resultados obtidos para a análise realizada sob a viga sanduíche onde considerou-se diferentes tipos de carregamentos e materiais, comparando as teorias de Euler-Bernoulli e Timoshenko para o elemento de viga no campo elástico, e no caso de painéis estes considerados anisotrópicos e compósitos, segundo a teoria de Love-Kirchhoff. $\mathrm{Na}$ presente dissertação essas teorias são estendidas ao comportamento viscoelástico e avalia-se a influência da interação dos materiais viscoelásticos no seu comportamento mecânico, formulando-se diferentes casos de estudo, o que permite avaliar não só diferentes condições, como também diferentes tipos de materiais e variação dimensional das camadas do elemento, o que abre as possibilidades para análises paramétricas mais completas.

A análise paramétrica para cada um dos elementos é realizada no Capítulo 6, onde é apresentada uma série de superfícies que permite avaliar a influência real de cada parâmetro avaliado no estudo, assim como também é quantificado a porcentagem de influência das diferentes variáveis e as combinações delas.

Finalmente, as conclusões da análise dos resultados obtidos ao longo da pesquisa e principalmente do Capítulo 5 e 6 são resumidas no Capitulo 7, enriquecendo o trabalho com 
dados práticos para o entendimento e a elaboração do projeto deste tipo de estruturas, concernentes à interação dos materiais e as condições impostas, as variáveis mais incidentes no comportamento das vigas do tipo sanduíche e dos painéis anisotrópicos, aportando ferramentas para a escolha das dimensões, do tipo de materiais quanto os carregamentos ou condições que permitem seu melhor comportamento estrutural, e propõe planos de pesquisa futuros baseados em alguns questionamentos que foram além do presente trabalho. 


\section{2 - REVISÃO BIBLIOGRÁFICA}

No presente Capítulo se apresenta uma breve revisão teórica da viscoelasticidade e os elementos estruturais do tipo viga e placa. Os aspectos aqui conceituados são fundamentos da formulação, implementação e verificação dos algoritmos propostos nos capítulos seguintes.

\section{1 - VISCOELASTICIDADE}

Os materiais viscoelásticos lineares caracterizam-se por terem um comportamento intermediário entre os sólidos elásticos lineares e os fluidos viscosos simples ou newtonianos. Materiais considerados como sólidos elásticos lineares atendem a lei de Hooke e, desta forma, aplica-se o conceito que as tensões e deformações são proporcionais, independentes do tempo, como se apresenta na

Figura 2.1 (a). A partir do comportamento dos materiais elásticos, apresentado na

Figura 2.1 (a), deduz-se uma propriedade intrínseca do material, chamada de módulo de elasticidade $\mathrm{E}$, que é a constante de proporcionalidade entre a deformação e a tensão que o corpo experimenta, em adiante, representado graficamente por uma mola.

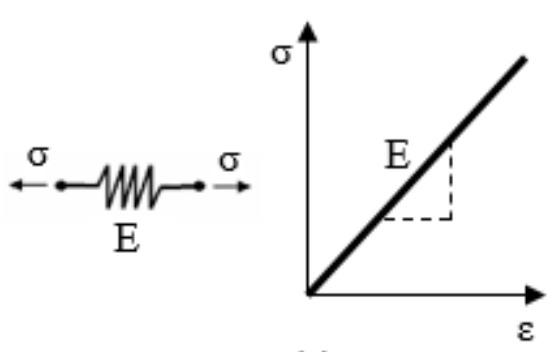

(a)

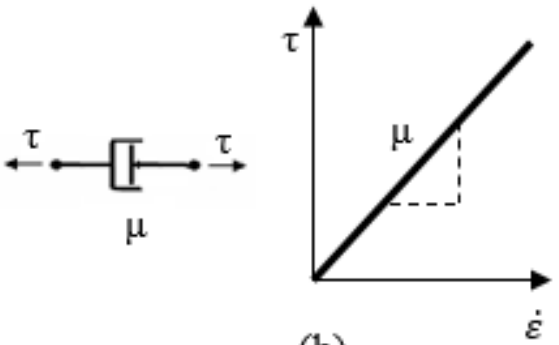

(b)

Figura 2.1 -Analogias mecânicas dos modelos elástico e viscoso simples

(a) Sólido elástico linear (Lei de Hooke). (b) Fluído simples (Newtoniano)

Quando se impõe um carregamento em um elemento elástico linear, este apresenta uma deformação diretamente proporcional ao carregamento imposto, dando origem à uma relação constitutiva correspondente à relação entre a tensão $\sigma$ e a deformação $\varepsilon$, dada pela Equação (2.1).

$$
\sigma=\mathrm{E} \varepsilon
$$

Fluidos viscosos simples, caracterizam-se por terem viscosidade constante ao longo do tempo, onde a relação entre o esforço cisalhante e a taxa de deformação é linear, assim 
carecem de propriedades elásticas, como é apresentado na Figura 2.1 (b), isto claro, com algumas exceções que apresentam propriedades elásticas como por exemplo o ar. Para os fluidos Newtonianos, geralmente representados graficamente por um amortecedor, quando uma tensão cisalhante $\tau$ é imposta, o corpo apresenta uma taxa de deformação $\dot{\varepsilon}$ diretamente proporcional ao carregamento, onde o meio dissipa a energia. A equação constitutiva está dada na Equação (2.2), onde $\mu$ representa a viscosidade.

$$
\tau=\mu \dot{\varepsilon}
$$

Um material é considerado exclusivamente viscoelástico se este tem a capacidade de armazenar energia de deformação como os sólidos elásticos e, além disto, dissipam esta energia segundo as leis dos Fluidos viscosos. Conhece-se que os materiais viscoelásticos, estando submetidos a tensão ou deformação constante, podem experimentar um dos seguintes comportamentos, para cada caso (Christensen, 1982; Mase, 1970): o fenômeno da fluência (creep), que acontece depois da deformação instantânea, quando o material é exposto a uma tensão constante $\left(\sigma=\sigma_{0}\right)$, fazendo com que a deformação aumente em função do tempo $(\varepsilon=\varepsilon(\mathrm{t}))$, e o fenômeno da relaxação, que ocorre quando, mantendo-se uma deformação constante, no meio contínuo $\left(\varepsilon=\varepsilon_{0}\right)$, onde a tensão inicial diminui ao longo do tempo em função deste $(\sigma=\sigma(t))$.

\subsection{1 - Analogias mecânicas}

As analogias mecânicas permitem explicar o comportamento elétrico e viscoelástico dos materiais, onde a tensão mecânica é correspondente à voltagem e a taxa de deformação seria análoga à corrente. $\mathrm{O}$ módulo de elasticidade é equivalente à capacitância do circuito, medindo a capacidade de armazenamento de energia, e a resistência do circuito é comparável com a viscosidade, medindo a capacidade para dissipar energia. Essa forma de visualização dos modelos viscoelásticos pretendem representar de forma simples tanto os efeitos elásticos quanto efeitos viscosos, adotando diferentes arranjos de molas e amortecedores, para assim representar adequadamente as condições de cada modelo a ser simulado.

\subsubsection{1 - Modelo de Maxwell}

Segundo múltiplos autores da literatura clássica e atual (Chaves, 2009; Christensen, 1982; Mase, 1970), o modelo viscoelástico de James Clerk Maxwell, é uma combinação de uma mola ou elemento elástico, e um amortecedor ou elemento viscoso, conectados em série, 
como se indica na Figura 2.2. Uma das limitações do modelo de Maxwell consiste em que este prevê um aumento linear da deformação ao longo do tempo quando a tensão é constante, mas a maioria de os polímeros mostram uma taxa de deformação diminuindo ao longo do tempo pelo efeito da viscoelasticidade.

Devido a isso, entre as principais aplicações desse modelo são modelagem de polímeros termoplásticos perto de sua temperatura de fusão, do concreto fresco e alguns metais próximos ao seu ponto de fusão (Prado, Valera, \& Cervantes, 2013).

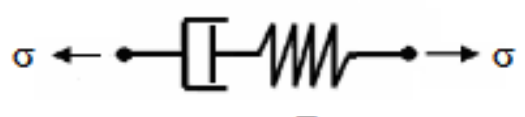

$\eta \quad \mathrm{E}$

Figura 2.2 - Modelo de Maxwell

A relação tensão-deformação $(\sigma-\varepsilon)$ para o modelo de Maxwell é dada pela soma da deformação individual de cada elemento e o esforço que experimentam individualmente será igual para ambos. Aplicando as equações constitutivas de cada elemento apresentadas nas Equações (2.1) e (2.2), pode-se deduzir a equação diferencial que descreve o comportamento do modelo de Maxwell na Equação (2.3). O desenvolvimento matemático anexou-se no numeral A.1 - .

$$
\dot{\varepsilon}=\frac{\dot{\sigma}}{\mathrm{E}}+\frac{\sigma}{\eta}
$$

Ao aplicar a condição de contorno para o carregamento $\sigma=\sigma_{0}$, constante para um tempo t $>0$ e substituindo essa condição para a solução da Equação diferencial (2.3), pode-se obter a resposta geral do comportamento a fluência como apresentado na Equação (2.4) e ilustrado na Figura 2.3, obtido matematicamente segundo anexo A.1.1 - .

$$
\varepsilon(\mathrm{t})=\frac{\sigma}{\mathrm{E}}+\frac{\sigma}{\eta} \mathrm{t}
$$

Na Figura 2.3, observa-se que no instante de aplicação da carga $\left(t>t_{0}=0\right)$, o elemento de Maxwell responde com uma deformação equivalente à deformação elástica e após a aplicação do carregamento, a deformação atende ao comportamento viscoso. Quando a carga é retirada do modelo $\left(t>t_{1}=0\right)$, ele recupera somente a parcela elástica de forma instantânea, por este motivo, a fluência é considerada reversível apenas para esta parcela, permanecendo deformado apenas o elemento viscoso. 


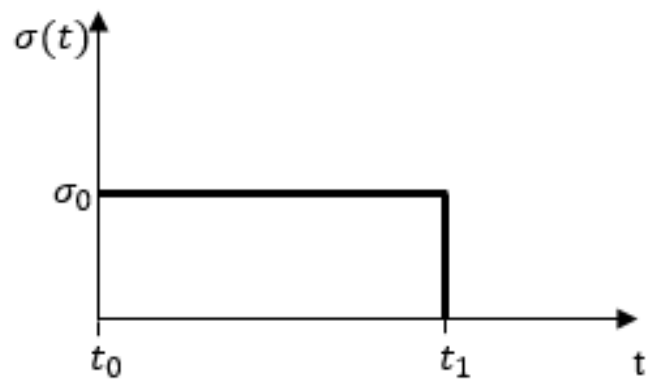

(a) Solicitação

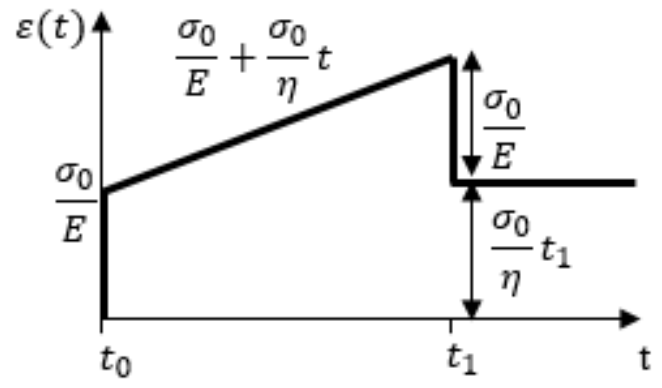

(b) Resposta

Figura 2.3 - Solicitação e resposta ao teste de relaxação para o elemento de Maxwell

O modelo de Maxwell a partir do tempo $t=0$ experimenta uma resposta instantânea devida à parcela elástica do sistema (representada pela mola), e tem um aumento constante e ilimitado das deformações nos tempos subsequentes. A deformação inicial dependerá do módulo de elasticidade $\mathrm{E}$, onde quanto mais rígido ou maior for o seu valor com respeito à viscosidade $\eta$, maior será sua resposta instantânea no tempo $t=0$.

Analisando o elemento de Maxwell submetido a uma deformação constante $\varepsilon=\varepsilon_{0}$, ou o teste de relaxação, obtém-se a resposta da Equação diferencial (2.3) para o comportamento à relaxação do elemento, dada pela Equação (2.5), obtida segundo desenvolvimento apresentado no anexo A.1.2 - .

$$
\sigma(\mathrm{t})=\varepsilon_{0} E \mathrm{e}^{-\frac{\mathrm{E}_{\mathrm{t}}}{\mathrm{t}}}
$$

O comportamento obtido pelo teste de relaxação sob o elemento de Maxwell, esquematicamente é descrito na Figura 2.4, onde pode-se apreciar como a tensão no elemento diminui ao longo do tempo mesmo e com uma solicitação constante, isto pelo efeito da viscosidade do elemento.

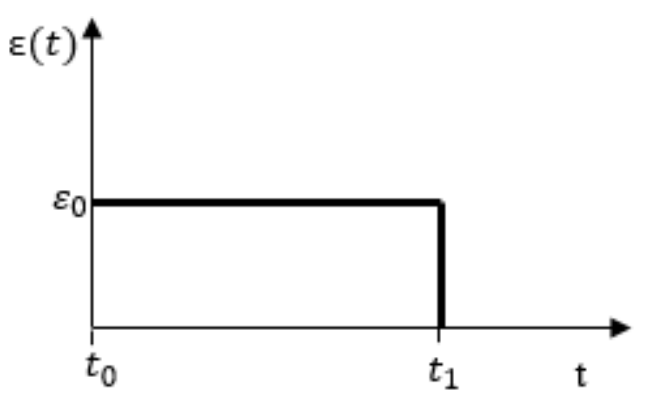

(a) Solicitação

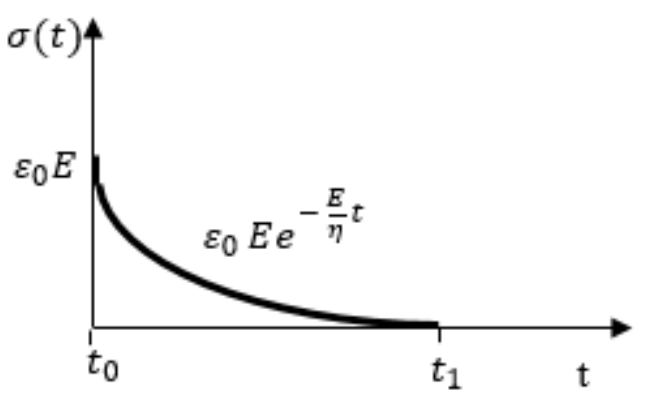

(b) Resposta

Figura 2.4 - Solicitação e resposta ao teste de relaxação para o elemento de Maxwell 


\subsubsection{2 - Modelo de Kelvin-Voigt}

O modelo proposto por Lorde Kelvin é um modelo reológico baseado na combinação combinada do elemento viscoso (amortecedor) com o elemento elástico (mola), ligados em paralelo, como se apresenta na Figura 2.5. O comportamento do modelo de Kelvin descreve o comportamento de um sólido viscoelástico, sendo assim, quando o modelo atende à um esforço de tensão nas extremidades, cada elemento do modelo, tanto da parte elástica quanto da parte viscosa, contribui quantitativamente no esforço do modelo. Esta contribuição conjunta na deformação é devida ao paralelismo da conexão dos elementos, desta forma, a deformação instantânea será nula por influência da viscosidade do amortecedor.

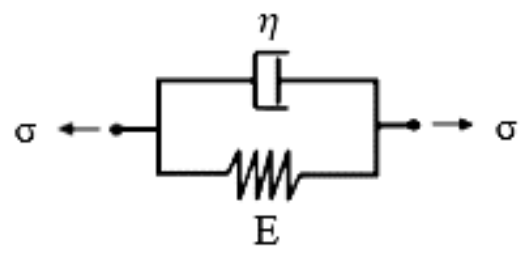

Figura 2.5 - Modelo de Kelvin

Assim, a relação da tensão-deformação para o modelo será dada pela soma das tensões de cada elemento e pelas deformações que são iguais, referindo-se dessa forma à parcela elástica e viscosa do modelo. Atendendo estas condições de contorno para o sistema e realizando uma análise análoga ao realizado para o sistema de Maxwell, pode-se obter a equação diferencial para descrever o comportamento do modelo de Kelvin, apresentado na Equação (2.6), desenvolvida matematicamente segundo apresentado no anexo A.2 - .

$$
\frac{\sigma}{\eta}=\frac{E}{\eta} \varepsilon+\dot{\varepsilon}
$$

Ao aplicar um carregamento $\sigma=\sigma_{0}$, constante para um tempo $t>0$, realiza-se um teste de fluência, como é apresentado na Figura 2.6.

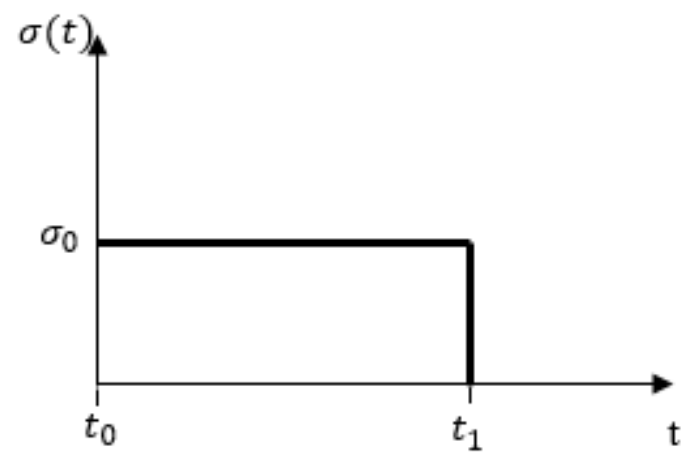

(a) Solicitação

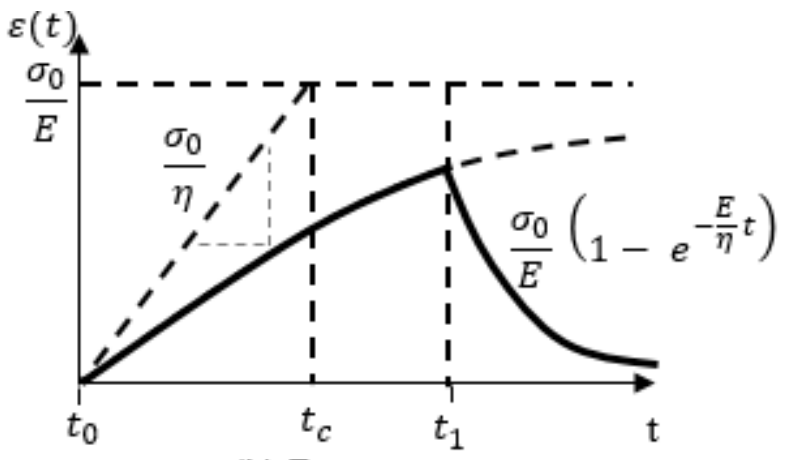

(b) Resposta

Figura 2.6 - Solicitação e resposta ao teste de fluência para o elemento de Kelvin 
Para determinar matematicamente o comportamento a fluência, descrito pela Equação (2.7), o procedimento é anexo no numeral A.2.1 - .

$$
\varepsilon(t)=\frac{\sigma_{0}}{E}\left(1-e^{-\frac{E}{\eta} t}\right)
$$

Observa-se que o modelo de Kelvin experimenta um aumento da deformação no instante da aplicação do carregamento, partindo da deformação instantânea que é nula, constituindo uma curva que tende ao valor do esforço que experimentaria exclusivamente o elemento elástico. Quando o carregamento é retirado, o modelo tem uma recuperação lenta exponencial com a taxa de $-E / \eta$. Ao analisar o modelo de Kelvin no teste de relaxação, isto é, submetendo este a uma deformação constante, obtém-se a resposta como se mostra na Equação (2.8).

$$
\begin{aligned}
& \sigma(\mathrm{t})=\varepsilon_{0}(\mathrm{Eu}(\mathrm{t})+\eta \delta(\mathrm{t})) \\
& \sigma\left(0^{+}\right) \rightarrow \infty \\
& \sigma(\infty)=\varepsilon_{0} E
\end{aligned}
$$

Na expressão (2.8), $\mathrm{u}(\mathrm{t})$ representa a função de Heaviside e $\delta(\mathrm{t})$ a função delta de Dirac. A função de Heaviside ou função degrau é a função descontínua de valor zero para argumento negativo, e um para argumento positivo, entanto que para argumento nulo seu valor é o intervalo aberto $(0 ; 1)$, sendo uma função muito usada como distribuição e seu comportamento apresenta-se segundo a Equação

$$
\mathrm{u}(\mathrm{t})=\left\{\begin{array}{l}
(0,0) \forall t<t_{1} \\
(1,0) \forall t>t_{1}
\end{array}\right.
$$

A distribuição ou função generalizada Delta de Dirac informalmente pode-se descrever como a derivada da função de Heaviside, mas pode-se descrever graficamente como apresentado na Figura 2.7.

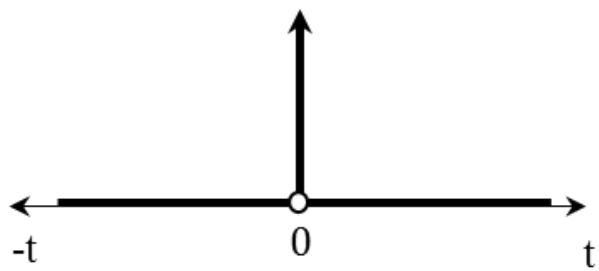

Figura 2.7 - Distribuição delta de Dirac. 
A resposta para relaxação do modelo de Kelvin não é considerada na literatura como apropriado para a modelagem de sólidos, sendo comumente usados os modelos compostos mais elementos, como o sólido padrão ou o modelo de Boltzmann.

\subsubsection{3 - Modelo do sólido linear padrão}

O modelo do sólido linear padrão estabelece uma associação em paralelo de um elemento elástico simples com um elemento de Maxwell, como se apresenta na Figura 2.8.

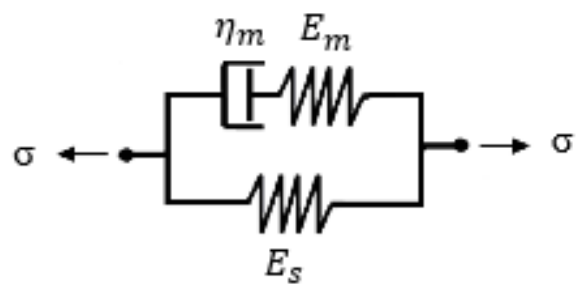

Figura 2.8 - Modelo sólido linear padrão

Para obter a equação diferencial característica do comportamento deste elemento, consideram-se iguais as deformações experimentadas tanto pelo elemento de Maxwell, quanto pelo elemento elástico, diferente dos esforços, que serão a somatória da parcela aportada por cada um dos elementos nomeados anteriormente (Christensen, 1982). Como resultado destas considerações, para o conjunto trabalhando em paralelo e aplicando as equações constitutivas de cada elemento, pode-se obter a equação diferencial representativa dada pela Equação (2.10), deduzida analiticamente no anexo A.3 - , tanto a Equação diferencial como as respostas respectivas aos testes de fluência e relaxação.

$$
\left(1+\frac{E_{s}}{E_{m}}\right) \dot{\varepsilon}+\frac{E_{s}}{\eta_{m}} \varepsilon=\frac{\dot{\sigma}}{E_{m}}+\frac{\sigma}{\eta_{m}}
$$

Considerando a equação constitutiva do sistema e avaliando as condições do teste de fluência, sendo essas um esforço constante ao longo do tempo, correspondente a $\sigma(\mathrm{t})=\sigma_{0}$ para $t>0$, pode ser resolvida obtendo-se a Equação (2.11).

$$
\begin{aligned}
& \varepsilon(\mathrm{t})=\sigma_{0} D(t) \\
& D(t)=\left(\frac{1}{E_{m}+E_{s}}+\frac{1}{E_{S}}\left(1-e^{-\frac{E_{s} E_{m}}{\eta_{m}\left(E_{m}+E_{s}\right)} t}\right)\right)
\end{aligned}
$$

Segundo a expressão (2.11), a resposta ao teste de fluência aporta matematicamente o comportamento à fluência $D(t)$ do material dada na Equação (2.12), sendo variável no 
tempo, independentemente do valor da tensão inicial aplicada $\sigma_{0}$, quem só aumentará escalar mente a resposta à fluência.

No caso do teste à relaxação do modelo do sólido padrão, considera-se uma deformação constante ao longo do tempo $\varepsilon(t)=\varepsilon_{0}$ para $t>0$, onde ao aplicar estas condições na Equação (2.10), obtém-se a solução ao teste de relaxação do sistema, segundo o apresentado na Equação (2.13).

$$
\begin{aligned}
& \sigma(\mathrm{t})=\varepsilon_{0} \mathrm{E}(\mathrm{t}) \\
& E(t)=\left(\mathrm{E}_{\mathrm{s}}+\mathrm{E}_{\mathrm{m}} \mathrm{e}^{-\frac{\mathrm{E}_{\mathrm{m}}}{\eta_{\mathrm{m}}} \mathrm{t}}\right)
\end{aligned}
$$

Note-se que na expressão (2.13), como resultado ao teste de relaxação, obteve-se a representação matemática da função de relaxação $E(t)$ apresentada na Equação (2.14), onde de forma análoga ao teste de fluência, a deformação correspondente ao deslocamento inicial imposto $\varepsilon_{0}$ atua como um escalar da relaxação.

\subsubsection{4 - Modelo de Boltzmann}

O modelo de Boltzmann considera um elemento de Kelvin e um elemento elástico simples operando em série, como é apresentado na Figura 2.9 (Christensen, 1982; Schapery, 1969).

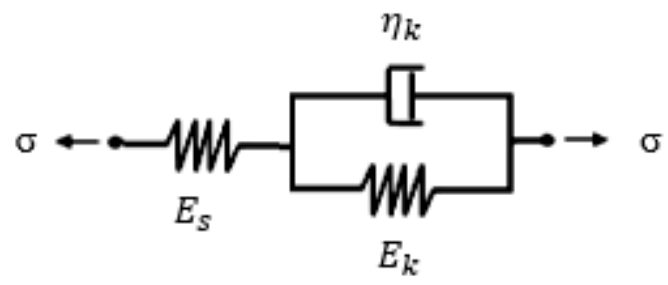

Figura 2.9 - Modelo de Boltzmann

De forma similar aos desenvolvimentos matemáticos feitos no caso do sólido padrão anterior, ou seja, considerando as equações conjuntas fundamentais para o modelo, onde para este caso, a deformação é a somatória das deformações individuais do elemento de Kelvin e do elemento elástico isolado, bem como o esforço para os dois elementos têm igual magnitude, como pode ser analisado no desenvolvimento matemático anexo no numeral A.4 - . Empregando as equações constitutivas do elemento de Kelvin e do elemento elástico, pode-se obter a equação diferencial característica do sistema, descrita na Equação (2.15).

$$
\left(1+\frac{E_{k}}{E_{s}}\right) \sigma+\frac{\eta_{k}}{E_{s}} \dot{\sigma}=E_{k} \varepsilon+\eta_{k} \dot{\varepsilon}
$$


Baseados na Equação (2.15) avaliando nesta as condições para obter a resposta à fluência, aplicando um esforço constante ao longo do tempo $\sigma(t)=\sigma_{0}$ para tempos $t>0$, solucionase a equação diferencial e obtém-se a resposta ao teste de fluência dada pelas Equações (2.16) e (2.17).

$$
\begin{aligned}
& \varepsilon(t)=\sigma_{0} D(t) \\
& D(t)=\left(\frac{1}{E_{s}}+\frac{1}{E_{k}}\left(1-e^{-\frac{E_{k}}{\eta_{k}} t}\right)\right)
\end{aligned}
$$

Para obter a resposta a relaxação do modelo, considera-se um carregamento constante ao longo do tempo, validando com isso as seguintes condições de contorno: $\varepsilon(0)=\varepsilon_{0}$ para tempo $\mathrm{t}>0$ e consequentemente $\dot{\varepsilon}(\mathrm{t})=0$. Desta forma o comportamento à relaxação avalia-se segundo as pelas Equações (2.18) e (2.19).

$$
\begin{aligned}
& \sigma(t)=\varepsilon_{0} E(t) \\
& E(t)=\frac{E_{s}}{\left(E_{s}+E_{k}\right)}\left(E_{k}+E_{s} \cdot e^{-\frac{E_{s}+E_{k}}{\eta_{k}} t}\right)
\end{aligned}
$$

\subsubsection{5 - Modelo de Burgers}

O modelo de Burgers é uma combinação de quatro parâmetros, sendo dois deles viscosos (amortecedores) e dois elásticos (molas), que agrupam-se em um modelo de Maxwell e um modelo de Kelvin-Voigt, conectados em série, como é representado graficamente na Figura 2.10 (Mase, 1970; Santos, 2008).

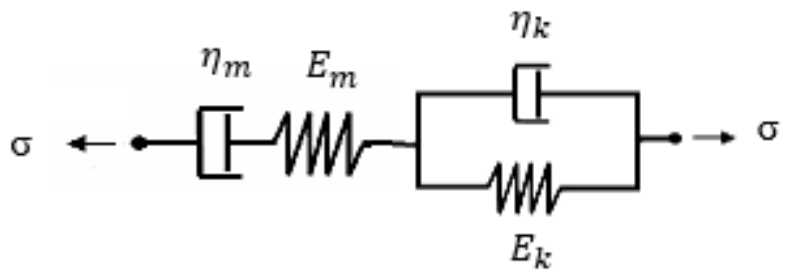

Figura 2.10 - Modelo de Burgers

O modelo de Burgers tem três etapas diferentes de deformação, como resposta à ordem dos seus elementos. Ao submeter o modelo de Burgers a uma tensão, esse experimenta numa primeira fase uma deformação instantânea devido ao elemento elástico do modelo de Maxwell, e logo advém uma segunda fase caracterizada por um amortecimento devido ao elemento viscoso do mesmo modelo. Por último, na terceira fase o elemento de Kelvin desenvolve a parte final das deformações, e consequentemente, a deformação total estará 
dada pela soma das parcelas dos elementos citados. No entanto, ao realizar o teste de relaxação, o componente elástico inicial produz uma recuperação instantânea, enquanto os outros elementos desencadeiam um retardo na recuperação total nos esforços internos do conjunto. Ao compatibilizar a deformação total como a soma de cada uma das três fases e substituindo as condições particulares dos modelos de Maxwell e Kelvin, origina-se a Equação diferencial governante para o modelo de Burguers, dada pela Equação (2.20).

$$
\ddot{\sigma}+\left(\frac{E_{m}}{\eta_{k}}+\frac{E_{k}}{\eta_{k}}+\frac{E_{m}}{\eta_{m}}\right) \dot{\sigma}+\frac{E_{k}}{\eta_{k}} \frac{E_{m}}{\eta_{m}} \sigma=E_{m} \ddot{\varepsilon}+\frac{E_{k} E_{m}}{\eta_{k}} \dot{\varepsilon}
$$

Dadas as três fases de deformação do modelo é de uso comum para modelagem de materiais betuminosos, enquanto o modelo de Maxwell, sólido linear padrão e o modelo de Boltzmann são mais usados para a descrição de materiais de construção civil de comportamento mais rígido (Christensen, 1982; de Araújo, Soares, de Holanda, Parente Jr., \& Evangelista Jr., 2010; Santos, 2008).

\subsubsection{6 - Modelo Generalizado de Maxwell ou Modelo de Wiechert}

O modelo generalizado de Maxwell consiste em uma distribuição do esforço em múltiplos elementos de Maxwell (N) e um elemento elástico independente, como mostrado na Figura 2.11 (Christensen, 1982; Evangelista Jr., 2006; Roylance, 2001; Schapery, Research, Division, of Aeronautics Astronautics, \& Sciences, 1965).

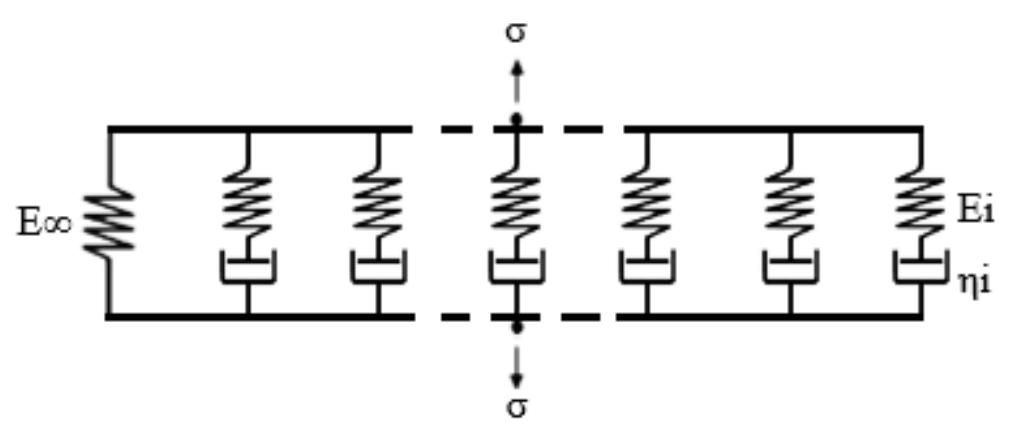

Figura 2.11-Modelo generalizado de Maxwell

O sistema pode ter tantos elementos de Maxwell quantos sejam necessários para aproximar a resposta que pretende-se representar $\varepsilon(t)$ ou $\sigma(t)$. Desta forma, a tensão total $\sigma$ é uniformemente distribuída para cada um dos elementos que componham o sistema, e é assumida por cada elemento de acordo a suas propriedades de rigidez e viscosidade particulares, incluindo o elemento elástico, sendo a tensão total o somatório das tensões 
assumidas por cada elemento. No campo das deformações, quando a deformação $\varepsilon$ imposta esta é igual para todos os elementos.

\subsubsection{7 - Modelo Generalizado de Kelvin - Voigt}

O modelo componha-se de $\mathrm{N}$ elementos de Kelvin conectados em série com um elemento independente elástico, como se mostra na Figura 2.12 (Christensen, 1982; Evangelista Jr., 2006; Roylance, 2001; Schapery et al., 1965).

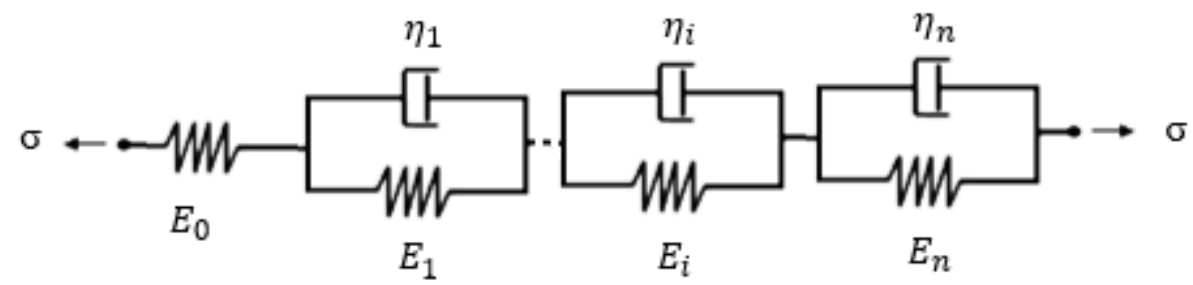

Figura 2.12 - Modelo generalizado de Kelvin

Cada um dos elementos que compõem o modelo, tanto a dupla do modelo de Kelvin quanto o elemento isolado, neste caso a mola, experimentam o mesmo esforço. No entanto, a deformação total do sistema corresponde à somatória da contribuição parcial de cada elemento.

\subsection{2 - Séries de Prony}

Os dados experimentais advindos dos testes de fluência ou relaxação precisam ser levados para uma forma matemática geral que permita o estudo do comportamento dos materiais viscoelásticos. Na literatura, encontra-se ampla aceitação dos modelos generalizados de Maxwell e Kelvin para a descrição dos fenômenos viscoelásticos (Evangelista Jr, 2006; Mottahedi, Dadalau, Hafla, \& Verl, 2011; S. Park \& Schapery, 1999; Tzikang, 2000).

Para determinar matematicamente a discretização das curvas que representam as propriedades de fluência e relaxação dos materiais viscoelásticos, considera-se a descrição dada pelos modelos generalizados de Maxwell e Kelvin, sendo que uma regressão matemática de boa aproximação aos dados obtidos nos ensaios de laboratório, é dada pelas chamadas séries de Prony. As séries de Prony podem ser usadas para descrever a propriedade viscoelástica da função fluência $\mathrm{D}(\mathrm{t})$, dada pela equação do tipo mostrada na Equação (2.21). A fluência estará dada pela parcela do elemento elástico ou viscoso independente e a somatória do aporte parcial de cada conjunto dos elementos do modelo generalizado de Maxwell. 


$$
D(t)=D_{0}+\sum_{i=1}^{N} D_{i}\left(1-e^{-\frac{t}{\tau_{i}}}\right)
$$

Assim, fazendo uma analogia correspondente ao modelo físico apresentado na Figura 2.11 e na Figura 2.12, onde $\mathrm{D}_{0}$ corresponde ao elemento independente simples, que é igual à função fluência avaliada no tempo zero $t=0$, Di é o coeficiente para elemento duplo linear, $\mathrm{N}$ o número destes elementos lineares, t será a variável tempo e $\tau_{\mathrm{i}}$ será o tempo de retardação. A retardação é proporcional à viscosidade do amortecedor atuante em cada dupla viscoelástica, e mede a taxa que tarda cada elemento em desenvolver sua deformação, logicamente, quanto maior seu valor maior o tempo para o elemento se deformar, e em forma geral pode-se considerar segundo a Equação (2.22).

$$
\tau_{\mathrm{i}}=\eta_{\mathrm{i}} \mathrm{D}_{\mathrm{i}}
$$

De forma análoga, a função do módulo de relaxação pode ser definida por essas séries, como se indica na Equação (2.23). A formulação matemática deste módulo dependerá da parcela do elemento independente do modelo generalizado de Maxwell, e a somatória do aporte parcial de cada conjunto de dois elementos, sendo $\mathrm{E}_{\infty} \mathrm{O}$ módulo do elemento independente e o módulo do material totalmente relaxado, Ei o módulo de elasticidade de cada elemento duplo, $\mathrm{N}$ o número dos elementos duplos lineares, t a variável tempo e $\rho_{\mathrm{i}}$ o tempo de relaxação.

$$
E(t)=E_{\infty}+\sum_{i=1}^{N} E_{i}\left(e^{-\frac{t}{\rho_{i}}}\right)
$$

Similar ao significado do tempo de retardação, o tempo de relaxação $\rho_{\mathrm{i}}$ corresponde ao tempo de cada um dos elementos duplos que precisa para relaxar, considerado segundo a Equação .

$$
\rho_{\mathrm{i}}=\frac{\eta_{\mathrm{i}}}{\mathrm{E}_{\mathrm{i}}}
$$

Quando nos materiais viscoelásticos o coeficiente de Poisson $v$ é invariável ao longo do tempo, e unicamente para essa condição, as funções de fluência à cisalhamento $J(t)$ e o módulo de cisalhamento $G(t)$ podem serem obtidas por relações elásticas, baseadas nas funções de fluência $D(t)$ e relaxação $E(t)$, respectivamente, segundo o apresentado nas Equações (2.25) e (2.26). 


$$
\begin{aligned}
& J(t)=2(1+v) D(t) \\
& G(t)=\frac{E(t)}{2(1+v)}
\end{aligned}
$$

Uma vez obtidas as funções de fluência ao cisalhamento $J(t)$ e o módulo de cisalhamento $\mathrm{G}(\mathrm{t})$ pelas relações elásticas entre as propriedades correspondentes, podem-se obter também as séries de Prony pertinentes, dadas respectivamente pelas Equações (2.27) e (2.28).

$$
\begin{aligned}
& J(t)=J_{0}+\sum_{i=1}^{N} J_{i}\left(1-e^{-\frac{t}{\tau_{i}}}\right) \\
& G(t)=G_{\infty}+\sum_{i=1}^{N} G_{i}\left(e^{-\frac{t}{\rho_{i}}}\right)
\end{aligned}
$$

As funções das propriedades viscoelásticas de comportamento inverso, ou seja, E(t) comparada com $\mathrm{D}(\mathrm{t})$ e $\mathrm{G}(\mathrm{t})$ comparada com $\mathrm{J}(\mathrm{t})$ não guardam uma relação linear. Devido a isto, deve ser realizada uma interconversão baseada no princípio de correspondência elástica-viscoelástica, como será apresentado na seção 0 .

\subsection{3 - Princípio de superposição de Boltzmann}

Para um material viscoelástico linear, a resposta total a um número de excitações individuais constitui-se da soma das respostas parciais que foram geradas por cada excitação atuando isoladamente (Christensen, 1982; Schapery, 1969).

Matematicamente, pode-se expressar isto como a resposta das séries de Prony descritas nas Equações (2.21) e (2.23), que sendo combinadas com o comportamento da viscoelasticidade linear, pode-se avaliar os esforços totais do corpo estudado, como mostrado nos gráficos da Figura 2.13. Ao analisar o caso (a) da Figura 2.13, pode-se considerar a tensão total que experimenta um corpo como o resultado da soma finita de cada um das tensões $\sigma_{i}$, correspondentes com cada um dos tempos de avaliação da função $t_{i}$.

No caso (b) da Figura 2.13, para cada tempo de avaliação $\tau$ corresponde uma tensão $\sigma$ no histórico das tensões, de igual forma, ao incrementar no tempo um diferencial $\mathrm{d} \tau$ correspondentemente gera um aumento nas tensões $d \sigma$, para cada diferencial avaliado da função arbitrada. 


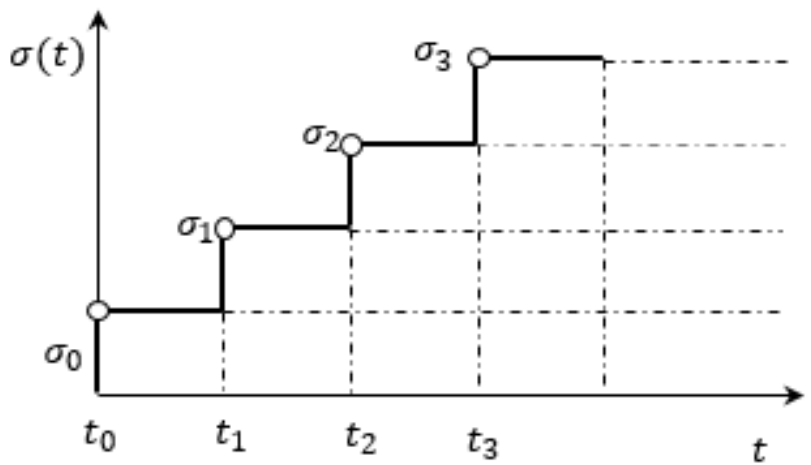

(a)

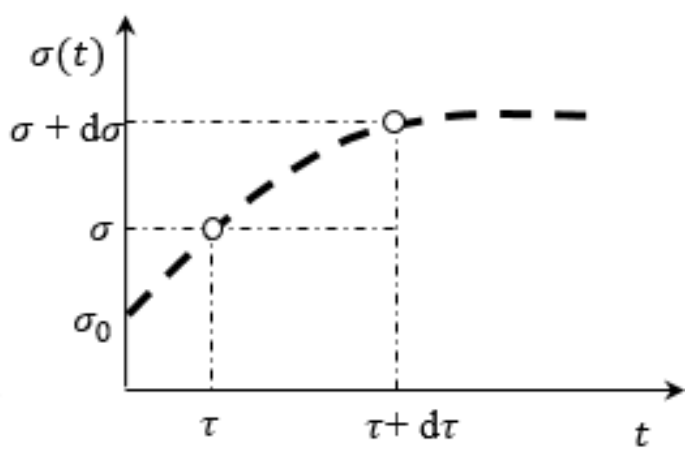

(b)

Figura 2.13- (a). Histórico em escada das tensões. (b) Histórico de tensões arbitrárias

Quando por exemplo realiza-se o teste de fluência em qualquer tipo de material viscoelástico, baseando-se na Figura 2.13 (a), valida-se a Equação (2.30).

$$
\begin{aligned}
& \varepsilon(t)=\sigma D(t)=\sigma_{0} D(t)+\sigma_{1} D\left(t-t_{1}\right)+\sigma_{2} D\left(t-t_{2}\right)+\sigma_{3} D\left(t-t_{3}\right) \\
& \varepsilon(t)=\sum_{i=0}^{3} \sigma_{i} D\left(t-t_{i}\right) \\
& \sigma(t)=\sum_{i=0}^{3} \varepsilon_{i} E\left(t-t_{i}\right)
\end{aligned}
$$

De forma análoga ao caso (a), no caso geral de solicitação segundo o caso (b) da Figura 2.13, considera-se a deformação em qualquer instante de tempo, originando as equações de solução geral da função deformação $\varepsilon(t)$ baseada na Equação (2.31) e da função de tensão $\sigma(\mathrm{t})$, obtida por analogia do procedimento, e apresentada na Equação (2.31). As equações que representam o comportamento geral à tensão e deformação são chamadas de equações hereditárias.

Essas equações hereditárias concatenam o uso do princípio da superposição, permitindo-se obter respostas mecânicas no domínio de tempo avaliadas a partir do tempo t $>0 \mathrm{e}$, consequentemente, o intervalo da integral estará definido entre o tempo zero até o tempo t, como é apresentado nas Equações (2.32) e (2.33).

$$
\begin{aligned}
& \varepsilon(t)=\int_{0}^{t} D(t-\tau) \frac{d \sigma(\tau)}{d \tau} d \tau \\
& \sigma(t)=\int_{0}^{t} E(t-\tau) \frac{d \varepsilon(\tau)}{d \tau} d \tau
\end{aligned}
$$

A integração das funções hereditárias, dadas nas Equações (2.32) e (2.33), resultam dada sua forma numa convolução de funções. A convolução de funções, representada pelo operador 
*, dada um par de funções $f$ e $g(f * g)$, corresponde a área subentendida pela superposição das duas funções, em função do deslocamento existente entre elas chamado de $\tau$, e apresentada na forma geral na Equação (2.34).

$$
f * g=\int_{-\infty}^{\infty} f(\mathrm{t}-\tau) g(\tau) \mathrm{d} \tau=\int_{-\infty}^{\infty} f(\tau) g(\mathrm{t}-\tau) \mathrm{d} \tau
$$

\subsection{4 - Princípio de correspondência elástica - viscoelástica (PCEV)}

Para a análise de qualquer modelo estrutural, dado uma geometria e um sistema de carregamentos impostos, as respostas de tensão e deformação são baseadas nas formulações matemáticas desenvolvidas para materiais elásticos. Ao avaliar o comportamento viscoelástico linear do material, corrobora-se que as respostas viscoelásticas convertem-se equivalentes às respostas dadas pelo comportamento elástico sendo transformadas ao espaço de Laplace, sendo este conceito amplamente difundido e chamado de Princípio de Correspondência Elástica Viscoelástica, nomeado posteriormente de PCEV (Christensen, 1982; Evangelista Jr., 2006; Muliana \& Haj-Ali, 2008; S. Park \& Schapery, 1999; Schapery, 1969).

A transformada de Laplace é um caso especial da Transformação Integral, permitindo decompor funções complexas ou de maior dificuldade de solução, em equações algébricas simples. Deste modo, as equações podem ser resolvidas mais facilmente em outro espaço, aplicando a transformada de Laplace. Essa transformação possui propriedades que, ao serem aplicadas nas funções, permitem obter a resposta no espaço de Laplace, e posteriormente, com o uso da transformada inversa obtém-se a resposta final no espaço do tempo (Fernández, 2007).

A transformada de Laplace $\bar{f}(s)=\mathfrak{L}\{f(t)\}$ para uma função qualquer $f(t)$, por definição, está dada pela Equação (2.35), sendo transformada a variável no espaço do tempo $t$ para a variável no espaço de Laplace $s$.

$$
\bar{f}(s)=\mathfrak{L}\{f(t)\}=\int_{0}^{\infty} f(t) e^{-s t} d t
$$

Essa transformação desde o espaço do tempo para o espaço de Laplace, obedece algumas propriedades básicas estabelecidas, sendo as utilizadas no presente trabalho apresentadas a seguir. Na Equação (2.36) $a$ e $b$ representam constantes, sendo a transformada de uma 
função multiplicada por uma constante resulta no valor da constante multiplicada pela transformada ao espaço de Laplace da função. A Equação (2.37) contempla a transformada ao espaço de Laplace da derivada enésima de uma função e a Equação (2.38) representa como a transformada da multiplicação de uma função exponencial e uma função $f(t)$, resulta na mesma função deslocada pelo valor do exponente $a$.

$$
\begin{aligned}
& \mathfrak{L}\{a f(t)+b g(t)\}=a \bar{f}(s)+b \bar{g}(s) \\
& \mathfrak{L}\left\{\frac{d^{n} f(t)}{d t^{n}}\right\}=s^{n} \bar{f}(s)-\sum_{k=1}^{n} s^{n-k} \frac{d^{k-1} f(0)}{d t^{k-1}} \\
& \mathfrak{L}\left\{e^{a t} f(t)\right\}=\bar{f}(s-a)
\end{aligned}
$$

Um dos operadores mais usados no espaço de Laplace é a convolução de um par de funções, sendo definida como a integral do produto de uma das funções por uma cópia deslocada e invertida da outra. Consequentemente, a função resultante será dependente do valor do deslocamento, sendo que o uso deste operador é validado para o espaço de Laplace na Equação (2.39).

$$
\bar{f}(s) * \bar{g}(s)=\mathfrak{L}\left\{\int_{0}^{t} f(t-\tau) g(\tau) d \tau\right\}=\mathfrak{L}\left\{\int_{0}^{t} f(\tau) g(t-\tau) d \tau\right\}
$$

A transformação para o espaço de Laplace das Equações (2.21) e (2.23), correspondentes às séries de Prony das funções fluência e relaxação, são dadas respectivamente pelas Equações (2.40) e (2.41).

$$
\begin{aligned}
& \bar{D}(s)=\frac{D_{0}}{s}+\sum_{i=1}^{N} D_{i}\left(\frac{1}{s}-\frac{1}{s+\frac{1}{\tau_{i}}}\right) \\
& \bar{E}(s)=\frac{E_{\infty}}{s}+\sum_{i=1}^{N} E_{i}\left(\frac{1}{s+\frac{1}{\rho_{i}}}\right)
\end{aligned}
$$

Baseados nas equações hereditárias correspondentes às funções de deformação $\varepsilon(t)$ e de tensão $\sigma(\mathrm{t})$, indicadas nas Equações (2.32) e (2.33), respectivamente, pode ser implementado o princípio de correspondência elástica viscoelástica, ou seja, transformando as equações hereditárias para o espaço de Laplace. Desta forma, obtém-se as relações apresentadas nas Equações (2.42) e (2.43). 


$$
\begin{aligned}
& \bar{\varepsilon}(s)=\mathcal{L}\left\{\int_{0}^{t} D(t-\tau) \frac{d \sigma(\tau)}{d \tau} d \tau\right\}=\bar{D}(s) s \bar{\sigma}(s) \\
& \bar{\sigma}(s)=\mathcal{L}\left\{\int_{0}^{t} E(t-\tau) \frac{d \varepsilon(\tau)}{d \tau} d \tau\right\}=\bar{E}(s) s \bar{\varepsilon}(s)
\end{aligned}
$$

Substituindo o resultado da Equação (2.43) na Equação (2.42), deduz-se a relação exata que existe entre as funções de fluência e do modulo de relaxação no espaço de Laplace, como é dada na Equação (2.44).

$$
\overline{\mathrm{D}}(\mathrm{s}) \overline{\mathrm{E}}(\mathrm{s})=\frac{1}{\mathrm{~s}^{2}}
$$

\subsection{5 - Inversão numérica de funções desde o espaço de Laplace para o domínio do tempo}

Usualmente, no estudo do comportamento mecânico de elementos estruturais, as expressões matemáticas da resposta das tensões ou deformações do elemento resultam muito mais simples de serem resolvidas no domínio de Laplace, do que as suas correspondentes expressões integradas no domínio do tempo. Por conseguinte, uma solução apropriada é a de tentar resolver essas equações de Laplace nesse domínio, e inverter a solução, de volta para o domínio do tempo.

Uma das maiores dificuldades no estudo da viscoelasticidade consiste em que, infelizmente, muitos materiais viscoelásticos precisam de serem matematicamente descritos com dez ou mais termos da série Prony, fazendo que a inversão da solução do espaço Laplace de forma analítica seja quase impossível de alcançar. Nesta secção apresentam-se alguns dos métodos numéricos mais difundidos para obter a inversão de funções do espaço de Laplace.

Existem diversos métodos para obter a inversão numérica de uma função no espaço de Laplace. Devido à correspondência elástica das funções viscoelásticas no espaço de Laplace, aplica-se o Princípio de Correspondência entre as funções para realizar suas interconvesões, e para isso procurou-se uma transformação inversa de Laplace que atendesse um alto nível de precisão.

Depois de estudar e tentar alguns métodos na presente pesquisa, entre eles o método matricial, o método do Stehfest, o método do Zakian, o método de Schapery, o método das séries de Fourier, entre outros, segundo o estudado por Hassanzadeh \& Pooladi-Darvish (2007) e Yonemoto, Hisakdo, \& Okumura (2002), concluiu-se que o método mais robusto e 
adequado para inverter funções complexas corresponde a uma regressão ao espaço no tempo dada por uma série de Fourier (Dubner \& Abate, 1968). No entanto e para realizar uma revisão completa dos métodos estes serão apresentados de forma geral nos itens subsequentes.

\subsubsection{1 - Método de Gaver-Stehfest}

Esta técnica de inversão numérica Laplace foi introduzida inicialmente por Graver (1966) e seu algoritmo fornecido por Stehfest (1979). Este método tem sido usado extensivamente em engenharia de petróleo e aproxima a solução no domínio do tempo utilizando a Equação

$$
\begin{aligned}
& f(t)=\frac{\ln 2}{t} \sum_{i=1}^{n} V_{i} F\left(\frac{\ln 2}{t} i\right) \\
& V_{i}=(-1)^{\left(\frac{n}{2}+1\right)} \sum_{k=\left(\frac{i+1}{2}\right)}^{\min \left(i, \frac{n}{2}\right)} \frac{k^{\left(\frac{n}{2}+1\right)}(2 k) !}{\left(\frac{n}{2}-k\right) ! k !(i-k) !(2 k-1) !}
\end{aligned}
$$

O parâmetro $n$ é o número de termos utilizados no somatório na Equação (2.45) e deve ser optimizado por tentativa e erro. Quanto maior o valor de $n$ maior a precisão do resultado, sendo aceitável o erro obtido para valores de $n$ nesta faixa $10 \leq n \leq 14$ (Hassanzadeh \& Pooladi-Darvish, 2007). O método resulta preciso quando a função do tempo está na forma de $e^{-t}$, no entanto, a aproximação depende enormemente da complexidade da função a ser transformada.

\subsubsection{2 - Método de Zakian}

O método de Zakian se aproxima da função no domínio do tempo usando uma série infinita de avaliações ponderadas de função de domínio, regidas pela Equação (2.47).

$$
f(t)=\frac{2}{t} \sum_{i=1}^{n} \operatorname{Re}\left(A_{i} F\left(\frac{\alpha_{i}}{t}\right)\right)
$$

As constantes $A_{i}$ e $\alpha_{i}$ para $\mathrm{n}=5$ estão dadas pela Tabela 2.1. O método de Zakian é fácil de aplicar, mas o parâmetro n deve ser optimizado para obter soluções precisas, apresentando bons resultados para funções exponenciais positivas (Hassanzadeh \& Pooladi-Darvish, 2007). 
Tabela 2.1 - Coeficientes Ai e $\alpha_{i}$ para o método de Zakian (Torres, 2013)*

\begin{tabular}{c|cc}
\hline$i$ & $\alpha$ & $A$ \\
\hline 1 & $12.83767675+\mathrm{j} 1.666063445$ & $-36902.08210+\mathrm{j} 196990.4257$ \\
2 & $12.22613209+\mathrm{j} 5.012718792$ & $+61277.02524-\mathrm{j} 95408.62551$ \\
3 & $10.93430308+\mathrm{j} 8.409673116$ & $-28916.56288+\mathrm{j} 18169.18531$ \\
4 & $8.776434715+\mathrm{j} 11.92185389$ & $+4655.361138-\mathrm{j} 1.901528642$ \\
5 & $5.225453361+\mathrm{j} 15.72952905$ & $-118.7414011-\mathrm{j} 141.3036911$ \\
\hline
\end{tabular}

*Ponto decimal da Tabela (.) em vez de (,), devido à representação numérica americana

\subsubsection{3 - Método de Schapery}

O método de Schapery é uma técnica simples de implementar e é adequado para a avaliação inicial da solução no domínio do tempo quando a solução de domínio de Laplace é da forma de $s f(s)=\operatorname{As}^{m}(m<1)$. Neste caso, existe uma relação entre a solução de tempo real e a sua forma no domínio de Laplace (Hassanzadeh \& Pooladi-Darvish, 2007), dada pela Equação (2.48).

$$
f(t) \approx[s F(s)]_{s=\frac{1}{\gamma^{t}}} ; \gamma=1,785
$$

\subsubsection{4 - Método das séries de Fourier}

A base matemática do método de inversão de funções desde o espaço de Laplace para o espaço do tempo usando as séries de Fourier, apresenta-se na Equação (2.49), onde F é a função a ser transformada, $\mathrm{j}=\sqrt{-1}$ e os parâmetros $\mathrm{b}$ e $\mathrm{n}$ são parâmetros a serem optimizados para aumentar a precisão do método (Dubner \& Abate, 1968).

$$
f(t)=\frac{e^{b t}}{t}\left[\frac{1}{2} F(b)+R e \sum_{k=1}^{n} F\left(b+j \frac{k \pi}{t}\right)(-1)^{k}\right]
$$

Utilizando um dos resultados obtidos na pesquisa de Torres (2013), pode-se inferir que a precisão do método é adequada para valores de bt $=4,5$ e $n=101$. No entanto, para obter os resultados do presente trabalho de pesquisa adotou-se bt $=4,5$ e $n \geq 1000$, com o objetivo de aumentar a precisão da função final obtida no espaço do tempo.

\subsection{6 - Princípio de superposição tempo - temperatura (PSTT)}

O PSTT estabelece que o comportamento tensão de formação em uma dada temperatura para uma determinada taxa de deformação será idêntico ao comportamento em outra temperatura para uma taxa de deformação diferente (Christensen, 1982; Schapery, 1969). Essa taxa de 
deformação calcula-se como um escalar que é função da temperatura na que é realizado o ensaio para a obtenção da curva reológica, comparada com a temperatura superior à que pretendem-se estudar os efeitos produzidos, sendo essa taxa calculada chamada fator de deslocamento tempo-temperatura $a_{t}(T)$, tal como é mostrado graficamente no esquema da Figura 2.14.

Quando um material responde com uma diminuição no tempo de relaxação ou retardo nos fenômenos da reologia ante um aumento na temperatura, comparada com uma temperatura inicial ou de referência, é chamado de material termo-reologicamente simples (MTRS) (Shah, 2008). O Princípio da Superposição Tempo-Temperatura é aplicável somente ao material desse tipo, implicando que um valor do módulo de relaxação, ou do módulo ao cisalhamento, pode ser obtido tanto a baixas temperaturas, ou seja, com longos períodos de carregamento, quanto a altas temperaturas, diminuindo os tempos de carregamento.

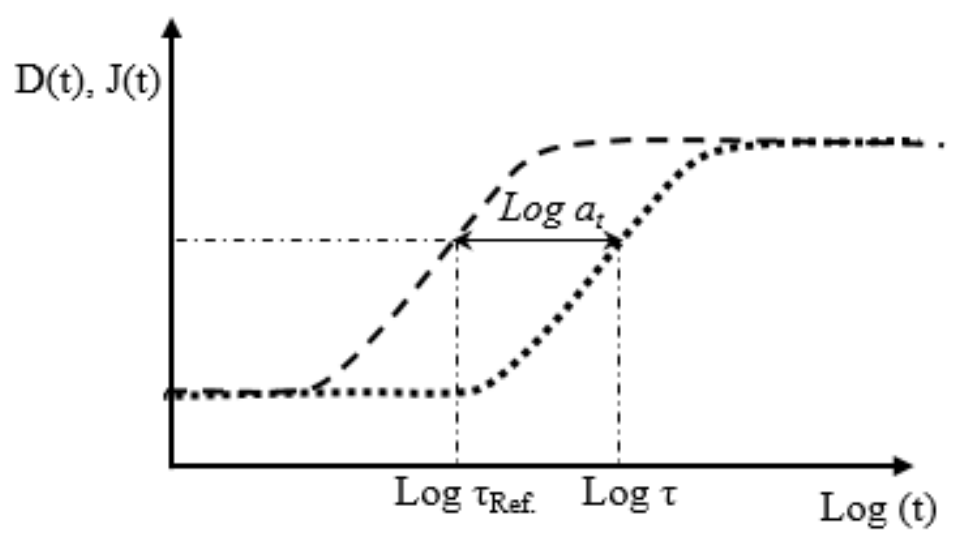

Figura 2.14 - Fator de deslocamento tempo-temperatura. Adaptado de Roylance (2001)

Assim, o fator de deslocamento tempo-temperatura pode ser definido como o deslocamento horizontal que deve ser aplicado à curva de mestra de uma das propriedades reológicas, medida a uma temperatura escolhida $\mathrm{T}$, com o objetivo de desprezá-la para uma curva medida em uma dada temperatura de referência $\tau$ Ref. (Roylance, 2001), isto sem modificar sua forma.

Segundo o apresentado na Figura 2.14, mesmo que para o exemplo tenha sido considerado um único tempo de avaliação na curva, o fator de deslocamento é a diferença entre as curvas descritas para cada um dos pontos correspondentes, conservando o mesmo valor para esses, pois de outra forma não poderia se garantir a permanência na forma da curva mestra, sendo 
assim que esse fator de deslocamento pode ser representado matematicamente pela Equação (2.50).

$$
\log \left(a_{t}\right)=\log \tau(T)-\log \tau\left(T_{R e f}\right)
$$

O fator de deslocamento $a_{t}$ pode ser determinado de três maneiras diferentes, sendo essas obtidas numericamente pela Equação de Arrhenius, e pela Equação de Willians-LandelFerry (EWLF) ou por métodos experimentais, onde os testes para um mesmo material são realizados a diferentes temperaturas para carregamentos normalizados (Christensen, 1982; Roylance, 2001).

Segundo a revisão feita por Portela (2011), a equação de Arrhenius providencia uma aproximação aos resultados reais no caso que a diferença entre a temperatura a ser deslocada e a temperatura de referência seja menor ou igual a $20^{\circ} \mathrm{C}$, ou seja $T-T_{r e f} \leq$ a $20^{\circ} \mathrm{C}$ enquanto se $T-T_{r e f}>$ a $20^{\circ} \mathrm{C}$ a EWLF é mais apropriada. Se a função do tempo de relaxação obedece à Equação (2.51), onde $E_{A}$ é a energia de ativação [J/mol], R é a constante dos gases ideais de 8,314 [J/ mol.K], T é a temperatura experimental e $\tau_{0}$ e o tempo da curva mestra, substituindo na Equação (2.50), pode ser obtido o fator de deslocamento tempotemperatura como se apresenta na Equação (2.52).

$$
\begin{aligned}
& \tau(T)=\tau_{0} e^{\frac{E_{A}}{R T}} \\
& \log \left(a_{t}\right)=\frac{E_{A}}{2,303 R}\left(\frac{1}{T}-\frac{1}{T_{\text {Ref. }}}\right)
\end{aligned}
$$

O valor 2,303 mostrado na Equação (2.52), é adicionado à formulação devido a que $\operatorname{Ln}(10) \cong 2,303$, sendo somente um valor de conversão. $\mathrm{O}$ fator de deslocamento obtido por essa formulação descreve perfeitamente o comportamento dos polímeros secundários, ou seja, polímeros de enlaces secundários e longas cadeias moleculares muito empacotadas, sendo materiais mais rígidos descritos pela formulação da EWLF apresentada na Equação (2.53).

$$
\log \left(\mathrm{a}_{\mathrm{t}}\right)=\frac{-\mathrm{C}_{1}\left(\mathrm{~T}-\mathrm{T}_{\text {Ref. }}\right)}{\mathrm{C}_{2}+\left(\mathrm{T}-\mathrm{T}_{\text {Ref. }}\right)}=\frac{-17,4\left(\mathrm{~T}-\mathrm{T}_{\text {Ref. }}\right)}{51,6+\left(\mathrm{T}-\mathrm{T}_{\text {Ref. }}\right)}
$$

$\mathrm{Na}$ Equação (2.53) os valores de $\mathrm{C}_{1}$ e $\mathrm{C}_{2}$ são constantes do material arbitrário, cujos valores dependem do tipo de material e da escolha da temperatura de referência $T_{R e f}$, Segundo 
Roylance (2001), dada uma $T_{\text {Ref. }}$ assumem-se os valores constantes apresentados na Equação citada, considerando esses como valores aplicáveis a uma ampla gama de polímeros.

Assim, o Princípio da Superposição Tempo-Temperatura pode ser explicado como a relação entre uma curva escolhida como referência de uma das propriedades viscoelásticas de fluência de um material, dada uma temperatura de ensaio, e uma família de curvas deslocadas horizontalmente, sendo suficiente uma vasta gama de tempo de avaliação, sendo a curva principal válida apenas à temperatura de referência, sendo utilizada em outras temperaturas através da passagem pelo valor de registro apropriado $a_{t}$.

Para avaliar o deslocamento correto da curva mestra à temperatura escolhida, o ajuste para uma menor temperatura diminui a taxa de fluência e aumentam os tempos de reação do material deslocando a curva para a direita, enquanto as temperaturas mais elevadas aumentam a taxa de fluência e diminuem o tempo de resposta, consequentemente deslocando a curva para a esquerda.

\section{2 - ELEMENTO ESTRUTURAL DE VIGA}

\subsection{1 - Modelo de viga de Euler-Bernoulli (MVEB)}

As vigas são consideradas de sólidos deformáveis, no entanto, no modelo de viga de EulerBernoulli realizam-se uma série de simplificações da teoria linear da elasticidade, permitindo assim calcular aproximadamente as tensões, deflexões e deformações de uma viga sob um determinado carregamento $\mathrm{q}(\mathrm{x})$, como se esta fosse um elemento unidimensional $\mathrm{e}$ solucionando uma equação diferencial linear de quarta ordem, dada pela Equação.

$$
\mathrm{EI} \frac{\mathrm{d}^{4} \mathrm{w}}{\mathrm{dx}^{4}}-\mathrm{q}(\mathrm{x})=0
$$

Esse modelo deve-se a Leonard Euler e Daniel Bernoulli, sendo esses os primeiros em dar solução as vigas, assumindo as seguintes simplificações ao modelo:

- Os deslocamentos verticais de todos os pontos de uma seção transversal são pequenos e iguais aos deslocamentos do eixo longitudinal da viga;

- O deslocamento lateral é nulo; 
- O material é elástico e linear;

- O coeficiente de Poisson assume-se como zero;

- As seções transversais planas normais ao eixo da viga antes da deformação, permanecem planas e ortogonais ao este eixo depois da deformação, como se apresenta na Figura 2.15.

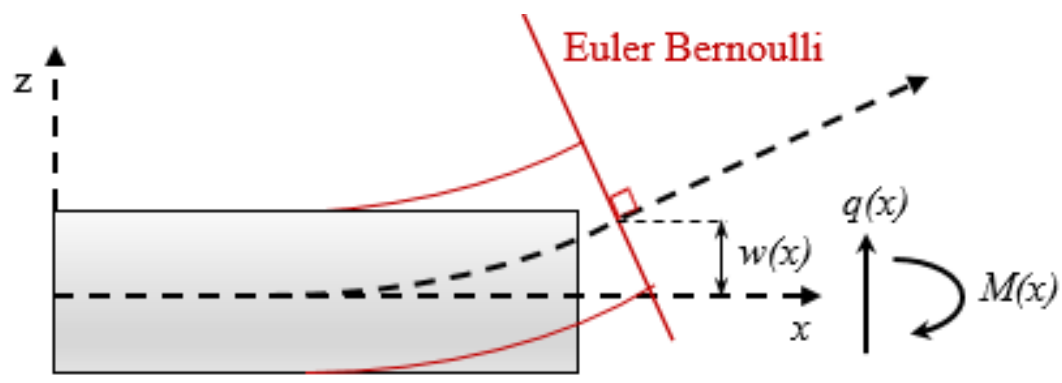

Figura 2.15 - Modelo de viga de Euler-Bernoulli

A viga, apresentada na Figura 2.16, se estende a partir de $x=0$ até o comprimento de $x=$ $L$, tem uma rigidez à flexão $E I$, onde E é o módulo de elasticidade do material e I é o momento de inércia respeito ao eixo de demanda da flexão. Na Figura 2.16 (a) considerouse um carregamento $q(x)$ dado em unidades de força por comprimento, sendo desconhecidos o deslocamento transversal $w(x)$, a rotação $\theta(x)$, o momento de flexão $M(x)$ e o esforço cortante $V(x)$. As respostas para cada um dos parâmetros da viga dependerão finalmente das convenções adotadas e das condições de contorno propostas para os pontos A e B.

Observe-se que os sinais positivos da Figura 2.16, presente nas funções do esforço cortante $V(x)^{+}$, momento de flexão $M(x)^{+}$, rotação $\theta(x)^{+}$e deflexão $w(x)^{+}$, correspondem ao sentido assumido como positivo nas formulações matemáticas e para as representações gráficas.

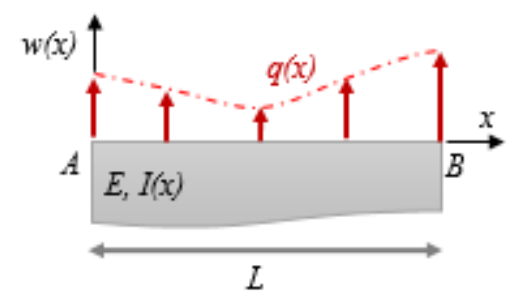

(a) Propriedades da viga e carregamento aplicado

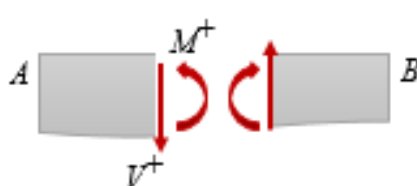

(b) Esforços internos da viga e convenção positiva do momento e do cortante

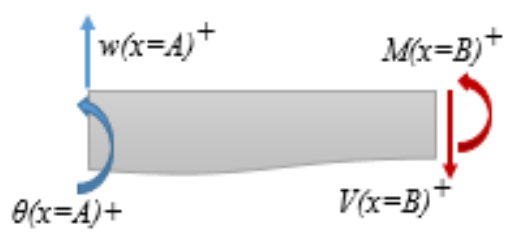

(c) Condiciones de contorno da viga e convenção positiva para o giro e o deslocamento

Figura 2.16 - Modelo viga de Euler - Bernoulli 
Para as considerações dadas na Figura 2.16, atendem-se algumas equações cinemáticas ou de movimento da viga, equações constitutivas e equações de equilíbrio. As equações chamadas de cinemáticas estarão restritas pelas condições assumidas nas Equações (2.55) e (2.56), onde é imposta uma rigidez em função da curvatura da viga $\rho(x)$,

$$
\begin{aligned}
& \theta(x)=\frac{\mathrm{dw}(x)}{\mathrm{dx}}=\mathrm{w}^{\prime}(x) \\
& \rho(x)=\frac{\mathrm{d}^{2} \mathrm{w}(\mathrm{x})}{\mathrm{dx}^{2}}=\mathrm{w}^{\prime \prime}(x)=\theta^{\prime}(x)
\end{aligned}
$$

As equações acima apresentadas consideram que as seções planas permanecem planas e normais ao plano neutro. Baseados nas restrições das Equações (2.55) e (2.56), obtém-se a equação constitutiva fundamental que dá origem aos modelos de segunda ordem, isto é obter o momento à flexão em função da curvatura e a rigidez flexional, como segue na Equação (2.57).

$$
M(x)=E I(x) \rho(x)
$$

Para esta consideração, assume-se I como o momento de inércia da seção transversal com relação ao eixo neutro, logo o momento de curvatura é consequência de assumir uma distribuição linear das deformações e tensões na seção transversal, princípio da mecânica dos materiais, permitindo também obter as equações de equilíbrio do sistema proposto nas Equações (2.58).

$$
V(x)=\frac{d M(x)}{d x}=M^{\prime}(x)
$$

Essa é a equação diferencial que corresponde ao modelo apresentado. Para obter as respostas esperadas é preciso aplicar as condições de contorno próprias aos tipos de restrições presentes nos apoios da viga.

$$
\begin{array}{lll}
A(x=0): & w=w_{A}, & \theta=\theta_{A} \\
B(x=L): & M=M_{B}, & V=V_{B}
\end{array}
$$

Quando é assumida uma condição de contorno, como por exemplo $w_{A}=\theta_{A}=0$, fisicamente isto tem um significado, neste caso a condição apresentada corresponde à viga de apoio engastado, onde $w_{A} \neq 0$ e $\theta_{A} \neq 0$, e em $x=L$ tem-se o extremo livre como se apresenta na Figura 2.17. 


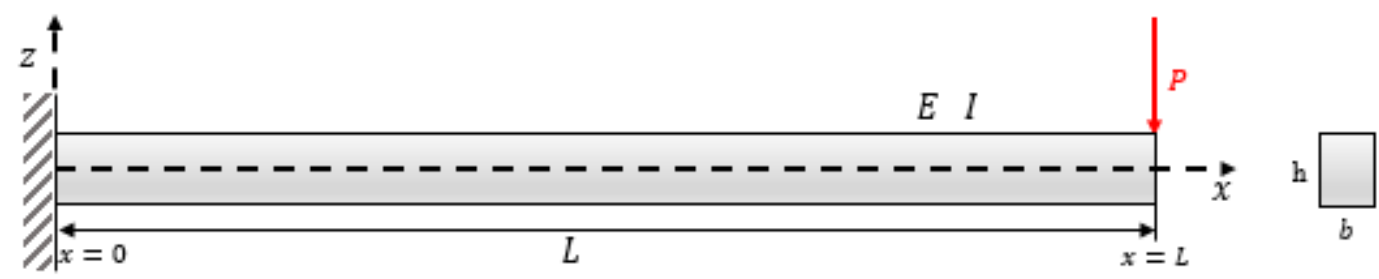

Figura 2.17 - Viga em balanço com carregamento pontual no extremo livre

Para as condições dadas na viga apresentada na Figura 2.17, podem-se obter as respostas em termos de momento, cisalhamento e deflexão. Aplicando a condição de contorno antes dada como exemplo de $A(x=0): \quad w_{A}=\theta_{A}=0$, e $B(x=L): \quad V_{B}=P, M_{B}=0$, obtendo-se as respostas dadas pelas Equações (2.61), (2.62) e (2.63).

$$
\begin{aligned}
& \mathrm{V}(\mathrm{x})=\mathrm{P} \\
& \mathrm{M}(\mathrm{x})=\mathrm{P}(\mathrm{x}-\mathrm{L}) \rightarrow \mathrm{M}(\mathrm{x}=0)=\mathrm{M}_{\max }=P L \\
& \mathrm{w}(\mathrm{x})=\frac{\mathrm{P} \mathrm{x}^{2}(3 \mathrm{~L}-\mathrm{x})}{6 \mathrm{E} I} \rightarrow \mathrm{w}(\mathrm{x}=\mathrm{L})=\mathrm{w}_{\max }=\frac{\mathrm{PL}^{3}}{3 \mathrm{EI}}
\end{aligned}
$$

De forma similar ao realizado para o caso da viga em balanço com diferentes condições de contorno, como por exemplo a simplesmente apoiada apresentada na Figura 2.18

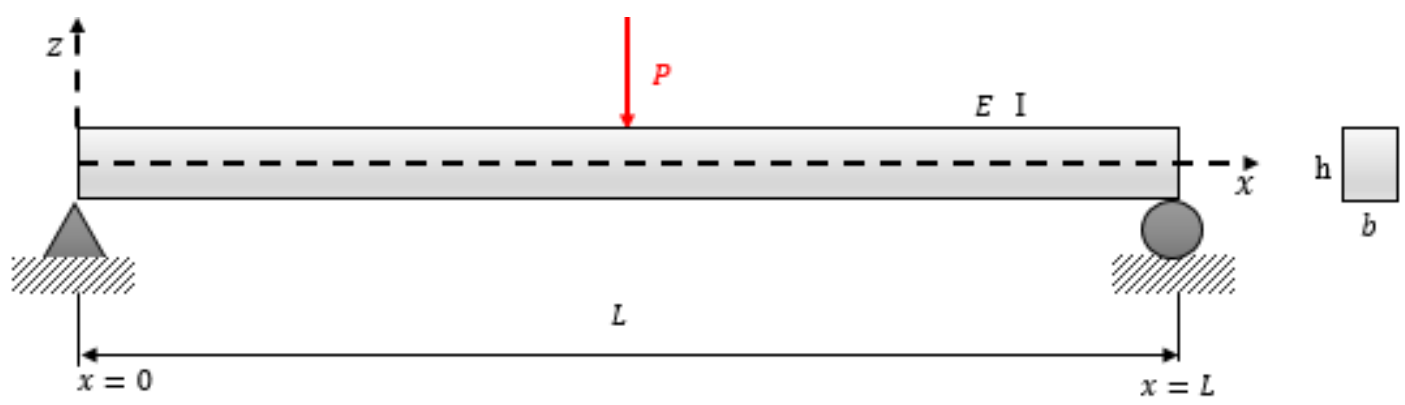

Figura 2.18 - Viga simplesmente apoiada com carregamento concentrado no centro

No caso apresentado na Figura 2.18, logicamente os maiores efeitos estarão no centro da viga que é precisamente onde está localizada a força P. Desta forma, como está apoiada tanto em A quanto em $B$, ou seja, tanto em $x=0$ quanto em $x=L$ respectivamente, a condição à considerar será $A(x=0): \quad w_{A}=M_{A}=0$ e $B(x=L): \quad w_{B}=M_{B}=0$, assim obtêm-se as Equações (2.64), (2.65) e (2.66)

$$
M(x)=\left\{\begin{array}{cl}
\frac{P x}{2} & 0 \leq x \leq \frac{L}{2} \\
\frac{P(L-x)}{2} & \frac{L}{2}<x \leq L
\end{array} \quad M\left(\frac{L}{2}\right)=\frac{P L}{4}\right.
$$




$$
\begin{aligned}
& V(x)=\left\{\begin{array}{cl}
\frac{P}{2} & 0 \leq x \leq \frac{L}{2} \\
-\frac{P}{2} & \frac{L}{2}<x \leq L
\end{array} \quad V(0)_{\text {Máx. }}=V(L)_{\text {Máx. }}=\frac{P}{2}\right.
\end{aligned}
$$

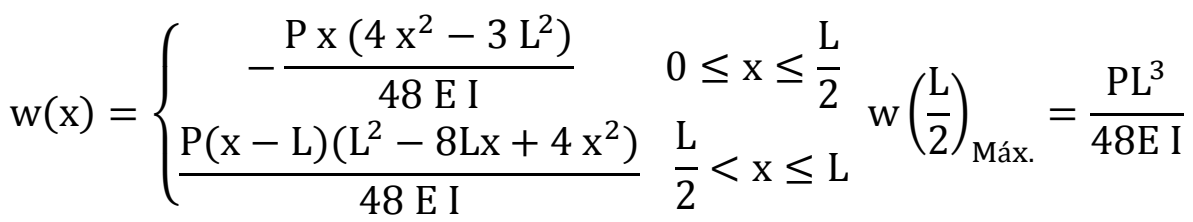

\subsection{2 - Modelo de viga de Timoshenko (MVT)}

Esta teoria foi desenvolvida pelo ucraniano Stepan Prokopovych Timoshenko, reconhecido cientista e engenheiro. O modelo leva em consideração o efeito do cisalhamento na deformação rotacional, tornando-o mais completo do que o modelo de Euler-Bernoulli para descrever o comportamento de viga. A equação resultante é de quarta ordem, mas há também uma segunda ordem presente devido à derivada espacial.

$$
E I \frac{d^{4} w}{d x^{4}}-q(x)+\frac{E I}{\kappa A G} \frac{d^{2} q(x)}{d x^{2}}=0
$$

Fisicamente, ao adicionar mecanismos de deformação se reduz eficazmente a rigidez da viga, enquanto que o resultado é uma maior deflexão sob uma carga estática. Se, por exemplo, para um material da viga dado o módulo de cisalhamento é muito alto (assumido matematicamente como "infinito"), a viga resulta altamente rígida ao corte, e os efeitos de rotação sob a inércia podem ser negligenciados, assim, a teoria da viga Timoshenko converge para a teoria viga comum de Euler-Bernoulli.

Para descrever melhor este efeito na Figura 2.19 apresenta-se uma representação física a diferença entre as duas teorias de viga: Euler-Bernoulli e Timoshenko. Na teoria estática da viga de Timoshenko desconsideram-se os efeitos axiais, e os deslocamentos da viga contêm os efeitos de rotação da viga, sendo $\varphi$ o ângulo de rotação da normal à superfície média da viga, e $w$ é o deslocamento da superfície média na direção z, como foi apresentado na Figura 2.19 . 


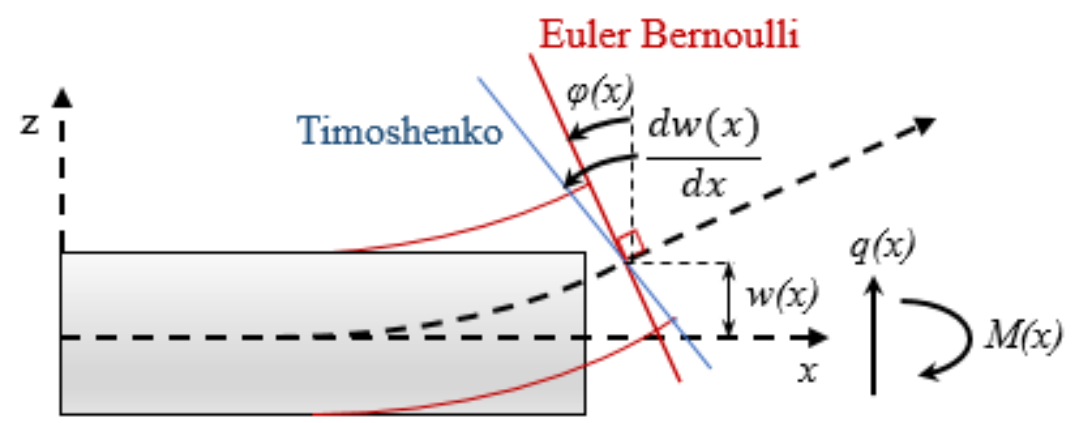

Figura 2.19 - Comparação dos modelos de viga de Euler-Bernoulli e de Timoshenko

Desta forma, as equações governantes correspondem ao sistema de equações diferenciais ordinárias dadas pelas Equações (2.68) e (2.69).

$$
\begin{aligned}
& \frac{d^{2}}{d x^{2}}\left(E I \frac{d \varphi(x)}{d x}\right)=q(x) \\
& \frac{d w(x)}{d x}=\varphi(x)-\frac{1}{\kappa A G}\left(\frac{d}{d x}\left(E I \frac{d \varphi(x)}{d x}\right)\right)
\end{aligned}
$$

Na Equação (2.69) aparecem os parâmetros $A$ que corresponde à área da seção da viga, $G$ que é o módulo ao cisalhamento e $\kappa$ que é chamado de coeficiente ao cisalhamento de Timoshenko, sendo este dependente da geometria da seção da viga. O coeficiente $\kappa$ aplicase como se apresenta na tabela seguinte:

Tabela 2.2 - Valores para área ao cisalhamento corregida em vigas

\begin{tabular}{cc}
\hline $\begin{array}{c}\text { Geometria da } \\
\text { seção da viga }\end{array}$ & $\begin{array}{c}\text { Área corrigida ao } \\
\text { cisalhamento } A^{\prime} \\
\mathrm{A}^{\prime}=\kappa \mathrm{A}\end{array}$ \\
\hline Retangular & $(5 / 6) \mathrm{A}$ \\
Circular & $(9 / 10) \mathrm{A}$ \\
\hline
\end{tabular}

Finalmente, conhecidos todos os parâmetros das Equações (2.68) e (2.69) combinadas deriva-se a solução geral ao problema da viga dada na Equação (2.70).

$$
E I \frac{d^{4} w(x)}{d x^{4}}=q(x)-\frac{E I}{A^{\prime} G} \frac{d^{2} q(x)}{d x^{2}}
$$

Obtida a equação diferencial se faz preciso determinar as condições de contorno próprias para obter o incremento das deformações por efeito do cisalhamento. Para isso serão consideradas as condições para o caso da viga em balanço cujas propriedades adotaram-se na Figura 2.17. Ao solucionar a equação diferencial (2.70) para as condições da viga em balanço apresentadas na seção 2.2.1 - , a Equação (2.63) pode-se complementar com a 
parcela ao cisalhamento, incrementando assim as deformações dependendo da rigidez ao cisalhamento, como se apresenta na Equação (2.71).

$$
w(x=L)=\frac{P L^{3}}{3 E I}+\frac{P L}{A^{\prime} G}
$$

De forma similar ao realizado para a viga em balanço, pode-se complementar as respostas máximas para uma viga simplesmente apoiada tanto com um carregamento pontual no centro referido na Figura 2.18.

$$
w\left(\frac{L}{2}\right)=\frac{P L^{3}}{48 E I}+\frac{P L}{4 A^{\prime} G}
$$

\subsection{3 - Modelo de viga sanduíche elástica}

Os elementos estruturais denominados viga sanduíche são muito utilizados na indústria aérea, aeroespacial e naval (Botelho, Silva, Pardini, \& Rezende, 2006). Na indústria das estruturas sanduíche, pretende-se basicamente aumentar a rigidez do elemento estrutural com o aumento da inércia usando materiais leves e de alta resistência, devido a isso, ganharam espaço materiais como as espumas de cloreto de poli vinilo, conhecidas como espumas de PVC, espumas de poliestireno e de poliuretano, quem além de rigidez e baixo peso (entre 100 e $500 \mathrm{~kg} / \mathrm{m}^{3}$ ), possuem também propriedades de isolamento térmico (Marinucci, 2011).

Na Figura 2.20 apresenta-se uma viga tipo sanduíche, onde as camadas externas, geralmente usadas de materiais metálicos, são a superior (camada 1) e a inferior (camada 2), e a camada central mais leve, geralmente de espumas rígidas é a camada 3. Cada camada da viga sanduíche possui uma altura $\mathrm{t}_{1}, \mathrm{t}_{2}$ e $\mathrm{h}_{3}$, respetivamente, e a base de comprimento b. Sobre a viga está atuante no centro pontualmente uma força $\mathrm{P}$, que para os cálculos imediatos vai ser considerada como constante (Huang, Gibson, \& Member, 1991; Rocca \& Nanni, 2004)

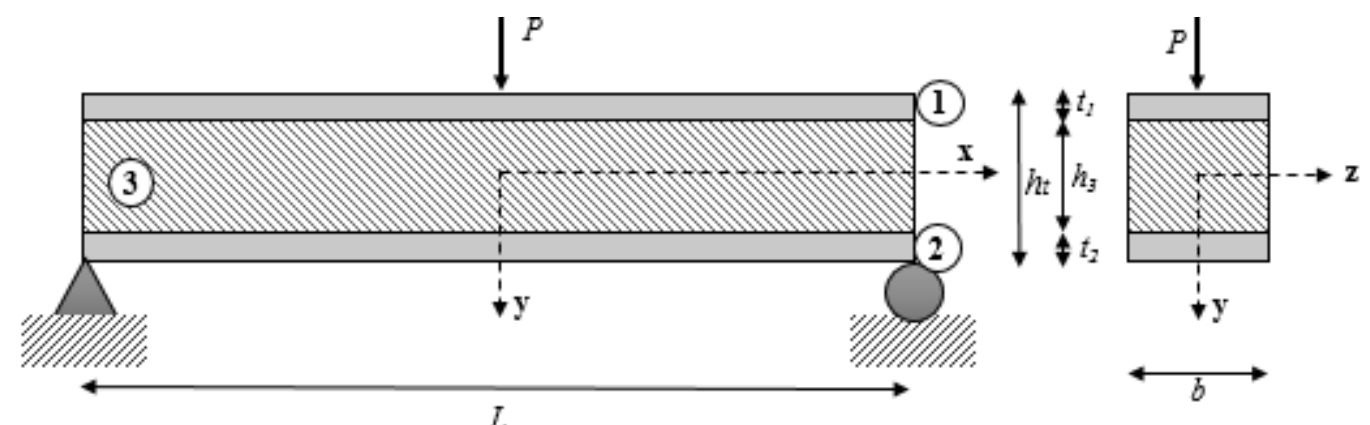

Figura 2.20 - Viga sanduíche simplesmente apoiada - perfil e seção transversal 
Baseado nestas condições e considerando para cada material o respectivo módulo de elasticidade $\left(\mathrm{E}_{\mathrm{i}}\right)$ e a inércia $\left(\mathrm{I}_{\mathrm{i}}\right)$, calcula-se como o primeiro parâmetro à rigidez a flexão do elemento estudado: EI, atribuindo a notação de $(E I)_{T}$ para esta e discriminando o $(E I)_{i}$, correspondente, a cada camada da viga de estudo segundo o apresentado nas Equações (2.73) e (2.74).

$$
\begin{aligned}
& (E I)_{T}=\begin{array}{c}
\left(E_{1} I_{1}+E_{2} I_{2}\right) \\
\text { Camadas elásticas }
\end{array}+\begin{array}{c}
E_{3} I_{3} \\
\text { Camada viscoelástica } \\
(\mathrm{EI})_{\mathrm{T}}=\mathrm{E}_{1}\left(\frac{\mathrm{bt}_{1}{ }^{3}}{12}+\mathrm{bt}_{1}\left(\frac{\mathrm{h}_{\mathrm{t}}}{2}-\frac{\mathrm{t}_{1}}{2}\right)^{2}\right)+\mathrm{E}_{2}\left(\frac{\mathrm{bt}_{2}{ }^{3}}{12}+\mathrm{bt}_{2}\left(\frac{\mathrm{h}_{\mathrm{t}}}{2}-\frac{\mathrm{t}_{2}}{2}\right)^{2}\right)+\mathrm{E}_{3}\left(\frac{\mathrm{bh}_{3}{ }^{3}}{12}\right)
\end{array}
\end{aligned}
$$

Baseados na resistência dos materiais e na teoria da flexão para viga de Euler-Bernoulli (Timoshenko, 1957), aplica-se a relação apresentada na Equação (2.57) entre a curvatura e o momento, assim valida-se a Equação (2.75).

$$
\frac{1}{\rho(x)}=\frac{M(x)}{(E I)_{T}}
$$

A deformada elástica para a condição da viga estudada por efeito de flexão pura $\delta_{\mathrm{f}}$, baseada na formulação anterior da Equação (2.66), está dada pela Equação (2.76), sendo amplamente conhecida.

$$
\delta_{\mathrm{f}}=\frac{\mathrm{PL}^{3}}{48 \mathrm{EI}}=\frac{\mathrm{PL}^{3}}{48(\mathrm{EI})_{\mathrm{T}}}
$$

O anterior é válido somente sob a teoria de viga de Euler-Bernoulli. Segundo a teoria da viga do Timoshenko, considera-se além da flexão pura o efeito que produz sobre a deformação total o esforço cortante atuante na viga $\delta_{\mathrm{v}}$, onde considera-se a rigidez ao cisalhamento do elemento. Desta forma, a formulação apresentada na Equação (2.72) contém o modulo de cisalhamento $\mathrm{G}$, um coeficiente de distorção dependente da geometria da viga $\kappa$ e a área da seção A, segundo a Tabela 2.2, a parcela ao cisalhamento se indica na Equação (2.77).

$$
\delta_{\mathrm{v}}=\frac{\mathrm{PL}}{4 \mathrm{~A}^{\prime} \mathrm{G}}
$$

Assim, obtém-se o valor da deformação elástica total no meio $\delta_{T}$ vão da estrutura $x=\frac{L}{2}$, a componente de flexão e a deformação de cisalhamento, como se mostra na seguinte expressão (2.78). 


$$
\begin{aligned}
& \delta_{\mathrm{T}}=\delta_{\mathrm{f}}+\delta_{\mathrm{v}} \\
& \delta_{\mathrm{T}}=\frac{\mathrm{PL}^{3}}{48(\mathrm{EI})_{\mathrm{T}}}+\frac{\mathrm{PL}}{4 \mathrm{~A}^{\prime} \mathrm{G}}
\end{aligned}
$$

Devido a isso, de forma análoga ao realizado com a rigidez flexional na Equação (2.73), na parcela ao cisalhamento, deve ser considerada o aporte de cada um dos materiais como é apresentado na Equação (2.79).

$$
\left(A^{\prime} G\right)_{T}=\kappa(A G)_{T}=\kappa\left(A_{1} G_{1}+A_{2} G_{2}+A_{3} G_{3}\right)
$$

Para a simplificação da Equação (2.79), quando são considerados alguns dos seus parâmetros como viscoelásticos, nota-se que as camadas externas da viga sanduíche são finas comparadas com o núcleo, sendo estas iguais em espessura e neste caso no material, ou seja $\mathrm{t}_{1}=\mathrm{t}_{2}$ e $\mathrm{E}_{1}=\mathrm{E}_{2}$. Quantitativamente, as camadas externas ocupam um espaço inferior ao um por cento, assim podem ser ignorados em tanto as condições em Equações (2.80) e (2.81) sejam cumpridas (Roberts-Tompkins, 2009; Rocca \& Nanni, 2004).

$$
\begin{aligned}
& 3\left(\frac{h_{3}+t_{2}}{t_{2}}\right)^{2}>100 \\
& \frac{E_{2}}{E_{3}} \frac{t_{2}\left(h_{3}+t_{2}\right)^{2}}{h_{3}{ }^{3}}>16,7
\end{aligned}
$$

Desta forma, a Equação (2.74) é reduzida a expressão (2.82) e elimina-se assim o problema matemático da soma das parcelas no denominador sendo o novo $(E I)_{e q}$ a rigidez a flexão equivalente. Aplica-se uma simplificação idêntica na Equação (2.79) para o módulo de cisalhamento, a ser feita na Equação (2.78), aplica- a rigidez a flexão equivalente obtida na Equação (2.82) e a simplificação feita para a rigidez ao cisalhamento da Equação (2.83).

$$
\begin{aligned}
& (\mathrm{EI})_{\mathrm{eq}} \cong \mathrm{E}_{2} \frac{\mathrm{bt_{2 }}\left(\mathrm{h}_{3}+\mathrm{t}_{2}\right)^{2}}{2} \\
& \left(\mathrm{~A}^{\prime} \mathrm{G}\right)_{\mathrm{eq}}=\kappa(\mathrm{AG})_{\mathrm{eq}} \cong \kappa \mathrm{A}_{3} \mathrm{G}_{3}
\end{aligned}
$$

Finalmente, tais simplificações são aplicadas na Equação (2.78) resultam na Equação (2.84).

$$
\delta_{\mathrm{T}}=\frac{\mathrm{PL}^{3}}{48(\mathrm{EI})_{\mathrm{eq}}}+\frac{\mathrm{PL}}{4 \kappa \mathrm{A}_{3} \mathrm{G}_{3}}
$$




\subsection{4 - Modelo de viga sanduíche considerando a viscoelasticidade dos materiais}

Considera-se uma viga sanduíche avaliando as propriedades viscoelásticas do material central, isso significa que as caraterísticas físicas do núcleo, como o módulo ao cisalhamento e o módulo de elasticidade, são variáveis ao longo do tempo. Assim, o método para a obtenção da solução analítica da deformação visco elástica que experimenta uma viga sanduíche simplesmente apoiada, com um carregamento concentrado no centro logra-se usando o princípio da correspondência elástica-viscoelástica.

A viga mencionada componha-se de duas camadas externas e um núcleo central de um material considerado como visco elástico, todos isotrópicos e lineares. Para o estudo do seu comportamento, consideram-se as dimensões mostradas na Figura 2.20 para o desenvolvimento das equações. Na Equação (2.85) apresenta-se a forma geral dos deslocamentos máximos da viga bi apoiada, onde $\mathrm{I}_{\text {mod. }}$ E um momento de inercia em função da relação no tempo zero entre as camadas elásticas e o núcleo vezes a inercia dessas mais a inercia do núcleo.

$$
\begin{aligned}
& \delta_{\mathrm{T}}=\frac{\mathrm{PL}^{3}}{48 \mathrm{E}_{3}(\mathrm{t}) \mathrm{I}_{\text {Mod. }}}+\frac{\mathrm{PL}}{4 \kappa \mathrm{A}_{3} \mathrm{G}_{3}(\mathrm{t})} \\
& \mathrm{I}_{\text {Mod }}=\frac{\mathrm{E}_{1,2}}{\mathrm{E}_{3}(0)}\left(\mathrm{I}_{1}+\mathrm{I}_{2}\right)+\mathrm{I}_{3}
\end{aligned}
$$

Aplicando o PCEV sob a Equação (2.84), e considerando tanto a parcela a flexão como a parcela ao cisalhamento em função do tempo, obtém-se a resposta viscoelástica no espaço de Laplace mostrada na Equação (2.87) e, onde o fator de correção por cisalhamento $\kappa$ adopta o valor de 1,2 dado para uma secção transversal retangular. (Huang et al., 1991).

$$
\begin{aligned}
& \bar{\delta}(\mathrm{s})=\frac{\overline{\mathrm{P}}(\mathrm{s}) \mathrm{L}^{3}}{48 \mathrm{~s} \overline{\mathrm{E}_{3}}(\mathrm{~s}) \mathrm{I}_{\mathrm{Mod}}}+\frac{\overline{\mathrm{P}}(\mathrm{s}) \mathrm{L}}{4 \kappa \mathrm{A}_{3} s \overline{\mathrm{G}_{3}}(\mathrm{~s})} \\
& \bar{\delta}(\mathrm{s})=\frac{\mathrm{L}^{3}}{48 \mathrm{I}_{\text {Mod }}} \overline{\mathrm{P}}(\mathrm{s}) \mathrm{s} * \overline{\mathrm{D}_{3}}(\mathrm{~s})+\frac{\mathrm{L}}{4 \kappa \mathrm{A}_{3}} \overline{\mathrm{P}}(\mathrm{s}) \mathrm{s} * \overline{\mathrm{D}_{3}}(\mathrm{~s})
\end{aligned}
$$

Do anterior, deduz-se que o componente de flexão da deformação contínua será invariável, enquanto que o componente de corte aumenta com o tempo na medida do módulo de cisalhamento do núcleo viscoelástico, eficazmente reduzido. Desta forma, aplicando este 
conceito na deformação elástica, pode-se obter a resposta viscoelástica em termos de fluência $\mathrm{D}(\mathrm{t})$ e fluência ao cisalhamento $\mathrm{J}(\mathrm{t})$, como se apresenta na Equação (2.88)

$$
\delta(t)=\frac{L^{3}}{48 I_{M o d}} \int_{0}^{t} D_{3}(t-\tau) \frac{d P(\tau)}{d \tau} d \tau+\frac{L}{4 \kappa A_{3}} \int_{0}^{t} J_{3}(t-\tau) \frac{d P(\tau)}{d \tau} d \tau
$$

As funções viscoelásticas do núcleo da viga sanduíche $\mathrm{D}(\mathrm{t})$ e $\mathrm{J}(\mathrm{t})$, podem serem representadas como a série de Prony correspondente, concordando com os desenvolvimentos matemáticos realizados nos numerais anteriores para as funções de fluência, correspondendo à formulação da forma da Equação (2.21) e (2.27), respectivamente.

\section{3 - ELEMENTO ESTRUTURAL DE PLACA}

\subsection{1 - Modelo de Lovel-Kirchhoff placa anisotrópica compósita}

O modelo de placas de Lovel-Kirchhoff é uma extensão do modelo de viga de EulerBernoulli, e foi desenvolvido em 1888 por Augustus Edward Hough Love1, usando premissas de Gustav Kirchhoff, formuladas em 1850. O modelo matemático é bidimensional e permite determinar tensões e deformações em placas finas, submetidas a forças e momentos, assumindo que uma superfície plana média pode ser usada para representar uma placa tridimensional de forma bidimensional (Timoshenko \& Woinowsky-krieger, 1959; A C Ugural, 1999).

As hipóteses cinemáticas consideradas neste modelo são as seguintes:

- Linhas retas normais à superfície média permanecem retas após a deformação

- Linhas retas normais à superfície média permanecem normais à superfície média após a deformação;

- A espessura da placa permanece a mesma durante a deformação.

Segundo as hipóteses anteriores, ao analisar um ponto de uma placa isotrópica e homogénea considerada indeformada, $x$ e $y$ são as coordenadas cartesianas da superfície média da placa e $z$ é a coordenada na direção da espessura, como se apresenta na Figura 2.21. Assim, o deslocamento desse ponto pode ser decomposto em uma soma vetorial do deslocamento da superfície média e um deslocamento $w$ perpendicular ao plano na direção $z$. 


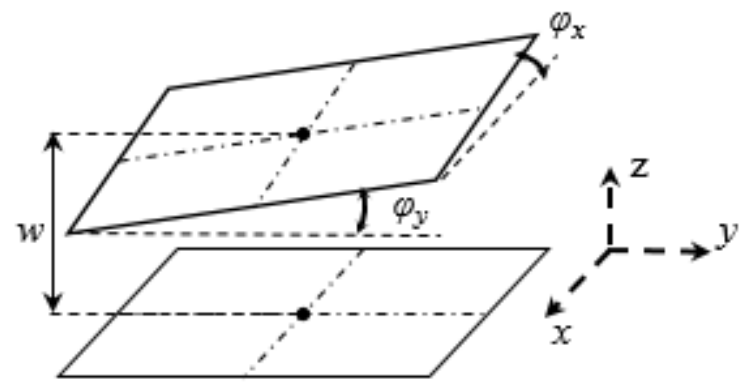

Figura 2.21 - Deslocamentos da placa de Lovel-Kirchhoff

Para uma placa considerada isotrópica e homogênea, sob um carregamento uniformemente distribuído $q$, estas condições do modelo podem serem traduzidas matematicamente na equação diferencial apresentada na Equação

$$
\begin{aligned}
& \frac{\partial^{4} w}{\partial x^{4}}+2 \frac{\partial^{4} w}{\partial x^{2} \partial y^{2}}+\frac{\partial^{4} w}{\partial y^{4}}=-\frac{q}{D} \\
& D=\frac{2 t^{3} E}{3\left(1-v^{2}\right)}
\end{aligned}
$$

Onde E é o módulo de elasticidade do material, v o módulo de Poisson e t é a espessura da placa. No entanto, ao pretender analisar uma placa anisotrópica e compósita de dois tipos de materiais, e simplesmente apoiada nas suas quatro bordas, como se apresenta na, a equação diferencial do sistema pode ser solucionada pelo método aproximado de Navier (Monforton \& Schmit, 1969; Reddy, Arciniega, \& Moleiro, 2010).

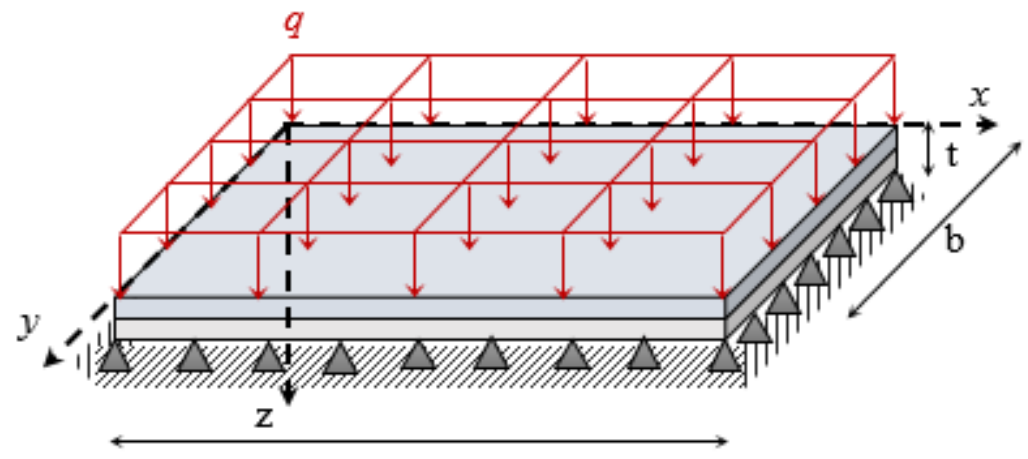

a

Figura 2.22 - Placa compósita simplesmente apoiada e com carregamento uniforme

O método de Navier é um método numérico aproximado aplicável com certas restrições, como por exemplo, pelo menos duas bordas da placa devem serem simplesmente apoiadas. Para aplicar o método com as condições para a placa de estudo inicialmente analisa-se a solução para uma placa anisotrópica e homogênea, segundo o apresentado nas Equações (2.91) e (2.92), onde $a$ e $b$ são as dimensões planas da placa, $q$ é o carregamento 
uniformemente distribuído, $m$ e $n$ são o número de termos do somatório considerados na Equação (2.93) para o cálculo do deslocamento máximo no centro da placa, e finalmente, na Equação (2.94) obtém-se a função de deflexões no sentido $x$ e $y$ dependente da deflexão máxima previamente obtida.

$$
\begin{aligned}
& s=\frac{a}{b} \\
& W_{m n}=\frac{16 q b^{4}}{\pi^{6} m n\left[D_{x x} m^{4} s^{4}+2\left(D_{x y}+2 D_{z z}\right) m^{2} n^{2} s^{2}+D_{y y} n^{4}\right]} \\
& w_{\text {máx. }}=\sum_{n=1}^{\infty} \sum_{m=1}^{\infty} W_{m n} \sin \left(\frac{m \pi}{2}\right) \sin \left(\frac{n \pi}{2}\right) \\
& w(x, y)=w_{\text {máx. }} \sin \left(\frac{\pi x}{a}\right) \sin \left(\frac{\pi y}{b}\right)
\end{aligned}
$$

Para avaliar a anisotropia e a composição de dois materiais na placa, adotou-se uma variável $\beta$ que será um fator de correção da resistência do sentido x comparado com o sentido y da placa, e mais um fator $\alpha$ que fará uma diminuição da rigidez da metade inferior da placa comparada com o material da sua metade superior. As propriedades do material da placa nas diferentes direções apresentam-se na Equação (2.95).

$$
\mathrm{D}=\left[\begin{array}{ccc}
D_{x x} & D_{x y} & D_{x z} \\
D_{x y} & D_{y y} & D_{y z} \\
D_{x z} & D_{y z} & D_{z z}
\end{array}\right]=\left[\begin{array}{ccc}
\beta D_{y y} & v D_{y y} & 0 \\
v D_{y y} & \frac{(\alpha+1) t^{3} E_{Y Y}}{24\left(1-v^{2}\right)} & 0 \\
0 & 0 & \frac{1-v}{2} D_{y y}
\end{array}\right]
$$

Assim, substituindo as propriedades dos materiais dadas na Equação (2.95) na Equação (2.92), obtêm-se a solução geral para uma placa anisotrópica de dois materiais considerando os materiais no campo elástico, segundo o apresentado na Equação (2.96).

$$
W_{m n}=\frac{384 b^{4}\left(1-v^{2}\right) q}{E_{Y Y}\left(\pi^{6} m n t^{3}\right)(\alpha+1)\left(\beta m^{4} s^{4}+2 m^{2} n^{2} s^{2}+n^{4}\right)}
$$

Finalmente, para obter o máximo deslocamento basta substituir o valor do $W_{m n}$ obtido na Equação (2.96) na Equação (2.93), e posteriormente na Equação (2.94) para lograr a função cartesiana das deflexões. Note-se que os resultados obtidos foram obtidos com base nas propriedades elásticas dos materiais, e que uma vez obtida a solução numérico-analítica aportada pelo método de Navier, esta metodologia pode ser estendida ao estudo da viscoelasticidade. 


\subsection{2 - Modelo de Lovel-Kirchhoff considerando a viscoelasticidade dos materiais}

Para considerar a viscoelasticidade dos materiais e obter os deslocamentos máximos ao longo do tempo, considera-se uma placa como apresentada na Figura 2.22, mas desta vez, o carregamento está dado por $q(t)$ e o a relaxação do material é $E_{Y Y}(t)$, transformando a Equação (2.96) na Equação (2.97).

$$
W_{m n}=\frac{384 b^{4}\left(1-v^{2}\right) q(t)}{E_{Y Y}(t)\left(\pi^{6} m n t^{3}\right)(\alpha+1)\left(\beta m^{4} s^{4}+2 m^{2} n^{2} s^{2}+n^{4}\right)}
$$

Aplicando o PCEV na Equação (2.97) resulta a Equação (2.98), para a resposta no Espaço de Laplace do valor $\overline{W_{m n}}$. Note-se que dada a forma da equação, esta resulta na convolução das funções $q^{\prime}(t)$ e $D_{Y Y}(t)$, sendo essa última dada segundo a Equação (2.99)

$$
\begin{aligned}
& \overline{W_{m n}}(\mathrm{~s})=\frac{384 b^{4}\left(1-v^{2}\right) q(s)}{s E_{Y Y}(s)\left(\pi^{6} m n t^{3}\right)(\alpha+1)\left(\beta m^{4} s^{4}+2 m^{2} n^{2} s^{2}+n^{4}\right)} \\
& \overline{W_{m n}}(\mathrm{~s})=\frac{384 b^{4}\left(1-v^{2}\right)}{\left(\pi^{6} m n t^{3}\right)(\alpha+1)\left(\beta m^{4} s^{4}+2 m^{2} n^{2} s^{2}+n^{4}\right)} q(s) s * D_{Y Y}(s) \\
& \mathrm{D}(t)=\left[\begin{array}{lll}
D_{x x}(t) & D_{x y}(t) & D_{x z}(t) \\
D_{x y}(t) & D_{y y}(t) & D_{y z}(t) \\
D_{x z}(t) & D_{y z}(t) & D_{z z}(t)
\end{array}\right] \\
& \mathrm{D}(t)=\left[\begin{array}{ccc}
\beta D_{y y}(t) & v D_{y y}(t) \\
v D_{y y}(t) & \frac{(\alpha+1) t^{3} E_{Y Y}(t)}{24\left(1-v^{2}\right)} & 0 \\
0 & 0 & \frac{1-v}{2} D_{y y}(t)
\end{array}\right]
\end{aligned}
$$

Solucionando a convolução das funções no espaço do tempo, obtém-se finalmente a função $W_{m n}(t)$, dada na expressão (2.100), e consequentemente tanto a função da deflexão máxima dependente do tempo como apresentado na Equação (2.101), tanto os deslocamentos cartesianos máximos, dados segundo a Equação (2.102).

$$
\begin{aligned}
& W_{m n}(t)=\frac{384 b^{4}\left(1-v^{2}\right)}{\left(\pi^{6} m n t^{3}\right)(\alpha+1)\left(\beta m^{4} s^{4}+2 m^{2} n^{2} s^{2}+n^{4}\right)} \int_{0}^{t} D(t-\tau) \frac{d q(\tau)}{d \tau} d \tau \\
& w_{\text {máx. }}(t)=\sum_{n=1}^{\infty} \sum_{m=1}^{\infty} W_{m n}(t) \sin \left(\frac{m \pi}{2}\right) \sin \left(\frac{n \pi}{2}\right) \\
& w(x, y, t)=w_{\text {máx. }}(t) \sin \left(\frac{\pi x}{a}\right) \sin \left(\frac{\pi y}{b}\right)
\end{aligned}
$$




\section{3 - FORMULAÇÃO DA ABORDAGEM}

Neste Capítulo apresentam-se a descrição dos quatro algoritmos numéricos necessários para o desenvolvimento da presente pesquisa. O primeiro algoritmo realiza a aproximação numérica por séries de Prony das funções de relaxação ou fluência dos materiais quando são considerados viscoelásticos; o segundo algoritmo permite a interconversão das funções viscoelásticas, ou seja, obter numericamente uma função em série de Prony de fluência ou relaxação, baseando-se na série de Prony correspondente à função inversa; e finalmente, proporcionam-se algoritmos incrementais para obter o histórico tanto no cálculo de tensões quanto no cálculo de deformações ou deslocamentos, permitindo obter a resposta ao longo do tempo que pretenda ser avaliado.

\section{1 - ALGORITMO DE REGRESSÃO ÀS SÉRIES DE PRONY}

Dos dados experimentais dos ensaios à fluência ou à relaxação dos materiais viscoelásticos, pode-se obter a curva característica do material e esta pode ser aproximada usando as séries de Prony mostradas nas Equações (2.21) e (2.23). Para avaliar a correspondência da curva obtida pela série de Prony, comparada com os dados iniciais, realiza-se uma minimização da norma da diferença entre os dados de laboratório, ou de um vetor dos valores dados de uma das funções, comparada com a função que iterativamente será aproximada numericamente, baseado no trabalho desenvolvido por Evangelista Jr. (2006).

Adotando esta função de minimização, o erro $\left\|e_{N}\right\|$ será medido pela norma da somatória das diferenças dos dados correspondentes para as funções mencionadas, como é apresentado na Equação (3.1), onde foi adotada a função fluência dos dados experimentais $D(t)_{e}$, com M número de dados, comparada com a função de fluência aproximada numericamente pela série de Prony $\mathrm{D}(\mathrm{t})_{\mathrm{p}}$.

$$
\left\|\mathrm{e}_{N}\right\|=\sqrt{\sum_{\mathrm{i}=1}^{\mathrm{M}}\left(\mathrm{D}(\mathrm{t})_{\mathrm{e}}-\mathrm{D}(\mathrm{t})_{\mathrm{p}}\right)_{\mathrm{i}}^{2}}
$$

Para conseguir que os dados sejam adequadamente descritos na série, é imperativo providenciar o número necessário, tanto de coeficientes como dos seus correspondentes exponentes, sendo este número aproximadamente o número inteiro de ordens de grandeza do tempo quando a função conhecida é plotada com o tempo em escala logarítmica. 
Obviamente o número de coeficientes e exponentes da série terão incidência definitiva na dificuldade para obter a série devido a que entre mais valores a procurar sejam a convergência, se faz mais complexa, e incidem também na descrição final dos dados realizados pela série, isto devido ao fato de ter menos coeficientes dos requeridos o erro será maior e, porém, a série obtida não será confiável para a obtenção de novos resultados numéricos baseados nesta.

Além disso, a obtenção dos mencionados parâmetros da série consiste num processo iterativo, sendo realizado um algoritmo matemático no programa Matlab como se descreve no Quadro 3.1 e se anexa no apêndice D.1, onde são consideradas para as funções fluência e relaxação as Equações (2.21) e (2.23), respectivamente, avaliando o erro segundo o mostrado na Equação (3.1), medindo o erro entre os dados iniciais e os valores obtidos com a série, providenciada pelo algoritmo apresentado graficamente na Figura 3.1.

Quadro 3.1 - Algoritmo para ajustar séries de Prony aos dados experimentais

\section{A. Dados iniciais}

1. Adota-se o número de coeficientes $(0,1, \ldots, \mathrm{N})$ e de exponentes $(1,2, \ldots, \mathrm{N})$;

2. Atribuição de valores iniciais para cada coeficiente e exponente;

\section{B. Aproximação numérica dos coeficientes e exponentes}

1. Avaliação dos coeficientes e exponentes adotados como valores iniciais e avaliação da função na forma correspondente Equação (2.21) para fluência, ou (2.23)para relaxação;

2. Aplicação do algoritmo de minimização (C): dados experimentais vs. função avaliada;

3. Avaliação do valor da função minimizada e do $\mathrm{N}$ adotado;

4. Aproximação numérica para atribuir novos valores para coeficientes e exponentes (volta ao ponto 1 ).

\begin{tabular}{|c|c|}
\hline \multicolumn{2}{|r|}{ C. Minimização } \\
\hline & $D_{i} \quad e \quad \tau_{i+1} \quad i=0,1, \ldots, N$ \\
\hline 1.1 Variáveis & $E_{i} \quad e \quad \rho_{i+1} \quad i=0,1, \ldots, N$ \\
\hline 1.2 Restricões & $D_{i}>0 \quad e \quad \tau_{i+1}>0 \quad i=0,1, \ldots, N$ \\
\hline 1.2 Kestriçoes & $E_{i}>0 \quad$ e $\quad \rho_{i+1}>0 \quad i=0,1, \ldots, N$ \\
\hline $\begin{array}{l}\text { Minimizar a Equação } \\
(3.1)\end{array}$ & $\begin{array}{l}\text { Se erro } \approx 0 \mathrm{Ne} \mathrm{D}(\mathrm{t})_{\mathrm{p}} \text { descrevem a função } \\
\text { Se não } \rightarrow \text { Novos valores } \rightarrow \text { Nova iteração }\end{array}$ \\
\hline
\end{tabular}

Para melhor compreensão da mecânica do algoritmo, assim como da iteração que é necessária para finalmente obter os valores da série de Prony que descreva corretamente a função ou de fluência ou de relaxação, comparados com os dados reais resultado de experimentos estáticos ou dinâmicos dos testes correspondentes à função estudada. 
Figura 3.1 - Descrição gráfica do algoritmo de regressão às séries de Prony

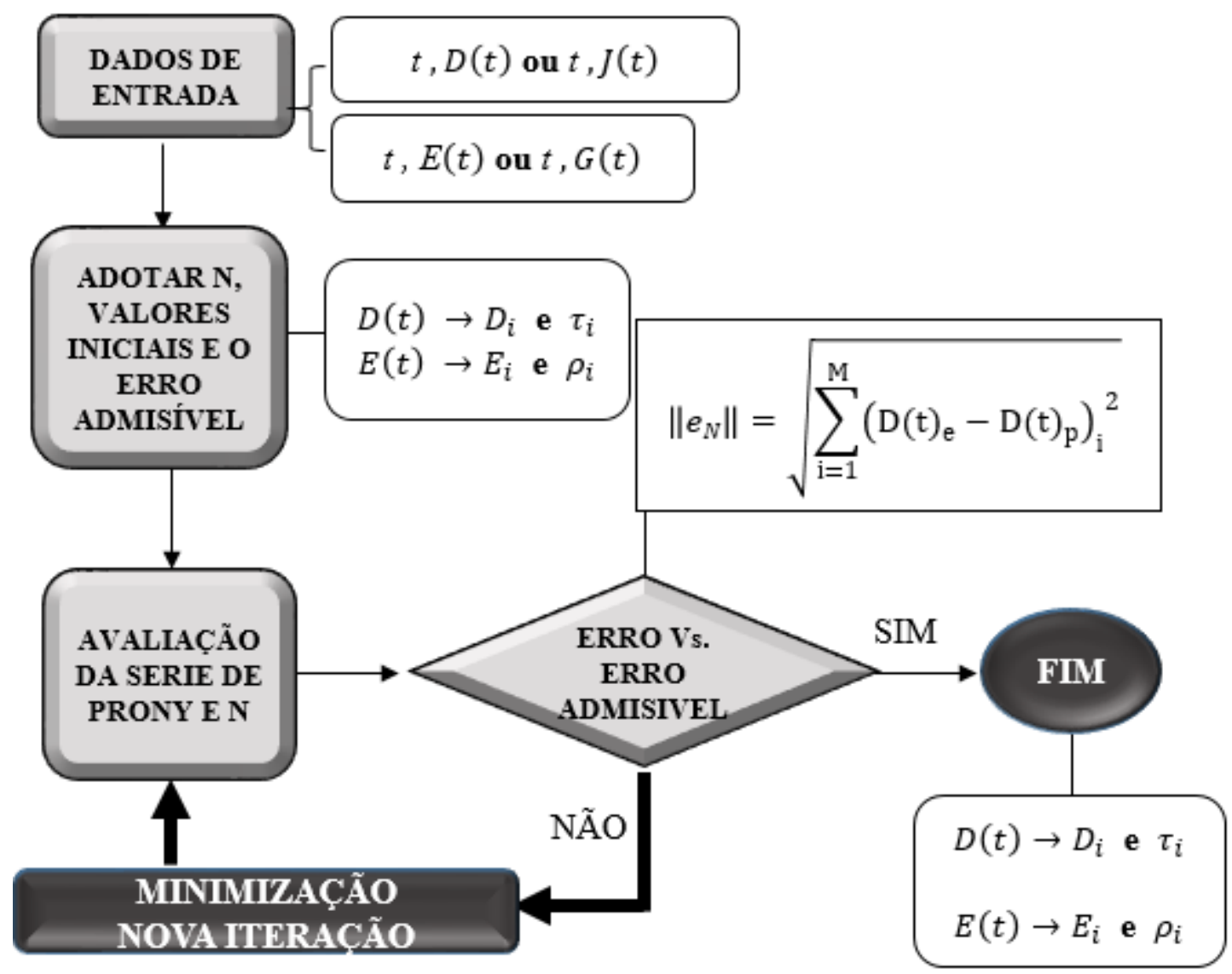

\section{2 - ALGORITMO DE INTERCONVERSÃO}

Uma vez obtida a série de Prony para uma das funções viscoelásticas, obtendo ou a função de fluência $D(t)$ ou a função relaxação $E(t)$, aplicando o algoritmo para a determinação de coeficientes mostrado no Quadro 3.1, para analisar o comportamento mecânico precisa-se contar com as duas propriedades.

Aproveitando o PCEV, pode ser obtida a interconversão ou da fluência para a relaxação, ou no sentido oposto, segundo o mostrado Equação (2.44), que aporta uma das interconvesões consideradas exatas (S. W. Park \& Kim, 1999). Desta forma, se converte a função da série de Prony conhecida para o espaço de Laplace, e posteriormente, obtêm-se a função oposta no mesmo espaço. Com a função procurada no espaço de Laplace, realiza-se a inversão desta ao espaço do tempo aplicando o método de inversão das séries de Fourier da Equação (2.49). 
Com a função procurada já no espaço do tempo, aplica-se o algoritmo para a determinação dos coeficientes da série de Prony apresentado no Quadro 3.1, usando como valores dos exponentes os mesmos valores obtidos para a série conhecida, diminuindo o problema matemático à procura de somente os coeficientes, isto se o erro relativo ser o suficientemente baixo, sendo calculado segundo a Equação (3.2).

$$
E_{R}\left(t_{i}\right)=\frac{\left|F_{A}\left(t_{i}\right)-F_{C}\left(t_{i}\right)\right|}{F_{A}\left(t_{i}\right)} \times 100
$$

$\mathrm{Na}$ Equação (3.2) o erro relativo $E_{R}$ é avaliado ponto a ponto para cada tempo $t_{i}$, onde são comparados os resultados da função calculada pelo algoritmo $F_{C}\left(t_{i}\right)$ comparada com o valor da função analítica nesse mesmo tempo avaliado $F_{A}\left(t_{i}\right)$, sendo apresentado o valor do erro em porcentagem.

Para minimizar o tempo de convergência do algoritmo e baseados no comportamento oposto das funções, uma boa primeira aproximação para os coeficientes das funções é o valor do inverso multiplicativo dos coeficientes da série conhecida. Segundo o procedimento relatado brevemente nos parágrafos anteriores, o algoritmo proposto é sucinto no Quadro 3.2.

Quadro 3.2 - Algoritmo de interconversão para as funções de fluência e relaxação

\section{A. Dados}

1. Número de coeficientes e de exponentes da série

2. Coeficientes e exponentes da série inicial $D(t)$ ou $E(t)$;

\section{B. Procedimento}

1. Transformar a função para o espaço de Laplace $\bar{D}(s)$ ou $\bar{E}(s)$ com as Equações (2.40) e (2.41) respectivamente;

2. Obter a função recíproca no espaço de Laplace usando a Equação (2.44);

3. Transforma-se a função obtida para o espaço do tempo usando as séries de Fourier, aplicando a Equação (2.49);

4. Adota-se os valores iniciais para os coeficientes e exponentes da série procurada no espaço do tempo;

5. Aplicação do algoritmo do Quadro 3.1 para obter os N coeficientes e exponentes da série;

Desta forma, pode ser obtida a função de fluência $\mathrm{D}(\mathrm{t})$ ou relaxação $\mathrm{E}(\mathrm{t})$, uma desde a outra, aplicando um dos inúmero de procedimentos de interconversão existentes, respeitando o número de coeficientes $\mathrm{N}$ da série de Prony da função inicial, aplicando o conceito de entre outros autores dado por Christensen (1982) para os dados iniciais, sendo a primeira tentativa os inversos multiplicativos e assim obter mais rapidamente a convergência do algoritmo. 
Para representar mais claramente o funcionamento do algoritmo, realizou-se uma descrição das etapas e as diferentes equações que intervém, proporcionada na como apresentada a continuação.

Figura 3.2 - Descrição gráfica do algoritmo de interconversão

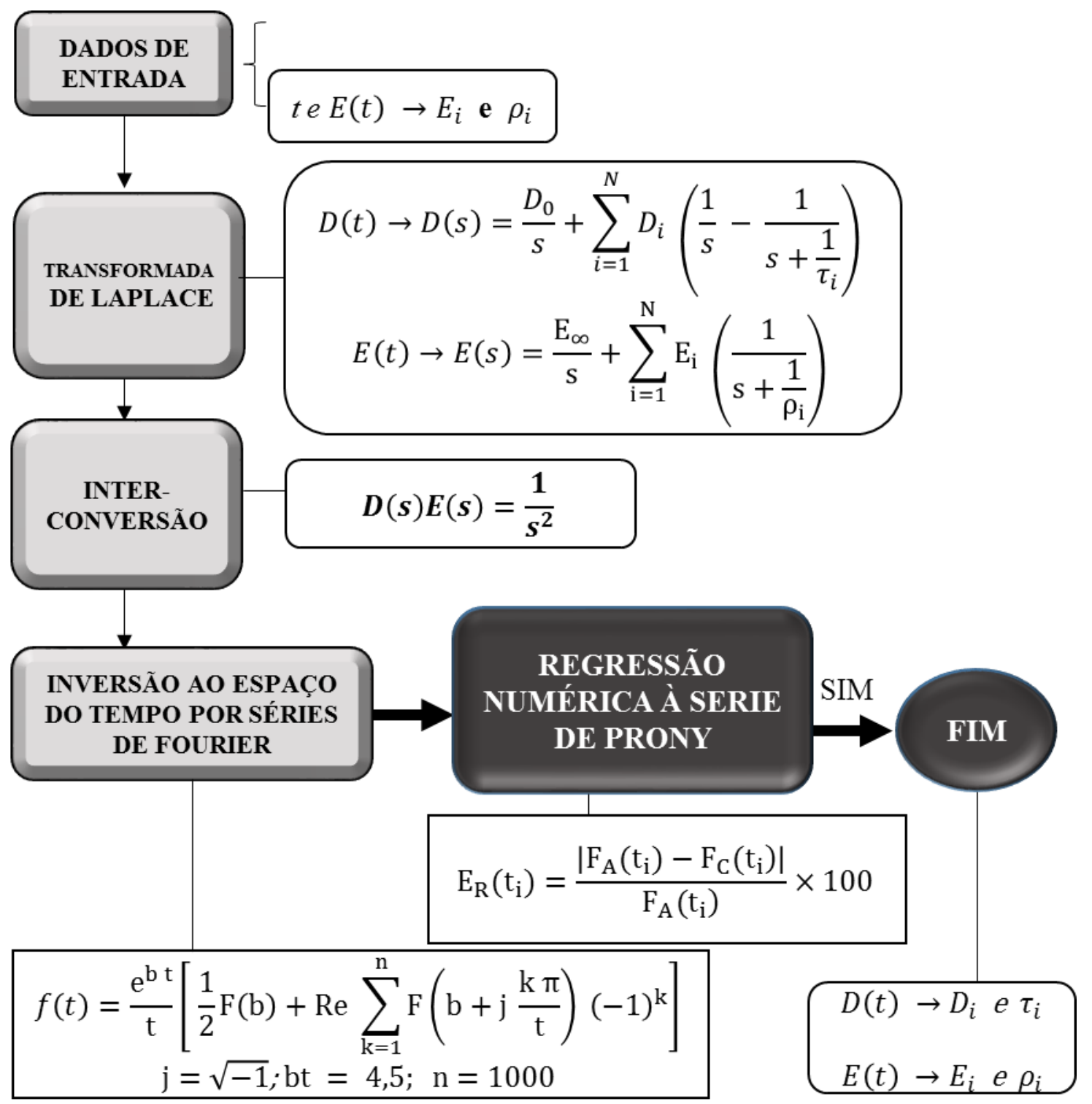

\section{3 - ALGORITMO INCREMENTAL DAS RELAÇÕES VISCOELÁSTICAS CONSTITUTIVAS}

Ao realizar a análise das respostas viscoelásticas dadas nos elementos estruturais compósitos estudados nesta pesquisa, é necessário aplicar um método eficiente para a obtenção das reais respostas dos corpos estudados ao longo do tempo, ou seja, um método que permita calcular o histórico temporal das deformações e das tensões que o elemento estrutural experimenta 
ao atuar sobre este os carregamentos ou as deformações, devido à sua demanda estrutural cotidiana. Desta forma, implementou-se o algoritmo incremental para obter as deformações e/ou tensões totais ao longo do tempo, permitindo analisar diferentes tipos de carregamento, deformações e respostas para os diferentes elementos focados neste estudo.

O método incremental unidimensional das relações constitutivas viscoelásticas foi desenvolvido baseado no princípio de superposição de Boltzmann e nas séries de Prony, sendo assim, a resposta viscoelástica total do corpo é um somatório de cada um dos incrementos de tensão ou deformação, correspondentes a cada incremento de tempo onde a função é avaliada. Este método foi desenvolvido por Zak (1968), sendo depois utilizado por White (1968) e Taylor, Pister, \& Goudreau (1970), sendo estes pesquisadores os que acrescentaram ao método o desenvolvimento para variações de temperatura.

\subsection{1 - ALGORITMO INCREMENTAL PARA CÁLCULO DO HISTÓRICO DE TENSÕES}

No Quadro 3.3 apresenta-se o algoritmo incremental no campo das tensões, correspondente ao desenvolvimento matemático para obter a solução numérica as respostas analíticas da forma da Equação (2.33).

Quadro 3.3 - Algoritmo incremental para o histórico de tensões

\section{A. Dados iniciais}

1. Tempo de avaliação;

2. Série de Prony para relaxação $\mathrm{E}(\mathrm{t}): \mathrm{N}+1$ coeficientes e $\mathrm{N}$ exponentes;

3. Função tensão ou carregamento $\sigma(\mathrm{t})$.

\begin{tabular}{|c|c|}
\hline \multicolumn{2}{|r|}{ B. Histórico incremental } \\
\hline & $\begin{array}{l}\text { - Considera-se cada incremento } \Delta \sigma=\Delta \sigma_{1}+\Delta \sigma_{2} \text { segundo a } \\
\text { Equação (3.5); }\end{array}$ \\
\hline $\begin{array}{l}\text { 1. Histórico } \\
\text { incremental da } \\
\text { função tensão }\end{array}$ & $\begin{array}{l}\text { - Implementa-se } \Delta \sigma_{1} \text { segundo a Equação (3.7) e } \Delta \varepsilon_{2} \text { segundo as } \\
\text { Equações (3.8) e (3.9), em função da série de Prony da função } \\
\text { relaxação } E(t) ;\end{array}$ \\
\hline$\sigma(\mathrm{t})$ & $\begin{array}{l}\text { - Após de calculado cada incremento de tensão } \Delta \sigma_{\mathrm{i}} \text {, acumula-se } \\
\text { posiçãa a posição para obter o histórico das deformaços ao longo } \\
\text { do tempo considerado. }\end{array}$ \\
\hline
\end{tabular}

No caso da avaliação do histórico de tensões unidimensional $\sigma(\mathrm{t})$, dado pela Equação (2.33), calcula-se o correspondente incremento de tensão $\Delta \sigma$ para cada diferencial de tempo $\Delta t$, como representado na Equação (3.3). 
Figura 3.3 - Descrição gráfica do algoritmo incremental para o histórico de tensões

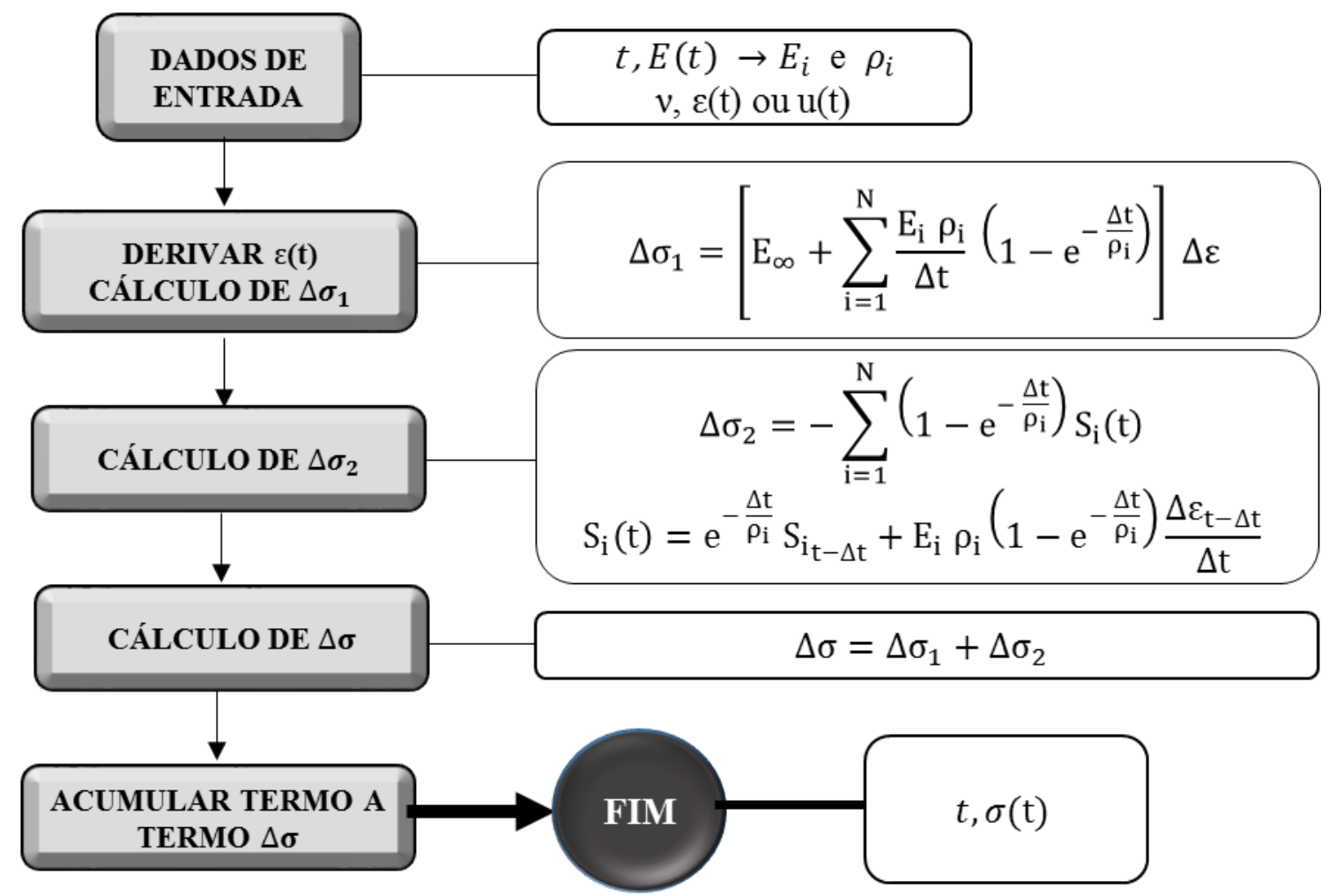

$$
\Delta \sigma=\sigma(\mathrm{t}+\Delta \mathrm{t})-\sigma(\mathrm{t})
$$

Substituindo a Equação (3.3) na Equação (2.33) pode-se obter a forma generalizada do incremento de tensão, como demonstrado na Equação (3.4).

$$
\Delta \sigma=\int_{0}^{\mathrm{t}+\Delta \mathrm{t}} \mathrm{E}(\mathrm{t}+\Delta \mathrm{t}-\tau) \frac{\partial \varepsilon}{\partial \tau} \mathrm{d} \tau-\int_{0}^{\mathrm{t}} \mathrm{E}(\mathrm{t}-\tau) \frac{\partial \varepsilon}{\partial \tau} \mathrm{d} \tau
$$

Distribuindo a equação anterior nos seus respectivos limites de integração, chega-se à Equação (3.5).

$$
\begin{aligned}
& \Delta \sigma=\int_{t}^{\mathrm{t}+\Delta \mathrm{t}} \mathrm{E}(\mathrm{t}+\Delta \mathrm{t}-\tau) \frac{\partial \varepsilon}{\partial \tau} \mathrm{d} \tau+\int_{0}^{\mathrm{t}}[\mathrm{E}(\mathrm{t}+\Delta \mathrm{t}-\tau)-\mathrm{E}(\mathrm{t}-\tau)] \frac{\partial \varepsilon}{\partial \tau} \mathrm{d} \tau \\
& \Delta \sigma=\Delta \sigma_{1}+\Delta \sigma_{2}
\end{aligned}
$$

A Equação (3.5) pode ser interpretada fisicamente, onde a primeira parcela representa a parte elástica do incremento de tensão, resultado de uma deformação dada; enquanto que a segunda parte, concebe a parte viscosa para a deformação imposta ao corpo. Esta formulação matemática depende tanto do incremento de deformação-tempo quanto do módulo de relaxação. No caso da parcela elástica da equação, pode-se avaliar a deformação entre seus limites de integração, onde o diferencial de tempo é muito pequeno, desta forma a 
deformação pode ser aproximada no intervalo de tempo como apresentado a seguir na Equação (3.6).

$$
\dot{\varepsilon}=\frac{\varepsilon_{\mathrm{t}+\Delta \mathrm{t}}-\varepsilon_{\mathrm{t}}}{\mathrm{t}+\Delta \mathrm{t}-\mathrm{t}}=\frac{\Delta \varepsilon}{\Delta \mathrm{t}}
$$

Considerando o resultado da Equação (3.6) e assumindo E(t) como uma série de Prony da forma da Equação (2.23), pode-se simplificar a parcela do incremento de tensão correspondente a $\Delta \sigma_{1}$ como se apresenta na Equação (3.7).

$$
\begin{aligned}
& \Delta \sigma_{1}=\frac{\Delta \varepsilon}{\Delta t} \int_{t}^{\mathrm{t}+\Delta \mathrm{t}}\left(\mathrm{E}_{\infty}+\sum_{\mathrm{i}=1}^{\mathrm{N}} \mathrm{E}_{\mathrm{i}} \mathrm{e}^{-\frac{(\mathrm{t}+\Delta \mathrm{t}-\tau)}{\rho_{\mathrm{i}}}}\right) \mathrm{d} \tau \\
& \Delta \sigma_{1}=\left[\mathrm{E}_{\infty}+\sum_{\mathrm{i}=1}^{\mathrm{N}} \frac{\mathrm{E}_{\mathrm{i}} \rho_{\mathrm{i}}}{\Delta \mathrm{t}}\left(1-\mathrm{e}^{-\frac{\Delta \mathrm{t}}{\rho_{\mathrm{i}}}}\right)\right] \Delta \varepsilon
\end{aligned}
$$

De forma análoga ao realizado para $\Delta \sigma_{1}$, utilizando o módulo de relaxação dado na Equação (2.23), avalia-se $\Delta \sigma_{2}$ como se apresenta na Equação (3.8).

$$
\begin{aligned}
& \Delta \sigma_{2}=-\sum_{i=1}^{N}\left(1-e^{-\frac{\Delta t}{\rho_{i}}}\right) \int_{0}^{t} E_{i} e^{-\frac{(t-\tau)}{\rho_{i}}} \frac{\partial \varepsilon}{\partial \tau} d \tau \\
& \Delta \sigma_{2}=-\sum_{i=1}^{N}\left(1-e^{-\frac{\Delta t}{\rho_{i}}}\right) S_{i}(t)
\end{aligned}
$$

Sendo que $S_{i}(t)$ corresponde a um termo variável em função de cada um dos termos da série de Prony, onde esse é responsável pelo incremento crescente ou decrescente da função avaliada até o tempo final, isto é desde tempo $t=0 \rightarrow t$. Assim, avalia-se a função $S_{i}(t)$ com a simplificação considerada na Equação (3.6) e substituindo a variável original t nos limites de integração, segundo a Equação (3.9).

$$
\begin{aligned}
& S_{i}(t)=\int_{0}^{t-\Delta t} E_{i} e^{-\frac{(t-\tau)}{\rho_{i}}} \frac{\partial \varepsilon}{\partial \tau} d \tau+\int_{t-\Delta t}^{t} E_{i} e^{-\frac{(t-\tau)}{\rho_{i}}} \frac{\partial \varepsilon}{\partial \tau} d \tau \\
& S_{i}(t)=e^{-\frac{\Delta t}{\rho_{i}}} S_{i_{t}-\Delta t}+E_{i} \rho_{i}\left(1-e^{-\frac{\Delta t}{\rho_{i}}}\right) \frac{\Delta \varepsilon_{t-\Delta t}}{\Delta t}
\end{aligned}
$$

Para solucionar e chegar finalmente à Equação (3.9), considera-se a primeira parcela como uma equação hereditária da forma da Equação (2.33), que constitui o valor da função num tempo anterior. A segunda parcela soluciona-se integrando e implementando nesta a 
aproximação da equação (3.6), desta forma obteve-se a solução completa para avaliação histórica de tensões para qualquer um par de funções deformação e relaxação.

O método desenvolvido acima tem sido amplamente utilizado e difundido em várias dissertações, artigos, teses, entre outros, os resultados das pesquisas realizadas por Zocher, Groves, \& Allen (1997), Evangelista Jr. (2006), Portela (2011) e Silva, Teófilo, Parente, Melo, \& Holanda (2013), foram baseadas neste método da forma como foi apresentada no presente capítulo.

\subsection{2 - ALGORITMO INCREMENTAL PARA CÁLCULO DO HISTÓRICO DE DEFORMAÇÕES}

No Quadro 3.4 proponha-se o algoritmo incremental para obter respostas no campo das deformações, ou seja, o algoritmo para dar solução ao problema matemático imposto na resposta analítica da forma da Equação (2.32).

Quadro 3.4 - Algoritmo incremental para o histórico de deformações

\section{A. Dados iniciais}

1. Tempo de avaliação;

2. Série de Prony para fluência $D(t): N+1$ coeficientes e $N$ exponentes;

3. Função deformação ou deslocamento $\varepsilon(\mathrm{t})$;

\begin{tabular}{cc}
\hline \multicolumn{3}{c}{ B. Histórico incremental } \\
\hline & Considera-se cada incremento $\Delta \varepsilon=\Delta \varepsilon_{1}+\Delta \varepsilon_{2}$ segundo a \\
& Equação (3.12); \\
1. Histórico & - Implementa-se $\Delta \varepsilon_{1}$ segundo a Equação (3.14) e $\Delta \varepsilon_{2}$ segundo as \\
incremental da & Equações (3.15) e (3.16), em função da série de Prony da função \\
função & fluência $\mathrm{D}(\mathrm{t}) ;$ \\
deformação $\varepsilon(\mathrm{t})$ & - Após de calculado cada incremento de deformação $\Delta \varepsilon_{\mathrm{i}}$, acumula- \\
& se posição a posição para obter o histórico das deformações ao \\
& longo do tempo considerado.
\end{tabular}

Na presente pesquisa foi desenvolvido o método incremental para o estudo das deformações, não sendo encontrado na literatura disponível, desenvolvido devido à importância para a análise das deformações das estruturas que pretendem-se estudar nesta pesquisa, segundo o esquematizado na Figura 3.4. 
Figura 3.4 - Descrição gráfica do algoritmo incremental para o histórico de deformações

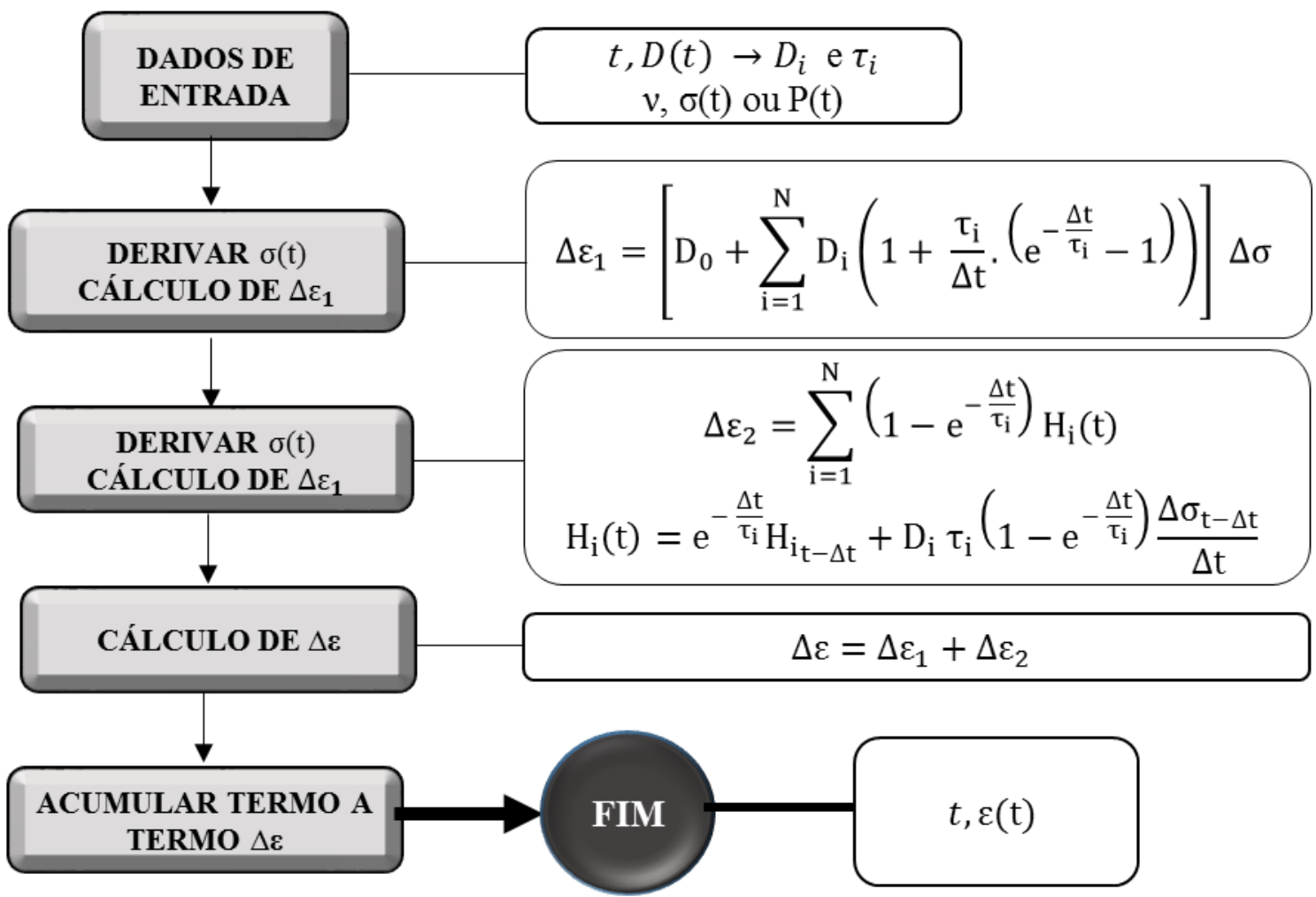

Aplicando uma analogia com o método estudado para obter as tensões, pode-se obter o histórico de deformações unidimensionais $\varepsilon(\mathrm{t})$, dado pela Equação (2.32), fazendo uso da função fluência $D(t)$ na forma exibida da série de Prony como na Equação (2.21), obtém-se como resultado a Equação (3.10).

$$
\Delta \varepsilon=\varepsilon(\mathrm{t}+\Delta \mathrm{t})-\varepsilon(\mathrm{t})
$$

Substituindo a Equação (3.10) na Equação (2.32) pode-se obter a forma generalizada do incremento da deformação. Assim, o histórico das deformações correspondentes para cada diferencial de tempo e tensão considera-se como se apresenta na Equação (3.11).

$$
\Delta \varepsilon=\int_{0}^{t+\Delta t} D(t+\Delta t-\tau) \frac{\partial \sigma}{\partial \tau} d \tau-\int_{0}^{t} D(t-\tau) \frac{\partial \sigma}{\partial \tau} d \tau
$$

Distribuindo a equação anterior nos seus respectivos limites de integração, chega-se à equação generalizada, surgindo duas parcelas diferenciadas para o diferencial da deformação segundo a Equação (3.12).

$$
\Delta \varepsilon=\int_{t}^{t+\Delta t} D(t+\Delta t-\tau) \frac{\partial \sigma}{\partial \tau} d \tau+\int_{0}^{t}[D(t+\Delta t-\tau)-D(t-\tau)] \frac{\partial \sigma}{\partial \tau} d \tau
$$




$$
\Delta \varepsilon=\Delta \varepsilon_{1}+\Delta \varepsilon_{2}
$$

Ao analisar a primeira parcela, pode-se notar que o intervalo de tempo é muito pequeno, permitindo aproximar a tensão entre os limites de integração, sendo um valor quase constante como se simplifica na Equação (3.13).

$$
\dot{\sigma}=\frac{\sigma_{t+\Delta t}-\sigma_{t}}{t+\Delta t-t}=\frac{\Delta \sigma}{\Delta t}
$$

Considerando o resultado da Equação (3.13), assumindo D(t) como uma série de Prony da forma da Equação (2.21), pode-se simplificar a parcela do incremento da deformação correspondente a $\Delta \varepsilon_{1}$ como é apresentado na Equação (3.14).

$$
\begin{aligned}
& \Delta \varepsilon_{1}=\frac{\Delta \sigma}{\Delta \mathrm{t}} \int_{\mathrm{t}}^{\mathrm{t}+\Delta \mathrm{t}}\left(\mathrm{D}_{0}+\sum_{\mathrm{i}=1}^{\mathrm{N}} \mathrm{D}_{\mathrm{i}}\left(1-\mathrm{e}^{-\frac{(\mathrm{t}+\Delta \mathrm{t}-\tau)}{\tau_{\mathrm{i}}}}\right)\right) \mathrm{d} \tau \\
& \Delta \varepsilon_{1}=\left[\mathrm{D}_{0}+\sum_{\mathrm{i}=1}^{\mathrm{N}} \mathrm{D}_{\mathrm{i}} \cdot\left(1+\frac{\tau_{\mathrm{i}}}{\Delta \mathrm{t}} \cdot\left(\mathrm{e}^{-\frac{\Delta \mathrm{t}}{\tau_{\mathrm{i}}}}-1\right)\right)\right] \Delta \sigma
\end{aligned}
$$

Para obter $\Delta \sigma_{2}$, considera-se o módulo de fluência dado pela Equação (2.21), sobre essa são realizadas as simplificações pertinentes aos respetivos limites de integração, e desta forma tem-se o resultado na Equação (3.15).

$$
\begin{aligned}
& \Delta \varepsilon_{2}=\sum_{i=1}^{N}\left(1-e^{-\frac{\Delta t}{\tau_{i}}}\right) \int_{0}^{t} D_{i} e^{-\frac{(t-\tau)}{\tau_{i}}} \frac{\partial \sigma}{\partial \tau} d \tau \\
& \Delta \varepsilon_{2}=\sum_{i=1}^{N}\left(1-e^{-\frac{\Delta t}{\tau_{i}}}\right) H_{i}(t)
\end{aligned}
$$

Sendo que $\mathrm{H}_{\mathrm{i}}(\mathrm{t})$ é análogo ao termo encontrado para o historial de esforços, mostrado na Equação (3.9), corresponde a um termo variável em função de cada um dos termos da série de Prony, que desta vez, correspondem aos termos da série de fluência. Avalia-se a função $\mathrm{H}_{\mathrm{i}}(\mathrm{t})$ com a simplificação considerada na Equação (3.13), posteriormente substituindo a variável original t nos limites de integração, como se apresenta a continuação na Equação (3.16).

$$
\begin{aligned}
& \mathrm{H}_{\mathrm{i}}(\mathrm{t})=\int_{0}^{\mathrm{t}-\Delta \mathrm{t}} \mathrm{D}_{\mathrm{i}} \mathrm{e}^{-\frac{(\mathrm{t}-\tau)}{\tau_{\mathrm{i}}}} \frac{\partial \sigma}{\partial \tau} \mathrm{d} \tau+\int_{\mathrm{t}-\Delta \mathrm{t}}^{\mathrm{t}} \mathrm{D}_{\mathrm{i}} \mathrm{e}^{-\frac{(\mathrm{t}-\tau)}{\tau_{\mathrm{i}}}} \frac{\partial \sigma}{\partial \tau} \mathrm{d} \tau \\
& \mathrm{H}_{\mathrm{i}}(\mathrm{t})=\mathrm{e}^{-\frac{\Delta \mathrm{t}}{\tau_{\mathrm{i}}}} \mathrm{H}_{\mathrm{i}_{\mathrm{t}-\Delta t}}+\mathrm{D}_{\mathrm{i}} \tau_{\mathrm{i}}\left(1-\mathrm{e}^{-\frac{\Delta \mathrm{t}}{\tau_{\mathrm{i}}}}\right) \frac{\Delta \sigma_{\mathrm{t}-\Delta \mathrm{t}}}{\Delta \mathrm{t}}
\end{aligned}
$$




\section{4 - VERIFICAÇÃO DOS ALGORITMOS PROPOSTOS}

Neste Capítulo se apresentam uma série de verificações para cada dos algoritmos formulados na presente pesquisa. Essas validações foram realizadas com base em dados experimentais, métodos analíticos e outros métodos numéricos, como por exemplo o método das diferenças finitas e o método dos elementos finitos, para assim garantir a veracidade dos resultados obtidos a partir desses algoritmos propostos.

\section{1 - ALGORITMO DE REGRESSÃo ÀS SÉRIES DE PRONY}

A validação realizou-se com os resultados obtidos experimentalmente por Plazek (1966), documentando o comportamento de fluência ao cisalhamento $J(t)$ do material poliestireno, sendo retomado por Ferry (1980) e posteriormente estudado para realizar uma aproximação numérica por séries de Prony no trabalho desenvolvido por Roberts-Tompkins (2009), significando a obtenção dos coeficientes da série de Prony.

A função $J(t)$ obtida por Roberts apresenta-se graficamente na Figura 4.1, e aplicando o algoritmo proposto na presente pesquisa, conseguiu-se uma aproximação muito boa na descrição dos dados dos aproximados por Roberts e apresentados na Tabela 4.1.

\begin{tabular}{cc|cc|cc}
\multicolumn{6}{c}{ Tabela $4.1-$ Dados de entrada para aproximação série de Prony J(t) } \\
\hline $\begin{array}{c}\mathrm{t} \\
{[\mathrm{h}]}\end{array}$ & $\begin{array}{c}\mathrm{J}(\mathrm{t}) \\
{[\mathrm{MPa}]}\end{array}$ & $\begin{array}{c}\mathrm{t} \\
{[\mathrm{h}]}\end{array}$ & $\begin{array}{c}\mathrm{J}(\mathrm{t}) \\
{[\mathrm{MPa}]}\end{array}$ & $\begin{array}{c}\mathrm{t} \\
{[\mathrm{h}]}\end{array}$ & $\begin{array}{c}\mathrm{J}(\mathrm{t}) \\
{[\mathrm{MPa}]}\end{array}$ \\
\hline 0 & 0,001350 & 200 & 2,826871 & 3000 & 4,359910 \\
1 & 0,146878 & 300 & 3,091189 & 4000 & 4,484265 \\
5 & 0,536633 & 400 & 3,250914 & 5000 & 4,575353 \\
10 & 0,863727 & 500 & 3,366806 & 6000 & 4,650541 \\
20 & 1,260952 & 600 & 3,461720 & 7000 & 4,716559 \\
30 & 1,496854 & 700 & 3,544522 & 8000 & 4,776195 \\
40 & 1,665629 & 800 & 3,618887 & 9000 & 4,830754 \\
50 & 1,802660 & 900 & 3,686539 & 10000 & 4,880973 \\
60 & 1,921629 & 1000 & 3,748453 & 15000 & 5,081537 \\
70 & 2,028171 & 2000 & 4,156121 & 20000 & 5,171758 \\
\hline
\end{tabular}

Desta maneira, como o algoritmo de aproximação precisa de dados de entrada, sendo de origem numérico ou experimental, adotou-se um vetor de dados da série obtida por RobertsTompkins (2009) é adotada como dados iniciais do algoritmo e obtiveram-se os resultados apresentados na Figura 4.1. 


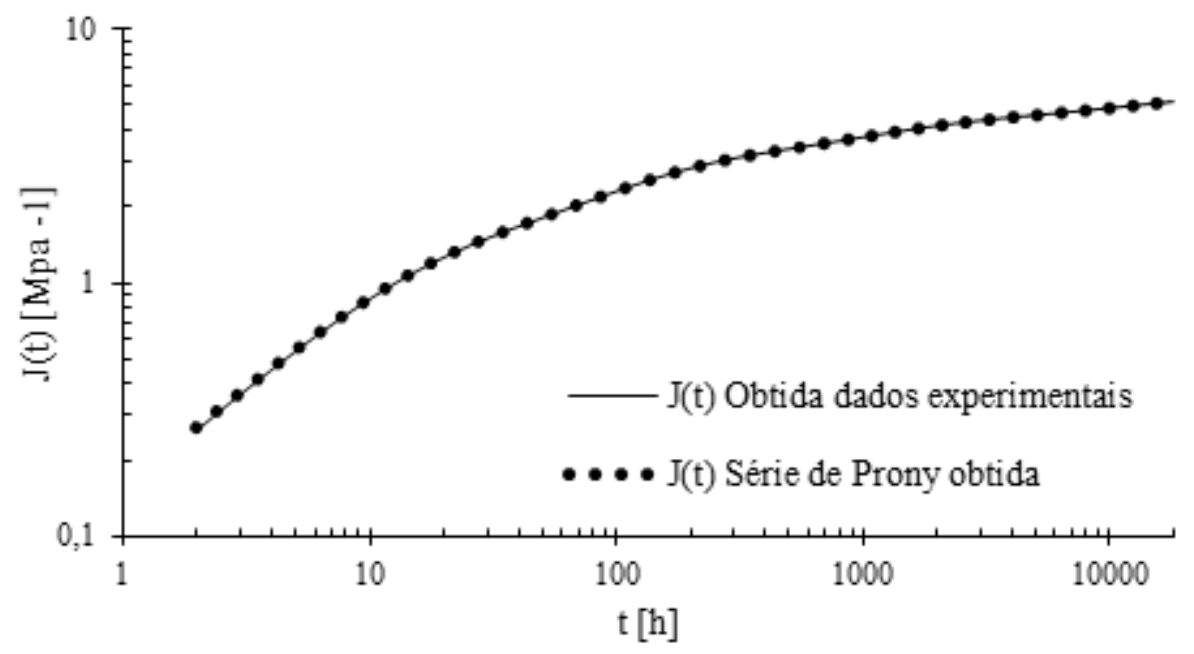

Figura 4.1 - Verificação do algoritmo de aproximação à série da função fluência ao cisalhamento $\mathrm{J}(\mathrm{t})$ do material poliestireno

Os resultados do algoritmo implementado segundo o apresentado na figura acima, são amplamente satisfatórios, sendo a série obtida indicada na Tabela 4.2, obtendo um erro $\left\|e_{N}\right\|=0,767135665$ ao serem analisados 18002 valores de tempo t, o que traduz que o erro para cada valor comparado com seu correspondente no tempo t avaliado não equivale ne a um $1 \%$, tal e como pode-se apreciar na Figura 4.1.

Nota-se que na série obtida enquanto os coeficientes multiplicadores $\mathrm{J}_{\mathrm{i}}$ resultam crescentes inicialmente, os termos finais da mesma são ou semelhantes ou decrescentes, sendo diferente ao comportamento dos exponentes $\tau_{i}$, que normalmente são aproximadamente uma ordem de grandeza a mais do que o exponente anterior. Para muitos dos materiais viscoelásticos o conceito anterior permite diminuir a procura de todos e cada um dos exponentes a só um, sendo os outros exponentes uma função do primeiro, como foi realizado neste caso com resultados satisfatórios, mas não é regra geral para todos os materiais viscoelásticos.

Tabela 4.2 - Coeficientes da série de Prony J(t) obtidos pelo algoritmo proposto

\begin{tabular}{ccc}
\hline $\mathbf{N}$ & $\boldsymbol{J}_{\boldsymbol{n}}\left[\mathbf{M P a}^{-\mathbf{1}}\right]$ & $\boldsymbol{\tau}_{\boldsymbol{n}}[\boldsymbol{h}]$ \\
\hline 0 & $1,20 \mathrm{E}-05$ & -- \\
1 & $2,65 \mathrm{E}-02$ & $9,98 \mathrm{E}-02$ \\
2 & $2,65 \mathrm{E}-02$ & $9,98 \mathrm{E}-01$ \\
3 & $9,96 \mathrm{E}-01$ & $9,98 \mathrm{E}+00$ \\
4 & $1,75 \mathrm{E}+00$ & $9,98 \mathrm{E}+01$ \\
5 & $1,33 \mathrm{E}+00$ & $9,98 \mathrm{E}+02$ \\
6 & $1,02 \mathrm{E}+00$ & $9,98 \mathrm{E}+03$ \\
7 & $1,92 \mathrm{E}-01$ & $9,98 \mathrm{E}+04$ \\
8 & $9,05 \mathrm{E}+00$ & $9,98 \mathrm{E}+05$ \\
\hline
\end{tabular}




\section{2 - ALGORITMO DE INTERCONVERSÃO}

\subsection{1 - Função obtida pelo algoritmo comparada com a resposta analítica do Modelo de Boltzmann}

A primeira série de Prony para testar o algoritmo de interconversão é a função relaxação E(t) usada por Torres (2013) segundo o mostrado na Equação (4.1).

$$
E(t)=E_{\infty}+E_{1} e^{-\frac{t}{\rho_{1}}}=1000+3000 e^{-\frac{t}{2}}
$$

Correspondente à Equação (4.1), o modelo de Boltzmann oferece uma solução analítica para validar o algoritmo de interconversão, sendo esses baseados nas Equações (2.16) e (2.18), como se mostra a continuação na Equação (4.2).

$$
\begin{aligned}
& D(t)=D_{0}+D_{1}\left(1-e^{-\frac{t}{\tau_{1}}}\right) \\
& D_{0}=\frac{1}{E_{\infty}+E_{1}} ; D_{1}=\frac{E_{1}}{E_{\infty}\left(E_{\infty}+E_{1}\right)} ; \tau_{1}=\rho_{1} \frac{\left(E_{\infty}+E_{1}\right)}{E_{\infty}}
\end{aligned}
$$

Assim, podem se comparar os resultados obtidos pela função analítica da fluência $D(t)$ na Equação (4.3), os valores correspondentes à série de Prony $\mathrm{D}_{0}, \mathrm{D}_{1}$ e $\tau_{1}$, obtidos pela aproximação numérica aplicando o algoritmo do Quadro 3.1, dada na Equação (4.4) e a função de fluência no espaço do tempo, obteve-se o resultado numérico seguinte:

$$
\begin{aligned}
& D(t)=2,5 E-4+7,5 E-4\left(1-e^{-\frac{t}{8}}\right) \\
& D(t)=2,50035981 E-4+7,5005022 E-4\left(1-e^{-\frac{t}{7,99807811}}\right)
\end{aligned}
$$

Para este caso particular, o tempo de relaxação e retardo não correspondem ao mesmo valor, mas para ter certeza da validade dos resultados obtidos, as diferenças entre as funções obtidas por inversão desde o espaço de Laplace ao espaço do tempo e a aproximação feita pela série da Equação (4.1), podem-se apreciar segundo as funções apresentadas na Figura 4.2. 


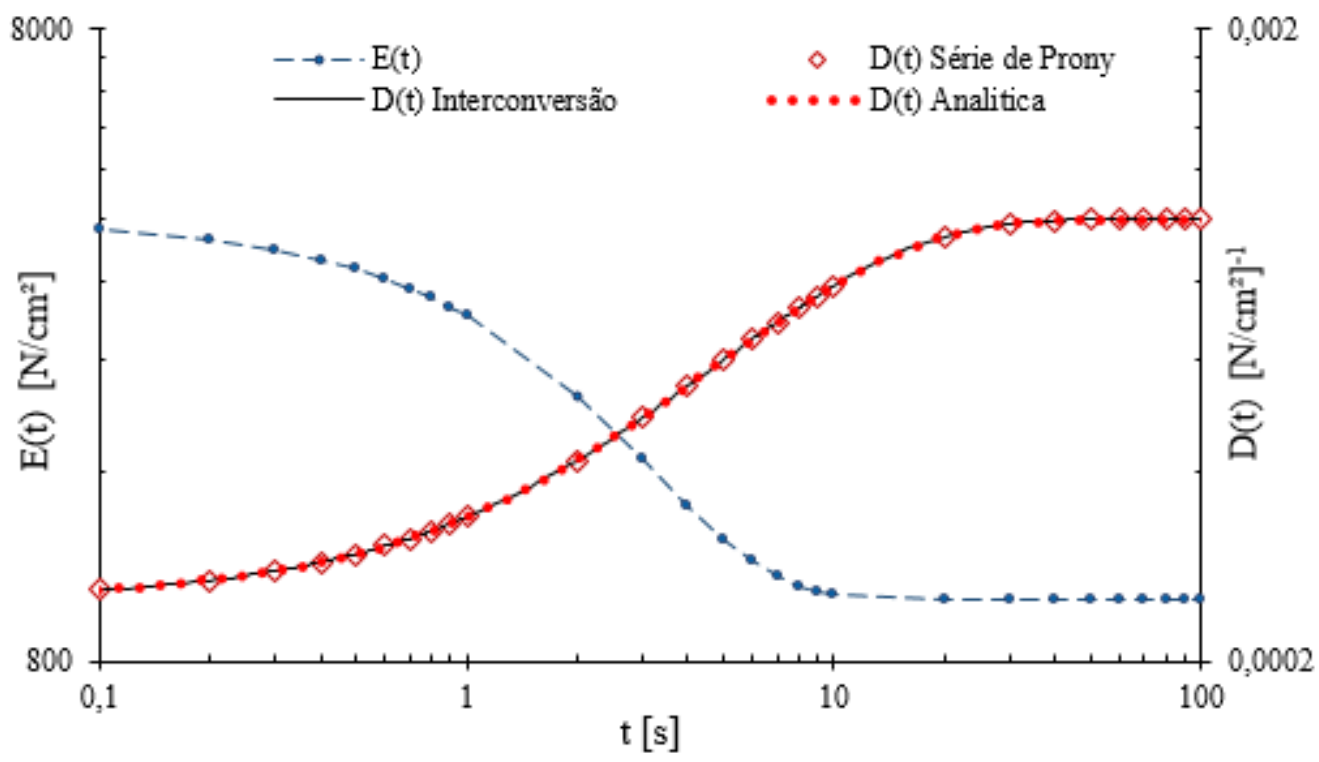

Figura 4.2 - Comparação das funções viscoelásticas E(t) e D(t) aplicando os algoritmos propostos

$\mathrm{Na}$ figura anterior, apresenta-se a função de relaxação $\mathrm{E}(\mathrm{t})$ na série de cor azul. Nota-se que esta função é origem da função fluência $\mathrm{D}(\mathrm{t})$ obtida, igualmente comparam-se as funções de fluência $\mathrm{D}(\mathrm{t})$, tanto a obtida pelo algoritmo de interconversão, no gráfico representada pela linha preta ponteada, quanto a função resultado do algoritmo de aproximação por séries de Prony, representada pela linha vermelha e a série analítica, apresentada pela série de pontos vermelhos. Para identificar a ordem de magnitude do erro entre a série obtida e a série analítica da função fluência $\mathrm{D}(\mathrm{t})$, o resultado do erro relativo $\mathrm{E}_{\mathrm{R}}$ medido entre as duas curvas é apresentada na Figura 4.3.

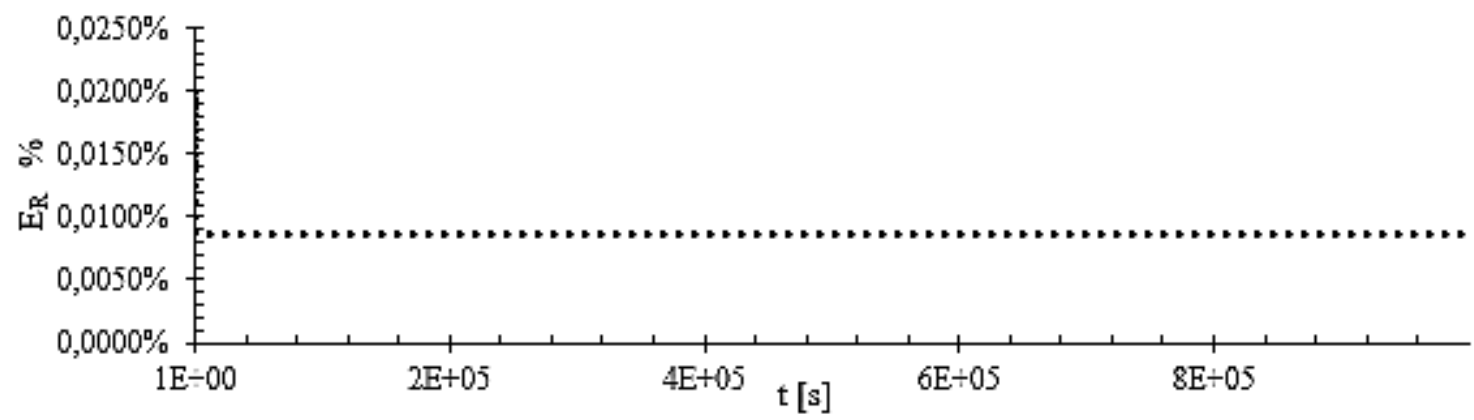

Figura 4.3 - ER calculado entre a função fluência $D(t)$ obtida Vs. $D(t)$ analítica

\subsection{2 - Interconversão da série E(t) do Poliuretano}

As espumas rígidas de poliuretano tem incontáveis utilidades dentro da indústria aérea, petrolífera e oceânica, sendo o seu comportamento mecânico estudado entre outros, por Lemos (2005), quem realizou no seu trabalho de pesquisa um estudo desse material e com seus dados experimentais, conseguiu a série de Prony para o comportamento de relaxação 
$\mathrm{E}(\mathrm{t})$, este resultado se apresenta na Tabela 4.3. Na mesma Tabela apresenta-se os resultados da série de fluência $\mathrm{D}(\mathrm{t})$ obtida por interconversão numérica utilizando o algoritmo proposto.

\begin{tabular}{cccc}
\multicolumn{5}{c}{ Tabela 4.3 - Séries de Prony do poliuretano } \\
\hline $\mathbf{N}$ & $\boldsymbol{E}_{\boldsymbol{n}}[\boldsymbol{M P a}]$ & $\boldsymbol{D}_{\boldsymbol{n}}\left[\boldsymbol{M P a}^{-1}\right]$ & $\boldsymbol{E x p}_{\boldsymbol{n}}[\boldsymbol{s}]^{*}$ \\
\hline$* *$ & $2,105 \mathrm{E}+01$ & $4,479 \mathrm{E}-02$ & -- \\
1 & $2,913 \mathrm{E}-01$ & $5,821 \mathrm{E}-04$ & 2583,49 \\
2 & $2,518 \mathrm{E}-01$ & $5,074 \mathrm{E}-04$ & 6128,77 \\
3 & $7,400 \mathrm{E}-01$ & $1,634 \mathrm{E}-03$ & 59401,1 \\
\hline \multicolumn{4}{c}{ * Para E(t) $\operatorname{Exp}_{\mathrm{n}}=\rho_{\mathrm{n}}$ e para $\mathrm{D}(\mathrm{t}) \mathrm{Exp}_{\mathrm{n}}=\tau_{\mathrm{n}}$} \\
** Para E(t) $\mathrm{N}=\infty$ e para $\mathrm{D}(\mathrm{t}) \mathrm{N}=0$.
\end{tabular}

A série à fluência do material $\mathrm{D}(\mathrm{t})$ obtida é obtida desde a função de relaxação dos dados experimentais de Lemos (2005), obteve-se a função de fluência do material segundo os resultados gráficos mostrados na Figura 4.4.

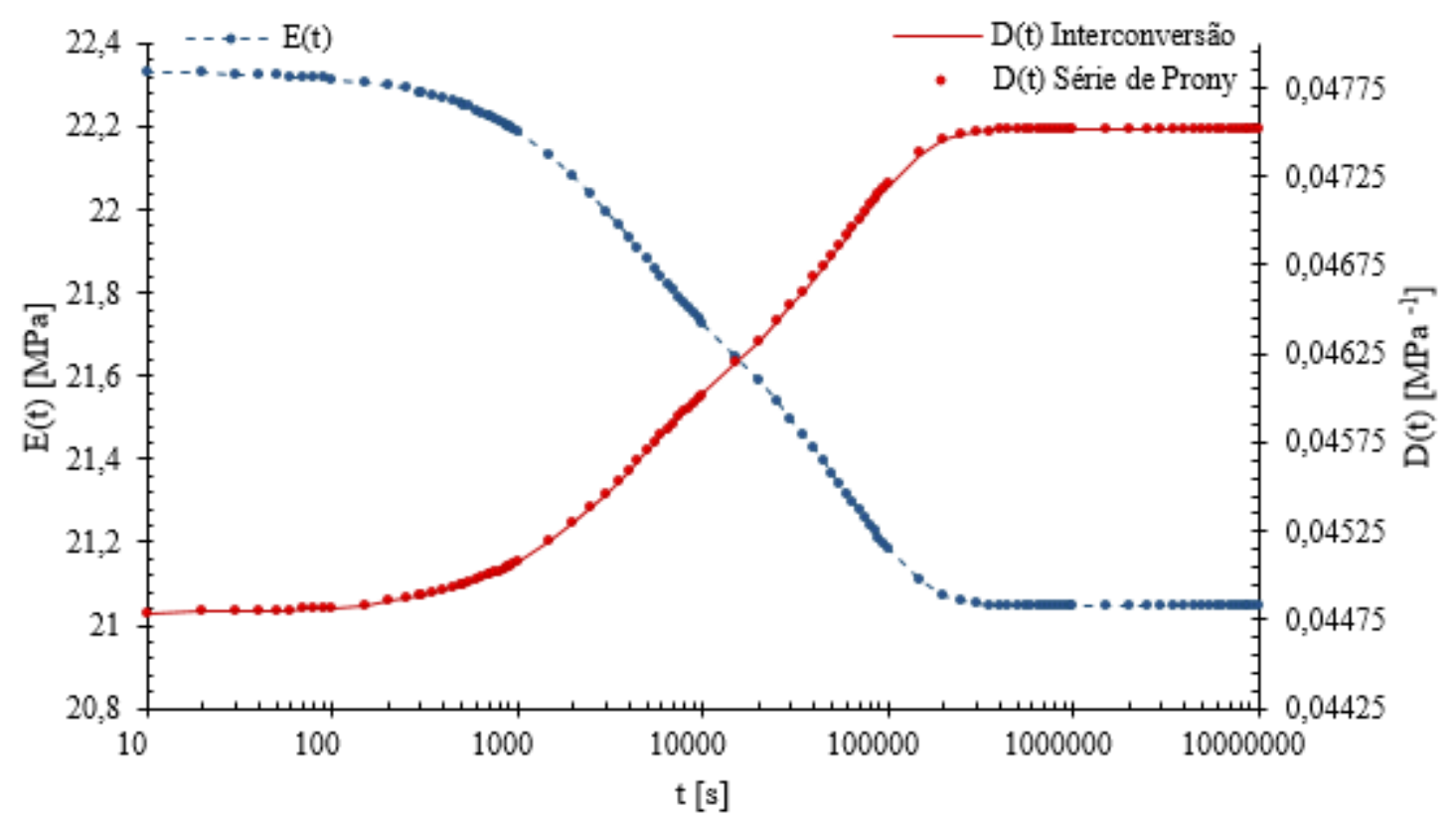

Figura 4.4 - Funções relaxação e fluência do Poliuretano

\subsection{3 - Interconversão de séries com maior número de coeficientes}

Devido à simplicidade da série testada, para realizar uma nova validação do algoritmo de interconversão, realizou-se um novo teste com uma série de maior número de coeficientes, desta vez, tomando a série de Prony correspondente ao módulo do cisalhamento G(t) utilizado no trabalho de Torres (2013). Para aplicar o algoritmo proposto e obter a série de Prony de fluência ao cisalhamento $J(t)$, sendo os dados iniciais e o resultado final da série 
obtida no espaço do tempo e cujos resultados são apresentados numericamente a continuação na Tabela 4.4.

Tabela 4.4 - Séries de Prony G(t) e J(t)

\begin{tabular}{|c|c|c|c|}
\hline $\mathbf{N}$ & $G_{n}[M P a]$ & $J_{n}\left[M P a^{-1}\right]$ & $\operatorname{Exp}_{n}[s] *$ \\
\hline$* *$ & $2,322 \mathrm{E}+02$ & $2,153 \mathrm{E}-03$ & -- \\
\hline 1 & $8,960 \mathrm{E}+01$ & $5,099 \mathrm{E}-04$ & $1,01 \mathrm{E}-10$ \\
\hline 2 & $4,552 \mathrm{E}+01$ & $3,479 \mathrm{E}-04$ & $3,260 \mathrm{E}-05$ \\
\hline 3 & $3,916 \mathrm{E}+01$ & $4,211 \mathrm{E}-04$ & $1,150 \mathrm{E}-03$ \\
\hline 4 & $2,631 \mathrm{E}+01$ & $3,352 \mathrm{E}-04$ & $4,290 \mathrm{E}-02$ \\
\hline 5 & $2,366 \mathrm{E}+01$ & $3,843 \mathrm{E}-04$ & $1,650 \mathrm{E}+00$ \\
\hline 6 & $7,940 \mathrm{E}+00$ & $1,450 \mathrm{E}-04$ & $4,930 \mathrm{E}+02$ \\
\hline
\end{tabular}

Numericamente a convergência do algoritmo é facilitada na procura somente dos coeficientes $J_{n}$, devido a que foram tomados os exponentes já conhecidos, ou seja $\rho_{n}=\tau_{n}$. Na Figura 4.5 apresentam-se graficamente a curva da função $G(t)$, a interconversão numérica dada pelos dados da série correspondente $\mathrm{J}(\mathrm{t})$ e finalmente a aproximação dada por séries de Prony lograda baseada nesses dados numéricos.

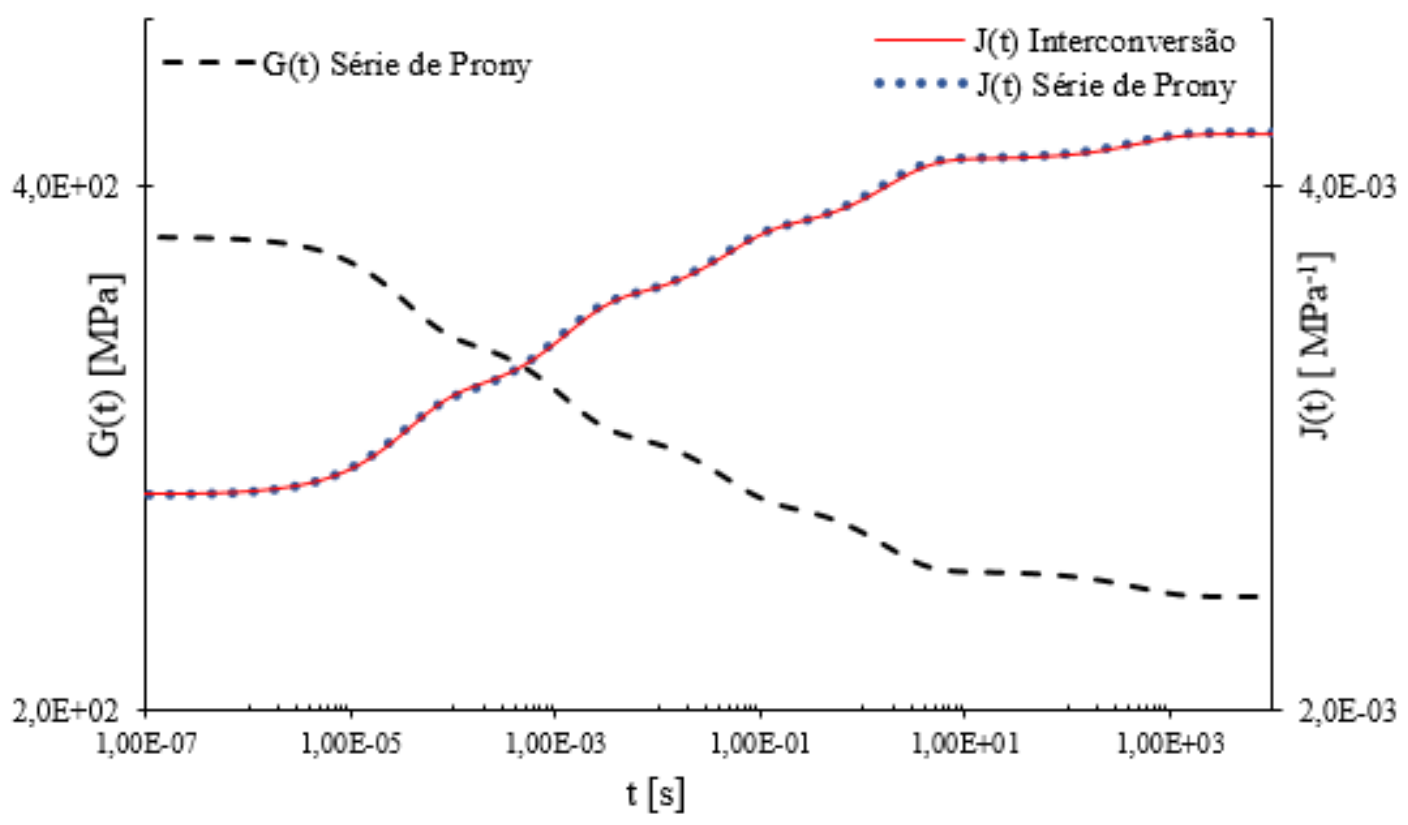

Figura 4.5 - Interconversão da função $G(t)$ para $J(t)$

Os resultados obtidos para a propriedade de fluência ao cisalhamento $J(t)$ obtida por interconversão desde a função do módulo ao cisalhamento $G(t)$, comparada com a série de 
Prony para aproximar o comportamento de $\mathrm{J}(\mathrm{t})$, são graficamente iguais, no entanto, para medir o erro relativo adequadamente esse resultado apresenta-se na Figura 4.6.

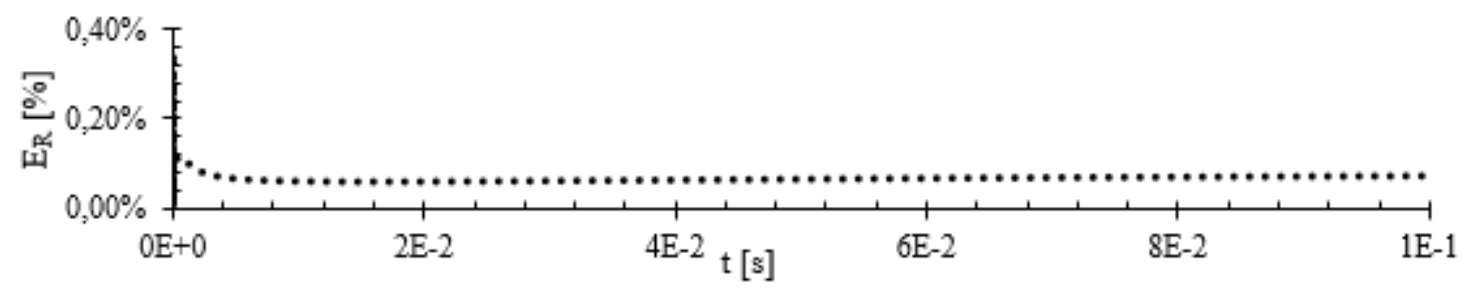

Figura 4.6 - ER calculado entre a série de Prony da fluência ao cisalhamento $J(t)$ Vs. J(t) resultado de interconversão

\subsection{4 - Interconversão elástica}

Quando é realizada uma interconversão entre as funções viscoelásticas correspondentes, obter as outras grandezas viscoelásticas pode ser realizado por interconvesões lineares, acatando as formulações desenvolvidas para este fim. Por exemplo, no exemplo baseado nos dados do Torres, baseou-se na função do módulo ao cisalhamento do material G(t), ou seja, que conhecendo o valor para o coeficiente de Poisson $v=0,30$ e sendo este constante no tempo, pode-se obter a função do módulo de relaxação $\mathrm{E}(\mathrm{t})$; analogamente a mesma interconversão elástica, pode ser realizada para as funções de fluência ao cisalhamento $J(t)$ e fluência $\mathrm{D}(\mathrm{t})$. Estes novos resultados apresentam-se a continuação na Figura 4.7.

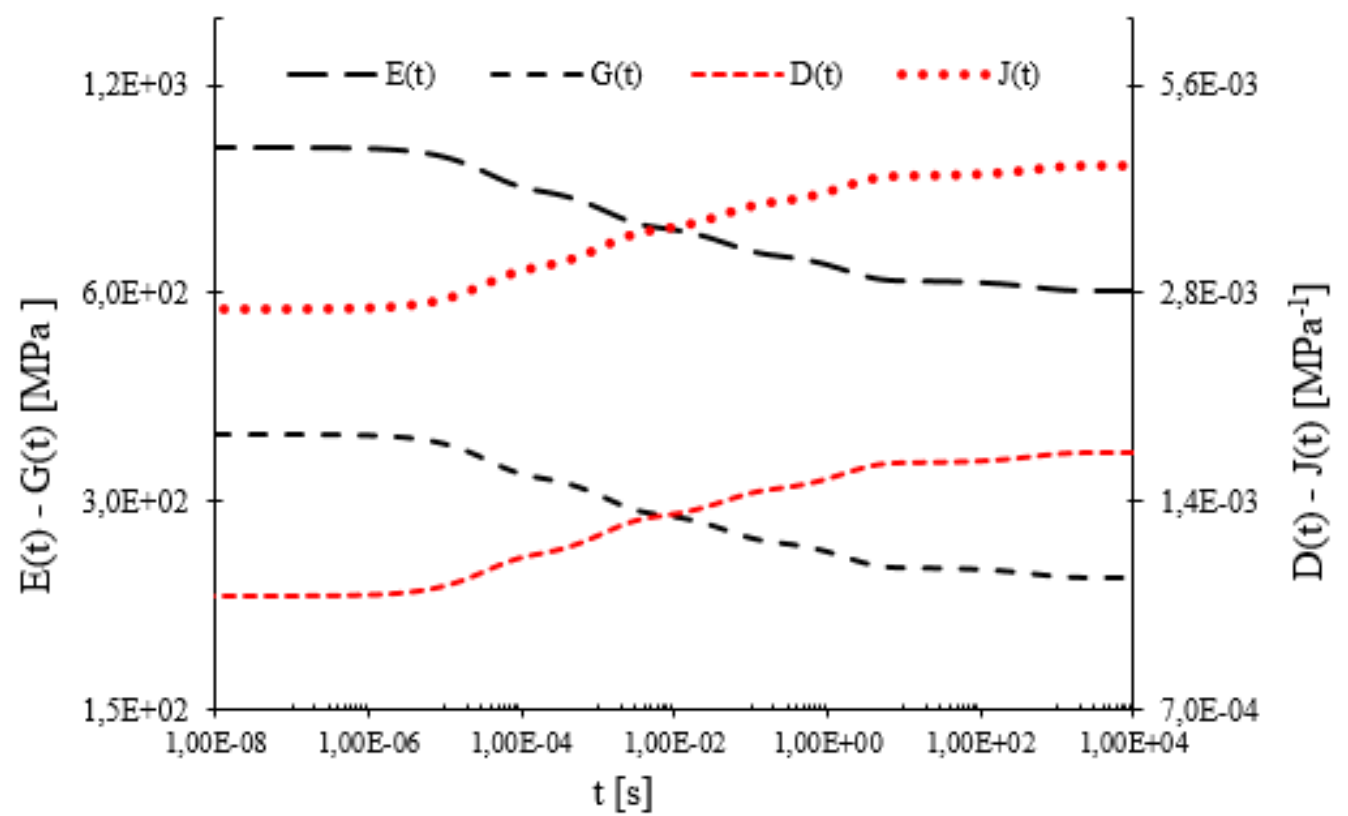

Figura 4.7 - Interconversão elástica das funções viscoelásticas 


\subsection{5 - Interconversão inversa}

Para conferir a qualidade dos resultados obtidos pela aplicação da interconversão numérica entre duas funções viscoelásticas, pode realizar-se a operação oposta, partindo da série obtida e procurando a série inicial. Desta forma, avaliando a diferença entre a série inicial e final obtida de volta, poderá ser comprovado que o algoritmo de interconversão apresenta acurácia adequada.

Assim, na última verificação do algoritmo proposto pretende-se fazer duas vezes a interconversão, isto é, tendo como dados iniciais os da série de Prony para o comportamento ao cisalhamento $G(t)$ e o módulo de Poisson, realiza-se uma interconversão elástica para obter a função $E(t)$, e uma primeira interconversão viscoelástica para obter a fluência ao cisalhamento $J(t)$. Do mesmo modo, com a função $J(t)$ obteve-se por interconversão elástica a função $\mathrm{D}(\mathrm{t}) \mathrm{e}$, finalmente para verificar o algoritmo proposto, obteve-se com a série obtida de fluência ao cisalhamento $\mathrm{J}(\mathrm{t})$ realizar de novo a interconversão viscoelástica para regressar à função inicial $\mathrm{G}(\mathrm{t})$ e compará-las. Do procedimento anteriormente descrito obteve-se os resultados da Tabela 4.5.

Tabela 4.5 - Séries de Prony dos parâmetros do material poli-isobutileno

\begin{tabular}{|c|c|c|c|c|c|c|}
\hline $\mathbf{N}$ & $G_{n}[P a]$ & $E[P a]$ & $J_{n}\left[\mathrm{~Pa}^{-1}\right]$ & $D_{n}\left[\mathrm{~Pa}^{-1}\right]$ & $G_{n}[P a]$ & $\operatorname{Exp}_{n}[s] *$ \\
\hline$* *$ & $1,430 \mathrm{E}+02$ & $3,804 \mathrm{E}+08$ & 7,846E-08 & $2,950 \mathrm{E}-08$ & $1,430 \mathrm{E}+02$ & -- \\
\hline 1 & $7,300 \mathrm{E}+06$ & $1,997 \mathrm{E}+13$ & $5,144 \mathrm{E}-08$ & $1,934 \mathrm{E}-08$ & $7,507 \mathrm{E}+06$ & $2,778 \mathrm{E}-02$ \\
\hline 2 & $4,900 \mathrm{E}+06$ & $1,256 \mathrm{E}+13$ & $1,082 \mathrm{E}-07$ & $4,067 \mathrm{E}-08$ & $4,721 \mathrm{E}+06$ & $5,556 \mathrm{E}-01$ \\
\hline 3 & $4,800 \mathrm{E}+05$ & $1,278 \mathrm{E}+12$ & $3,245 \mathrm{E}-07$ & $1,220 \mathrm{E}-07$ & $4,804 \mathrm{E}+05$ & $5,556 \mathrm{E}+00$ \\
\hline 4 & $5,700 \mathrm{E}+04$ & $1,514 \mathrm{E}+11$ & $1,977 \mathrm{E}-06$ & $7,433 \mathrm{E}-07$ & $5,692 \mathrm{E}+04$ & $5,556 \mathrm{E}+01$ \\
\hline 5 & $6,400 \mathrm{E}+03$ & $1,707 \mathrm{E}+10$ & $3,073 \mathrm{E}-06$ & $1,155 \mathrm{E}-06$ & $6,418 \mathrm{E}+03$ & $5,556 \mathrm{E}+02$ \\
\hline 6 & $1,300 \mathrm{E}+03$ & $3,461 \mathrm{E}+09$ & $4,702 \mathrm{E}-06$ & $1,768 \mathrm{E}-06$ & $1,301 \mathrm{E}+03$ & $5,556 \mathrm{E}+03$ \\
\hline 7 & $1,000 \mathrm{E}+02$ & $2,643 \mathrm{E}+08$ & $6,177 \mathrm{E}-03$ & $2,322 \mathrm{E}-03$ & $9,937 \mathrm{E}+01$ & $5,556 \mathrm{E}+04$ \\
\hline
\end{tabular}

Os resultados numéricos não permitem enxergar sobre a aproximação real da série de início e a de regressão, na Figura 4.8 são apresentados graficamente os resultados para as séries de Prony apresentadas na Tabela 4.5 , onde a série $\mathrm{G}(\mathrm{t})$ é dada pela linha vermelha, a série $\mathrm{E}(\mathrm{t})$ paralela à primeira e de cor azul claro, a série de $\mathrm{J}(\mathrm{t})$ obtida por interconversão de cor amarela, a série $\mathrm{J}(\mathrm{t})$ calculada está em cor verde, a série $\mathrm{D}(\mathrm{t})$ obtida por escalar da série $\mathrm{J}(\mathrm{t})$ de cor marrom e finalmente a série $G(t)$ recalculada por interconversão da série $J(t)$, tal e como se apresenta na Figura 4.8. 


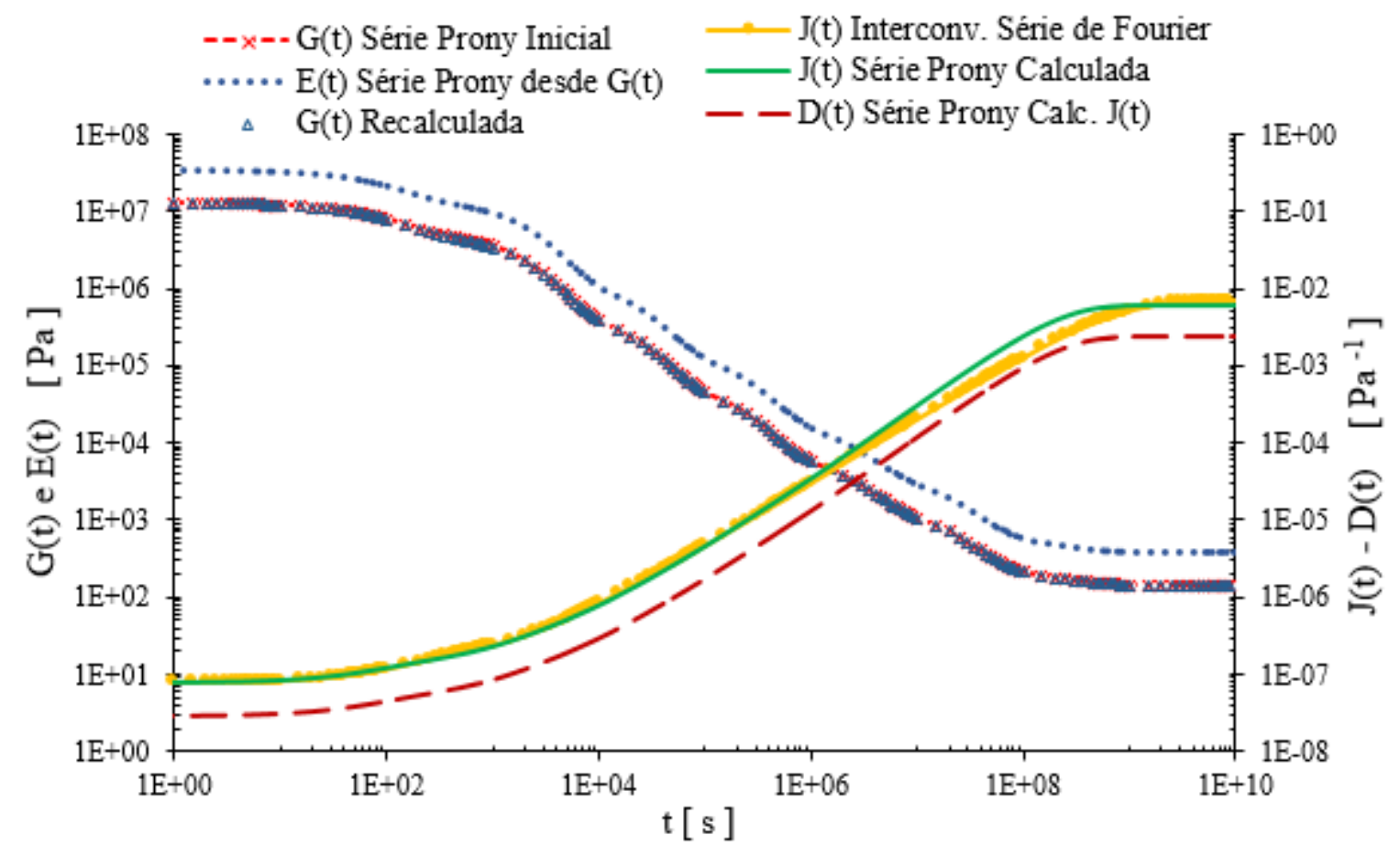

Figura 4.8 - Comparação gráfica das propriedades viscoelásticas do material poliisobutileno

Para finalmente concluir esta validação, os resultados da interconversão realizada para a série do módulo de cisalhamento $\mathrm{G}(\mathrm{t})$ do poli-isobutileno, depois de serem realizadas duas aplicações do algoritmo, sendo avaliado segundo o erro relativo apresentado na Figura 4.9.

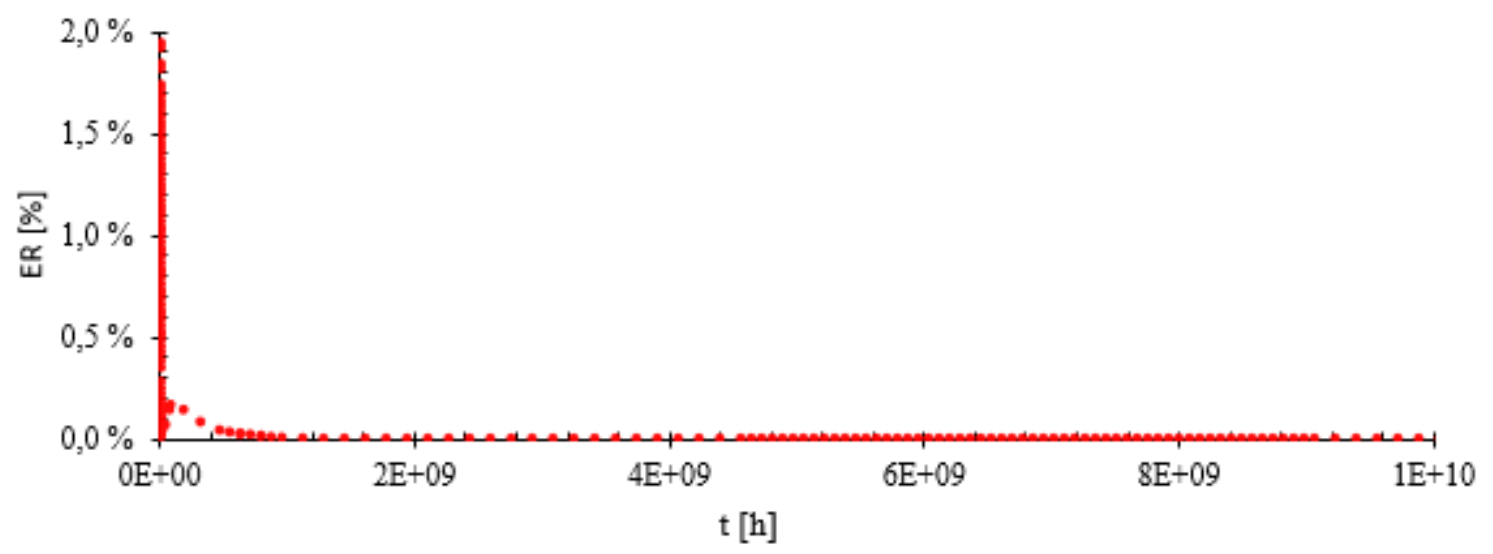

Figura 4.9 - ER função $G(t)$ recalculada por duas interconvesões Vs. G(t) inicial

Os resultados obtidos na Figura 4.9 permitem verificar quantitativamente a eficiência e alta aproximação da metodologia proposta, sendo os resultados mais do que satisfatórios e consequentemente, tanto o algoritmo de interconversão e procedimentos, como os resultados com ele obtidos, são confiáveis para os estudos a serem realizados nas seguintes etapas da presente pesquisa. 


\section{3 - ALGORITMO INCREMENTAL DAS RELAÇÕES VISCOELÁSTICAS CONSTITUTIVAS}

Para verificar os resultados numéricos obtidos pelas soluções para as equações chamadas de hereditárias, ou seja as Equações (2.32) e (2.33), um dos métodos mais difundidos e aceitos na literatura atual é a implementação destas equações numa modelagem feita por elementos finitos, sendo considerado o efeito viscoelástico em cada um dos diferenciais de tempo. $\mathrm{O}$ método dos elementos finitos solucionou os problemas matemáticos e computacionais devidos ao amplo espaço necessário para armazenagem dos dados obtidos, tanto pelo método da integração direta, quanto por outros métodos implementados até sua aparição, otimizando dessa forma o tempo computacional e diminuindo os passos de tempo necessários para obter alta confiabilidade na resposta final obtida (Hammerand, 1999).

\subsection{1 - CALCULO DE TENSÕES OU TESTES DE RELAXAÇÃO}

Um teste de relaxação consiste em infligir um deslocamento $u(t)$ no corpo estudado, o que produz uma deformação interna $\varepsilon(\mathrm{t})$, causando ao longo do tempo um aumento das tensões internas conforme o deslocamento imposto. Para validar o algoritmo incremental à relaxação analisa-se diferentes modelos e deformações impostas, como será mostrado nos itens subsequentes.

\subsubsection{1 - Modelo do sólido linear padrão}

No modelo apresentado na Figura 2.8, estudou-se quando sobre o modelo é realizado um teste de relaxação, ou seja, onde a deformação interna do corpo, consequência do deslocamento imposto, é constante ao longo do tempo. Portanto, para obter a validação do algoritmo numérico, considerando a solução analítica obtida na Equação (2.13), adota-se uma deformação constante $\varepsilon(\mathrm{t})=\varepsilon_{0}=50 \mathrm{~m} / \mathrm{m}$ com um tempo de análise sendo de 60 segundos, como se apresenta na Figura 4.11.

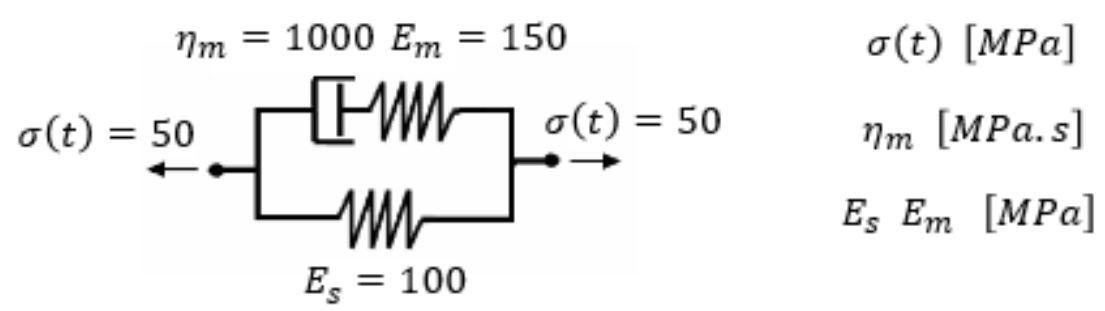

Figura 4.10 - Valores e unidades adotados para o Modelo do sólido linear padrão 
Analogamente ao estudo realizado para este modelo na validação do algoritmo incremental para fluência, adotaram-se os dados considerados para o modelo de Boltzmann no estudo realizado por Carvalho (2014) mostrados na Figura 4.10. A resposta analítica do sistema para a deformação imposta, é dada segundo a Equação (2.13) que substituindo os dados adotados acima adotados converte-se na expressão (4.5).

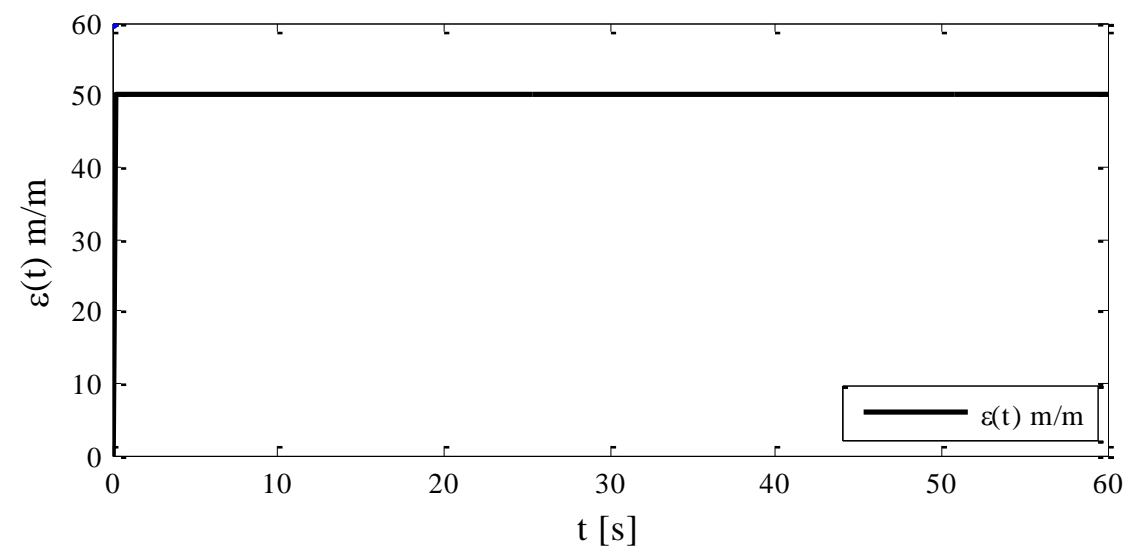

Figura 4.11 - Deformação imposta ao Modelo do sólido linear padrão

$$
\begin{aligned}
& \sigma(t)=\varepsilon_{0}\left(100+150 \cdot e^{-\frac{150}{1000} t}\right)=\sigma(t)=\varepsilon_{0}\left(E_{\infty}+E_{1} \cdot e^{-\frac{t}{\rho_{1}}}\right) \\
& \sigma(t)=50\left(100+150 \cdot e^{-\frac{t}{20 / 3}}\right)
\end{aligned}
$$

Como a função de relaxação pode ser obtida da solução analítica dada pela Equação (4.5), obtendo os parâmetros desta série para $n=1$, o comportamento à relaxação do modelo estudado está representado na Figura 4.12.

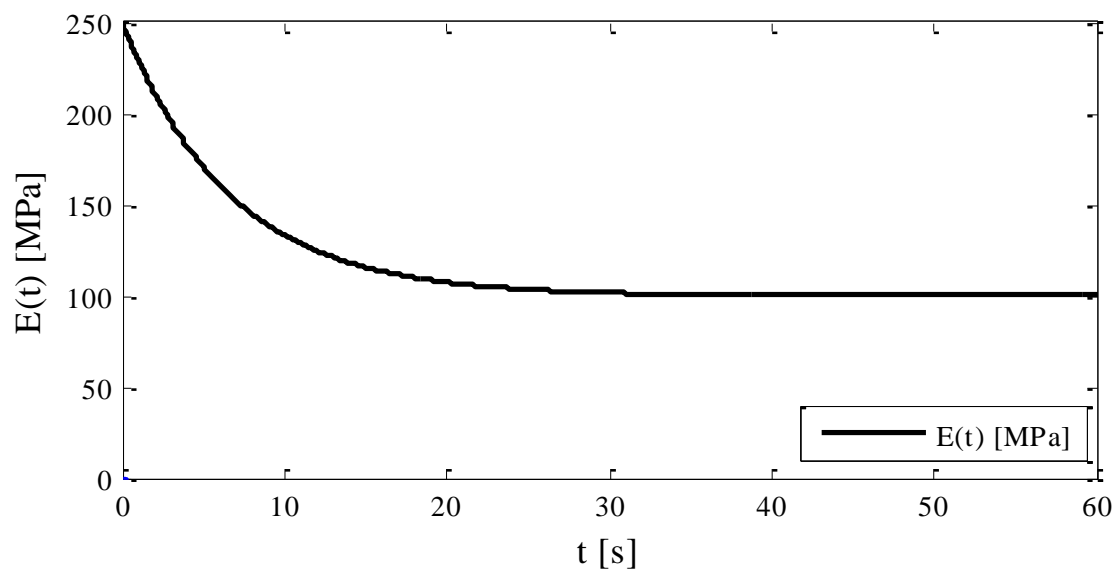

Figura 4.12 - Função relaxação E(t) para teste do Modelo do sólido linear padrão Adotados os dados de entrada para o algoritmo incremental, avaliam-se os resultados deste algoritmo para diferentes diferenciais de tempo $\delta t$, adotando a mesma avaliação realizada 
pra o algoritmo incremental para fluência avaliam-se $\delta t=0,05 ; 0,1 ; 0,25 ; 0,5$ e $1 \mathrm{~s}$, obtivendo-se os resultados da Figura 4.13.
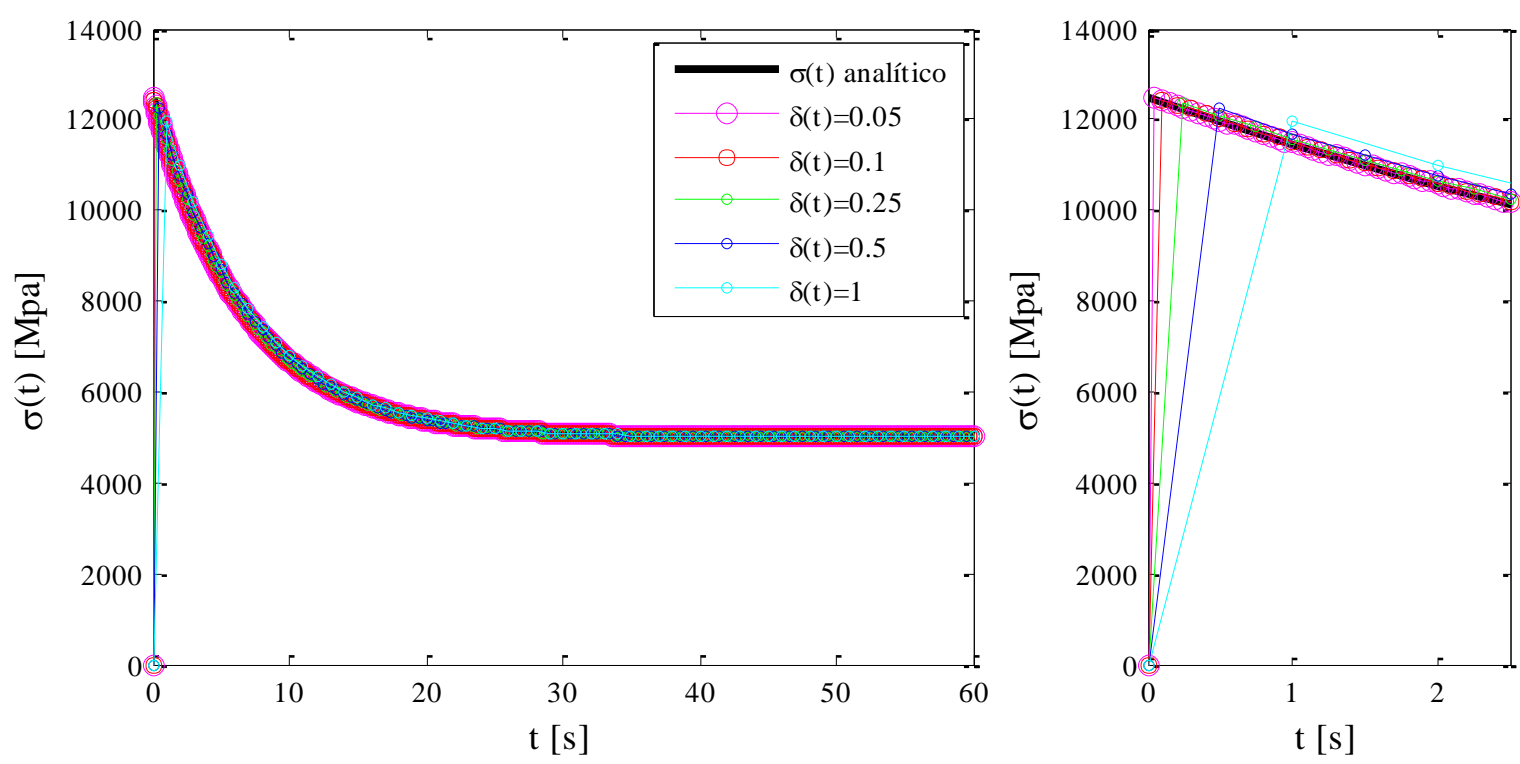

(a) curva total. (b) detalhe nos tempos iniciais

Figura 4.13 - Resultados do algoritmo incremental à relaxação para diferentes $\delta \mathrm{t}$

Segundo os resultados obtidos, valida-se amplamente o algoritmo incremental à relaxação, sendo mais do que satisfatória a aproximação comparado com a resposta analítica do modelo do sólido padrão. Nota-se que o algoritmo não têm muita sensibilidade ao tamanho do intervalo e será adotado um $t=0,2 \mathrm{~s}$ para as validações subsequentes.

\subsubsection{2 - Modelo de Boltzmann}

Para a validação do algoritmo aplicado ao modelo de Boltzmann do tipo apresentado na Figura 2.9, adotaram-se os dados utilizados por Carvalho (2014), os dados para o modelo de Boltzmann indicados na Figura 4.21 e para a deformação adota-se $\varepsilon_{0}=50 \mathrm{~m} / \mathrm{m}$ apresentada na Figura 4.11, que considerando-os na solução analítica dada na Equação (2.18), esta converte-se na Equação (4.6).

$$
\begin{aligned}
& \sigma(t)=\varepsilon_{0} \frac{150}{(100+150)}\left(100+150 \mathrm{e}^{-\frac{100+150}{1000} \mathrm{t}}\right) \\
& \sigma(\mathrm{t})=\varepsilon_{0}\left(\mathrm{E}_{\infty}+\mathrm{E}_{1} \mathrm{e}^{-\frac{\mathrm{t}}{\rho_{1}}}\right)=50\left(60+90 \mathrm{e}^{-\frac{\mathrm{t}}{4}}\right)
\end{aligned}
$$

Implementando os valores adotados sob o modelo de Boltzmann, a função relaxação deste estará dada pela série de Prony apresentada graficamente na Figura 4.1. 


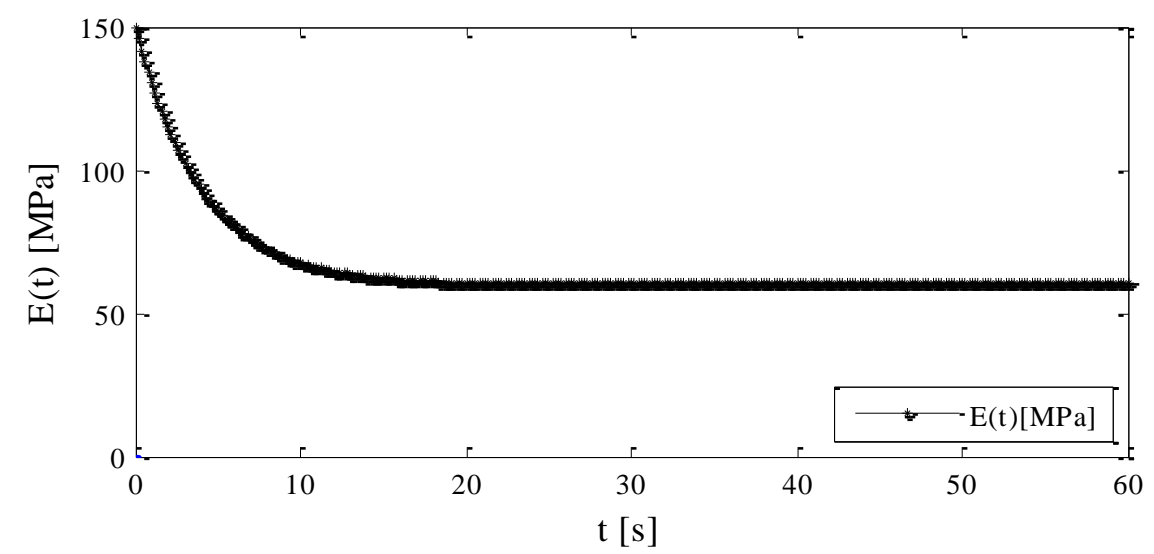

Figura 4.14 - Função relaxação E(t) para teste no Modelo de Boltzmann

Com os dados do modelo de Boltzmann e com a resposta analítica é testado o algoritmo incremental para relaxação, obtendo como resultado o apresentado na Figura 4.15.

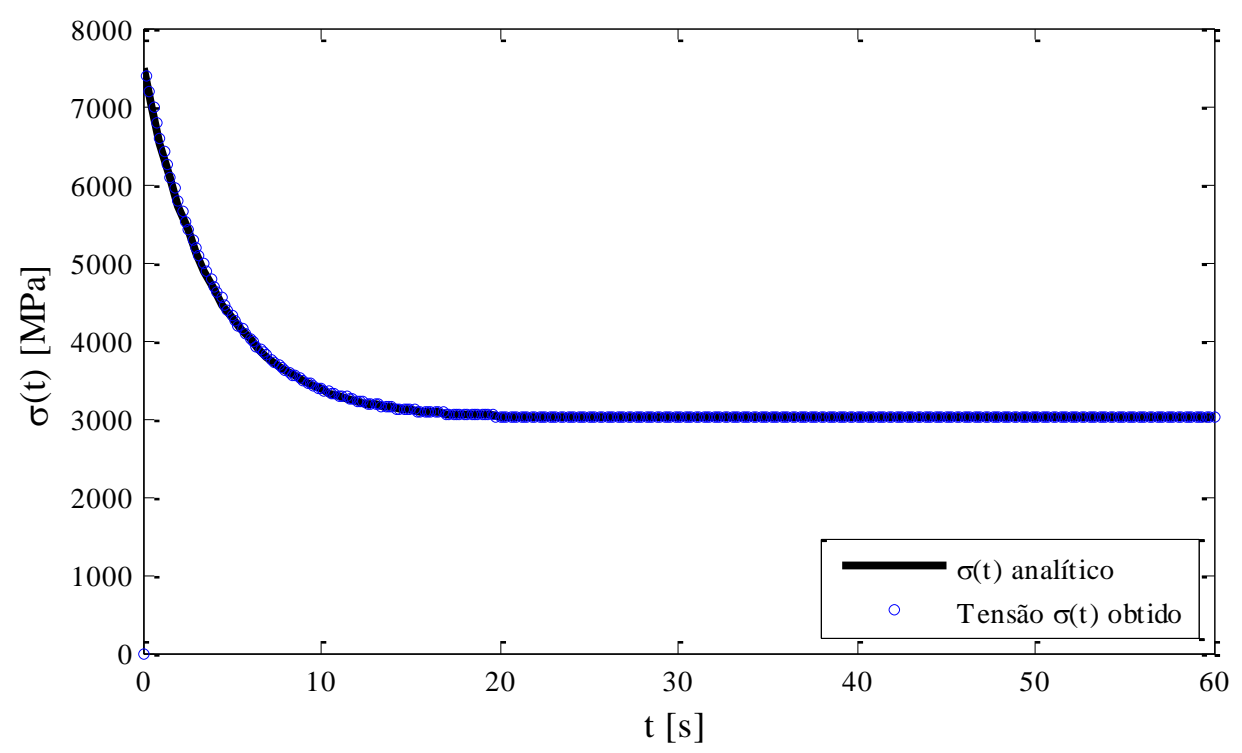

Figura 4.15 - Resultados do algoritmo incremental à relaxação com $\delta \mathrm{t}=0,2 \mathrm{~s}$

Os resultados obtidos com o algoritmo foram mais do que satisfatórios para um deslocamento constante imposto no modelo de Boltzmann. Para avaliar outro tipo de comportamento, baseados na pesquisa realizada por Carvalho (2014), o histórico das tensões ao longo do tempo pelo método das diferenças finitas é obtida segundo as Equações (4.7) e (4.8).

$$
\begin{aligned}
& \Delta \sigma_{i}=\left[E_{k} \varepsilon_{i}+\eta_{k} \frac{\Delta \varepsilon_{i}}{\Delta t_{i}}-\sigma_{i}\left(1+\frac{E_{k}}{E_{s}}\right)\right] \frac{E_{s}}{\eta_{k}} \Delta t_{i} \\
& \sigma_{i+1}=\sigma_{i}+\Delta \sigma_{i}
\end{aligned}
$$


O segundo teste a ser realizado no modelo de Boltzmann consiste num passo de deformação constante $\varepsilon_{0}=50 \mathrm{~m} / \mathrm{m}$ até um tempo $t_{1}=20 \mathrm{seg}$, onde advém um descarregamento instantâneo, permanecendo assim até o tempo final de avaliação $t_{2}=60 \mathrm{seg}$ segundo o mostrado na Figura 4.16.

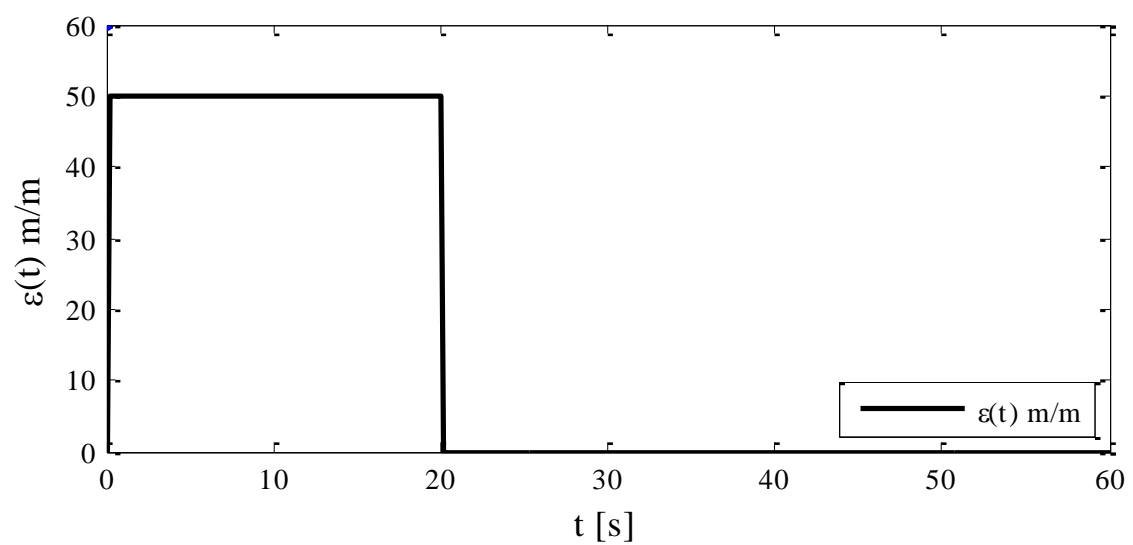

Figura 4.16 - Segunda deformação imposta ao Modelo de Boltzmann

Segundo a deformação correspondente ao deslocamento imposto ao modelo de Boltzmann apresentado na Figura 4.16, obteve-se o resultado pelo algoritmo da incrementação para relaxação e o resultado pelo método das diferenças finitas descrito segundo as Equações (4.7) e (4.8). Essa comparação apresenta-se graficamente na Figura 4.17.

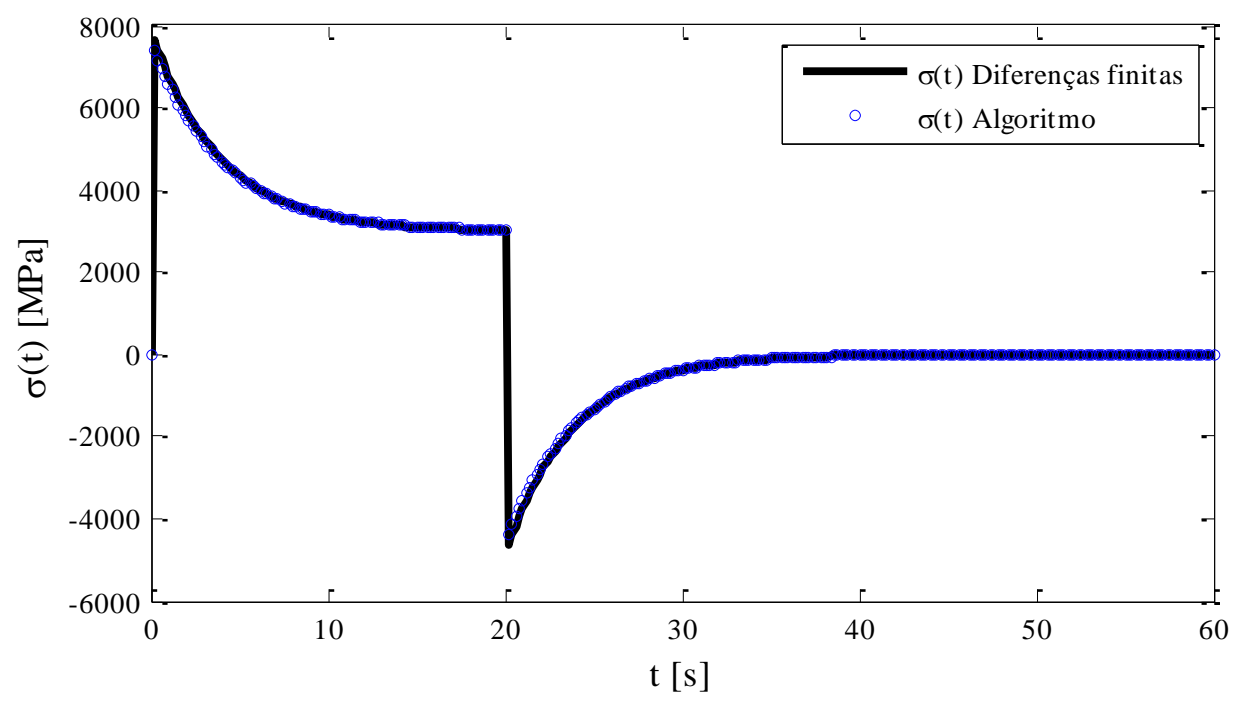

Figura 4.17 - Resultados comparativos método das diferenças finitas vs. método incremental para relaxação com $\delta \mathrm{t}=0,2 \mathrm{seg}$.

Segundo os resultados obtidos para os dois testes de deformação impostos ao modelo de Boltzmann, tanto o mostrado na Figura 4.15 onde a deformação é constante ao longo do tempo e comparou-se com o resultado dado pela formulação analítica, quanto o apresentado 
na Figura 4.17 onde a deformação é variável e comparou-se com o resultado obtido pelo método das diferenças finitas, concluiu-se que os resultados obtidos usando o algoritmo incremental são satisfatórios o bastante como para validar esse algoritmo para testes de relaxação.

\subsubsection{3 - Barra engastada}

A barra que se expõe na Figura 4.18 está engastada no ponto $x=0$, experimenta uma força $q(t)$ variável ao longo do tempo e um deslocamento $u(t)$ variável também. A área da barra A e o módulo de relaxação $E(t)$ adotados terão os valores apresentados na Tabela 4.6

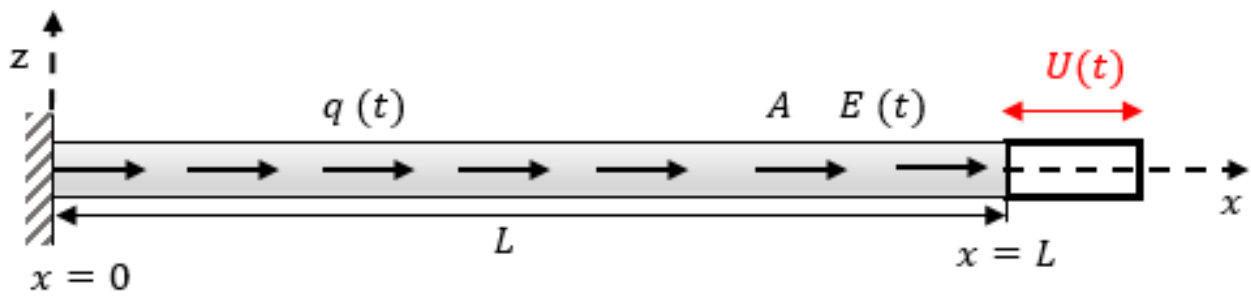

Figura 4.18 - Barra engastada de material visco elástico com deslocamento dependente do tempo

A solução elástica analítica foi dada na Equação (4.16) e as condições de contorno para este caso em $x=0$ e $x=L$ são dadas nas Equações (4.9) e (4.10), respectivamente.

$$
\begin{aligned}
& u(0)=0 \\
& u(L)=u_{l}
\end{aligned}
$$

A solução para as deformações na barra em função de $x$ e de $q(x)$ no comportamento elástico do material $\sigma(x)$ é dado na Equação (4.11). Para quantificar a variabilidade dos esforços ao considerar viscoelasticidade do material e avaliando as funções consideradas variáveis ao longo do tempo, a Equação $\sigma(x)$ transforma-se na Equação $\sigma(x, t)$, como é mostrado na Equação (4.11).

$$
\begin{aligned}
& \sigma(x)=-\frac{q}{A} x\left(x-\frac{L}{2}\right)+\frac{u_{l}}{L} E \\
& \sigma(x, t)=-\frac{q(t)}{A}\left(x-\frac{L}{2}\right)+\frac{u_{l}(t)}{L} E(t)
\end{aligned}
$$

De forma análoga às validações anteriores pode-se obter a resposta de tensão para o modelo da barra usando o princípio de correspondência, como se apresenta na Equação (4.12). 


$$
\sigma(x, t)=\mathcal{L}^{\text {inv }}\{\sigma v(x, s)\}=-\frac{q(t)}{A}\left(x-\frac{L}{2}\right)+\frac{1}{L} \int_{0}^{t} E(t-\tau) \frac{\partial u l}{\partial \tau} d \tau
$$

Para dar solução numérica aplicando o algoritmo incremental, os valores numéricos das propriedades da barra e o teste de relaxação, adotam-se os dados da função de relaxação e deformação resultado do deslocamento segundo os dados apresentados na Tabela 4.6.

Tabela 4.6 - Parâmetros de avaliação para o deslocamento de uma barra viscoelástica

\begin{tabular}{ccc}
\hline Parâmetro & Valor & Unidades \\
\hline$A$ & 1 & $\mathrm{~cm}^{2}$ \\
$q(t)$ & 0,1 & $\frac{\mathrm{N}}{\mathrm{cm}}$ \\
$u(t)$ & 0,025 ou $0,0025 \mathrm{t}$ & $\mathrm{m}$ \\
$E(t)$ & $1000+3000 \mathrm{e}^{-\frac{\mathrm{t}}{2}}$ & $\frac{\mathrm{N}}{\mathrm{cm}^{2}}$ \\
$D(t)$ & $2,5 \mathrm{E}^{-4}+7,501 \mathrm{E}^{-4}\left(1-\mathrm{e}^{-\frac{\mathrm{t}}{8}}\right)$ & $\left(\frac{\mathrm{N}}{\mathrm{cm}^{2}}\right)^{-1}$ \\
$\mathrm{~L}$ & 10 & $\mathrm{~cm}$ \\
\hline
\end{tabular}

Desta forma, foram realizados os testes de relaxação correspondentes à formulação da Equação (4.12), considerando a função de deformação ao deslocamento imposto $u(t)$ num primero teste constante e num segundo teste variável. A resposta viscoelástica do histórico de tensões quando $\mathrm{u}(\mathrm{t})=0,025 \mathrm{~m} / \mathrm{m}$ se apresenta a seguir na Figura 4.19.

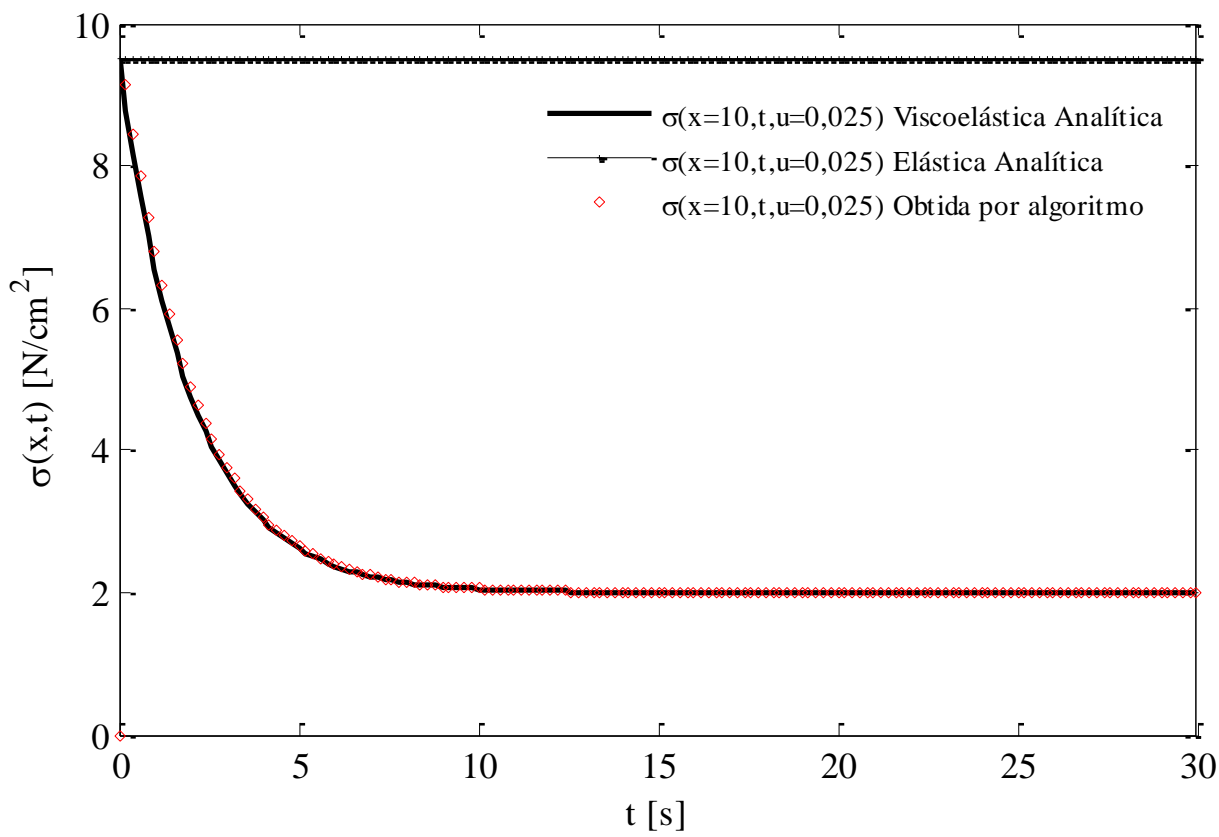

Figura 4.19 - Tensão para barra quando a força $q(\mathrm{t})$ e o deslocamento $\mathrm{u}(\mathrm{x}, \mathrm{t})$ constantes

Como era de se esperar, as tensões sob a barra diminuem ao longo do tempo pela natureza do material, além disso, os resultados obtidos pelo algoritmo resultaram concordantes com 
os analíticos acrescentando a validade do algoritmo proposto. Um teste a mais do algoritmo basea-se em submeter a mesma barra viscoelástica sob um deslocamento variável no tempo, neste caso $\mathrm{u}(\mathrm{t})=0,0025 \mathrm{t} \mathrm{m} / \mathrm{m}$, e os resultados apresentam-se na Figura 4.20.

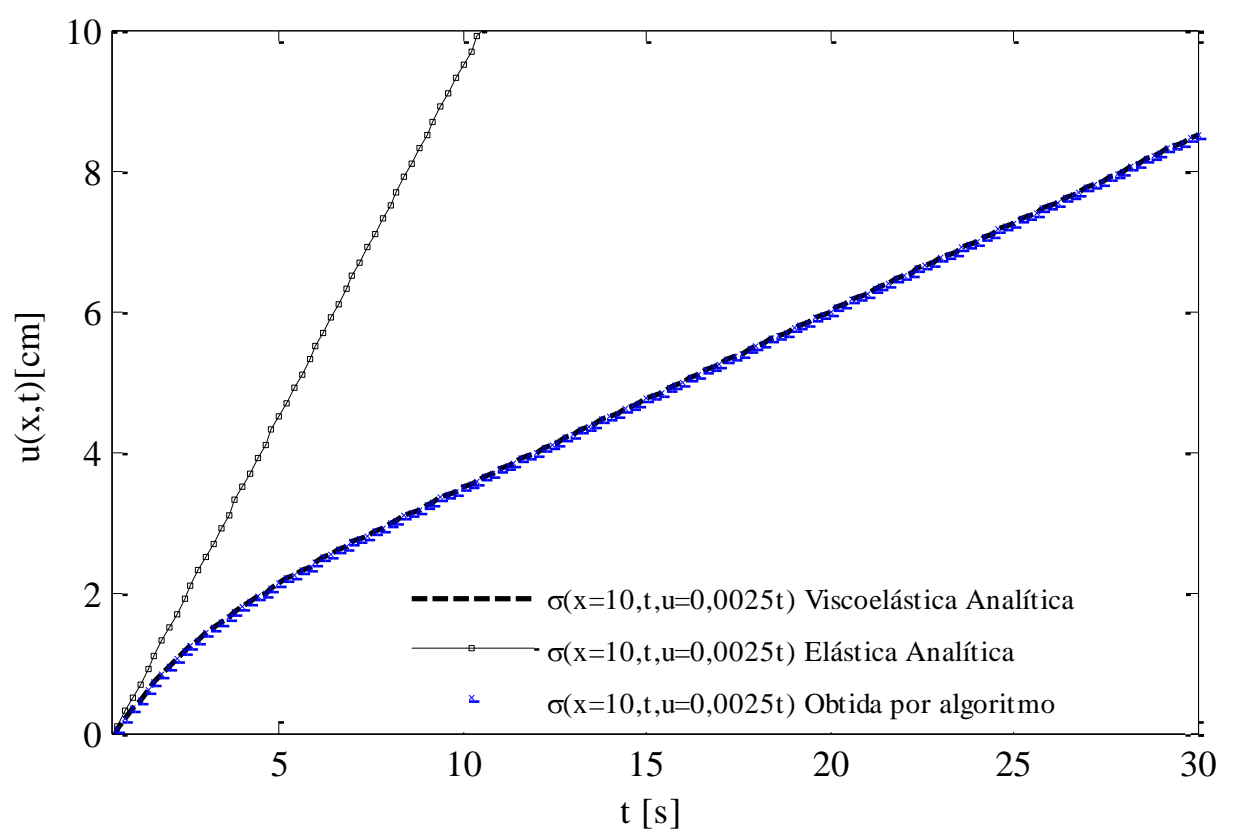

Figura 4.20 - Tensão para barra quando $\mathrm{q}(\mathrm{t})$ é constante e o deslocamento $\mathrm{u}(\mathrm{x}, \mathrm{t})$ variável

\subsection{2 - CÁlCULO DE DEFORMAÇÕES OU TESTES DE FLUÊNCIA}

Um teste de fluência consiste em impor uma força $\mathrm{P}(\mathrm{t})$ no corpo estudado, o que internamente produz no corpo uma tensão interna $\sigma(\mathrm{t})$, o que causa ao longo do tempo um aumento das deformações no sentido da força imposta. Para verificar o algoritmo considerase diferentes modelos e tensões impostas, como será mostrado nos subitens seguintes.

\subsubsection{1 - Modelo de Boltzmann}

Implementou-se de forma semelhante ao realizado sobre o Modelo do sólido linear padrão sobre a solução analítica do Modelo de Boltzmann, na procura da função fluência na forma das séries de Prony, sendo adotados para os elementos do modelo citado os dados da Figura 4.21 .

$$
\sigma(t)=50
$$

Figura 4.21 - Valores e unidades adotados para o Modelo de Boltzmann 
Da solução analítica obtida na Equação (2.16), e substituindo os dados acima adotados para o estudo do modelo de Boltzmann, obteve-se a expressão (4.13).

$$
\begin{aligned}
& \varepsilon(t)=\sigma_{0}\left(\frac{1}{E_{s}}+\frac{1}{E_{k}}\left(1-e^{-\frac{E_{k}}{\eta_{k}} t}\right)\right) \\
& \varepsilon(t)=\sigma_{0}\left(D_{0}+D_{1}\left(1-e^{-\frac{t}{\tau_{1}}}\right)\right) \\
& \varepsilon(t)=\sigma_{0}\left(\frac{1}{100}+\frac{1}{150}\left(1-e^{-\frac{t}{20 / 3}}\right)\right)
\end{aligned}
$$

Como a função de fluência pode ser obtida da solução analítica, e obtendo os parâmetros desta série para $\mathrm{n}=1$ o comportamento à fluência do modelo estudado é o apresentado na Figura 4.22.

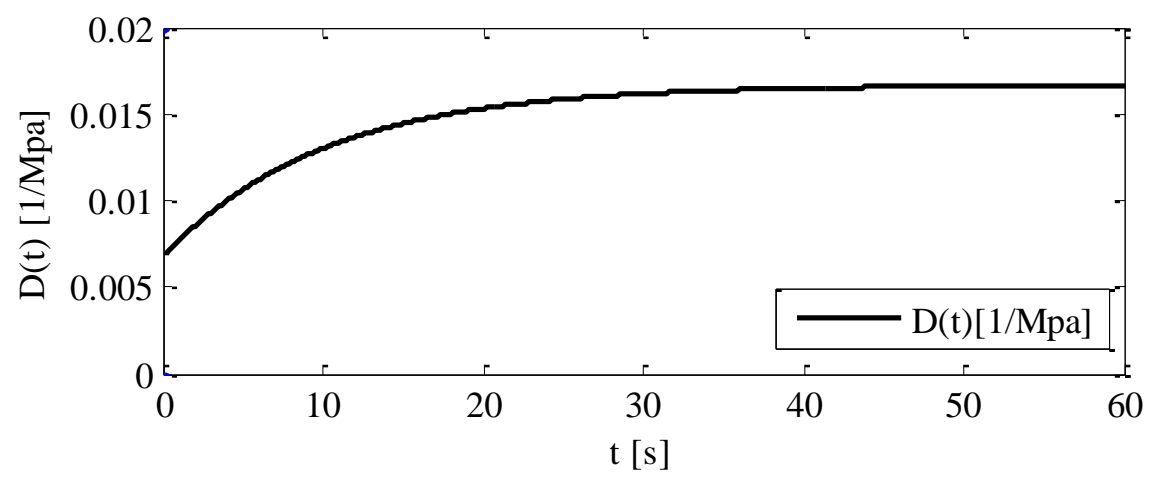

Figura 4.22 - Função fluência para o Modelo de Boltzmann

Uma vez adquiridos todos os dados necessários para aplicar o algoritmo incremental apresentado no Quadro 3.4, avaliam-se os resultados deste algoritmo para diferentes diferenciais de tempo $\delta$ t, tendo como objetivo determinar a sensibilidade do algoritmo ao tamanho de $\delta \mathrm{t}$, incorporando ao estudo $\delta \mathrm{t}=0,05 ; 0,1 ; 0,25 ; 0,5 \mathrm{e} 1$, obtendo os resultados consignados na Figura 4.23.

Pode-se observar na Figura 4.23 que os resultados obtidos são muito próximos à função dada pela solução analítica, mesmo com um segundo. A Figura 4.23(b) mostra os dados num espaço de tempo menor para assim poder apreciar as diferenças, como se apresenta na parte direita do gráfico. 

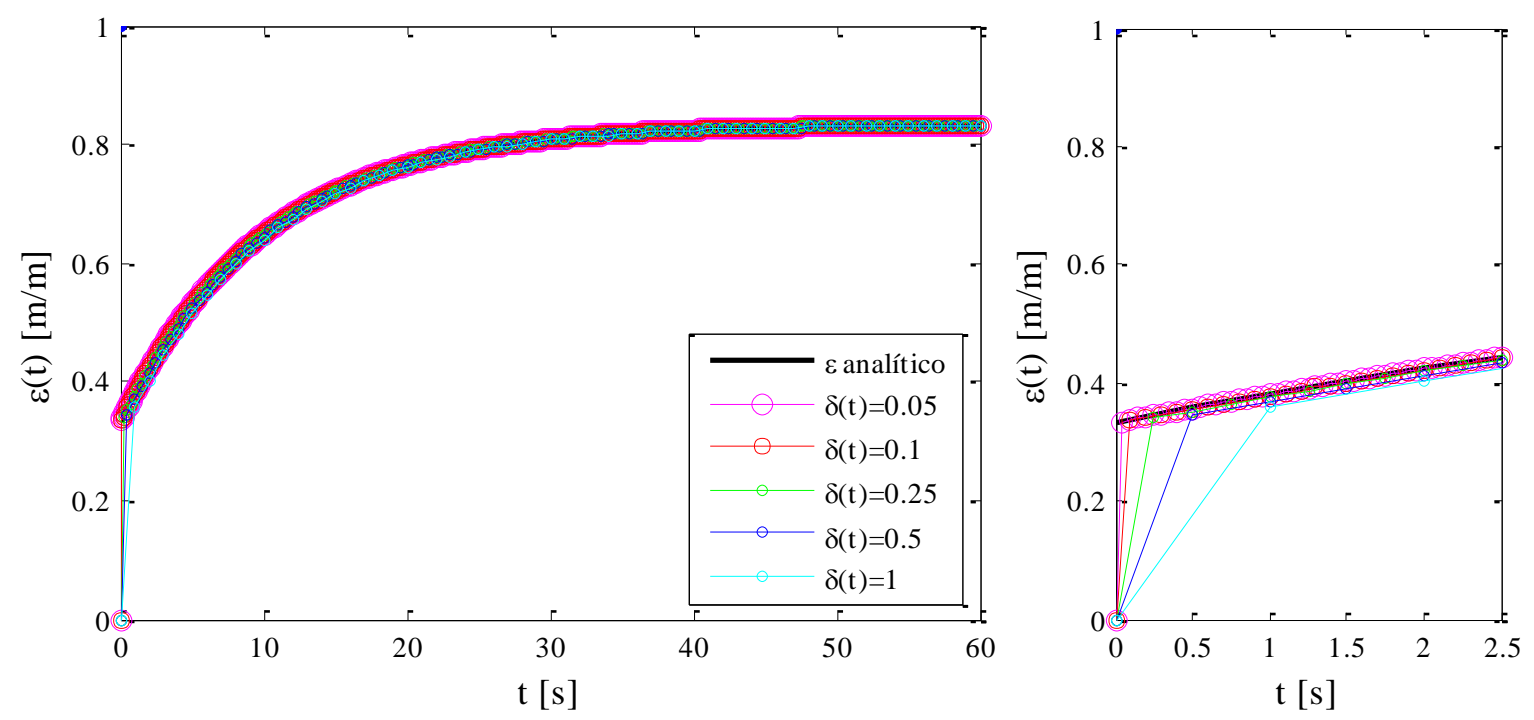

(a) curva total. (b) detalhe nos tempos iniciais

Figura 4.23 - Deformação $\varepsilon(\mathrm{t})$ obtida pelo algoritmo incremental para diferentes $\delta(\mathrm{t})$

Considerando que a deformação obtida com o valor de $\delta \mathrm{t}=0,25$ segundos resulta muito próxima da solução analítica sem ter um elevado custo computacional, os resultados adiante se obterão com um $\delta \mathrm{t}=0,2 \mathrm{~s}$. Por outra parte, na pesquisa realizada por Carvalho (2014) foram desenvolvidas respostas para outro tipo de esforços impostos ao Modelo de Boltzmann, obtendo as respostas pelo método das diferenças finitas cuja resposta é dada pelas as Equações (4.14) e (4.15).

$$
\begin{aligned}
& \Delta \mathrm{E}_{\mathrm{i}}=\left[\sigma_{\mathrm{i}}\left(1+\frac{\mathrm{E}_{\mathrm{k}}}{\mathrm{E}_{\mathrm{s}}}\right)+\frac{\eta_{\mathrm{k}}}{\mathrm{E}_{\mathrm{s}}} \frac{\Delta \sigma_{\mathrm{i}}}{\Delta \mathrm{t}_{\mathrm{i}}}-\mathrm{E}_{\mathrm{k}} \varepsilon_{\mathrm{i}}\right] \frac{1}{\eta_{\mathrm{k}}} \Delta \mathrm{t}_{\mathrm{i}} \\
& \varepsilon_{\mathrm{i}+1}=\varepsilon_{\mathrm{i}}+\Delta \mathrm{E}_{\mathrm{i}}
\end{aligned}
$$

Para determinar o comportamento dos resultados obtidos usando o algoritmo incremental, realiza-se a comparação com duas funções diferentes de tensão impostas ao Modelo de Boltzmann na dissertação de Carvalho (2014), estas são os Testes 1 e 2: o Teste 1 consiste num passo de tensão constante $\sigma_{0}=50 \mathrm{MPa}$ até um tempo $\mathrm{t}_{1}=20 \mathrm{~s}$, onde ocorre um descarregamento instantâneo; o Teste 2 consta de três etapas de tensão: uma primeira etapa de tensão linearmente crescente até o tempo $t_{1}=20 \mathrm{~s}$, uma segunda etapa de tensão constante $\sigma_{0}=50 \mathrm{MPa}$ e uma etapa final no tempo $\mathrm{t}_{2}=40 \mathrm{~s}$ onde advém um descarregamento instantâneo. Os testes descritos anteriormente podem ser melhor entendidos segundo o mostrado na Figura 4.24. 


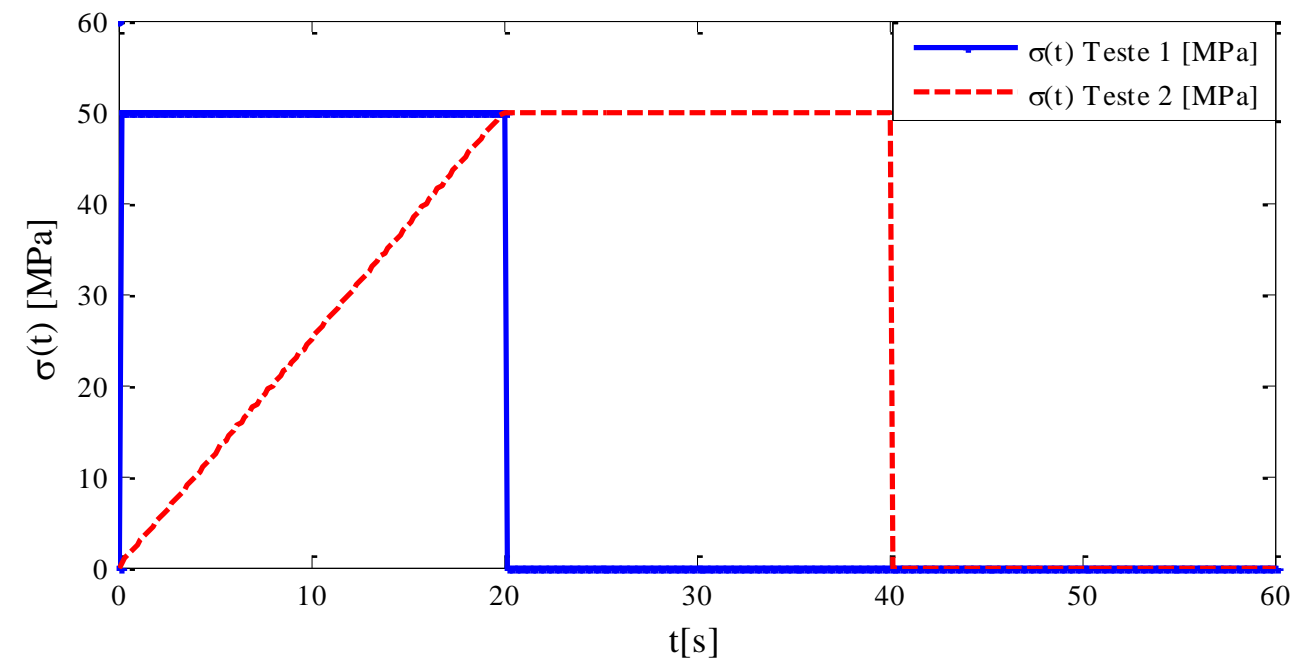

Figura 4.24 - Testes 1 e 2 para o Modelo de Boltzmann Adaptado de Carvalho (2014)

Implementando para a presente validação o algoritmo incremental apresentado no Quadro 3.4, com a função de fluência da Figura 4.22, comparou-se com os resultados obtidos na pesquisa de Carvalho (2014) apresentados na Figura 4.25.

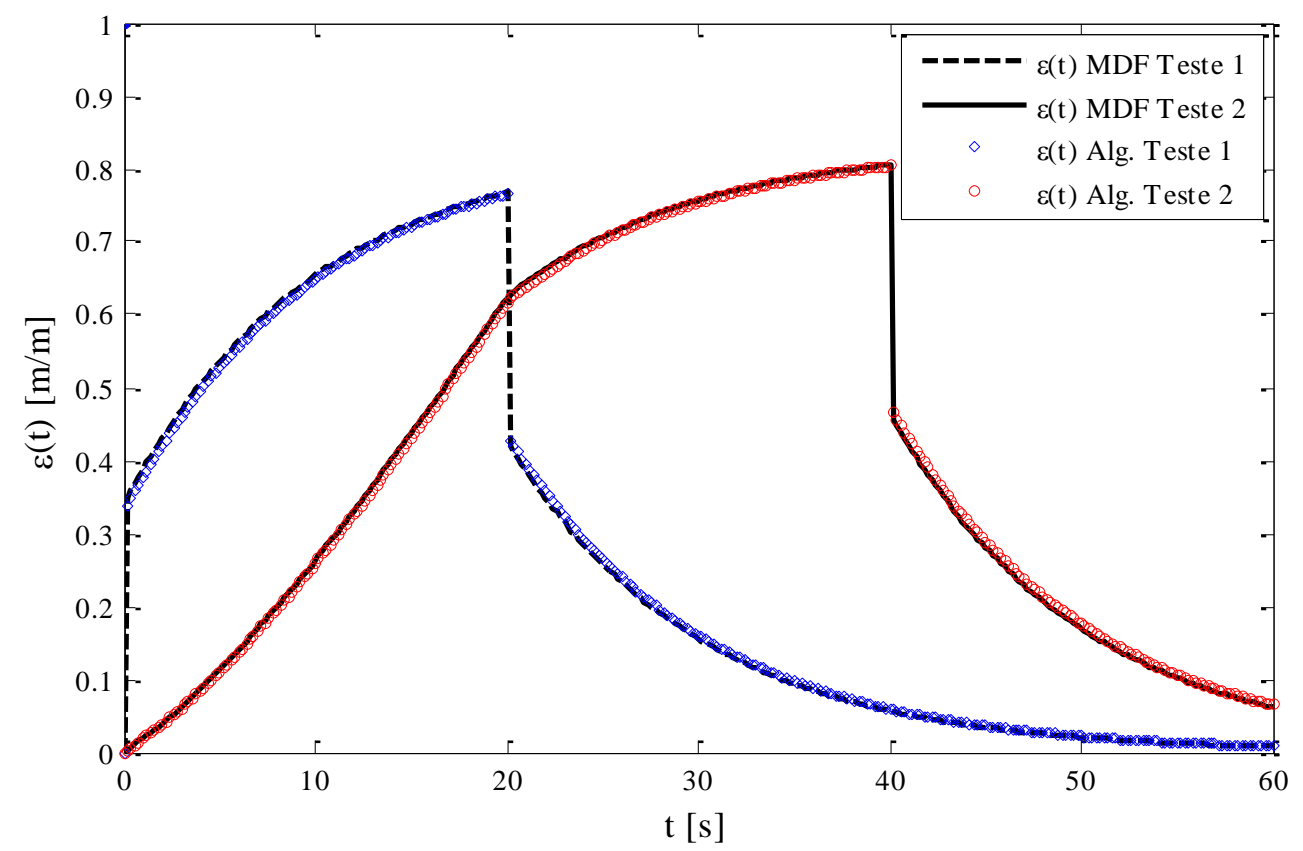

Figura 4.25 - Resultados comparativos método das diferenças finitas vs. método incremental para fluência com $\delta \mathrm{t}=0,2 \mathrm{~s}$.

Segundo os resultados apresentados na Figura 4.25, ao comparar o método das diferenças finitas e o método incremental das funções viscoelásticas, base para a presente pesquisa, pode-se concluir que a precisão do método é adequada, não só para carregamentos constantes como também para variáveis ao longo do tempo. 


\subsubsection{2 - Barra carregada axialmente}

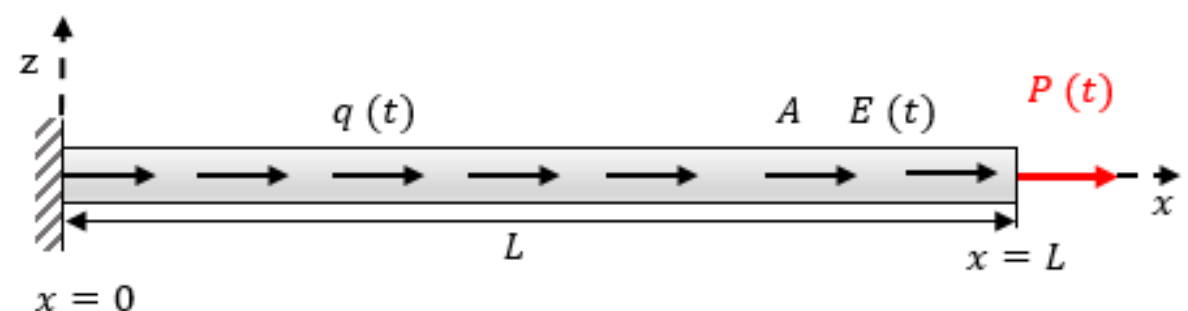

Figura 4.26 - Barra engastada com carregamento axial dependente do tempo

A verificação aqui desenvolvida realiza-se com base no trabalho de doutorado concluído por Torres (2013). A barra que se mostra na Figura 4.26 está engastada no ponto $\mathrm{x}=0$, experimenta uma força $\mathrm{q}(\mathrm{t})$ variável ao longo da barra e uma força de tração $\mathrm{P}(\mathrm{t})$ variável ao longo do tempo. A área da barra A é considerada constante, no entanto, o módulo de relaxação $\mathrm{E}(\mathrm{t})$ é variável ao longo do tempo e se apresentará como uma série de Prony. A solução elástica analítica para a barra é como se indica na Equação (4.16) e as condições de contorno para $\mathrm{x}=0$ e $\mathrm{x}=\mathrm{L}$ são dadas nas Equações (4.17) e (4.18), respectivamente, sendo $\mathrm{u}(\mathrm{x})$ o deslocamento da barra.

$$
\begin{aligned}
& A E \frac{d^{2} u(x)}{d x^{2}}+q(x)=0 \\
& u(0)=0 \\
& A E \frac{d u(L)}{d x}=P
\end{aligned}
$$

A solução para a barra em função de x e de um carregamento $q(x)$ como uma constante, está dada pela Equação (4.19) . Ao considerar esta resposta em função do tempo, a solução geral muda como se apresenta na Equação (4.20).

$$
\begin{aligned}
& u(x)=-\frac{q}{2 A E} x^{2}+\frac{P+q L}{A E} x \\
& u(x, t)=-\frac{q(t)}{2 A E} x^{2}+\frac{P(t)+q(t) L}{A E} x
\end{aligned}
$$

Aplicando o princípio de correspondência elástica-viscoelástica no espaço de Laplace, e aplicando as condições geométricas e viscoelásticas do material da barra, a Equação (4.20) transforma-se na Equação (4.21). 


$$
\begin{aligned}
& \mathrm{u}(\mathrm{x}, \mathrm{s})=\mathcal{L}\{\mathrm{u}(\mathrm{x}, \mathrm{t})\}=-\frac{\overline{\mathrm{q}}(\mathrm{s})}{2 \mathrm{As} \overline{\mathrm{E}}(\mathrm{s})} \mathrm{x}^{2}+\frac{\overline{\mathrm{P}}(\mathrm{s})+\overline{\mathrm{q}}(\mathrm{s}) \mathrm{L}}{\mathrm{As} \overline{\mathrm{E}}(\mathrm{s})} \mathrm{x} \\
& \mathrm{u}(\mathrm{x}, \mathrm{s})=\mathcal{L}\{\mathrm{u}(\mathrm{x}, \mathrm{t})\}=-\frac{\overline{\mathrm{q}}(\mathrm{s})}{2 \mathrm{~A}} \mathrm{~s} \overline{\mathrm{D}}(\mathrm{s}) \mathrm{x}^{2}+\frac{\overline{\mathrm{P}}(\mathrm{s})+\overline{\mathrm{q}}(\mathrm{s}) \mathrm{L}}{\mathrm{A}} \mathrm{s} \overline{\mathrm{D}}(\mathrm{s}) \mathrm{x}
\end{aligned}
$$

Atendendo o resultado obtido na Equação (2.44) e substituindo na Equação (4.21), obtémse a resposta para o fenômeno da fluência no espaço de Laplace mostrado na Equação (2.43) e posteriormente a resposta geral no tempo dada na Equação (4.22).

$$
u(x, t)=-\frac{x^{2}}{2 A} \int_{0}^{t} D(t-\tau) \frac{\partial q}{\partial \tau} d \tau+\frac{x}{A}\left[\int_{0}^{t} D(t-\tau) \frac{\partial P}{\partial \tau} d \tau+L \int_{0}^{t} D(t-\tau) \frac{\partial q}{\partial \tau} d \tau\right]
$$

Uma vez obtida a resposta analítica geral para o deslocamento na barra estudada, incluindo a consideração da viscoelasticidade do material, adotam-se os dados da Tabela 4.7. Considerando as funções $q(\mathrm{t}), \mathrm{P}(\mathrm{t})$, um tempo de avaliação de 30 segundos e um diferencial de tempo $\delta \mathrm{t}=0,2 \mathrm{~s}$, escolha baseada nos resultados obtidos na Figura 4.13.

Tabela 4.7 - Parâmetros de avaliação para o deslocamento de uma barra viscoelástica

\begin{tabular}{ccc}
\hline Parâmetro & Valor & Unidades \\
\hline$A$ & 1 & $\mathrm{~cm}^{2}$ \\
$q(t)$ & 0,1 & $\frac{\mathrm{N}}{\mathrm{cm}}$ \\
$P(t)$ & 10 ou $0,1 \mathrm{t}$ & $\mathrm{N}$ \\
$E(t)$ & $1000+3000 \mathrm{e}^{-\frac{\mathrm{t}}{2}}$ & $\frac{\mathrm{N}}{\mathrm{cm}^{2}}$ \\
$D(t)$ & $2,5 \mathrm{E}^{-4}+7,501 \mathrm{E}^{-4}\left(1-\mathrm{e}^{-\frac{\mathrm{t}}{8}}\right)$ & $\left(\frac{\mathrm{N}}{\mathrm{cm}^{2}}\right)^{-1}$ \\
$\mathrm{Lm}$ & 10 & \\
\hline
\end{tabular}

Baseando-se na formulação mostrada acima, aplica-se o algoritmo incremental para obter o deslocamento que experimenta a barra ao longo do tempo, os resultados obtidos pelo algoritmo proposto apresentam-se na Figura 4.27. Nota-se que os resultados obtidos pelo algoritmo incremental são equivalentes; também pode-se ressaltar a enorme diferença que estabelece no deslocamento da barra ao longo do tempo, a consideração ou não das suas propriedades viscoelásticas, sendo neste caso específico mais de três vezes seu valor para a avaliação num tempo de só 30 segundos, ainda assumindo um carregamento $\mathrm{P}(\mathrm{t})$ constante ao longo do tempo. 


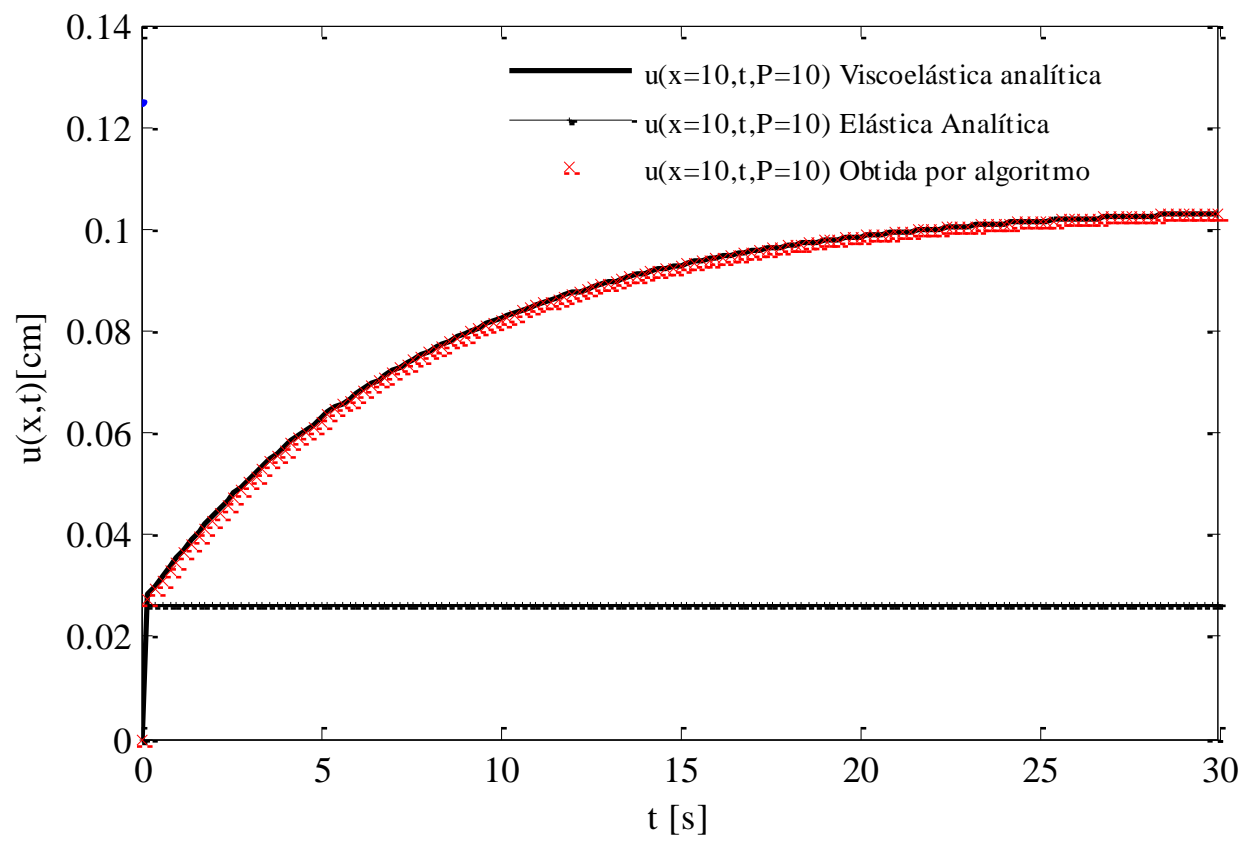

Figura 4.27 - Verificação do algoritmo incremental da barra engastada para $P(t)=10$ e

$$
\mathrm{q}(\mathrm{t})=0,1
$$

Na seguinte verificação considerou-se $P(t)=0,1 t$. Ao avaliar esta condição da força, a solução analítica dada pela Equação (4.22) resume-se numa parcela dependente da convolução e uma multiplicação de funções para as outras duas parcelas devido ao valor constante da função q(t), como é apresentado na Figura 4.28.

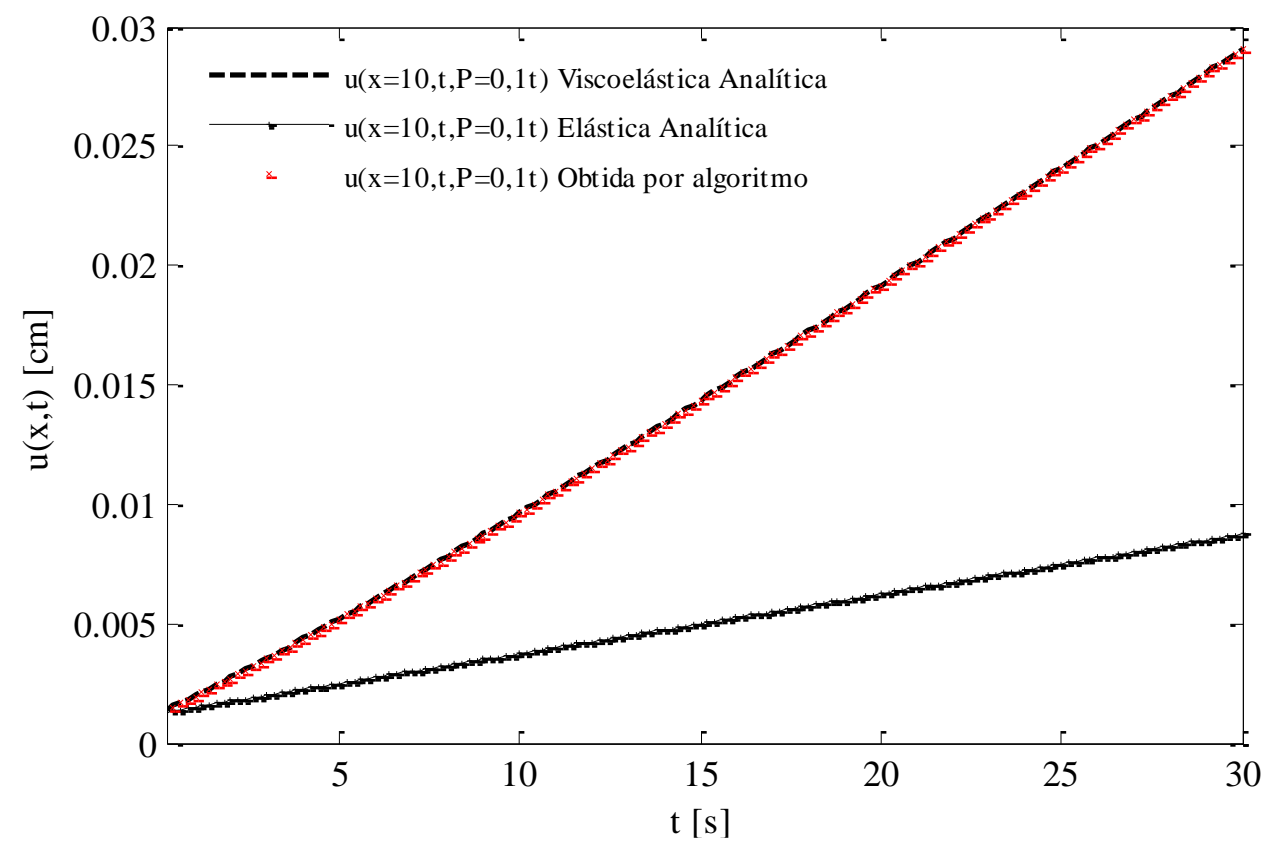

Figura 4.28 - Verificação do algoritmo incremental da barra engastada sendo $P(t)=0,1$ t e $\mathrm{q}(\mathrm{t})=0,1$ 
Segundo o mostrado nas figuras anteriores, mesmo com elementos muito simples e até com carregamentos constantes no tempo o algoritmo consegue representar as respostas viscoelásticas analíticas que não envolvem convolução.

Os resultados viscoelásticos comparados com os elásticos permitem mostrar a evidente a importância do estudo dos efeitos da viscoelasticidade no comportamento mecânico dos elementos estruturais, devido a que a desconsideração destes pode provocar falhas tanto no dimensionamento e concepção das estruturas, quanto no seu comportamento ao longo da sua vida útil.

\subsubsection{3 - Viga Engastada}

Para verificar o algoritmo aplicado à viga avaliou-se o resultado com a resposta obtida pelo MEF baseado num exercício simples desenvolvido na tese doutoral do Torres (2013), onde estuda-se uma viga em balanço sujeita a uma carga $P(t)$, como se apresenta na Figura 4.29.

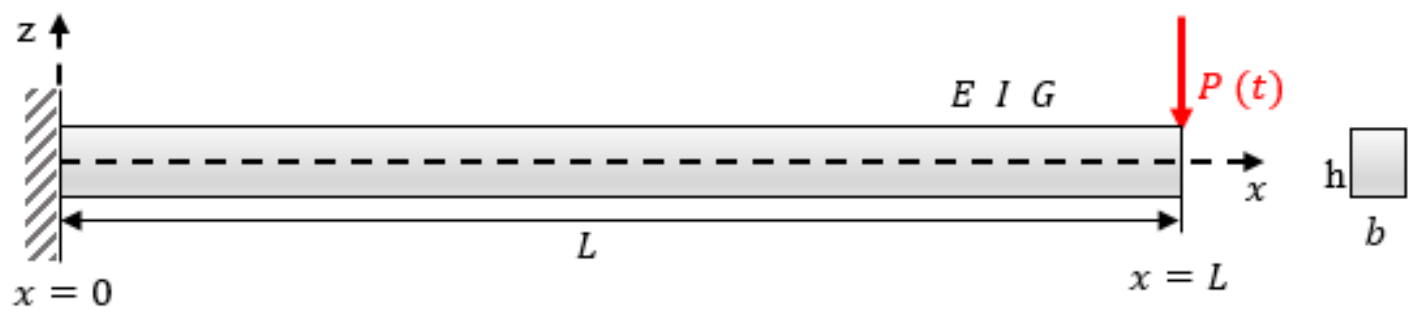

Figura 4.29 - Viga em balanço submetida ao carregamento $\mathrm{P}(\mathrm{t})$

Os parâmetros geométricos da viga engastada que motiva a presente verificação adotaramse segundo os dados registrados na Tabela 4.8.

Tabela 4.8 - Parâmetros geométricos da viga engastada

\begin{tabular}{ccc}
\hline Parâmetro & Valor & Unidade \\
\hline$h$ & 1 & $\mathrm{~cm}$ \\
$b$ & 1 & $\mathrm{~cm}$ \\
$L$ & 4 & $\mathrm{~cm}$ \\
$E(t)$ & $1000+3000 \mathrm{e}^{-\frac{\mathrm{t}}{2}}$ & $\frac{\mathrm{N}}{\mathrm{cm}^{2}}$ \\
$D(t)$ & $2,5 \mathrm{E}^{-4}+7,501 \mathrm{E}^{-4}\left(1-\mathrm{e}^{-\frac{\mathrm{t}}{8}}\right)$ & $\left(\frac{\mathrm{N}}{\mathrm{cm}^{2}}\right)^{-1}$ \\
\hline
\end{tabular}

Foram consideradas quatro tipos de carga diferentes, cada uma têm como máximo valor $\mathrm{P}=$ 6,6 $\mathrm{N}$ e tmáx. refere-se ao instante do tempo em que a carga máxima é aplicada. A descrição matemática de cada um dos carregamentos aplicados à viga apresenta-se na Tabela 4.9 
Tabela 4.9 - Carregamentos impostos na viga em balanço

\begin{tabular}{cccc}
\hline Tipos de Carregamentos & $\begin{array}{c}\mathrm{t}_{\text {máx. }}[\mathrm{s}] \\
1\end{array}$ & $\begin{array}{c}\text { Função do Carregamento } \\
{[\mathrm{N}]}\end{array}$ \\
\hline 2 & 0 & $\mathrm{P}(t)=6,6$ \\
3 & 20 & $\mathrm{P}(t)=\frac{t}{t_{\max }} 6,6$ \\
& Sonstante & 1 & $P(t)=\left(\frac{1-\cos \left(\frac{2 \pi t}{2 . t_{\max }}\right)}{2}\right) 6,6$ \\
4 & Sinusoidal & $P(t)=\left(\frac{1-\cos \left(\frac{2 \pi t}{2 . t_{\max }}\right)}{2}\right) 6,6$ \\
$P(t)=0$
\end{tabular}

Nota-se que a viga estudada é exposta a diferentes tipos de carregamentos, desde um carregamento constante até carregamentos impulsivos e cíclicos, o que permitirá um melhor entendimento do seu comportamento viscoelástico. A representação gráfica dos carregamentos está apresentada na Figura 4.30.

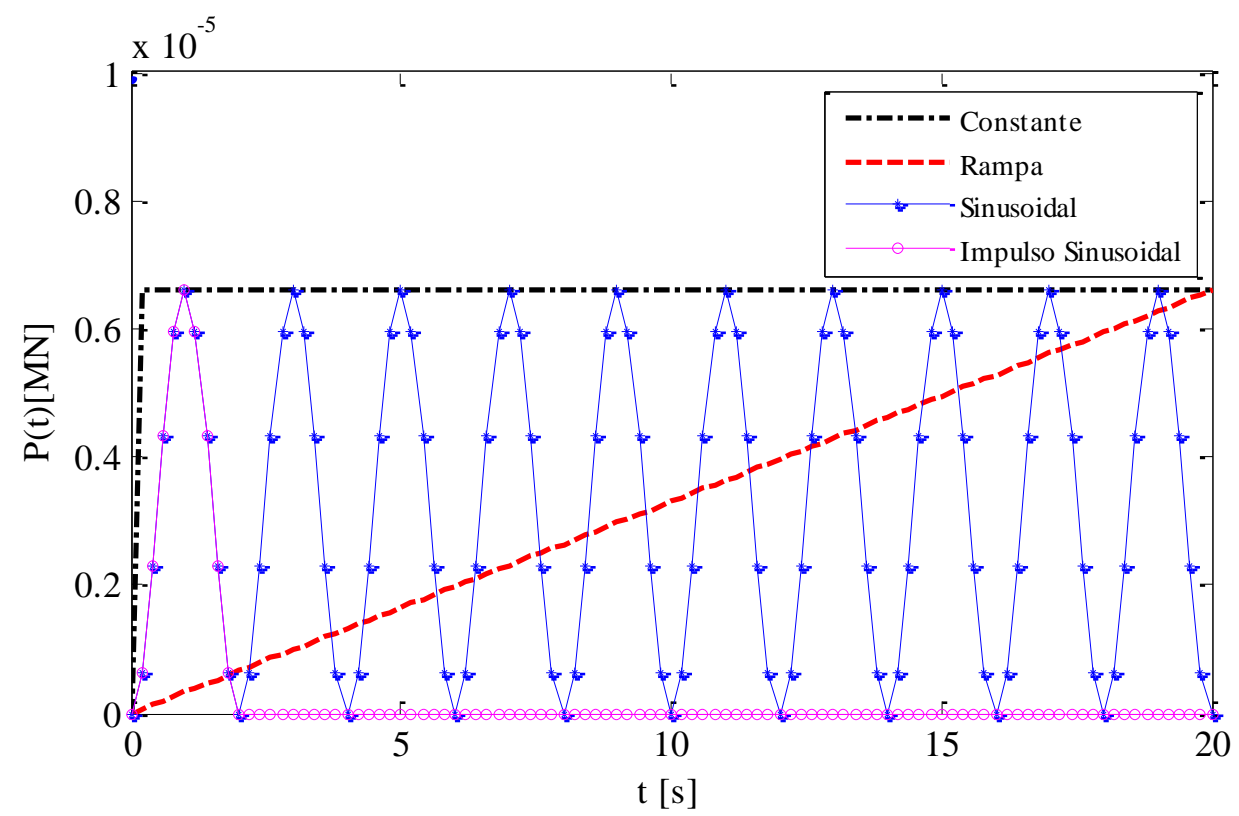

Figura 4.30 - Carregamentos apresentados na Tabela 4.7

Segundo a teoria de Euler-Bernoulli, o deslocamento para uma viga em balanço com carregamento concentrado no extremo livre está dado pela Equação (4.23), que consegue-se transformar aplicando o PCEV tem-se a Equação (4.23).

$$
u(x=L, t)=\frac{L^{3}}{3 I} \int_{0}^{t} D(t-\tau) \frac{\partial P}{\partial \tau} d \tau
$$


Os resultados dos deslocamentos produzidos pelo MVEB em condições elásticas e viscoelásticas devida aos quatro carregamentos impostos e solucionando a Equação (4.23), apresenta-se na Figura 4.32 e na Figura 4.33. Note-se que ao aplicar o carregamento constante o do tipo 1 , o deslocamento vertical $u(x=L, t)$ da viga descreve graficamente $o$ comportamento da série de Prony para o comportamento à fluência do material. $\mathrm{O}$ efeito da viscoelasticidade utilizado o algoritmo $\operatorname{com} \delta \mathrm{t}=0,2 \mathrm{~s}$, permite ver a diferença nos deslocamentos da viga, isto comparando as condições viscoelásticas com as elásticas, sendo que a deformação final no tempo de $20 \mathrm{~s}$ em condições elásticas é menos da terceira parte do que é o valor do deslocamento com o mesmo carreamento considerando a viscoelasticidade, o que valida a importância do estudo da influência da viscoelasticidade dos materiais no comportamento das vigas.

No caso dos carregamentos variáveis como os do tipo 2 e 3 , a evolução das deflexões da viga aumentam conforme aumenta ou diminui o carregamento, sem que isto implique que uma vez descarregada a viga instantaneamente eliminará o deslocamento, como pode ser observado na curva do carregamento tipo 4. Isso é devido à consideração dos materiais como no comportamento viscoelástico; uma vez descarregado o material, os deslocamentos diminuem na taxa de relaxação do material até chegar a zero e não instantaneamente.

Segundo a teoria de viga de Timoshenko, para a viga em balanço os deslocamentos verticais elásticos estão dados pela Equação (2.71), no entanto, usando o PCEV, essa equação transforma-se para a Equação (4.24) segundo o apresentado na continuação na Equação (4.24).

$$
\mathrm{u}(\mathrm{x}=\mathrm{L}, \mathrm{t})=\frac{\mathrm{L}^{3}}{3 \mathrm{I}} \int_{0}^{\mathrm{t}} \mathrm{D}(\mathrm{t}-\tau) \frac{\partial \mathrm{P}}{\partial \tau} \mathrm{d} \tau+\frac{\mathrm{L}}{\mathrm{A}} \int_{0}^{\mathrm{t}} \mathrm{J}(\mathrm{t}-\tau) \frac{\partial \mathrm{P}}{\partial \tau} \mathrm{d} \tau
$$

Resolvendo pelo algoritmo a Equação (4.24), dados os carregamentos $\mathrm{P}(\mathrm{t})$ apresentados na Figura 4.30, obterem-se os resultados apresentados na Figura 4.33. Comparando os resultados obtidos considerando a formulação da viga de Timoshenko com a viga de EulerBernoulli, encontra-se um incremento nas deflexões máximas da viga. Essa diferença foi no máximo valor de 4,875\%, que ainda para essa viga em particular são uns poucos milímetros, para outros casos de viga com maior comprimento pode representar uma diferença considerável. 
Para verificar mais uma vez o algoritmo aplicado para determinar os resultados apresentados na Figura 4.32 e na Figura 4.33, modelou-se a viga no aplicativo SHAY (Evangelista Jr, 2014). Esse programa foi desenvolvido na Universidade de Brasília, ainda não foi patenteado e baseado na teoria dos elementos finitos, sendo obtidos os deslocamentos para a viga em balanço modelando cada um dos carregamentos propostos das modelações feitas nesse programa.

A Figura 4.31 ilustra a malha de elementos finitos da viga de dimensões segundo a Tabela 4.8, onde os deslocamentos são extraídos para comparação no ponto de aplicação da força $\mathrm{P}(\mathrm{t})$. A geometria da viga corresponde à indicada na Figura 4.29 e malha de elementos finitos foi gerada com 400 elementos do tipo quadrilaterais de oito nós Q8 de oito nós, considerando o material viscoelástico correspondente às séries de Prony das Equações (4.1) e (4.4).

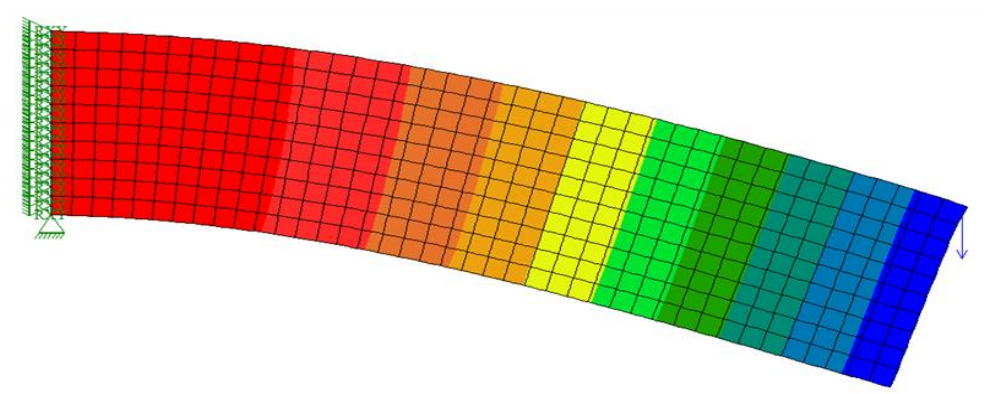

Figura 4.31 - Malha deformada obtido pelo programa SHAY (Evangelista Jr, 2014)

Para poder comparar os resultados obtidos pelo método dos elementos finitos com os resultados obtidos numericamente pelo algoritmo proposto, foi usado o mesmo diferencial de tempo, isto quer dizer, que para os dois tipos de resultados $\delta t=0,2 \mathrm{~s}$, obtendo os deslocamentos para cada tipo de carregamento segundo o apresentado na na Figura 4.32 e na Figura 4.33.

Nessas Figuras, se comparam os resultados das deflexões máximas da viga em balanço, obtidos para o modelo de Timoshenko em condições elásticas MVTe, o modelo de viga de Euler-Bernoulli em condições viscoelásticas MVEBv, o modelo de viga de Timoshenko para as duas parcelas viscoelásticas MVTvv e finalmente comparados com o resultado do modelo realizado pelo método dos elementos finitos em condições viscoelásticas MEFv. 


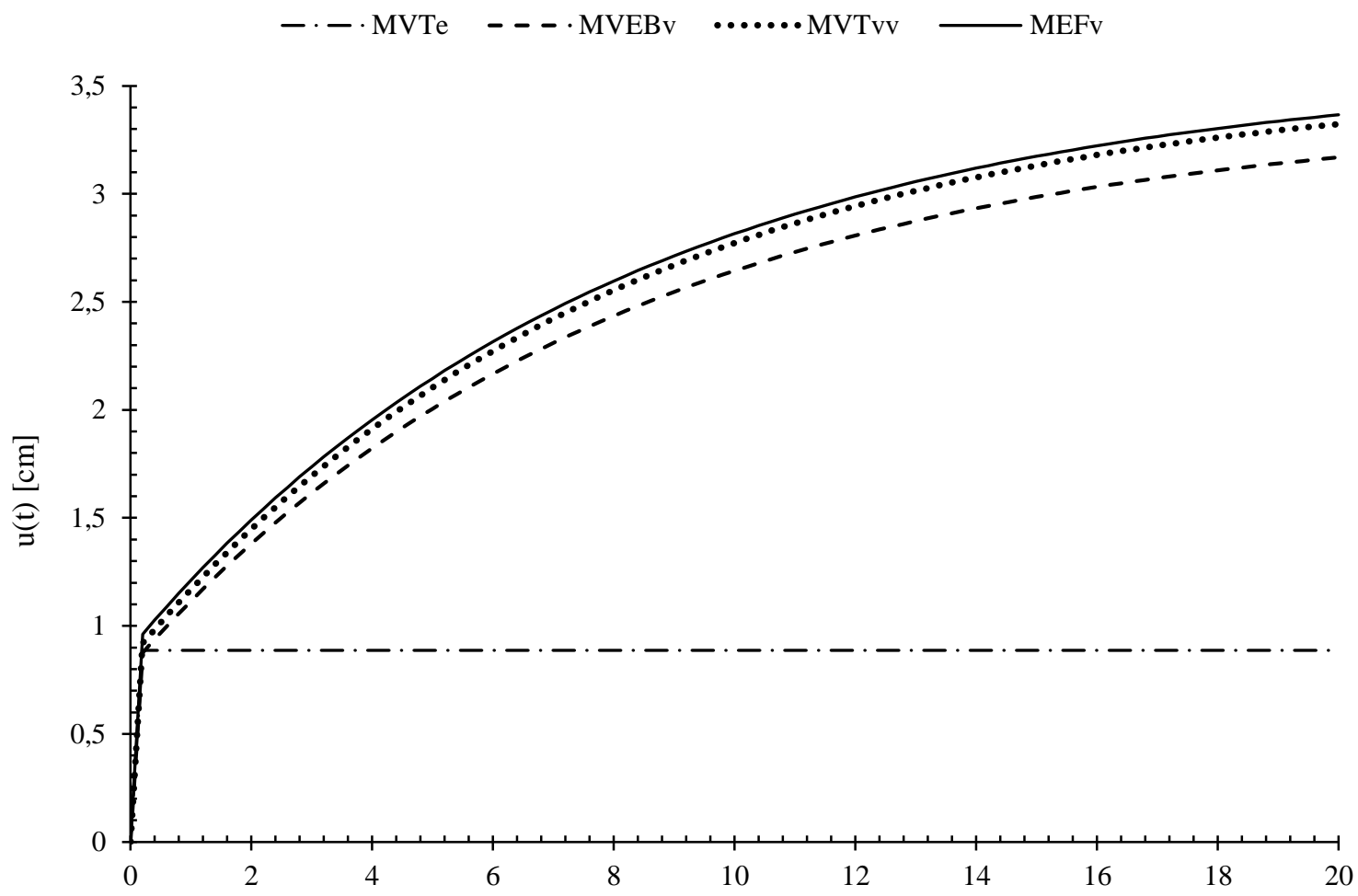

(a) Deflexões máximas viga engastada carregamento constante -.-MVTe - - - MVEBv $\cdots \cdot . \cdot$ MVTvv $\longrightarrow$ MEFv

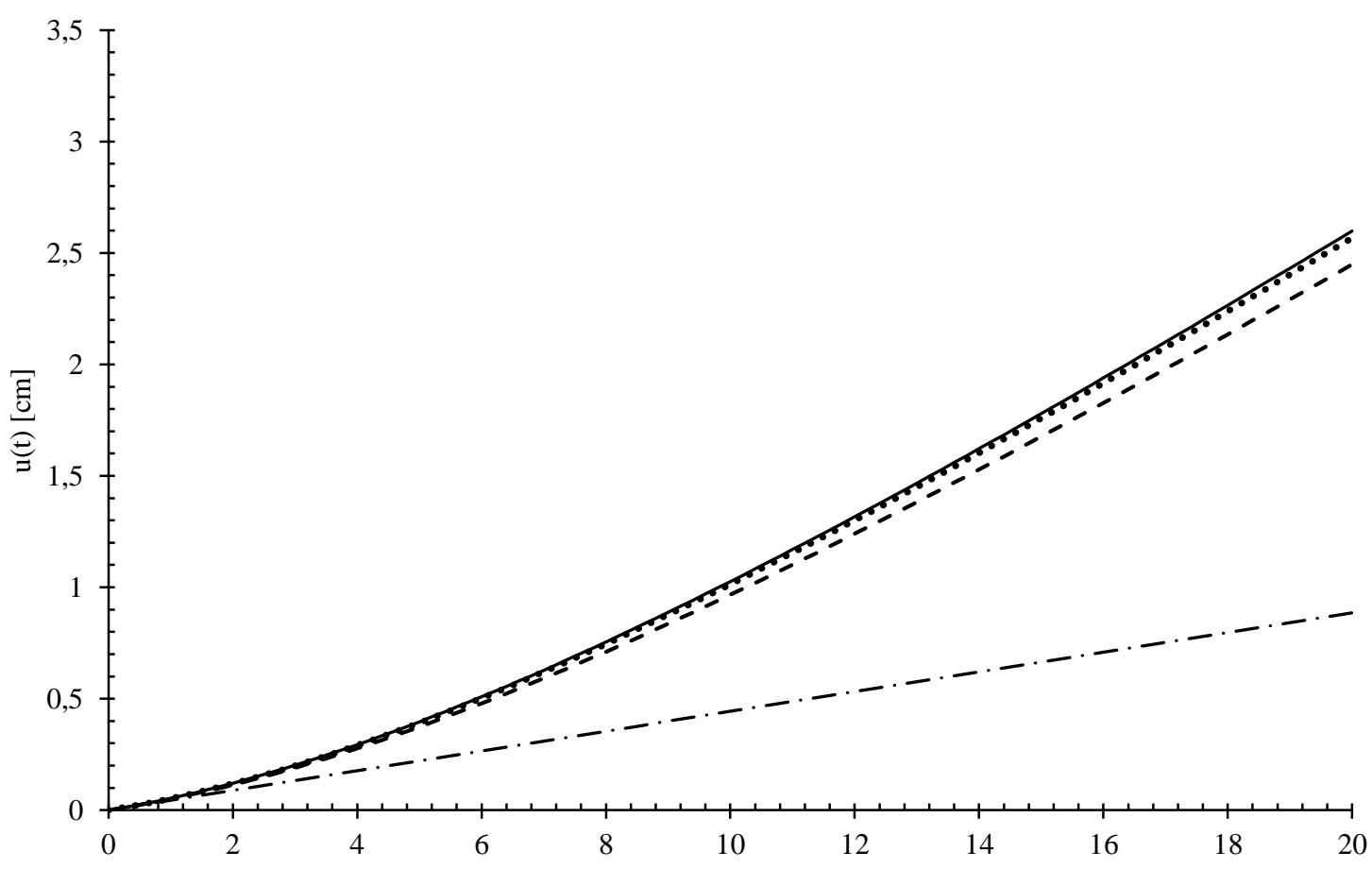

$\mathrm{t}[\mathrm{s}]$

(b) Deflexões máximas viga engastada carregamento de rampa

Figura 4.32 - Deflexões máximas da viga engastada para os carregamentos constante e de rampa 


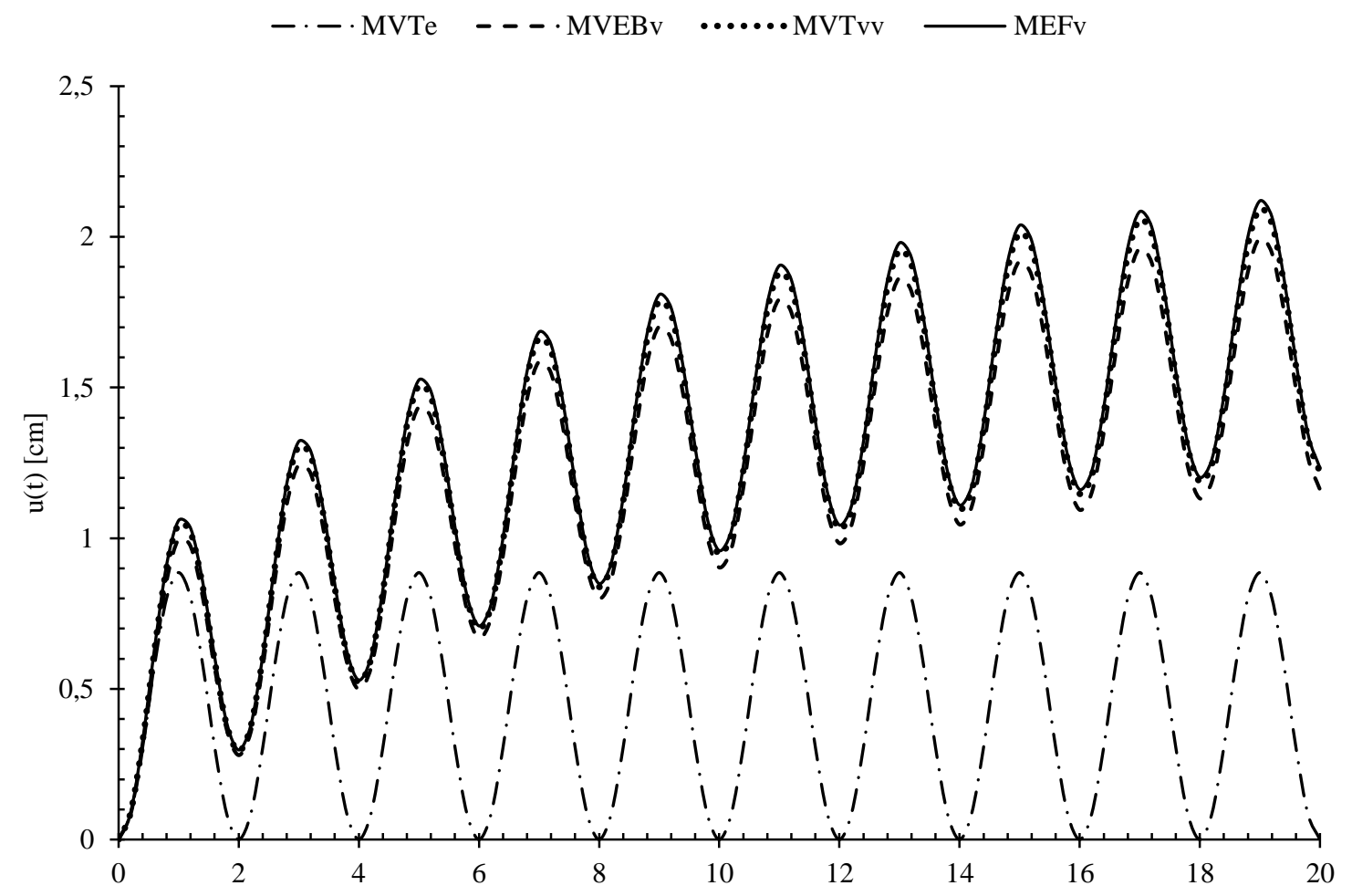

(a) Deflexões máximas viga engastada carregamento sinusoidal

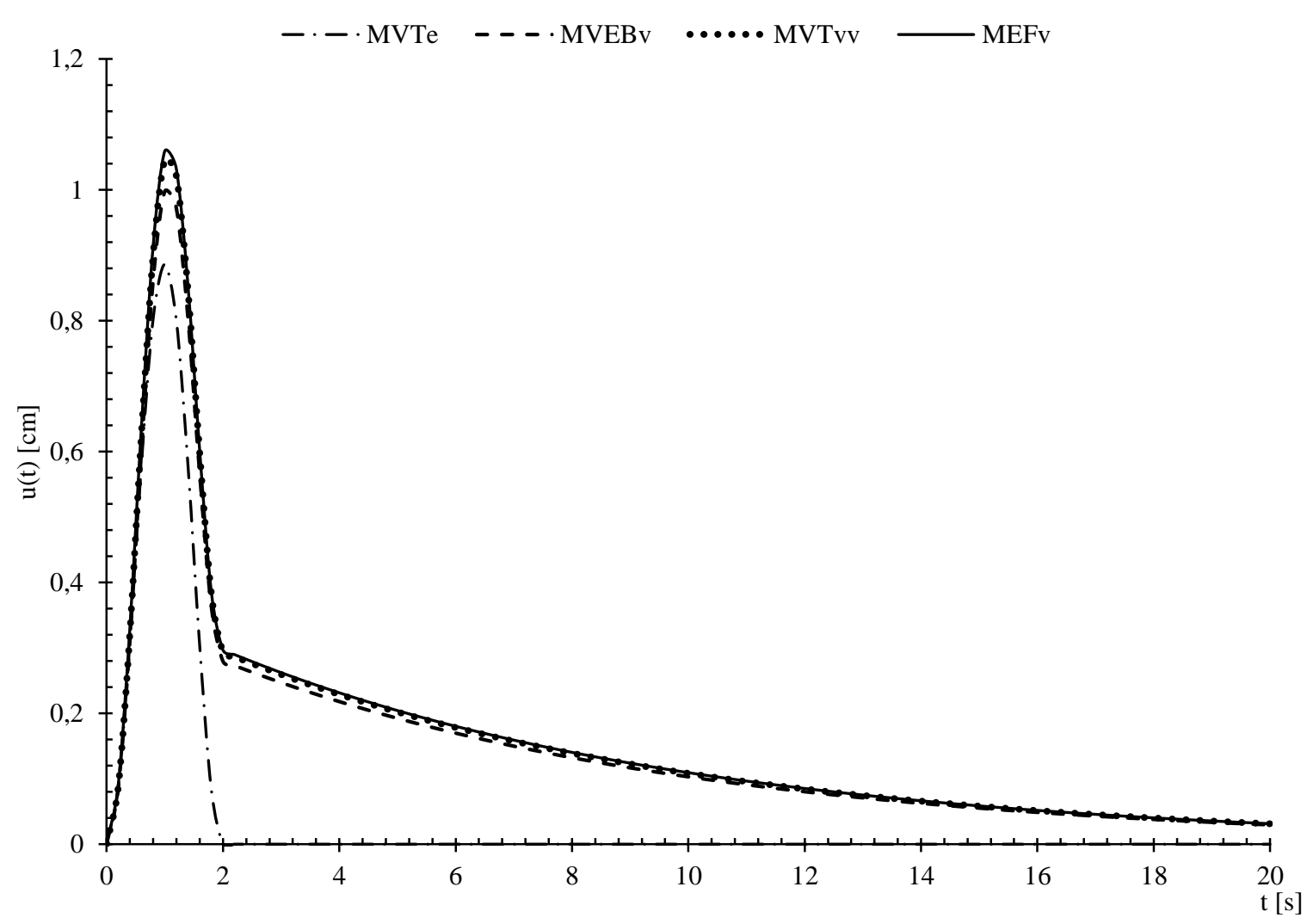

(b) Deflexões máximas viga engastada carregamento de impulso sinusoidal

Figura 4.33 - Deflexões máximas da viga engastada para os carregamentos sinusoidal e de impulso sinusoidal 
Graficamente pode se comprovar que os resultados obtidos por elementos finitos e pelo algoritmo proposto são concordantes, mas, aproveitando que os maiores efeitos numéricos se obtiveram com o modelo da viga de Timoshenko com o material considerado viscoelástico, pode-se medir em detalhe a diferença quantitativa entre os resultados obtidos por esse modelo e compará-los com o MEF e é apresentada na Figura 4.34.

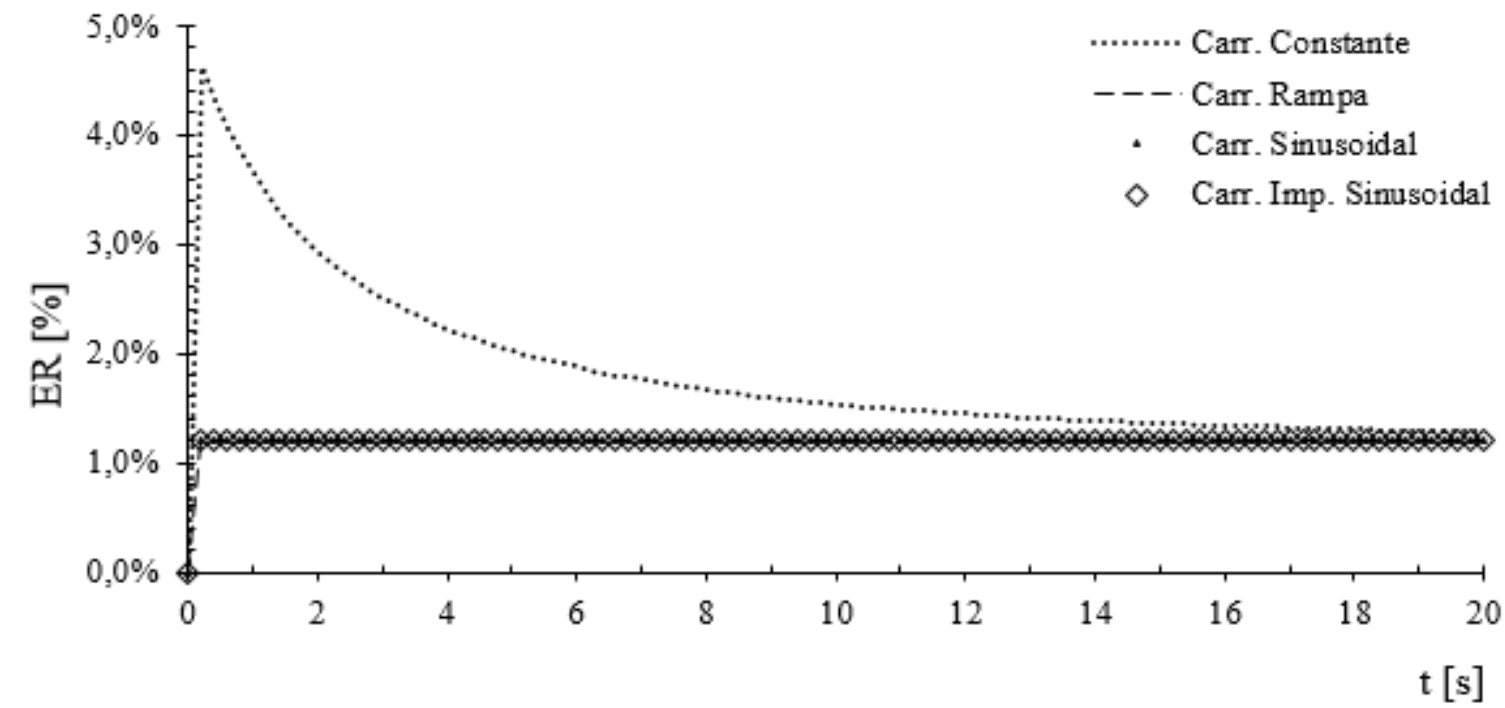

Figura 4.34 - Diferença quantitativa deslocamento u(t) MEF vs. viga de Timoshenko

Baseados no anterior, pode-se concluir que o algoritmo é apropriado para descrever o comportamento viscoelástico de elementos estruturais como vigas, ainda sendo os resultados obtidos pelo MEF superiores em valor aos obtidos pelo algoritmo, a diferença é muito pequena, além disso, para tempos superiores, a diferença estabiliza para todos os tipos de carregamentos, sendo pouco superior ao $1 \%$. 


\section{5 - ANÁLISE DO COMPORTAMENTO MECÂNICO DE ELEMENTOS ESTRUTURAIS COMPÓSITOS}

No presente Capítulo se apresenta um estudo de como afeita o aumento das deformações a consideração da viscoelasticidade em elementos estruturais compósitos tipo viga. $\mathrm{Na}$ primeira parte estudou-se a viga sanduíche quando experimenta diferentes tipos de carregamentos dinâmicos e estáticos, estudando a variabilidade dos seus materiais e dimensões. Na segunda parte realizou-se um estudo paramétrico baseado na teoria de superfícies com equações de segundo grau.

\section{1 - VIGA SANDUÍCHE VISCOELÁSTICA}

\subsection{1 - PARÂMETROS GEOMÉTRICOS, MATERIAIS E CARREGAMENTOS}

Para as comparações que se pretendem realizar na presente pesquisa, adota-se uma viga sanduíche de geometria e o carregamento definidos e indicados na Figura 5.1, onde consideram-se o módulo de elasticidade E, o módulo ao cisalhamento $\mathrm{G}$ e o coeficiente de Poisson $v$ como propriedades dos materiais da viga, $\mathrm{P}(\mathrm{t})$ como o carregamento pontual imposto no centro e os materiais foram subdivididos nas camadas elásticas (1 e 2) e as camadas do núcleo viscoelástico (3 e 4).

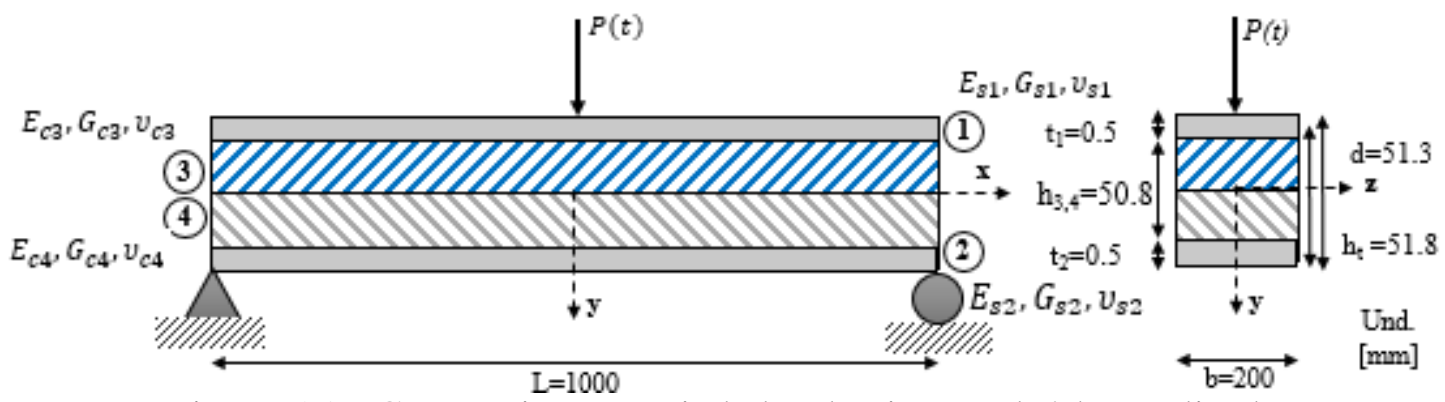

Figura 5.1 - Geometria e propriedades da viga sanduíche analisada

Dado que um dos materiais de núcleo de estruturas compósitas mais comuns são a espuma de poliestireno (PS) com peles de alumínio, esses materiais foram escolhidos para serem usados na viga do presente estudo. Para analisar a influência da viscoelasticidade nos deslocamentos da viga sanduíche precisa-se das propriedades viscoelásticas do material do núcleo, sendo obtidas com base nos dados experimentais obtidos por Ferry (1980) num ensaio de fluência ao cisalhamento do material poliestireno. 
Baseando-se nesses dados experimentais foi obtida a série de Prony $J(t)$ aplicando os algoritmos de interconversão e aproximação às séries de Prony verificados nas seções 3.1 e 3.2 - , foram obtidas as séries de fluência $D(t)$ e relaxação $E(t)$. Na Figura 5.2 se apresentam os dados experimentais do ensaio do Ferry (1980) da propriedade $J(t)$, a série de Prony que representa matematicamente estes dados, a representação da série $\mathrm{D}(\mathrm{t})$ e posteriormente tanto os dados da interconversão de $\mathrm{E}(\mathrm{t})$ como a série obtida a partir de esses valores, provando a correta interconversão dos dados realizando a interconversão inversa, ou seja, desde $E(t)$ para $D(t)$, sendo amplamente satisfatórios os resultados obtidos.

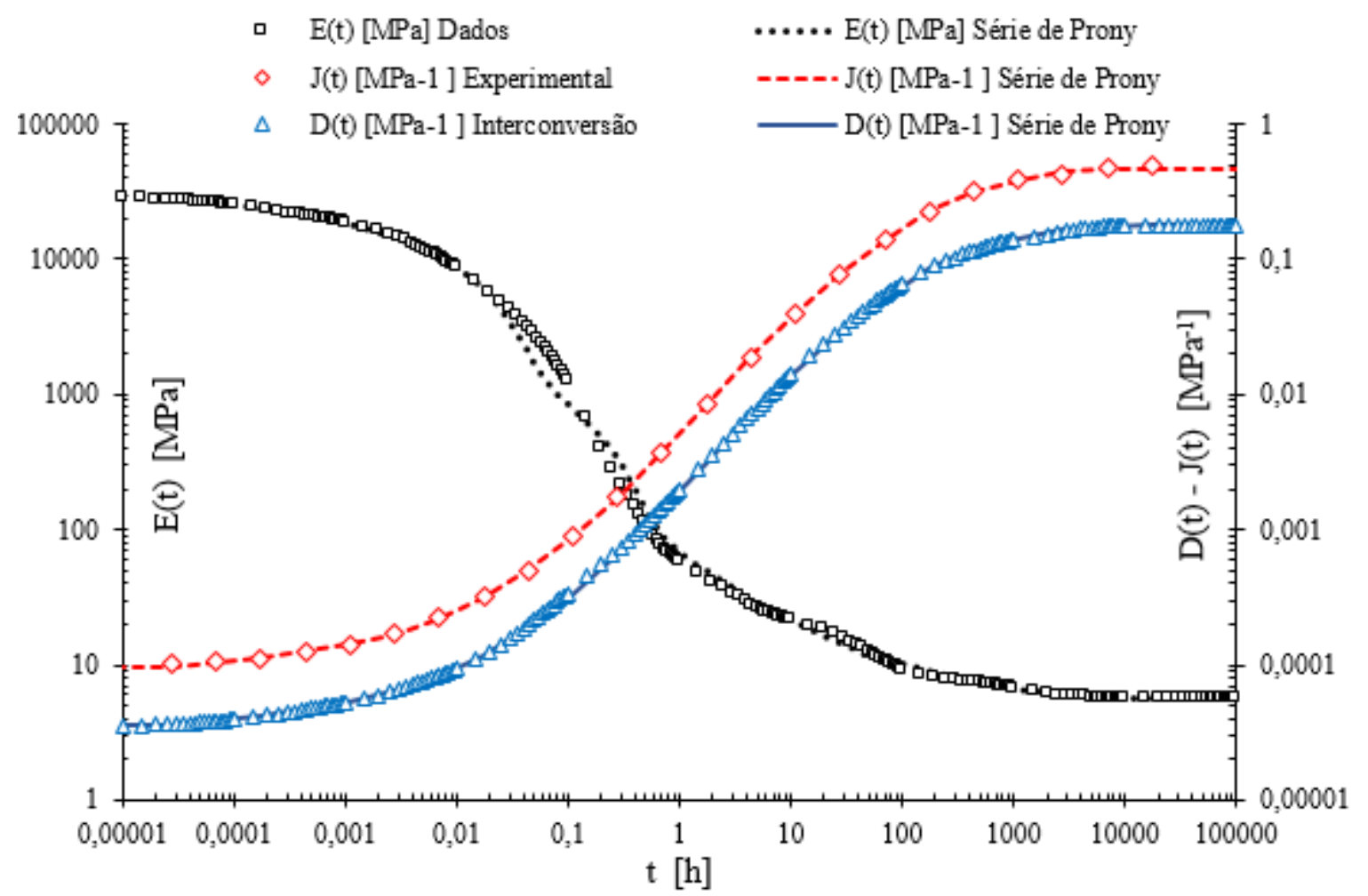

Figura 5.2 - Funções de fluência e relaxação da espuma rígida de poliestireno (PS)

As funções que originaram a Figura 5.2 estão dadas por nove coeficientes e oito exponentes, isto dado a variação dos valores de cada uma das propriedades em aproximadamente oito ordens de grandeza no tempo, sendo apresentados os valores na Tabela 5.1

A análise paramétrica a ser realizada na viga de geometria e materiais já definidos, separa por casos de estudo as diferentes variações dadas segundo as avaliações dos modelos de viga apresentados no numeral 0, sendo os seis casos de estudo os seguintes: o Modelo de viga de Euler-Bernoulli (MVEB) avalia as condições elásticas do modelo da viga de EulerBernoulli, o Modelo de viga de Euler-Bernoulli viscoelástico (MVEBv) reformula o MVEB considerando a viscoelasticidade do material do núcleo de um material, o Modelo de viga de 
Timoshenko (MVT) considera as condições elásticas para a formulação da viga de Timoshenko, o MVTev contempla neste ultimo modelo a viscoelasticidade ao cisalhamento e a simplificação do $(E I)_{e q}$, o MVTvv não realiza a simplificação feita no MVTev e finalmente, o MVTvv 2 que considera a viscoelasticidade segundo o MVTvv quando o núcleo se compõe de dois materiais viscoelásticos, sendo um mais rígido do que o outro $\alpha$ vezes. $\mathrm{O}$ anterior pode-se resumir segundo se apresenta na Tabela 5.2.

Tabela 5.1 - Coeficientes séries de Prony $\mathrm{J}(\mathrm{t}), \mathrm{D}(\mathrm{t})$ e E(t) do PS

\begin{tabular}{|c|c|c|c|c|}
\hline $\mathbf{N}$ & $J_{n}\left[M P a^{-1}\right]$ & $D_{n}\left[M P a^{-1}\right]$ & $E[M P a]$ & $\operatorname{Exp}_{n}[s] *$ \\
\hline$* *$ & 9,33E-05 & 3,51E-05 & $5,65 \mathrm{E}+00$ & -- \\
\hline 1 & $2,15 \mathrm{E}-05$ & $8,10 \mathrm{E}-06$ & $5,46 \mathrm{E}+03$ & $1,66 \mathrm{E}-04$ \\
\hline 2 & 2,57E-05 & $9,65 \mathrm{E}-06$ & $7,98 \mathrm{E}+03$ & $1,66 \mathrm{E}-03$ \\
\hline 3 & $1,16 \mathrm{E}-04$ & 4,34E-05 & $1,36 \mathrm{E}+04$ & $1,66 \mathrm{E}-02$ \\
\hline 4 & $1,46 \mathrm{E}-04$ & 5,49E-05 & $1,32 \mathrm{E}+03$ & $1,66 \mathrm{E}-01$ \\
\hline 5 & $1,33 \mathrm{E}-03$ & 4,98E-04 & $6,63 \mathrm{E}+01$ & $1,66 \mathrm{E}+00$ \\
\hline 6 & $4,31 \mathrm{E}-02$ & $1,62 \mathrm{E}-02$ & $1,68 \mathrm{E}+01$ & $1,66 \mathrm{E}+01$ \\
\hline 7 & 2,47E-01 & $9,30 \mathrm{E}-02$ & $4,56 \mathrm{E}+00$ & $1,66 \mathrm{E}+02$ \\
\hline 8 & $1,78 \mathrm{E}-01$ & $6,71 \mathrm{E}-02$ & $1,95 \mathrm{E}+00$ & $1,66 \mathrm{E}+03$ \\
\hline
\end{tabular}

Tabela 5.2 - Condições de avaliação da viga sanduíche

\begin{tabular}{|c|c|c|c|c|c|c|c|}
\hline Camada & Prop. & $\begin{array}{r}\text { Caso I } \\
\text { MVEB } \\
\end{array}$ & $\begin{array}{l}\text { Caso II } \\
\text { MVEBv }\end{array}$ & $\begin{array}{c}\text { Caso III } \\
\text { MVT }\end{array}$ & $\begin{array}{l}\text { Caso IV } \\
\text { MVTev }\end{array}$ & $\begin{array}{l}\text { Caso V } \\
\text { MVTvv }\end{array}$ & $\begin{array}{l}\text { Caso VI } \\
\mathrm{MVTvv}_{2}\end{array}$ \\
\hline \multirow{2}{*}{$\begin{array}{c}\text { Externa } \\
\text { (Alumínio) }\end{array}$} & $E_{S 1}=E_{S 2}$ & 70000 & 70000 & 70000 & 70000 & 70000 & 70000 \\
\hline & $v_{S 1}=v_{S 2}$ & 0,35 & 0,35 & 0,35 & 0,35 & 0,35 & 0,35 \\
\hline \multirow{6}{*}{$\begin{array}{l}\text { Núcleo } \\
\text { (Poliestireno } \\
\text { PS) }\end{array}$} & $E_{C 3}$ & 28480 & $E_{C 3}(t)$ & 28480 & $f\left(E_{S 1}\right)^{*}$ & $E_{C 3}(t)$ & $E_{C 3}(t)$ \\
\hline & $G_{C 3}$ & - & - & 10706,66 & $G_{C 3}(t)$ & $G(t)_{C 3}$ & $G(t)_{C 3}$ \\
\hline & $v_{C 3}$ & 0,33 & 0,33 & 0,33 & 0,33 & 0,33 & 0,33 \\
\hline & $E_{C 4}$ & 28480 & $E_{C 3}(t)$ & 28480 & $f\left(E_{s 1}\right)^{*}$ & $\alpha E_{C 3}(t)$ & $\alpha E_{C 3}(t)$ \\
\hline & $G_{C 4}$ & - & - & 10706,66 & $G_{C 3}(t)$ & $\alpha G_{C 3}(t)$ & $\alpha G_{C 3}(t)$ \\
\hline & $v_{C 4}$ & 0,33 & 0,33 & 0,33 & 0,33 & 0,33 & 0,33 \\
\hline
\end{tabular}

$E_{s i}, E_{c i}, G_{c i}[M P a] v_{s i}, v_{c i}$ [Adimensional]

$\alpha$ : Coeficiente de modificação da rigidez. Caso $5 \alpha=1$, Caso $6 \alpha=0,75, \alpha=0,5$ e $\alpha=0,25$

* Rigidez flexional EI é função do modulo de elasticidade das camadas externas $E_{s 1}$.

O carregamento imposto ao elemento estrutural está dado por três tipos diferentes de carregamentos, sendo comum para todos o valor máximo de $1000 \mathrm{~N}$ e para cada um deles 
um período de tempo $\mathrm{T}$ sendo que em cada caso o máximo valor é alcançado no $t=T / 2$. $\mathrm{O}$ Carregamento tipo 1 (CT1) é do tipo rampa, onde aumenta linearmente ao valor máximo até o valor de tempo $t=T / 2$ e depois permanece constante ao longo do tempo como se apresenta na Figura 5.3, sendo a rampa inicial avaliada para quatro períodos diferentes $\mathrm{T}=0,1,1,10$ e $100[\mathrm{~h}]$.

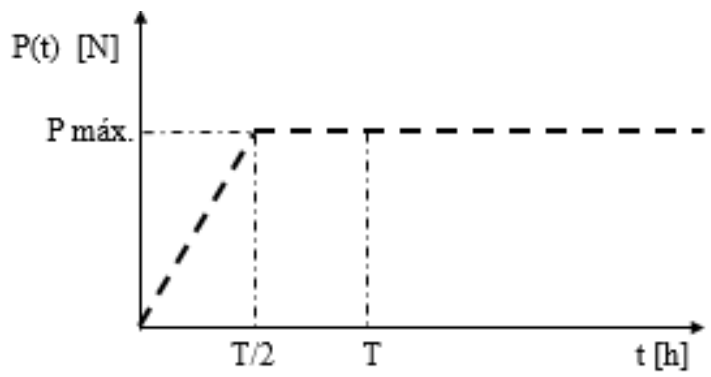

Figura 5.3 - Carregamento CT1 (rampa)

O segundo tipo de carregamento considerado no presente estudo (CT2) é um carregamento impulsivo do tipo sinusoidal, isto para analisar a influência da aplicação da carga nos deslocamentos centrais da viga, também pretende-se comparar dois tipos diferentes de carregamentos impulsivos, cada um com um tempo de período de $\mathrm{T}=0,1,1,10$ e 100 [h] com o máximo da carga $P(t)=1000 N$ no tempo $t=\frac{T}{2}$, como apresenta-se na Figura 5.4.

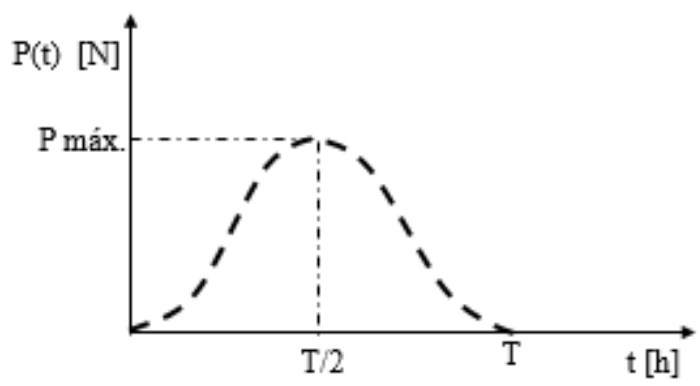

Figura 5.4 - Carregamento CT2 (impulso sinusoidal)

O terceiro e último tipo de carregamento (CT3) consiste num carregamento impulsivo de rampa que se desenvolve em três etapas de tempo $t=T / 3$, no primer tercio o carregamento aumenta linearmente até o máximo valor de $P(t)=1000 \mathrm{~N}$, permanecendo constante desde $T / 3 \leq t \leq 2 T / 3$ e posteriormente no tercio final sofre um descarregamento constante até zero no tempo $t=T$, como se apresenta na Figura 5.5. 


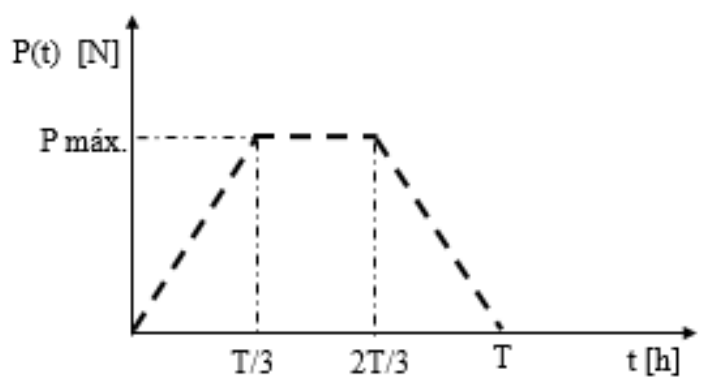

Figura 5.5 - Carregamento CT3 (impulso rampa)

\subsection{2 - VERIFICAÇÃO DO ALGORITMO PARA O PCEV DE VIGAS SANDUÍCHE}

Ao tentar comparar os efeitos na deflexão resultantes da consideração dos modelos analíticos de viga de Euler Bernoulli e de Timoshenko, ou seja, o efeito da consideração ou não do cisalhamento em elementos de viga sanduíche. Para isso avaliou-se as condições elásticas dos modelos comparado com um modelo de elementos finitos ou MEF, isto para verificar o modelo numérico e posteriormente poder extrapolar esta formulação das condições elásticas ás condições viscoelásticas.

A modelagem feita em elementos finitos realizou-se no programa SHAY (Evangelista Jr, 2014), reproduzindo as condições elásticas do modelo com uma malha de 4400 elementos quadrilaterais tipo Q8, considerando integração não linear em oito nós por elemento e modelada com as condiciones de apoio e o carregamento máximo, como se apresenta na Figura 5.6, e concordante com as dimensões dadas na Figura 5.1 e os materiais segundo cada caso descrito na Tabela 5.2.

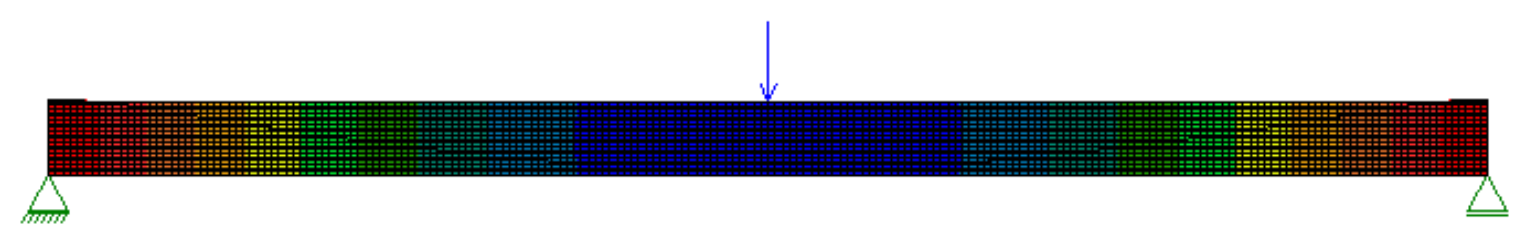

Figura 5.6 - Malha deformada da viga sanduíche obtido pelo SHAY (Evangelista Jr, 2014)

Os resultados obtidos no programa SHAY correspondentes às deflexões obtidas pelo modelo de elementos finitos MEF, foram comparadas com as respostas do modelo de EulerBernoulli MVEB e o modelo de viga de Timoshenko MVT como se apresenta na Tabela 5.3. 
Tabela 5.3 - Comparação das deflexões máximas da viga

\begin{tabular}{c|ccc}
\hline Parâmetro & $\begin{array}{c}\text { MEF 4400 } \\
\text { Elementos }\end{array}$ & MVEB & $\begin{array}{c}\text { MVT } \\
\text { analítico }\end{array}$ \\
\hline $\begin{array}{c}\text { Deflexão } \\
{[\mathrm{mm}]}\end{array}$ & 0,2918 & 0,2934 & 0,2946 \\
\hline $\begin{array}{c}\text { Diferença } \\
{[\mathrm{mm}]}\end{array}$ & 0,0028 & 0,0012 & Referência \\
\hline Erro \% & $0,94 \%$ & $0,40 \%$ & Referência \\
\hline
\end{tabular}

Na Tabela 5.3 consignaram-se os deslocamentos no centro da viga dos diferentes modelos para o carregamento de $\mathrm{P}=1000[\mathrm{~N}]$, isso devido a que esse valor corresponde também ao máximo valor da carga em cada um dos tipos de carregamento a serem avaliados, e consequentemente, em condições elásticas esse máximo valor produzirá a máxima deflexão. Também permite visualizar que o MVEB descreve aproximadamente as deflexões na viga estudada, isto válido somente neste caso pois se o material do núcleo fosse menos rígido do que a espuma utilizada os deslocamentos do MVEB e o MVT seriam notoriamente diferentes.

A verificação do modelo em condições viscoelásticas baseia-se na aplicação do algoritmo apresentado no item 4.3.2.3 - com a formulação dos deslocamentos no centro da viga, isto considerando a parcela de flexão aportada pelo MVEB em função do $I_{M o d}$ (apresentado na Equação (2.86) e cujo algoritmo descreve-se no anexo C.7), que estabelece a relação elástica do material das camadas externas e o material do núcleo no tempo zero, e na parcela ao cisalhamento incrementada pelo MVT em função da área que suporta o cortante, o coeficiente de Timoshenko ao cisalhamento e o fator $\alpha=1$ como se apresenta na Equação (5.1).

$$
\delta\left(\frac{\mathrm{L}}{2}, \mathrm{t}\right)=\frac{\mathrm{L}^{3}}{48 \mathrm{I}_{\text {Mod }}} \int_{0}^{\mathrm{t}} \mathrm{D}(\mathrm{t}-\tau) \frac{\mathrm{dP}(\tau)}{\mathrm{d} \tau} \mathrm{d} \tau+\frac{\mathrm{L}}{4 \alpha \kappa \mathrm{A}_{\mathrm{C} 3,4}} \int_{0}^{\mathrm{t}} \mathrm{J}(\mathrm{t}-\tau) \frac{\mathrm{dP}(\tau)}{\mathrm{d} \tau} \mathrm{d} \tau
$$

Aplicando na Equação (5.1) o algoritmo incremental para a solução do problema de convolução numérica, usando as séries de Prony que descrevem as propriedades de fluência $D(t)$ e fluência à cisalhamento $J(t)$ podem ser obtidos os deslocamentos no centro da viga. Para avaliar tais deflexões é usando no MEF a série de relaxação $E(t)$, sendo avaliado dois carregamentos do tipo 1 para os períodos $\mathrm{T}=0,1$ e 10 [h], e um carregamento do tipo 2 para $\mathrm{T}=10[\mathrm{~h}]$. Os resultados obtidos pelo MEF comparado com o algoritmo proposto para obter 
as deflexões no centro da viga segundo as considerações do MVTvv apresentam-se na Figura 5.7 .

Note-se na Figura 5.7 que as deflexões obtidas pelo algoritmo proposto comparado com o MEF muito semelhantes, mas, para avaliar a porcentagem real do erro tomando como parâmetro de comparação os deslocamentos obtidos pelo MEF avaliou-se o erro ponto a ponto da série de resultados obtidos segundo a Equação (5.2) e apresentados na Figura 5.8.

$$
\operatorname{Erro}(\mathrm{t})=\frac{\left|\delta\left(\frac{\mathrm{L}}{2}, \mathrm{t}\right)_{\mathrm{MEF}}-\delta\left(\frac{\mathrm{L}}{2}, \mathrm{t}\right)_{\mathrm{C} 5}\right|}{\delta\left(\frac{\mathrm{L}}{2}, \mathrm{t}\right)_{\mathrm{MEF}}} \times 100[\%]
$$

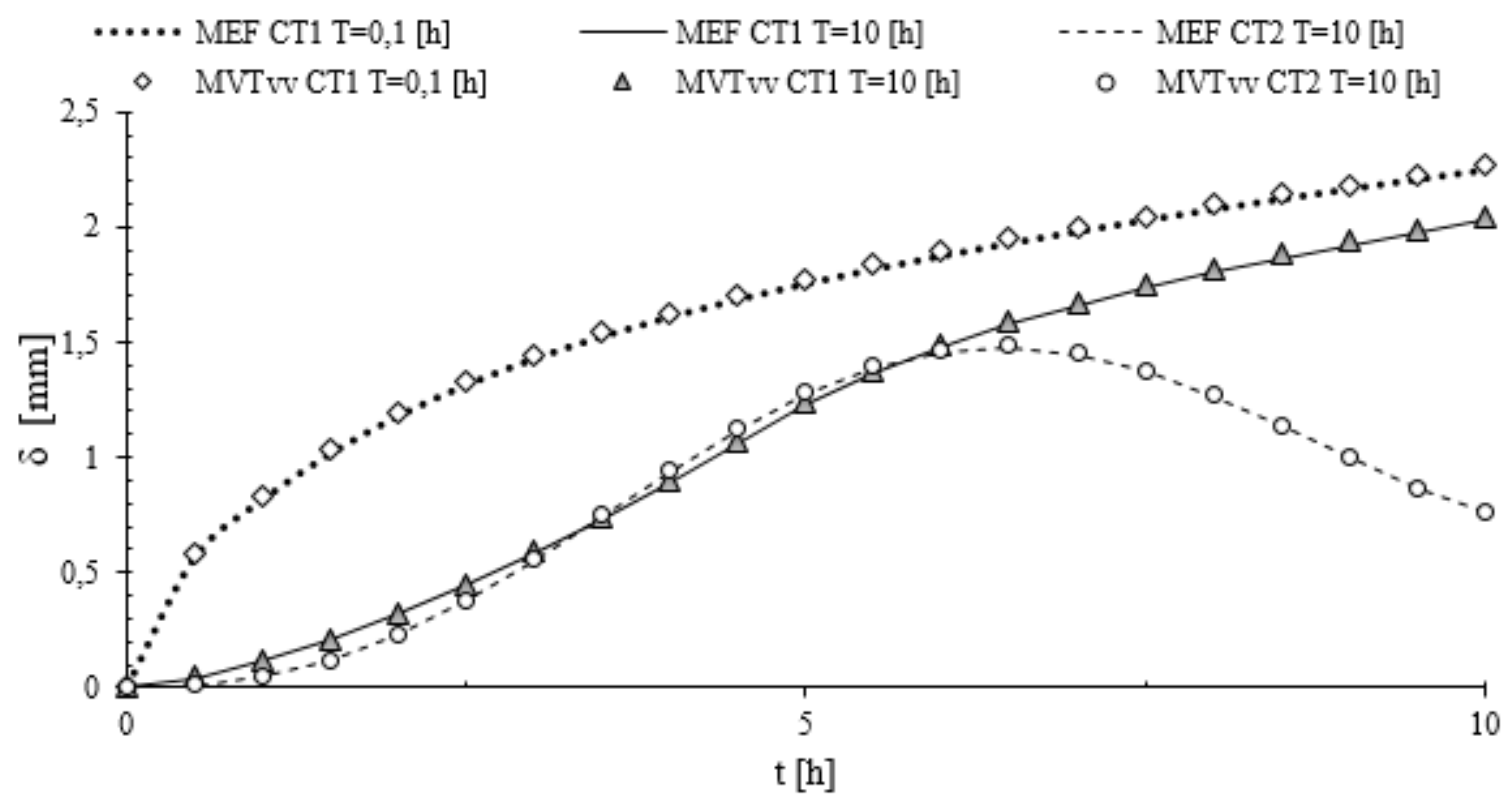

Figura 5.7 - Verificação das deflexões obtidas MVTvv Vs. MEF

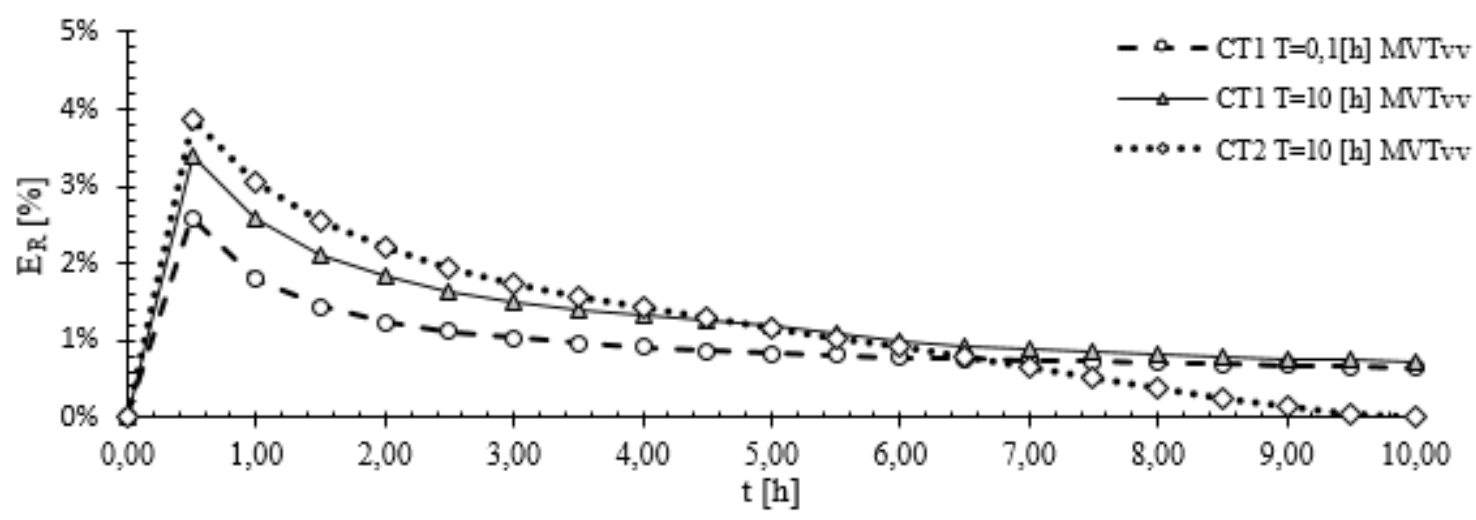

Figura 5.8 - Erro MVTvv Vs. MEF

As verificações realizadas ao algoritmo com um método amplamente validado e aceito, como o método dos elementos finitos obtendo um erro porcentual no superior ao $4 \%$ permite 
avaliar o algoritmo proposto como de alta confiabilidade, podendo assim ser utilizado na pesquisa do presente trabalho.

\subsection{3 - ANÁLISE DOS MODELOS MATEMÁTICOS CONSERANDO VARIAÇÃO DE PARÂMETROS}

\subsubsection{1 - Caso I: MVEB elástico linear}

O Caso I avalia o modelo elástico da viga de Euler-Bernoulli, ou seja, as deflexões no centro da viga considerando os deslocamentos da parcela de flexão unicamente, como se explica na Equação (5.3). A rigidez à flexão dada por EI é calculado segundo o desenvolvido na Equação (5.4) com os dados geométricos apresentados na Figura 5.1 e as propriedades dos materiais especificadas na Tabela 5.2.

$$
\begin{aligned}
& \delta\left(\frac{\mathrm{L}}{2}\right)_{\mathrm{C} 1}=\frac{\mathrm{PL}^{3}}{48 \mathrm{EI}}=\frac{(1000) 1^{3}}{48.71387,843} 1 \mathrm{e} 3 \\
& \delta\left(\frac{\mathrm{L}}{2}\right)_{\mathrm{C} 1}=0,291833[\mathrm{~mm}] \\
& \mathrm{EI}=2 \mathrm{E}_{\mathrm{s} 1}\left(\frac{\mathrm{b} \mathrm{t}_{1}{ }^{3}}{12}+\mathrm{b} \mathrm{t}_{1}\left(\frac{\mathrm{h}_{\mathrm{t}}}{2}-\frac{\mathrm{t}_{1}}{2}\right)^{2}\right)+2 \mathrm{E}_{\mathrm{v} 3}\left(\frac{\mathrm{b} \mathrm{h}_{3}{ }^{3}}{3}\right) \\
& \mathrm{EI}=2\left(70 \mathrm{E} 9\left(\frac{(0,2) 5 \mathrm{E}-4^{3}}{12}+(0,2) 5 \mathrm{E}-4^{3}(0,0257)^{2}\right)\right. \\
& \mathrm{EI}=71387,843\left[\mathrm{Nm}^{2}\right]
\end{aligned}
$$

Como o MVEB é um modelo elástico, os máximos deslocamentos obtidos na viga ao longo do tempo serão proporcionais ao aumento ou diminuição do carregamento, tendo como máximo o valor de $0,291833[\mathrm{~mm}]$ quando o carregamento atende o valor de $1000 \mathrm{~N}$. Doravante para avaliar a variável do tempo, este, será normalizado em função de cada período do carregamento imposto, segundo a Equação (5.5).

$$
\mathrm{t}_{\mathrm{N}}=\frac{\mathrm{t}_{\mathrm{i}}}{\mathrm{T}_{\mathrm{j}}}[\mathrm{h} / \mathrm{h}]
$$

A normalização do variável tempo permitirá que os resultados obtidos para cada os três tipos de carregamentos, dados para cada um dos quatro períodos considerados, seja comparável, e desta forma, avaliar a influência do período e do tipo de carregamento para cada caso de 
estudo proposto na Tabela 5.2. Assim, os deslocamentos no centro da viga para o CT1 apresentam-se na Figura 5.9 (a), do CT2 Figura 5.9 (b) e do CT3 na Figura 5.9 (c). Note-se na Figura 5.9 (a), que o deslocamento descreve exatamente a forma do carregamento tipo 1 para todos os períodos, o que é lógico tanto para o caso1 quanto para o MVT, isto devido a que são os dois casos em que são considerados os materiais em condições elásticas ao longo do tempo.

Na Figura 5.9 (c) a curva descreve o impulso sinusoidal imposto segundo a Figura 5.5, e os deslocamentos descrevem o impulso de rampa, voltando ao valor zero quando o carregamento é retirado depois do impulso no tempo $t=T$. Logicamente, para os casos que consideram a viscoelasticidade do material do núcleo, espera-se um incremento nas deflexões máximas e que a descrição das curvas correspondentes aos diferentes períodos não descreva a mesma tendência, diferente do atual caso de estudo MVEB.

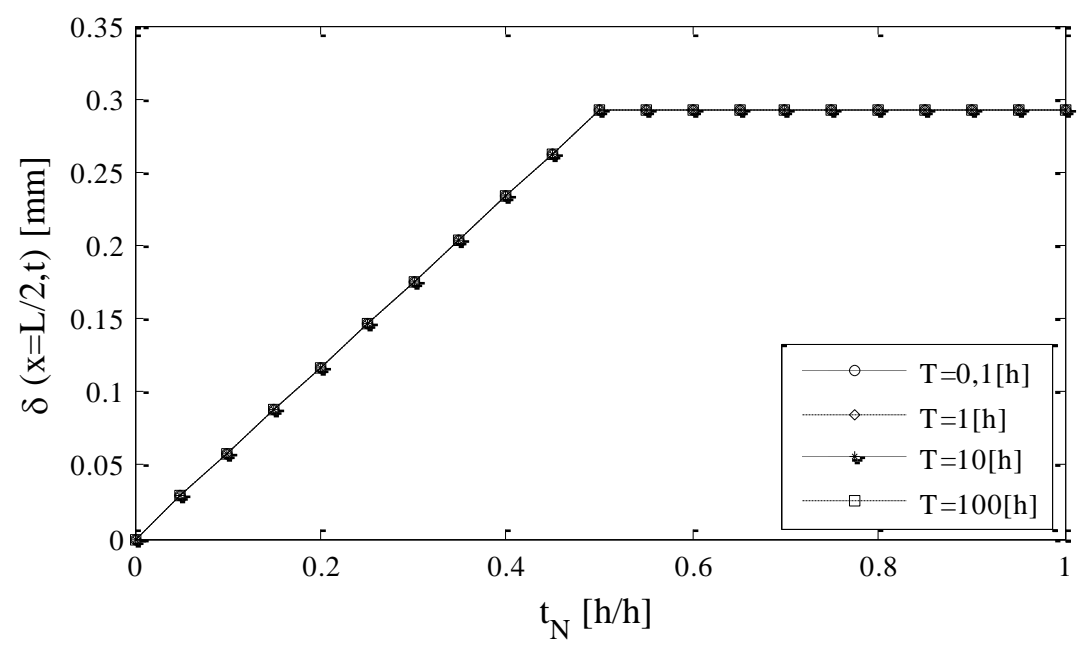

(a). $\delta(\mathrm{L} / 2, \mathrm{t})[\mathrm{mm}] \mathrm{MVEB} \mathrm{CT} 1$

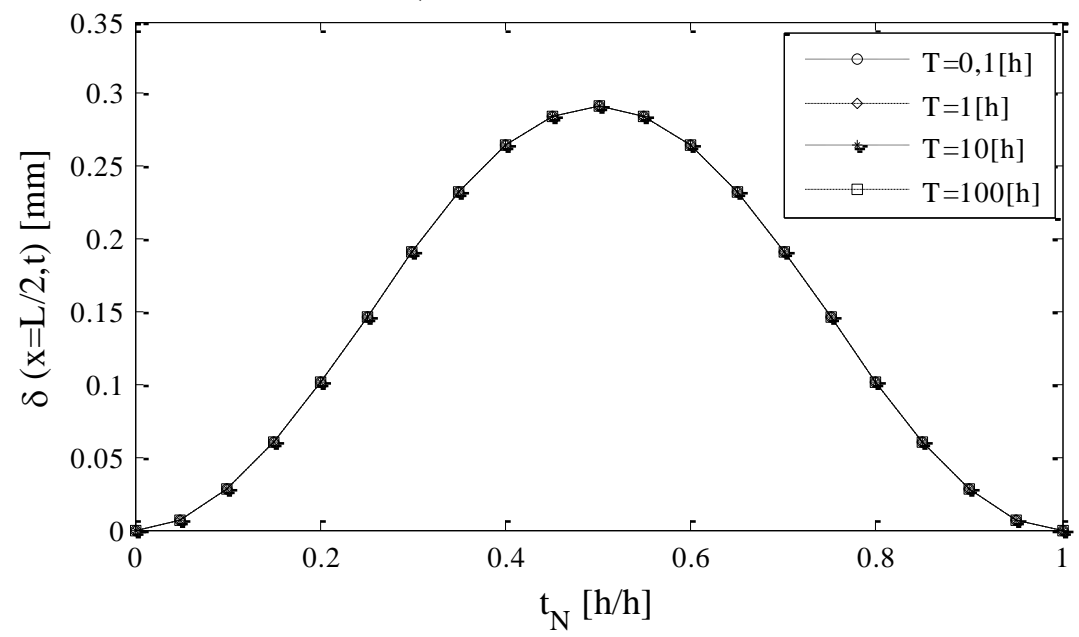

(b). $\delta(\mathrm{L} / 2, \mathrm{t})[\mathrm{mm}]$ MVEB CT2 


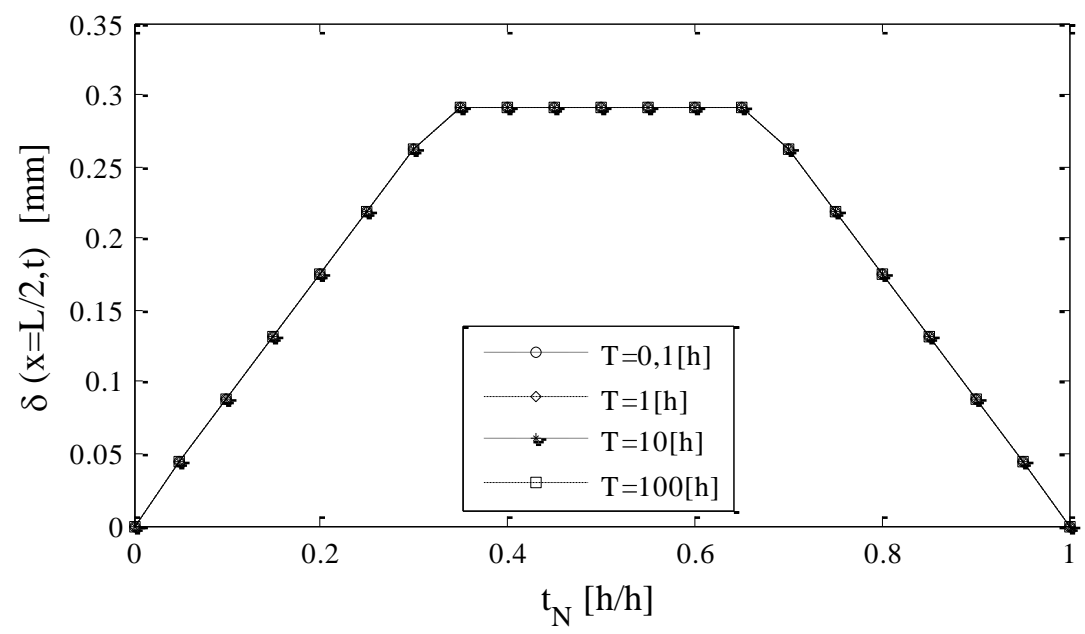

(c) $\delta(\mathrm{L} / 2, \mathrm{t})[\mathrm{mm}]$ MVEB CT3

Figura $5.9-\delta(\mathrm{L} / 2, \mathrm{t})[\mathrm{mm}] \mathrm{MVEB}$

\subsubsection{2 - Caso II: MVEB viscoelástico}

Para conseguir comparar os efeitos numéricos da consideração da viscoelasticidade num modelo originalmente elástico, realiza-se um estudo das condições elásticas para validar o modelo numérico e posteriormente poder extrapolar esta formulação das condições elásticas para as viscoelásticas, como corresponde aos casos 1 e 2, aplicado ao modelo matemático da viga de Euler Bernoulli.

Baseando-se em alguns testes preliminares realizados na presente pesquisa com outros materiais viscoelásticos no núcleo, o efeito do cisalhamento é de vital importância no estudo das vigas sanduíche em quanto menor seja a resistência do material do núcleo comparado com a resistência à flexão do material das peles externas.

Embora no PS não seja tão importante a parcela ao cisalhamento quanto para outros materiais, como por exemplo o PU, é preciso avaliar tanto os comportamento independente da parcela de flexão quanto o incremento das deflexões por efeito do cisalhamento, que combinadas outorgam nos resultados um erro inferior ao $5 \%$ como já foi verificado no numeral 5.1.2 - .

Para avaliar o MVEBv ou a influência da viscoelasticidade na parcela de flexão, considerase as condições exatas da rigidez à flexão para o MVEB, obtendo uma equação em função do módulo de relaxação do núcleo $\mathrm{E}_{\mathrm{C} 3}$. Obtendo a relação entre o módulo de elasticidade das camadas externas $\mathrm{E}_{\mathrm{s} 1}$ e o módulo de relaxação do material viscoelástico no tempo inicial 
$\mathrm{E}_{\mathrm{C} 3}(0)$, simplifica-se o modelo matemático e consequentemente o valor da inercia à flexão será o resultado das operações algébricas pertinentes e chamado de $\mathrm{I}_{\text {Mod }}$, calculado segundo a Equação (2.86). O resultado analítico dos deslocamentos está dado pela Equação (5.6)

$$
\begin{aligned}
& \delta\left(\frac{\mathrm{L}}{2}\right)_{\text {MVEBv }}=\frac{\mathrm{P}(\mathrm{t}) \mathrm{L}^{3}}{48 \mathrm{EI}}=\frac{\mathrm{P}(\mathrm{t}) \mathrm{L}^{3}}{48 \mathrm{E}_{\mathrm{C} 3,4}(\mathrm{t}) \mathrm{I}_{\mathrm{Mod}}} \\
& \delta\left(\frac{\mathrm{L}}{2}\right)_{\text {MVEBv }}=\frac{\mathrm{P}(\mathrm{t}) \cdot \mathrm{L}^{3}}{48 \mathrm{E}_{\mathrm{C} 3,4}(\mathrm{t}) \mathrm{I}_{\mathrm{Mod}}}
\end{aligned}
$$

Da relação elástica que descreve o deslocamento no centro da viga dada na Equação (5.6), procede-se a aplicar o PCEV para mudar das condições elásticas às viscoelásticas e obter a resposta ao longo do tempo para qualquer tipo de carregamento, como se descreve na Equação (5.7).

$$
\begin{aligned}
& \delta\left(\frac{\mathrm{L}}{2}, \mathrm{~s}\right)_{\mathrm{MVEBv}}=\frac{\mathrm{P}(\mathrm{s}) \mathrm{L}^{3}}{48 \mathrm{sE}_{\mathrm{C} 3}(\mathrm{~s}) \mathrm{I}_{\mathrm{Mod}}}=\frac{\mathrm{L}^{3} \mathrm{P}(\mathrm{s}) \mathrm{sD}(\mathrm{s})}{48 \mathrm{I}_{\mathrm{Mod}}}=\frac{\mathrm{L}^{3}(\mathrm{P}(\mathrm{s}) \mathrm{s} * \mathrm{D}(\mathrm{s}))}{48 \mathrm{I}_{\mathrm{Mod}}} \\
& \delta\left(\frac{\mathrm{L}}{2}, \mathrm{t}\right)_{\mathrm{MVEBv}}=\frac{\mathrm{L}^{3}}{48 \mathrm{I}_{\mathrm{Mod}}} \int_{0}^{\mathrm{t}} \mathrm{D}(\mathrm{t}-\tau) \frac{\mathrm{dP}(\tau)}{\mathrm{d} \tau} \mathrm{d} \tau
\end{aligned}
$$

Dada a Equação (5.7) e aplicando o algoritmo incremental, obterem-se os resultados dos deslocamentos no centro da viga ao longo do tempo sendo avaliados desde $t_{N}=0$ até $t_{N}=$ 1, avaliando cada um dos períodos $\mathrm{T}$ para cada tipo de carregamento, sendo discriminados na Figura 5.10 (a) as deflexões máximas obtidas pelo carregamento do tipo 1, na Figura 5.10 (b) as deflexões devidas ao carregamento tipo 2 e as correspondentes ao carregamento tipo 3 na Figura 5.10 (c).

Os resultados da Figura 5.10 (a) permitem visualizar que entre maior é o tempo de permanência do carregamento maiores são também as deflexões, aumentam ao longo do tempo sem incrementar a magnitude do carregamento, e depois do tempo $t_{N}=1 / 2 \mathrm{com}$ a mesma magnitude do carregamento os deslocamentos continuam aumentando.

As curvas das deflexões apresentam uma mudança na concavidade passando de côncava a convexa depois do $t_{N}=1 / 2$, e no tempo $t_{N}=1$ a máxima deflexão aumenta na medida que aumentam os períodos de aplicação do carregamento. 


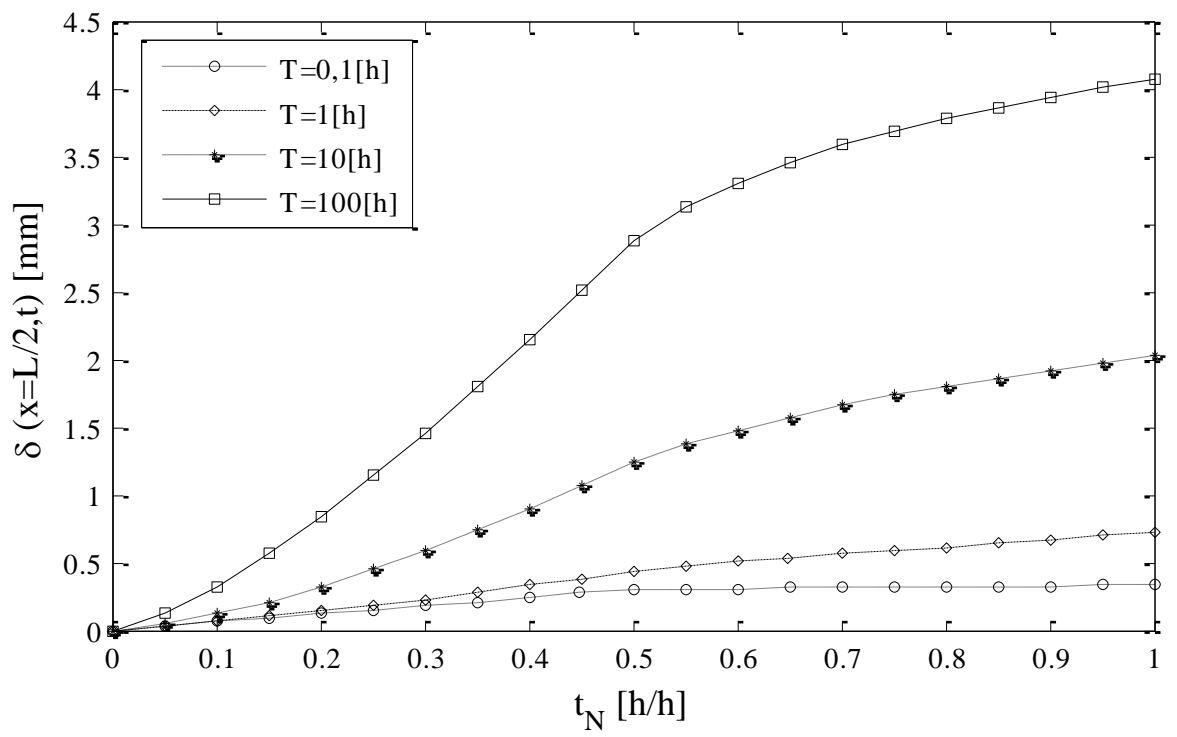

(a) $\delta(\mathrm{L} / 2, \mathrm{t})[\mathrm{mm}] \mathrm{MVEBv} \mathrm{CT} 1$

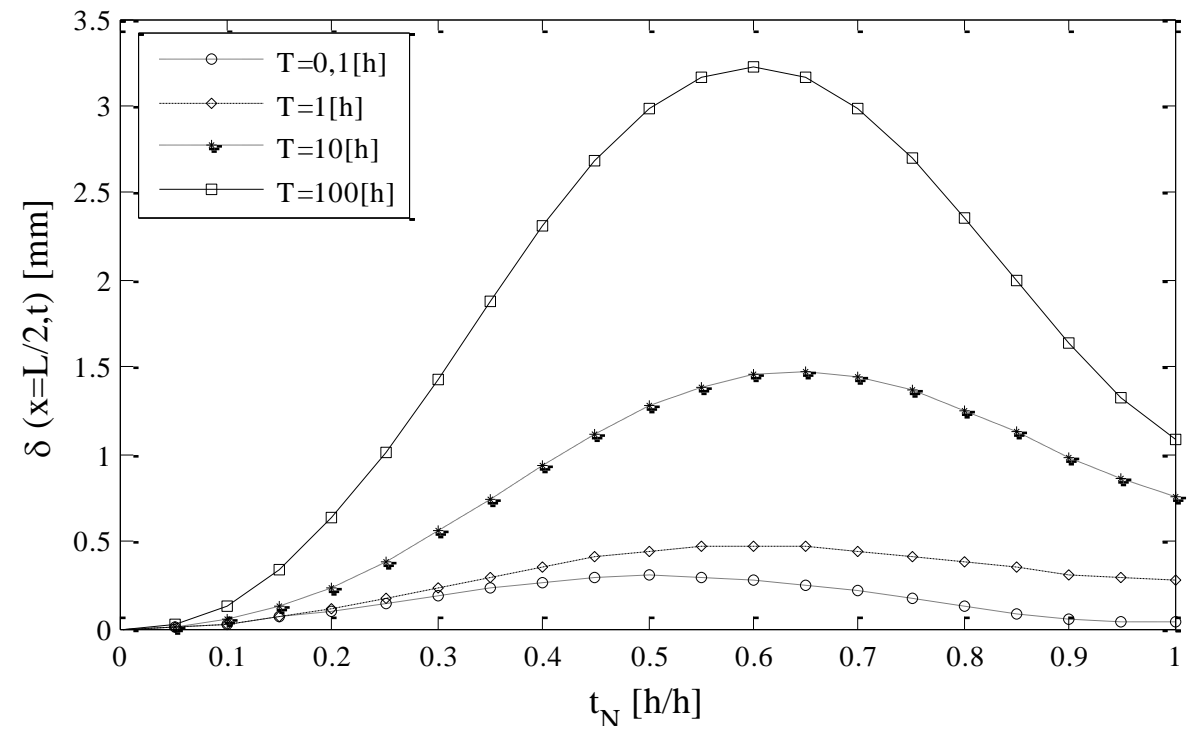

(b) $\delta(\mathrm{L} / 2, \mathrm{t})[\mathrm{mm}] \mathrm{MVEBv} \mathrm{CT} 2$

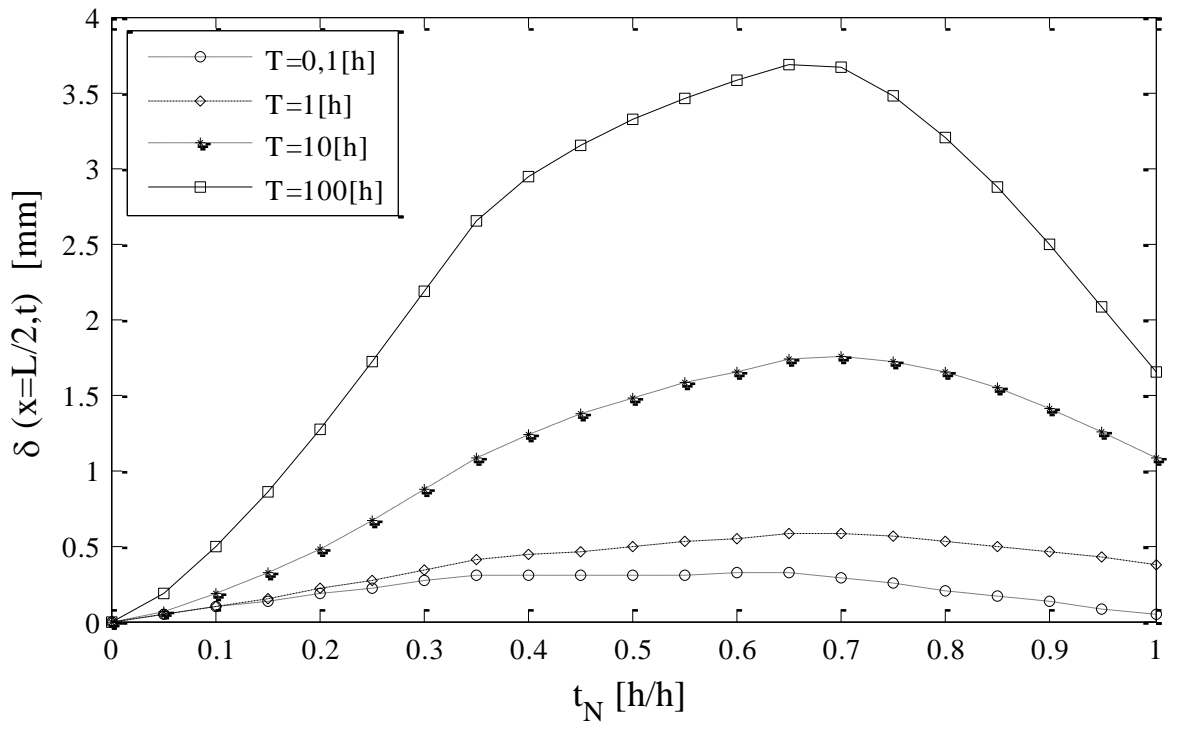

(c). $\delta(\mathrm{L} / 2, \mathrm{t})[\mathrm{mm}] \mathrm{MVEBv}$ CT3

Figura $5.10-\delta(\mathrm{L} / 2, \mathrm{t})[\mathrm{mm}] \mathrm{MVEBv}$ 
No caso das deflexões máximas obtidas devido ao carregamento tipo 2 apresentadas na Figura 5.10 (b), o aumento na magnitude dessas são proporcionais ao aumento do período de permanência do impulso sinusoidal. Esses deslocamentos centrais são inferiores aos obtidos para o carregamento do tipo 1 comparando período a período, sendo interessante que o tempo onde é máximo dos deslocamentos não coincide com o tempo onde é aplicado o máximo carregamento $t_{N}=1 / 2$, variando para cada um dos períodos dos impulsos aplicados na estrutura.

As deflexões devidas ao impulso de rampa, aumentam em função do aumento do período avaliado de forma similar aos resultados obtidos pela aplicação do impulso sinusoidal, sim embargo, a magnitude dos máximos valores são menores que as obtidas no mesmo período para o carregamento tipo rampa e superiores os obtidos com o impulso sinusoidal, isto devido à permanência do carregamento no tercio central, onde as mudanças nas três etapas do impulso de rampa não coincidem os tempos dos pontos de inflexão da curva do carregamento com os deslocamentos produzidos por este num período dado.

\subsubsection{3 - Caso III: MVT elástico}

O MVT considera o modelo de viga de Timoshenko em condições elásticas, avaliando as condições geométricas da Figura 5.1 e as propriedades dos materiais correspondentes apresentadas na Tabela 5.2. Esse modelo para uma viga simplesmente apoiada determina que as deflexões máximas são dadas pela Equação (5.4) substituída na Equação (5.8).

$$
\begin{aligned}
& \delta\left(\frac{\mathrm{L}}{2}\right)_{\mathrm{MVT}}=\frac{\mathrm{PL}^{3}}{48 \mathrm{EI}}+\frac{\mathrm{PL}}{4 \mathrm{kA}_{\mathrm{C} 3,4} \mathrm{G}_{\mathrm{C} 3,4}} \\
& \delta\left(\frac{\mathrm{L}}{2}\right)_{\mathrm{MVT}}=\left(\frac{(1000) 1^{3}}{48(71387,843)}+\frac{(1000) 1}{4 \frac{5}{6}((0,2) 0,0513) 10706,66 \mathrm{E} 6}\right) 1 \mathrm{E} 3 \\
& \delta\left(\frac{\mathrm{L}}{2}\right)_{\mathrm{MVT}}=0,294593[\mathrm{~mm}]
\end{aligned}
$$

A Equação (5.8) determina o máximo valor elástico do deslocamento no centro da viga na consideração do modelo de viga de Timoshenko, onde são consideradas nas deflexões tanto o aporte pela flexão quanto o aporte dado pela parcela ao cisalhamento. Do anterior, analogamente ao MVEB, os deslocamentos descreveram para cada tipo de carregamento uma única linha da forma do carregamento, apresentando os resultados para o CT1 na Figura 5.11 (a), para o CT2 na Figura 5.11 (b) e para o CT3 na Figura 5.11 (c). 


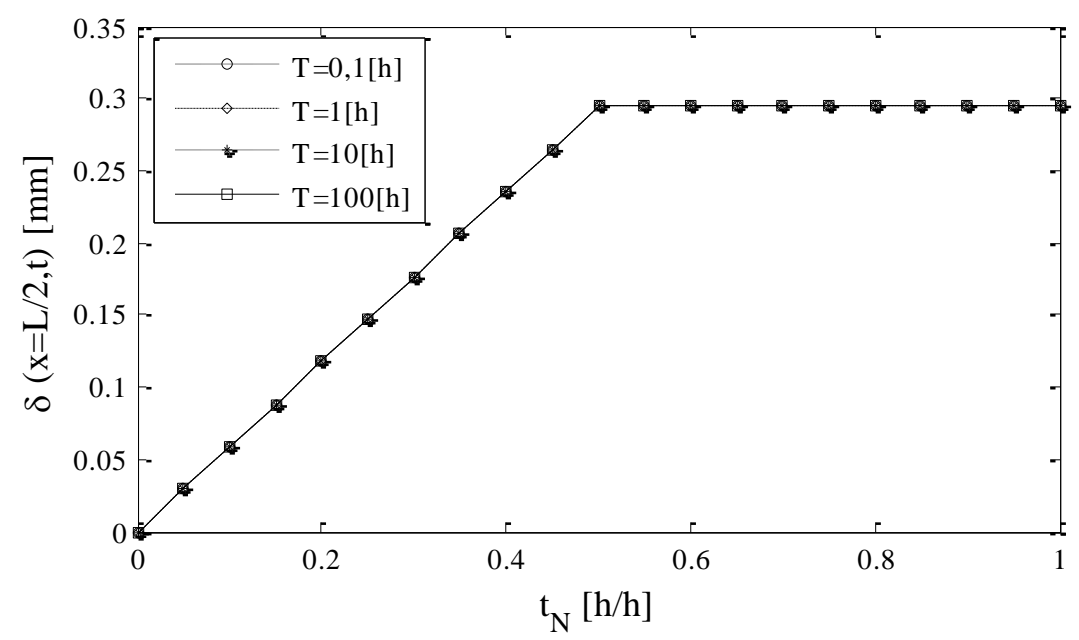

(a) $\delta(\mathrm{L} / 2, \mathrm{t})[\mathrm{mm}] \mathrm{MVT}$ CT1

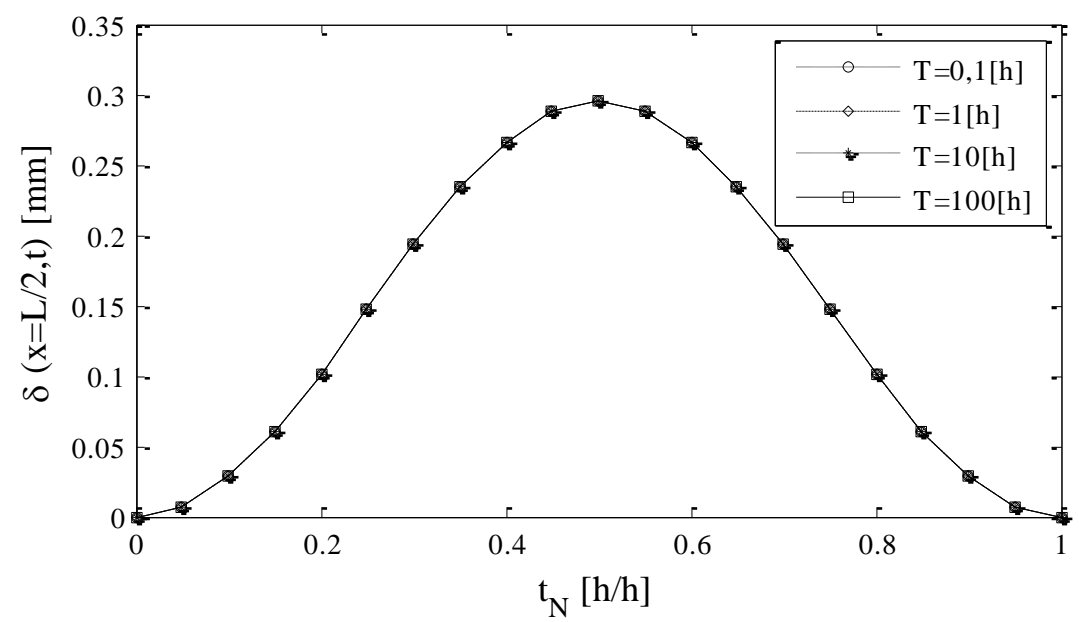

(b) $\delta(\mathrm{L} / 2, \mathrm{t})[\mathrm{mm}] \mathrm{MVT}$ CT2

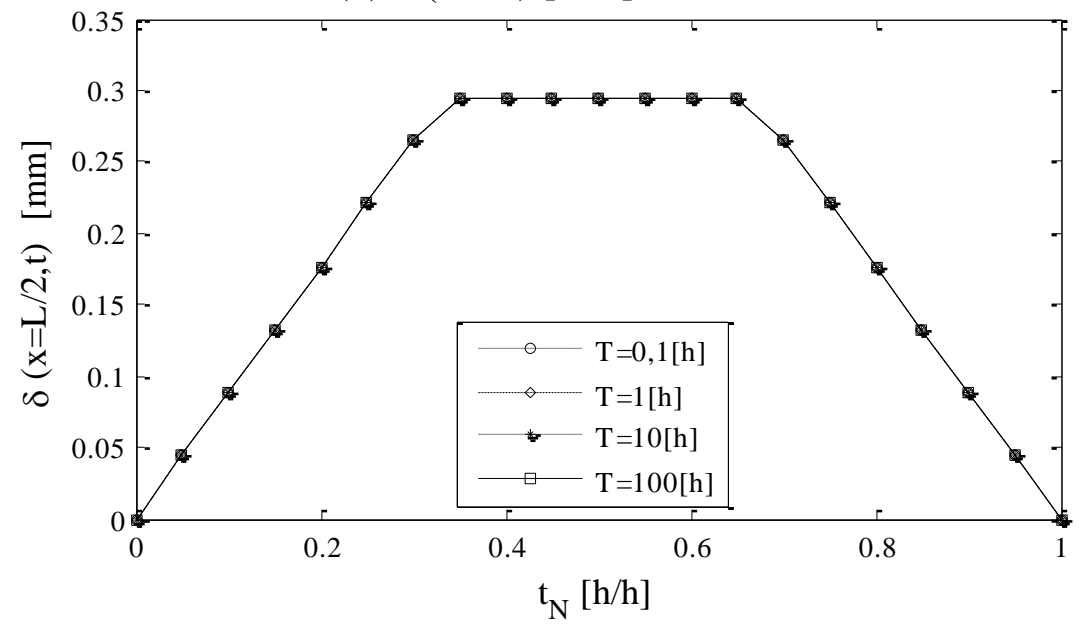

(c) $\delta(\mathrm{L} / 2, \mathrm{t})[\mathrm{mm}] \mathrm{MVT}$ CT3

Figura $5.11-\delta(\mathrm{L} / 2, \mathrm{t})[\mathrm{mm}] \mathrm{MVT}$

No caso dos carregamentos impulsivos tipo 1 e 2, apresentados correspondentemente nas Figura 5.11 (a) e Figura 5.11(b), o máximo valor do deslocamento no centro da viga dado pela Equação (5.8) é obtido em cada impulso nos tempos onde o carregamento é máximo, ou seja, $P(t)=1000 \mathrm{~N}$. 


\subsubsection{4 - Caso IV: MVT flexão elástica e cisalhamento viscoelástico}

O MVTev baseia-se nos princípios apresentados na revisão realizada no Capítulo 2, item 2.2.3 - , onde o primeiro passo para o estudo da estrutura proposta na Figura 5.1 é classificala segundo suas relações geométricas.

$$
\mathrm{b}=200[\mathrm{~mm}]>\mathrm{h}_{\mathrm{C} 3,4}=50,8[\mathrm{~mm}] \mathbf{O K}
$$

Segundo a comparação feita na Equação (5.9), a base é maior do que a altura e consequentemente a viga considera-se como larga. No caso de estudo, as camadas elásticas externas são iguais em espessura e material, por esse motivo deve se realizar a medição de magnitude do módulo de elasticidade do núcleo comparado com o módulo das camadas externas, e assim medir adequadamente sua influência na flexão.

$$
4 \frac{\mathrm{E}_{\mathrm{s} 1}}{\mathrm{E}_{\mathrm{c} 1}} \frac{\mathrm{t}_{1}}{\mathrm{~h}_{\mathrm{C} 3,4}} \frac{\mathrm{d}}{\mathrm{h}_{\mathrm{C} 3,4}}=4 \frac{70000}{28479,714} \frac{0,5}{50,8} \frac{51,3}{50,8}=0,0977>\mathbf{1 0 0} \mathbf{N} \tilde{\mathbf{O}} \mathbf{0 K}
$$

A incidência das camadas externas na resistência a flexão não é desprezível como pode-se constatar na Equação (5.10). Além desse teste, devem constatar-se as Equações (5.11) e (5.12), sendo que a magnitude do núcleo é muito maior do que a espessura das camadas externas, assim, avalia-se se a rigidez à flexão poderia ou não ser desprezada.

$$
\begin{aligned}
& \frac{d}{t_{1}}=\frac{51,3}{0,5}=102,60>5,77 \text { OK } \\
& \frac{E_{s 1}}{E_{c 1}} \frac{t_{1} \cdot d^{2}}{h_{C 3,4}{ }^{3}}=\frac{70000}{28479,714} \frac{0,5 \cdot 51,3^{2}}{50,8^{3}}=0,02467>\mathbf{1 6}, 7 \text { NÃO OK }
\end{aligned}
$$

Os resultados nas três avaliações anteriores, permitem assegurar que a simplificação da rigidez à flexão da viga deixando-a em função unicamente do módulo de elasticidade elástico das camadas exteriores, proposto na literatura como geral para as vigas sanduíche, não representa as condições da viga de estudo.

No entanto, o MVTev será estudado para demostrar que dependendo do tipo de material a ser colocado na viga sanduíche, dadas simplificações não aportam deslocamentos máximos corretos nos estudos da influência da viscoelasticidade. A relação da rigidez a flexão equivalente $(\mathrm{EI})_{e q}$ calcula-se segundo a Equação (5.13). 


$$
\begin{aligned}
& (E I)_{\mathrm{eq}}=\mathrm{E}_{\mathrm{s} 1} \frac{\mathrm{bt}_{1} \mathrm{~d}^{2}}{2}=70000 \mathrm{e} 6 \frac{(0,2)(0,0005) 0,0513^{2}}{2} \\
& (\mathrm{EI})_{\mathrm{eq}}=9210,915\left[\mathrm{~N} \cdot \mathrm{m}^{2}\right]
\end{aligned}
$$

Uma vez calculado o $(\mathrm{EI})_{e q}$ procede-se a obter a forma analítica das deflexões máximas na viga sanduíche com as condições propostas na literatura, nomeadas no presente estudo de MVTev e modelado matematicamente segundo a Equação (5.14).

$$
\begin{aligned}
& \delta\left(\frac{\mathrm{L}}{2}\right)_{\mathrm{MVTev}}=\frac{\mathrm{PL}^{3}}{48(\mathrm{EI})_{\mathrm{eq}}}+\frac{\mathrm{PL}}{4 \kappa \mathrm{A}_{\mathrm{C} 3-4} \mathrm{G}_{\mathrm{C} 3-4}(\mathrm{t})} \\
& \delta\left(\frac{\mathrm{L}}{2}, \mathrm{~s}\right)_{\mathrm{MVTev}}=\frac{\mathrm{P}(\mathrm{s}) \mathrm{L}^{3}}{48(\mathrm{EI})_{\mathrm{eq}}}+\frac{\mathrm{P}(\mathrm{s}) \mathrm{L}}{4 \mathrm{ksG}_{\mathrm{MVT}-4}(\mathrm{~s})} \\
& \delta\left(\frac{\mathrm{L}}{2}, \mathrm{t}\right)_{\text {MVTev }}=\frac{\mathrm{P}(\mathrm{t}) \mathrm{L}^{3}}{48(\mathrm{EI})_{\mathrm{eq}}}+\frac{\mathrm{L}}{4 \kappa \mathrm{A}_{\mathrm{C} 3,4}} \int_{0}^{\mathrm{t}} \mathrm{J}(\mathrm{t}-\tau) \frac{\mathrm{dP}(\tau)}{\mathrm{d} \tau} \mathrm{d} \tau
\end{aligned}
$$

Aplicando o algoritmo incremental podem-se obter os deslocamentos no centro da viga sanduíche de estudo, dado pela consideração elástica da parcela de flexão e viscoelástica na parcela ao cisalhamento.

Os resultados obtidos aplicando o carregamento tipo 1 apresentam-se na Figura 5.12 (a), para o carregamento tipo 2 ou impulso sinusoidal na Figura 5.12 (b) e para o carregamento tipo 3 ou impulso de rampa na Figura 5.12 (c). Pode-se observar na Figura 5.12 (a), que o aumento dos deslocamentos por efeito somente da parcela de cisalhamento e com a flexão dependente unicamente do módulo de elasticidade das peles elásticas o aumento nas deflexões é quase elástico mas, com uma magnitude maior.

De forma análoga ao aumento dos deslocamentos quase elástico na forma e de maior magnitude dado no carregamento do tipo 1, acontece com os carregamentos impulsivos, cujos resultados apresentam-se na Figura 5.12 (b) e na Figura 5.12 (c), e a diferença nos deslocamentos para os diferentes períodos de aplicação do carregamento é quase que igual, apresentando um incremento um pouco mais notório no máximo período $\mathrm{T}=100 \mathrm{~h}$ em todos os carregamentos. 


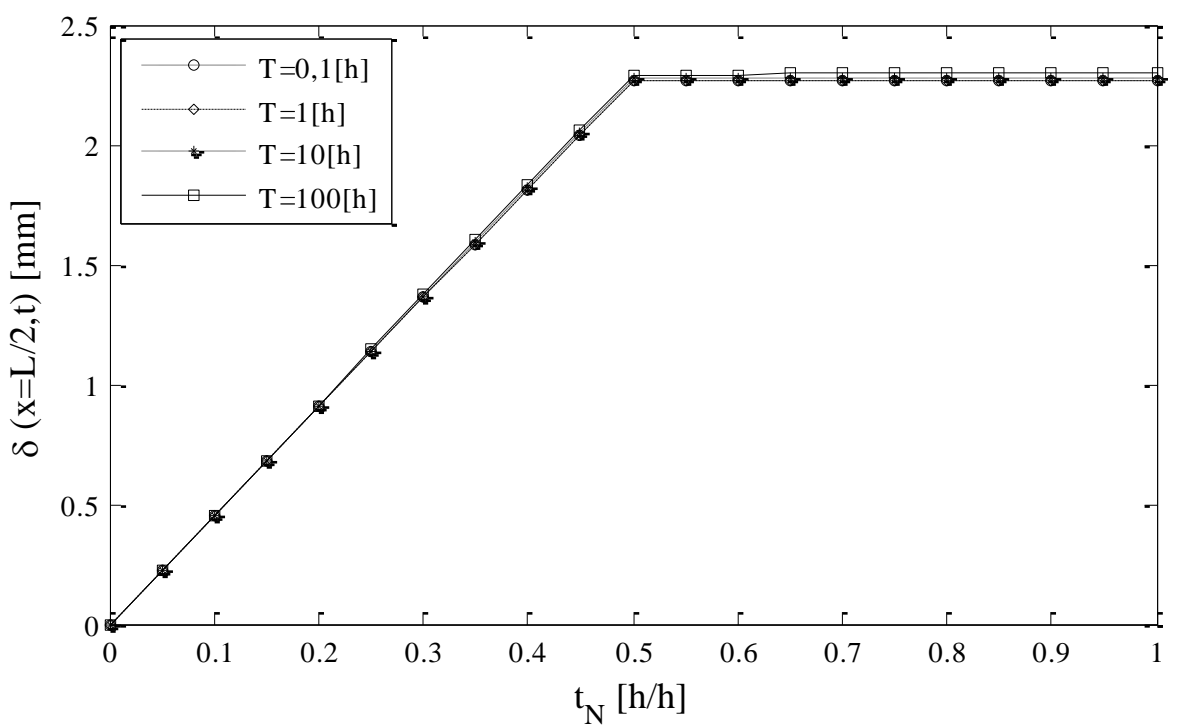

(a) $\delta(\mathrm{L} / 2, \mathrm{t})[\mathrm{mm}]$ MVTev CT1

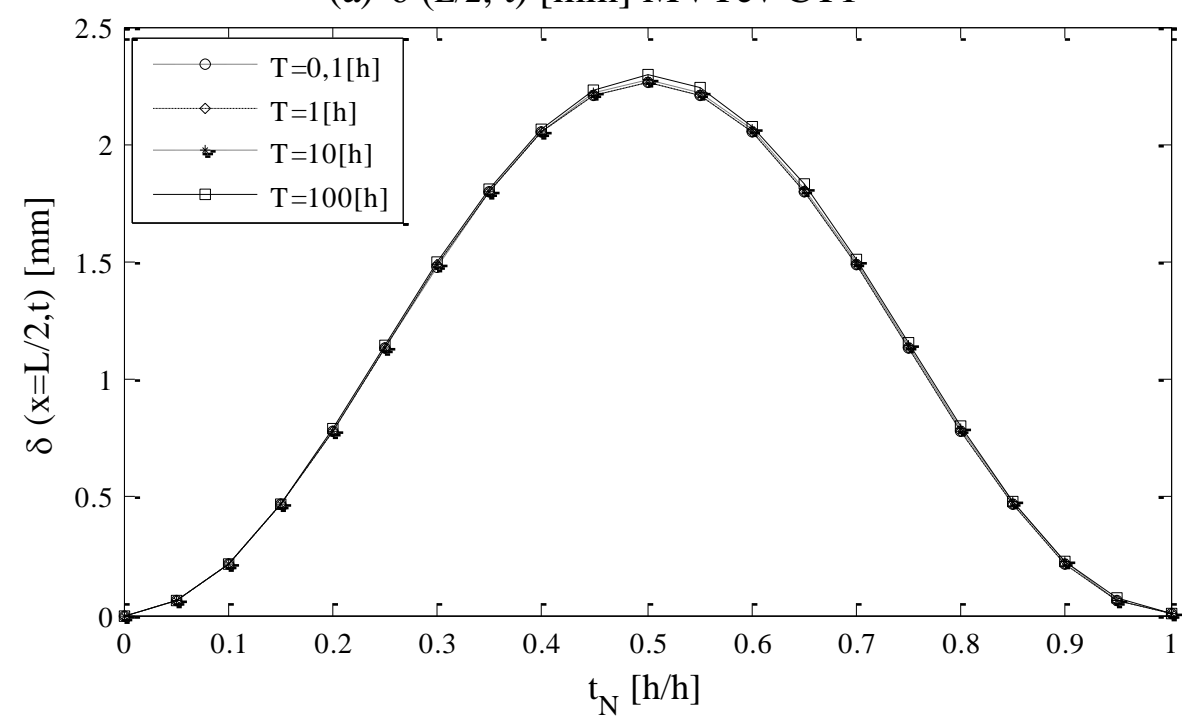

(b) $\delta(\mathrm{L} / 2, \mathrm{t})[\mathrm{mm}]$ MVTev CT2

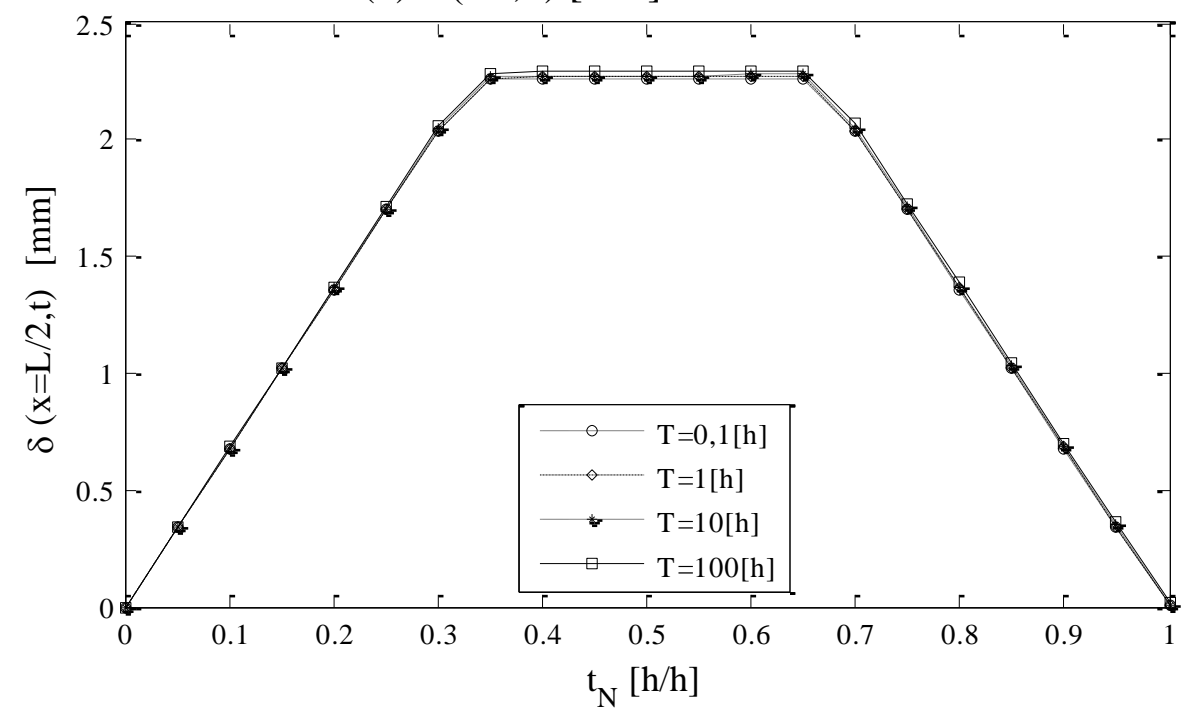

(c) $\delta(\mathrm{L} / 2, \mathrm{t})[\mathrm{mm}] \mathrm{MVTev}$ CT3

Figura $5.12-\delta(\mathrm{L} / 2, \mathrm{t})[\mathrm{mm}] \mathrm{MVTev}$ 


\subsubsection{5 - Caso V: MVT viscoelástico $\alpha=1$}

O MVTvv ou modelo de viga de Timoshenko considerando as parcelas de flexão e cisalhamento viscoelásticas, pretende medir quantitativamente o quanto influi nas deflexões da viga de estudo a consideração aproximada da rigidez flexional do MVTev comparada com a consideração exata da mesma. Assim, o MVTvv será representado analiticamente pela Equação (5.15).

$$
\begin{aligned}
& \delta\left(\frac{L}{2}\right)_{\mathrm{MVTvv}}=\frac{P L^{3}}{48 I_{M o d} E_{C 3,4}(t)}+\frac{P L}{4 \kappa A_{C 3,4} G_{C 3,4}(t)} \\
& \delta\left(\frac{L}{2}, s\right)_{M V T v v}=\frac{P(s) \cdot L^{3}}{48 I_{M o d} s E_{C 3,4}(s)}+\frac{P(\mathrm{~s}) \mathrm{L}}{4 \kappa s \mathrm{G}_{\mathrm{C} 3,4}(s)} \\
& \delta\left(\frac{L}{2}, t\right)_{M V T v v}=\frac{L^{3}}{48 I_{M o d}} \int_{0}^{t} D(t-\tau) \frac{d P(\tau)}{d \tau} d \tau+\frac{\mathrm{L}}{4 \kappa \mathrm{A}_{\mathrm{C} 3,4}} \int_{0}^{\mathrm{t}} \mathrm{J}(\mathrm{t}-\tau) \frac{\mathrm{dP}(\tau)}{\mathrm{d} \tau} \mathrm{d} \tau
\end{aligned}
$$

Aplicando sobre a Equação (5.15) o algoritmo incremental obtém-se os deslocamentos no centro da viga considerando tanto na flexão quanto no cortante a viscoelasticidade do material do núcleo, obtendo um significativo aumento nos deslocamentos centrais.

As deflexões viscoelásticas da viga de estudo quando experimenta o carregamento do tipo 1 consignam-se na Figura 5.13 (a), onde fica evidente que a consideração da viscoelasticidade do núcleo aumentam em mais de dez vezes os deslocamentos obtidos no MVT em condições elásticas e para o material utilizado no núcleo, a incidência do cisalhamento não resulta em mudanças superiores ao 5\% dos deslocamentos obtidos considerando viscoelasticidade somente na parcela de flexão, segundo o estudado no MVEBv.

Os resultados obtidos para os carregamentos 1, 2 e 3 apresentam um comportamento similar ao observado no MVEBv, mas com um pequeno aumento nas deflexões, inferior ao $5 \% \mathrm{em}$ cada um dos períodos correspondentes, isto devido à influência do cisalhamento no comportamento mecânico total. Nóte-se que no caso dos carregamentos impulsivos, ao considerar a viscoelasticidade mesmo uma vez e retirado o carreamento os deslocamentos não desaparecem com a ausência do carregamento no tempo $t_{N}=1$, assim como também não obtém o pico de deslocamento máximo no tempo $\mathrm{t}_{\mathrm{N}}=1 / 2$. 


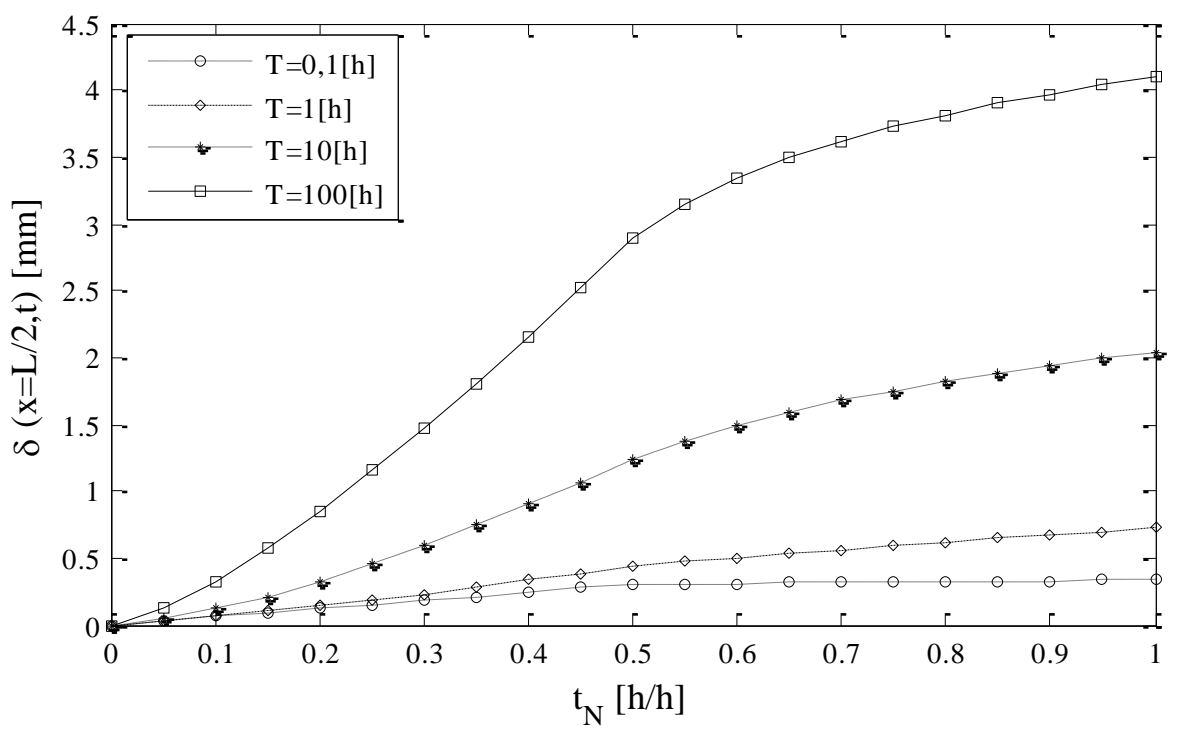

(a) $\delta(\mathrm{L} / 2, \mathrm{t})[\mathrm{mm}]$ MVTvv CT1

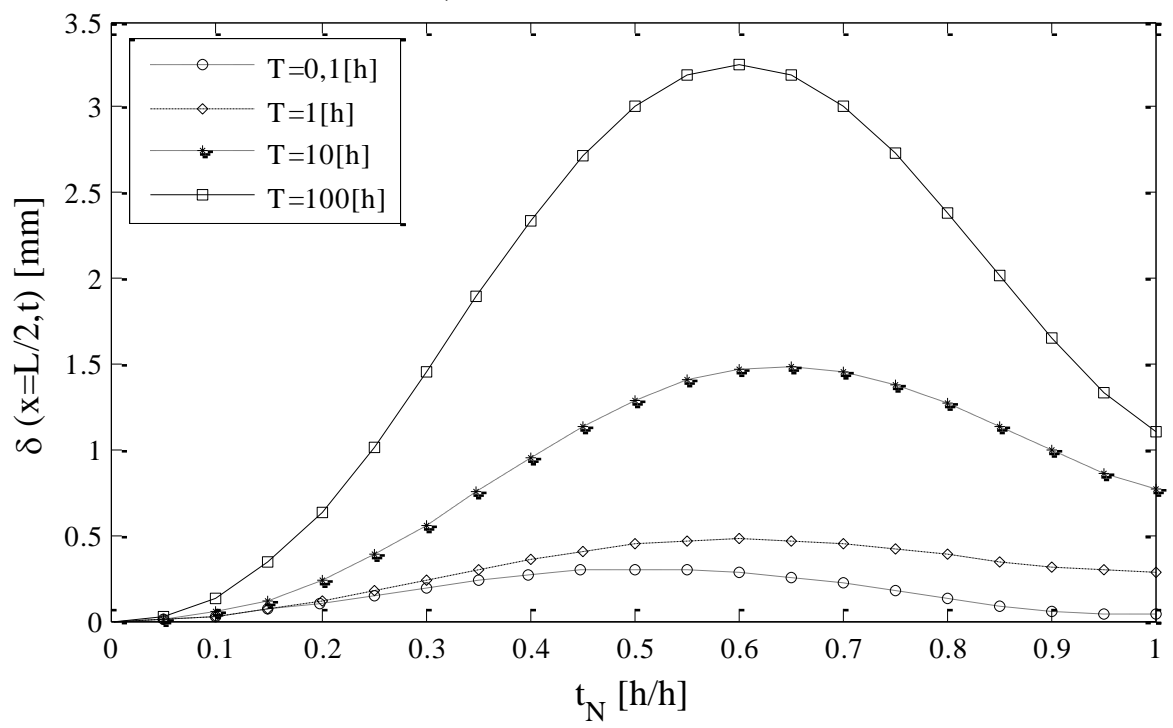

(b) $\delta(\mathrm{L} / 2, \mathrm{t})[\mathrm{mm}] \mathrm{MVTvv}$ CT2

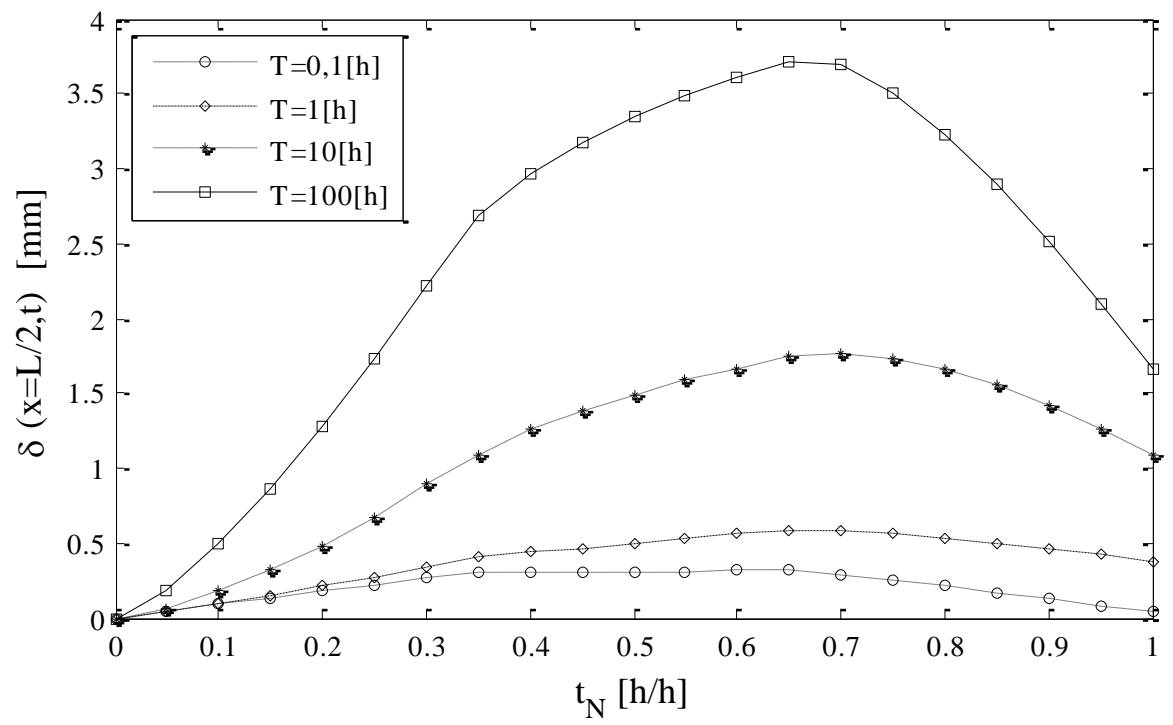

(c) $\delta(\mathrm{L} / 2, \mathrm{t})[\mathrm{mm}] \mathrm{MVTvv}$ CT3

Figura $5.13-\delta(\mathrm{L} / 2, \mathrm{t})[\mathrm{mm}] \mathrm{MVTvv}$ 
Os deslocamentos obtidos pelo carregamento tipo 3, consignados na Figura 5.13 (c), são superiores que os obtidos pelo impulso sinusoidal do mesmo período de aplicação T, isso devido à permanência do carregamento máximo no tercio central do período.

\subsubsection{6 - Caso VI: MVT viscoelástico $\boldsymbol{\alpha}=\mathbf{0 , 7 5}$}

O MVTvv2 consiste numa modificação da rigidez da metade inferior do núcleo, considerando um $75 \%$ da rigidez da espuma de poliestireno. Essa diminuição da rigidez altera o modelo pois o valor do $I_{M o d}$ é reavaliado conforme o material inferior do núcleo for menor rígido, enquanto menos rígido for mais desloca o eixo neutro da viga para cima do centroide, cujo algoritmo é anexado no numeral C.7. Assim, e baixo essas considerações as deflexões máximas dadas no $\mathrm{MVTvv}_{2}$ estarão regidas pela Equação (5.16).

$$
\delta\left(\frac{L}{2}, t\right)_{M V T v v 2}=\frac{L^{3}}{48 I_{M o d}} \int_{0}^{t} D(t-\tau) \frac{d P(\tau)}{d \tau} d \tau+\frac{\mathrm{L}}{4 \kappa \mathrm{A}_{\mathrm{C} 3,4}} \int_{0}^{\mathrm{t}} \mathrm{J}(\mathrm{t}-\tau) \frac{\mathrm{dP}(\tau)}{\mathrm{d} \tau} \mathrm{d} \tau
$$

Baseados nos princípios da resistência dos materiais, espera-se que quanto menos rígido seja o material da metade inferior da viga sanduíche maiores serão os deslocamentos no centro da viga por efeito dos carregamentos. Na Figura 5.14 (a) apresenta-se a análise de deflexões para os carregamento do tipo 1 ou de rampa, obtendo para a diminuição da rigidez do $25 \%$ um aumento nas deflexões de aproximadamente $12 \%$, o que permite concluir que a diminuição da rigidez e o aumento das deflexões máximas não guarda uma relação inversamente proporcional, como é de se esperar com os materiais elásticos.

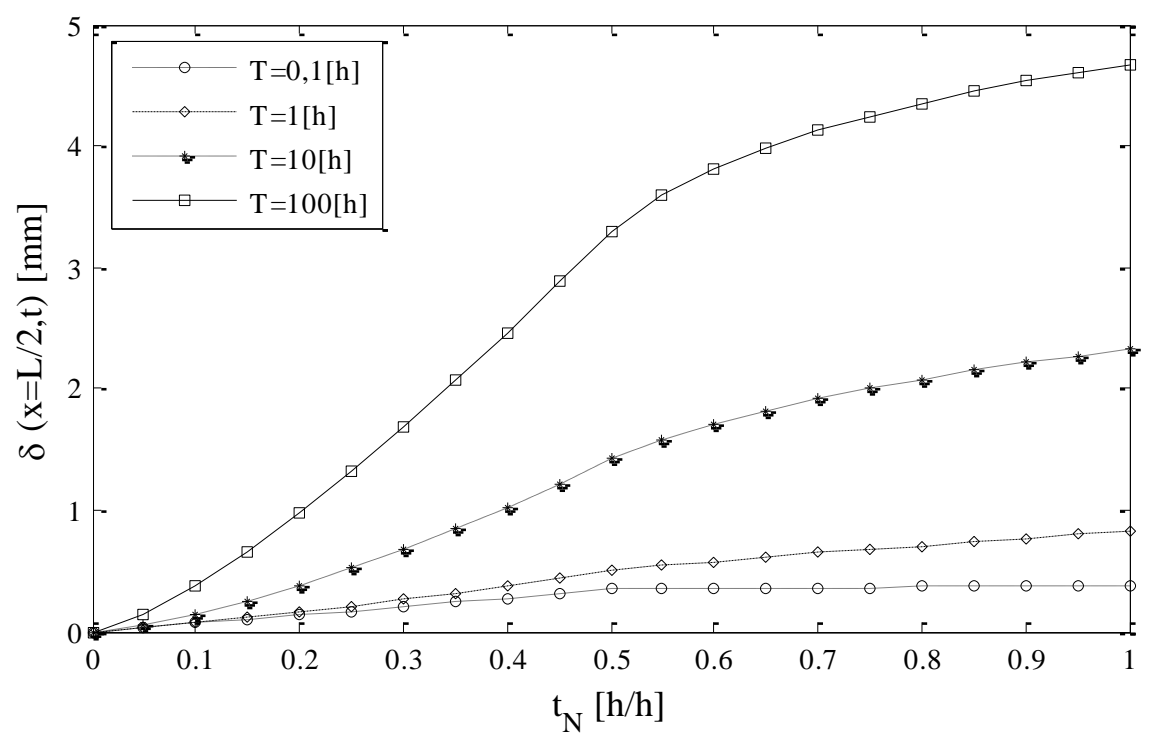

(a) $\delta(\mathrm{L} / 2, \mathrm{t})[\mathrm{mm}] \mathrm{MVTVv}_{2} \mathrm{CT} 1 \alpha=0,75$ 


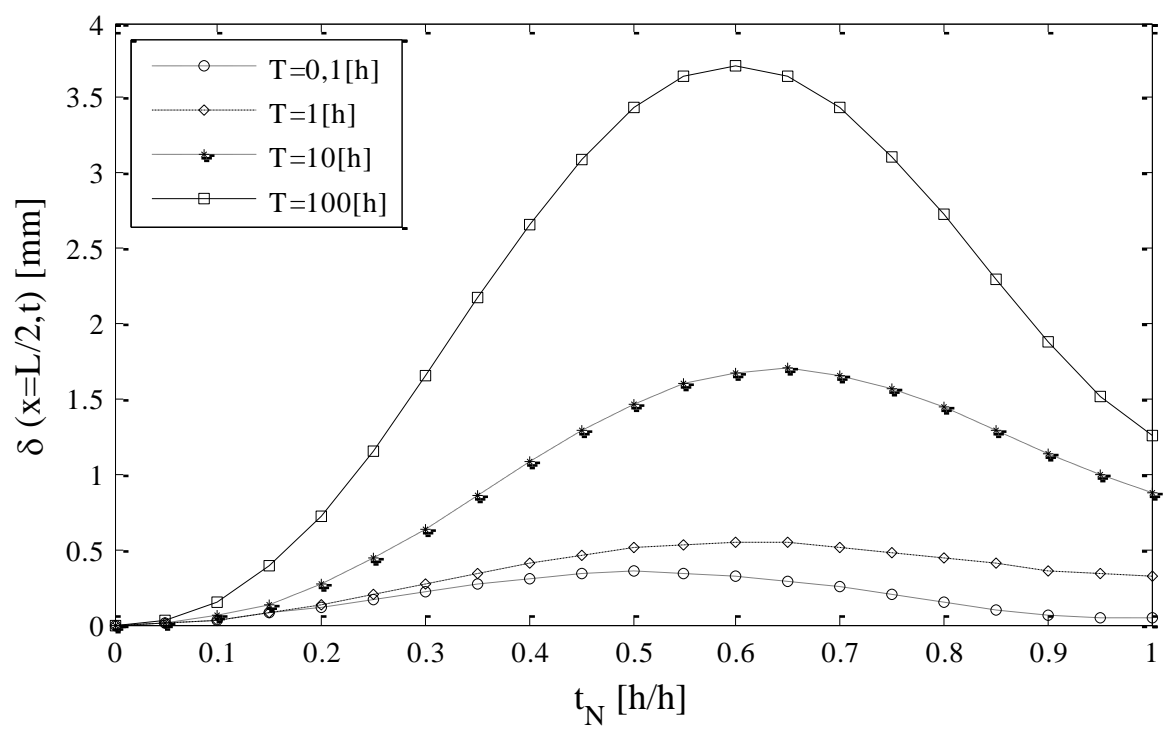

(b) $\delta(\mathrm{L} / 2, \mathrm{t})[\mathrm{mm}] \mathrm{MVTvv}_{2} \mathrm{CT} 2 \alpha=0,75$

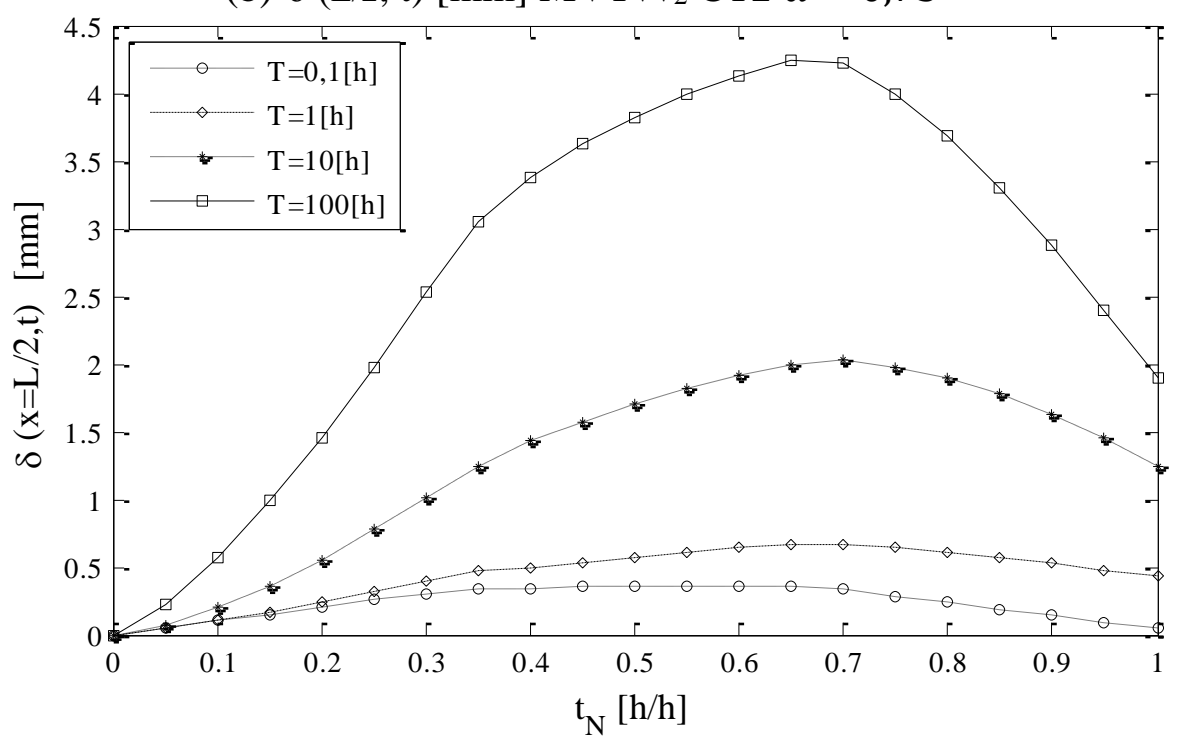

(c) $\delta(\mathrm{L} / 2, \mathrm{t})[\mathrm{mm}] \mathrm{MVTvv}_{2} \mathrm{CT} 3 \alpha=0,75$

Figura $5.14-\delta(\mathrm{L} / 2, \mathrm{t})[\mathrm{mm}] \mathrm{MVTvv}_{2} \alpha=0,75$

No caso do impulso sinusoidal, as deflexões máximas obtidas para o MVTvv2 estão apresentadas na Figura 5.14 (b), onde de forma análoga ao acontecido com o carregamento do tipo 1 , os deslocamentos no centro da viga são superiores aos obtidos no MVTvv, e da mesma forma o pico do valor máximo não coincidem nos diferentes valores do período da carga T. O impulso de rampa gera no MVTvv2 um aumento das deflexões ao longo do tempo por efeito da perda de resistência da metade inferior do núcleo. $\mathrm{O}$ aumento no pico do valor máximo dos deslocamentos no centro da viga aumenta perto de um $15 \%$ o que valida a conservação do aumento dos deslocamentos sobre o MVTvv, e ainda sobre os obtidos pelo carregamento do impulso sinusoidal. 


\subsubsection{7 - Caso VI: MVT viscoelástico $\boldsymbol{\alpha}=\mathbf{0 , 5 0}$}

Devido a que o MVTvv2 apresenta um comportamento semelhante dependente do tipo de carregamento e o período avaliado, entre menor é o valor do parâmetro $\alpha$ maiores são as deflexões obtidas. Assim quando o carregamento 1 é imposto e $\alpha=0,50$ o aumento dos deslocamentos comparado com os obtidos para $\alpha=0,75$ comparados entre os correspondentes T, são superiores num 20\% aproximadamente, e apresentam-se na Figura 5.15 (a).

Esse mesmo efeito pode-se avaliar na Figura 5.15 (b), onde consignaram-se os deslocamentos máximos obtidos no centro da viga por efeito do carregamento do tipo 2 e na Figura 5.15 (c) onde apresentam-se as deflexões máximas obtidas pelo carregamento do tipo 3.

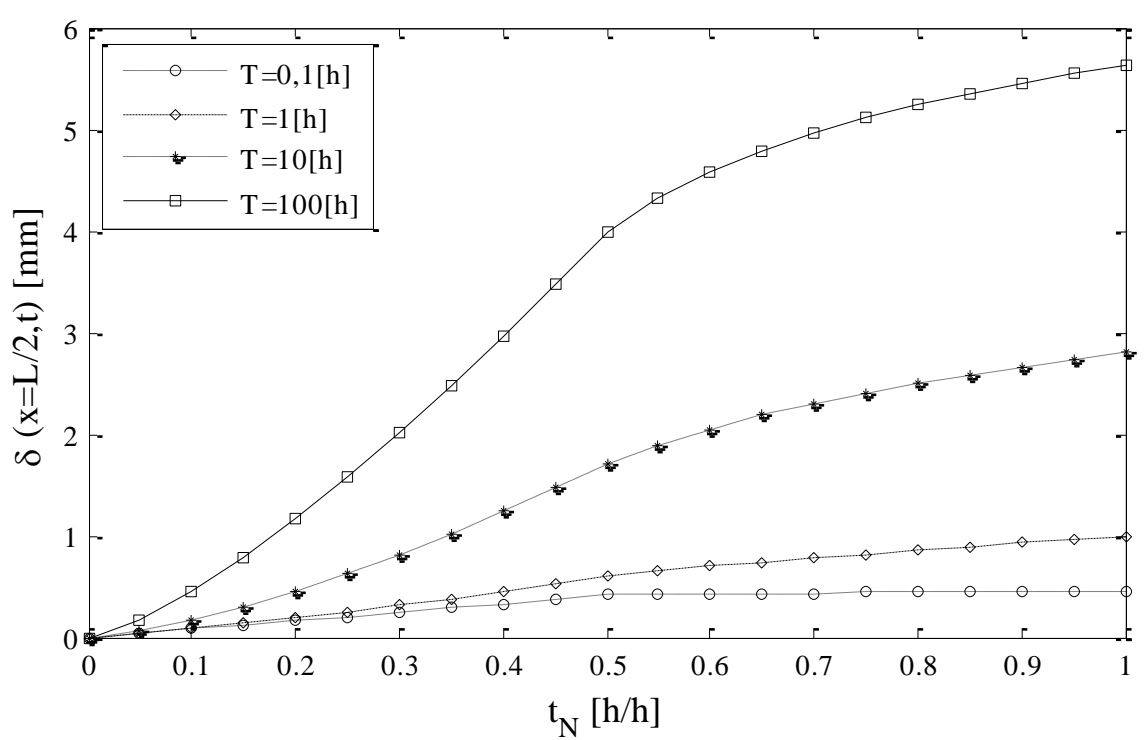

(a) $\delta(\mathrm{L} / 2, \mathrm{t})[\mathrm{mm}] \mathrm{MVTvv}_{2} \mathrm{CT} 1 \alpha=0,5$

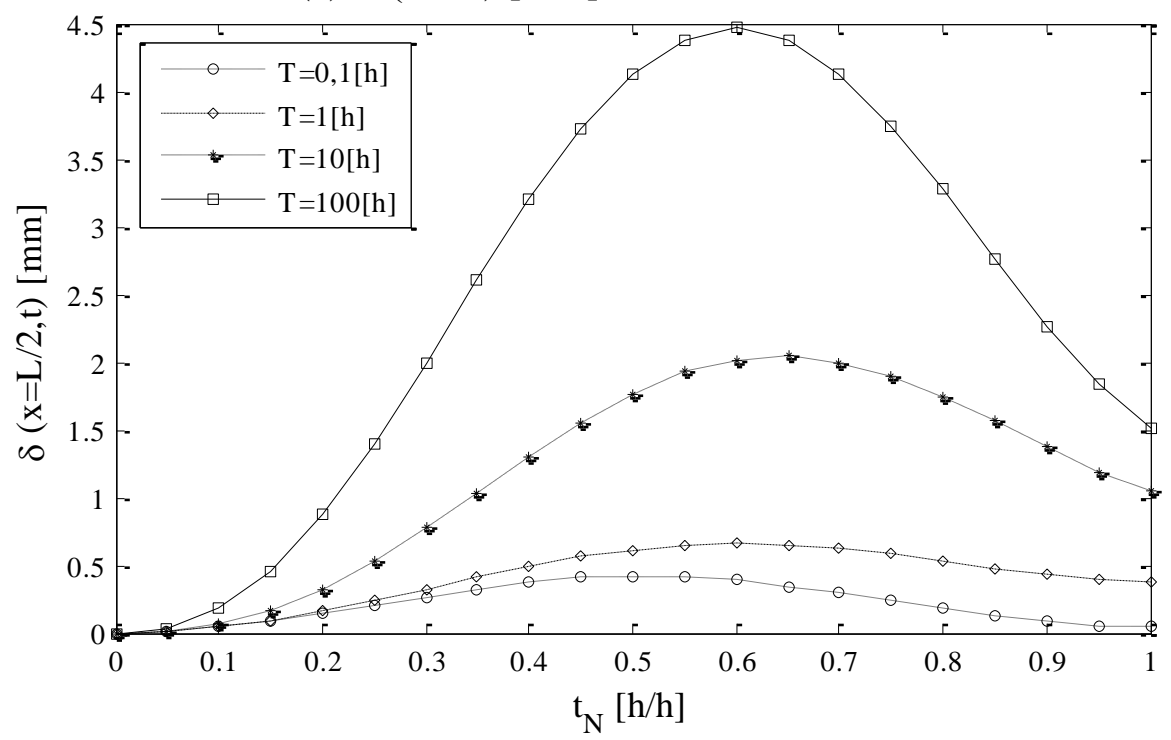

(b) $\delta(\mathrm{L} / 2, \mathrm{t})[\mathrm{mm}] \mathrm{MVTvv}_{2} \mathrm{CT} 2 \alpha=0,5$ 


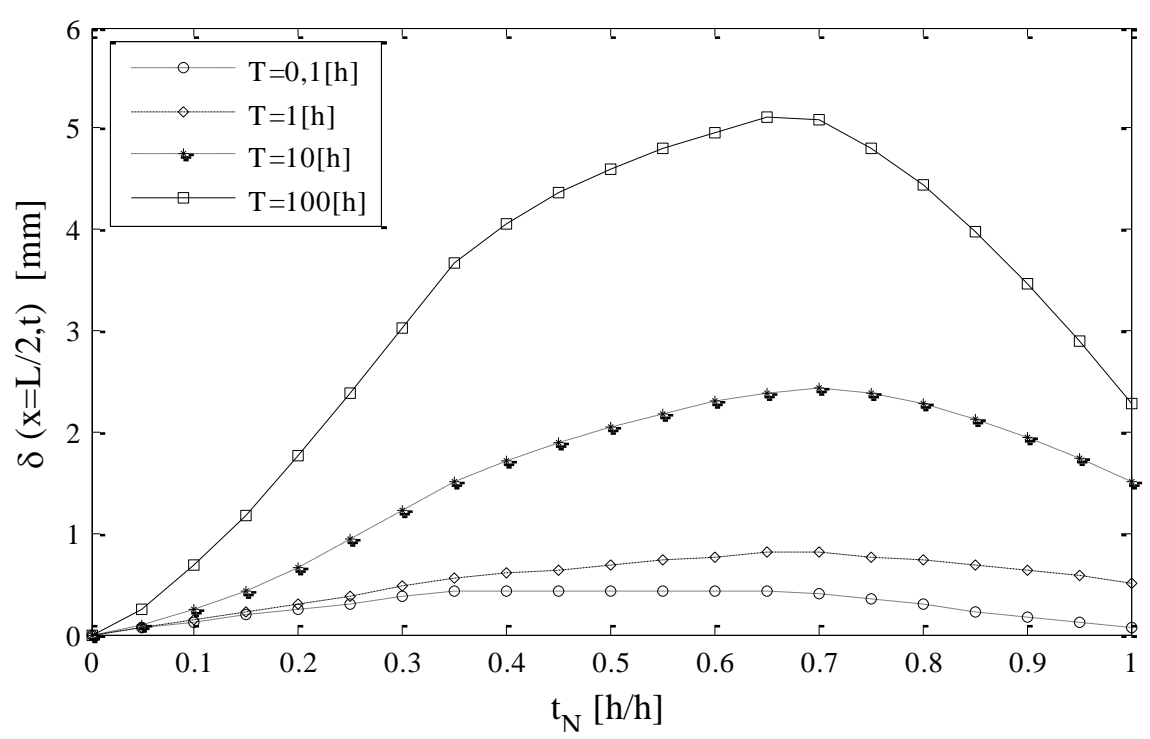

(c) $\delta(\mathrm{L} / 2, \mathrm{t})[\mathrm{mm}] \mathrm{MVTvv}_{2} \mathrm{CT} 3 \alpha=0,5$

Figura $5.15-\delta(\mathrm{L} / 2, \mathrm{t})[\mathrm{mm}] \mathrm{MVTvv}_{2} \alpha=0,5$

\subsubsection{8 - Caso VI: MVT viscoelástico $\boldsymbol{\alpha}=\mathbf{0 , 2 5}$}

$\mathrm{O} \mathrm{MVTvv}_{2}$ quando a resistência à flexão da metade inferior do núcleo diminui num $75 \%$, ou seja, $\alpha=0,25$, aumentam os deslocamentos máximos até num $30 \%$ aproximadamente comparado com os deslocamentos para $\alpha=0,50$, e aumentam aproximadamente num $85 \%$ comparado com o MVTvv.

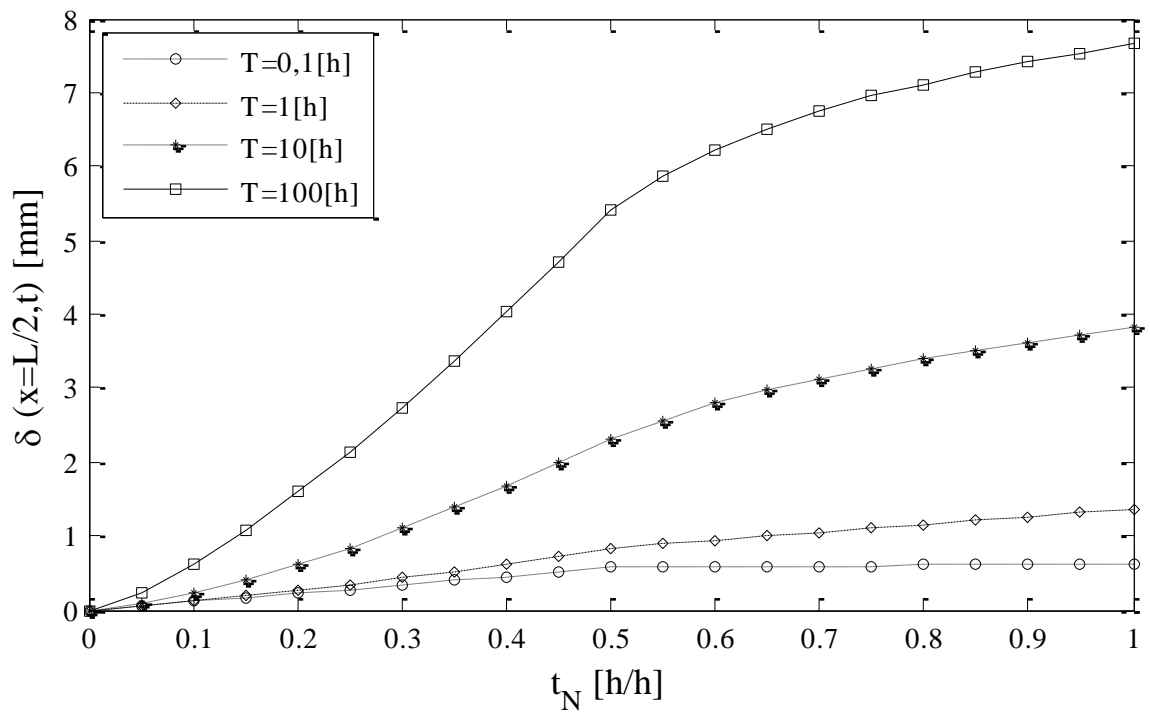

(a) $\delta(\mathrm{L} / 2, \mathrm{t})[\mathrm{mm}] \mathrm{MVTVV} 2 \mathrm{CT} 1 \alpha=0,25$ 


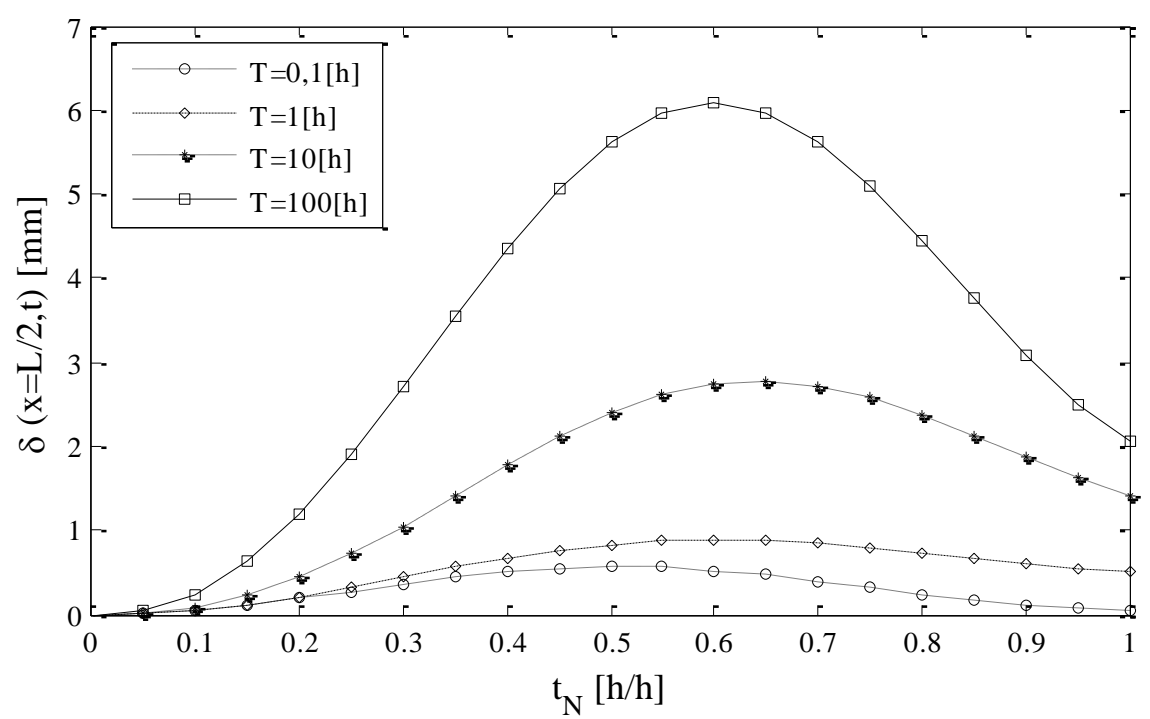

(c) $\delta(\mathrm{L} / 2, \mathrm{t})[\mathrm{mm}]$ MVTVV2 CT2 $\alpha=0,25$

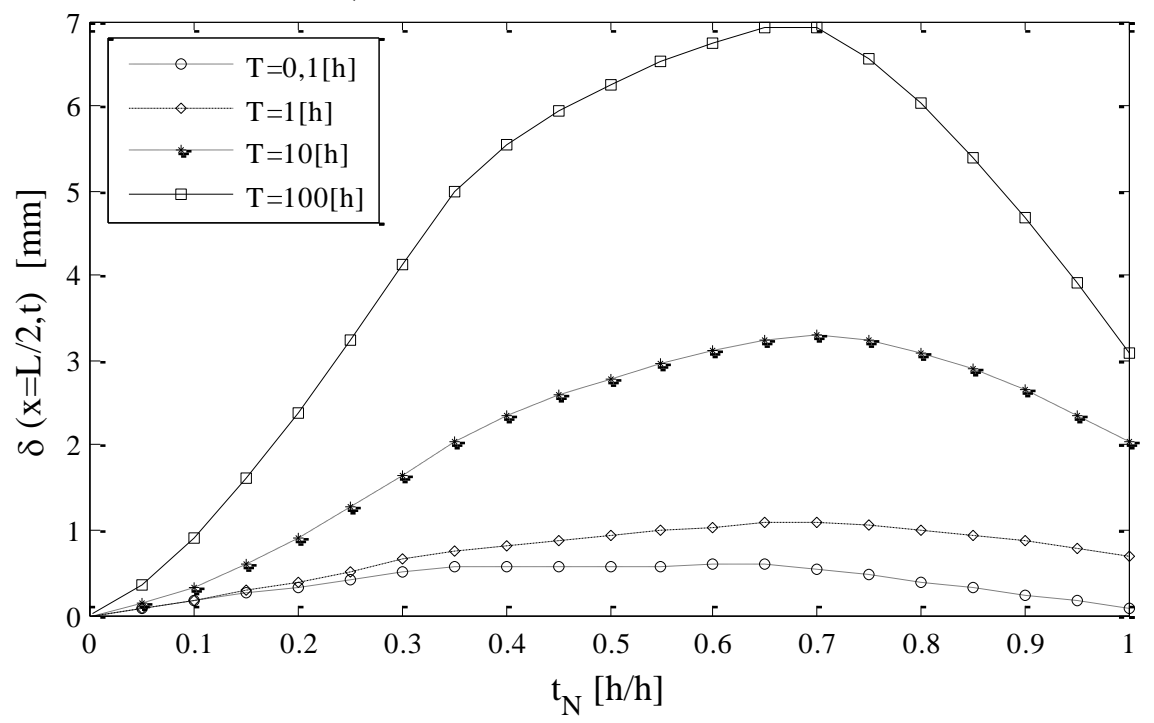

(c) $\delta(\mathrm{L} / 2, \mathrm{t})[\mathrm{mm}] \mathrm{MVTVV} 2 \mathrm{CT} 3 \alpha=0,25$

Figura $5.16-\delta(\mathrm{L} / 2, \mathrm{t})[\mathrm{mm}] \mathrm{MVTvv}_{2} \alpha=0,25$

Assim valida-se mais uma vez quanto a diminuição da rigidez aumentam as deflexões no centro da viga devido ao mesmo carregamento no mesmo período de aplicação. Na Figura 5.16 (a) apresentam-se os resultados das deflexões máximas por efeito do carregamento de rampa, na Figura 5.16 (b) pelo carregamento de impulso sinusoidal e na Figura 5.16 (a), as obtidas pelo impulso de rampa, que apresentam a mesma tendência do que os gráficos do $\mathrm{MVTvv}_{2}$ quando $\alpha=0,50$ mas com o aumento correspondente. 


\subsection{4 - COMPARAÇÃO PARAMÉTRICA NORMALIZADA}

Baseando-se nos resultados obtidos pelo algoritmo numérico e na procura de comparar sob um mesmo patamar tais resultados, realizou-se uma normalização das deflexões máximas obtidas em cada um dos casos estudos.

Para isso adotou-se como padrão de comparação o modelo de viga de Timoshenko em condições elásticas como unidade de medição para todos os casos, desta forma, cada uma das deflexões caso a caso $\delta_{C i}$ serão normalizadas comparadas ao MVT como se apresenta na Equação (5.17).

$$
\delta_{N}=\frac{\delta_{C i}\left(t, T_{j}\right)}{\delta_{C 3}}=\frac{\delta_{i}\left(t, T_{j}\right)}{\delta_{M V T}}[\mathrm{~mm} / \mathrm{mm}]
$$

\subsubsection{1 $-\delta_{\mathrm{N}}$ Caso I: MVEB elástico}

As deflexões normalizadas para os diferentes carregamentos segundo as condições avaliadas no MVEB estão condensadas na Tabela 5.4. Para o tempo da aplicação do carregamento máximo nos carregamentos de rampa ou tipo 1, o de impulso sinusoidal ou tipo 2 e para o impulso de rampa ou do tipo 3 o comportamento é igual.

O MVEB em condições elásticas alcança um 99,10\% dos deslocamentos máximos obtidos nas condições elásticas do MVT, descrevendo a forma do tipo do carregamento como se apresentam no anexo A.1. Note-se que por tratar-se de um modelo elástico todos os períodos T para cada tipo de carregamento descrevem a mesma curva de deflexões normalizadas.

Tabela $5.4-$ MVEB $\delta_{N}(L / 2, t)$

\begin{tabular}{c|cccc|ccc|ccccc}
\hline $\mathrm{t}_{\mathrm{N}}$ & \multicolumn{4}{|c|}{$\delta_{\mathrm{N}}[\mathrm{mm} / \mathrm{mm}] \mathrm{CT} 1$ Rampa } & \multicolumn{3}{c|}{$\delta_{\mathrm{N}}[\mathrm{mm} / \mathrm{mm}] \mathrm{CT} 2$ Imp. Sinusoidal } & \multicolumn{3}{c}{$\delta_{\mathrm{N}}[\mathrm{mm} / \mathrm{mm}]$ CT3 Imp. Rampa } \\
{$[\mathrm{h} / \mathrm{h}]$} & $\mathrm{T}=0,1 \mathrm{~h}$ & $\mathrm{~T}=1 \mathrm{~h}$ & $\mathrm{~T}=10 \mathrm{~h}$ & $\mathrm{~T}=100 \mathrm{~h}$ & $\mathrm{~T}=0,1 \mathrm{~h}$ & $\mathrm{~T}=1 \mathrm{~h}$ & $\mathrm{~T}=10 \mathrm{~h}$ & $\mathrm{~T}=100 \mathrm{~h}$ & $\mathrm{~T}=0,1 \mathrm{~h}$ & $\mathrm{~T}=1 \mathrm{~h}$ & $\mathrm{~T}=10 \mathrm{~h}$ & $\mathrm{~T}=100 \mathrm{~h}$ \\
\hline 0,1 & 0,198 & 0,198 & 0,198 & 0,198 & 0,095 & 0,095 & 0,095 & 0,095 & 0,297 & 0,297 & 0,297 & 0,297 \\
0,2 & 0,396 & 0,396 & 0,396 & 0,396 & 0,342 & 0,342 & 0,342 & 0,342 & 0,594 & 0,594 & 0,594 & 0,594 \\
0,3 & 0,594 & 0,594 & 0,594 & 0,594 & 0,648 & 0,648 & 0,648 & 0,648 & 0,892 & 0,892 & 0,892 & 0,892 \\
0,4 & 0,793 & 0,793 & 0,793 & 0,793 & 0,896 & 0,896 & 0,896 & 0,896 & $\mathbf{0 , 9 9 1}$ & $\mathbf{0 , 9 9 1}$ & $\mathbf{0 , 9 9 1}$ & $\mathbf{0 , 9 9 1}$ \\
0,5 & 0,991 & 0,991 & 0,991 & 0,991 & $\mathbf{0 , 9 9 1}$ & $\mathbf{0 , 9 9 1}$ & $\mathbf{0 , 9 9 1}$ & $\mathbf{0 , 9 9 1}$ & $\mathbf{0 , 9 9 1}$ & $\mathbf{0 , 9 9 1}$ & $\mathbf{0 , 9 9 1}$ & $\mathbf{0 , 9 9 1}$ \\
0,6 & 0,991 & 0,991 & 0,991 & 0,991 & 0,896 & 0,896 & 0,896 & 0,896 & $\mathbf{0 , 9 9 1}$ & $\mathbf{0 , 9 9 1}$ & $\mathbf{0 , 9 9 1}$ & $\mathbf{0 , 9 9 1}$ \\
0,7 & 0,991 & 0,991 & 0,991 & 0,991 & 0,648 & 0,648 & 0,648 & 0,648 & 0,892 & 0,892 & 0,892 & 0,892 \\
0,8 & 0,991 & 0,991 & 0,991 & 0,991 & 0,342 & 0,342 & 0,342 & 0,342 & 0,594 & 0,594 & 0,594 & 0,594 \\
0,9 & 0,991 & 0,991 & 0,991 & 0,991 & 0,095 & 0,095 & 0,095 & 0,095 & 0,297 & 0,297 & 0,297 & 0,297 \\
$\mathbf{1}$ & $\mathbf{0 , 9 9 1}$ & $\mathbf{0 , 9 9 1}$ & $\mathbf{0 , 9 9 1}$ & $\mathbf{0 , 9 9 1}$ & 0,000 & 0,000 & 0,000 & 0,000 & 0,000 & 0,000 & 0,000 & 0,000 \\
\hline
\end{tabular}




\subsubsection{2 $-\delta_{\mathrm{N}}$ Caso II: MVEB viscoelástico}

Como o MVEBv contempla a viscoelasticidade na parcela de flexão aportada pelo MVEB, na medida que incrementa o período de permanência do carregamento aumentam também as deflexões no centro da viga em relação ao MVT, como pode-se constatar na Tabela 5.5.

Tabela $5.5-$ MVEBv $\delta_{N}(\mathrm{~L} / 2, \mathrm{t})$

\begin{tabular}{c|cccc|cccc|cccc}
\hline $\mathrm{t}_{\mathrm{N}}$ & \multicolumn{4}{|c|}{$\delta_{\mathrm{N}}[\mathrm{mm} / \mathrm{mm}]$} & $\mathrm{CT} 1$ Rampa & \multicolumn{3}{c|}{$\delta_{\mathrm{N}}[\mathrm{mm} / \mathrm{mm}]$ CT2 Imp. Sinusoidal } & \multicolumn{3}{c}{$\delta_{\mathrm{N}}[\mathrm{mm} / \mathrm{mm}]$ CT3 Imp. Rampa } \\
{$[\mathrm{h} / \mathrm{h}]$} & $\mathrm{T}=0,1 \mathrm{~h}$ & $\mathrm{~T}=1 \mathrm{~h}$ & $\mathrm{~T}=10 \mathrm{~h}$ & $\mathrm{~T}=100 \mathrm{~h}$ & $\mathrm{~T}=0,1 \mathrm{~h}$ & $\mathrm{~T}=1 \mathrm{~h}$ & $\mathrm{~T}=10 \mathrm{~h}$ & $\mathrm{~T}=100 \mathrm{~h}$ & $\mathrm{~T}=0,1 \mathrm{~h}$ & $\mathrm{~T}=1 \mathrm{~h}$ & $\mathrm{~T}=10 \mathrm{~h}$ & $\mathrm{~T}=100 \mathrm{~h}$ \\
\hline 0,1 & 0,199 & 0,215 & 0,394 & 1,105 & 0,095 & 0,100 & 0,159 & 0,441 & 0,298 & 0,323 & 0,590 & 1,658 \\
0,2 & 0,400 & 0,473 & 1,091 & 2,861 & 0,344 & 0,387 & 0,789 & 2,135 & 0,600 & 0,710 & 1,637 & 4,291 \\
0,3 & 0,604 & 0,775 & 1,989 & 4,954 & 0,655 & 0,794 & 1,885 & 4,863 & 0,906 & 1,162 & 2,984 & 7,431 \\
0,4 & 0,812 & 1,117 & 3,029 & 7,268 & 0,913 & 1,205 & 3,190 & 7,844 & 1,019 & 1,468 & 4,212 & 9,960 \\
0,5 & 1,024 & 1,499 & 4,178 & 9,739 & $\mathbf{1 , 0 2 2}$ & 1,502 & 4,324 & 10,118 & 1,037 & 1,675 & 5,018 & 11,263 \\
0,6 & 1,041 & 1,703 & 5,021 & 11,223 & 0,946 & $\mathbf{1 , 6 0 8}$ & 4,946 & 10,944 & $\mathbf{1 , 0 5 7}$ & 1,872 & 5,614 & 12,151 \\
0,7 & 1,061 & 1,899 & 5,636 & 12,152 & 0,717 & 1,516 & $\mathbf{4 , 8 9 7}$ & $\mathbf{1 0 , 1 1 0}$ & 0,979 & $\mathbf{1 , 9 6 0}$ & $\mathbf{5 , 9 5 4}$ & $\mathbf{1 2 , 4 5 6}$ \\
0,8 & 1,082 & 2,087 & 6,119 & 12,827 & 0,427 & 1,297 & 4,264 & 8,019 & 0,702 & 1,797 & 5,587 & 10,857 \\
0,9 & 1,104 & 2,266 & 6,521 & 13,354 & 0,191 & 1,065 & 3,351 & 5,543 & 0,421 & 1,560 & 4,778 & 8,461 \\
1 & $\mathbf{1 , 1 2 6}$ & $\mathbf{2 , 4 3 7}$ & $\mathbf{6 , 8 7 3}$ & $\mathbf{1 3 , 7 9 2}$ & 0,104 & 0,939 & 2,563 & 3,696 & 0,136 & 1,251 & 3,669 & 5,576 \\
\hline
\end{tabular}

Segundo os resultados apresentados na Tabela 5.5, ao comparar os três tipos de carregamento, de forma geral os carregamentos impulsivos no tempo $t_{N}=1 / 2$ são superiores ao $\mathrm{CT} 1$, enquanto no tempo $\mathrm{t}_{\mathrm{N}}=1$ este último apresenta os máximos efeitos por conta do descarregamento dos CT2 e CT3, impulsivos.

Os resultados gráficos dos deslocamentos normalizados para o Caso II, correspondentes aos CT1, CT2 e CT3 encontram-se no Anexo A.2. Ao comparar as respostas do impulso sinusoidal com as obtidas pelo $\mathrm{CT} 1$, no tempo $t_{\mathrm{N}}=1 / 2$ é superior, mas no tempo $\mathrm{t}_{\mathrm{N}}=1$ é 10 vezes menor, e comparado com o impulso de rampa, esse último supera os deslocamentos máximos obtidos para o CT2 por conta da permanência no tercio central do carregamento constante.

\subsubsection{3 $-\delta_{\mathrm{N}}$ Caso III: MVT elástico}

Como o MVT é o padrão de comparação os resultados consignam-se na Tabela 5.6. Note-se que para cada caso, por esse caso ser o padrão de comparação, o máximo valor será a unidade ao ser atingido o carregamento máximo de $1000 \mathrm{~N}$, assim correspondentemente para o CT1, CT2 e CT3 apresentam-se os resultados no Anexo A.3. 
Tabela $5.6-\operatorname{MVT} \delta_{\mathrm{N}}(\mathrm{L} / 2, \mathrm{t})$

\begin{tabular}{c|cccc|cccc|cccc}
\hline $\mathrm{t}_{\mathrm{N}}$ & \multicolumn{4}{|c|}{$\delta_{\mathrm{N}}[\mathrm{mm} / \mathrm{mm}]$ CT1 Rampa } & \multicolumn{3}{c|}{$\delta_{\mathrm{N}}[\mathrm{mm} / \mathrm{mm}]$ CT2 Imp. Sinusoidal } & \multicolumn{3}{c}{$\delta_{\mathrm{N}}[\mathrm{mm} / \mathrm{mm}]$ CT3 Imp. Rampa } \\
{$[\mathrm{h} / \mathrm{h}]$} & $\mathrm{T}=0,1 \mathrm{~h}$ & $\mathrm{~T}=1 \mathrm{~h}$ & $\mathrm{~T}=10 \mathrm{~h}$ & $\mathrm{~T}=100 \mathrm{~h}$ & $\mathrm{~T}=0,1 \mathrm{~h}$ & $\mathrm{~T}=1 \mathrm{~h}$ & $\mathrm{~T}=10 \mathrm{~h}$ & $\mathrm{~T}=100 \mathrm{~h}$ & $\mathrm{~T}=0,1 \mathrm{~h}$ & $\mathrm{~T}=1 \mathrm{~h}$ & $\mathrm{~T}=10 \mathrm{~h}$ & $\mathrm{~T}=100 \mathrm{~h}$ \\
\hline 0,1 & 0,200 & 0,200 & 0,200 & 0,200 & 0,095 & 0,095 & 0,095 & 0,095 & 0,300 & 0,300 & 0,300 & 0,300 \\
0,2 & 0,400 & 0,400 & 0,400 & 0,400 & 0,345 & 0,345 & 0,345 & 0,345 & 0,600 & 0,600 & 0,600 & 0,600 \\
0,3 & 0,600 & 0,600 & 0,600 & 0,600 & 0,655 & 0,655 & 0,655 & 0,655 & 0,900 & 0,900 & 0,900 & 0,900 \\
0,4 & 0,800 & 0,800 & 0,800 & 0,800 & 0,905 & 0,905 & 0,905 & 0,905 & $\mathbf{1 , 0 0 0}$ & $\mathbf{1 , 0 0 0}$ & $\mathbf{1 , 0 0 0}$ & $\mathbf{1 , 0 0 0}$ \\
0,5 & 1,000 & 1,000 & 1,000 & 1,000 & $\mathbf{1 , 0 0 0}$ & $\mathbf{1 , 0 0 0}$ & $\mathbf{1 , 0 0 0}$ & $\mathbf{1 , 0 0 0}$ & $\mathbf{1 , 0 0 0}$ & $\mathbf{1 , 0 0 0}$ & $\mathbf{1 , 0 0 0}$ & $\mathbf{1 , 0 0 0}$ \\
0,6 & 1,000 & 1,000 & 1,000 & 1,000 & 0,905 & 0,905 & 0,905 & 0,905 & $\mathbf{1 , 0 0 0}$ & $\mathbf{1 , 0 0 0}$ & $\mathbf{1 , 0 0 0}$ & $\mathbf{1 , 0 0 0}$ \\
0,7 & 1,000 & 1,000 & 1,000 & 1,000 & 0,655 & 0,655 & 0,655 & 0,655 & 0,900 & 0,900 & 0,900 & 0,900 \\
0,8 & 1,000 & 1,000 & 1,000 & 1,000 & 0,345 & 0,345 & 0,345 & 0,345 & 0,600 & 0,600 & 0,600 & 0,600 \\
0,9 & 1,000 & 1,000 & 1,000 & 1,000 & 0,095 & 0,095 & 0,095 & 0,095 & 0,300 & 0,300 & 0,300 & 0,300 \\
$\mathbf{1}$ & $\mathbf{1 , 0 0 0}$ & $\mathbf{1 , 0 0 0}$ & $\mathbf{1 , 0 0 0}$ & $\mathbf{1 , 0 0 0}$ & 0,000 & 0,000 & 0,000 & 0,000 & 0,000 & 0,000 & 0,000 & 0,000 \\
\hline
\end{tabular}

5.1.4.4 $-\delta_{\mathrm{N}}$ Caso IV: MVTev flexão elástica e cisalhamento viscoelástico

O comportamento viscoelástico somente da parcela de cisalhamento e a consideração da aproximação da rigidez a flexão $E I \approx(E I)_{e q}$. adverte um aumento nos deslocamentos perto de oito vezes a mais dos deslocamentos elásticos exatos, mas com um comportamento quase que elástico pois os valores máximos dos deslocamentos correspondem também ao tempo em que o carregamento aplicado é maior, sendo evidente que este modelo matemático não descreve adequadamente o comportamento viscoelástico, al menos não para o núcleo de PS.

Tabela $5.7-$ MVTev $\delta_{N}(L / 2, t)$

\begin{tabular}{c|cccc|cccc|cccc}
\hline $\mathrm{t}_{\mathrm{N}}$ & \multicolumn{3}{|c|}{$\delta_{\mathrm{N}}[\mathrm{mm} / \mathrm{mm}]$ CT1 Rampa } & \multicolumn{3}{c|}{$\delta_{\mathrm{N}}[\mathrm{mm} / \mathrm{mm}]$ CT2 Imp. Sinusoidal } & \multicolumn{3}{c}{$\delta_{\mathrm{N}}[\mathrm{mm} / \mathrm{mm}]$ CT3 Imp. Rampa } \\
{$[\mathrm{h} / \mathrm{h}]$} & $\mathrm{T}=0,1 \mathrm{~h}$ & $\mathrm{~T}=1 \mathrm{~h}$ & $\mathrm{~T}=10 \mathrm{~h}$ & $\mathrm{~T}=100 \mathrm{~h}$ & $\mathrm{~T}=0,1 \mathrm{~h}$ & $\mathrm{~T}=1 \mathrm{~h}$ & $\mathrm{~T}=10 \mathrm{~h}$ & $\mathrm{~T}=100 \mathrm{~h}$ & $\mathrm{~T}=0,1 \mathrm{~h}$ & $\mathrm{~T}=1 \mathrm{~h}$ & $\mathrm{~T}=10 \mathrm{~h}$ & $\mathrm{~T}=100 \mathrm{~h}$ \\
\hline 0,1 & 1,537 & 1,538 & 1,539 & 1,546 & 0,734 & 0,734 & 0,735 & 0,737 & 2,306 & 2,306 & 2,309 & 2,319 \\
0,2 & 3,075 & 3,076 & 3,081 & 3,098 & 2,656 & 2,656 & 2,660 & 2,673 & 4,612 & 4,613 & 4,622 & 4,647 \\
0,3 & 4,612 & 4,614 & 4,625 & 4,653 & 5,031 & 5,033 & 5,043 & 5,071 & 6,919 & 6,921 & 6,938 & 6,980 \\
0,4 & 6,150 & 6,153 & 6,171 & 6,211 & 6,953 & 6,956 & 6,975 & 7,019 & 7,687 & 7,692 & 7,718 & 7,772 \\
0,5 & 7,687 & 7,692 & 7,717 & 7,770 & $\mathbf{7 , 6 8 7}$ & $\mathbf{7 , 6 9 2}$ & $\mathbf{7 , 7 1 9}$ & $\mathbf{7 , 7 7 3}$ & $\mathbf{7 , 6 8 8}$ & 7,694 & 7,725 & 7,784 \\
0,6 & 7,688 & 7,694 & 7,725 & 7,784 & 6,954 & 6,960 & 6,991 & 7,048 & $\mathbf{7 , 6 8 8}$ & $\mathbf{7 , 6 9 5}$ & $\mathbf{7 , 7 3 1}$ & $\mathbf{7 , 7 9 3}$ \\
0,7 & 7,688 & 7,696 & 7,731 & 7,793 & 5,032 & 5,039 & 5,071 & 5,121 & 6,919 & 6,929 & 6,966 & 7,028 \\
0,8 & 7,688 & 7,697 & 7,736 & 7,799 & 2,657 & 2,665 & 2,693 & 2,728 & 4,613 & 4,624 & 4,659 & 4,709 \\
0,9 & 7,688 & 7,699 & 7,739 & 7,804 & 0,735 & 0,743 & 0,765 & 0,786 & 2,307 & 2,318 & 2,349 & 2,383 \\
1 & $\mathbf{7 , 6 8 8}$ & $\mathbf{7 , 7 0 1}$ & $\mathbf{7 , 7 4 3}$ & $\mathbf{7 , 8 0 8}$ & 0,001 & 0,009 & 0,024 & 0,035 & 0,001 & 0,012 & 0,035 & 0,053 \\
\hline
\end{tabular}

Os resultados gráficos para cada um dos carregamentos apresentam-se no Anexo B.4.

\subsubsection{5 - $\delta_{\mathrm{N}}$ Caso V: MVTvv viscoelástico $\boldsymbol{\alpha}=\mathbf{1}$}

Os resultados do Caso $\mathrm{V}$ das deflexões máximas normalizadas ao considerar a viscoelasticidade tanto na parcela de flexão quanto na parcela ao cisalhamento, correspondente aos modelos verificados com o MEF, permitem visualizar a importância do estudo da viscoelasticidade dos materiais, isto pois o aumento dos deslocamentos em comparação com os materiais elásticos vão desde um $14 \%$ superiores para um CT1 num 
tempo muito rápido até quase 14 vezes para a permanência do carregamento de rampa de 100 h. Os resultados para todos os carregamentos apresentam-se na Tabela 5.8.

Para os carregamentos impulsivos CT2 e CT3, o máximo valor do deslocamento só acontece no $\mathrm{t}_{\mathrm{N}}=1 / 2$ para pulsos muito rápidos, na medida que o pulso permanece mais tempo sob a estrutura o tempo de ocorrência desse deslocamento máximo é deslocado à direita desse valor, sendo no CT3 até de no $\mathrm{t}_{\mathrm{N}}=0,7$ para $\mathrm{T}=100 \mathrm{~h}$. Os resultados gráficos do MVTvv2 apresentam-se no Anexo B.5.

Tabela $5.8-\operatorname{MVTvv} \delta_{\mathrm{N}}(\mathrm{L} / 2, \mathrm{t})$

\begin{tabular}{c|cccc|cccc|cccc}
\hline $\mathrm{t}_{\mathrm{N}}$ & \multicolumn{3}{|c|}{$\delta_{\mathrm{N}}[\mathrm{mm} / \mathrm{mm}]$ CT1 Rampa } & \multicolumn{3}{c|}{$\delta_{\mathrm{N}}[\mathrm{mm} / \mathrm{mm}]$ CT2 Imp. Sinusoidal } & \multicolumn{3}{c}{$\delta_{\mathrm{N}}[\mathrm{mm} / \mathrm{mm}]$ CT3 Imp. Rampa } \\
{$[\mathrm{h} / \mathrm{h}]$} & $\mathrm{T}=0,1 \mathrm{~h}$ & $\mathrm{~T}=1 \mathrm{~h}$ & $\mathrm{~T}=10 \mathrm{~h}$ & $\mathrm{~T}=100 \mathrm{~h}$ & $\mathrm{~T}=0,1 \mathrm{~h}$ & $\mathrm{~T}=1 \mathrm{~h}$ & $\mathrm{~T}=10 \mathrm{~h}$ & $\mathrm{~T}=100 \mathrm{~h}$ & $\mathrm{~T}=0,1 \mathrm{~h}$ & $\mathrm{~T}=1 \mathrm{~h}$ & $\mathrm{~T}=10 \mathrm{~h}$ & $\mathrm{~T}=100 \mathrm{~h}$ \\
\hline 0,1 & 0,201 & 0,217 & 0,397 & 1,115 & 0,096 & 0,100 & 0,160 & 0,446 & 0,301 & 0,326 & 0,596 & 1,673 \\
0,2 & 0,403 & 0,478 & 1,101 & 2,888 & 0,347 & 0,390 & 0,796 & 2,155 & 0,605 & 0,717 & 1,652 & 4,332 \\
0,3 & 0,610 & 0,782 & 2,008 & 5,001 & 0,662 & 0,801 & 1,903 & 4,909 & 0,914 & 1,173 & 3,012 & 7,501 \\
0,4 & 0,819 & 1,128 & 3,058 & 7,337 & 0,922 & 1,216 & 3,220 & 7,919 & 1,029 & 1,482 & 4,251 & 10,054 \\
0,5 & 1,033 & 1,513 & 4,217 & 9,831 & $\mathbf{1 , 0 3 2}$ & 1,516 & 4,364 & 10,213 & 1,047 & 1,690 & 5,066 & 11,369 \\
0,6 & 1,051 & 1,719 & 5,069 & 11,329 & 0,955 & $\mathbf{1 , 6 2 3}$ & $\mathbf{4 , 9 9 3}$ & $\mathbf{1 1 , 0 4 8}$ & $\mathbf{1 , 0 6 7}$ & 1,890 & 5,667 & 12,266 \\
0,7 & 1,071 & 1,917 & 5,690 & 12,267 & 0,723 & 1,531 & 4,943 & 10,206 & 0,988 & $\mathbf{1 , 9 7 9}$ & $\mathbf{6 , 0 1 1}$ & $\mathbf{1 2 , 5 7 4}$ \\
0,8 & 1,093 & 2,107 & 6,176 & 12,948 & 0,431 & 1,309 & 4,304 & 8,095 & 0,709 & 1,814 & 5,640 & 10,960 \\
0,9 & 1,115 & 2,288 & 6,583 & 13,480 & 0,193 & 1,075 & 3,382 & 5,596 & 0,425 & 1,575 & 4,823 & 8,541 \\
1 & $\mathbf{1 , 1 3 7}$ & $\mathbf{2 , 4 6 0}$ & $\mathbf{6 , 9 3 8}$ & $\mathbf{1 3 , 9 2 2}$ & 0,105 & 0,948 & 2,587 & 3,731 & 0,137 & 1,263 & 3,704 & 5,629 \\
\hline
\end{tabular}

\subsubsection{6 $-\delta_{\mathrm{N}}$ Caso VI: $M V_{T} v_{2}$ viscoelástico $\boldsymbol{\alpha}=\mathbf{0 , 7 5}$}

No modelo viscoelástico de Timoshenko considerando uma diminuição da rigidez da metade inferior do núcleo apresentam-se na Tabela 5.9 e os resultados gráficos mostram-se no Anexo B.6. Dos resultados obtidos pode-se concluir que essa diminuição da rigidez, como era esperado, repercute num aumento das deflexões máximas da viga sanduíche, mas na diminuição do $25 \%$ o aumento das deflexões no pior dos casos, um $30 \%$ para o CT1 e num $15 \%$ no CT2 e no CT3.

Tabela $5.9-\mathrm{MVTvv}_{2} \alpha=0,75 \delta_{\mathrm{N}}(\mathrm{L} / 2, \mathrm{t})$

\begin{tabular}{|c|c|c|c|c|c|c|c|c|c|c|c|c|}
\hline \multirow{2}{*}{$\begin{array}{c}\mathrm{t}_{\mathrm{N}} \\
{[\mathrm{h} / \mathrm{h}]}\end{array}$} & \multicolumn{4}{|c|}{$\delta_{\mathrm{N}}[\mathrm{mm} / \mathrm{mm}] \mathrm{CT} 1 \mathrm{Rampa}$} & \multicolumn{4}{|c|}{$\delta_{\mathrm{N}}[\mathrm{mm} / \mathrm{mm}] \mathrm{CT} 2 \mathrm{Imp}$. Sinusoidal } & \multicolumn{4}{|c|}{$\delta_{\mathrm{N}}[\mathrm{mm} / \mathrm{mm}]$ CT3 Imp. Rampa } \\
\hline & $\mathrm{T}=0,1 \mathrm{~h}$ & $\mathrm{~T}=1 \mathrm{~h}$ & $\mathrm{~T}=10 \mathrm{~h}$ & $\mathrm{~T}=100 \mathrm{~h}$ & $\mathrm{~T}=0,1 \mathrm{~h}$ & $\mathrm{~T}=1 \mathrm{~h}$ & $\mathrm{~T}=10 \mathrm{~h}$ & $\mathrm{~T}=100 \mathrm{~h}$ & $\mathrm{~T}=0,1 \mathrm{~h}$ & $\mathrm{~T}=1 \mathrm{~h}$ & $\mathrm{~T}=10 \mathrm{~h}$ & $\mathrm{~T}=100 \mathrm{~h}$ \\
\hline 0,1 & 0,229 & 0.248 & 0453 & 1,272 & 0,109 & 0,115 & 0,183 & & 0,343 & 371 & 0,680 & 1,909 \\
\hline 0,2 & 60 & 0,545 & 256 & 294 & 0,396 & 0,445 & 0,908 & 2,458 & 0,690 & 0,8 & 85 & 4,941 \\
\hline 0,3 & 95 & & & & & & & & 43 & & & 56 \\
\hline 0,4 & 0,935 & 1,2 & & 69 & 1,0 & & 3 & 9 & 73 & 0 & 19 & 11,468 \\
\hline 0,5 & 79 & 1,726 & 4 & 213 & 1,1 & 1, & 4 , & & 94 & 3 & 778 & 12,968 \\
\hline 0,6 & 1,199 & 1, & & 22 & 1, & & 5 & & 217 & & 54 & 13,990 \\
\hline 0,7 & 1,222 & 2,187 & & & 0,8 & 1,746 & 38 & 11,641 & 127 & 2 , & 356 & 14,342 \\
\hline 0,8 & 46 & 2403 & 7045 & 14,769 & 0,4 & 1,493 & 4,910 & 9,233 & 0,808 & 2,069 & 6,433 & 12,501 \\
\hline 0,9 & 271 & 2,609 & & & 0,2 & 6 & & & 0,485 & & 01 & 9,742 \\
\hline 1 & 1,297 & 2,806 & 7,913 & 15,880 & 0,120 & 1,081 & 2,951 & 4,255 & 0,156 & 1,441 & 4,225 & 6,420 \\
\hline
\end{tabular}


Segundo o incremento entre os Casos V e VI, pode-se concluir que a relação existente entre a diminuição da rigidez e o aumento dos deslocamentos centrais não é inversamente proporcional, e depende além de $\alpha$ do tipo de carregamento e da duração deste.

\subsubsection{7 $-\delta_{\mathrm{N}}$ Caso VI: MVTvv2 viscoelástico $\boldsymbol{\alpha}=\mathbf{0 , 5}$}

De forma similar ao analisado no numeral 4.4.7, ou diminuir ainda mais o valor de $\alpha$, as deflexões máximas continuam em aumento, mas desta vez, para todos os carregamentos em $\mathrm{T}=1$, o aumento entre os máximos valores dos resultados obtidos com $\alpha=0,5$ e $\alpha=0,75$ foram aproximadamente um $20 \%$. Os resultados numéricos do presente caso de estudo apresentam-se na Tabela 5.10 e os gráficos correspondentes anexam-se na seção B.7.

Tabela $5.10-\mathrm{MVTvv}_{2} \alpha=0,50 \delta_{\mathrm{N}}(\mathrm{L} / 2, \mathrm{t})$

\begin{tabular}{c|cccc|cccc|cccc}
\hline $\mathrm{t}_{\mathrm{N}}$ & \multicolumn{4}{|c|}{$\delta_{\mathrm{N}}[\mathrm{mm} / \mathrm{mm}]$ CT1 Rampa } & \multicolumn{3}{c|}{$\delta_{\mathrm{N}}[\mathrm{mm} / \mathrm{mm}]$ CT2 Imp. Sinusoidal } & \multicolumn{3}{c}{$\delta_{\mathrm{N}}[\mathrm{mm} / \mathrm{mm}]$ CT3 Imp. Rampa } \\
{$[\mathrm{h} / \mathrm{h}]$} & $\mathrm{T}=0,1 \mathrm{~h}$ & $\mathrm{~T}=1 \mathrm{~h}$ & $\mathrm{~T}=10 \mathrm{~h}$ & $\mathrm{~T}=100 \mathrm{~h}$ & $\mathrm{~T}=0,1 \mathrm{~h}$ & $\mathrm{~T}=1 \mathrm{~h}$ & $\mathrm{~T}=10 \mathrm{~h}$ & $\mathrm{~T}=100 \mathrm{~h}$ & $\mathrm{~T}=0,1 \mathrm{~h}$ & $\mathrm{~T}=1 \mathrm{~h}$ & $\mathrm{~T}=10 \mathrm{~h}$ & $\mathrm{~T}=100 \mathrm{~h}$ \\
\hline 0,1 & 0,275 & 0,298 & 0,545 & 1,531 & 0,131 & 0,138 & 0,220 & 0,612 & 0,413 & 0,447 & 0,818 & 2,297 \\
0,2 & 0,554 & 0,656 & 1,512 & 3,965 & 0,477 & 0,536 & 1,093 & 2,959 & 0,831 & 0,984 & 2,268 & 5,947 \\
0,3 & 0,837 & 1,074 & 2,757 & 6,865 & 0,908 & 1,100 & 2,612 & 6,739 & 1,255 & 1,611 & 4,135 & 10,298 \\
0,4 & 1,125 & 1,548 & 4,198 & 10,072 & 1,265 & 1,670 & 4,421 & 10,870 & 1,412 & 2,034 & 5,836 & 13,802 \\
0,5 & 1,419 & 2,077 & 5,790 & 13,496 & $\mathbf{1 , 4 1 7}$ & 2,081 & 5,992 & 14,021 & 1,437 & 2,321 & 6,954 & 15,607 \\
0,6 & 1,443 & 2,360 & 6,958 & 15,552 & 1,311 & $\mathbf{2 , 2 2 8}$ & $\mathbf{6 , 8 5 4}$ & $\mathbf{1 5 , 1 6 6}$ & $\mathbf{1 , 4 6 5}$ & 2,595 & 7,780 & 16,838 \\
0,7 & 1,471 & 2,632 & 7,811 & 16,840 & 0,993 & 2,102 & 6,786 & 14,010 & 1,357 & $\mathbf{2 , 7 1 7}$ & $\mathbf{8 , 2 5 1}$ & $\mathbf{1 7 , 2 6 1}$ \\
0,8 & 1,500 & 2,892 & 8,479 & 17,775 & 0,591 & 1,797 & 5,909 & 11,112 & 0,973 & 2,490 & 7,742 & 15,045 \\
0,9 & 1,530 & 3,140 & 9,036 & 18,506 & 0,265 & 1,475 & 4,643 & 7,682 & 0,584 & 2,162 & 6,621 & 11,725 \\
1 & $\mathbf{1 , 5 6 1}$ & $\mathbf{3 , 3 7 7}$ & $\mathbf{9 , 5 2 4}$ & $\mathbf{1 9 , 1 1 2}$ & 0,144 & 1,301 & 3,551 & 5,122 & 0,188 & 1,734 & 5,085 & 7,727 \\
\hline
\end{tabular}

\subsubsection{8 $-\delta_{\mathrm{N}}$ Caso VI: MVT viscoelástico $\boldsymbol{\alpha}=\mathbf{0 , 2 5}$}

Analogamente ao acontecido nos numerais anteriores do Caso VI, na diminuição da rigidez continuam aumentando os valores dos deslocamentos no centro da viga por efeito dos mesmos carregamentos, mas desta vez comparados os resultados obtidos com aumentaram num $35 \%$.

Os resultados do Caso VI para $\alpha=0,25 \alpha=0,25$ em representação numérica apresentamse na Tabela 5.11, e graficamente anexaram-se na seção A.8. 
Tabela $5.11-\mathrm{MVTvv}_{2} \alpha=0,25 \delta_{\mathrm{N}}(\mathrm{L} / 2, \mathrm{t})$

\begin{tabular}{c|cccc|cccc|cccc}
\hline $\mathrm{t}_{\mathrm{N}}$ & \multicolumn{4}{|c|}{$\delta_{\mathrm{N}}[\mathrm{mm} / \mathrm{mm}]$ CT1 Rampa } & \multicolumn{3}{c|}{$\delta_{\mathrm{N}}[\mathrm{mm} / \mathrm{mm}]$ CT2 Imp. Sinusoidal } & \multicolumn{3}{c}{$\delta_{\mathrm{N}}[\mathrm{mm} / \mathrm{mm}]$ CT3 Imp. Rampa } \\
{$[\mathrm{h} / \mathrm{h}]$} & $\mathrm{T}=0,1 \mathrm{~h}$ & $\mathrm{~T}=1 \mathrm{~h}$ & $\mathrm{~T}=10 \mathrm{~h}$ & $\mathrm{~T}=100 \mathrm{~h}$ & $\mathrm{~T}=0,1 \mathrm{~h}$ & $\mathrm{~T}=1 \mathrm{~h}$ & $\mathrm{~T}=10 \mathrm{~h}$ & $\mathrm{~T}=100 \mathrm{~h}$ & $\mathrm{~T}=0,1 \mathrm{~h}$ & $\mathrm{~T}=1 \mathrm{~h}$ & $\mathrm{~T}=10 \mathrm{~h}$ & $\mathrm{~T}=100 \mathrm{~h}$ \\
\hline 0,1 & 0,374 & 0,405 & 0,741 & 2,081 & 0,179 & 0,187 & 0,299 & 0,831 & 0,562 & 0,607 & 1,112 & 3,122 \\
0,2 & 0,753 & 0,892 & 2,055 & 5,388 & 0,648 & 0,729 & 1,485 & 4,022 & 1,129 & 1,338 & 3,083 & 8,083 \\
0,3 & 1,137 & 1,459 & 3,747 & 9,331 & 1,234 & 1,495 & 3,550 & 9,159 & 1,706 & 2,189 & 5,620 & 13,996 \\
0,4 & 1,529 & 2,104 & 5,706 & 13,690 & 1,720 & 2,270 & 6,008 & 14,775 & 1,919 & 2,765 & 7,932 & 18,760 \\
0,5 & 1,928 & 2,823 & 7,869 & 18,343 & $\mathbf{1 , 9 2 6}$ & 2,829 & 8,143 & 19,056 & 1,953 & 3,154 & 9,452 & 21,213 \\
0,6 & 1,961 & 3,207 & 9,457 & 21,138 & 1,781 & $\mathbf{3 , 0 2 8}$ & $\mathbf{9 , 3 1 5}$ & $\mathbf{2 0 , 6 1 3}$ & $\mathbf{1 , 9 9 1}$ & 3,527 & 10,574 & 22,885 \\
0,7 & 1,999 & 3,577 & 10,616 & 22,888 & 1,350 & 2,856 & 9,223 & 19,042 & 1,844 & $\mathbf{3 , 6 9 2}$ & $\mathbf{1 1 , 2 1 5}$ & $\mathbf{2 3 , 4 6 0}$ \\
0,8 & 2,039 & 3,931 & 11,524 & 24,159 & 0,804 & 2,443 & 8,031 & 15,103 & 1,322 & 3,385 & 10,523 & 20,448 \\
0,9 & 2,080 & 4,268 & 12,282 & 25,152 & 0,360 & 2,005 & 6,311 & 10,441 & 0,793 & 2,938 & 8,998 & 15,936 \\
1 & $\mathbf{2 , 1 2 1}$ & $\mathbf{4 , 5 9 0}$ & $\mathbf{1 2 , 9 4 4}$ & $\mathbf{2 5 , 9 7 6}$ & 0,196 & 1,768 & 4,827 & 6,961 & 0,255 & 2,357 & 6,911 & 10,502 \\
\hline
\end{tabular}

5.1.4.9 - Comparação dos casos de estudo para o $\mathrm{T}=1[\mathrm{~h}]$

A primeira comparação a ser realizada é a dos valores dos máximos deslocamentos no centro da viga por efeito de cada tipo de carregamentos CT1, CT2 e CT3. Essas deflexões máximas dependendo do modelo a ser estudado, o máximo valor será atingido no tempo $\mathrm{t}_{\mathrm{N}}$ máx, e os resultados estão apresentados graficamente na Figura 5.17.

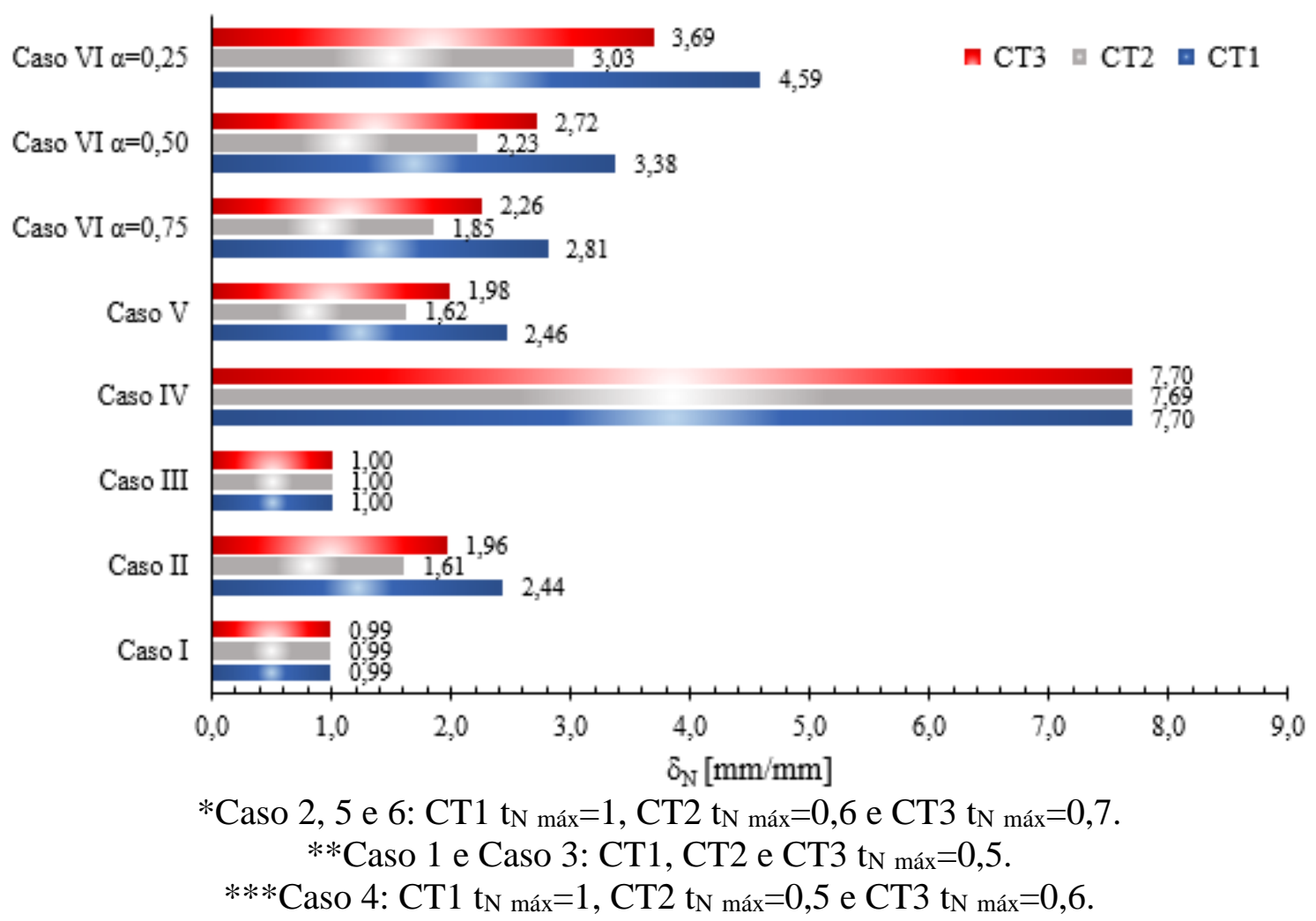

Figura 5.17 - Comparação dos casos de estudo para $\mathrm{T}=1[\mathrm{~h}] \mathrm{t}_{\mathrm{N}}$ máx.

Dessa comparação, é claro que o tipo de carregamento com os maiores deslocamentos é o CT1, seguido pelo CT3 e não muito distante o CT2. Isto pode-se explicar devido à 
permanência do carregamento máximo de $1000 \mathrm{~N}$ no tercio central do período T. A seguinte comparação a ser feita é no tempo $\mathrm{t}_{\mathrm{N}}=1$, apresentado na Figura 5.18.

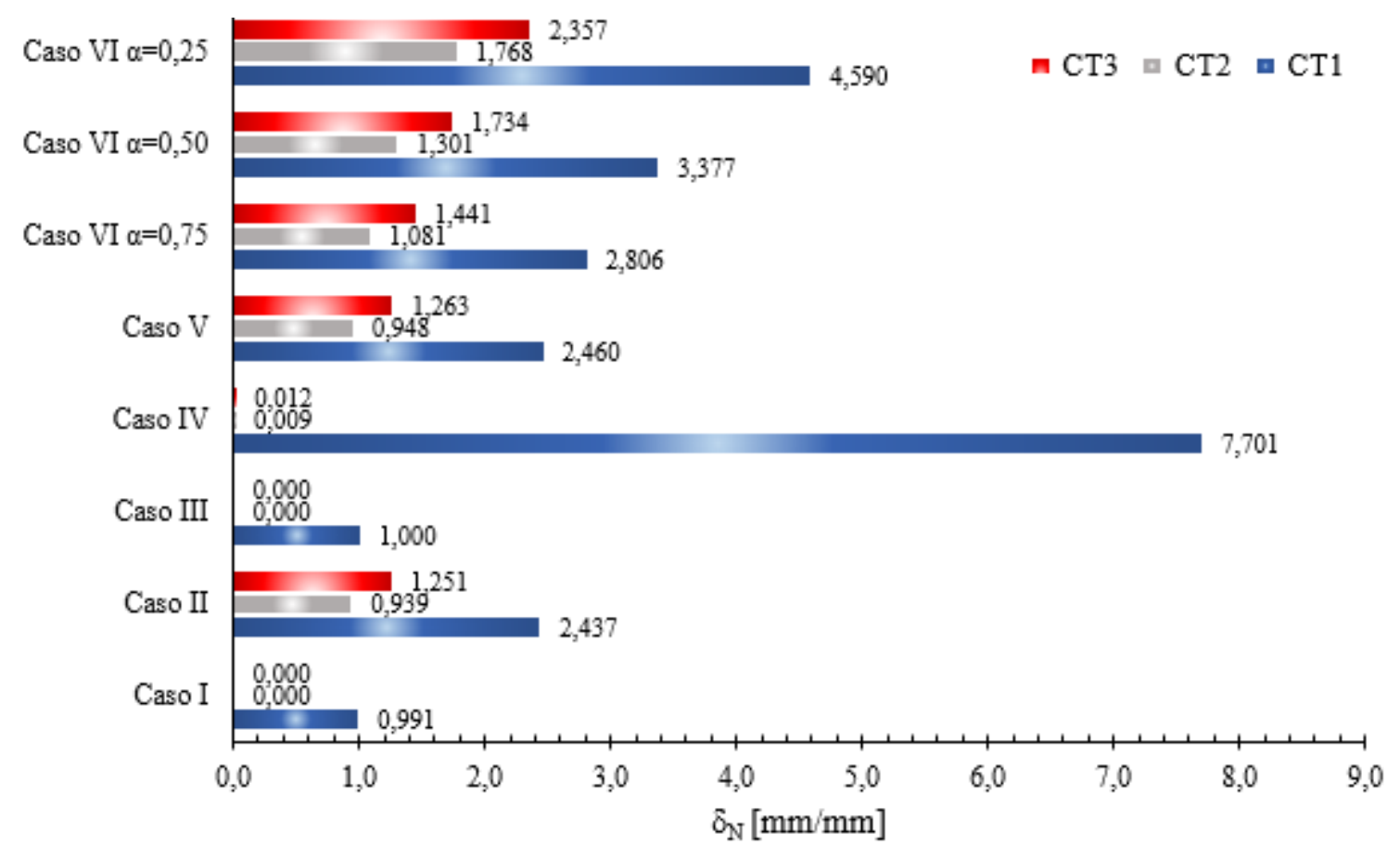

Figura 5.18 - Comparação dos casos de estudo para $T=1[h] \mathrm{t}_{\mathrm{N}}=1$

Segundo a Figura 5.18, diferente à perda total dos deslocamentos no tempo de desaparição da carga para os modelos elásticos, nos modelos viscoelásticos no tempo $\mathrm{T}$ não são instantaneamente eliminadas as deflexões, sendo em ordem de incidência desde o que mas afeita ate o carregamento que menos, o CT1, CT3 e o CT2.

5.1.4.10 - Comparação dos casos de estudo para o T=100 [h]

De forma análoga ao realizado para os carregamentos de período $\mathrm{T}=1$, realizaram-se as duas comparações, tanto para o tempo das máximas deflexões quanto para o período final $\mathrm{T}$, correspondentes ao mesmo comportamento apresentado para o os carregamentos de períodos $\mathrm{T}=1$, mas com valores superiores até em 5 vezes dos deslocamentos normalizados obtidos nesse período.

Os resultados para CT1, CT2 e CT3 nos diferentes casos de estudo apresentam-se na Figura 5.19 para os $t_{N}$ máx e na Figura 5.20 para $t_{N}=1$. 


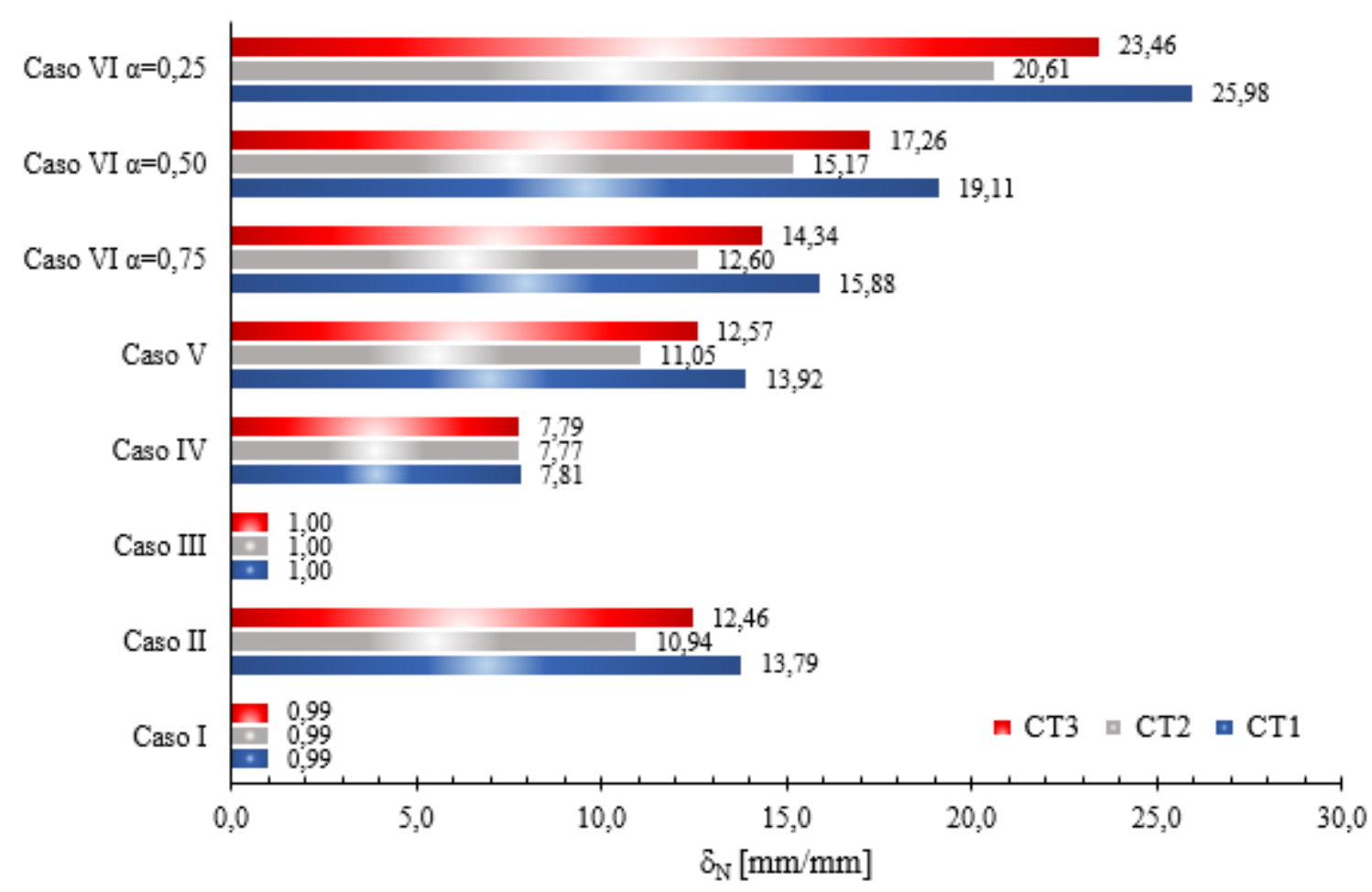

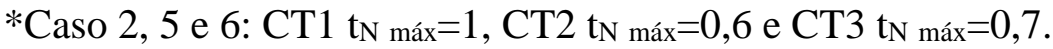
**Caso 1 e Caso 3: CT1, CT2 e CT3 $\mathrm{t}_{\mathrm{N} \text { máx }}=0,5$

*** Caso 4: CT1 $\mathrm{t}_{\mathrm{N} \text { máx }}=1, \mathrm{CT} 2 \mathrm{t}_{\mathrm{N} \text { máx }}=0,5$ e CT3 $\mathrm{t}_{\mathrm{N} \text { máx }}=0,6$.

Figura 5.19 - Comparação dos casos de estudo para $\mathrm{T}=100$ [h] $\mathrm{t}_{\mathrm{N}}$ máx.

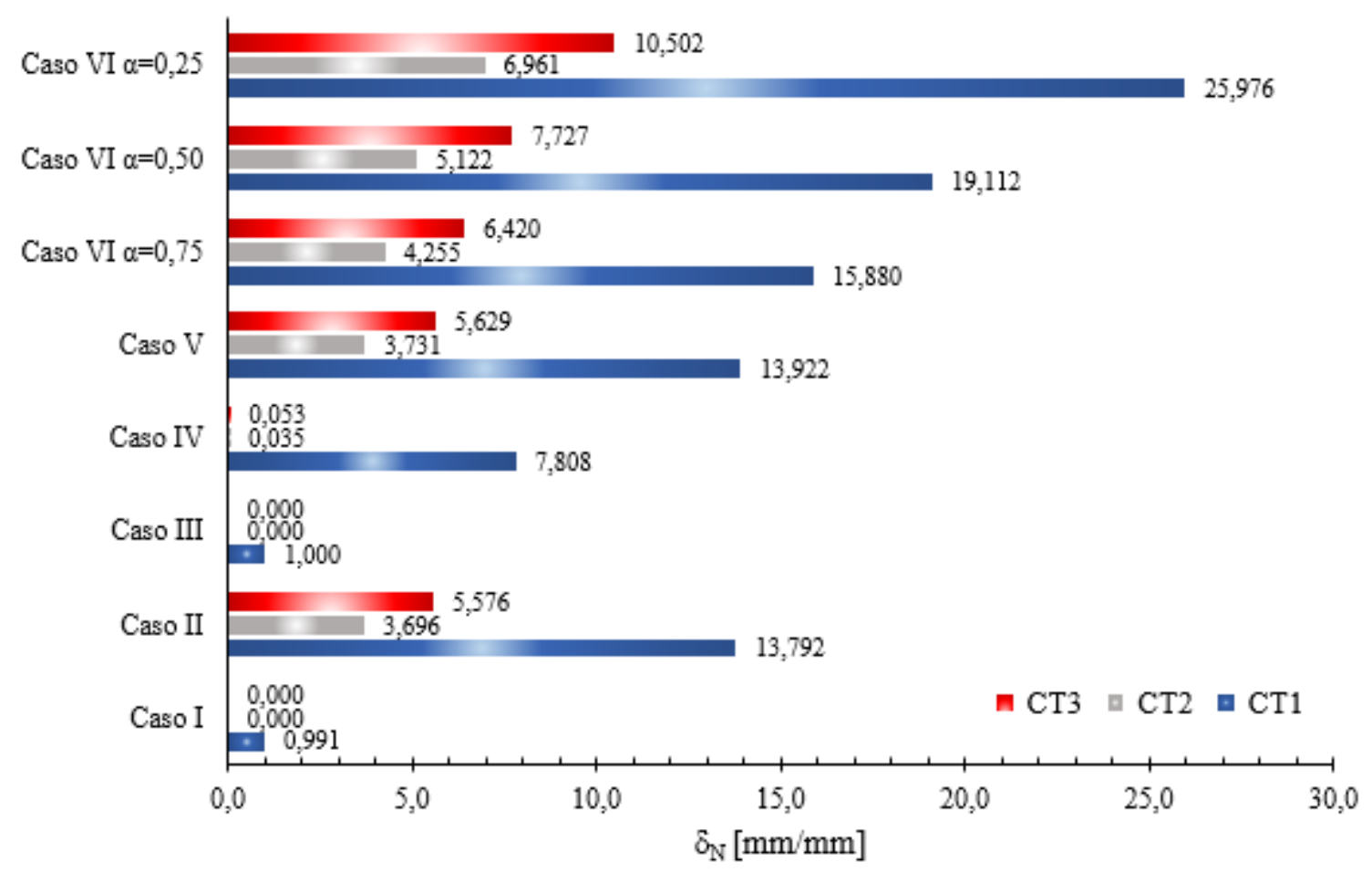

Figura 5.20 - Comparação dos casos de estudo para $\mathrm{T}=100[\mathrm{~h}] \mathrm{t}_{\mathrm{N}}=1$ 


\section{2 - PLACA ANISOTRÓPICA COMPÓSITA VISCOELÁSTICA}

Para analisar o comportamento de uma placa anisotrópica tipo, adota-se como material a espuma de poliestireno, sendo seu comportamento viscoelástico apresentado na Figura 5.2 e na Tabela 5.1. Adotou-se também um coeficiente de Poisson constante $v=0,33$ e a geometria apresentada na Figura 5.21.

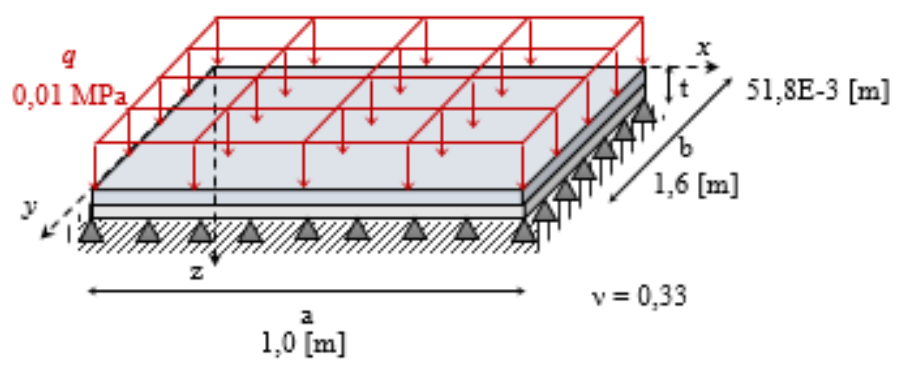

Figura 5.21 - Dimensões geométricas da placa anisotrópica

Nóte-se que a placa a ser estudada é simplesmente apoiada nas suas quatro bordas e esta submetida a um carregamento $q$ uniformemente distribuído. Além disso, a placa tem a mesma espessura da viga sanduíche estudada, e de forma análoga ao estudo realizado nesta, considera um comportamento alterado pelo fator $\alpha$ na metade inferior do núcleo, para simular a diferencia entre a fluência à flexão e a compressão.

Como a placa é considerada anisotrópica, ou seja, que têm comportamentos diferentes nas suas três direções. Desta forma, a Equação (2.99) transforma-se na Equação (5.18).

$$
\begin{aligned}
\mathrm{D}(t) & =\left[\begin{array}{lll}
D_{x x}(t) & D_{x y}(t) & D_{x z}(t) \\
D_{x y}(t) & D_{y y}(t) & D_{y z}(t) \\
D_{x z}(t) & D_{y z}(t) & D_{z z}(t)
\end{array}\right] \\
\mathrm{D}(t) & =\left[\begin{array}{ccc}
\beta D_{y y}(t) & 0,33 D_{y y}(t) & 0 \\
0,33 D_{y y}(t) & \frac{(\alpha+1) 51,8 E-3^{3} E_{Y Y}(t)}{21,3864} & 0 \\
0 & 0 & 0,335 D_{y y}(t)
\end{array}\right]
\end{aligned}
$$

Assim, e substituindo os valores da Equação (5.18) nas Equações (2.100), (2.101) e (2.102), pode-se obter as deflexões máximas para quaisquer valor de $\alpha$ e $\beta$ ao longo do tempo, permitindo avaliar a influência temporal do carregamento $q$. 


\subsection{1 - AVALIAÇÃO DO COMPORTAMENTO DA PLACA ANISOTRÓPICA VISCOELÁSTICA PARA $\alpha=\beta=0,5$}

Para avaliar o comportamento da influência tanto da diminuição da resistência do material à tração e a compressão, medida pelo valor de $\alpha$, quanto a influência da resistência de uma direção comparada com a outra, adotada com a variação de $\beta$, adoraram-se inicialmente os valores de $\alpha=\beta=0,5$. Analisaram-se três tempos diferentes $t=0,1,10$ e $1000[h]$, para assim avaliar as deflexões na placa, como se apresentam, correspondentemente, na Figura 5.22, na Figura 5.23 e na Figura 5.24.

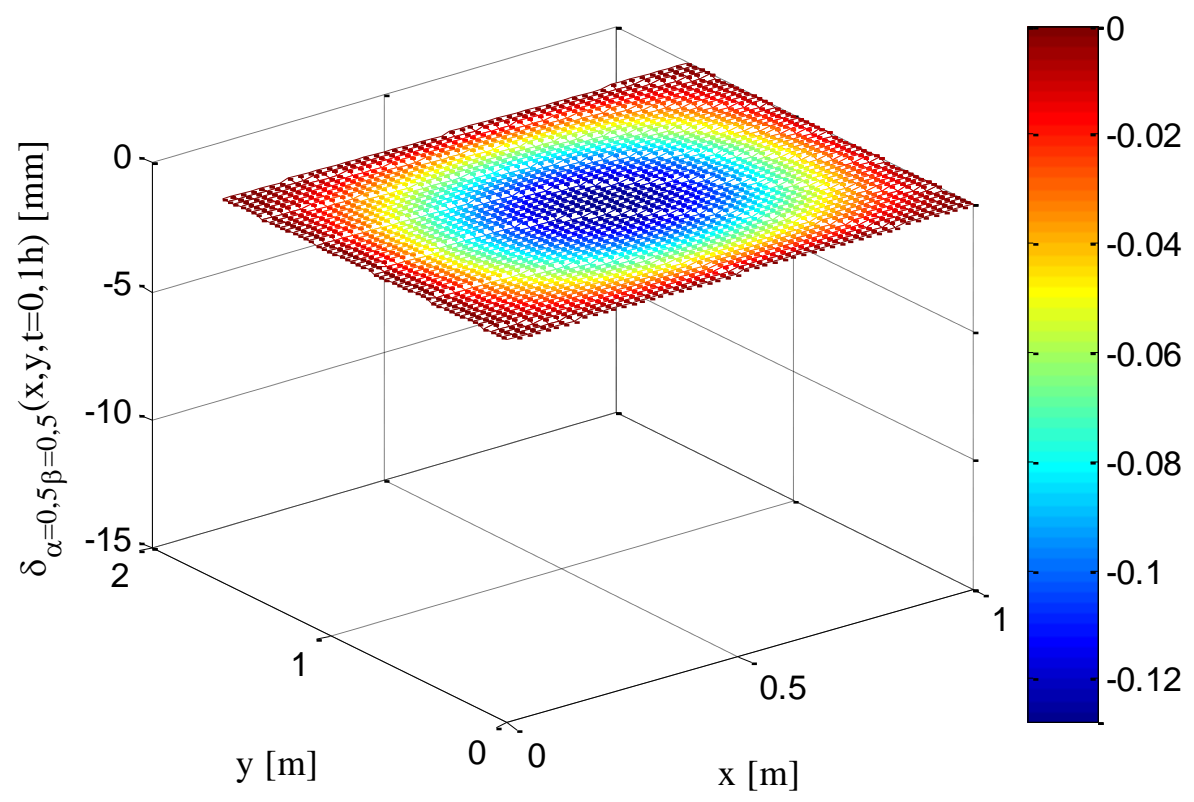

Figura 5.22 - Deslocamentos máximos placa anisotrópica $\mathrm{t}=0,1[\mathrm{~h}] \alpha=\beta=0,5$

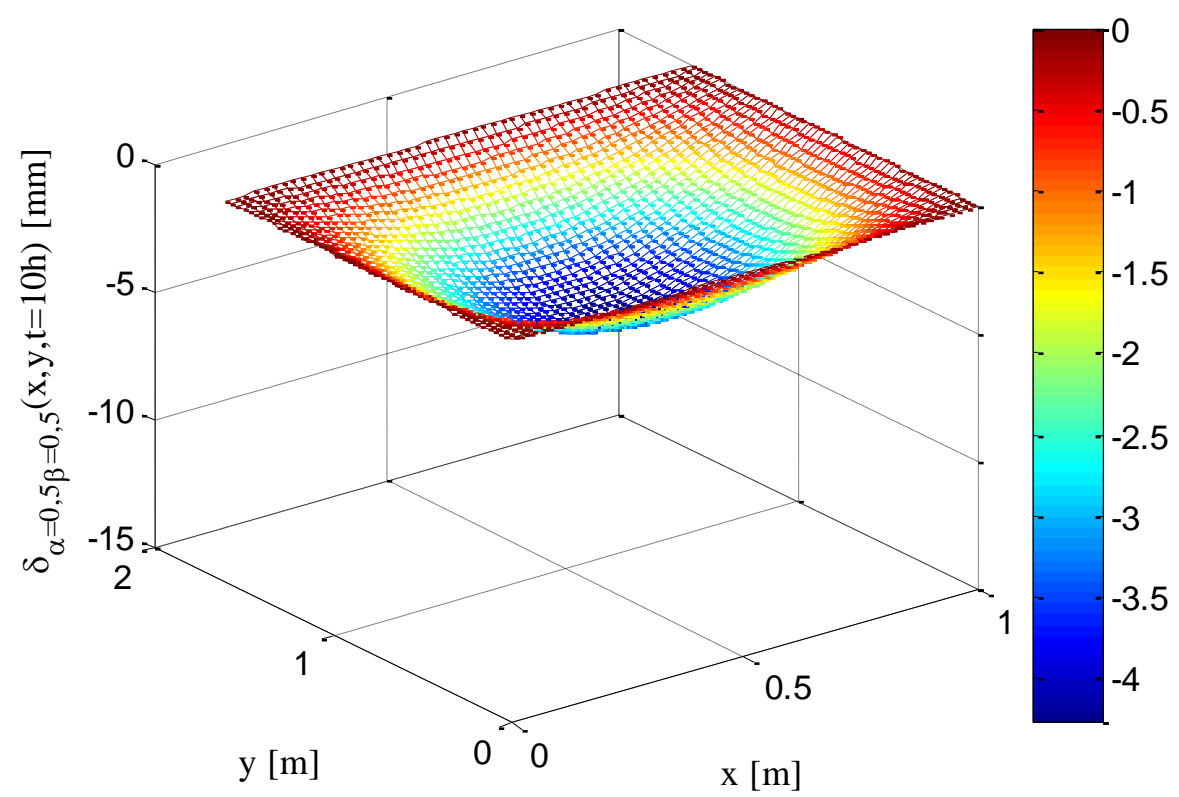

Figura 5.23 - Deslocamentos máximos placa anisotrópica $\mathrm{t}=10[\mathrm{~h}] \alpha=\beta=0,5$ 


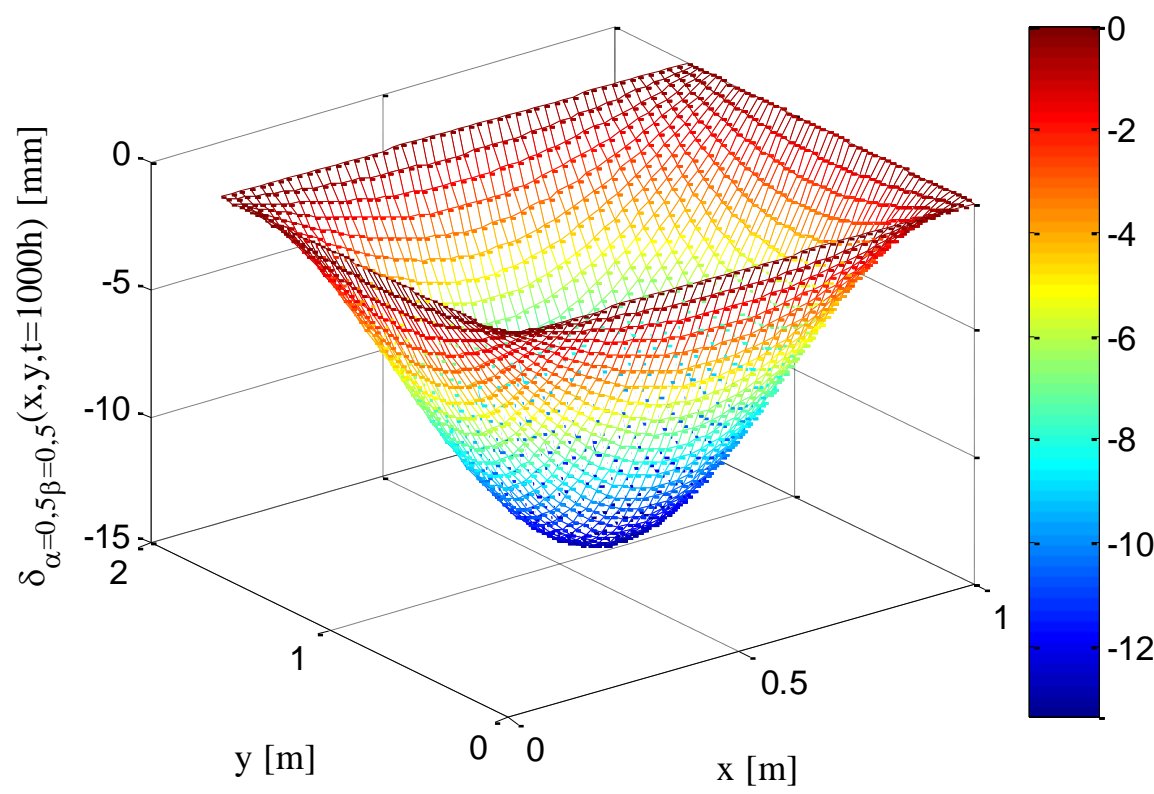

Figura 5.24 - Deslocamentos máximos placa anisotrópica $\mathrm{t}=1000[\mathrm{~h}] \alpha=\beta=0,5$

Segundo os deslocamentos máximos da placa quando $\alpha=\beta=0,5$, pode se apreciar como no tempo de $t=0,1$ h, ou seja, um carregamento instantâneo, as deflexões máximas são quase nulas, enquanto para $\mathrm{t}=10$ horas era de $4 \mathrm{~mm}$ e já no tempo de $\mathrm{t}=1000 \mathrm{~h}$ as deflexões chegam aos 13,5 mm, o que demostra como as deflexões podem ser progressivas de modo que pode comprometer a estabilidade estrutural, por efeito da viscoelasticidade do material.

\subsection{2 - AVALIAÇÃO DO COMPORTAMENTO DA PLACA ANISOTRÓPICA VISCOELÁSTICA PARA $\alpha=\beta=1$}

De forma análoga ao realizado no numeral anterior, desta vez avaliam-se as deflexões sem a afeitação por efeito da tração sob o material, ou seja, $\alpha=1$, e a placa será considerada isotrópica, $\beta=1$. Desta forma, pode ser avaliado realmente tanto a influência da anisotropia quanto a influência real da tração sobre a metade inferior da placa, por efeito da flexão.

Os resultados para as deflexões máximas obtidas para os tempos $t=0,1,10$ e $1000 \mathrm{~h}$ se registram na Figura 5.25, na Figura 5.26 e na Figura 5.27. Os valores máximos desses gráficos foram de aproximadamente $0,1 \mathrm{~mm}, 3 \mathrm{~mm}$ e $9,2 \mathrm{~mm}$. O anterior, comparado com as máximas deflexões obtidas quando $\alpha=\beta=0,5$ permitem afirmar que os aumentos dessas deflexões máximas por efeito num $50 \%$ da anisotropia e de $50 \%$ de diferença do material à tração, refletem num aumento de $20-46 \%$ nas deflexões. 


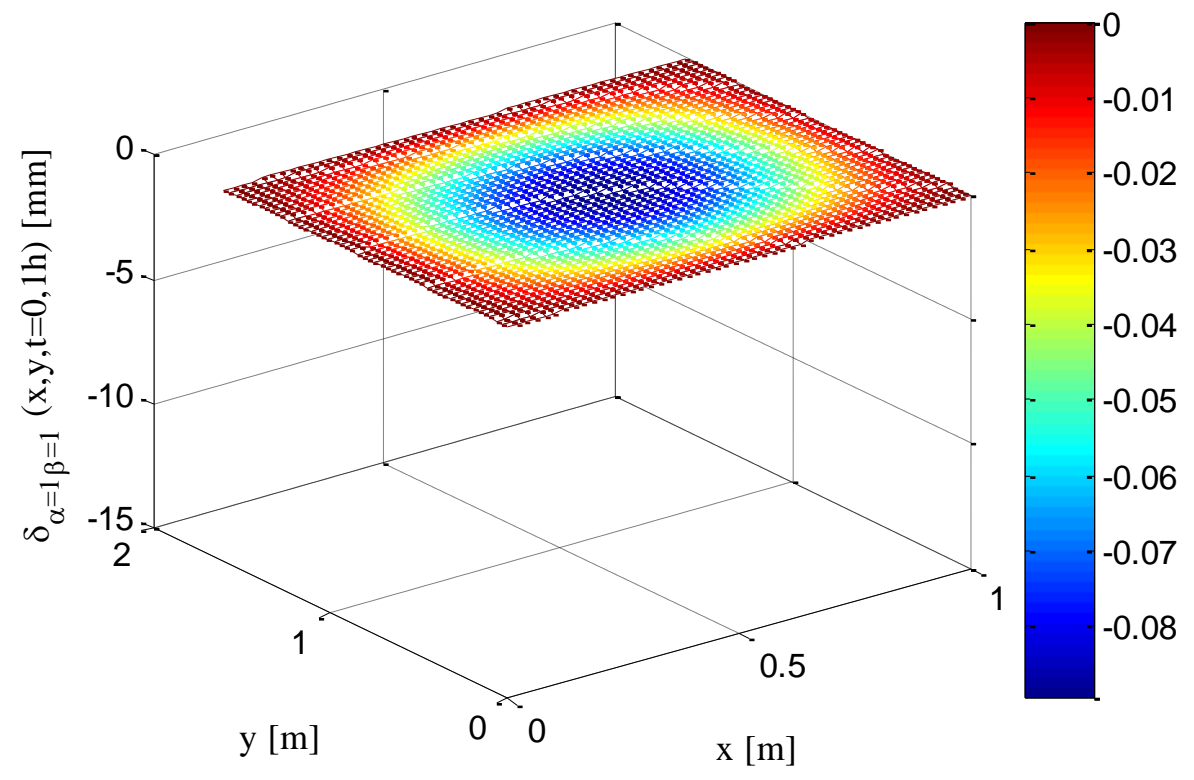

Figura 5.25 - Deslocamentos máximos placa anisotrópica $\mathrm{t}=0,1[\mathrm{~h}] \alpha=\beta=1$

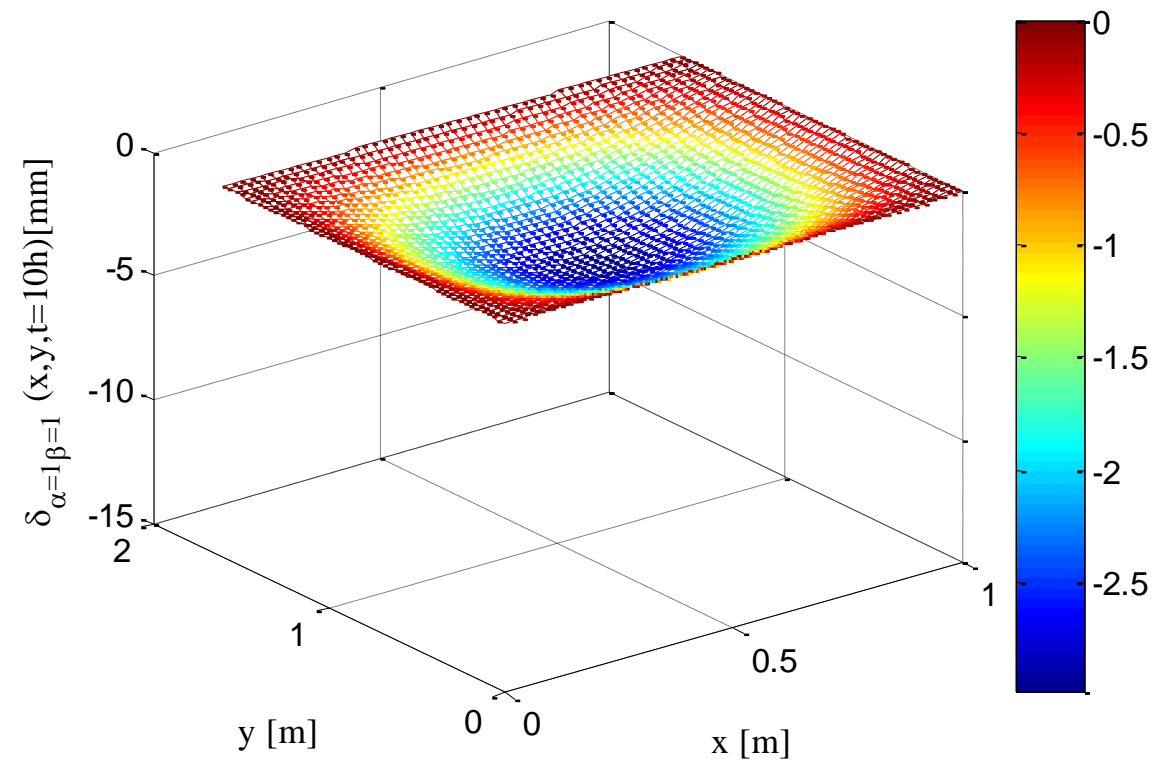

Figura 5.26 - Deslocamentos máximos placa anisotrópica $\mathrm{t}=10[\mathrm{~h}] \alpha=\beta=1$

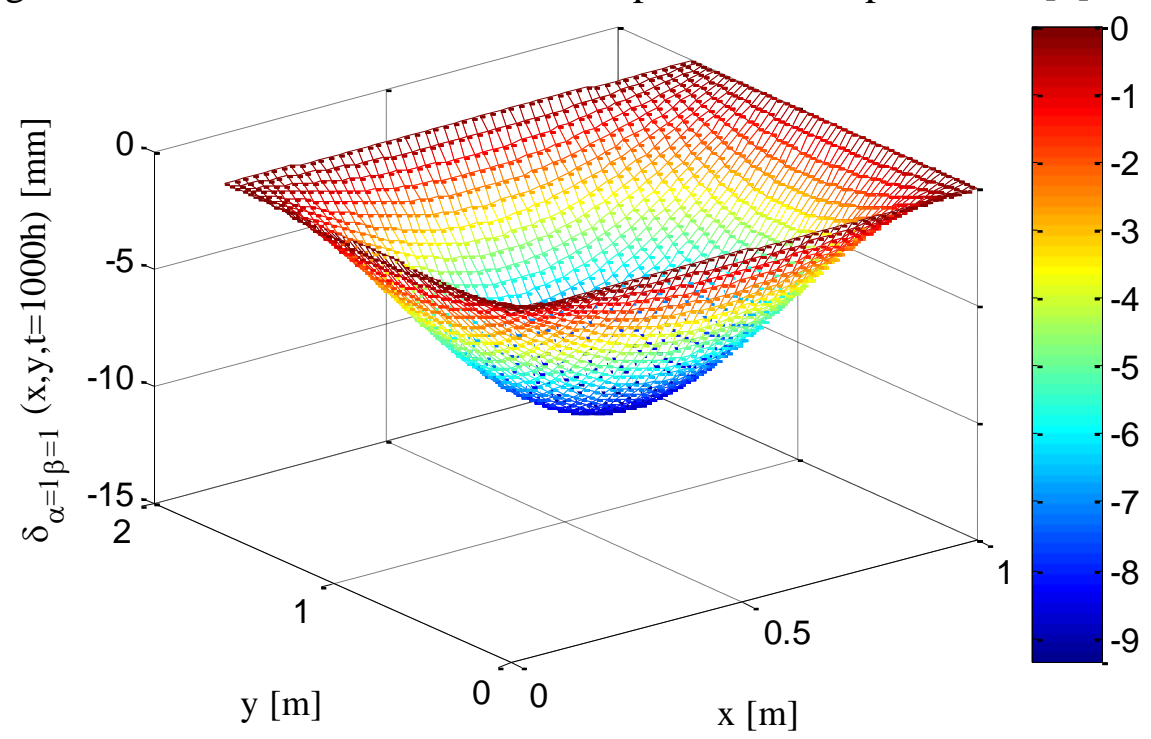

Figura 5.27 - Deslocamentos máximos placa anisotrópica $\mathrm{t}=1000[\mathrm{~h}] \alpha=\beta=1$ 
Assim, pode-se ver a influência dos fatores $\alpha$ e $\beta$ no comportamento da placa anisotrópica compósita proposta, mas, é preciso realizar um estudo paramétrico que permita ver o quanto influem e de que forma esses parâmetros $\alpha$ e $\beta$.

Dos resultados obtidos na presente avaliação, é importante ressaltar a importância da permanência do carregamento, pois em tempos muito altos, como por exemplo $t=1000 \mathrm{~h}, \mathrm{o}$ que equivale a pouco mais de 41 dias, os deslocamentos já são importantes, sendo mais preocupante ainda quando no caso de edifícios, as placas de concreto estão projetadas para durar 50 anos e carregamentos pequenos podem, ao longo desse período, desencadear deflexões máximas importantes para seu desempenho e devem ser avaliadas corretamente na etapa de projeto. 


\section{6- ANÁLISE DE SENSIBILIDADE POR EXPERIMENTOS NUMÉRICOS E SUPERFICIES DE RESPOSTA}

\section{1 - VIGA SANDUÍCHE VISCOELÁSTICA}

A análise de sensibilidade paramétrica consiste em avaliar o valor dos deslocamentos obtidos na viga sanduíche, ao variar um número de parâmetros definido, cada um com três possíveis valores. $\mathrm{O}$ valor da variável sem alterações chamada de $\mu$ e um valor definido de desvio chamado de $\sigma \mu$, sendo que cada variável pode ter ou o valor de $\mu$, ou o valor de $\mu+\sigma \mu$ ou o valor de $\mu-\sigma \mu$, como é apresentado na Tabela 6.1.

Tabela 6.1 - Variação dos parâmetros de estudo

\begin{tabular}{c|cccccc}
\hline \multicolumn{7}{c}{ Condições de referência } \\
\hline \multirow{3}{*}{$\mu$} & $\begin{array}{c}\mathrm{E} 1=\mathrm{E} 2 \\
{[\mathrm{MPa}]}\end{array}$ & $\begin{array}{c}\mathrm{h} 1=\mathrm{h} 2 \\
{[\mathrm{~m}]}\end{array}$ & $\begin{array}{c}\alpha \\
{[-]}\end{array}$ & $\begin{array}{c}\mathrm{T} \\
{[\mathrm{h}]}\end{array}$ & $\begin{array}{c}\text { Pmáx. } \\
{[\mathrm{MN}]}\end{array}$ & $\begin{array}{c}\mathrm{L} \\
{[\mathrm{m}]}\end{array}$ \\
\cline { 2 - 7 } & 70000 & $5,00 \mathrm{E}-04$ & 0,5 & 10 & $1,00 \mathrm{E}-03$ & 1 \\
\hline \multicolumn{7}{c}{ Desviação } \\
\hline \multirow{5}{*}{$\sigma \mu$} & $\mathrm{E} 1=\mathrm{E} 2$ & $\mathrm{~h} 1=\mathrm{h} 2$ & $\alpha$ & $\mathrm{T}$ & Pmáx. & $\mathrm{L}$ \\
& {$[\mathrm{MPa}]$} & {$[\mathrm{m}]$} & {$[-]$} & {$[\mathrm{h}]$} & {$[\mathrm{MN}]$} & {$[\mathrm{m}]$} \\
\cline { 2 - 7 } & 17500 & $1,25 \mathrm{E}-04$ & 0,25 & 5 & $4,00 \mathrm{E}-04$ & 0,25 \\
\hline \multirow{3}{*}{$\mathrm{Vr}}$. & $\mathrm{E} 1=\mathrm{E} 2$ & $\mathrm{~h} 1=\mathrm{h} 2$ & $\alpha$ & $\mathrm{T}$ & Pmáx. & $\mathrm{L}$ \\
& {$[\mathrm{MPa}]$} & {$[\mathrm{m}]$} & {$[-]$} & {$[\mathrm{h}]$} & {$[\mathrm{MN}]$} & {$[\mathrm{m}]$} \\
\hline$\mu-\sigma \mu$ & 52500 & 0,000375 & 0,25 & 5 & 0,0006 & 0,75 \\
$\mu$ & 70000 & 0,0005 & 0,5 & 10 & 0,001 & 1 \\
$\mu+\sigma \mu$ & 87500 & 0,000625 & 0,75 & 15 & 0,0014 & 1,25 \\
\hline
\end{tabular}

Adota-se um número finito de combinações aleatórias e posteriormente procede-se a determinar os valores dos deslocamento, onde as variáveis não consideradas no estudo permanecem com os valores propostos na Figura 5.1 e as variáveis comtempladas no estudo adotam os valores correspondentes à combinação avaliada, sendo as variações exclusivas a um dos três valores possíveis por variável, e finalmente poder obter as deflexões no tempo $t_{N}=1 / 2$ e $t_{N}=1$. Os valores possíveis por variável e as variáveis a serem estudadas no presente estudo apresentam-se na Tabela 6.1.

O tipo de carregamento imposto é o carregamento do tipo 1 ou de rampa, isso porque esse tipo de carregamento obteve os máximos deslocamentos centrais em comparação com os carregamentos impulsivos do mesmo período de aplicação T. A análise paramétrica permite obter uma função geral de segundo grau que permite determinar em qualquer valor das variáveis consideradas, dada por 28 coeficientes, um coeficiente independente das variáveis 
que representa a media dos valores, chamada de $\phi$, e 27 coeficientes que multiplicam cada uma das seis variáveis sendo os primeiros coeficientes multiplicando linearmente cada variável, um segundo grupo de coeficientes que multiplica cada variável ao quadrado e finalmente um coeficiente para cada combinação possível entre as seis variáveis, tal como é sucinto na Equação (6.1).

$$
\begin{aligned}
\boldsymbol{\delta}\left(\frac{L}{2}, t_{N}\right)=\phi & +\beta_{1} x_{1}+\beta_{2} x_{2} \ldots+\beta_{6} x_{6}+\beta_{7} x_{1}{ }^{2}+\beta_{8} x_{2}{ }^{2} \ldots+\beta_{12} x_{6}{ }^{2} \\
& +\beta_{13} x_{1} x_{2}+\beta_{14} x_{1} x_{3}+\cdots+\beta_{25} x_{4} x_{5}+\beta_{26} x_{4} x_{6}++\beta_{27} x_{5} x_{6}
\end{aligned}
$$

Os valores de cada um dos coeficientes $\beta_{i}$, quando $\mathrm{i}=0 . . .27$, multiplicam as variáveis $x_{j}$, quando $\mathrm{j}=1$...6. Os valores dos 28 coeficientes a serem achados se obtêm baseado na resolução matricial dada pela expressão da Equação (6.2).

$$
\boldsymbol{\beta}_{i}=\left(\boldsymbol{X}^{\prime} \boldsymbol{X}\right)^{-1} \boldsymbol{X}^{\prime} \boldsymbol{\delta}\left(\frac{L}{2}, t_{N}\right)
$$

A matriz $\mathbf{X}$ referida na Equação (6.2) é uma matriz de coeficientes de desvio, sendo que neste caso particular, correspondente aos coeficientes resultado das 54 combinações aleatórias propostas apresentadas no anexo C.1, para as quais foram calculadas as deflexões máximas para os tempos $\mathrm{t}=\mathrm{T} / 2 \mathrm{e} \mathrm{t}=\mathrm{T}$, correspondentes aos vetores $\delta$ da Equação (6.1). Obtidos os vetores dos 28 coeficientes de regressão estes estão consignados na coluna 3 e 4 da Tabela 6.2.

Nesta tabela na primeira coluna assigna o coeficiente a uma variável conhecida, na segunda coluna o nome da variável que multiplica o coeficiente, na terceira e quarta coluna consigna os valores do coeficiente de regressão obtidos para $t_{N}=1 / 2$ e $t_{N}=1$ com base na Equação (6.2) e a matriz X dada segundo os dados apresentados no Anexo C.2.

Nas colunas 5 e 6 da Tabela 6.2 se escreveram os coeficientes obtidos em porcentagem, sendo referidos ao coeficiente independente que representa o valor da media, tal e como se apresenta na Equação (6.3).

$$
\beta_{i}=\frac{\beta_{i}}{\phi} \times 100
$$


Tabela 6.2 - Coeficientes de regressão da função deslocamento em $t_{N}=1 / 2$ e $t_{N}=1$

\begin{tabular}{|c|c|c|c|c|c|c|c|c|}
\hline \multicolumn{4}{|c|}{ Coeficientes de regressão } & \multicolumn{2}{|c|}{$\begin{array}{l}\text { Coeficientes de } \\
\text { regressão \% }\end{array}$} & \multicolumn{3}{|c|}{$\begin{array}{l}\text { Coeficiente de regressão } \\
\text { variável numérica }\end{array}$} \\
\hline Variável & $\begin{array}{c}\text { Coef. de } \\
\text { regressão }\end{array}$ & $t_{N}=1 / 2$ & $\mathrm{t}_{\mathrm{N}}=1$ & $t_{N}=1 / 2$ & $\mathrm{t}_{\mathrm{N}}=1$ & Coef. real & $t_{N}=1 / 2$ & $\mathrm{t}_{\mathrm{N}}=1$ \\
\hline$\phi$ & $x 0$ & 1,706 & 3,146 & $100,00 \%$ & $100,00 \%$ & $\xi 0$ & $3,6 \mathrm{E}+00$ & $5,6 \mathrm{E}+00$ \\
\hline$E$ & $x 1$ & $-0,087$ & $-0,162$ & $-5,11 \%$ & $-5,16 \%$ & $\xi 1$ & $5,4 \mathrm{E}-06$ & $1,1 \mathrm{E}-05$ \\
\hline $\mathrm{h}$ & $x 2$ & $-0,089$ & $-0,164$ & $-5,20 \%$ & $-5,22 \%$ & $\xi 2$ & $1,9 \mathrm{E}+03$ & $3,5 \mathrm{E}+03$ \\
\hline$\alpha$ & $x 3$ & $-0,499$ & $-0,925$ & $-29,24 \%$ & $-29,41 \%$ & $\xi 3$ & $2,0 \mathrm{E}+00$ & $3,1 \mathrm{E}+00$ \\
\hline $\mathrm{T}$ & $x 4$ & 0,559 & 0,769 & $32,80 \%$ & $24,46 \%$ & $\xi 4$ & $-1,4 \mathrm{E}-01$ & $-2,0 \mathrm{E}-01$ \\
\hline Pmáx. & $x 5$ & 0,734 & 1,361 & $43,05 \%$ & $43,27 \%$ & $\xi 5$ & $-2,7 \mathrm{E}+03$ & $-4,5 \mathrm{E}+03$ \\
\hline $\mathrm{L}$ & $x 6$ & 1,351 & 2,507 & $79,24 \%$ & $79,70 \%$ & $\xi 6$ & $-8,6 \mathrm{E}+00$ & $-1,4 \mathrm{E}+01$ \\
\hline$E^{\wedge} 2$ & $x 1^{\wedge} 2$ & 0,022 & 0,033 & $1,27 \%$ & $1,05 \%$ & $\xi 1^{\wedge} 2$ & $7,1 \mathrm{E}-11$ & $1,1 \mathrm{E}-10$ \\
\hline $\mathrm{h}^{\wedge} 2$ & $x 2^{\wedge} 2$ & 0,000 & $-0,002$ & $0,00 \%$ & $-0,05 \%$ & $\xi 2^{\wedge} 2$ & $-8,4 \mathrm{E}+02$ & $-1,1 \mathrm{E}+05$ \\
\hline$\alpha^{\wedge} 2$ & $x 3^{\wedge} 2$ & 0,171 & 0,318 & $10,01 \%$ & $10,12 \%$ & $\xi 3^{\wedge} 2$ & $2,7 \mathrm{E}+00$ & $5,1 \mathrm{E}+00$ \\
\hline $\mathrm{T}^{\wedge} 2$ & $x 4^{\wedge} 2$ & $-0,116$ & $-0,152$ & $-6,80 \%$ & $-4,84 \%$ & $\xi 4^{\wedge} 2$ & $-4,6 \mathrm{E}-03$ & $-6,1 \mathrm{E}-03$ \\
\hline Pmáx^2 & $x 5^{\wedge} 2$ & $-0,003$ & $-0,007$ & $-0,18 \%$ & $-0,24 \%$ & $\xi 5^{\wedge} 2$ & $-1,9 \mathrm{E}+04$ & $-4,7 \mathrm{E}+04$ \\
\hline $\mathrm{L}^{\wedge} 2$ & $x 6^{\wedge} 2$ & 0,323 & 0,598 & $18,91 \%$ & $19,02 \%$ & $\xi 6^{\wedge} 2$ & $5,2 \mathrm{E}+00$ & $9,6 \mathrm{E}+00$ \\
\hline E.h & $x 1 . x 2$ & $-0,012$ & $-0,022$ & $-0,69 \%$ & $-0,70 \%$ & $\xi 1 . \xi 2$ & $-5,4 \mathrm{E}-03$ & $-1,0 \mathrm{E}-02$ \\
\hline E. $\alpha$ & $x 1 . x 3$ & 0,058 & 0,106 & $3,39 \%$ & $3,39 \%$ & $\xi 1 . \xi 3$ & $1,3 \mathrm{E}-05$ & $2,4 \mathrm{E}-05$ \\
\hline E.T & $x 1 . x 4$ & $-0,023$ & $-0,031$ & $-1,32 \%$ & $-0,98 \%$ & $\xi_{1} . \xi_{4}$ & $-2,6 \mathrm{E}-07$ & $-2,6 \mathrm{E}-07$ \\
\hline E.Pmáx & $x 1 . x 5$ & $-0,029$ & $-0,054$ & $-1,68 \%$ & $-1,71 \%$ & $\xi 1 . \xi_{5}$ & $-4,1 \mathrm{E}-03$ & $-7,7 \mathrm{E}-03$ \\
\hline E.L & $x 1 . x 6$ & $-0,077$ & $-0,141$ & $-4,50 \%$ & $-4,50 \%$ & $\xi 1 . \xi 6$ & $-1,8 \mathrm{E}-05$ & $-3,2 \mathrm{E}-05$ \\
\hline h. $\alpha$ & $x 2 . x 3$ & 0,049 & 0,091 & $2,90 \%$ & $2,90 \%$ & $\xi 2 . \xi 3$ & $1,6 \mathrm{E}+03$ & $2,9 \mathrm{E}+03$ \\
\hline h.T & $x 2 . x 4$ & $-0,023$ & $-0,031$ & $-1,33 \%$ & $-0,99 \%$ & $\xi 2 . \xi_{4}$ & $-3,6 \mathrm{E}+01$ & $-5,0 \mathrm{E}+01$ \\
\hline h.Pmáx & $x 2 . x 5$ & $-0,039$ & $-0,072$ & $-2,28 \%$ & $-2,28 \%$ & $\xi 2 . \xi 5$ & $-7,8 \mathrm{E}+05$ & $-1,4 \mathrm{E}+06$ \\
\hline h.L & $x 2 . x 6$ & $-0,059$ & $-0,110$ & $-3,49 \%$ & $-3,49 \%$ & $\xi 2 . \xi 6$ & $-1,9 \mathrm{E}+03$ & $-3,5 E+03$ \\
\hline$\alpha . T$ & $x 3 . x 4$ & $-0,159$ & $-0,219$ & $-9,33 \%$ & $-6,96 \%$ & $\xi 3 . \xi 4$ & $-1,3 \mathrm{E}-01$ & $-1,8 \mathrm{E}-01$ \\
\hline a.Pmáx & $x 3 . x 5$ & $-0,182$ & $-0,335$ & $-10,66 \%$ & $-10,66 \%$ & $\xi 3 . \xi 5$ & $-1,8 \mathrm{E}+03$ & $-3,4 \mathrm{E}+03$ \\
\hline$\alpha . \mathrm{L}$ & $x 3 . x 6$ & $-0,334$ & $-0,622$ & $-19,61 \%$ & $-19,77 \%$ & $\xi 3 . \xi 6$ & $-5,4 \mathrm{E}+00$ & $-1,0 \mathrm{E}+01$ \\
\hline T.Pmáx & $x 4 . x 5$ & 0,204 & 0,280 & $11,94 \%$ & $8,90 \%$ & $\xi 4 . \xi 5$ & $1,0 \mathrm{E}+02$ & $1,4 \mathrm{E}+02$ \\
\hline T.L & $x 4 . x 6$ & 0,422 & 0,581 & $24,76 \%$ & $18,47 \%$ & $\xi 4 . \xi 6$ & 3,4E-01 & 4,6E-01 \\
\hline Pmáx.L & $x 5 . x 6$ & 0,519 & 0,957 & $30,41 \%$ & $30,41 \%$ & $\xi 5 . \xi 6$ & $5,2 \mathrm{E}+03$ & $9,6 \mathrm{E}+03$ \\
\hline
\end{tabular}

Desta forma pode-se apreciar claramente quais são as variáveis comandantes na função da deflexão no centro da viga, tanto no tempo $t_{N}=1 / 2$ quanto no tempo $t_{N}=1$. Os coeficientes obtidos devem ser transformados à variável natural para poder obter com esses o valor real das deflexões, fazendo as transformações dadas pela Equação (6.4).

$$
x_{j}=\frac{\xi_{j}-\xi_{0}}{d \xi_{j}}
$$

Na Equação (6.4) $\xi_{0}=\mu, d \xi_{j}=\sigma \mu$ e $\xi_{j}$ o valor da variável que quer-se avaliar, desta forma substituíram-se as seis transformações de variável $x_{j}$ dada pela Equação (6.4) na Equação 
(6.1), com cada um dos valores dos coeficientes encontrados multiplicando $x_{j}$ e desta forma se obtém os coeficientes em variável natural consignados nas colunas 8 e 9 da Tabela 6.2.

\subsection{1 - Deflexões máximas avaliadas em $\mathrm{t}_{\mathrm{N}}=1 / 2$}

Da Tabela 6.2 na coluna 3 tomaram-se os coeficientes porcentuais em relação ao valor médio destes e obtiveram-se os resultados consignados na Figura 6.1, onde se evidencia claramente os parâmetros de maior influência tanto para o aumento das deflexões (valores positivos) quanto na diminuição (valores negativos).

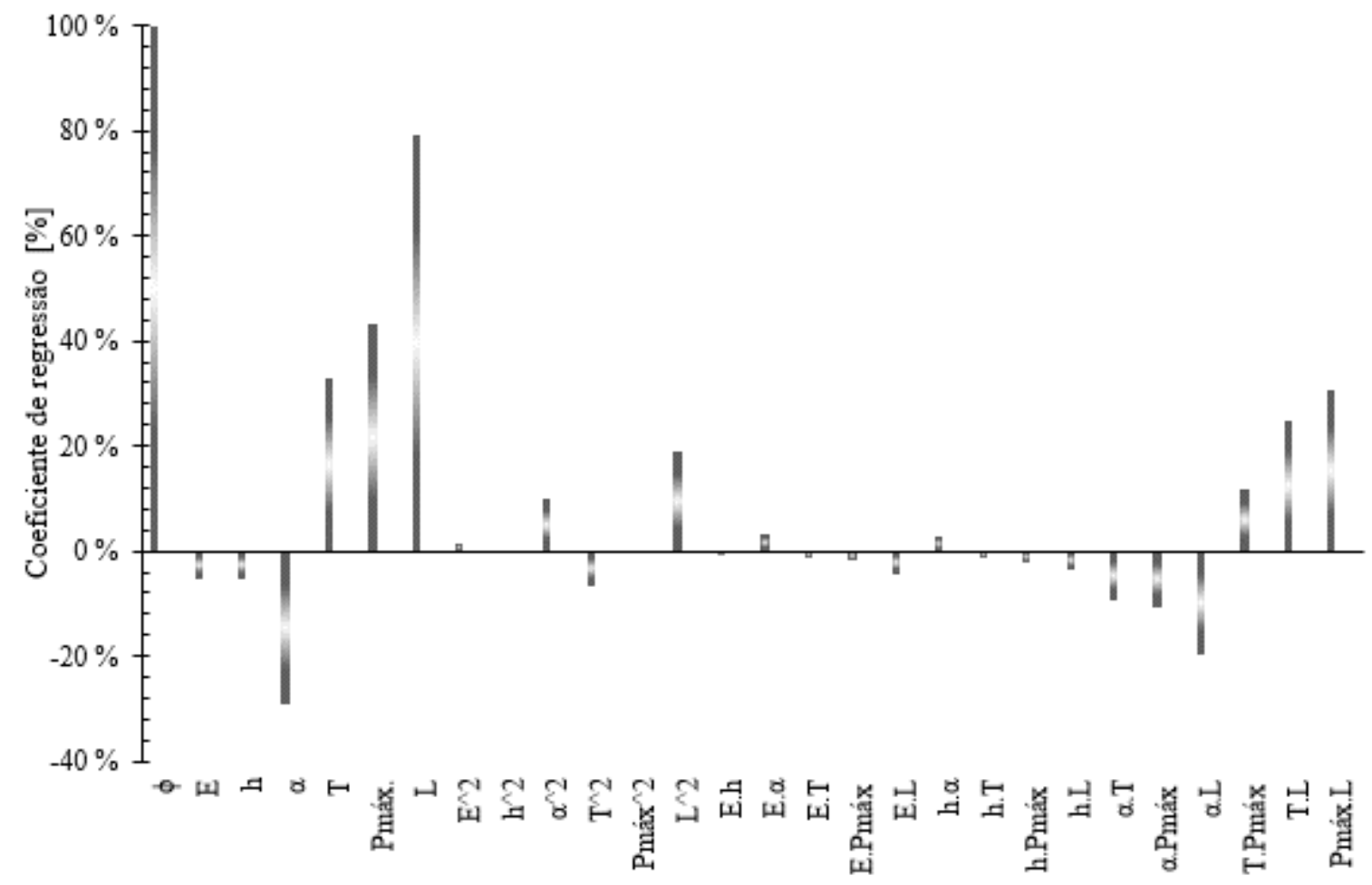

Figura 6.1 - Comparação porcentual dos coeficientes de regressão da função deflexão em $\mathrm{t}_{\mathrm{N}}=1 / 2$

$\mathrm{O}$ aumento das deflexões máximas no tempo $\mathrm{t}_{\mathrm{N}}=1 / 2$ dependem em ordem de importância das seguintes variáveis: o comprimento da viga $L$, a magnitude máxima do carregamento $\mathrm{P}$ máx. e o período de aplicação do carregamento T. Oposto desses, enquanto maior for o valor de $\alpha$ diminuem as deflexões máximas, sendo este o sentido do sinal negativo apresentado pelo coeficiente da variável.

As variáveis estudadas são lineares e por isso os coeficientes das variáveis de segundo grau são tão baixos em comparação com os coeficientes de primeira ordem. Já nas combinações das variáveis apresentam uma variação considerável as interações dadas entre P máx. e L, T e L, T e P máx. e na diminuição $\alpha$ e L. Para analisar melhor o comportamento de cada uma 
dessas iterações entre as variáveis, avaliaram-se as deflexões máximas adotando um intervalo de valores perto do valor inicial da variável. Assim, a iteração das variáveis P máx. e L apresenta-se na Figura 6.2.

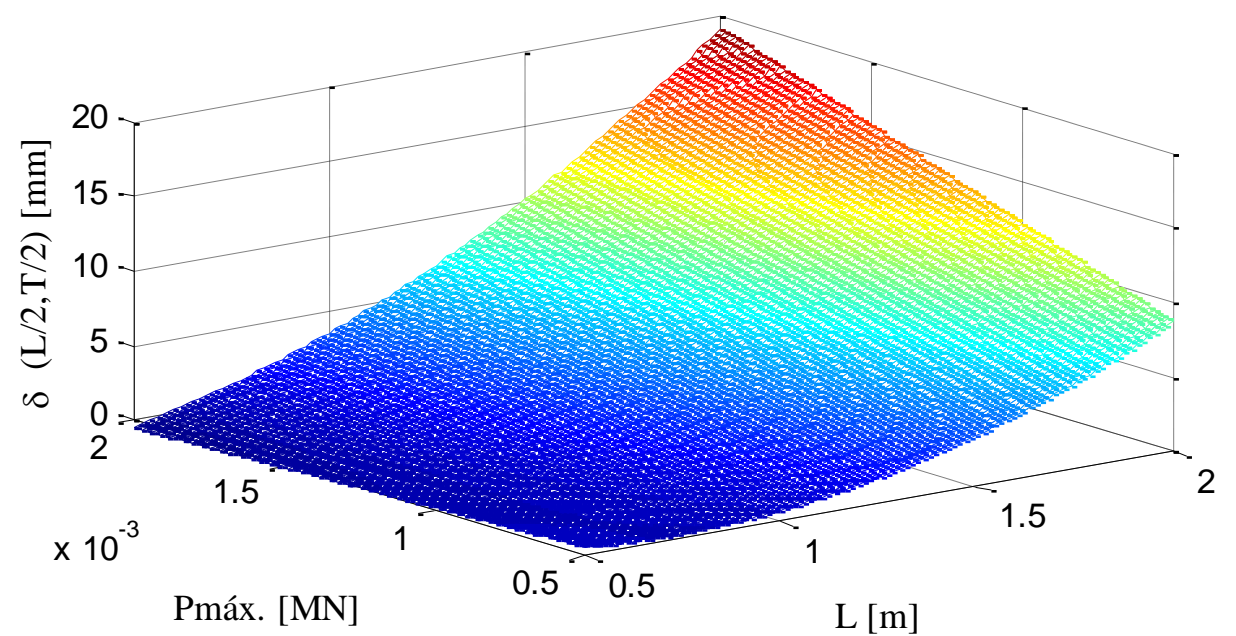

Figura 6.2 - Avaliação de L Vs. P máx. no aumento das deflexões em $\mathrm{t}_{\mathrm{N}}=1 / 2$

Como era de se esperar dados os resultados dos coeficientes porcentuais, a Figura 6.2 confirma que enquanto maiores foram os parâmetros de comprimento $L$ e magnitude máxima do carregamento P máx., maiores serão também as deflexões máximas. Espera-se que um comportamento similar seja apresentado na iteração do comprimento L comparado com o período de aplicação do carregamento T, apresentado na Figura 6.8, e da iteração da máxima magnitude do carregamento $\mathrm{P}$ máx. e o período no que esta é aplicada $\mathrm{T}$, apresentada na Figura 6.9.

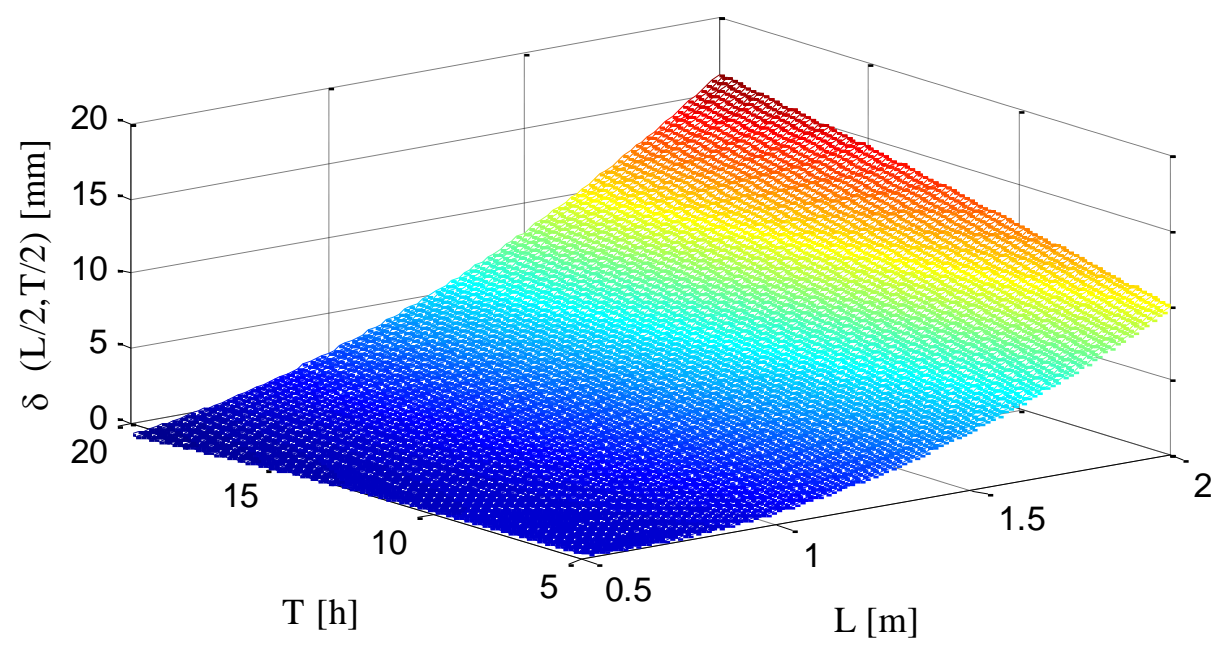

Figura 6.3 - Avaliação de L Vs. T no aumento das deflexões em $t_{N}=1 / 2$

Na Figura 6.3 se evidencia a maior influência do comprimento L comparado com o parâmetro do período T. Note-se que o período T só influi para comprimentos superiores ao 
valor de $\mathrm{L}=1 \mathrm{~m}$, ou seja, superiores ao valor médio do comprimento, e são levemente inferiores às deflexões obtidas na iteração de L e Pmáx. Na Figura 6.9 o aumento dos deslocamentos centrais da viga aumenta por efeito do aumento das variáveis T e P máx, mas o aumento é inferior ao obtido pelas iterações da Figura 6.3 e menores ainda do que as apresentadas na Figura 6.2.

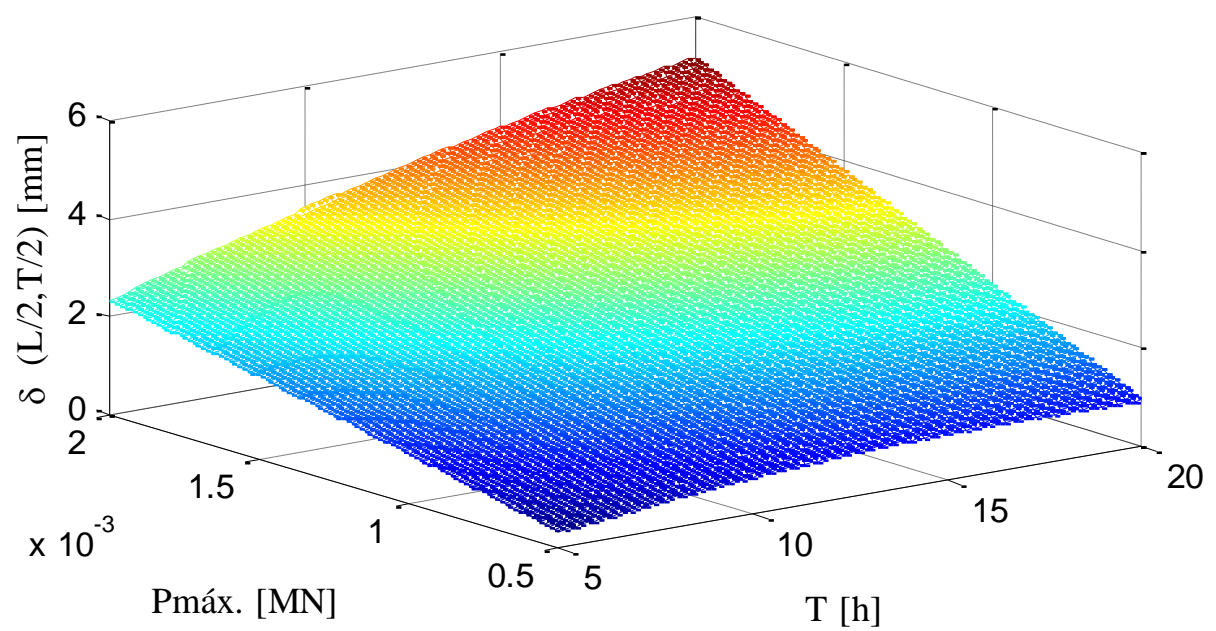

Figura 6.4 - Avaliação de P máx. Vs. T no aumento das deflexões em $\mathrm{t}_{\mathrm{N}}=1 / 2$

Na quarta iteração estudada o parâmetro $\alpha$ tem a maior incidência negativa, ou seja, entre maior for esse parâmetro menores são os deslocamentos, sem embargo, o parâmetro L têm a maior influência positiva ou no aumento dos deslocamentos da viga na seção central. Assim, este comportamento é apresentado graficamente na Figura 6.5.

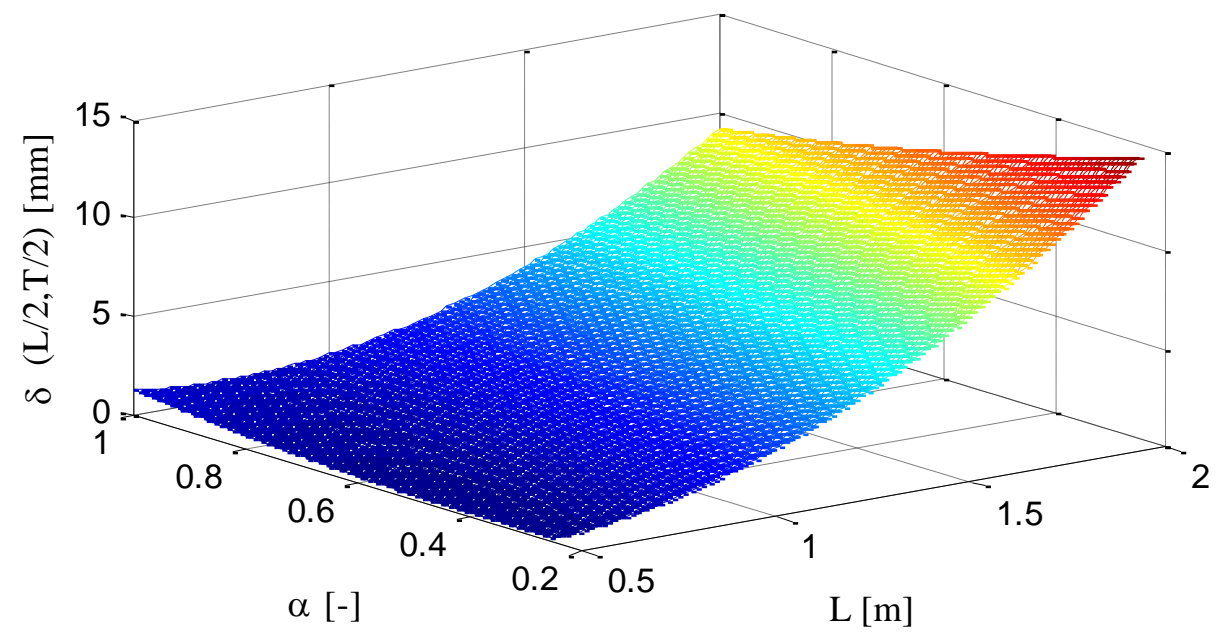

Figura 6.5 - Avaliação de $\alpha$ Vs. L no aumento das deflexões em $t_{N}=1 / 2$ 
Desta forma, uma análise paramétrica pode ser utilizada em múltiplas aplicações para avaliar corretamente o quanto é importante a variação de um parâmetro específico, e assim lograr optimizações nas estruturas estudadas, neste caso das vigas sanduíche com núcleo de espuma rígida de poliestireno.

\subsection{2 - Deflexões máximas avaliadas em $\mathrm{t}_{\mathrm{N}}=1 / 2$}

Análogo ao procedimento realizado para as variáveis analisadas no numeral 6.1.1 - , realizou-se uma exposição gráfica da influência de cada uma das variáveis medida pelo porcentagem de influência de cada um dos coeficientes que multiplicam as variáveis no tempo $t_{N}=1$, apresentado na Figura 6.6. Note-se que a tendência dada pelos coeficientes no tempo $t_{N}=1$ é similar à dada no tempo $t_{N}=1 / 2$, isto deve-se a que o material do núcleo conserva o comportamento em condições viscoelásticas.

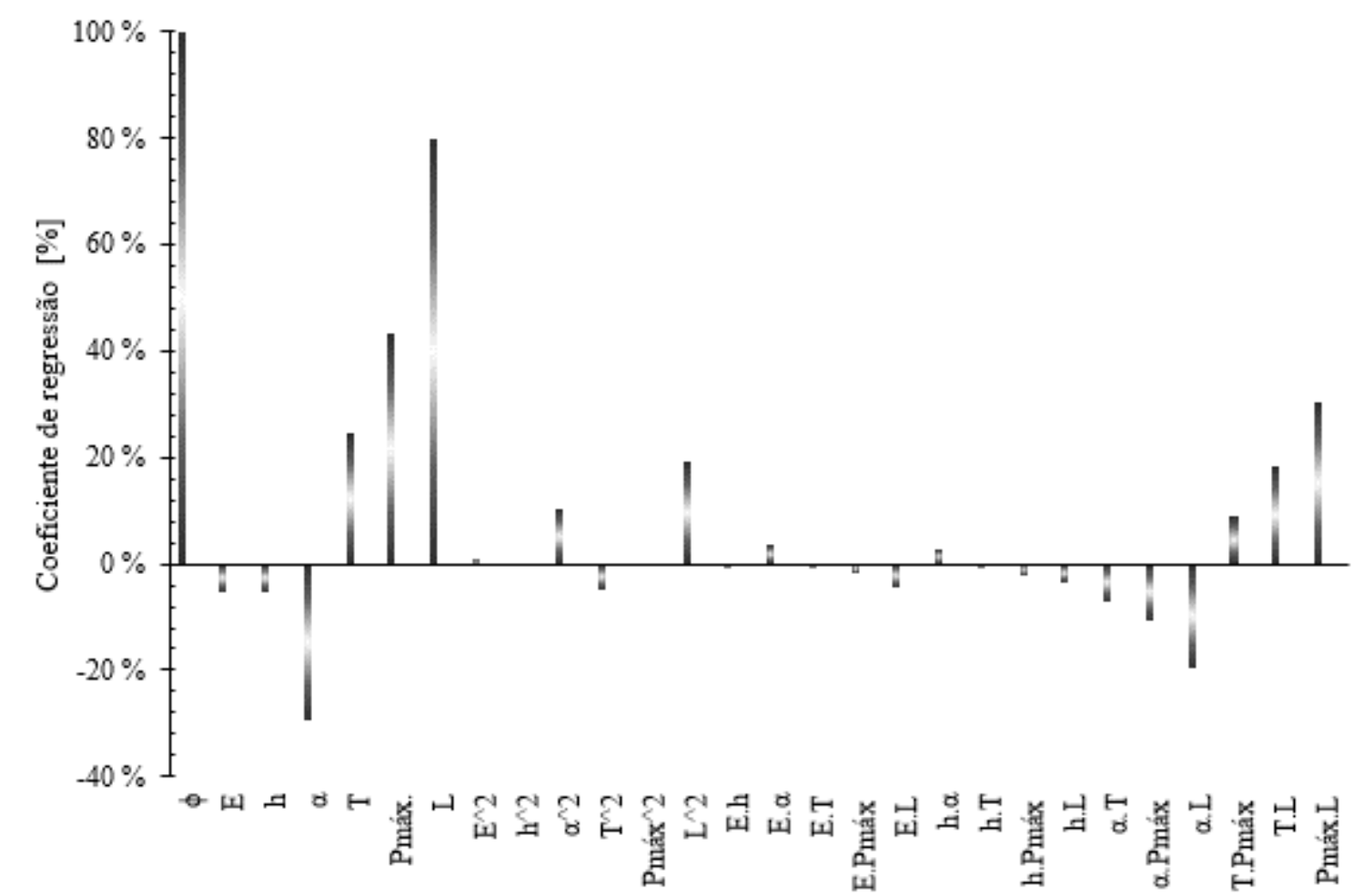

Figura 6.6 - Comparação porcentual dos coeficientes de regressão da função deflexão em $\mathrm{t}_{\mathrm{N}}=1$

Como os parâmetros que influenciam o aumento e diminuição dos deslocamentos máximos no tempo $t_{N}=1$ são os mesmos que na avaliação de $t_{N}=1 / 2$, por tanto, realizaram-se as mesmas comparações paramétricas e foram consignadas assim: na Figura 6.7 a comparação do comprimento L com a magnitude máxima do carregamento P máx, na Figura 6.8 comparouse o comprimento L e o período do carregamento T, na Figura 6.9 avaliou-se a máxima 
magnitude do carregamento P máx. e o período de aplicação do carregamento T, e finalmente na Figura 6.10 comparou-se $\alpha$ e o comprimento L.

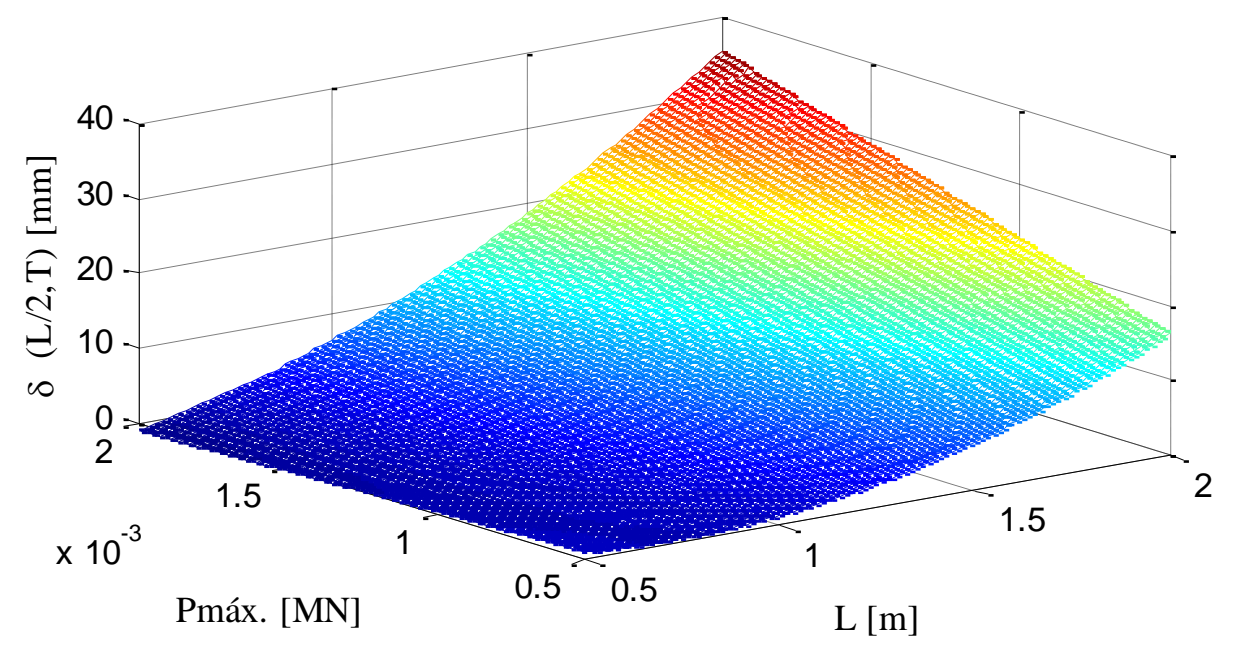

Figura 6.7 - Avaliação de L Vs. P máx. no aumento das deflexões em $\mathrm{t}_{\mathrm{N}}=1$

Na comparação da Figura 6.7 apresenta-se a mesma tendência que na avaliação feita no tempo $t_{N}=1 / 2$, sem embargo, os valores das deflexões máximas dadas pelo aumento dos valores das variáveis L e P máx. produzem na estrutura deslocamentos maiores do que no tempo $t_{\mathrm{N}}=1 / 2$, isto devido ao tipo de carregamento avaliado, no entanto se tivesse sido escolhido um carregamento impulsivo muito possivelmente o comportamento para $t_{N}=1$ seria totalmente diferente.

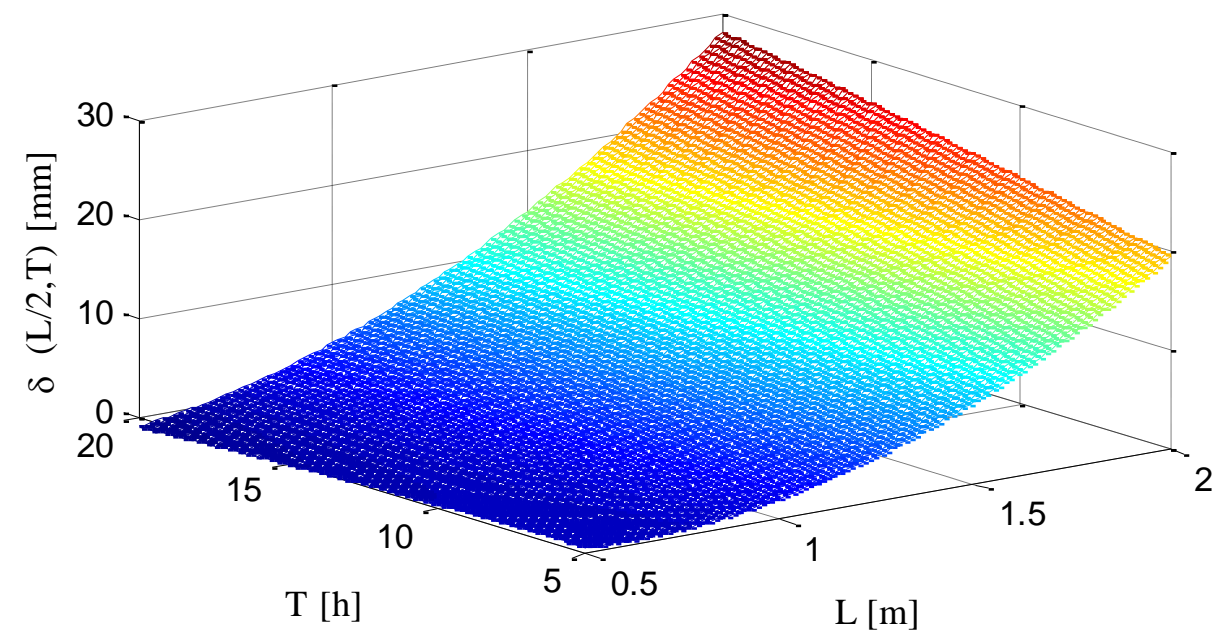

Figura 6.8 - Avaliação de L Vs. T no aumento das deflexões em $t_{N}=1$

Note-se que os comportamentos apresentados nas Figuras correspondentes para $t_{N}=1$ comparadas com as de $t_{N}=1 / 2$ são similares, sendo superiores os deslocamentos obtidos para 
$t_{N}=1$, isto devido ao efeito da viscoelasticidade ainda depois do carregamento ser constante no tempo no carregamento do tipo 1 .

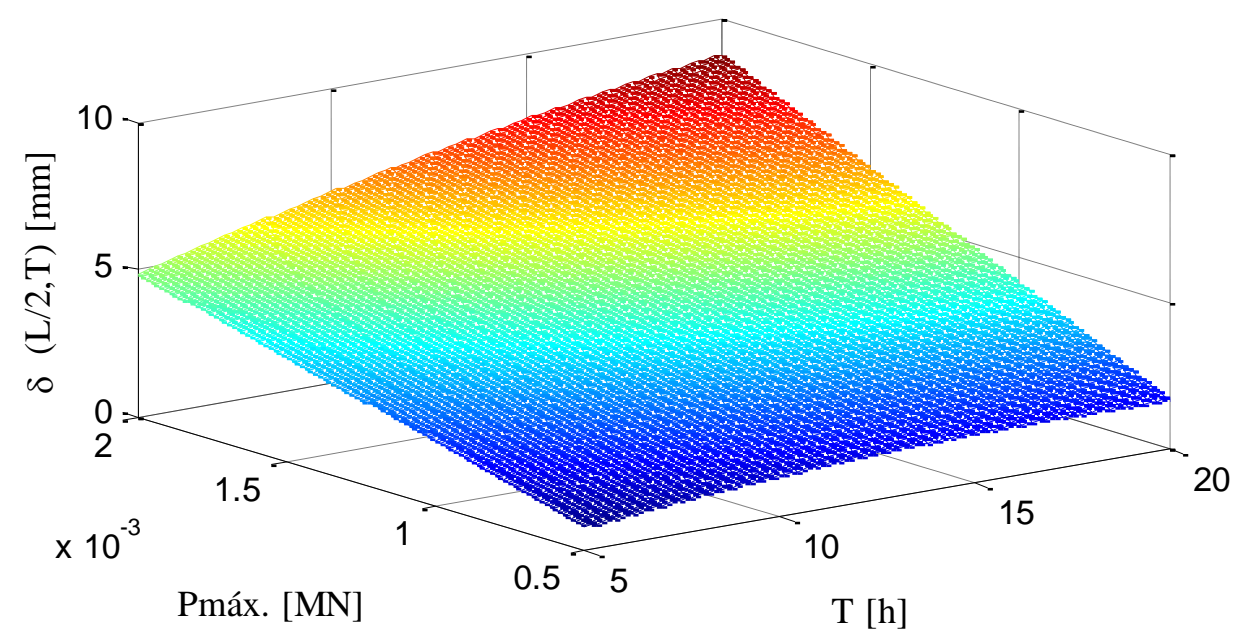

Figura 6.9 - Avaliação de P máx. Vs. T no aumento das deflexões em $t_{N}=1$

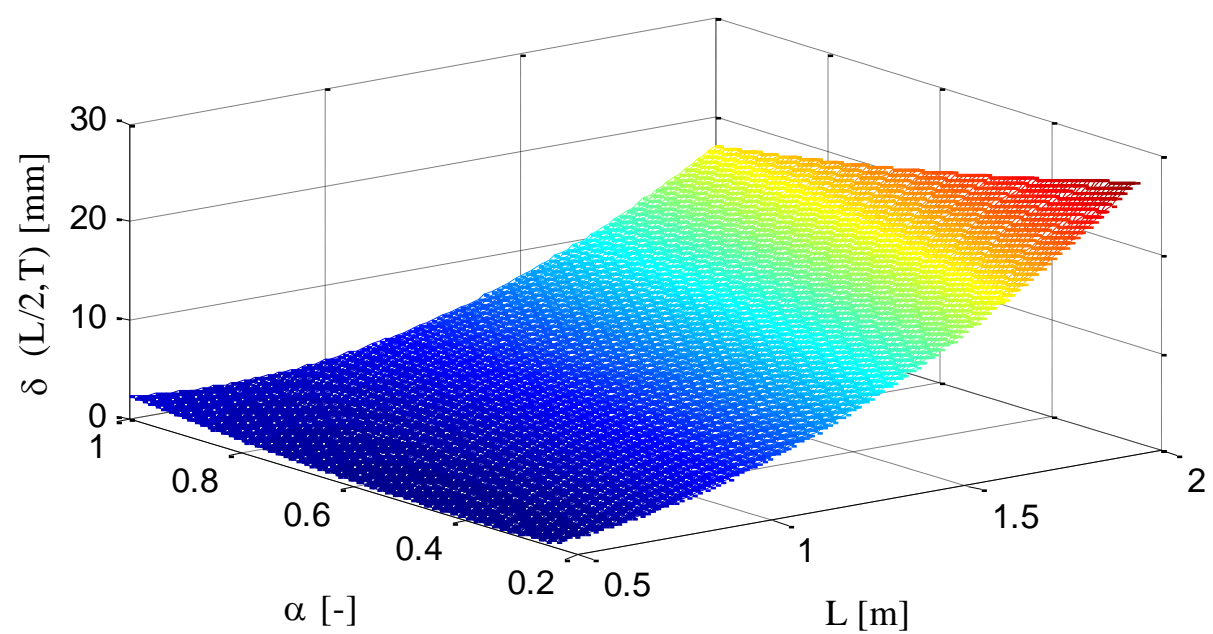

Figura 6.10 - Avaliação de L Vs. $\alpha$ no aumento das deflexões em $t_{N}=1$

Segundo as análises realizadas na presente pesquisa pode-se concluir que utilizando algoritmos numéricos para avaliar propriedades mecânicas dos materiais de forma rápida, eficiente e com alta confiabilidade. Em quanto para um algoritmo numérico é questão de minutos obter, por exemplo, os resultados dos 54 casos avaliados na análise de sensibilidade paramétrica, de ser necessário realiza-lo por exemplo num programa de elementos finitos o usuário teria que realizar 54 modelos e analisar um a um para obter os resultados, o que com o algoritmo proposto otimiza tempo e esforço, além de que o erro dos resultados finais contemplam um erro desprezível. 


\section{2 - PLACA ANISOTRÓPICA COMPÓSITA}

Segundo o analisado no Capítulo 5, numeral 5.2.1 e 5.2.2, os parâmetros $\alpha$ e $\beta$ têm grande influência sob as deflexões máximas na placa estudada, e apresentada na Figura 5.21. Para isto, avalia-se as deflexões máximas normalizadas $\delta_{N}$, calculadas segundo a Equação (6.5).

$$
\delta_{N}=\frac{\delta_{x=a / 2, y=b / 2}\left(t_{j}, \alpha, \beta\right)}{\delta_{x=\frac{a}{2}, y=\frac{b}{2}}\left(t_{j}, \alpha=1, \beta=1\right)}[\mathrm{mm} / \mathrm{mm}]
$$

As deflexões máximas calculadas para os tempos $\mathrm{t}=0,1$ e $10 \mathrm{~h}$ apresentam-se correspondentemente na Figura 6.11 e na Figura 6.12, onde pode-se apreciar claramente a influência não linear dos parâmetros, sendo mais não linear o parâmetro $\beta$, ou seja, tem uma maior não linearidade a anisotropia comparada com a mudança na resistência do material à tração.

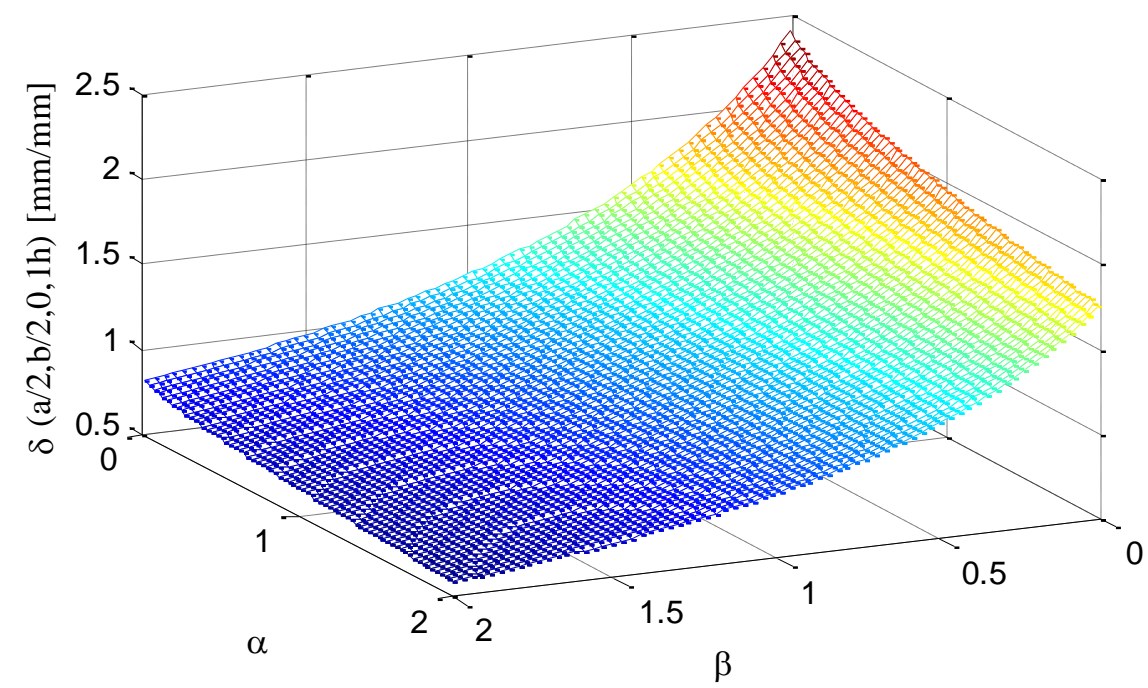

Figura 6.11 - Avaliação de.$\alpha$ Vs. $\beta$ no aumento das deflexões em $\mathrm{t}=0,1[\mathrm{~h}]$

Também pode-se concluir que nos efeitos normalizados, al comparar a Figura $6.11 \mathrm{com}$ a superfície da Figura 6.12, a tendência paramétrica é similar, sem importar o tempo de avaliação e permanência do carregamento $q$. Também resulta interessante o efeito obtido quando os dois parâmetros são nulos, pois as deflexões aumentam perto de 2,5 vezes.

Quando os valores desses parâmetros são $\alpha=\beta=2$, o valor do deslocamento é 0,5 vezes, ou seja, é o aporte real da placa no sentido x e considerando somente a metade da seção. 


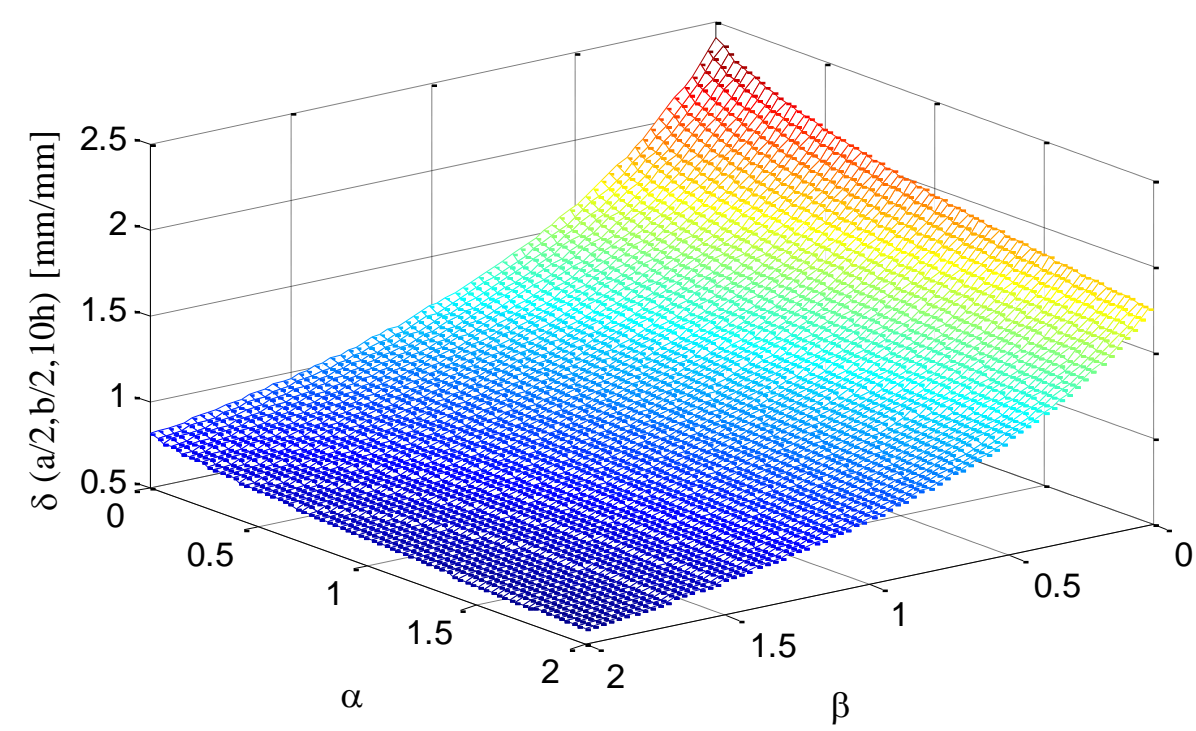

Figura 6.12 - Avaliação de . $\alpha$ Vs. $\beta$ no aumento das deflexões em $\mathrm{t}=10$ [h]

Segundo os resultados obtidos no presente estudo, ao estudar o efeito da viscoelasticidade em placas, é de grande importância tanto a determinação experimental da resistência do material tanto nas diferentes direções, quanto a diferencia dos testes à fluência realizados em tração e compressão, sendo parâmetros definitivos a terem em consideração para o cálculo realista de deflexões máximas. 


\section{7 - CONCLUSÕES E SUGESTÕES PARA TRABALHOS FUTUROS 7.1 - CONCLUSÕES}

Os métodos numéricos formulados e verificados para a análise da viscoelasticidade são aplicáveis em inúmeros elementos estruturais compósitos, tanto como foi mostrado nas diferentes verificações realizadas, onde analisou-se o comportamento viscoelástico desde modelos até elementos estruturais como barras e vigas, obtendo resultados com uma garantida aproximação aos resultados obtidos pelos diferentes métodos numéricos e analíticos comparados.

Os métodos numéricos implementados na presente pesquisa: o método de aproximação às séries de Prony, os métodos de interconversão elástica e viscoelástica e o método incremental tanto no campo das tensões quanto das deformações, provaram serem altamente confiáveis, uma vez que o erro dos resultados obtidos na aplicação da metodologia, em comparação com os obtidos pelo MEF, não é mais do que 4,5\%, e esse valor corresponde somente nos tempos iniciais, diminuindo menos do que $1 \%$ em tempos posteriores.

Além disso, a portabilidade e eficiência dos métodos numéricos permitiram realizar estudos de sensibilidade por superfícies de resposta, conseguindo como dados de entrada múltiplas combinações paramétricas de forma rápida, oposto do amplo tempo investido na geração de modelos individuais pelo MEF, sem sacrificar a exatidão da resposta mecânica dos elementos estruturais em condições elásticas ou viscoelásticas.

Pode-se concluir também que os carregamentos de maior impacto nas vigas sanduíche são os carregamentos permanentes, e aumentam gradualmente a importância os carregamentos impulsivos enquanto mais tempo permanecem sobre o elemento estrutural. Ao mesmo tempo, conclui-se que o modelo de viga de Timoshenko viscoelástico é capaz de descrever adequadamente a máxima deflexão de vigas sanduíche de qualquer tipo de material do núcleo, sendo os parâmetros que têm a maior influência sobre o aumento das deflexões máximas quando a viga possui núcleo de poliestireno: o comprimento da viga, a magnitude e o período de carga.

A influência da rigidez do núcleo regulada pelo parâmetro $\alpha$ é negativa, significando que as deflexões máximas diminuem quanto maior é o parâmetro $\alpha$. O parâmetro $\alpha$ foi utilizado para avaliar que devido a propriedade da fluência ser superior em compressão do que em 
tração, assim, ao diminuir a rigidez da metade do núcleo aumenta a precisão sobre os efeitos reais da viscoelasticidade, devido a que essa metade da viga experimenta tensão de tração pelo efeito da flexão.

A propriedade da fluência é superior em compressão do que em tração, assim, ao diminuir a rigidez da metade do núcleo aumenta a precisão sobre os efeitos reais da viscoelasticidade. No estudo de placas anisotrópicas, o aumento das deflexões depende da relação existente entre os parâmetros viscoelásticos nas diferentes direções, e o comportamento do material viscoelástico a tração.

A metodologia implementada para a realização do presente estudo pode-se utilizar para o estudo de qualquer tipo de estrutura conhecendo a solução analítica elástica, aplicado o princípio de correspondência elástica-viscoelástica, tenha uma solução viscoelástica envolvendo a convolução da função de fluência ou a função de algum dos módulos, dependendo se a análise mecânica seja projetada no campo das tensões ou das deformações, atingindo os dois casos nas validações realizadas ao longo da pesquisa apresentada.

\section{2 - SUGESTÕES PARA TRABALHOS FUTUROS}

Como recomendações para trabalhos futuros e para desenvolvimentos de novas avaliações estruturais empregando a metodologia neste trabalho desenvolvida, propõe-se:

- Otimizar o algoritmo de aproximação proposto, para melhorar a descrição final dos dados experimentais dada pela aproximação matemática das séries de Prony a fim de diminuir ainda mais o erro entre as verificações realizadas pelo MEF e o algoritmo incremental.

- Aplicar o algoritmo incremental em outros problemas de valor inicial para avaliação de tensões e deformações.

- Estender a metodologia proposta para elementos estruturais compósitos cilíndricos com influência de diferenciais de temperatura.

- Baseados na metodologia do presente trabalho avaliar o efeito da temperatura no aumento das deflexões de elementos estruturais compósitos laminados.

- Implementar sobre o algoritmo incremental os princípios da mecânica da fratura para avaliação de falha do elemento estrutural; 
- Experimentação com testes de fluência em vigas sanduíche para validação do método numérico proposto na presente pesquisa;

- Implementar o algoritmo incremental para variáveis de estado e aplicando outras formas das propriedades viscoelásticas. 


\section{REFERÊNCIAS BIBLIOGRÁFICAS}

Bazant, Z. P., Asce, H. M., Yu, Q., \& Li, G.-H. (2012a). Excessive Long-Time Deflections of Prestressed Box Girders. I: Record-Span Bridge in Palau and Other Paradigms. Journal of Structural Engineering ASCE, 1, 676-686. http://doi.org/10.1061/(ASCE)ST.1943-541X

Bazant, Z. P., Asce, H. M., Yu, Q., \& Li, G.-H. (2012b). Excessive Long-Time Deflections of Prestressed Box Girders. II: Numerical Analysis and Lessons Learned. Journal of Structural Engineering ASCE, 1, 687-696. http://doi.org/10.1061/(ASCE)ST.1943$541 X$

Bazant, Z. P., Yu, Q., Kim, K.-T., Hubler, M. H., Smilauer, V., Vráblik, L., ... Kristek, V. (2011). Excessive multi-decade deflections of prestressed concrete bridges: how to avoid them and how to exploit their monitoring to improve creep prediction model. Fib Symposium Prague 2011, 827-830.

Botelho, E., Silva, R., Pardini, L., \& Rezende, M. (2006). A review on the development and properties of continuous fiber/epoxy/aluminum hybrid composites for aircraft structures. Materials Research, 9(3), 247-256.

Carvalho, M. A. de. (2014). Estudo numérico-analítico de modelos reológicos unidimensionais viscoelásticos, elastoplásticos e viscoplásticos. Dissertação de Mestrado. Universidade de Brasília.

Chaves, E. W. V. (2009). Mecánica del médio Continuo (Modelos Constitutivos). Ciudad Real.

Christensen, R. M. (1982). Theory of Viscoelasticity: An introduction (First edit). New York - USA: Courier Corporation.

De Araújo, P. C., Soares, J. B., de Holanda, Á. S., Parente Jr., E., \& Evangelista Jr., F. (2010). Dynamic viscoelastic analysis of asphalt pavements using a finite element formulation. Road Materials and Pavement Design, 11(2), 409-433. http://doi.org/10.1080/14680629.2010.9690282

Dubner, H., \& Abate, J. (1968). Numerical Inversion of Laplace Transforms by Relating Them to the Finite Fourier Cosine Transform. Journal of the ACM.

Evangelista Jr, F. (2014). SHAY. Brasília, Brasil.: Universidade de Brasília. Programa sem patente.

Evangelista Jr., F. (2006). Análise quasi-estática e dinâmica de pavimentos asfálticos. Dissertação de Mestrado. Universidade Federal do Ceará.

Fernández, C. R. R. (2007). Transformada de Laplace y ecuaciones de Volterra. ugr.es. Santiago de Chile: Universidad Santiago de Chile.

Ferry, J. D. (1980). Viscoelastic properties of polymers. Viscoelastic properties of polymers. John Wiley \& Sons, Incorporated. 
Hammerand, D. (1999). Geometrically-linear and nonlinear analysis of linear viscoelastic composites using the finite element method. Virginia Polytechnic Institute and State University.

Hassanzadeh, H., \& Pooladi-Darvish, M. (2007). Comparison of different numerical Laplace inversion methods for engineering applications. Applied Mathematics and Computation, 189(2), 1966-1981. http://doi.org/10.1016/j.amc.2006.12.072

Huang, J., Gibson, L. J., \& Member, A. (1991). Creep of sandwich beams with polymer foam cores. Journal of Materials in Civil Engineering 2 (3), 2(3), 171-182.

Lemos, C. A. D. de. (2005). Análise de Fadiga em Risers Flexiveis. COPPE/UFRJ.

Marinucci, G. (2011). Materiais compósitos poliméricos: Fundamentos e tecnologia. Artliber Editora Ltda.

Mase, G. E. (1970). Serie de compendios Shaum - problemas de mecânica del médio contínuo. Michigan: McGraw-Hill.

Monforton, G., \& Schmit, L. (1969). Finite element analysis of sandwich plates and cylindrical shells with laminated faces. Air force flight dynamics laboratory AFFDL. Cleveland, Ohio, USA.

Mottahedi, M., Dadalau, A., Hafla, A., \& Verl, A. (2011). Numerical analysis of relaxation test based on Prony series material model. Stuttgart Research Centre for Simulation Technology (SRC SimTech), (2009), 1-10.

Muliana, A. H., \& Haj-Ali, R. (2008). A multi-scale framework for layered composites with thermo-rheologically complex behaviors. International Journal of Solids and Structures, 45(10), 2937-2963. http://doi.org/10.1016/j.ijsolstr.2008.01.015

Park, S., \& Schapery, R. (1999). Methods of interconversion between linear viscoelastic material functions. Part I-A numerical method based on Prony series. International Journal of Solids and Structures.

Park, S. W., \& Kim, Y. R. (1999). Interconversion between relaxation modulus and creep compliance for viscoelastic solids. Journal of Materials in Civil Engineering, (February), 76-82.

Plazek, D. J. (1966). Temperature Dependence of the Viscoelastic Behavior of Polystyrene. The Journal of Phisical Chemistry, 53(1957), 3480-3487.

Portela, E. (2011). Análise viscoelástica de materiais asfálticos considerando os efeitos da temperatura e do dano. Dissertação de Mestrado. Universidade Federal do Ceará.

Prado, A. O., Valera, J. O. A., \& Cervantes, O. R. (2013). Introducción a la mecánica del medio continuo. Ciudad de México. México: Universidad Nacional Autónoma de México. 
Reddy, J. N., Arciniega, R. A., \& Moleiro, F. (2010). Finite element analysis of composite plates and shells. Encyclopedia of Aerospace Engineering, 1-19.

Roberts-Tompkins, A. L. (2009). Viscoelastic analysis of sandwich beams having aluminum and fiber-reinforced polymer skins with a polystyrene foam core. Texas A\&M University.

Rocca, S., \& Nanni, A. (2004). Design, fabrication, and testing of low-profile composite bypass road panel: Phase I. Missouri.

Roylance, D. (2001). Engineering viscoelasticity. Materials Science and Engineering, 1-37.

Santos, J. P. L. (2008). Análise de modelos reológicos viscoelásticos através de formulações mistas em elementos finitos. Vasa. Dissertação de Mestrado. Universidade Federal do Rio de Janeiro, COPPE.

Schapery, R. A. (1969). On the characterization of nonlinear viscoelastic materials. Polymer Engineering and Science, 9(4), 295-310. http://doi.org/10.1002/pen.760090410

Schapery, R. A., Research, A. F. S. C., Division, T., of Aeronautics Astronautics, \& Sciences, E. (1965). An Engineering Theory of Nonlinear Viscoelasticity with Applications. College Station - Texas - USA: Pergamon Press.

Shah, S. (2008). Coupled heat conduction and deformation in a viscoelastic composite cylinder. Texas A\&M University. Texas A\&M University.

Silva, R. F. Da, Teófilo, F. A. F., Parente, E., Melo, A. M. C. De, \& Holanda, Á. S. De. (2013). Optimization of composite catenary risers. Marine Structures, 33, 1-20. http://doi.org/10.1016/j.marstruc.2013.04.002

Taylor, R. L., Pister, K. S., \& Goudreau, G. L. (1970). Thermomechanical Analysis of Viscoelastic Solids. Int J Numer Methods Eng, 2(1), 45-59.

Timoshenko, S. (1957). Resistencia de materiales (Volumen 2). Madrid: Espasa-Calpe, S.A.

Timoshenko, S., \& Woinowsky-krieger, S. (1959). Theory of plates and shells (Second Edi). United States: McGraw-Hill.

Torres, J. L. G. (2013). Three-dimensional numerical analysis of reflective cracks in airfield pavements. University of Illinois at Urbana-Champaign.

Tzikang, C. (2000). Determining a Prony series for a viscoelastic material from time varying strain data. The NASA STI Program Office, (May). Retrieved from http://dl.acm.org/citation.cfm?id=886732

Ugural, A. C. (1999). Stresses in Plates and Shells. McGraw-Hill. Retrieved from https://books.google.com.br/books?id=RwknQAAACAAJ 
Ugural, A. C. (2009). Computational Mechanics and Applied Analysis - Stresses in Beams, Plates, and Shells (Thirth E.). New York - USA: CRC Press - Taylor \& Francis Group. http://doi.org/143980270X

White, J. (1968). Finite elements in linear viscoelasticity. 2nd Conference on Matrix Methods in Structural Mechanics. Dayton, OH, USA.

Yonemoto, A., Hisakdo, T., \& Okumura, K. (2002). An improvement of convergence of fftbased numerical inversion of laplace transforms. IEEE International Symposium on Circuits and Systems, 769-772.

Zak, A. R. (1968). Structural analysis of realistic solid propellant materials. Journal of Spacecraft and Rockets, 5(3), 270-275. http://doi.org/10.2514/3.29237

Zocher, M., Groves, S., \& Allen, D. (1997). A three-dimensional finite element formulation for thermoviscoelastic orthotropic media. International Journal for Numerical Methods in Engineering, 2288(December 1995), 2267-2288. 
ANEXOS 


\section{A - DESENVOLVIMENTO MATEMÁTICO DA SOLUÇÃO ÀS EQUAÇÕES DIFERENCIAIS DAS ANALOGIAS MECÂNICAS}

\section{A.1 - MODELO DE MAXWELL}

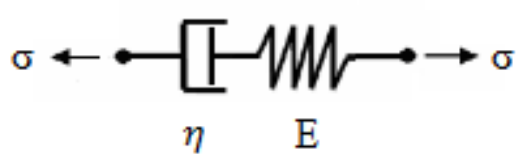

Figura A.1 - Modelo de Maxwell

Equações constitutivas da parcela elástica:

$$
\begin{aligned}
& \sigma=E \varepsilon \\
& \varepsilon_{e}=\frac{\sigma}{E} \\
& \dot{\varepsilon}_{e}=\frac{\dot{\sigma}}{E}
\end{aligned}
$$

Equações constitutivas da parcela viscosa:

$$
\begin{aligned}
& \sigma=\eta \dot{\varepsilon} \\
& \dot{\varepsilon}_{v}=\frac{\sigma}{\eta}
\end{aligned}
$$

Equações constitutivas do modelo de Maxwell

$$
\begin{aligned}
& \varepsilon=\varepsilon_{e}+\varepsilon_{v} \rightarrow \varepsilon(t)=\varepsilon_{e}(t)+\varepsilon_{v}(t) \\
& \dot{\varepsilon}=\dot{\varepsilon}_{e}+\dot{\varepsilon}_{v} \rightarrow \dot{\varepsilon}(t)=\dot{\varepsilon}_{e}(t)+\dot{\varepsilon}_{v}(t)
\end{aligned}
$$

Equação diferencial característica do sistema:

$$
\dot{\varepsilon}=\frac{\dot{\sigma}}{E}+\frac{\sigma}{\eta}
$$

\section{A.1.1 - Teste de fluência}

Condições de contorno

$$
\begin{aligned}
& \sigma=\sigma_{0} \\
& \varepsilon_{v}(0)=0 \\
& \varepsilon_{e}(0)=\frac{\sigma_{0}}{E}
\end{aligned}
$$

Análise da parcela elástica:

$$
\dot{\varepsilon}_{e}(t)=\frac{\dot{\sigma}}{E}
$$




$$
\int \dot{\varepsilon}_{e}(t) d t=\int \frac{\dot{\sigma}}{E} d t \rightarrow \varepsilon_{e}(t)=\frac{\sigma}{E}+c_{1}
$$

Aplicando as condições de contorno dadas na Equação (A.11) na Equação (A.12), pode-se obter a constante $\mathrm{c}_{1}$ :

$$
\begin{aligned}
& \varepsilon_{e}(0)=\frac{\sigma_{0}}{E}=\frac{\sigma_{0}}{E}+c_{1} \rightarrow c_{1}=0 \\
& \varepsilon_{e}(t)=\frac{\sigma}{E}
\end{aligned}
$$

Análise da parcela viscosa:

$$
\begin{aligned}
& \dot{\varepsilon}_{v}(t)=\frac{\sigma}{\eta} \\
& \int \dot{\varepsilon} d t=\int \frac{\sigma}{\eta} d t \rightarrow \varepsilon_{v}(t)=\frac{\sigma}{\eta} t+c_{2}
\end{aligned}
$$

Aplicando as condições de contorno dadas na Equação (A.10) na Equação (A.14), pode-se obter a constante $\mathrm{c}_{2}$ :

$$
\begin{aligned}
\varepsilon_{v}(0) & =0=\frac{\sigma_{0}}{\eta}(0)+c_{2} \rightarrow c_{2}=0 \\
\varepsilon_{v}(t) & =\frac{\sigma}{\eta} t
\end{aligned}
$$

Finalmente, substituindo as Equações (A.9) e (A.13) na Equação (A.6), obtém-se a solução do modelo de Maxwell na resposta para fluência, apresentado na Equação (A.16).

$$
\begin{aligned}
& \varepsilon(t)=\varepsilon_{e}(t)+\varepsilon_{v}(t) \\
& \varepsilon(t)=\frac{\sigma}{E}+\frac{\sigma}{\eta} t
\end{aligned}
$$

\section{A.1.2 - Teste de relaxação}

Condições de contorno

$$
\begin{aligned}
& \varepsilon(t)=\varepsilon_{0} u(t) ; u(t) \text { função Heaveside } \\
& \dot{\varepsilon}(t)=0 ; \rightarrow t>0 \\
& \sigma_{0}=\varepsilon_{0} E
\end{aligned}
$$

Avaliando a equação diferencial do modelo, dada na Equação (A.8) dada a condição de contorno (A.18), obtém-se a função geral da tensão. 


$$
\begin{aligned}
& \dot{\varepsilon}=\frac{\dot{\sigma}}{E}+\frac{\sigma}{\eta} \rightarrow 0=\frac{\dot{\sigma}}{E}+\frac{\sigma}{\eta} \\
& \int \frac{\dot{\sigma}}{\sigma} d t=-\int \frac{E}{\eta} d t \rightarrow \ln \sigma(t)=-\frac{E}{\eta} t+c_{3} \\
& \sigma(t)=c_{3} e^{-\frac{E}{\eta} t}
\end{aligned}
$$

Avaliando a condição inicial da Equação (A.19) na equação (A.20), pode-se obter a resposta do modelo de Maxwell para relaxação $\sigma(t)$.

$$
\begin{aligned}
& \sigma(0)=\varepsilon_{0} E=c_{3} e^{-\frac{E}{\eta}(0)} \rightarrow c_{3}=\varepsilon_{0} E \\
& \sigma(t)=\varepsilon_{0} E e^{-\frac{E}{\eta} t}
\end{aligned}
$$

\section{A.2 - MODELO DE KELVIN}

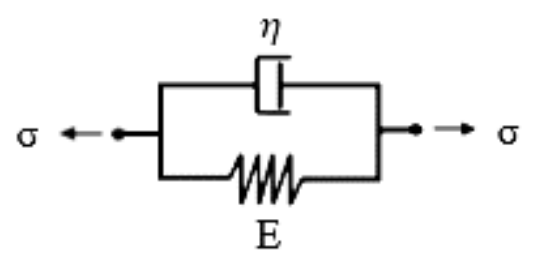

Figura A.2 - Modelo de Kelvin-Voigth

Equações constitutivas da parcela elástica:

$$
\begin{aligned}
\sigma_{e} & =\varepsilon E \\
\varepsilon_{e} & =\frac{\sigma}{E} \\
\dot{\varepsilon}_{e} & =\frac{\dot{\sigma}}{E}
\end{aligned}
$$

Equações constitutivas da parcela viscosa:

$$
\begin{aligned}
& \sigma_{v}=\underset{\sigma}{\dot{\varepsilon}} \\
& \dot{\varepsilon}_{v}=\frac{\sigma}{\eta}
\end{aligned}
$$

Equações constitutivas do modelo de Maxwell

$$
\begin{aligned}
& \varepsilon=\varepsilon_{e}=\varepsilon_{v} \rightarrow \varepsilon(t)=\varepsilon_{e}(t)=\varepsilon_{v}(t) \\
& \sigma=\sigma_{e}+\sigma_{v} \rightarrow \sigma=\varepsilon E+\eta \dot{\varepsilon}
\end{aligned}
$$

Equação diferencial característica do sistema:

$$
\frac{\sigma}{\eta}=\frac{E}{\eta} \varepsilon+\dot{\varepsilon}
$$




\section{A.2.1 - Teste de fluência}

Condições de contorno

$$
\begin{aligned}
& \varepsilon\left(0^{+}\right)=0 \\
& \varepsilon(\infty)=\frac{\sigma_{0}}{E}
\end{aligned}
$$

A equação diferencial que descreve o modelo de Kelvin, dada na Equação (A.29) pode-se solucionar pelo método de Bernoulli para equações diferenciais de primeira ordem.

$$
\varepsilon(t)=\frac{\frac{\sigma}{\eta} e^{\frac{E}{\eta} t} \frac{\eta}{E}+c_{4}}{e^{\frac{E}{\eta} t}}=\frac{\sigma}{E}+c_{4} e^{-\frac{E}{\eta} t}
$$

Aplicando a condição de contorno dada na Equação (A.30) na Equação (A.32), pode-se obter a constante $c_{4}$ e a solução geral para as deformações do modelo de Kelvin-Voigt.

$$
\begin{aligned}
& \varepsilon(0)=0=\frac{\sigma_{0}}{E}+c_{4} e^{-\frac{E}{\eta}(0)} \rightarrow c_{4}=-\frac{\sigma_{0}}{E} \\
& \varepsilon(t)=\frac{\sigma_{0}}{E}\left(1-e^{-\frac{E}{\eta} t}\right)
\end{aligned}
$$

\section{A.2.2 - Teste de relaxação}

Condições de contorno

$$
\begin{aligned}
& \sigma(\infty)=\varepsilon_{0} \mathrm{E} \\
& \sigma\left(0^{+}\right)=\infty \\
& \dot{\varepsilon}(t)=0 ; \rightarrow t>0
\end{aligned}
$$

Aplicando a condição de contorno dada na Equação (A.36) na transformada de Laplace da Equação (A.29), pode-se obter a função que representa o comportamento à relaxação do modelo de Kelvin, tanto no espaço de Laplace como se apresenta na Equação (A.37), tanto no espaço do tempo com a transformada inversa aplicada na Equação (A.38).

$$
\begin{aligned}
& \mathcal{L}\left\{\frac{\sigma}{\eta}=\frac{E}{\eta} \varepsilon+\dot{\varepsilon}\right\} \rightarrow \frac{1}{\eta} \mathcal{L}\{\sigma\}=\frac{E}{\eta} \mathcal{L}\{\varepsilon\}+\mathcal{L}\{\dot{\varepsilon}\} \\
& \frac{1}{\eta} \mathcal{L}\{\sigma\}=\frac{1}{s}\left(s+\frac{E}{\eta}\right) \varepsilon_{0} \rightarrow \mathcal{L}\{\sigma\}=\eta \varepsilon_{0}+\frac{E}{s} \varepsilon_{0} \\
& \mathcal{L}\{\sigma\}=\varepsilon_{0}(\eta \mathcal{L}\{\delta(t)\}+\mathrm{E} \mathcal{L}\{u(t)\}) \\
& \sigma(t)=\mathcal{L}^{i n v}\{\sigma\}=\varepsilon_{0}(\eta \delta(t)+\mathrm{E} u(t)) ; \quad \delta(t) \text { Função Delta de Dirac }
\end{aligned}
$$




\section{A.3 - MODELO DO SÓLIDO LINEAR PADRÃO}

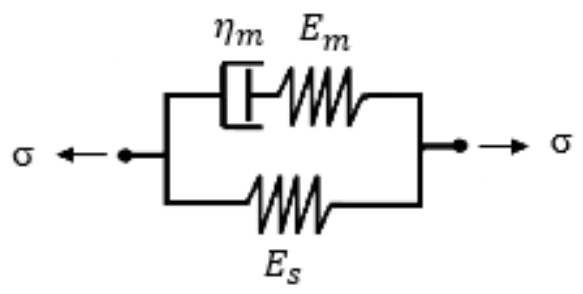

Figura A.3 - Modelo sólido linear padrão

Equações constitutivas para a componente de Maxwell

Equação cinética

$$
\sigma_{m}=\sigma_{\eta m}=\sigma_{E m}
$$

Equação cinemática

$$
\begin{aligned}
& \varepsilon_{m}=\varepsilon_{\eta m}+\varepsilon_{E m} \\
& \dot{\varepsilon}_{m}=\dot{\varepsilon}_{\eta m}+\dot{\varepsilon}_{E m} \\
& \dot{\varepsilon}_{m}=\frac{\sigma_{\eta m}}{\eta_{m}}+\frac{\dot{\sigma}_{E m}}{E_{m}}
\end{aligned}
$$

Equações constitutivas

$$
\begin{aligned}
\sigma_{E m} & =E_{m} \varepsilon_{E m} \rightarrow \varepsilon_{E m}=\frac{\sigma_{E m}}{E_{m}} \\
\dot{\varepsilon}_{E m} & =\frac{\dot{\sigma}_{E m}}{E_{m}} \\
\dot{\varepsilon}_{\eta m} & =\frac{\sigma_{\eta m}}{\eta_{m}}
\end{aligned}
$$

Equações constitutivas para a componente elástica independente

$$
\begin{gathered}
\sigma_{s}=\varepsilon_{s} E_{s} \\
\dot{\sigma}_{s}=\dot{\varepsilon}_{s} E_{s}
\end{gathered}
$$

Equações constitutivas para a o conjunto Maxwell-mola

Equação cinética

$$
\begin{aligned}
& \sigma=\sigma_{m}+\sigma_{s} \rightarrow \sigma_{m}=\sigma-\sigma_{s} \\
& \dot{\sigma}_{m}=\dot{\sigma}-\dot{\sigma}_{s}
\end{aligned}
$$


Equação cinemática

$$
\varepsilon=\varepsilon_{m}=\varepsilon_{s}
$$

Equação diferencial do sistema

$$
\begin{aligned}
& \dot{\varepsilon}_{m}=\frac{\sigma_{\eta m}}{\eta_{m}}+\frac{\dot{\sigma}_{E m}}{E_{m}} \rightarrow \dot{\varepsilon}_{m}=\frac{\sigma_{E m}}{\eta_{m}}+\frac{\dot{\sigma}_{E m}}{E_{m}} \rightarrow \dot{\varepsilon}_{m}=\frac{\sigma-\sigma_{s}}{\eta_{m}}+\frac{\dot{\sigma}-\dot{\sigma}_{s}}{E_{m}} \\
& \dot{\varepsilon}_{m}=\frac{\sigma-E_{s} \cdot \varepsilon_{s}}{\eta_{m}}+\frac{\dot{\sigma}-E_{s} \cdot \dot{\varepsilon}_{s}}{E_{m}} \rightarrow \dot{\varepsilon}=\frac{\sigma}{\eta_{m}}-\frac{E_{s} \cdot \varepsilon}{\eta_{m}}+\frac{\dot{\sigma}}{E_{m}}-\frac{E_{s} \cdot \dot{\varepsilon}}{E_{m}} \\
& \left(1+\frac{E_{s}}{E_{m}}\right) \dot{\varepsilon}+\frac{E_{s}}{\eta_{m}} \varepsilon=\frac{\dot{\sigma}}{E_{m}}+\frac{\sigma}{\eta_{m}}
\end{aligned}
$$

\section{A.3.1 - Teste de fluência}

Condições de contorno

$$
\begin{aligned}
& \sigma(t)=\sigma_{0} ; \quad t>0 \\
& \dot{\sigma}(t)=0
\end{aligned}
$$

Aplicando as condições de contorno dadas nas equações (A.51) e (A.52), pode-se obter da equação diferencial (A.50) uma forma matemática solucionável pelo método de Bernoulli, dado que é uma equação diferencial de primer ordem, apresentada na Equação (A.53).

$$
\begin{aligned}
& \left(1+\frac{E_{s}}{E_{m}}\right) \dot{\varepsilon}+\frac{E_{s}}{\eta_{m}} \varepsilon=\frac{\dot{\sigma}}{E_{m}}+\frac{\sigma}{\eta_{m}} \rightarrow\left(1+\frac{E_{s}}{E_{m}}\right) \dot{\varepsilon}+\frac{E_{s}}{\eta_{m}} \varepsilon=\frac{(0)}{E_{m}}+\frac{\sigma}{\eta_{m}} \\
& \left(\frac{E_{m}+E_{s}}{E_{m}}\right) \dot{\varepsilon}+\frac{E_{s}}{\eta_{m}} \varepsilon=\frac{\sigma}{\eta_{m}} \rightarrow \dot{\varepsilon}+\frac{E_{s}}{\eta_{m}} \frac{E_{m}}{E_{m}+E_{s}} \varepsilon=\frac{\sigma}{\eta_{m}} \frac{E_{m}}{E_{m}+E_{s}} \\
& \dot{\varepsilon}+\frac{E_{s} . E_{m}}{\eta_{m}\left(E_{m}+E_{s}\right)} \varepsilon=\sigma \frac{E_{m}}{\eta_{m}\left(E_{m}+E_{s}\right)}
\end{aligned}
$$

Com a equação diferencial característica, obtém-se a solução geral do comportamento à fluência do sólido linear padrão.

$$
\varepsilon(t)=\frac{e^{-\int \frac{E_{S} E_{m}}{\eta_{m}\left(E_{m}+E_{S}\right)} d t}}{\left[\int \sigma \frac{E_{m}}{\eta_{m}\left(E_{m}+E_{S}\right)} e^{\int \frac{E_{S} E_{m}}{\eta_{m}\left(E_{m}+E_{S}\right)} d t} d t+c_{5}\right]^{-1}}
$$




$$
\varepsilon(t)=\frac{\sigma(t)}{E_{S}}+c_{5} e^{-\frac{E_{S} E_{m}}{\eta_{m}\left(E_{m}+E_{S}\right)} t}
$$

Para obter a constante $c_{5}$ e a solução particular da equação diferencial, tem que se estabelecer uma condição de contorno que permita avaliar a equação obtida tomando o intervalo $(0, t)$ como uma análise da função nos valores próximos pela esquerda e direita ao zero $\left(0^{-}\right.$, $0^{+}$), como se apresenta na Equação (A.55).

$$
\begin{aligned}
& \left(1+\frac{E_{s}}{E_{m}}\right) \dot{\varepsilon}+\frac{E_{s}}{\eta_{m}} \varepsilon=\frac{\dot{\sigma}}{E_{m}}+\frac{\sigma}{\eta_{m}} \\
& \int_{0}^{t}\left(1+\frac{E_{s}}{E_{m}}\right) \dot{\varepsilon} d t+\int_{0}^{t} \frac{E_{s}}{\eta_{m}} \varepsilon d t=\int_{0}^{t} \frac{\dot{\sigma}}{E_{m}} d t+\int_{0}^{t} \frac{\sigma}{\eta_{m}} d t \\
& \left(1+\frac{E_{s}}{E_{m}}\right) \int_{0^{-}}^{0^{+}} \dot{\varepsilon} d t+\frac{E_{s}}{\eta_{m}} \int_{0^{-}}^{0^{+}} \varepsilon d t=\frac{1}{E_{m}} \int_{0^{-}}^{0^{+}} \dot{\sigma} d t+\frac{1}{\eta_{m}} \int_{0^{-}}^{0^{+}} \sigma d t \\
& \left(1+\frac{E_{s}}{E_{m}}\right) \varepsilon\left(0^{+}\right)=\frac{1}{E_{m}} \sigma\left(0^{+}\right) \rightarrow \varepsilon\left(0^{+}\right)=\frac{\frac{\sigma\left(0^{+}\right)}{E_{m}}}{\frac{E_{m}+E_{s}}{E_{m}}} \\
& \varepsilon\left(0^{+}\right)=\frac{\sigma\left(0^{+}\right)}{E_{m}+E_{s}}
\end{aligned}
$$

Com a condição de contorno adicional dada pela Equação (A.55), e substituindo-a na Equação (A.54), finalmente, obtém-se o comportamento do sólido padrão à fluência.

$$
\begin{aligned}
& \varepsilon(t)=\frac{\sigma(t)}{E_{s}}+c_{5} \cdot e^{-\frac{E_{s} \cdot E_{m}}{\eta_{m}\left(E_{m}+E_{s}\right)} t} \rightarrow c_{5}=\sigma_{0}\left(\frac{1}{E_{m}+E_{s}}-\frac{1}{E_{s}}\right) \\
& \varepsilon(t)=\sigma_{0}\left(\frac{1}{E_{s}}+\left(\frac{1}{E_{m}+E_{s}}-\frac{1}{E_{s}}\right) e^{-\frac{E_{S} E_{m}}{\eta_{m}\left(E_{m}+E_{s}\right)} t}\right)
\end{aligned}
$$

\section{A.3.2 - Teste de relaxação}

Condições de contorno

$$
\begin{aligned}
& \varepsilon(0)=\varepsilon_{0} ; \quad t>0 \\
& \dot{\varepsilon}(t)=0
\end{aligned}
$$

Aplicando as condições (A.57) e (A.58) na equação diferencial geral equação(A.50), podese obter a resposta para relaxação do sistema. 


$$
\begin{aligned}
& \sigma(t)=\frac{e^{-\int \frac{E_{m}}{\eta_{m}} d t}}{\left[\int \frac{E_{m} E_{s}}{\eta_{m}} \varepsilon_{0} e^{\int \frac{E_{m}}{\eta_{m}} d t} d t+c_{6}\right]^{-1}} \\
& \sigma(t)=\varepsilon_{0} E_{s}+c_{6} e^{-\frac{E_{m}}{\eta_{m}} t}
\end{aligned}
$$

Avaliando a condição de contorno adicional dada na Equação (A.55), sendo substituída na Equação (A.59) obtém-se a resposta à relaxação do modelo do sólido padrão.

$$
\begin{aligned}
& \sigma\left(0^{+}\right)=\left(E_{m}+E_{s}\right) \varepsilon_{0} \\
& \left(E_{m}+E_{s}\right) \varepsilon_{0}=\varepsilon_{0} E_{s}+c_{6} e^{-\frac{E_{m}}{\eta_{m}}(0)} \rightarrow c_{6}=\varepsilon_{0} E_{m} \\
& \sigma(t)=\varepsilon_{0}\left(E_{s}+E_{m} e^{-\frac{E_{m}}{\eta_{m}} t}\right)
\end{aligned}
$$

\section{A.4 - MODELO DE BOLTZMANN}

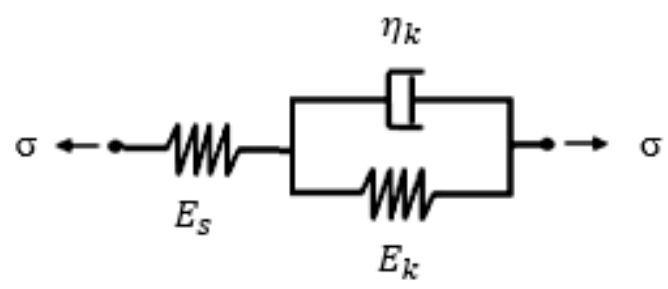

Figura A.4 - Modelo de Boltzmann

Equações constitutivas para a componente de Kelvin-Voitg

Equação cinética

$$
\begin{aligned}
& \sigma_{k}=\sigma_{E k}+\sigma_{\eta k} \\
& \dot{\sigma}_{k}=\dot{\sigma}_{E k}+\dot{\sigma}_{\eta k}
\end{aligned}
$$

Equação cinemática

$$
\begin{aligned}
& \varepsilon_{k}=\varepsilon_{\eta k}=\varepsilon_{E k} \\
& \dot{\varepsilon}_{k}=\dot{\varepsilon}_{\eta k}=\dot{\varepsilon}_{E k}
\end{aligned}
$$

Equações constitutivas

$$
\begin{gathered}
\sigma_{E k}=E_{E k} \varepsilon_{E k} \\
\dot{\sigma}_{E k}=E_{E k} \dot{\varepsilon}_{E k}
\end{gathered}
$$




$$
\sigma_{\eta k}=\eta_{\eta k} \dot{\varepsilon}_{\eta k}
$$

Equações constitutivas para a componente elástica independente

$$
\begin{gathered}
\sigma_{s}=\varepsilon_{s} E_{s} \\
\dot{\sigma}_{s}=\dot{\varepsilon}_{s} E_{s}
\end{gathered}
$$

Equações constitutivas para a o conjunto Maxwell-mola

Equação cinética

$$
\begin{aligned}
& \sigma=\sigma_{k}=\sigma_{s} \\
& \dot{\sigma}=\dot{\sigma}_{k}=\dot{\sigma}_{s}
\end{aligned}
$$

Equação cinemática

$$
\begin{aligned}
& \varepsilon=\varepsilon_{k}+\varepsilon_{s} \rightarrow \varepsilon_{k}=\varepsilon-\varepsilon_{s} \\
& \dot{\varepsilon}_{k}=\dot{\varepsilon}-\dot{\varepsilon}_{s}
\end{aligned}
$$

Equação diferencial do sistema

$$
\begin{aligned}
& \sigma=\sigma_{E k}+\sigma_{\eta k} \rightarrow \sigma=E_{E k} \varepsilon_{E k}+\eta_{\eta k} \dot{\varepsilon}_{\eta k} \rightarrow \sigma=E_{E k} \varepsilon_{k}+\eta_{\eta k} \dot{\varepsilon}_{k} \\
& \sigma=E_{E k}\left(\varepsilon-\varepsilon_{s}\right)+\eta_{\eta k}\left(\dot{\varepsilon}-\dot{\varepsilon}_{s}\right) \\
& \sigma=E_{E k} \varepsilon-E_{E k} \frac{\sigma}{E_{S}}+\eta_{\eta k} \dot{\varepsilon}-\eta_{\eta k} \frac{\dot{\sigma}}{E_{s}} \\
& \left(1+\frac{E_{E k}}{E_{S}}\right) \sigma+\frac{\eta_{\eta k}}{E_{s}} \dot{\sigma}=E_{E k} \varepsilon+\eta_{\eta k} \dot{\varepsilon}
\end{aligned}
$$

\section{A.4.1 - Teste de fluência}

Condições de contorno

$$
\begin{aligned}
& \sigma(t)=\sigma_{0} ; \quad t>0 \\
& \dot{\sigma}(t)=0
\end{aligned}
$$

Aplicando as condições de contorno dadas nas equações (A.75) e(A.76), pode-se obter da equação diferencial (A.74) uma forma matemática solucionável pelo método de Bernoulli, dado que é uma equação diferencial de primer ordem, apresentada na Equação (A.77). 


$$
\begin{aligned}
& \left(1+\frac{E_{E k}}{E_{s}}\right) \sigma_{0}+\frac{\eta_{\eta k}}{E_{s}}(0)=E_{E k} \varepsilon+\eta_{\eta k} \dot{\varepsilon} \\
& \left(\frac{E_{s}+E_{E k}}{\eta_{\eta k} \cdot E_{s}}\right) \sigma_{0}=\frac{E_{E k}}{\eta_{\eta k}} \varepsilon+\dot{\varepsilon}
\end{aligned}
$$

Com a equação diferencial característica, obtém-se a solução geral do comportamento à fluência do modelo de Boltzmann.

$$
\begin{aligned}
\varepsilon(t) & =\frac{e^{-\int \frac{E_{E k}}{\eta_{\eta k}} d t}}{\left[\int\left(\frac{E_{S}+E_{E k}}{\eta_{\eta k} E_{S}}\right) \sigma e^{\int \frac{E_{E k}}{\eta_{\eta k}} d t} d t+c_{7}\right]^{-1}} \\
\varepsilon(t) & =\left(\frac{1}{E_{E k}}+\frac{1}{E_{S}}\right) \sigma_{0}+c_{7} e^{-\frac{E_{E k}}{\eta_{\eta k}} t}
\end{aligned}
$$

Para obter a constante $c_{7}$ e a solução particular da equação diferencial, tem que se estabelecer uma condição de contorno que permita avaliar a equação obtida tomando o intervalo $(0, t)$ como uma análise da função nos valores próximos pela esquerda e direita ao zero $\left(0^{-}\right.$, $0^{+}$), como se apresenta na Equação .(A.79).

$$
\begin{aligned}
& \left(1+\frac{E_{E k}}{E_{S}}\right) \sigma+\frac{\eta_{\eta k}}{E_{S}} \dot{\sigma}=E_{E k} \varepsilon+\eta_{\eta k} \dot{\varepsilon} \\
& \left(1+\frac{E_{E k}}{E_{S}}\right) \int_{0^{-}}^{0^{+}} \sigma d t+\frac{\eta_{\eta k}}{E_{S}} \int_{0^{-}}^{0^{+}} \dot{\sigma} d t=E_{E k} \int_{0^{-}}^{0^{+}} \varepsilon d t+\eta_{\eta k} \int_{0^{-}}^{0^{+}} \dot{\varepsilon} d t \rightarrow \\
& \varepsilon\left(0^{+}\right)=\frac{1}{E_{S}} \sigma\left(0^{+}\right)
\end{aligned}
$$

Com a condição de contorno adicional dada pela Equação (A.79)(A.55), e substituindo-a na Equação (A.54), finalmente, obtém-se o comportamento do sólido padrão à fluência, dado pela Equação (A.80).

$$
\begin{aligned}
& \varepsilon\left(0^{+}\right)=\frac{\sigma_{0}}{E_{E k}}+\frac{\sigma_{0}}{E_{S}}+c_{7} \cdot e^{-\frac{E_{E k}}{\eta_{\eta k}}\left(0^{+}\right)} \rightarrow \frac{\sigma_{0}}{E_{S}}=\frac{\sigma_{0}}{E_{E k}}+\frac{\sigma_{0}}{E_{S}}+c_{7} e^{0} \\
& c_{7}=\frac{\sigma_{0}}{E_{S}}-\frac{\sigma_{0}}{E_{S}}-\frac{\sigma_{0}}{E_{E k}} \rightarrow c_{7}=-\frac{\sigma_{0}}{E_{E k}} \\
& \varepsilon(t)=\sigma_{0}\left(\frac{1}{E_{S}}+\frac{1}{E_{E k}}\left(1-e^{-\frac{E_{E k}}{\eta_{\eta k}} t}\right)\right)
\end{aligned}
$$




\section{A.4.2 - Teste de relaxação}

Condições de contorno

$$
\begin{aligned}
& \varepsilon(0)=\varepsilon_{0} ; \quad t>0 \\
& \dot{\varepsilon}(t)=0
\end{aligned}
$$

Aplicando as condições (A.57) e (A.58) na equação diferencial geral Equação (A.50), podese obter a resposta para relaxação do sistema.

$$
\begin{aligned}
& \left(1+\frac{\mathrm{E}_{\mathrm{Ek}}}{\mathrm{E}_{\mathrm{s}}}\right) \sigma+\frac{\eta_{\eta \mathrm{k}}}{\mathrm{E}_{\mathrm{s}}} \dot{\sigma}=\mathrm{E}_{\mathrm{Ek}} \varepsilon+\eta_{\eta \mathrm{k}}(0) \\
& \frac{\mathrm{E}_{\mathrm{s}}}{\eta_{\eta \mathrm{k}}}\left(1+\frac{\mathrm{E}_{\mathrm{Ek}}}{\mathrm{E}_{\mathrm{s}}}\right) \sigma+\dot{\sigma}=\frac{\mathrm{E}_{\mathrm{s}}}{\eta_{\eta \mathrm{k}}} \mathrm{E}_{\mathrm{Ek}} \varepsilon \\
& \frac{E_{s} \cdot E_{E k}}{\eta_{\eta k}}\left(\frac{1}{E_{E k}}+\frac{1}{E_{S}}\right) \sigma+\dot{\sigma}=\frac{E_{s} \cdot E_{E k}}{\eta_{\eta k}} \varepsilon \\
& \sigma(t)=\frac{e^{-\int \frac{E_{s} \cdot E_{E k}}{\eta_{\eta k}}\left(\frac{1}{E_{E k}}+\frac{1}{E_{S}}\right) d t}}{\left[\int \frac{E_{s} \cdot E_{E k}}{\eta_{\eta k}} \cdot \varepsilon_{0} \cdot e^{\int \frac{E_{S} \cdot E_{E k}}{\eta_{\eta k}}\left(\frac{1}{E_{E k}}+\frac{1}{E_{S}}\right) d t} d t+c_{8}\right]^{-1}} \\
& \sigma(t)=\frac{1}{\left(\frac{1}{E_{E k}}+\frac{1}{E_{S}}\right)} \varepsilon_{0}+c_{8} e^{-\frac{E_{s} \cdot E_{E k}}{\eta_{\eta k}}\left(\frac{1}{E_{E k}}+\frac{1}{E_{S}}\right) t}
\end{aligned}
$$

Avaliando a condição de contorno adicional dada na Equação (A.79), sendo substituída na Equação (A.83)(A.59), obtém-se a resposta à relaxação do modelo de Boltzmann.

$$
\begin{aligned}
& \sigma\left(0^{+}\right)=\varepsilon_{0} E_{S} \\
& \sigma\left(0^{+}\right)=\frac{1}{\left(\frac{1}{E_{E k}}+\frac{1}{E_{S}}\right)} \varepsilon_{0}+c_{8} e^{-\frac{E_{S} \cdot E_{E k}}{\eta_{\eta k}}\left(\frac{1}{E_{E k}}+\frac{1}{E_{S}}\right)(0)} \\
& \varepsilon_{0} E_{S}=\frac{1}{\left(\frac{1}{E_{E k}}+\frac{1}{E_{S}}\right)} \varepsilon_{0}+c_{8} e^{0} \rightarrow c_{8}=\varepsilon_{0}\left(E_{S}-\frac{1}{\left(\frac{1}{E_{E k}}+\frac{1}{E_{S}}\right)}\right) \\
& \sigma(t)=\varepsilon_{0}\left(\frac{1}{\left(\frac{1}{E_{E k}}+\frac{1}{E_{S}}\right)}+\left(E_{S}-\frac{1}{\left(\frac{1}{E_{E k}}+\frac{1}{E_{S}}\right)}\right) e^{-\frac{E_{S} \cdot E_{E k}}{\eta_{\eta k}}\left(\frac{1}{E_{E k}}+\frac{1}{E_{S}}\right) t}\right) \\
& \sigma(t)=\varepsilon_{0} \frac{E_{S}}{\left(E_{S}+E_{E k}\right)}\left(E_{E k}+E_{S} e^{-\frac{E_{S}+E_{E k}}{\eta_{\eta k}} t}\right)
\end{aligned}
$$




\section{B - DESLOCAMENTOS MÁXIMOS NORMALIZADOS}

\section{B.1 - $\delta_{\mathrm{N}}$ CASO I: MVEB ELÁSTICO}

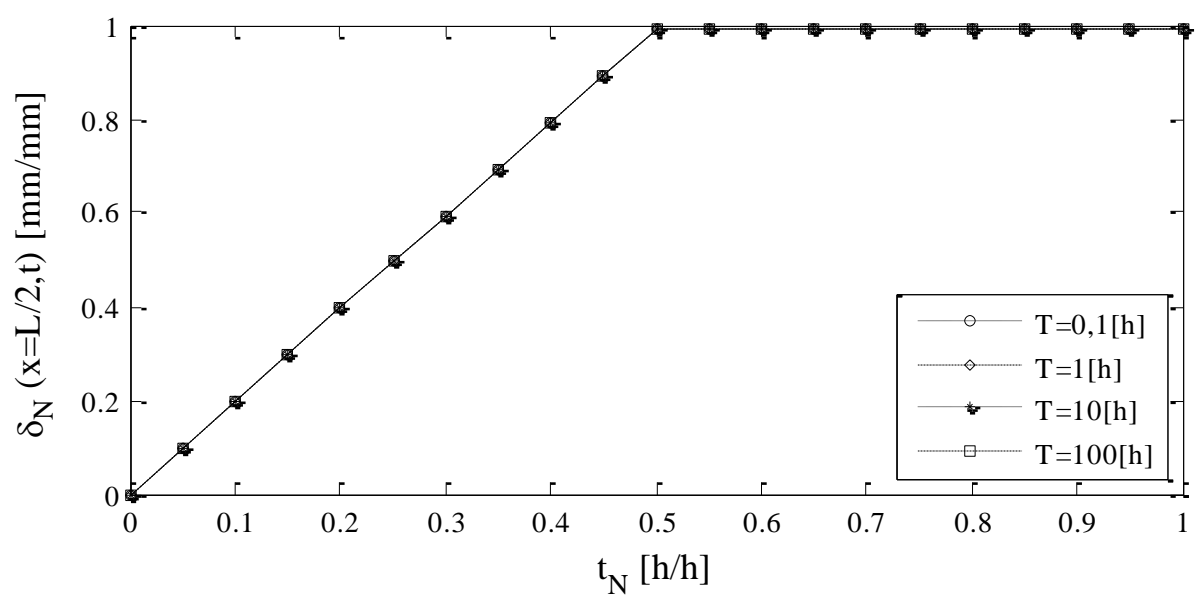

(a) $\delta_{\mathrm{N}}(\mathrm{L} / 2, \mathrm{t})[\mathrm{mm} / \mathrm{mm}]$ MVEB CT1

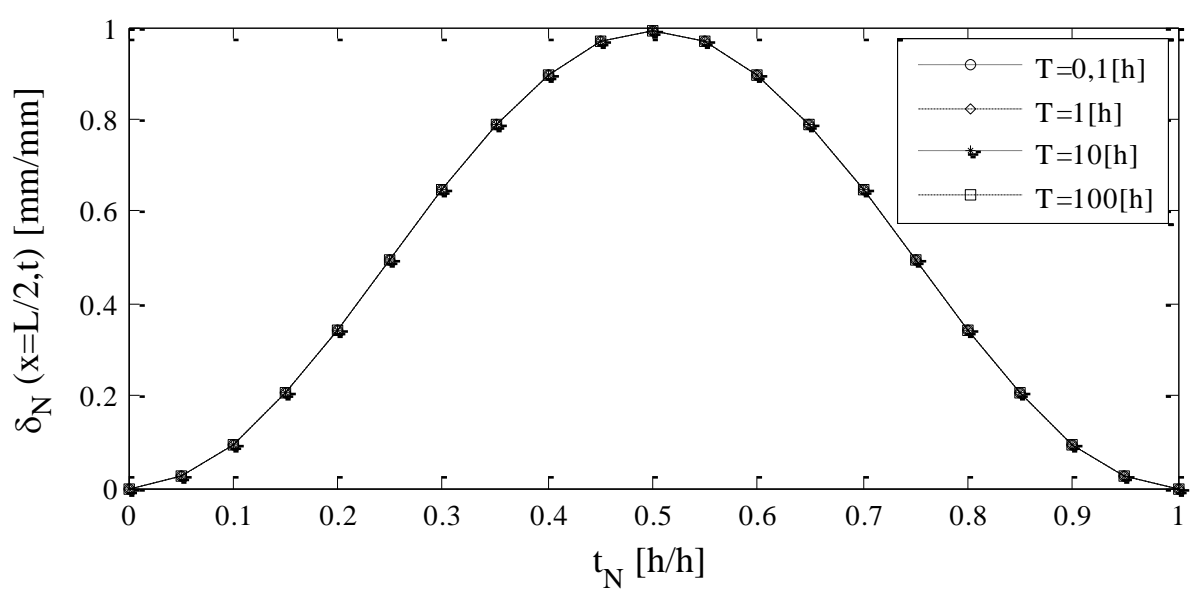

(b) $\delta_{\mathrm{N}}(\mathrm{L} / 2, \mathrm{t})[\mathrm{mm} / \mathrm{mm}]$ MVEB CT2

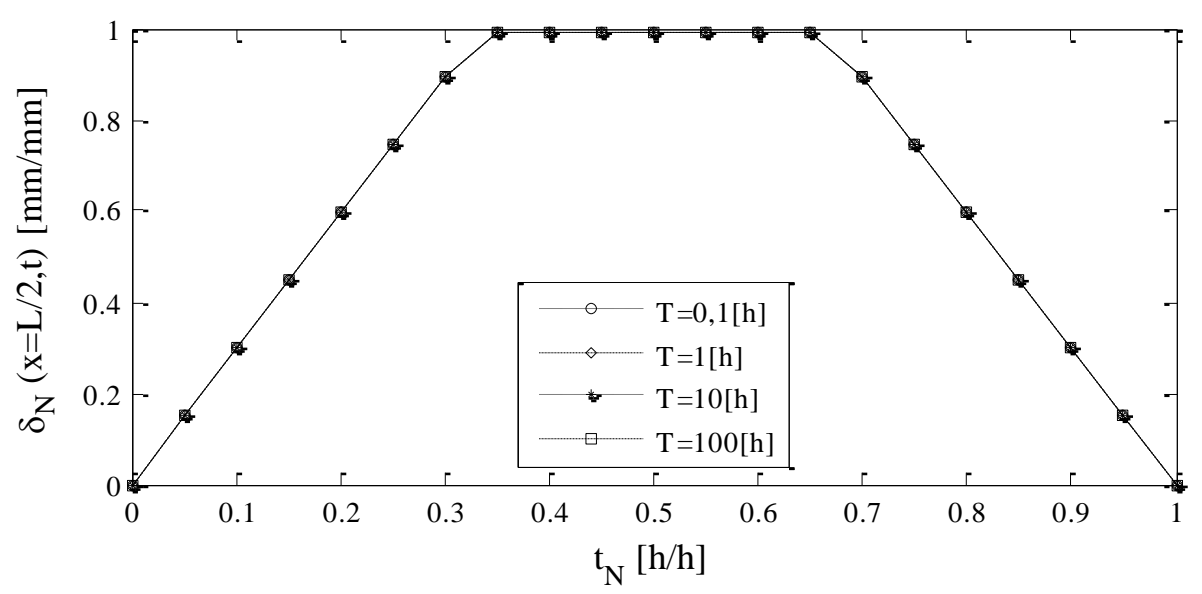

(c) $\delta_{\mathrm{N}}(\mathrm{L} / 2, \mathrm{t})[\mathrm{mm} / \mathrm{mm}]$ MVEB CT3

Figura B. $1-\delta_{\mathrm{N}}(\mathrm{L} / 2, \mathrm{t})[\mathrm{mm} / \mathrm{mm}]$ MVEB 


\section{B.2 - $\delta_{\mathrm{N}}$ CASO II: MVEB VISCOELÁSTICO}

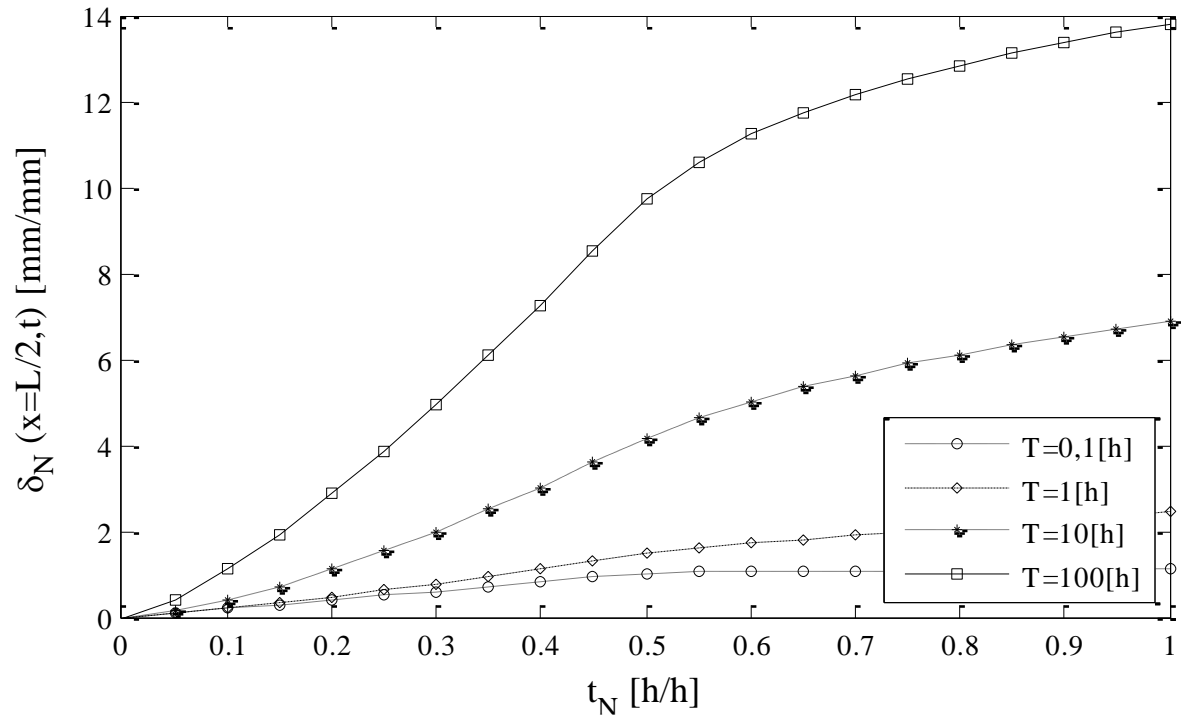

(a) $\delta_{\mathrm{N}}(\mathrm{L} / 2, \mathrm{t})[\mathrm{mm} / \mathrm{mm}]$ MVEBV CT1

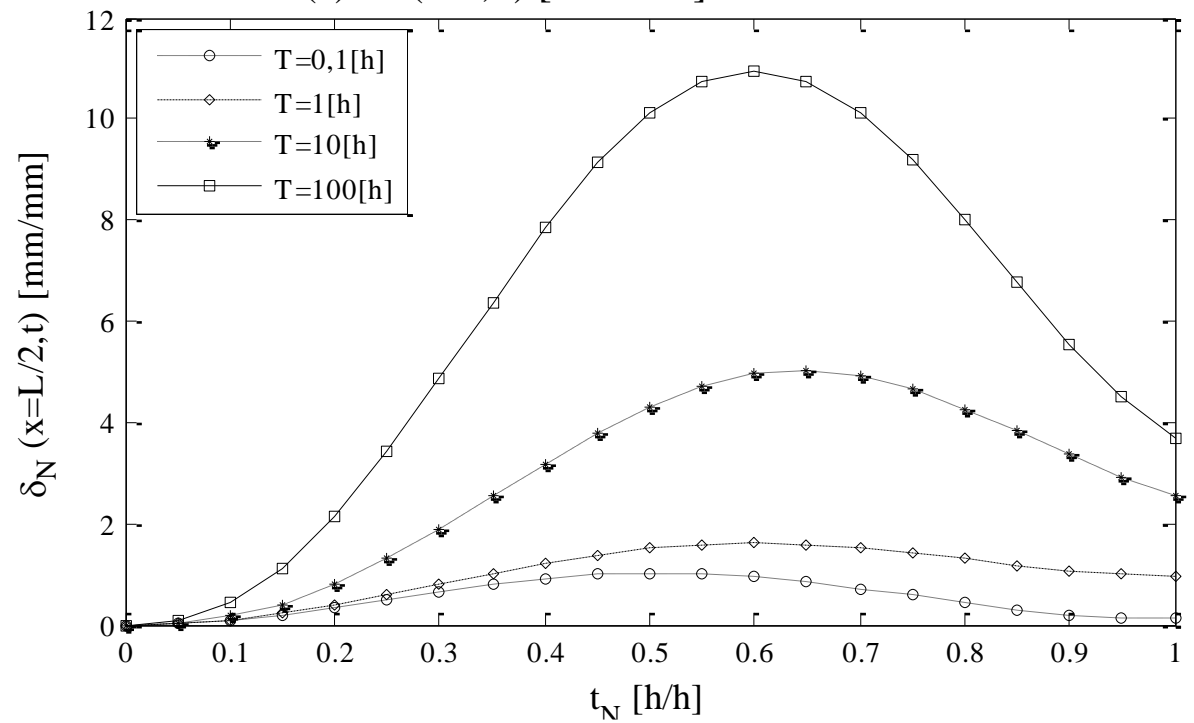

$\delta_{\mathrm{N}}(\mathrm{L} / 2, \mathrm{t})[\mathrm{mm} / \mathrm{mm}]$ MVEBV CT2

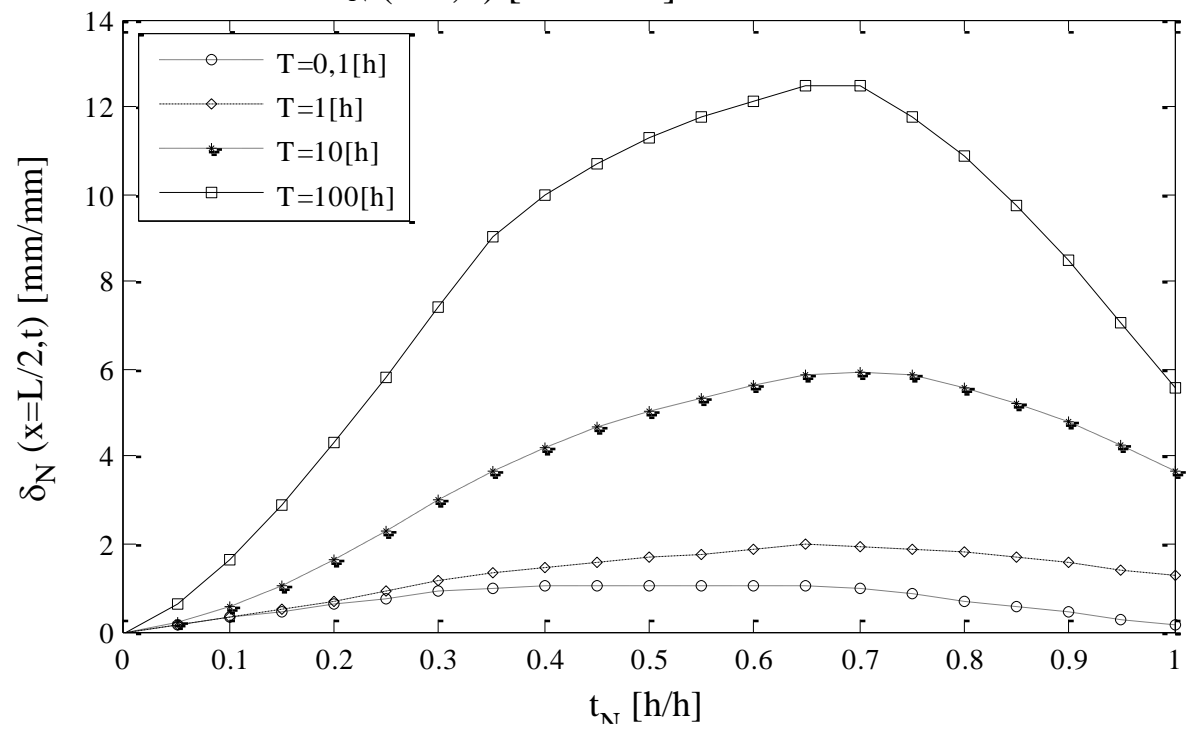

(c) $\delta_{\mathrm{N}}(\mathrm{L} / 2, \mathrm{t})[\mathrm{mm} / \mathrm{mm}] \mathrm{MVEBv} \mathrm{CT} 3$

Figura B.2 $-\delta_{\mathrm{N}}(\mathrm{L} / 2, \mathrm{t})[\mathrm{mm} / \mathrm{mm}] \mathrm{MVEBv}$ 


\section{B.3 - סN CASO III: MVT ELÁSTICO}

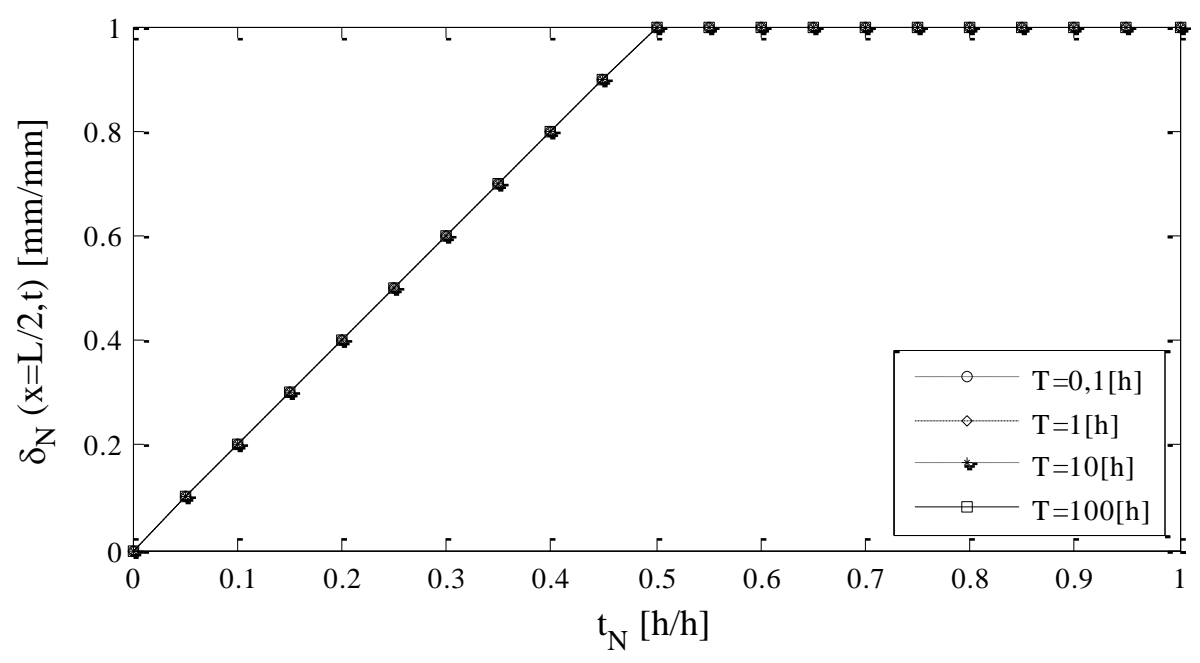

(a) $\delta_{\mathrm{N}}(\mathrm{L} / 2, \mathrm{t})[\mathrm{mm} / \mathrm{mm}]$ MVT CT1

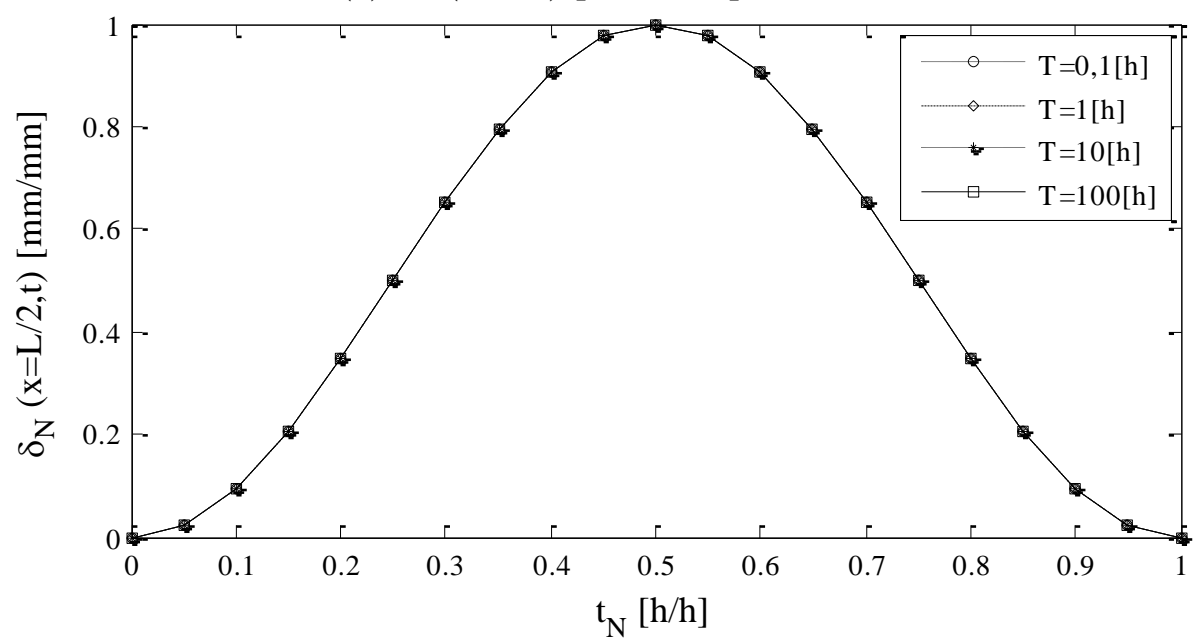

(b) $\delta_{\mathrm{N}}(\mathrm{L} / 2, \mathrm{t})[\mathrm{mm} / \mathrm{mm}] \mathrm{MVT}$ CT2

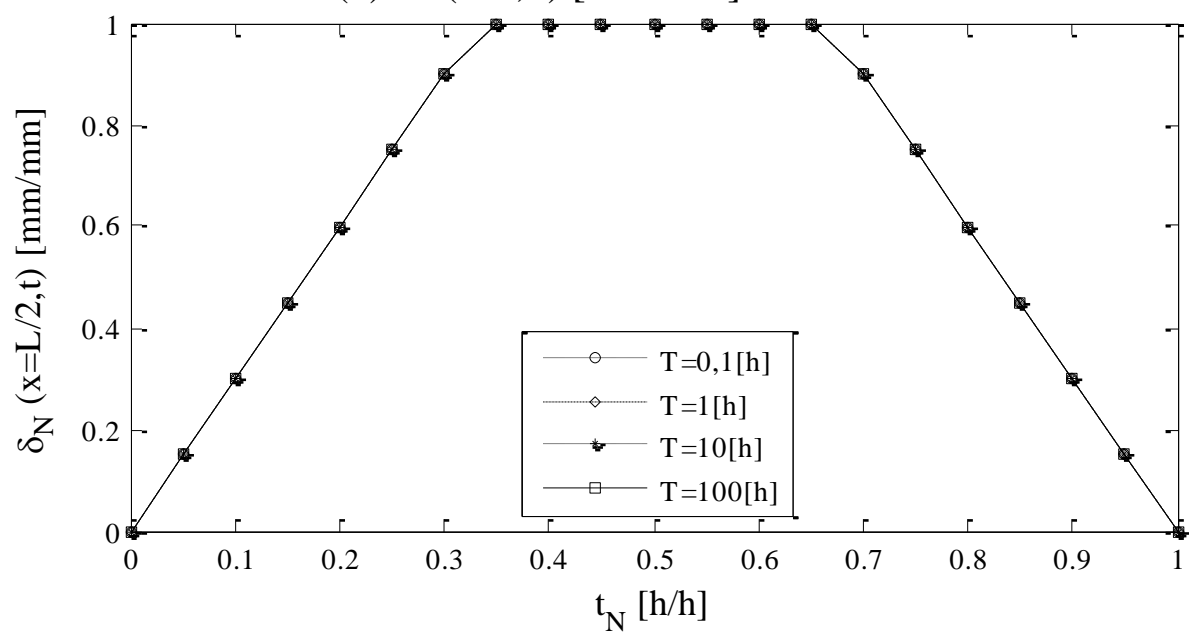

(c) $\delta_{\mathrm{N}}(\mathrm{L} / 2, \mathrm{t})[\mathrm{mm} / \mathrm{mm}]$ MVT CT3

Figura B. $3-\delta_{\mathrm{N}}(\mathrm{L} / 2, \mathrm{t})[\mathrm{mm} / \mathrm{mm}] \mathrm{MVT}$ 


\section{B.4 - $\delta_{\mathrm{N}}$ CASO IV: MVT flexão Elástica e cisalhamento viscoelástico}

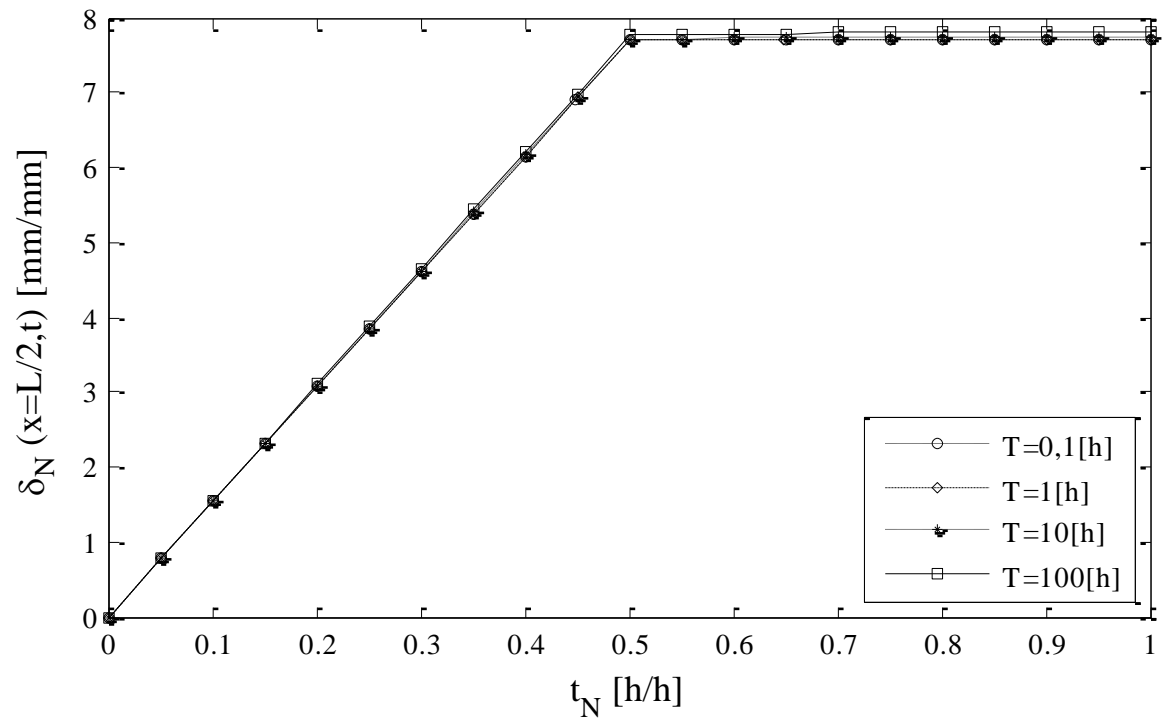

$\delta_{\mathrm{N}}(\mathrm{L} / 2, \mathrm{t})[\mathrm{mm} / \mathrm{mm}] \mathrm{MVTev}$ CT1

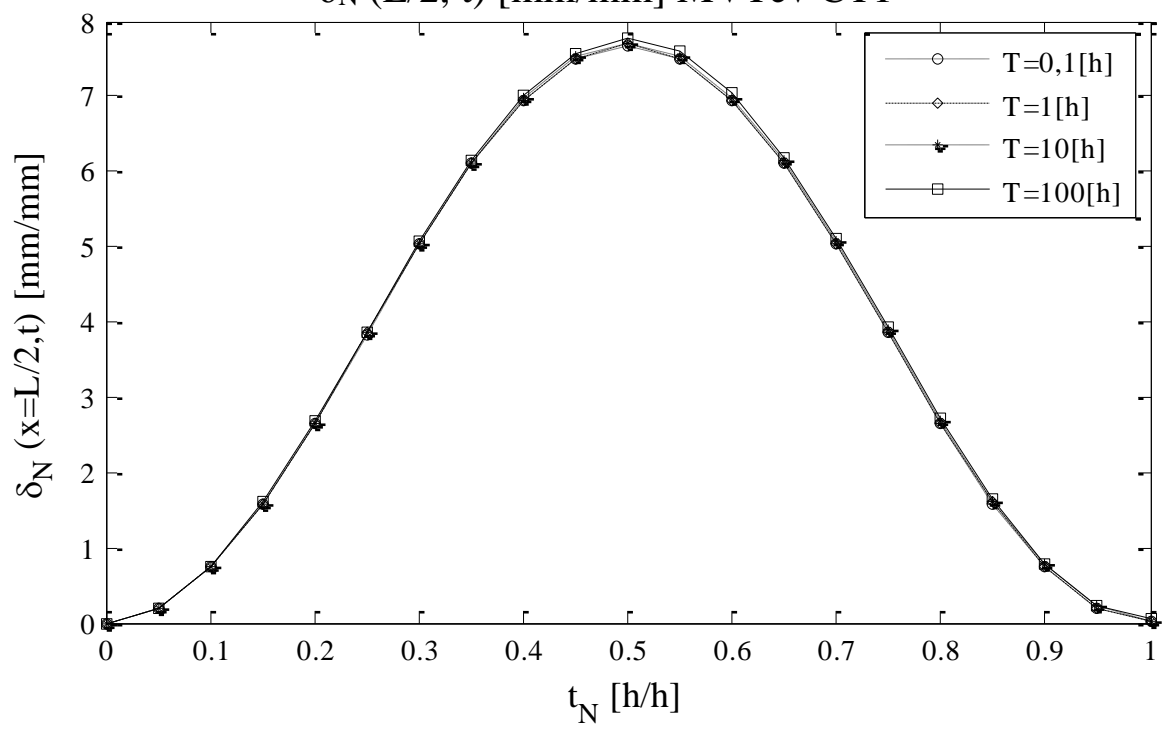

$\delta_{\mathrm{N}}(\mathrm{L} / 2, \mathrm{t})[\mathrm{mm} / \mathrm{mm}]$ MVTev CT2

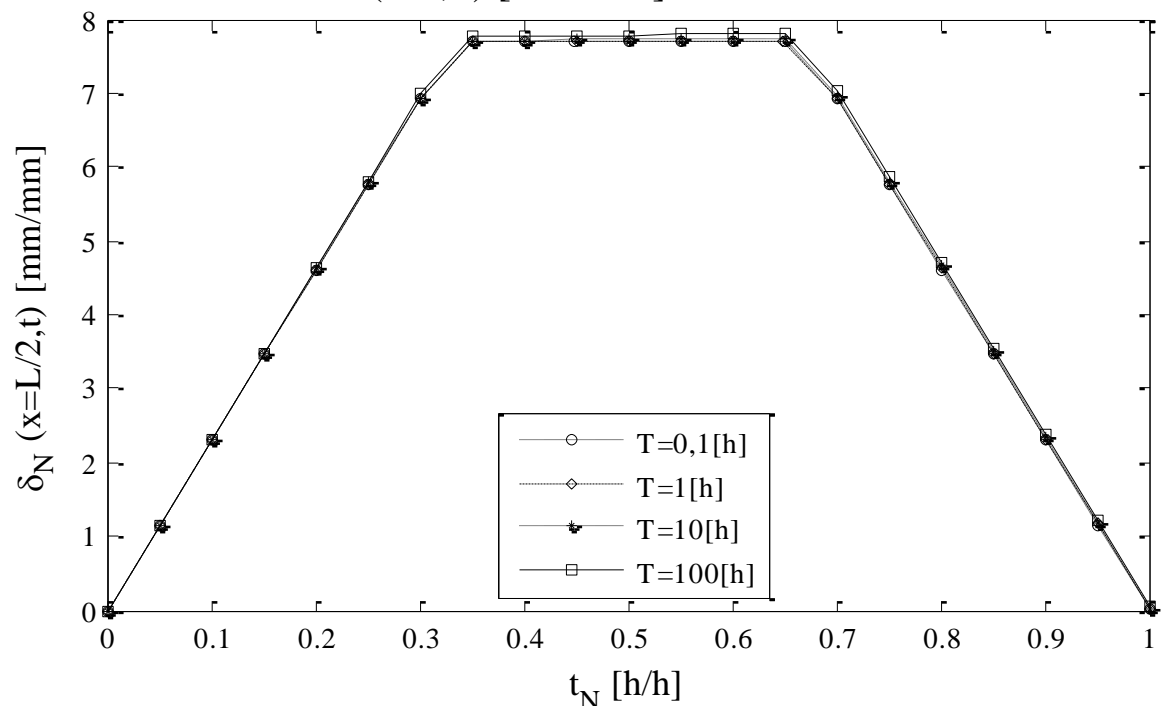

(c) $\delta_{\mathrm{N}}(\mathrm{L} / 2, \mathrm{t})[\mathrm{mm} / \mathrm{mm}]$ MVTev CT3

Figura B.4 - $\delta_{\mathrm{N}}(\mathrm{L} / 2, \mathrm{t})[\mathrm{mm} / \mathrm{mm}] \mathrm{MVTev}$ 


\section{B.5 - סN CASO V: MVT VISCOELÁSTICO}

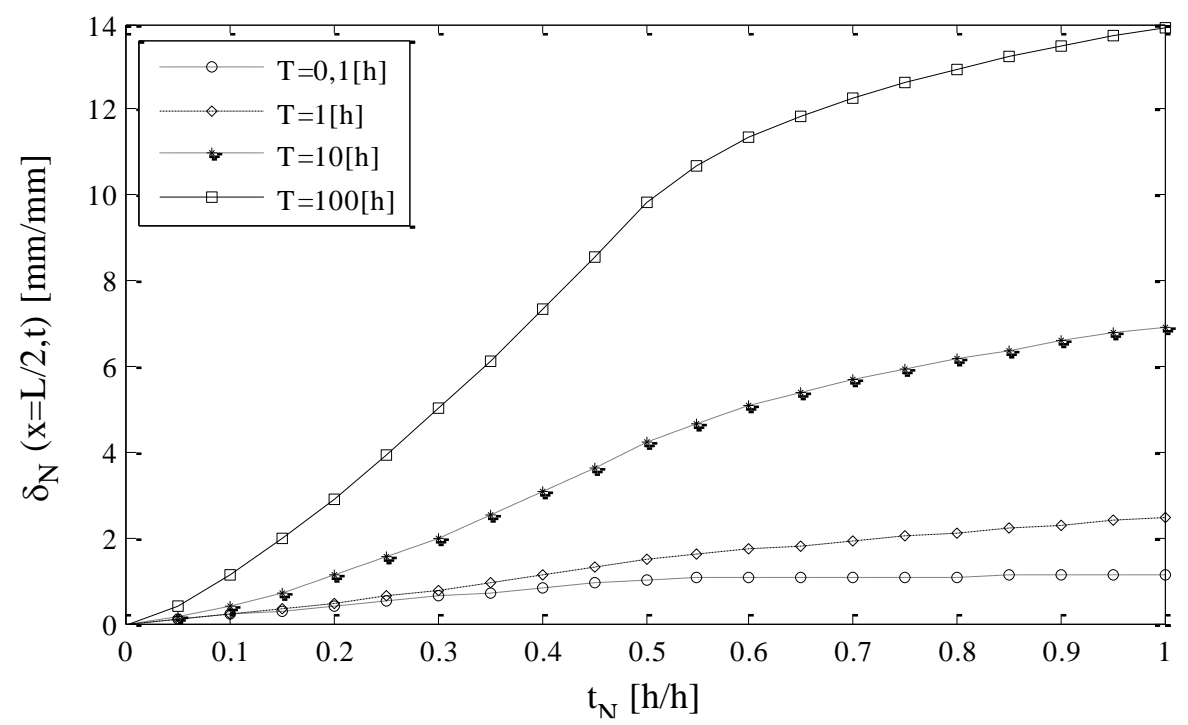

(a) $\delta_{\mathrm{N}}(\mathrm{L} / 2, \mathrm{t})[\mathrm{mm} / \mathrm{mm}] \mathrm{MVTvv}$ CT1

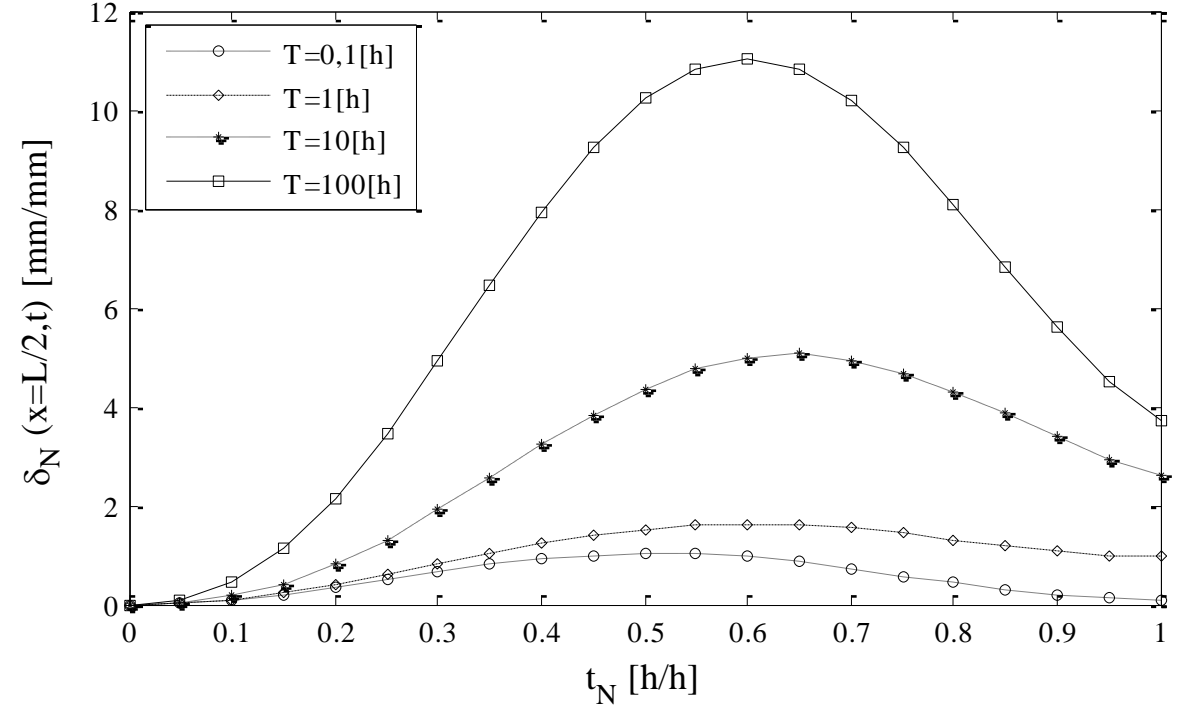

(b) $\delta_{\mathrm{N}}(\mathrm{L} / 2, \mathrm{t})[\mathrm{mm} / \mathrm{mm}]$ MVTvv CT2

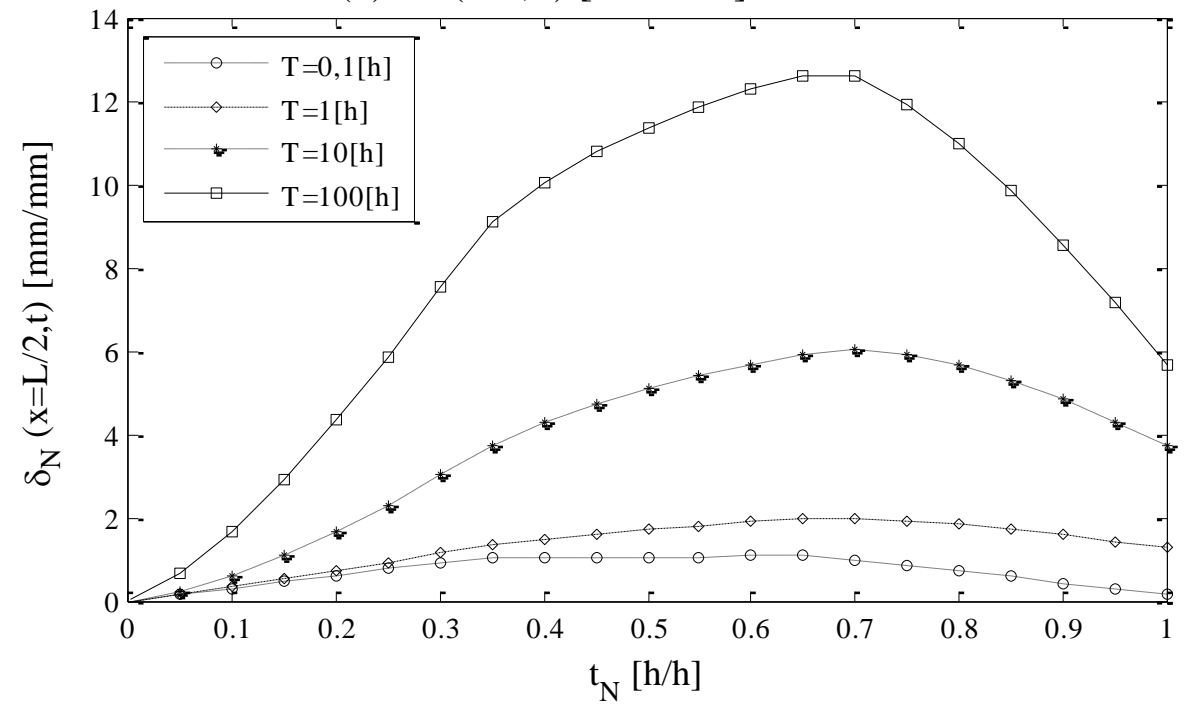

(c) $\delta_{\mathrm{N}}(\mathrm{L} / 2, \mathrm{t})[\mathrm{mm} / \mathrm{mm}] \mathrm{MVTVv}$ CT3

Figura B.5 - $\delta_{\mathrm{N}}(\mathrm{L} / 2, \mathrm{t})[\mathrm{mm} / \mathrm{mm}] \mathrm{MVTvv}$ 


\section{B.6 - $\delta_{\mathrm{N}}$ CASO VI: MVT VISCOELÁSTICO $\alpha=0,75$}

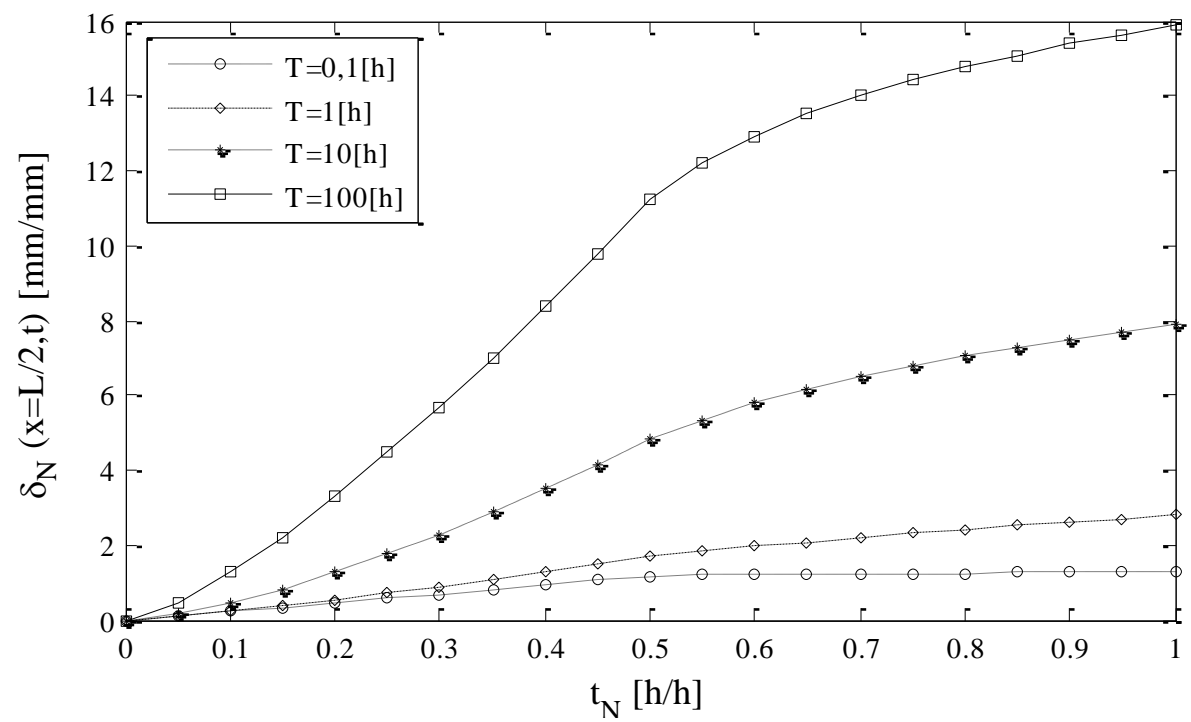

(a) $\delta_{\mathrm{N}}(\mathrm{L} / 2, \mathrm{t})[\mathrm{mm} / \mathrm{mm}] \mathrm{MVTVV} 2 \mathrm{CT} 1 \alpha=0,75$

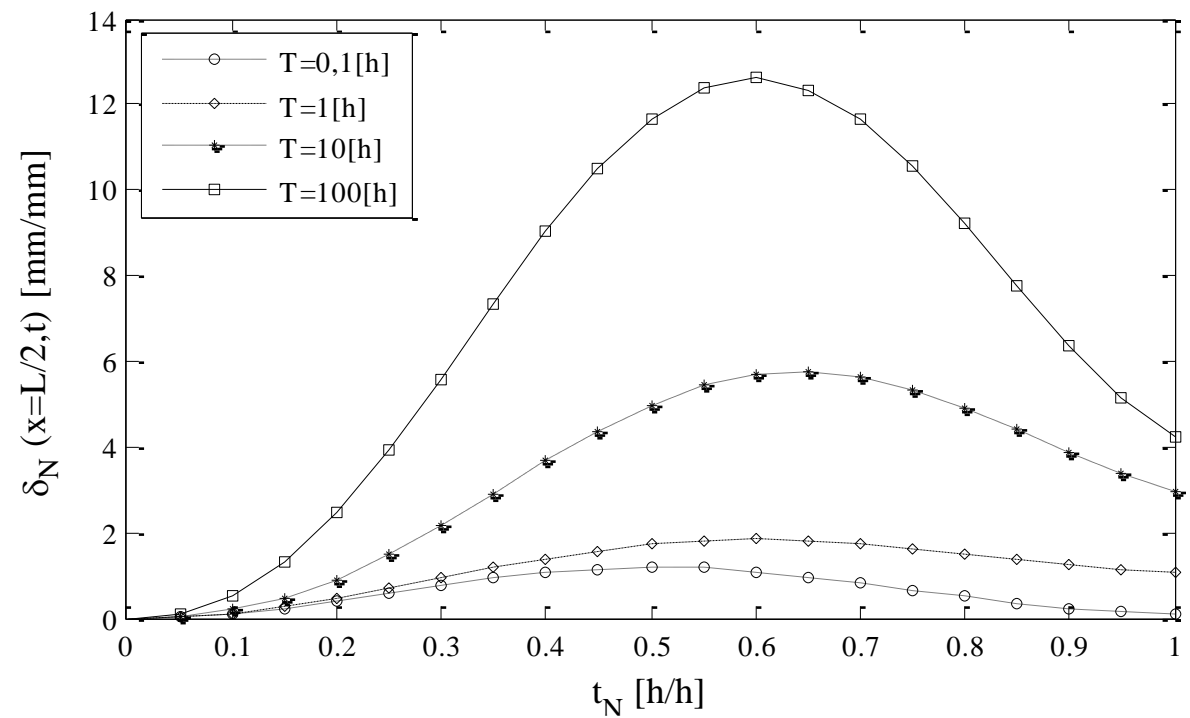

(b) $\delta_{\mathrm{N}}(\mathrm{L} / 2, \mathrm{t})[\mathrm{mm} / \mathrm{mm}]$ MVTVV2 CT2 $\alpha=0,75$

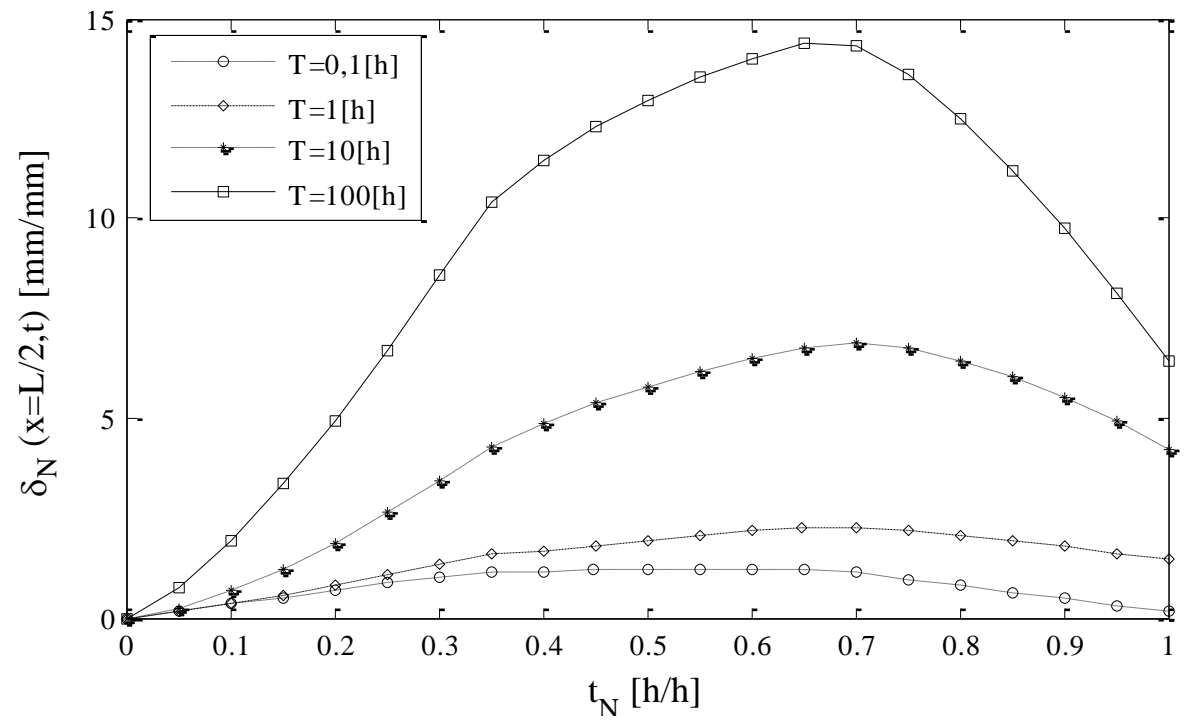

$\delta_{\mathrm{N}}(\mathrm{L} / 2, \mathrm{t})[\mathrm{mm} / \mathrm{mm}]$ MVTVV2 CT3 $\alpha=0,75$

Figura B.6 - $\delta_{\mathrm{N}}(\mathrm{L} / 2, \mathrm{t})[\mathrm{mm} / \mathrm{mm}] \mathrm{MVTvv}_{2} \alpha=0,75$ 


\section{B.7 - $\delta_{\mathrm{N}}$ CASO VI: MVT VISCOELÁSTICO $\alpha=0,50$}

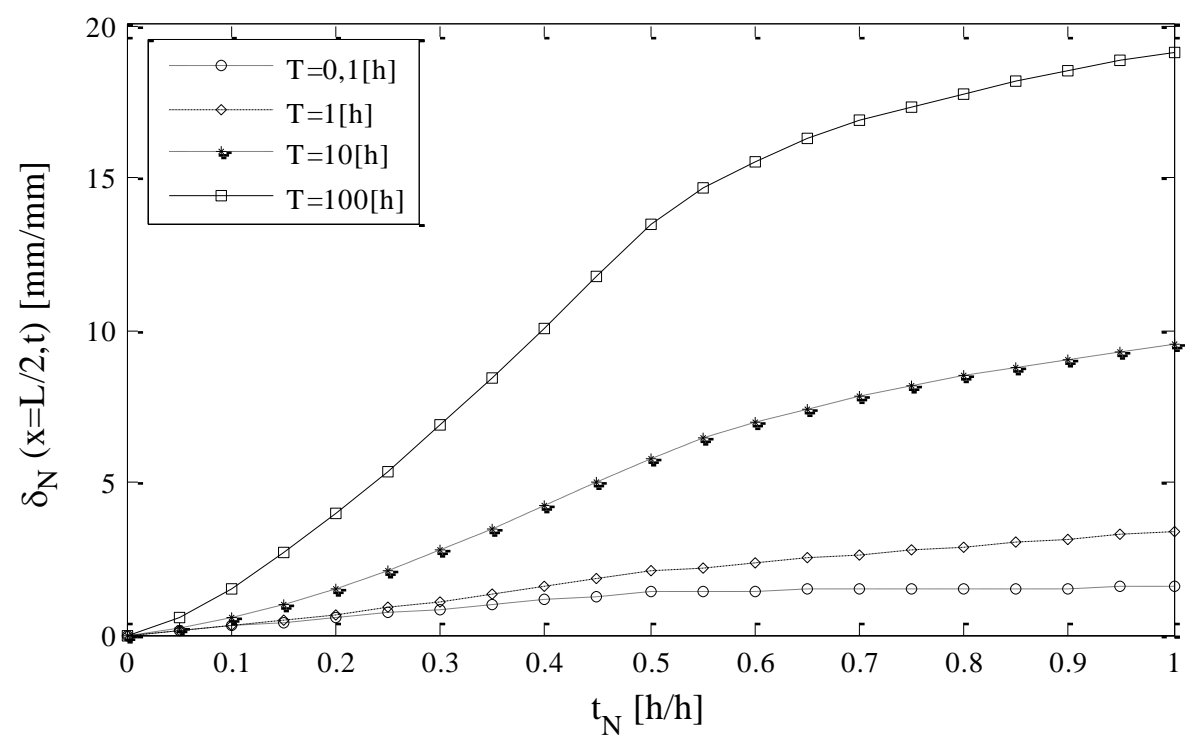

(a) $\delta_{\mathrm{N}}(\mathrm{L} / 2, \mathrm{t})[\mathrm{mm} / \mathrm{mm}] \mathrm{MVTvv}_{2} \mathrm{CT} 1 \alpha=0,5$

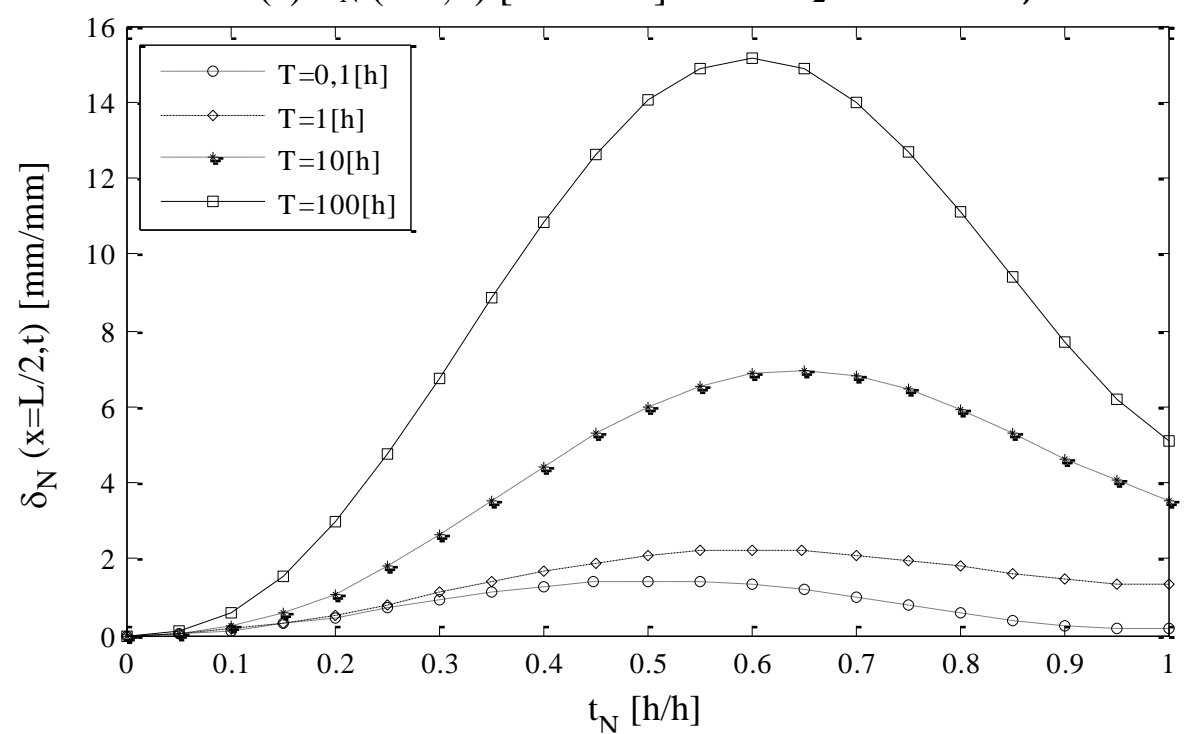

(b) $\delta_{\mathrm{N}}(\mathrm{L} / 2, \mathrm{t})[\mathrm{mm} / \mathrm{mm}] \mathrm{MVTVv}_{2} \mathrm{CT} 2 \alpha=0,5$

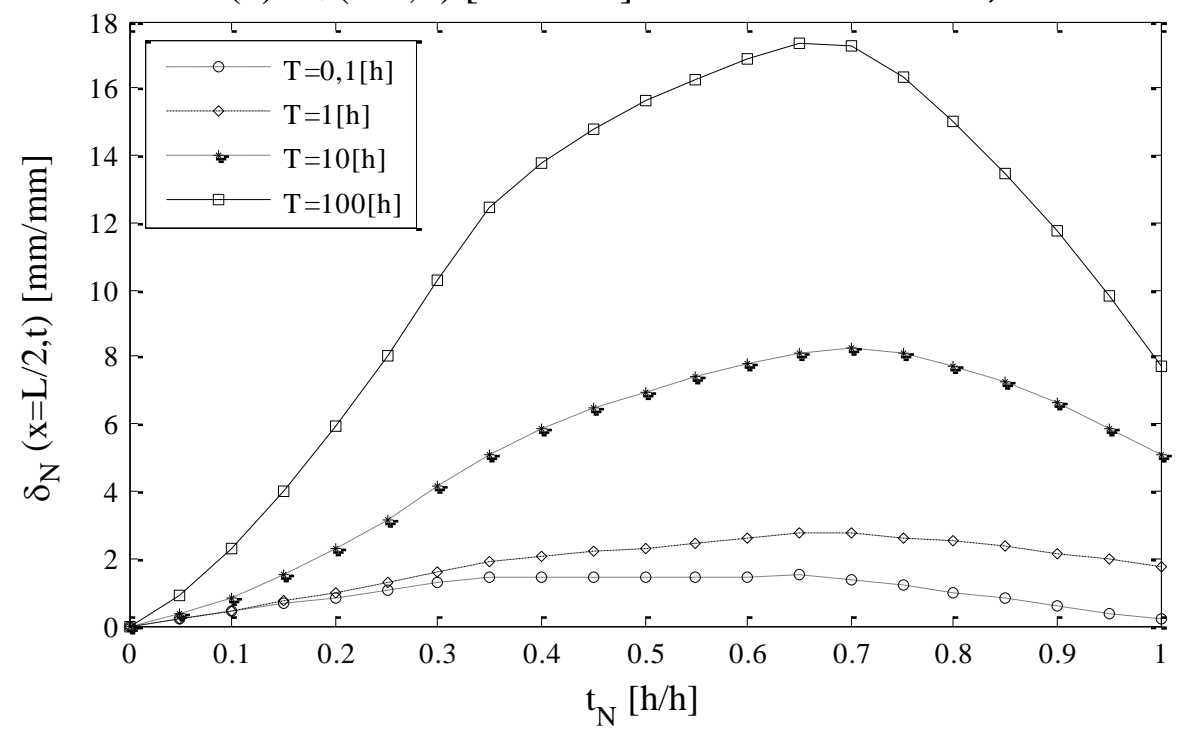

$\delta_{\mathrm{N}}(\mathrm{L} / 2, \mathrm{t})[\mathrm{mm} / \mathrm{mm}] \mathrm{MVTvv}_{2} \mathrm{CT} 3 \alpha=0,5$

Figura B.7 $-\delta_{\mathrm{N}}(\mathrm{L} / 2, \mathrm{t})[\mathrm{mm} / \mathrm{mm}] \mathrm{MVTvv}_{2} \alpha=0,5$ 


\section{B.8 - $\delta_{\mathrm{N}}$ CASO VI: MVT VISCOELÁSTICO $\alpha=0,25$}

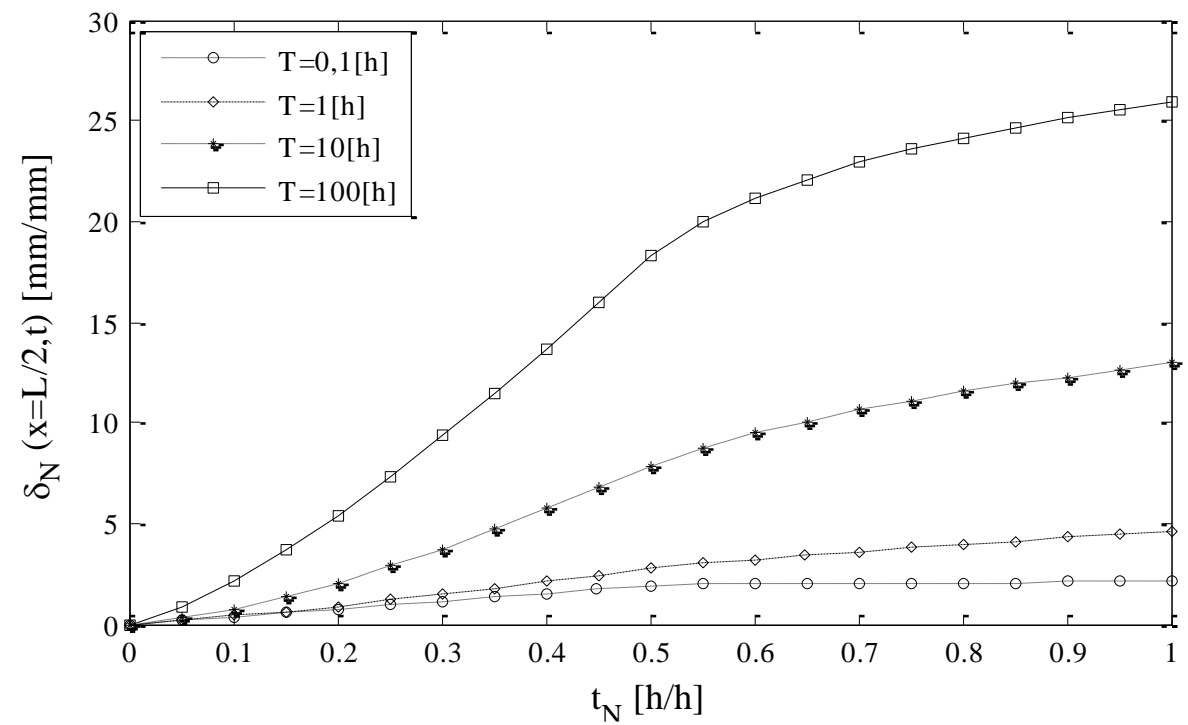

(a) $\delta_{\mathrm{N}}(\mathrm{L} / 2, \mathrm{t})[\mathrm{mm} / \mathrm{mm}] \mathrm{MVTvv}_{2} \mathrm{CT} 1 \alpha=0,25$

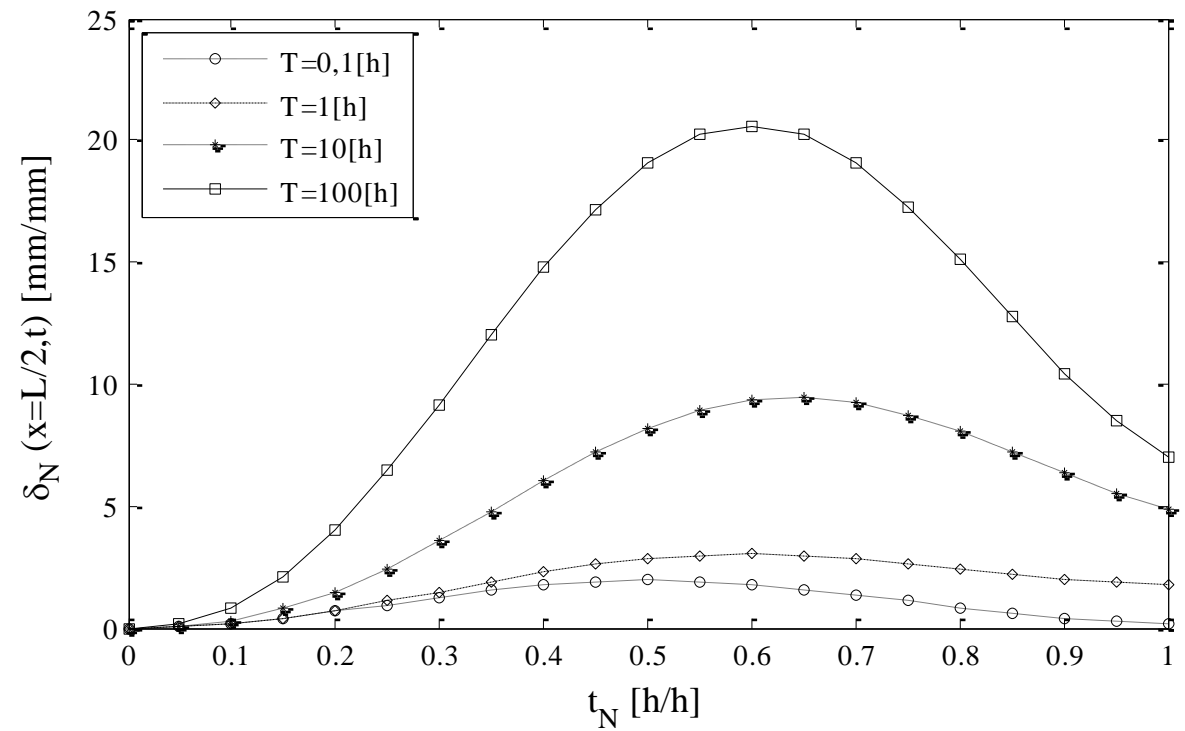

(b) $\delta_{\mathrm{N}}(\mathrm{L} / 2, \mathrm{t})[\mathrm{mm} / \mathrm{mm}] \mathrm{MVTvv}_{2} \mathrm{CT} 2 \alpha=0,25$

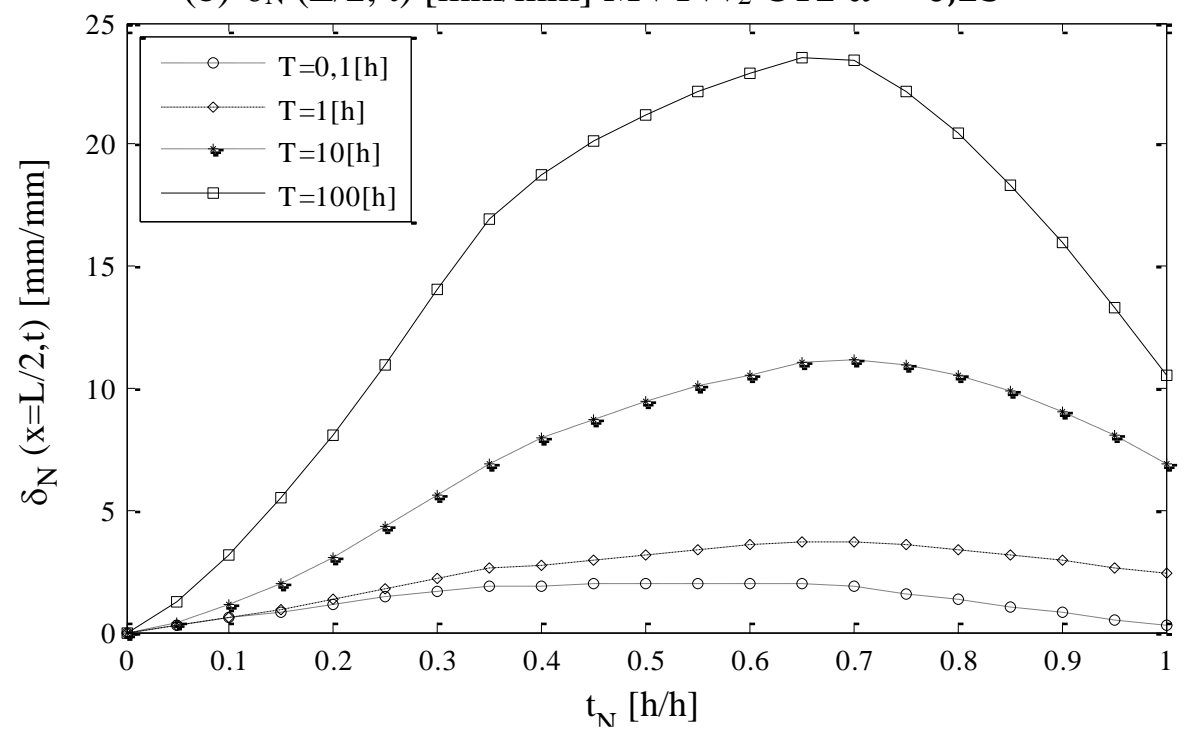

(c) $\delta_{\mathrm{N}}(\mathrm{L} / 2, \mathrm{t})[\mathrm{mm} / \mathrm{mm}] \mathrm{MVT} \mathrm{vv_{2 }}$ CT3 $\alpha=0,25$

Figura B.8 $-\delta_{\mathrm{N}}(\mathrm{L} / 2, \mathrm{t})[\mathrm{mm} / \mathrm{mm}] \mathrm{MVTvv}_{2} \alpha=0,25$ 


\section{C - PARÂMETROS ESTUDO DE SENSIBILIDADE}

\section{C.1 - DEFLEXÕES DADOS 54 COMBINAÇÕES DE 6 VARIÁVEIS}

\begin{tabular}{|c|c|c|c|c|c|c|c|c|}
\hline \# & $\begin{array}{l}\mathrm{E} 1=\mathrm{E} 2 \\
{[\mathrm{MPa}]}\end{array}$ & $\begin{array}{c}\mathrm{h} 1=\mathrm{h} 2 \\
{[\mathrm{~m}]}\end{array}$ & $\alpha$ & $\begin{array}{c}\mathrm{T} \\
{[\mathrm{h}]} \\
\end{array}$ & $\begin{array}{l}\text { Pmáx. } \\
{[\mathrm{MN}]}\end{array}$ & $\begin{array}{c}\mathrm{L} \\
{[\mathrm{m}]}\end{array}$ & $\begin{array}{c}\delta(\mathrm{T} / 2) \\
{[\mathrm{mm}]}\end{array}$ & $\begin{array}{l}\delta(\mathrm{T}) \\
{[\mathrm{mm}]}\end{array}$ \\
\hline 1 & 52500 & 0,000375 & 0,5 & 5 & 0,001 & 1 & 1,19 & 2,51 \\
\hline 2 & 52500 & 0,000375 & 0,5 & 15 & 0,001 & 1 & 2,29 & 4,03 \\
\hline 3 & 52500 & 0,000625 & 0,5 & 5 & 0,001 & 1 & 1,11 & 2,34 \\
\hline 4 & 52500 & 0,000625 & 0,5 & 15 & 0,001 & 1 & 2,13 & 3,75 \\
\hline 5 & 87500 & 0,000375 & 0,5 & 5 & 0,001 & 1 & 1,11 & 2,34 \\
\hline 6 & 87500 & 0,000375 & 0,5 & 15 & 0,001 & 1 & 2,14 & 3,76 \\
\hline 7 & 87500 & 0,000625 & 0,5 & 5 & 0,001 & 1 & 1,00 & 2,10 \\
\hline 8 & 87500 & 0,000625 & 0,5 & 15 & 0,001 & 1 & 1,92 & 3,37 \\
\hline 9 & 70000 & 0,000375 & 0,25 & 10 & 0,0006 & 1 & 1,49 & 2,74 \\
\hline 10 & 70000 & 0,000375 & 0,25 & 10 & 0,0014 & 1 & 3,47 & 6,40 \\
\hline 11 & 70000 & 0,000375 & 0,75 & 10 & 0,0006 & 1 & 0,88 & 1,63 \\
\hline 12 & 70000 & 0,000375 & 0,75 & 10 & 0,0014 & 1 & 2,06 & 3,80 \\
\hline 13 & 70000 & 0,000625 & 0,25 & 10 & 0,0006 & 1 & 1,31 & 2,41 \\
\hline 14 & 70000 & 0,000625 & 0,25 & 10 & 0,0014 & 1 & 3,05 & 5,62 \\
\hline 15 & 70000 & 0,000625 & 0,75 & 10 & 0,0006 & 1 & 0,82 & 1,51 \\
\hline 16 & 70000 & 0,000625 & 0,75 & 10 & 0,0014 & 1 & 1,91 & 3,53 \\
\hline 17 & 70000 & 0,0005 & 0,25 & 5 & 0,001 & 0,75 & 0,63 & 1,34 \\
\hline 18 & 70000 & 0,0005 & 0,25 & 5 & 0,001 & 1,25 & 2,90 & 6,12 \\
\hline 19 & 70000 & 0,0005 & 0,25 & 15 & 0,001 & 0,75 & 1,22 & 2,15 \\
\hline 20 & 70000 & 0,0005 & 0,25 & 15 & 0,001 & 1,25 & 5,59 & 9,81 \\
\hline 21 & 70000 & 0,0005 & 0,75 & 5 & 0,001 & 0,75 & 0,39 & 0,82 \\
\hline 22 & 70000 & 0,0005 & 0,75 & 5 & 0,001 & 1,25 & 1,77 & 3,74 \\
\hline 23 & 70000 & 0,0005 & 0,75 & 15 & 0,001 & 0,75 & 0,75 & 1,31 \\
\hline 24 & 70000 & 0,0005 & 0,75 & 15 & 0,001 & 1,25 & 3,41 & 5,99 \\
\hline 25 & 52500 & 0,0005 & 0,5 & 5 & 0,0006 & 1 & 0,69 & 1,45 \\
\hline 26 & 52500 & 0,0005 & 0,5 & 5 & 0,0014 & 1 & 1,61 & 3,39 \\
\hline 27 & 52500 & 0,0005 & 0,5 & 15 & 0,0006 & 1 & 1,33 & 2,33 \\
\hline 28 & 52500 & 0,0005 & 0,5 & 15 & 0,0014 & 1 & 3,10 & 5,44 \\
\hline 29 & 87500 & 0,0005 & 0,5 & 5 & 0,0006 & 1 & 0,63 & 1,33 \\
\hline 30 & 87500 & 0,0005 & 0,5 & 5 & 0,0014 & 1 & 1,47 & 3,10 \\
\hline 31 & 87500 & 0,0005 & 0,5 & 15 & 0,0006 & 1 & 1,21 & 2,13 \\
\hline 32 & 87500 & 0,0005 & 0,5 & 15 & 0,0014 & 1 & 2,83 & 4,97 \\
\hline 33 & 70000 & 0,000375 & 0,5 & 10 & 0,0006 & 0,75 & 0,46 & 0,84 \\
\hline 34 & 70000 & 0,000375 & 0,5 & 10 & 0,0006 & 1,25 & 2,08 & 3,84 \\
\hline 35 & 70000 & 0,000375 & 0,5 & 10 & 0,0014 & 0,75 & 1,07 & 1,96 \\
\hline 36 & 70000 & 0,000375 & 0,5 & 10 & 0,0014 & 1,25 & 4,86 & 8,97 \\
\hline 37 & 70000 & 0,000625 & 0,5 & 10 & 0,0006 & 0,75 & 0,42 & 0,77 \\
\hline 38 & 70000 & 0,000625 & 0,5 & 10 & 0,0006 & 1,25 & 1,90 & 3,51 \\
\hline 39 & 70000 & 0,000625 & 0,5 & 10 & 0,0014 & 0,75 & 0,97 & 1,80 \\
\hline 40 & 70000 & 0,000625 & 0,5 & 10 & 0,0014 & 1,25 & 4,44 & 8,19 \\
\hline 41 & 52500 & 0,0005 & 0,25 & 10 & 0,001 & 0,75 & 1,05 & 1,94 \\
\hline 42 & 52500 & 0,0005 & 0,25 & 10 & 0,001 & 1,25 & 4,82 & 8,89 \\
\hline 43 & 52500 & 0,0005 & 0,75 & 10 & 0,001 & 0,75 & 0,63 & 1,16 \\
\hline 44 & 52500 & 0,0005 & 0,75 & 10 & 0,001 & 1,25 & 2,86 & 5,27 \\
\hline 45 & 87500 & 0,0005 & 0,25 & 10 & 0,001 & 0,75 & 0,93 & 1,71 \\
\hline 46 & 87500 & 0,0005 & 0,25 & 10 & 0,001 & 1,25 & 4,24 & 7,82 \\
\hline 47 & 87500 & 0,0005 & 0,75 & 10 & 0,001 & 0,75 & 0,58 & 1,08 \\
\hline 48 & 87500 & 0,0005 & 0,75 & 10 & 0,001 & 1,25 & 2,66 & 4,90 \\
\hline 49 & 70000 & 0,0005 & 0,5 & 10 & 0,001 & 1 & 1,71 & 3,15 \\
\hline 50 & 70000 & 0,0005 & 0,5 & 10 & 0,001 & 1 & 1,71 & 3,15 \\
\hline 51 & 70000 & 0,0005 & 0,5 & 10 & 0,001 & 1 & 1,71 & 3,15 \\
\hline 52 & 70000 & 0,0005 & 0,5 & 10 & 0,001 & 1 & 1,71 & 3,15 \\
\hline 53 & 70000 & 0,0005 & 0,5 & 10 & 0,001 & 1 & 1,71 & 3,15 \\
\hline 54 & 70000 & 0,0005 & 0,5 & 10 & 0,001 & 1 & 1,71 & 3,15 \\
\hline
\end{tabular}


C.2 - MATRIX X

\begin{tabular}{|c|c|c|c|c|c|c|c|c|c|c|c|c|c|c|c|c|c|c|c|c|c|c|c|c|c|c|c|}
\hline$\theta$ & $\bar{X}$ & 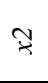 & 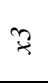 & 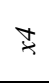 & 8 & $\bar{z}$ & $\leqq$ & స్తు & $\widehat{్}$ & $\underset{⿱ 亠 乂}{*}$ & $\leqslant$ & گ્o & $\stackrel{7}{x}$ & $\stackrel{3}{3}$ & $\underset{3}{\stackrel{Z}{3}}$ & $\stackrel{?}{3}$ & 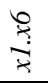 & 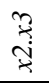 & 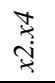 & ְ̊ & 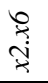 & $\stackrel{Z}{Z}$ & $\stackrel{?}{3}$ & 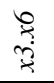 & $\frac{\mathfrak{Z}}{\mathfrak{z}}$ & 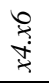 & 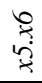 \\
\hline 1 & -1 & -1 & 0 & -1 & 0 & 0 & 1 & 1 & 0 & 1 & 0 & 0 & 1 & 0 & 1 & 0 & 0 & 0 & 1 & 0 & 0 & 0 & 0 & 0 & 0 & 0 & 0 \\
\hline 1 & -1 & -1 & 0 & 1 & 0 & 0 & 1 & 1 & 0 & 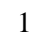 & 0 & 0 & 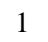 & 0 & -1 & 0 & 0 & 0 & -1 & 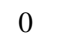 & 0 & & 0 & 0 & & 0 & \\
\hline 1 & -1 & 1 & 0 & -1 & 0 & 0 & 1 & 1 & 0 & 1 & 0 & 0 & -1 & 0 & 1 & 0 & 0 & 0 & -1 & 0 & 0 & & 0 & 0 & & 0 & \\
\hline 1 & -1 & 1 & 0 & 1 & 0 & 0 & 1 & 1 & 0 & 1 & 0 & 0 & -1 & 0 & -1 & 0 & 0 & 0 & 1 & 0 & 0 & 0 & 0 & 0 & 0 & 0 & 0 \\
\hline 1 & 1 & -1 & 0 & -1 & 0 & 0 & 1 & 1 & 0 & 1 & 0 & 0 & -1 & 0 & -1 & 0 & 0 & 0 & 1 & 0 & 0 & & 0 & 0 & & 0 & \\
\hline 1 & 1 & -1 & 0 & 1 & 0 & 0 & 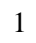 & 1 & 0 & 1 & 0 & 0 & -1 & 0 & 1 & 0 & 0 & 0 & -1 & 0 & 0 & & 0 & 0 & & 0 & 0 \\
\hline 1 & 1 & 1 & 0 & -1 & 0 & 0 & 1 & 1 & 0 & 1 & 0 & 0 & 1 & 0 & -1 & 0 & 0 & 0 & -1 & 0 & 0 & & 0 & 0 & & 0 & 0 \\
\hline 1 & 1 & 1 & 0 & 1 & 0 & 0 & 1 & 1 & 0 & 1 & 0 & 0 & 1 & 0 & 1 & 0 & 0 & 0 & 1 & 0 & 0 & & 0 & 0 & & 0 & 0 \\
\hline 1 & 0 & -1 & -1 & 0 & -1 & 0 & 0 & 1 & 1 & 0 & 1 & 0 & 0 & 0 & 0 & 0 & 0 & 1 & 0 & 1 & 0 & & 1 & 0 & & 0 & 0 \\
\hline 1 & 0 & -1 & -1 & 0 & 1 & 0 & 0 & 1 & 1 & 0 & 1 & 0 & 0 & 0 & 0 & 0 & 0 & 1 & 0 & -1 & 0 & c & -1 & 0 & & 0 & 0 \\
\hline 1 & 0 & -1 & 1 & 0 & -1 & 0 & 0 & 1 & 1 & 0 & 1 & 0 & 0 & 0 & 0 & 0 & 0 & -1 & 0 & 1 & 0 & & -1 & 0 & & 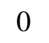 & \\
\hline 1 & 0 & -1 & 1 & 0 & 1 & 0 & 0 & 1 & 1 & 0 & 1 & 0 & L & 0 & 0 & 0 & 0 & -1 & 0 & -1 & 0 & & 1 & 0 & & 0 & 0 \\
\hline 1 & 0 & 1 & -1 & 0 & -1 & 0 & 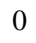 & 1 & 1 & 0 & 1 & 0 & 0 & 0 & 0 & 0 & 0 & -1 & 0 & -1 & 0 & & 1 & 0 & & 0 & 0 \\
\hline 1 & 0 & 1 & -1 & 0 & 1 & 0 & 0 & 1 & 1 & 0 & 1 & 0 & 0 & 0 & 0 & 0 & 0 & -1 & 0 & 1 & 0 & ( & -1 & 0 & ( & 0 & 0 \\
\hline 1 & 0 & 1 & 1 & 0 & -1 & 0 & 0 & 1 & 1 & 0 & 1 & 0 & 0 & 0 & 0 & 0 & 0 & & 0 & -1 & 0 & & -1 & 0 & & 0 & \\
\hline 1 & 0 & 1 & 1 & 0 & 1 & 0 & 0 & 1 & 1 & 0 & 1 & 0 & 0 & 0 & 0 & 0 & 0 & 1 & 0 & 1 & 0 & & & 0 & & 0 & 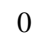 \\
\hline 1 & 0 & 0 & -1 & -1 & 0 & 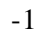 & 0 & 0 & 1 & 1 & 0 & 1 & 0 & 0 & 0 & 0 & 0 & 0 & 0 & 0 & 0 & 1 & 0 & 1 & 0 & 1 & 0 \\
\hline 1 & 0 & 0 & -1 & -1 & 0 & 1 & 0 & 0 & 1 & 1 & 0 & 1 & 0 & 0 & 0 & 0 & 0 & 0 & 0 & 0 & 0 & 1 & 0 & -1 & 0 & -1 & 0 \\
\hline 1 & 0 & 0 & -1 & 1 & 0 & -1 & 0 & 0 & 1 & 1 & 0 & 1 & 0 & 0 & 0 & 0 & 0 & 0 & 0 & 0 & 0 & - & 0 & 1 & & -1 & 0 \\
\hline 1 & 0 & 0 & -1 & 1 & 0 & 1 & 0 & 0 & 1 & 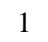 & 0 & 1 & 0 & U & 0 & 0 & 0 & 0 & 0 & 0 & 0 & & 0 & -1 & 0 & 1 & 0 \\
\hline 1 & 0 & 0 & 1 & -1 & 0 & -1 & 0 & 0 & 1 & 1 & . & 1 & 0 & 0 & 0 & 0 & 0 & 0 & 0 & 0 & 0 & -1 & 0 & -1 & 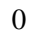 & 1 & 0 \\
\hline 1 & 0 & 0 & 1 & -1 & 0 & 1 & 0 & 0 & 1 & 1 & 0 & 1 & 0 & 0 & 0 & 0 & 0 & 0 & 0 & 0 & 0 & - & 0 & 1 & 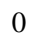 & -1 & 0 \\
\hline 1 & 0 & 0 & 1 & 1 & 0 & -1 & 0 & 0 & 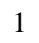 & 1 & 0 & 1 & 0 & 0 & 0 & 0 & 0 & 0 & 0 & 0 & 0 & & 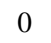 & -1 & & -1 & 0 \\
\hline 1 & 0 & 0 & 1 & 1 & 0 & 1 & 0 & 0 & 1 & 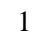 & 0 & 1 & 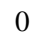 & 0 & 0 & 0 & 0 & 0 & 0 & 0 & 0 & & 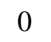 & 1 & & 1 & 0 \\
\hline 1 & -1 & 0 & 0 & -1 & -1 & 0 & 1 & 0 & 0 & 1 & 1 & 0 & 0 & 0 & 1 & 1 & 0 & 0 & 0 & 0 & 0 & ( & 0 & 0 & 1 & 0 & 0 \\
\hline 1 & -1 & 0 & 0 & -1 & 1 & 0 & 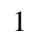 & 0 & 0 & 1 & 1 & 0 & 0 & 0 & 1 & -1 & 0 & 0 & 0 & 0 & 0 & ( & 0 & 0 & -1 & 0 & 0 \\
\hline 1 & -1 & 0 & 0 & 1 & -1 & ( & 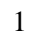 & 0 & 0 & 1 & 1 & 0 & 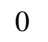 & 0 & -1 & 1 & 0 & 0 & 0 & 0 & 0 & & 0 & 0 & -1 & 0 & 0 \\
\hline 1 & -1 & 0 & 0 & 1 & 1 & c & 1 & 0 & ( & 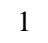 & 1 & 0 & 0 & 0 & -1 & -1 & 0 & 0 & 0 & 0 & 0 & & 0 & 0 & & 0 & 0 \\
\hline 1 & 1 & 0 & 0 & -1 & -1 & 0 & 1 & 0 & 0 & 1 & 1 & 0 & 0 & 0 & -1 & -1 & 0 & 0 & 0 & 0 & 0 & & 0 & 0 & 1 & 0 & 0 \\
\hline 1 & 1 & 0 & 0 & -1 & 1 & 0 & 1 & 0 & 0 & 1 & 1 & 0 & 0 & 0 & -1 & 1 & 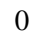 & 0 & 0 & 0 & 0 & c & 0 & 0 & -1 & 0 & 0 \\
\hline 1 & 1 & 0 & 0 & 1 & -1 & ( & 1 & 0 & 0 & 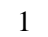 & 1 & 0 & 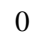 & 0 & 1 & -1 & 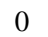 & 0 & 0 & 0 & 0 & & 0 & 0 & -1 & 0 & 0 \\
\hline 1 & 1 & 0 & 0 & 1 & 1 & c & 1 & 0 & 0 & 1 & & 0 & 0 & 0 & & 1 & 0 & 0 & 0 & 0 & 0 & & 0 & 0 & & 0 & 0 \\
\hline 1 & 0 & -1 & 0 & 0 & -1 & -1 & 0 & 1 & 0 & 0 & 1 & 1 & 0 & 0 & 0 & 0 & 0 & 0 & 0 & 1 & 1 & c & 0 & 0 & 0 & 0 & 1 \\
\hline 1 & 0 & -1 & 0 & 0 & -1 & 1 & 0 & 1 & 0 & 0 & 1 & 1 & 0 & 0 & 0 & 0 & 0 & 0 & 0 & 1 & -1 & 0 & 0 & 0 & 0 & 0 & -1 \\
\hline 1 & 0 & -1 & 0 & 0 & 1 & - & 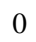 & 1 & 0 & 0 & 1 & 1 & 0 & 0 & 0 & 0 & 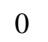 & 0 & 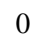 & -1 & 1 & c & 0 & 0 & 0 & 0 & -1 \\
\hline 1 & 0 & -1 & 0 & 0 & 1 & 1 & 0 & 1 & 0 & 0 & 1 & 1 & 0 & 0 & 0 & 0 & 0 & 0 & 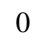 & -1 & -1 & ( & 0 & 0 & 0 & 0 & 1 \\
\hline 1 & 0 & 1 & 0 & 0 & -1 & -1 & 0 & 1 & 0 & 0 & 1 & 1 & 0 & 0 & 0 & 0 & 0 & 0 & 0 & -1 & -1 & c & 0 & 0 & 0 & 0 & 1 \\
\hline 1 & 0 & 1 & 0 & 0 & -1 & 1 & 0 & 1 & 0 & 0 & 1 & 1 & 0 & 0 & 0 & 0 & 0 & 0 & 0 & -1 & 1 & 0 & 0 & 0 & 0 & 0 & -1 \\
\hline 1 & 0 & 1 & 0 & 0 & 1 & -1 & 0 & 1 & 0 & 0 & 1 & 1 & 0 & 0 & 0 & 0 & 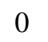 & 0 & 0 & 1 & -1 & c & 0 & 0 & 0 & 0 & -1 \\
\hline 1 & 0 & 1 & 0 & 0 & 1 & 1 & 0 & 1 & 0 & 0 & 1 & 1 & 0 & 0 & 0 & 0 & 0 & 0 & 0 & 1 & 1 & c & 0 & 0 & 0 & 0 & 1 \\
\hline 1 & -1 & 0 & -1 & 0 & 0 & -1 & 1 & 0 & 1 & 0 & 0 & 1 & 0 & 1 & 0 & 0 & 1 & 0 & 0 & 0 & 0 & ( & 0 & 1 & 0 & 0 & 0 \\
\hline 1 & -1 & 0 & -1 & 0 & 0 & 1 & 1 & 0 & 1 & 0 & 0 & 1 & 0 & 1 & 0 & 0 & -1 & 0 & 0 & 0 & 0 & 0 & 0 & -1 & 0 & 0 & 0 \\
\hline 1 & -1 & 0 & 1 & 0 & 0 & -1 & 1 & 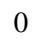 & 1 & 0 & 0 & 1 & 0 & -1 & 0 & 0 & 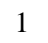 & . & 0 & 0 & 0 & 0 & 0 & -1 & 0 & 0 & 0 \\
\hline 1 & -1 & 0 & 1 & 0 & 0 & 1 & 1 & 0 & 1 & 0 & 0 & 1 & 0 & - & 0 & 0 & - & 0 & 0 & 0 & 0 & ( & 0 & 1 & 0 & 0 & 0 \\
\hline 1 & 1 & 0 & -1 & 0 & 0 & - & 1 & 0 & 1 & 0 & 0 & 1 & 0 & -1 & 0 & 0 & -1 & 0 & 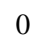 & 0 & 0 & 0 & 0 & 1 & 0 & 0 & 0 \\
\hline 1 & 1 & 0 & -1 & 0 & 0 & 1 & 1 & 0 & 1 & 0 & 0 & 1 & 0 & -1 & 0 & 0 & 1 & 0 & 0 & 0 & 0 & 0 & 0 & -1 & 0 & 0 & 0 \\
\hline 1 & 1 & 0 & 1 & 0 & 0 & -1 & 1 & 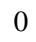 & 1 & 0 & 0 & 1 & 0 & 1 & 0 & 0 & -1 & 0 & 0 & 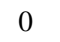 & 0 & 0 & 0 & -1 & 0 & 0 & 0 \\
\hline 1 & 1 & 0 & 1 & 0 & 0 & 1 & 1 & 0 & 1 & 0 & 0 & 1 & 0 & 1 & 0 & 0 & 1 & 0 & 0 & $\sigma$ & 0 & ( & 0 & 1 & ( & 0 & 0 \\
\hline 1 & 0 & 0 & 0 & 0 & 0 & 0 & 0 & 0 & 0 & 0 & 0 & 0 & o & 0 & 0 & 0 & . & 0 & 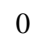 & 0 & 0 & c & 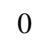 & 0 & ( & 0 & 0 \\
\hline 1 & 0 & 0 & 0 & 0 & 0 & 0 & 0 & 0 & 0 & 0 & 0 & 0 & 0 & 0 & 0 & 0 & 0 & 0 & 0 & 0 & 0 & 0 & 0 & 0 & 0 & 0 & 0 \\
\hline 1 & 0 & 0 & 0 & 0 & 0 & 0 & 0 & 0 & 0 & 0 & , & 0 & 0 & 0 & 0 & 0 & 0 & 0 & 0 & 0 & 0 & 0 & 0 & 0 & 0 & 0 & 0 \\
\hline 1 & 0 & 0 & 0 & 0 & 0 & 0 & 0 & 0 & 0 & 0 & 0 & 0 & 0 & 0 & 0 & 0 & 0 & 0 & 0 & 0 & 0 & ( & 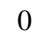 & 0 & & 0 & 0 \\
\hline 1 & 0 & 0 & 0 & 0 & 0 & 0 & 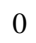 & 0 & 0 & 0 & 0 & 0 & 0 & 0 & 0 & 0 & 0 & 0 & 0 & $\sigma$ & 0 & 0 & 0 & 0 & 0 & 0 & 0 \\
\hline 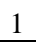 & 0 & 0 & 0 & 0 & 0 & 0 & 0 & 0 & 0 & 0 & 0 & 0 & 0 & 0 & 0 & 0 & 0 & 0 & 0 & 0 & 0 & 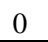 & 0 & 0 & 0 & 0 & 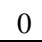 \\
\hline
\end{tabular}




\section{D - ALGORITMOS EM MATLAB}

\section{D.1 - ALGORITMO DE APROXIMAÇÃO ÀS SÉRIES DE PRONY APLICADO AO}

\section{EXEMPLO 4.1.1}

function [Compliance_norm N J_coeff FVAL EXITFLAG] = Compliance_script2() $\% \%$ Programa que avalia uma série de dados experimentais e aproxima uma função em forma de série de Prony

clc; clear all; close all; format long;

$\% \%$ Dados Iniciais

a1 $=0.01 *[1.8837 .565 .85037 .637 .675 .213200 .05]^{\prime} ;$

\% Série Jn de Rs-Tomp.

a2 = [1 101001000100001000001000000 10000000]'; \% Exp. série de Rs-Tomp.

t_data $=[0: 1: 18000] ;$

[Jt,t_data] = Compliance $\left(\mathrm{a} 1, \mathrm{a} 2, \mathrm{t} \_\right.$data $) ; \quad \%$ dados de entrada

figure(1)

plot(t_data,Jt,'r--');

hold on

Jt_data(:,1) = t_data;

Jt_data $(:, 2)=\mathrm{Jt}$;

$\% \%$ Dados entrada da optimização e medição do erro

time $=0.0100000$

$\mathrm{K}=0.28$;

$\mathrm{FVAL}=1$;

EXITFLAG $=-10$

Jnorm $=100$;

while Jnorm $>1$

time $=$ time $^{*} 1.2$

$\mathrm{K}=\mathrm{K}$

J_coeff_0 $=\mathrm{K}+$ zeros $(9,1)$;

J_coeff_O $(10,1)=$ time;

$\mathrm{A}=$-eye $(10)$

$\mathrm{b}=\operatorname{zeros}(10,1)$;

[J_coeff,FVAL,EXITFLAG] = fmincon $\left(@\left(J \_c o e f f\right)\right.$

fitCreep(J_coeff,Jt_data),J_coeff_0,A,b);

Jnorm $=$ fitCreep $\left(J_{-}\right.$coeff,Jt_data);

J_coeff

FVAL;

EXITFLAG;

end

a3 $=0.915 * J \_c o e f f(1: 9)$

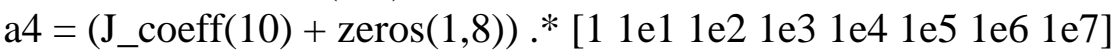

$\mathrm{t}=[0: 1000: 18000]$

$[\mathrm{Jt} 1, \mathrm{t}]=$ Compliance $(\mathrm{a} 3, \mathrm{a} 4, \mathrm{t})$;

$\operatorname{plot}\left(\mathrm{t}, \mathrm{Jt} 1, \mathrm{boo}^{\prime}\right)$;

title('FLUÊNCIA D(t)')

xlabel('TEMPO t horas')

ylabel('D(t)')

legend('D(t) Analitica Teses Roberts-Tompkins','D(t) Série de Prony Obtida',4)

$\mathrm{Jt} 1(1)$

end 


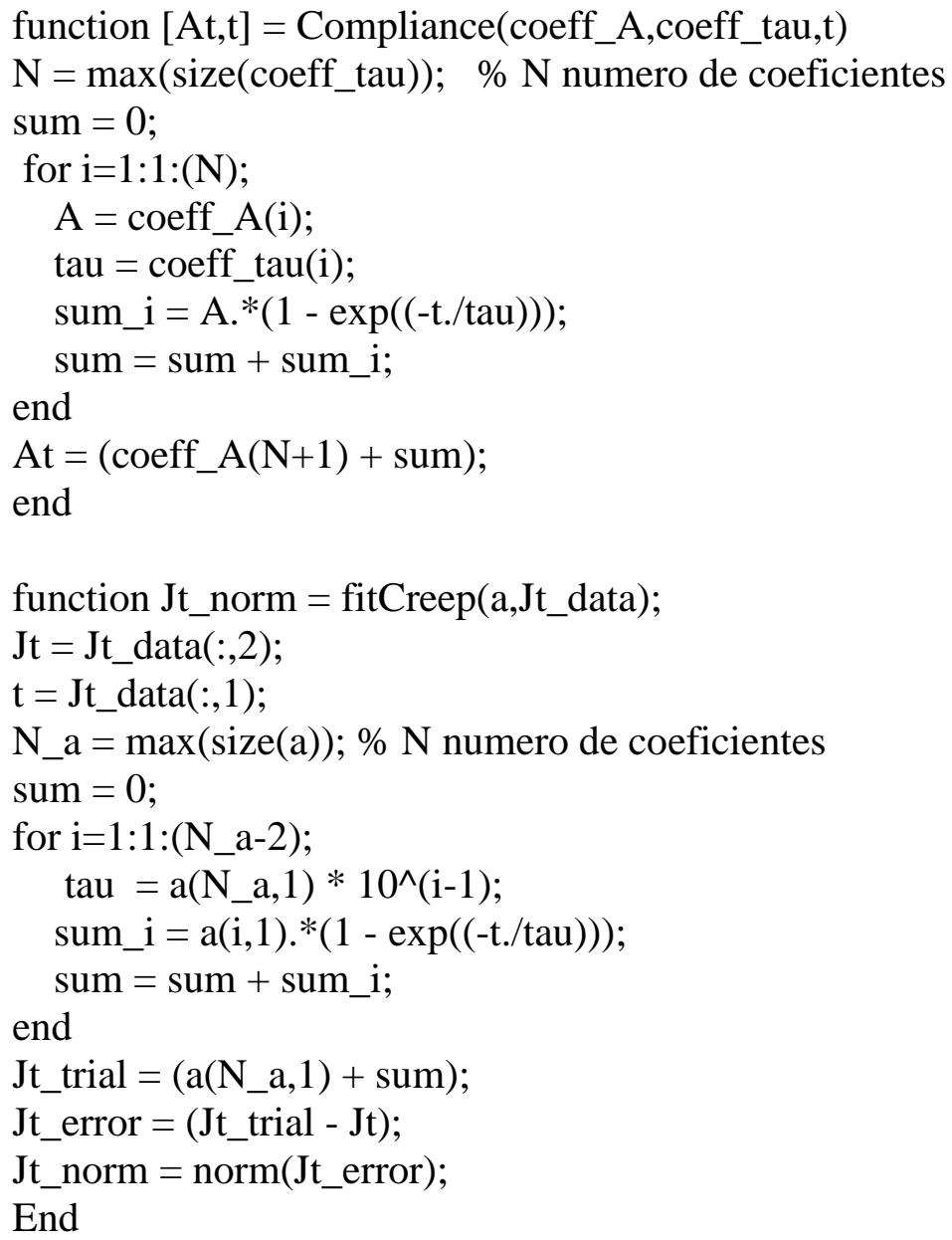

\section{D.2 - ALGORITMO DE INTERCONVERSÃO DE G(T) PARA J(T)}

function $[\mathrm{ft}]=$ ilaplace_fourier $(\mathrm{t})$

clear all; clc; close all; format long;

$\% \%$ Declaração de variáveis

$\mathrm{k} \_\mathrm{n}=1000 ; \quad$ b_const $=4.5$;

$\mathrm{G} 1=[7.3 \mathrm{E} 6$ 4.9E6 0.48E6 57E3 6.4E3 1.3E3 0.1E3 0.143E3]; \% Pa

Rho1= [100 2000 2E4 2E5 2E6 2E7 4E8]; $\%$ Seg $\mathrm{v}=0.33$;

\% Cálculo da distribução do tempo

$\mathrm{t} 1=14 ; \%$ Numero de ordens de grandeza

Expini $=-1$

$\mathrm{t} 2=9 * 2 ; \%$ Numero de pontos por ordem de grandeza

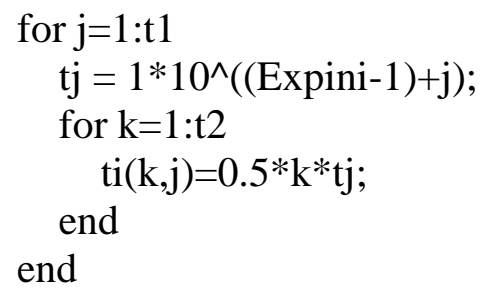




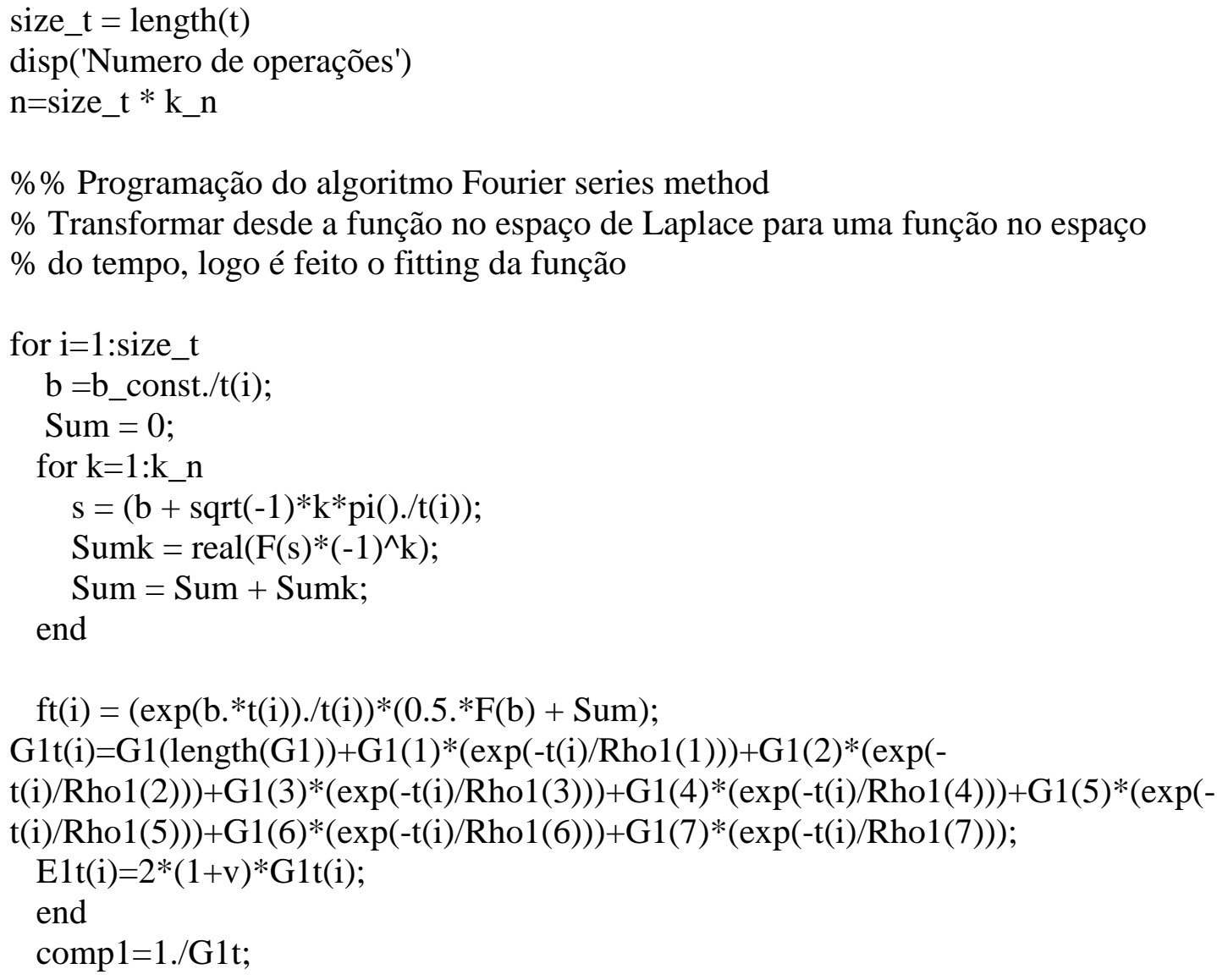


$\mathrm{F}=1 . /\left(\mathrm{Fufc}^{*}\left(\mathrm{~s}^{\wedge} 2\right)\right)$

end

\section{D.3 - ALGORITMO DE INTERCONVERSÃO DE D(t) PARA E(t)}

function $\mathrm{ft}=$ ilaplace_fourier $(\mathrm{t})$

clear all; clc; close all; format long;

$\% \%$ Declaração de variáveis

$\mathrm{k} \_\mathrm{n}=1000 ; \quad$ b_const $=4.5$;

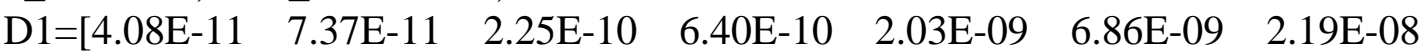

6.50E-08 1.37E-07 6.93E-08 1.45E-07 4.47E-10];

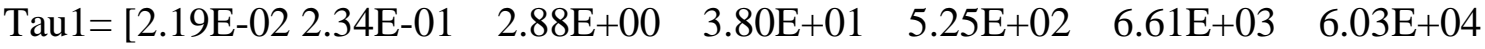

$5.89 \mathrm{E}+05 \quad 4.27 \mathrm{E}+06 \quad 2.57 \mathrm{E}+07 \quad 2.95 \mathrm{E}+08]$

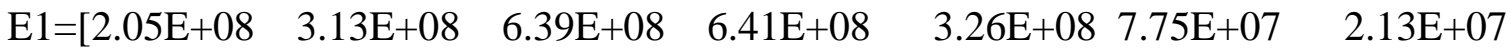

$8.83 \mathrm{E}+06 \quad 8.85 \mathrm{E}+05 \quad 8.64 \mathrm{E}+05 \quad 9.28 \mathrm{E}+05 \quad 2.23 \mathrm{E}+06] ;$

Rho1= Tau 1

\% Cálculo da distribuição do tempo

$\mathrm{t} 1=14 ; \%$ Numero de ordens de grandeza

$\mathrm{t} 2=9 ; \%$ Numero de pontos por ordem de grandeza

Expini $=-4$;

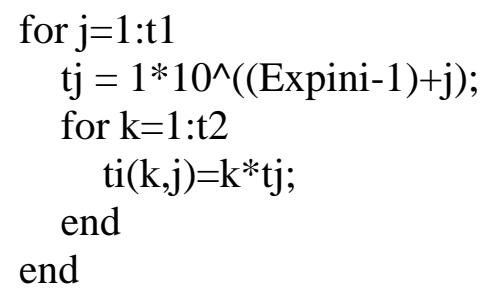

$\mathrm{t}(:, 1)=[\mathrm{ti}(:, 1) ; \mathrm{ti}(:, 2) ; \mathrm{ti}(:, 3) ; \mathrm{ti}(:, 4) ; \mathrm{ti}(:, 5) ; \mathrm{ti}(:, 6) ; \operatorname{ti}(:, 7) ; \mathrm{ti}(:, 8) ; \mathrm{ti}(:, 9) ; \operatorname{ti}(:, 10) ; \mathrm{ti}(:, 11) ; \mathrm{ti}(:, 12) ; \mathrm{ti}(:, 1$ 3);ti(:,14)];

size_t $=$ length $(\mathrm{t})$;

disp('Numero de operações')

$\mathrm{n}=$ size_t $* \mathrm{k} \_\mathrm{n}$

$\% \%$ Programação do algoritmo Fourier series method

\% Transformar desde a função no espaço de Laplace para uma função no espaço

$\%$ do tempo, logo é feito o fitting da função

for $\mathrm{i}=1$ :size_t

$\mathrm{b}=\mathrm{b} \_$const./t(i);

Sum $=0$;

for $\mathrm{k}=1: \mathrm{k} \_\mathrm{n}$

$\mathrm{s}=\left(\mathrm{b}+\operatorname{sqrt}(-1)^{*} \mathrm{k}^{*} \mathrm{pi}() . / \mathrm{t}(\mathrm{i})\right)$;

Sumk $=\operatorname{real}\left(\mathrm{F}(\mathrm{s})^{*}(-1)^{\wedge} \mathrm{k}\right)$;

Sum $=$ Sum + Sumk;

end

$\mathrm{ft}(\mathrm{i})=(\exp (\mathrm{b} \cdot * \mathrm{t}(\mathrm{i})) \cdot / \mathrm{t}(\mathrm{i})) *(0.5 \cdot * \mathrm{~F}(\mathrm{~b})+\mathrm{Sum})$;

$\mathrm{D} 1 \mathrm{t}(\mathrm{i})=\mathrm{D} 1($ length$(\mathrm{D} 1))+\mathrm{D} 1(1) *(1-\exp (-\mathrm{t}(\mathrm{i}) / \mathrm{Tau} 1(1)))+\mathrm{D} 1(2) *(1-\exp (-$

$\mathrm{t}(\mathrm{i}) / \mathrm{Tau} 1(2)))+\mathrm{D} 1(3) *(1-\exp (-\mathrm{t}(\mathrm{i}) / \mathrm{Tau} 1(3)))+\mathrm{D} 1(4) *(1-\exp (-\mathrm{t}(\mathrm{i}) / \mathrm{Tau} 1(4)))+\mathrm{D} 1(5) *(1-\exp (-$

$\mathrm{t}(\mathrm{i}) / \mathrm{Tau} 1(5)))+\mathrm{D} 1(6) *(1-\exp (-\mathrm{t}(\mathrm{i}) / \mathrm{Tau} 1(6)))+\mathrm{D} 1(7) *(1-\exp (-\mathrm{t}(\mathrm{i}) / \mathrm{Tau} 1(7)))+\mathrm{D} 1(8) *(1-\exp (-$ 
$\mathrm{t}(\mathrm{i}) / \mathrm{Tau} 1(8)))+\mathrm{D} 1(9) *(1-\exp (-\mathrm{t}(\mathrm{i}) / \mathrm{Tau} 1(9)))+\mathrm{D} 1(10) *(1-\exp (-\mathrm{t}(\mathrm{i}) / \mathrm{Tau} 1(10)))+\mathrm{D} 1(11) *(1-$ $\exp (-\mathrm{t}(\mathrm{i}) / \mathrm{Tau} 1(11)))$;

$\mathrm{E} 1 \mathrm{t}(\mathrm{i})=\mathrm{E} 1($ length$(\mathrm{E} 1))+\mathrm{E} 1(1) *(\exp (-\mathrm{t}(\mathrm{i}) / \mathrm{Rho} 1(1)))+\mathrm{E} 1(2) *(\exp (-$

$\mathrm{t}(\mathrm{i}) / \mathrm{Rho} 1(2)))+\mathrm{E} 1(3) *(\exp (-\mathrm{t}(\mathrm{i}) / \mathrm{Rho} 1(3)))+\mathrm{E} 1(4) *(\exp (-\mathrm{t}(\mathrm{i}) / \mathrm{Rho} 1(4)))+\mathrm{E} 1(5) *(\exp (-$

$\mathrm{t}(\mathrm{i}) / \mathrm{Rho} 1(5)))+\mathrm{E} 1(6) *(\exp (-\mathrm{t}(\mathrm{i}) / \mathrm{Rho} 1(6)))+\mathrm{E} 1(7) *(\exp (-\mathrm{t}(\mathrm{i}) / \mathrm{Rho} 1(7)))+\mathrm{E} 1(8) *(\exp (-$

$\mathrm{t}(\mathrm{i}) / \mathrm{Rho} 1(8)))+\mathrm{E} 1(9) *(\exp (-\mathrm{t}(\mathrm{i}) / \mathrm{Rho} 1(9)))+\mathrm{E} 1(10) *(\exp (-\mathrm{t}(\mathrm{i}) / \mathrm{Rho} 1(10)))+\mathrm{E} 1(11)^{*}(\exp (-$ $\mathrm{t}(\mathrm{i}) / \operatorname{Rho1}(11)))$;

end

figure (1)

$\log \log \left(\mathrm{t}, \mathrm{ft},{ }^{\prime}-\mathrm{r}^{\prime}\right)$

hold on

$\log \log \left(\mathrm{t}, 1 . / \mathrm{D} 1 \mathrm{t},{ }^{\prime}-{ }^{*} \mathrm{~g} \mathrm{~g}^{\prime}\right)$

$\log \log \left(\mathrm{t}, \mathrm{E} 1 \mathrm{t}, \mathrm{\prime}^{-}-\mathrm{ob} \mathrm{b}^{\prime}\right)$

title('Função de Relaxação no espaço do Tempo E(t)')

xlabel('tempo t [s]')

ylabel('E(t) [N/m²]')

legend('E(t) calculado','E(t) 1/D(t)','E(t)Analitica','Location','southwest')

figure (2)

$\log \log \left(\mathrm{t}, \mathrm{D} 1 \mathrm{t}, \mathrm{\prime}^{-o b}\right)$

title('Função de Fluência no espaço do Tempo D(t)')

xlabel('tempo t $\left.[\mathrm{s}]^{\prime}\right)$

ylabel $\left({ }^{\prime} \mathrm{D}(\mathrm{t})\left[\mathrm{N} / \mathrm{m}^{\wedge} 2\right]^{\wedge}-1^{\prime}\right)$

end

function $\mathrm{F}=\mathrm{F}(\mathrm{s})$;

$\mathrm{D} 1=[4.08 \mathrm{E}-11 \quad 7.37 \mathrm{E}-11 \quad 2.25 \mathrm{E}-10 \quad 6.40 \mathrm{E}-10 \quad 2.03 \mathrm{E}-09 \quad 6.86 \mathrm{E}-09 \quad 2.19 \mathrm{E}-08$

6.50E-08 1.37E-07 6.93E-08 1.45E-07 4.47E-10];

Tau $1=\left[\begin{array}{llllll}2.19 \mathrm{E}-02 & 2.34 \mathrm{E}-01 \quad 2.88 \mathrm{E}+00 & 3.80 \mathrm{E}+01 & 5.25 \mathrm{E}+02 & 6.61 \mathrm{E}+03 & 6.03 \mathrm{E}+04\end{array}\right.$

$5.89 \mathrm{E}+05 \quad 4.27 \mathrm{E}+06 \quad 2.57 \mathrm{E}+07 \quad 2.95 \mathrm{E}+08]$;

Fufc $=\mathrm{D} 1($ length $(\mathrm{D} 1)) / \mathrm{s}+\mathrm{D} 1(1) *(1 / \mathrm{s}-1 /(\mathrm{s}+(1 / \mathrm{Tau} 1(1))))+\mathrm{D} 1(2) *(1 / \mathrm{s}-$

$1 /(\mathrm{s}+(1 / \operatorname{Tau} 1(2))))+\mathrm{D} 1(3) *(1 / \mathrm{s}-1 /(\mathrm{s}+(1 / \mathrm{Tau} 1(3))))+\mathrm{D} 1(4) *(1 / \mathrm{s}-$

$1 /(\mathrm{s}+(1 / \mathrm{Tau} 1(4))))+\mathrm{D} 1(5) *(1 / \mathrm{s}-1 /(\mathrm{s}+(1 / \mathrm{Tau} 1(5))))+\mathrm{D} 1(6) *(1 / \mathrm{s}-$

$1 /(\mathrm{s}+(1 / \mathrm{Tau} 1(6))))+\mathrm{D} 1(7) *(1 / \mathrm{s}-1 /(\mathrm{s}+(1 / \mathrm{Tau} 1(7))))+\mathrm{D} 1(8) *(1 / \mathrm{s}-$

$1 /(\mathrm{s}+(1 / \mathrm{Tau} 1(8))))+\mathrm{D} 1(9) *(1 / \mathrm{s}-1 /(\mathrm{s}+(1 / \mathrm{Tau} 1(9))))+\mathrm{D} 1(10) *(1 / \mathrm{s}-$

$1 /(\mathrm{s}+(1 / \mathrm{Tau} 1(10))))+\mathrm{D} 1(11) *(1 / \mathrm{s}-1 /(\mathrm{s}+(1 / \mathrm{Tau} 1(11)))) ;$

$\mathrm{F}=1 . /\left(\mathrm{Fufc}^{*}\left(\mathrm{~s}^{\wedge} 2\right)\right)$

end

\section{D.4 - ALGORITMO INCREMENTAL DAS DEFORMAÇÕES APLICADO À VERIFICAÇÃO DO ITEM 4.3.4.2}

function [ ] = FDdsigval( )

$\% \%$ Programa que calcula a evolução das tensões ao longo do tempo

$\%$ em um elemento unidimensional com a imposição de uma função de

$\%$ tensão (tenta-se reproduz o exercício do marcos $\mathrm{tf}=60 \mathrm{e} \mathrm{dt=0.2)}$

clc; close all; format long; 
$\% \%$ Declaração de variáveis

$\mathrm{tf}=60$

\% Tempo total de avaliação segundos

$\mathrm{dt}=\left[\begin{array}{lllll}0.05 & 0.1 & 0.25 & 0.5 & 1\end{array}\right] ; \quad \%$ Diferencial de tempo dt

$\mathrm{t} 1=\mathrm{dt}$

$\%$ Tempo em horas do Esforço max /=

$\mathrm{P}=50 ; \mathrm{E} 0=150 ; \mathrm{Ek}=100 ;$ Neta=1000; \% Tensão maxima Sigma em Mpa, Mod. Elast.

Mola simples, Mod. E. Mola Kelvin, Viscosidade

Kelvin

D0 $=1 / \mathrm{E} 0 ; \quad \mathrm{D} 1=1 / \mathrm{Ek}$;

Tau $1=$ Neta/Ek;

$\mathrm{t} 1=1 * \mathrm{dt}$

$\mathrm{D}=[\mathrm{D} 0 \mathrm{D} 1]^{\prime} ;$

Tau=[Tau1]';

\% Obtenção dos coeficientes da série de Prony $\mathrm{D}(\mathrm{t})$

$\%$ Obtenção dos exponentes da série de Prony $\mathrm{D}(\mathrm{t})$

$\%$ Tempo em seg do Esforço max /=

$\%$ Coeficientes da série de Prony D(t) desde D0 até Dn

$\%$ Exponentes da série de Prony $\mathrm{D}(\mathrm{t})$ desde D0 até Dn

$\% \%$ Calculo do vetor tensão

$\mathrm{CM} 1=$ funsig $(\mathrm{tf}, \mathrm{t} 1(1), \mathrm{dt}(1), \mathrm{P}) ; \quad \mathrm{tt} 1=\mathrm{CM} 1(:, 1) ; \quad \mathrm{CM} 1=\mathrm{CM} 1(:, 2)$;

$\mathrm{CM} 2=$ funsig(tf,t1(2), $\operatorname{dt}(2), \mathrm{P}) ; \quad \mathrm{tt} 2=\mathrm{CM} 2(:, 1) ; \mathrm{CM} 2=\mathrm{CM} 2(:, 2)$;

$\mathrm{CM} 3=$ funsig $(\mathrm{tf}, \mathrm{t} 1(3), \mathrm{dt}(3), \mathrm{P}) ; \quad \mathrm{tt} 3=\mathrm{CM} 3(:, 1) ; \quad \mathrm{CM} 3=\mathrm{CM} 3(:, 2)$;

CM4=funsig(tf,t1(4),dt(4),P); tt4=CM4(:,1); CM4=CM4(:,2);

CM5=funsig(tf,t1(5),dt(5),P); tt5=CM5(:,1); CM5=CM5(:,2);

$\%$ Calculo e grafico da função $\mathrm{D}(\mathrm{t})$

$\mathrm{Dt}=\operatorname{ExpM}(\mathrm{D}, \mathrm{Tau}, \mathrm{tt} 1)$;

$\% \%$ Cálculo do Delta Deformação \%\%

$\% \%$ Cálculo do $\{$ Delta $t\},\{$ delta tensão $\}$ e $\{$ delta tensão/delta $t\}$

dSdtDS1=der(tt1,CM1); dS1=dSdtDS1(:,1); dt1=dSdtDS1(:,2); DS1=dSdtDS1(:,3);

$\mathrm{dSdtDS} 2=\operatorname{der}(\mathrm{tt} 2, \mathrm{CM} 1) ; \mathrm{dS} 2=\mathrm{dSdtDS} 2(:, 1) ; \mathrm{dt} 2=\mathrm{dSdtDS} 2(:, 2) ; \quad \operatorname{DS} 2=\mathrm{dSdtDS} 2(:, 3)$;

$\mathrm{dSdtDS} 3=\mathrm{der}(\mathrm{tt} 3, \mathrm{CM} 1) ; \quad \mathrm{dS} 3=\mathrm{dSdtDS} 3(:, 1) ; \quad \mathrm{dt} 3=\mathrm{dSdtDS} 3(:, 2) ; \quad \mathrm{DS} 3=\mathrm{dSdtDS} 3(:, 3)$;

dSdtDS4=der(tt4,CM1); dS4=dSdtDS4(:,1); dt4=dSdtDS4(:,2); DS4=dSdtDS4(:,3);

dSdtDS5=der(tt5,CM1); dS5=dSdtDS5(:,1); dt5=dSdtDS5(:,2); DS5=dSdtDS5(:,3);

$\% \%$ Cálculo do Delta Deformação 1

DD1_1=def1(D,Tau,dt(1),dS1);

DD1_2=def1(D,Tau,dt(2),dS2);

DD1_3=def1(D,Tau,dt(3),dS3);

DD1_4=def1(D,Tau,dt(4),dS4);

DD1_5=def1(D,Tau,dt(5),dS5);

$\% \%$ Cálculo do Delta Def 2

DD2_1=def2(D,Tau,dt(1),DS1);

DD2_2=def2(D,Tau,dt(2),DS2);

DD2_3=def2(D,Tau,dt(3),DS3);

DD2_4=def2(D,Tau,dt(4),DS4);

DD2_5=def2(D,Tau,dt(5),DS5);

$\% \%$ Cálculo do Delta Sigma total

DT1=DD1_1+DD2_1; DT1=cumsum(DT1);

DT2=DD1_2+DD2_2; $\quad$ DT2=cumsum(DT2);

DT3=DD1_3+DD2_3; $\quad$ DT3=cumsum(DT3);

DT4=DD1_4+DD2_4; $\quad$ DT4=cumsum(DT4);

DT5=DD1_5+DD2_5; DT5=cumsum(DT5);

$\% \%$ Gráficos

figure(1)

plot(tt1(:,1),CM1(:,1),'k','LineWidth',2);

hold on 
$\operatorname{plot}(0,1.2 * \mathrm{P})$

title(' \{lsigma\}(t) [MPa]','FontName','Times New

Roman','FontSize',12,'FontWeight','bold')

xlabel('t [s]','FontName','Times New Roman','FontSize',10,'FontWeight','bold')

ylabel('\{lsigma\}(t) [MPa]','FontName','Times New

Roman','FontSize',10,'FontWeight','bold')

legend('\{\sigma\}(t) $[\mathrm{MPa}] ', 4)$

set(gca,'FontName','Times New Roman','FontSize',10,'LineWidth',0.1)

hold off

figure(2)

$\operatorname{plot}\left(\mathrm{tt} 1(:, 1), \mathrm{Dt}(:, 1),{ }^{\prime} \mathrm{k}\right.$ ','LineWidth',2);

hold on

$\operatorname{plot}(0,0)$;

$\operatorname{plot}(0,1.2 * \max (\mathrm{Dt}))$

\%title('Função de Fluência D(t)','FontName','Times New

Roman','FontSize',12,'FontWeight','bold')

xlabel('t [s]','FontName','Times New Roman','FontSize',10,'FontWeight','bold')

ylabel('D(t) [1/Mpa]','FontName','Times New Roman','FontSize',10,'FontWeight','bold')

legend('D(t)[1/Mpa]',4)

set(gca,'FontName','Times New Roman','FontSize',10,'LineWidth',0.1)

hold off

figure(3)

$\% \%$ Resposta analítica

$\mathrm{t}=(0: 0.5: \mathrm{tf})^{\prime}$;

$\operatorname{def} 0=\max (\mathrm{CM} 1)$

sig_analitico $=$ def0. $*((1 / \mathrm{E} 0)+((1 / \mathrm{Ek}) *(1-\exp (-($ Ek/Neta $) . * \mathrm{t}))))$;

plot $\left(\mathrm{t}, \mathrm{sig} \_\right.$analitico,'k','LineWidth',2);

hold on

\%title('Deformação \{lepsilon\}(t)','FontName','Times New

Roman','FontSize',12,'FontWeight','bold')

xlabel('t [s]','FontName','Times New Roman','FontSize',10,'FontWeight','bold')

ylabel('\{lepsilon\}(t) [m/m]','FontName','Times New

Roman','FontSize',10,'FontWeight','bold')

$\% \%$ Resposta para os diferentes deltas de $\mathrm{t}$

plot(tt1(:,1),DT1(:,1),'m-o','LineWidth',0.5,'MarkerSize',1);

plot(tt2(:,1),DT2(:,1),'r-o','LineWidth',0.5,'MarkerSize',2);

plot(tt3(:,1),DT3(:,1),'g-o','LineWidth',0.5,'MarkerSize',3);

plot(tt4(:,1),DT4(:,1),'b-o','LineWidth',0.5,'MarkerSize',4);

plot(tt5(:,1),DT5(:,1),'c-o','LineWidth',0.5,'MarkerSize',5);

legend('\{lepsilon $\}$ analítico', $\{\backslash$ delta $\}(t)=0.05^{\prime},{ }^{\prime}\{\backslash$ delta $\}(t)=0.1^{\prime},{ }^{\prime}\{\backslash$ delta $\}(t)=0.25^{\prime},{ }^{\prime}\{$ delta $\}(t)$

$=0.5^{\prime},{ }^{\prime}\{\backslash$ delta $\left.\}(\mathrm{t})=1^{\prime}, 4\right)$

set(gca,'FontName','Times New Roman','FontSize',8,'LineWidth',0.1)

$\operatorname{plot}(0,1)$;

end

function $[\operatorname{ExpM}]=\operatorname{ExpM}(\mathrm{D}, \mathrm{Tau}, \mathrm{t})$

$\% \%$ Calcula função de fluêcia $\mathrm{D}(\mathrm{t})$ desde $\mathrm{D} 0$ ate $\mathrm{Dn}$ ou $\mathrm{D}(\mathrm{t})$ desde $\mathrm{D} 1$ ate Dn num tempo $\mathrm{t}$

$\mathrm{n}=$ length$(\mathrm{Tau}) ; \mathrm{m}=$ length $(\mathrm{t})$;

for $\mathrm{k}=1: \mathrm{m}$

$\mathrm{D} 0=\mathrm{D}(1)$;

for $\mathrm{i}=1: \mathrm{n}$ 


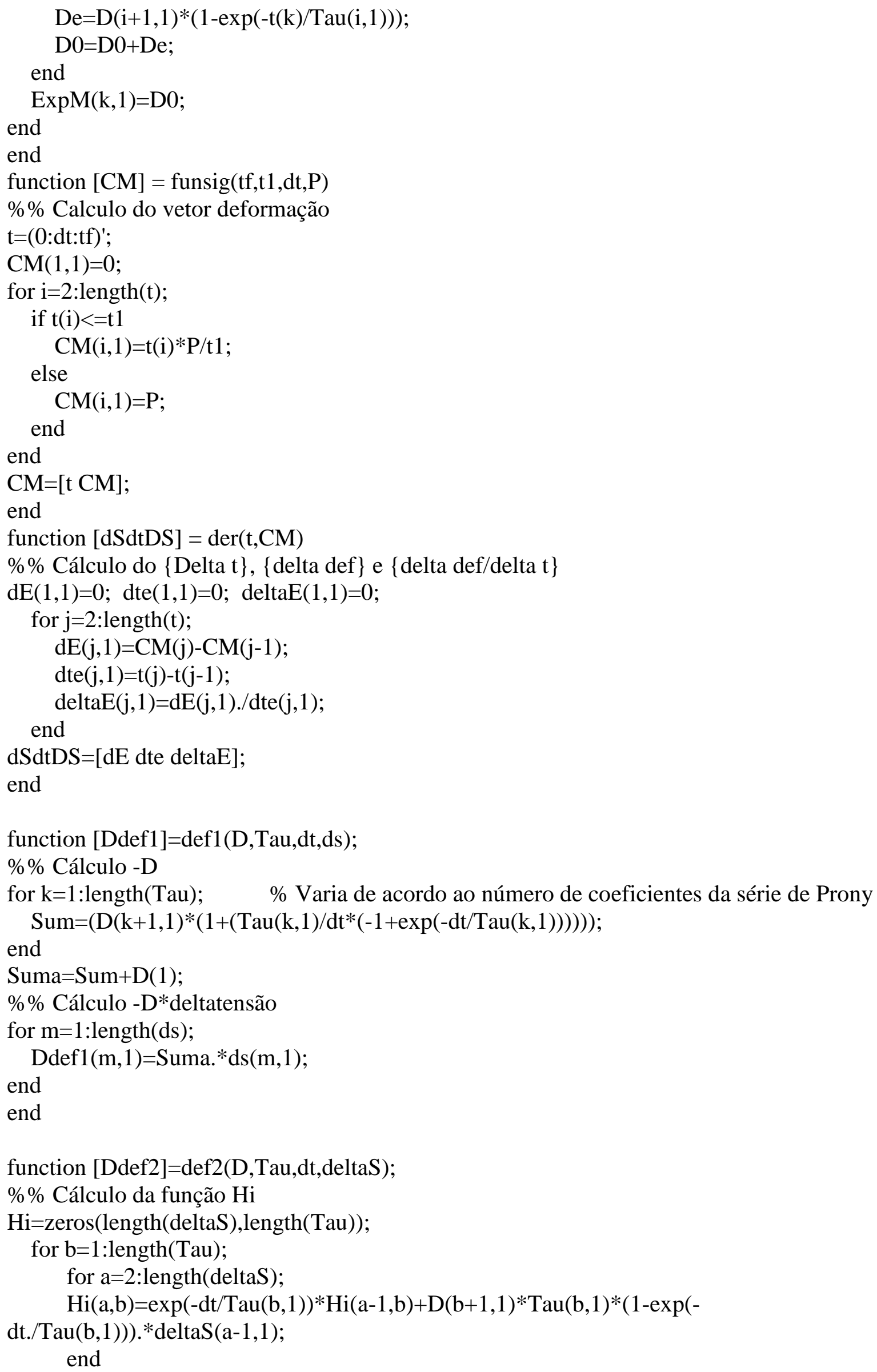


end

$\% \%$ Cálculo da função -a*Hi

Sum=zeros(length(deltaS),length(Tau));

for $b=1$ :length(Tau);

for $\mathrm{a}=2$ :length(deltaS);

$\operatorname{Sum}(a, b)=(1-\exp (-d t . / \operatorname{Tau}(b, 1))) . * H i(a, b)$;

end

end

Sum2=zeros(length(deltaS $), 1)$;

for $\mathrm{i}=1$ :length(Tau)

$\operatorname{Sum}(:, \mathrm{i})$

$\operatorname{Sum} 2(:, 1)=\operatorname{Sum}(:, \mathrm{i})+\operatorname{Sum} 2(:, 1)$;

end

Ddef2=Sum2;

End

\section{D.5 - ALGORITMO INCREMENTAL DAS TENSÕES APLICADO À VERIFICAÇÃO DO ITEM 4.3.2.2}

function [] = FEddefvalBoltz()

$\% \%$ Programa que calcula a evolução das tensões ao longo do tempo em um elemento \%unidimensional com a imposição de uma função de deformação (tenta-se reproduz o \$exercicio do Carvalho pag 95

$\mathrm{tf}=60$ e $\mathrm{dt}=0.2$ )

clc; format long; close all;

$\% \%$ Declaração de variaveis

$\mathrm{tf}=60 ; \quad \%$ Tempo total de avaliação Horas

$\mathrm{dt}=[0.2]^{\prime} ; \quad$ \% Diferencial de tempo dt

$\mathrm{P}=50$; Deformação maxima em $\mathrm{m} / \mathrm{m}$

$\mathrm{t} 1=\mathrm{dt} ; \quad \%$ Tempo em horas do Esforço max $/=$

$\mathrm{E}=[150$ 100]'; $\quad$ \% Coeff função relaxação Einf, E1 exercicio de Marcos Boltzmann

neta=1000; $\quad$ \% Coeff parcela viscosa função relaxação exercicio de Marcos

Boltzmann

$\operatorname{def} 0=\mathrm{P} ; \mathrm{Ek}=\mathrm{E}(2) ; \mathrm{n}=$ neta $; \mathrm{E} 0=\mathrm{E}(1) ; \mathrm{tt}=(0: 0.5: \mathrm{tf})^{\prime} ;$

$\mathrm{E} 1=[\mathrm{Ek} * \mathrm{E} 0 /(\mathrm{Ek}+\mathrm{E} 0) \mathrm{E} 0 \wedge 2 /(\mathrm{Ek}+\mathrm{E} 0)]]^{\prime} \%$ Coeff função relaxação E0, E1 serie de prony

$\mathrm{E}(\mathrm{t})$ Boltzmann

Tau1=neta/(sum(E)); $\quad$ \% Coeff tempo de relaxação Tau1=neta/(E0+Ek)

$\mathrm{Tau}=[\mathrm{Tau} 1]$;

$\% \%$ Calculo do vetor deformação

$\mathrm{CM} 1=f u n d e r(\mathrm{tf}, \mathrm{t} 1(1), \mathrm{dt}(1), \mathrm{P}) ; \quad \mathrm{tt} 1=\mathrm{CM} 1(:, 1) ; \mathrm{CM} 1=\mathrm{CM} 1(:, 2) ;$

$\% \%$ Calculo e grafico da função $\mathrm{E}(\mathrm{t})$

$\mathrm{Et}=\mathrm{ExpM}(\mathrm{E} 1, \mathrm{Tau}, \mathrm{tt} 1)$

$\% \%$ Cálculo do Delta sigma $\% \%$

$\% \%$ Cálculo do $\{$ Delta $\mathrm{t}\},\{$ delta def $\}$ e $\{$ delta def/delta $\mathrm{t}\}$

dEdtDE1=der(tt1,CM1); dE1=dEdtDE1(:,1); dt1=dEdtDE1(:,2); DE1=dEdtDE1(:,3); 
$\% \%$ Cálculo do Delta Sigma 1

DS1_1=sigma1(E1,Tau,dt(1),dE1);

$\% \%$ Cálculo do Delta Sigma 2

DS2_1=sigma2(E1,Tau,dt(1),DE1);

$\% \%$ Cálculo do Delta Sigma total

DT1=DS1_1+DS2_1; DT1=cumsum(DT1);

$\% \%$ Gráficos

figure(1)

plot(tt1(:,1),CM1(:,1),'k','LineWidth',2);

hold on

$\operatorname{plot}(0,1.2 * \mathrm{P})$

title('Deformação \{lepsilon \}(t) m/m','FontName','Times New

Roman','FontSize',12,'FontWeight','bold')

xlabel('Tempo t [Seg]','FontName','Times New Roman','FontSize',10,'FontWeight','bold')

ylabel('Deformação \{lepsilon\}(t) m/m','FontName','Times New

Roman','FontSize',10,'FontWeight','bold')

legend('Deformação \{lepsilon \}(t) m/m',4)

set(gca,'FontName','Times New Roman','FontSize',10,'LineWidth',0.1)

hold off

figure(2)

plot(tt1(:,1),Et(:,1),'k-*','LineWidth',1,'MarkerSize',3);

hold on

$\operatorname{plot}(0,0)$;

\%title('Função de Relaxação E(t)','FontName','Times New

Roman','FontSize',12,'FontWeight','bold')

xlabel('Tempo [s]','FontName','Times New Roman','FontSize',10,'FontWeight','bold')

ylabel('E(t) [MPa]','FontName','Times New Roman','FontSize',10,'FontWeight','bold')

legend('Função de Relaxação E(t)',4)

set(gca,'FontName','Times New Roman','FontSize',10,'LineWidth',0.1)

hold off

$\% \%$

figure(3)

$\% \%$ Resposta analítica

sig_analitico $=\operatorname{def} 0 *(\mathrm{E} 0 /(\mathrm{Ek}+\mathrm{E} 0)) *((\mathrm{E} 0 * \exp (-((\mathrm{E} 0+\mathrm{Ek}) / \mathrm{neta}) * \mathrm{tt}))+\mathrm{Ek})$;

plot(tt,sig_analitico,'k','LineWidth',2.5);

hold on

\%title('Esforço de Tensão \{ \sigma\}(t)','FontName','Times New

Roman','FontSize',12,'FontWeight','bold')

xlabel('Tempo [s]','FontName','Times New Roman','FontSize',10,'FontWeight','bold')

ylabel(' \\sigma\}(t)[MPa]','FontName','Times New

Roman','FontSize',10,'FontWeight','bold')

$\% \%$ Resposta para os diferentes deltas de $\mathrm{t}$

plot(tt1(:,1),DT1(:,1),'bo','LineWidth',0.1,'MarkerSize',3);

legend('Tensão $\{\backslash \operatorname{sigma}\}(t)$ analítico','Tensão $\{\backslash$ sigma $\}(t)$ obtido',4) 
set(gca,'FontName','Times New Roman','FontSize',10,'LineWidth',0.1)

end

function $[\mathrm{ExpM}]=\operatorname{ExpM}(\mathrm{E}, \mathrm{Tau}, \mathrm{t})$

$\% \%$ Calcula a função de fluêcia $\mathrm{E}(\mathrm{t})$ desde $\mathrm{E} 0$ ate $\mathrm{En}$ ou $\mathrm{E}(\mathrm{t})$ desde $\mathrm{E} 1$ ate En num tempo $\mathrm{t}$ $\mathrm{n}=$ length $(\mathrm{Tau}) ; \mathrm{m}=$ length $(\mathrm{t})$;

for $\mathrm{k}=1: \mathrm{m}$

$\mathrm{E} 0=\mathrm{E}(1)$;

for $\mathrm{i}=1: \mathrm{n}$

$\mathrm{Ee}=\mathrm{E}(\mathrm{i}+1,1)^{*} \exp (-\mathrm{t}(\mathrm{k}) . / \mathrm{Tau}(\mathrm{i}, 1))$;

$\mathrm{E} 0=\mathrm{E} 0+\mathrm{Ee}$

end

$\operatorname{ExpM}(\mathrm{k}, 1)=\mathrm{E} 0$;

end

end

function $[\mathrm{CM}]=$ funder $(\mathrm{tf}, \mathrm{t} 1, \mathrm{dt}, \mathrm{P})$

$\% \%$ Calculo do vetor deformação

$\mathrm{t}=(0: \mathrm{dt}: \mathrm{tf})^{\prime}$;

$\mathrm{CM}(1,1)=0$;

for $\mathrm{i}=2$ :length $(\mathrm{t})$;

if $\mathrm{t}(\mathrm{i})<=\mathrm{t} 1$

$\mathrm{CM}(\mathrm{i}, 1)=\mathrm{t}(\mathrm{i}) * \mathrm{P} / \mathrm{t} 1$

else

$\mathrm{CM}(\mathrm{i}, 1)=\mathrm{P}$;

end

end

$\mathrm{CM}=[\mathrm{t} \mathrm{CM}]$;

end

function $[\mathrm{dEdtDE}]=\operatorname{der}(\mathrm{t}, \mathrm{CM})$

$\% \%$ Cálculo do $\{$ Delta $\mathrm{t}\},\{$ delta def $\}$ e $\{$ delta def/delta $\mathrm{t}\}$

$\mathrm{dE}(1,1)=0 ; \operatorname{dte}(1,1)=0 ; \operatorname{deltaE}(1,1)=0$;

for $\mathrm{j}=2$ :length $(\mathrm{t})$;

$\mathrm{dE}(\mathrm{j}, 1)=\mathrm{CM}(\mathrm{j})-\mathrm{CM}(\mathrm{j}-1)$;

$\operatorname{dte}(\mathrm{j}, 1)=\mathrm{t}(\mathrm{j})-\mathrm{t}(\mathrm{j}-1)$;

$\operatorname{deltaE}(\mathrm{j}, 1)=\mathrm{dE}(\mathrm{j}, 1) . / \operatorname{dte}(\mathrm{j}, 1)$;

end

$\mathrm{dEdtDE}=[\mathrm{dE}$ dte deltaE $]$;

end

function [Dsigma1]=sigma1(E,Tau,dt,dE);

$\% \%$ Cálculo -E

Sum $=0 ; \quad \%$ Acumulador de somatoria

for $\mathrm{k}=1$ :length(Tau); $\quad \%$ Varia de acordo ao número de coeficientes da série de Prony

$\mathrm{Sum}=(\mathrm{E}(\mathrm{k}+1,1) * \mathrm{Tau}(\mathrm{k}, 1) / \mathrm{dt}) *(1-\exp (-\mathrm{dt} / \mathrm{Tau}(\mathrm{k}, 1)))$;

end

Suma $=$ Sum $+\mathrm{E}(1)$;

$\% \%$ Cálculo -E*deltadeformação

for $\mathrm{m}=1$ :length $(\mathrm{dE})$; 


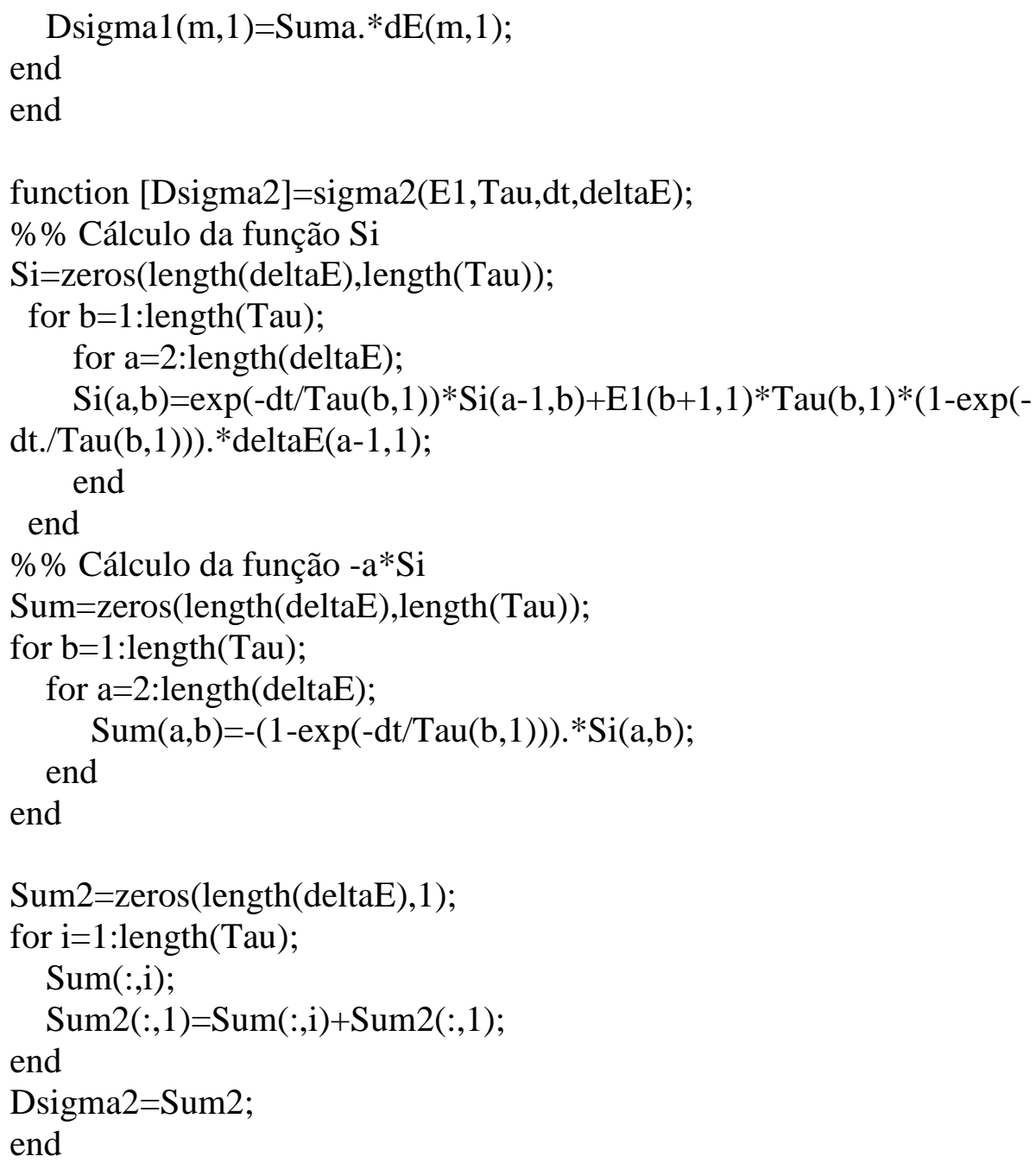

\section{D.6 - ALGORITMO DA FUNÇÃO PARA AVALIAR Imod E Ac DA VIGA SANDUÍCHE}

function $[\mathrm{Sol}]=$ cen_i_a(Et,Hc,b)

$\% \%$ Calcula o centroide em função da mudança na rigidez na metade inferior do núcleo

\% Entrada: Et=[E1 E2 E3 E4]'; \%Hc=[h1 h2 h3 h4]'; \%b=base da viga

$\% \%$ Cálculo do novo centroide desde extremo superior

$\mathrm{n} 1=\operatorname{Et}(1,1) / \operatorname{Et}(3,1) ; \quad \mathrm{n} 4=\operatorname{Et}(4,1) / \operatorname{Et}(3,1)$;

$\mathrm{h} 1=\mathrm{Hc}(1,1) ; \mathrm{h} 2=\mathrm{Hc}(2,1) ; \mathrm{h} 3=\mathrm{Hc}(3,1) ; \mathrm{h} 4=\mathrm{Hc}(4,1)$;

Aihi $=n 1 * b * h 1 *(h 1 / 2)+b * h 3 *(h 1+h 3 / 2)+n 4 * b * h 4 *(h 1+h 3+h 4 / 2)+n 1 * b * h 2 *(h 1+h 3+h 4+h 2$

/2);

Amod=n1*b*h1+b*h3+n4*b*h4+n1*b*h2;

$\mathrm{y}=$ Aihi/Amod;

$\% \%$ Cálculo da nova inercia modificada [ $\left.\mathrm{m}^{\wedge} 4\right]$

$\mathrm{ht}=\mathrm{h} 1+\mathrm{h} 2+\mathrm{h} 3+\mathrm{h} 4 ; \quad \mathrm{z}=\mathrm{ht}-\mathrm{y}$;

$\mathrm{I} 1=(\mathrm{n} 1 * \mathrm{~b} * \mathrm{~h} 1 \wedge 3) / 12+\mathrm{n} 1 * \mathrm{~b} * \mathrm{~h} 1 *(\mathrm{y}-\mathrm{h} 1 / 2)^{\wedge} 2$;

$\mathrm{I} 3=\left(b^{*} h 3^{\wedge} 3\right) / 12+\left(b^{*} h 3 *(y-h 1-h 3 / 2)^{\wedge} 2\right)$; 
$\mathrm{I} 4=\left(\mathrm{n} 4 * \mathrm{~b} * \mathrm{~h} 4{ }^{\wedge} 3\right) / 12+\left(\mathrm{n} 4 * \mathrm{~b} * \mathrm{~h} 4 *(\mathrm{z}-\mathrm{h} 2-\mathrm{h} 4 / 2)^{\wedge} 2\right) ;$

$\mathrm{I} 2=\left(\mathrm{n} 1 * \mathrm{~b} * \mathrm{~h} 2{ }^{\wedge} 3\right) / 12+\mathrm{n} 1 * \mathrm{~b} * \mathrm{~h} 2 *(\mathrm{z}-\mathrm{h} 2 / 2)^{\wedge} 2$

Imod=[I1 I2 I3 I4]; $\quad \%$ Inercia da viga modificada $\mathrm{em} \mathrm{m}^{\wedge} 4$

$\% \%$ Cálculo da área a cortante modificada [m²]

$\mathrm{A} 1=\mathrm{n} 1 * \mathrm{~b} * \mathrm{~h} 1 ; \quad \mathrm{A} 2=\mathrm{n} 1 * \mathrm{~b} * \mathrm{~h} 2$;

$\mathrm{A} 3=\mathrm{b} * \mathrm{~h} 3 ; \quad \mathrm{A} 4=\mathrm{n} 4 * \mathrm{~b} * \mathrm{~h} 4$;

$\mathrm{Ac}=(\mathrm{A} 3+\mathrm{A} 4)$

end

Sol=[Imod Ac];

end 